Prepared in cooperation with Charleston Water System

\title{
Characterization of Water Quality in Bushy Park Reservoir, South Carolina, 2013-15
}

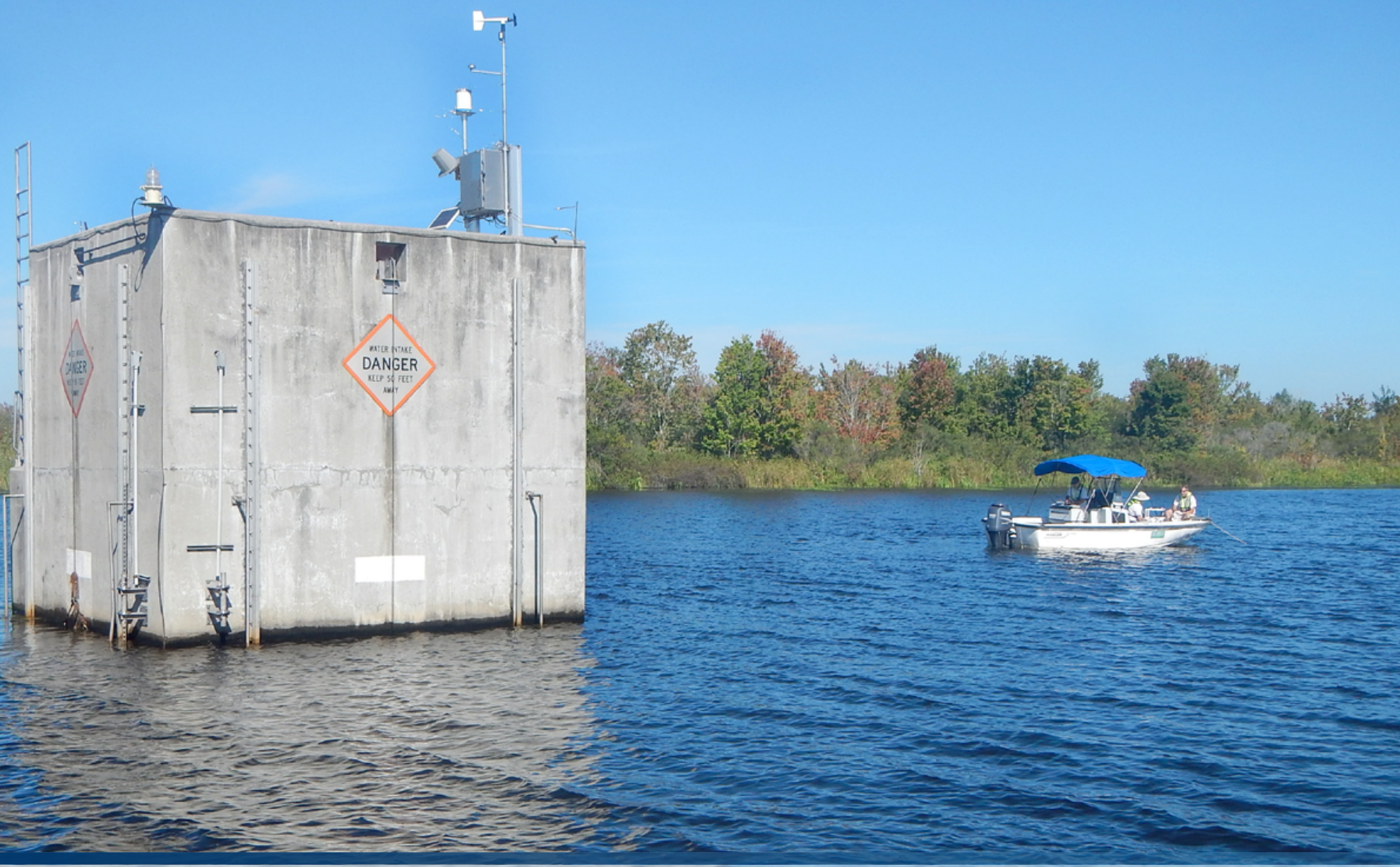

Scientific Investigations Report 2018-5010 


\section{Cover.}

Front-U.S. Geological Survey (USGS) field crew near the Charleston Water System intake on Bushy Park Reservoir, August 2014. Photograph by Michael Hall, retired USGS.

Back-USGS field equipment, including autonomous underwater vehicle and multiparameter sonde, prior to deployment, August 2014. Photograph by Celeste Journey, USGS. 


\section{Characterization of Water Quality in Bushy Park Reservoir, South Carolina, 2013-15}

By Paul A. Conrads, Celeste A. Journey, Matthew D. Petkewich, Timothy H. Lanier, and Jimmy M. Clark

Prepared in cooperation with Charleston Water System

Scientific Investigations Report 2018-5010 


\title{
U.S. Department of the Interior \\ RYAN K. ZINKE, Secretary
}

\section{U.S. Geological Survey William H. Werkheiser, Deputy Director exercising the authority of the Director}

\author{
U.S. Geological Survey, Reston, Virginia: 2018
}

For more information on the USGS - the Federal source for science about the Earth, its natural and living resources, natural hazards, and the environment-visit https://www.usgs.gov or call 1-888-ASK-USGS.

For an overview of USGS information products, including maps, imagery, and publications, visit https://store.usgs.gov.

Any use of trade, firm, or product names is for descriptive purposes only and does not imply endorsement by the U.S. Government.

Although this information product, for the most part, is in the public domain, it also may contain copyrighted materials as noted in the text. Permission to reproduce copyrighted items must be secured from the copyright owner.

Suggested citation:

Conrads, P.A., Journey, C.A., Petkewich, M.D., Lanier, T.H., and Clark, J.M., 2018, Characterization of water quality in Bushy Park Reservoir, South Carolina, 2013-15: U.S. Geological Survey Scientific Investigations Report 2018-5010, 175 p., https://doi.org/10.3133/sir20185010.

ISSN 2328-0328 (online) 


\section{Acknowledgments}

The complexity of the study required interagency cooperation in addition to individual contributions. The authors thank the staff of Charleston Water System (CWS) and, in particular, Kin Hill, Chief Executive Officer, Andy Fairey, Chief Operating Officer, and Jane Bryne, Director of Water Treatment, for their technical assistance and coordination in this project. The authors also thank Mark Valerio of South Carolina Electric and Gas for the daily Williams Station plant operating data and Rebecca Thames of CWS for providing laboratory data. The authors also thank the CWS and U.S. Geological Survey reviewers for their thoughtful reviews and constructive comments.

"It is not length of life, but depth of life." - Ralph Waldo Emerson

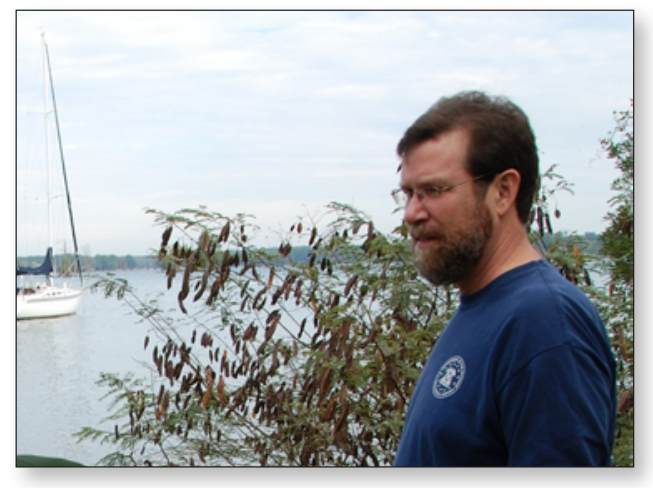

Paul A. Conrads, 1957-2017 



\section{Contents}

Acknowledgments ……...................................................................................................................

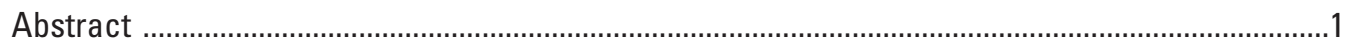

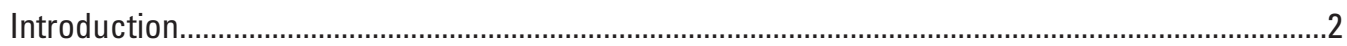

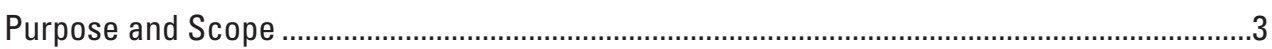

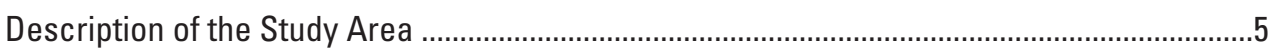

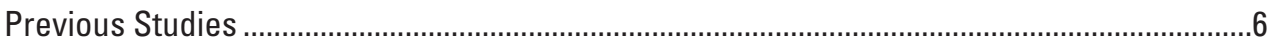

Approach and Methods ..........................................................................................................

Discrete Water-Quality Data Collection.................................................................................13

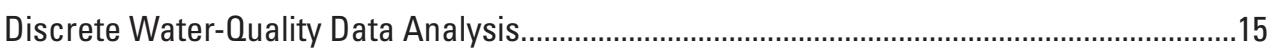

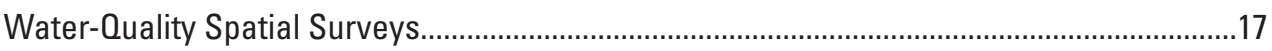

Verification of Physical Properties Measured by the Autonomous

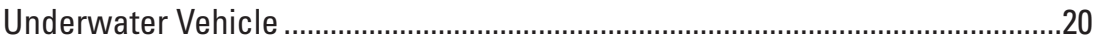

Discrete Data Quality Assurance and Quality Control ...........................................................22

Relation Between Sonde Measurements and Laboratory Analysis of Chlorophyll a ..............23

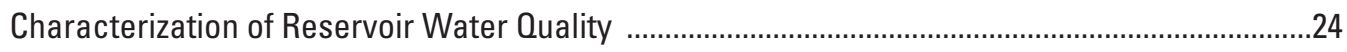

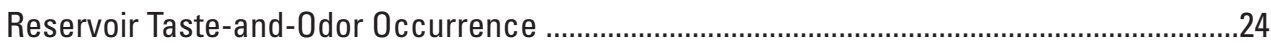

Seasonal Occurrence of Taste-and-Odor Compounds .......................................................2

Characterization of Water-Quality Conditions in Bushy Park Reservoir ...................................27

Spatial and Seasonal Changes in Water-Quality Conditions in Bushy Park Reservoir ...........31

Spatial and Seasonal Variation in Phytoplankton Community Structure

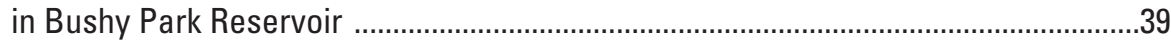

Relation of Environmental Conditions to Taste-and-Odor Occurrence ....................................44

Synoptic Assessment of Taste-and-Odor Occurrence in the Bushy Park Reservoir by the Charleston Water System Treatment Plant ........................................45

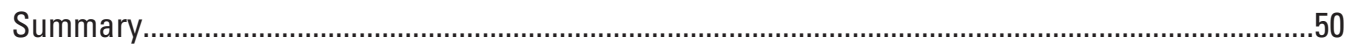

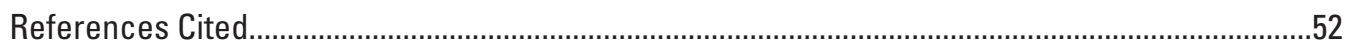

Appendix 1. Operation and data processing of the EcoMapper Iver2 autonomous underwater vehicle ........................................................................................................72

Appendix 2. Plots showing 2D longitudinal profiles for seven parameters for 16 autonomous underwater vehicle water-quality surveys ..................................................78

Appendix 3. Water-quality profile data collected from the Bushy Park Reservoir, near Goose Creek, South Carolina, between September 2013 and April 2015.

Appendix 4. Summary of the quality assurance and quality control data collected in Bushy Park Reservoir, near Goose Creek, South Carolina, September 2013 to April 2015.

Appendix 5. Analytical results for water-column samples collected in Bushy Park Reservoir, near Goose Creek, South Carolina, September 2013 to April 2015 


\section{Figures}

1. Map showing Bushy Park Reservoir, near Goose Creek, South Carolina, and location of industrial withdrawal intakes. 3

2. Graph showing precipitation at the Charleston Water System Intake (station 0217206110), daily flows and 7-day average flows in Durham Canal, and withdrawal rates by the Williams Station from Bushy Park Reservoir for the period September 1, 2013, to December 31, 2015.

3. Map showing locations and names of water-quality sampling sites and industrial withdrawal intakes in the Bushy Park Reservoir, September 2013 to April 2015 .9

4. Diagrams of the autonomous underwater vehicle used for water-quality surveys in Bushy Park Reservoir, September 2013 to April 2015: major components, including a closeup of the water-quality sensors inside the flowthrough cap, and three survey modes (constant depth, constant altitude, and undulation)........14

5. Diagram showing examples of three mission routes used by the autonomous underwater vehicle during water-quality surveys on Bushy Park Reservoir, September 2013 to April 2015: centerline, "zigzag," and "lawnmower"

6. Side-scan sonar image from autonomous underwater vehicle of the lower reach of Bushy Park Reservoir on September 17 and 18, 2013.

7. Examples of the autonomous underwater vehicle missions and data collection at Bushy Park Reservoir on September 17 and 18, 2013: plan view showing a "lawnmower" mission path and bathymetry depths, side view showing chlorophyll data from a surface mission and undulating mission, and detail of the two missions looking upstream from the Back River Dam

8. Longitudinal plot of water temperature depth profile from the autonomous underwater vehicle survey of the lower end of Bushy Park Reservoir near the Back River Dam to the powerlines near site CWS-3 and below the confluence with Durham Canal for June 10, 2014

9. Scatterplot of total organic carbon concentrations and ultraviolet absorbance at 254 nanometers in water-column samples collected in Bushy Park Reservoir, 2013 to 2015

10. Scatterplot of laboratory-derived chlorophyll a concentrations and estimated total chlorophyll concentrations from in situ fluorescence measured with a YSI 6025 probe in Bushy Park Reservoir, 2013 to 2015.

11. Graphs showing the temporal variability in taste-and-odor concentrations as combined geosmin and 2-methyisobornel concentrations in raw blended (Bushy Park Reservoir and Edisto River), settled, and finished water and the corresponding powdered activated carbon doses used by Charleston Water Systems as a treatment technique in the spring and fall of 2013

12. Geosmin and 2-methylisoborneol concentrations at selected locations plotted by distance from Bushy Park Reservoir Dam for sampling events from September 2013 to April 2015.

13. Boxplots of dissolved organic carbon concentrations, dissolved oxygen concentration as percent saturation, ultraviolet absorbance at 254 nanometers, and total organic carbon at seven locations in Bushy Park Reservoir, September 2013 to April 2015.

14. Boxplots of total nitrogen, dissolved nitrate plus nitrite, total phosphorus, and dissolved orthophosphate concentrations at seven locations in Bushy Park Reservoir, September 2013 to April 2015 
15. Boxplots of specific conductance at 25 degrees Celsius, total hardness concentration, and dissolved iron concentration at seven locations in Bushy Park Reservoir, September 2013 to April 2015

16. Boxplots of actinomycetes, chlorophyll $a$, geosmin, and 2-methylisoborneol concentrations at seven locations in Bushy Park Reservoir, September 2013 to April 2015

17. Boxplots of dissolved nitrate plus nitrite, chlorophyll $a$, geosmin, and 2-methylisoborneol concentrations at all seven locations by season in Bushy Park Reservoir, September 2013 to April 2015.

18. Heat map of standardized cyanobacteria cell densities for potential taste-andodor-producing genera in Bushy Park Reservoir, reordered by results of the hierarchical cluster analysis similarity profile results

19. Two-dimensional nonmetric scaling graph of the pattern of fourth-root transformed cyanobacteria cell densities, standardized as percentage of total sample, in Bushy Park Reservoir for selected seasons in 2014.

20. Map showing the area of the synoptic assessment of taste-and-odor occurrence in Edisto River and Bushy Park Reservoir, April 2015

21. Graphs showing the temporal variability in geosmin concentrations in Bushy Park tunnel, raw blended (Bushy Park Reservoir and Edisto River), and finished water and corresponding water temperatures in Bushy Park tunnel in April 2015.

22. Scatterplots of ultraviolet absorbance at 254 nanometers and geosmin concentrations against conservative tracer of specific conductance to support the evaluation of mixing relations between two source waters (Edisto River, Bushy Park Reservoir at the Charleston Water Intake), source water in the supply tunnels, and raw mixed or blended water at the Hanahan Water Treatment Plant near Goose Creek, South Carolina

\section{Tables}

1. Timeline of U.S. Geological Survey water-quality data collection, surveys, and South Carolina Electric and Gas Company monthly average withdrawal rates in Bushy Park Reservoir, near Goose Creek, South Carolina, September 2013 to May 2015

2. Description of the selected reservoir locations for discrete sampling of water chemistry and algal taxonomy in Bushy Park Reservoir, September 2013 to April 2015.

3. Description of the analytical tests performed by the U.S. Geological Survey National Water Quality Laboratory and National Environmental Laboratory Accreditation Program-certified contract laboratory on water samples from Bushy Park Reservoir, 2013 to 2015

4. Manufacturer's specifications for the water-quality sensors in the handheld water-quality sondes and in the bulkhead sonde of the autonomous underwater vehicle....

5. Accuracy ratings of the autonomous underwater vehicle water-quality sensors and the surveys for the Bushy Park Reservoir water-quality study, September 2013 to April 2015 
6. Statistical summary of the field measurements made during discrete watercolumn sampling at selected locations in Bushy Park Reservoir, September 2013 to April 2015

7. Statistical summary of major ion, trace metal, and organic carbon concentrations in discrete water-column samples collected at selected locations in Bushy Park Reservoir, September 2013 to April 2015

8. Statistical summary of the nutrient, chlorophyll $a$, actinomycetes, and taste-andodor concentrations in discrete water-column samples collected at selected locations in Bushy Park Reservoir, September 2013 to April 2015

9. Summary of the permutation one-factor test and pairwise Wilcoxon multiple comparison tests to identify differences in environmental conditions in Bushy Park Reservoir, September 2013 to April 2015, between shallow and deep samples.....

10. Summary of the permutation one-factor test and pairwise Wilcoxon multiple comparison tests to identify differences in environmental conditions in Bushy Park Reservoir, September 2013 to April 2015, among sites.

11. Summary of the permutation one-factor test and pairwise Wilcoxon multiple comparison tests to identify differences in environmental conditions in Bushy Park Reservoir, September 2013 to April 2015, among seasons

12. Summary of phytoplankton taxonomic data by major algal group as biovolume and cell density for selected locations in Bushy Park Reservoir, September 2013 to April 2015

13. Summary of the permutation one-factor test and pairwise Wilcoxon multiple comparison tests to identify differences in phytoplankton and cyanobacteria biovolume and cell density in Bushy Park Reservoir, September 2013 to April 2015, among sites and seasons

14. Summary of the multivariate statistical tests on phytoplankton community data as biovolumes in Bushy Park Reservoir, 2013 to 2014.

15. Spearman correlation coefficients and probability values between two taste-andodor compounds, geosmin and 2-methylisoborneol, algal pigments, and associated environmental factors in Bushy Park Reservoir near the Charleston Water Intake, September 2013 to April 2015.

16. Spearman correlation coefficients and probability values between two taste-andodor compounds, geosmin and 2-methylisoborneol, algal pigments, and associated environmental factors at all locations in Bushy Park Reservoir, September 2013 to April 2015

17. Measurements of selected properties in water from Bushy Park Reservoir during the second taste-and-odor event sampling of the U.S. Geological Survey investgation in April 2015. 


\section{Conversion Factors}

U.S. customary units to International System of Units

\begin{tabular}{|c|c|c|}
\hline Multiply & By & To obtain \\
\hline \multicolumn{3}{|c|}{ Length } \\
\hline foot $(\mathrm{ft})$ & 0.3048 & meter $(\mathrm{m})$ \\
\hline mile (mi) & 1.609 & kilometer $(\mathrm{km})$ \\
\hline \multicolumn{3}{|c|}{ Area } \\
\hline square mile $\left(\mathrm{mi}^{2}\right)$ & 2.590 & square kilometer $\left(\mathrm{km}^{2}\right)$ \\
\hline \multicolumn{3}{|c|}{ Flow rate } \\
\hline cubic foot per second $\left(\mathrm{ft}^{3} / \mathrm{s}\right)$ & 0.02832 & cubic meter per second $\left(\mathrm{m}^{3} / \mathrm{s}\right)$ \\
\hline million gallons per day (Mgal/d) & 0.04381 & cubic meter per second $\left(\mathrm{m}^{3} / \mathrm{s}\right)$ \\
\hline
\end{tabular}

International System of Units to U.S. customary units

\begin{tabular}{lll}
\hline \multicolumn{1}{c}{ Multiply } & \multicolumn{1}{c}{ By } & \multicolumn{1}{c}{ To obtain } \\
\hline & Length & \\
\hline centimeter $(\mathrm{cm})$ & 0.3937 & inch (in.) \\
millimeter $(\mathrm{mm})$ & 0.03937 & inch (in.) \\
meter $(\mathrm{m})$ & 3.281 & foot (ft) \\
kilometer $(\mathrm{km})$ & 0.6214 & mile (mi) \\
\hline
\end{tabular}

Temperature in degrees Fahrenheit $\left({ }^{\circ} \mathrm{F}\right)$ may be converted to degrees Celsius $\left({ }^{\circ} \mathrm{C}\right)$ as follows:

$$
{ }^{\circ} \mathrm{C}=\left({ }^{\circ} \mathrm{F}-32\right) / 1.8 .
$$

Temperature in degrees Celsius $\left({ }^{\circ} \mathrm{C}\right)$ may be converted to degrees Fahrenheit $\left({ }^{\circ} \mathrm{F}\right)$ as follows:

$$
{ }^{\circ} \mathrm{F}=\left(1.8 \times{ }^{\circ} \mathrm{C}\right)+32 \text {. }
$$

\section{Datum}

Vertical coordinate information is referenced to either the North American Vertical Datum of 1988 (NAVD 88) or the World Geodetic System of 1984 (WGS 84).

Horizontal coordinate information is referenced to the North American Datum of 1983 (NAD 83).

Altitude, as used in this report, refers to distance above the vertical datum.

\section{Supplemental Information}

Specific conductance is given in microsiemens per centimeter at 25 degrees Celsius $\left(\mu \mathrm{S} / \mathrm{cm}\right.$ at $\left.25^{\circ} \mathrm{C}\right)$. 


\section{Abbreviations}

\begin{tabular}{|c|c|}
\hline ADCP & acoustic Doppler current profiler \\
\hline AIA & Actinomycete Isolation Agar \\
\hline ANOSIM & analysis of similarity test \\
\hline AUV & autonomous underwater vehicle \\
\hline AVM & acoustic velocity meter \\
\hline $\mathrm{BGA}$ & blue-green algae \\
\hline $\mathrm{cm} / \mathrm{s}$ & centimeter per second \\
\hline CPW & Charleston Public Works \\
\hline CRP & Cooper River Partners \\
\hline CWS & Charleston Water System \\
\hline DAL & double-agar layer \\
\hline DO & dissolved oxygen \\
\hline $\mathrm{DOC}$ & dissolved organic carbon \\
\hline DVL & Doppler velocity lags \\
\hline EFDC & Environmental Fluid Dynamics Code \\
\hline EPA & U.S. Environmental Protection Agency \\
\hline FNU & formazin nephelometric units \\
\hline $\mathrm{ft} / \mathrm{s}$ & foot per second \\
\hline GPS & Global Positioning System \\
\hline $\mathrm{Hz}$ & hertz \\
\hline $\mathrm{kHz}$ & kilohertz \\
\hline LRL & laboratory reporting level \\
\hline $\mathrm{mg} / \mathrm{L}$ & milligram per liter \\
\hline $\mathrm{MHz}$ & megahertz \\
\hline MIB & 2-methylisoborneol \\
\hline $\mathrm{mL}$ & milliliter \\
\hline $\mathrm{m} / \mathrm{s}$ & meter per second \\
\hline $\mathrm{ng} / \mathrm{L}$ & nanogram per liter \\
\hline nMDS & nonmetric multidimensional scaling analysis \\
\hline NTU & nephelometric turbidity units \\
\hline NWIS & National Water Information System \\
\hline NWQL & National Water Quality Laboratory \\
\hline PAC & powdered activated carbon \\
\hline PAR & photosynthetically active radiation \\
\hline
\end{tabular}




$\begin{array}{ll}\text { RFU } & \text { relative fluorescence units } \\ \text { RPD } & \text { relative percent difference } \\ \text { SCDHEC } & \text { South Carolina Department of Health and Environmental Control } \\ \text { SCDNR } & \text { South Carolina Department of Natural Resources } \\ \text { SCE\&G } & \text { South Carolina Electric and Gas } \\ \text { SPME } & \text { solid-phase microextraction } \\ \text { SRP } & \text { safe return path } \\ \text { SSC } & \text { suspended-sediment concentration } \\ \text { TN:TP } & \text { total nitrogen to total phosphorus ratio } \\ \text { T\&O } & \text { taste and odor } \\ \text { TOC } & \text { total organic carbon } \\ \text { USGS } & \text { U.S. Geological Survey } \\ \text { UVA } & \text { ultraviolet absorbance } \\ \text { UVC } & \text { underwater vehicle console } \\ \text { UV-Vis } & \text { ultraviolet-visible spectrum } \\ \text { WHO } & \text { World Health Organization } \\ \text { YSI } & \text { Yellow Springs Instrument } \\ \mu \mathrm{H} / \mathrm{L} & \text { microgram per liter } \\ \mu \mathrm{m}^{3} / \mathrm{mL} & \text { cubic micrometer per milliliter } \\ \mu \mathrm{mol} / \mathrm{s}-\mathrm{m}^{2} & \text { micromole per second per square meter }\end{array}$





\title{
Characterization of Water Quality in Bushy Park Reservoir, South Carolina, 2013-15
}

\author{
By Paul A. Conrads, Celeste A. Journey, Matthew D. Petkewich, Timothy H. Lanier, and Jimmy M. Clark
}

\section{Abstract}

The Bushy Park Reservoir is the principal water supply for 400,000 people in the greater Charleston, South Carolina, area, which includes homes as well as businesses and industries in the Bushy Park Industrial Complex. Charleston Water System and the U.S. Geological Survey conducted a cooperative study during 2013-15 to assess the circulation of Bushy Park Reservoir and its effects on water-quality conditions, specifically, recurring taste-and-odor episodes. This report describes the water-quality data collected for the study that included a combination of discrete water-column sampling at seven locations in the reservoir and longitudinal water-quality profiling surveys of the reservoir and tributaries to characterize the temporal and spatial water-quality dynamics of Bushy Park Reservoir. Water-quality profiling surveys were conducted with an autonomous underwater vehicle equipped with a multiparameter water-quality-sonde bulkhead. Data collected by the autonomous underwater vehicle included water temperature, dissolved oxygen, $\mathrm{pH}$, specific conductance, turbidity, total chlorophyll as fluorescence (estimate of algal biomass), and phycocyanin as fluorescence (estimate of cyanobacteria biomass) data.

Characterization of the water-quality conditions in the reservoir included comparison to established State nutrient guidelines, identification of any spatial and seasonal variation in water-quality conditions and phytoplankton community structures, and assessment of the degree of influence of waterquality conditions related to Foster Creek and Durham Canal inflows, especially during periods of elevated taste-and-odor concentrations. Depth-profile and autonomous underwater vehicle survey data were used to identify areas within the reservoir where greater phytoplankton and cyanobacteria densities were most likely occurring.

Water-quality survey results indicated that Bushy Park Reservoir tended to stratify thermally at a depth of about 20 feet from June to early October. The stratification was limited to the deeper portions of the reservoir near the dam and often dissipated within the reservoir near the CWS intake less than a mile upstream from the dam. Where thermally stratified, a corresponding depletion of dissolved oxygen also occurred at about the same depth and resulted in an anoxic hypolimnion below the 25 -foot depth and an increase in specific conductance, likely due to re-mobilized metals and phosphorus under reducing conditions. In general, chlorophyll estimated from fluorescence exhibited some spatial variation, but no strong consistent pattern or "hot spot" was observed. Phycocyanin, estimated from relative fluorescence unit output as blue-green algae cell density, periodically seemed to be greater in the upper portion of the reservoir, but those differences may be attributed to increased turbidity and the potential change in phytoplankton community structure that affects fluorescence. Increased phycocyanin was observed at about the 10-foot depth during the summer months.

A constant production of 2-methylisoborneol (MIB) near the dam and geosmin in the middle and upper portions of the reservoir appears to be occurring during the summer and early fall in the reservoir, but concentrations of these compounds tend to be between 10 and 15 nanograms per liter, which is at the Charleston Water System treatment threshold. At the Bushy Park Reservoir intake, the dominant taste-and-odor compound tended to be MIB, measured at a 2- or 3-to-1 ratio with geosmin during the summer and fall. During springtime episodes, however, when taste-and-odor compound concentrations typically are elevated above the Charleston Water System treatment threshold, the spatial distribution of geosmin concentrations greater than 15 nanograms per liter ( 28 to 38 nanograms per liter) was best explained by in situ production in the lower portion of the Bushy Park Reservoir near the dam rather than transport from Foster Creek. This pattern seems to indicate a possible shift in phytoplankton communities (or, at least, cyanobacteria communities) from MIB producers to geosmin producers.

The spatial and seasonal assessment of water-quality conditions in Bushy Park Reservoir identified seasonal differences in water chemistry and spatial differences between the upper and lower portions of the reservoir that correspond to the location of elevated geosmin concentrations. On the basis of the spatial and seasonal assessment of actinomycetes concentrations compared to taste-and-odor compound concentrations, cyanobacteria production likely was the dominant source of the taste-and-odor episodes rather than actinomycetes. The lack of spatial and seasonal patterns in actinomycetes concentrations did not correspond to the springtime geosmin 
concentrations that were elevated above the Charleston Water System treatment threshold in the lower portion of the reservoir. Additionally, actinomycetes concentrations, although ubiquitous, had a median of about 9 and maximum of about 20 colonies per milliliter, which can be considered low for elevated taste-and-odor compound production. Nonetheless, the potential exists for actinomycetes to be a secondary source of taste-and-odor production and could explain some of the ubiquitous occurrence of low-level taste-and-odor production, such as MIB concentrations, observed throughout the summer and early fall months.

When evaluated by biovolume, cyanobacteria were not the dominant phytoplankton group in Bushy Park Reservoir during the study period. Dolichospermum planctonicum (previously Anabaena planktonica) was the dominant genera of the cyanobacteria group during spring periods. The geosmin-producing genera that were identified in the 2014 and 2015 spring communities in Bushy Park Reservoir were not observed in the 1999 and 2000 algal taxonomic data.

A more robust examination of phytoplankton species was conducted by using a multivariate analysis that identified seasonal changes in phytoplankton community structure. These seasonal phytoplankton communities appeared to be explained by seasonal changes in water chemistry and may be responsible for episodes of taste-and-odor occurrence, especially geosmin. The most probable source of geosmin identified during the study was $D$. planctonicum.

In a synoptic sampling event during a taste-and-odor episode in April 2015, cyanobacteria, not acinomycetes, also was indicated to be the more prevalent source of the geosmin. Although the Edisto River intake and its associated supply tunnel to the treatment facility had relatively high actinomycetes concentrations (130 and 140 colonies per milliliter, respectively) compared to the Bushy Park intake and tunnel ( 2 colonies per milliliter), corresponding geosmin concentrations were below 5 nanograms per liter for source water from the Edisto River intake and tunnel. Elevated geosmin concentrations above the Charleston Water System treatment threshold were identified in source waters from the Bushy Park Reservoir. The cyanobacteria community at the sampled sites in April 2015 was statistically similar to the community in the Bushy Park Reservoir in April 2014, when geosmin concentrations also were elevated. The only geosminproducing genus identified at the Bushy Park intake, however, was $D$. planctonicum.

\section{Introduction}

Currently (2017), the Bushy Park Reservoir is the principal water supply for 400,000 people in the greater Charleston, South Carolina, area, including homes as well as businesses and industries in the Bushy Park Industrial Complex (Charleston Water System, 2016). The Bushy Park Industrial Complex, located near Goose Creek and north of
Charleston, was established in 1954 along the east bank of the Back River and the west bank of the Cooper River. To provide water to the industrial users, a freshwater reservoir was constructed by impounding the Back River at the southern end near the confluence with the Cooper River (fig. 1). Durham Canal was constructed as a conduit between the northern end of the reservoir and the freshwater reach of the West Branch of the Cooper River.

Bushy Park Reservoir is a relatively shallow impoundment with a subtropical climate, and, although there is an adequate supply of freshwater, there are water-quality concerns related to taste and odor ( $\mathrm{T} \& \mathrm{O})$. In general, $\mathrm{T} \& \mathrm{O}$ episodes are common in reservoirs used for drinking water throughout the United States (Paerl and others, 2001; Taylor and others, 2006; Jüttner and Watson, 2007). The occurrence of trans-1,10-dimethyl-trans-9-decalol (geosmin) and 2-methylisoborneol (MIB), which produce musty, earthy tastes and odors in drinking water, represents one of the primary causes of T\&O episodes (Suffet and others, 1996). Although not a human health problem, geosmin and MIB are problematic in drinking water because the human detection threshold for these compounds is extremely low (10 nanograms per liter [ng/L]); Wnorowski, 1992; Young and others, 1996), and conventional water-treatment procedures (particle separation, oxidation, and adsorption) typically do not reduce concentrations below the threshold level (Suffet and others, 1996). The production and release of geosmin and MIB have been related to bacteria (actinomycetes) typically found in the soil and certain species of cyanobacteria (also known as blue-green algae [BGA]). Geosmin- and MIB-producing cyanobacterial blooms are attributed to a range of environmental factors, including nutrient concentrations and ratios, light availability, water temperatures, water-column stability, and flushing rates (Downing and others, 2001; Paerl and others, 2001; Mau and others, 2004; Dzialowski and others, 2009). The complex interaction among the physical, chemical, and biological processes within lakes and reservoirs often makes it difficult to identify primary environmental factors that cause the production and release of these cyanobacterial by-products. Nonetheless, an understanding of the environmental factors that control cyanobacteria dominance in reservoirs has allowed water-resource and watershed managers to apply management strategies to prevent conditions under which cyanobacteria dominate (Downing and others, 2001; Taylor and others, 2006). Remediation efforts of reservoir conditions where cyanobacteria dominance occurred has hinged upon a strong scientific understanding of the mechanisms controlling the algal community (Downing and others, 2001; Taylor and others, 2006).

As part of a long-range planning process, the Charleston Water System (CWS) requested assistance from the U.S. Geological Survey (USGS) in assessing the circulation of Bushy Park Reservoir and its effects on water quality. The South Carolina Surface Water Withdrawal, Permitting Use, and Reporting Act of 2011 (http://www.scstatehouse.gov/code/ t49c004.php) has affected the permitting and operations of 

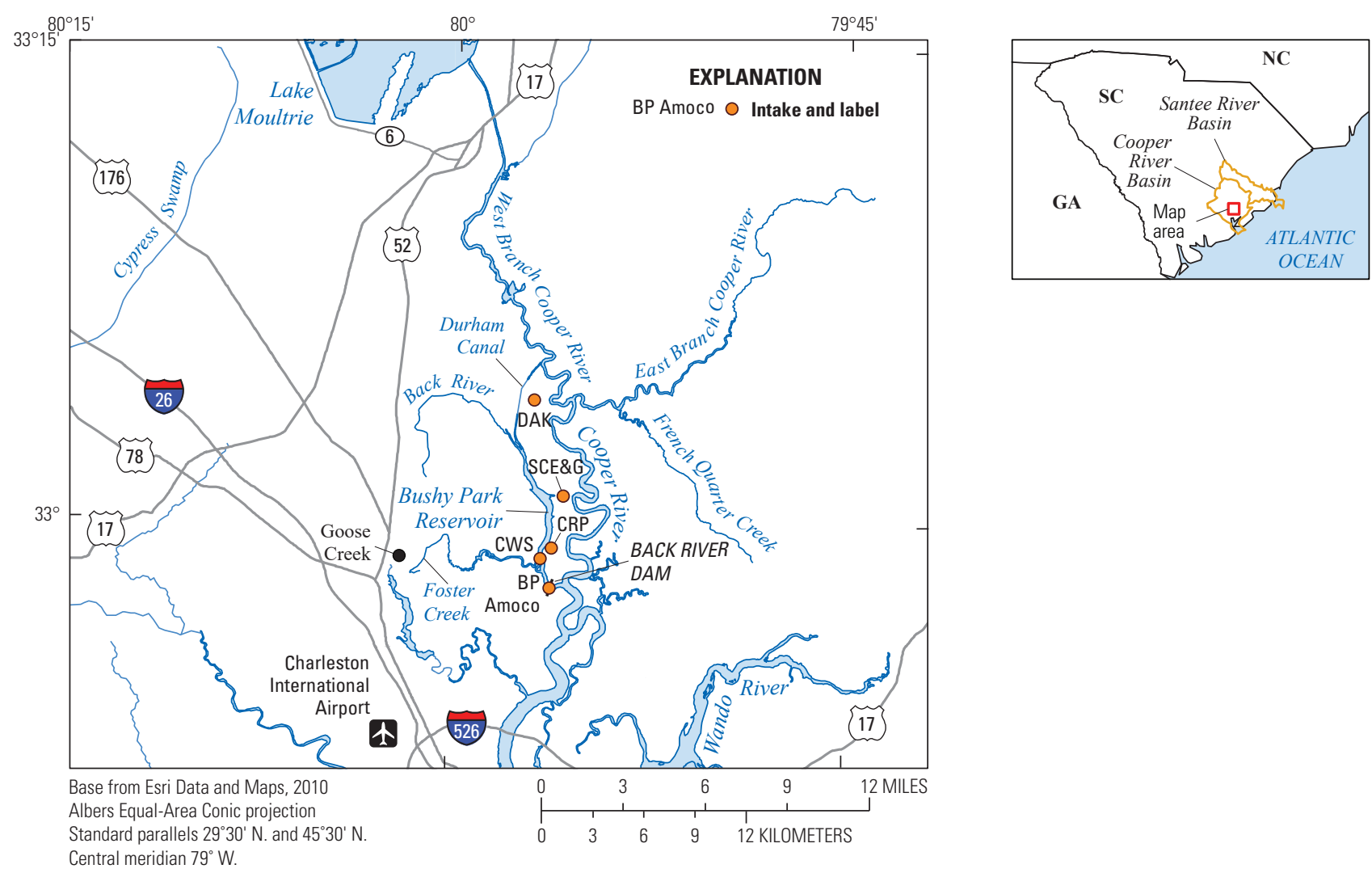

Figure 1. Bushy Park Reservoir, near Goose Creek, South Carolina, and location of industrial withdrawal intakes [BP Amoco, British Petroleum Amoco; DAK, DAK Americas; SCE\&G, South Carolina Electric and Gas Williams Station; CRP, Cooper River Partners; CWS, Charleston Water System].

the Bushy Park Reservoir, and as a result, there has been an immediate need for hydrologic, hydrodynamic, and waterquality data and analysis to inform water-resource planning for the Charleston area. The USGS, in cooperation with the CWS, conducted a 21-month investigation to address five areas of interest for CWS in their long-range planning process:

1. Hydrologic monitoring of the reservoir to establish a water budget and document reservoir circulation dynamics;

2. Flow monitoring in the water-supply tunnel to compute flow from Bushy Park Reservoir;

3. Water-quality sampling, profiling, and continuous monitoring to understand the causes of $\mathrm{T} \& \mathrm{O}$ occurrence;

4. Technical evaluation of an existing hydrodynamic and water-quality simulation model for the reservoir; and

5. Preliminary evaluation of alternative reservoir operations scenarios.

\section{Purpose and Scope}

This report addresses the third area of concern in the study by describing the collection and analysis of data to characterize the water quality of the Bushy Park Reservoir from September 2013 to May 2015 (table 1). The first two areas of concern, hydrologic data, and reservoir circulation and flow monitoring of the water-supply tunnel, are addressed in Conrads and others (2017b). The water-quality datacollection network was designed to provide data that describe the chemical, physical, and biological processes that influence (1) geosmin and MIB occurrence in this source-water reservoir, (2) cyanobacterial abundance, and (3) occurrence of geosmin-producing and toxin-producing genera of cyanobacteria. The possibility that actinomycetes may be a source of geosmin was also evaluated.

The water-quality data collection effort, which began in the fall of 2013 and ended in the spring of 2015, enhanced the existing continuous monitoring network by including spatial water-quality surveys that were conducted using an autonomous underwater vehicle (AUV), discrete sampling and profiling of water-quality conditions, and continuous flow monitoring in one of the water-supply tunnels. The spatial 


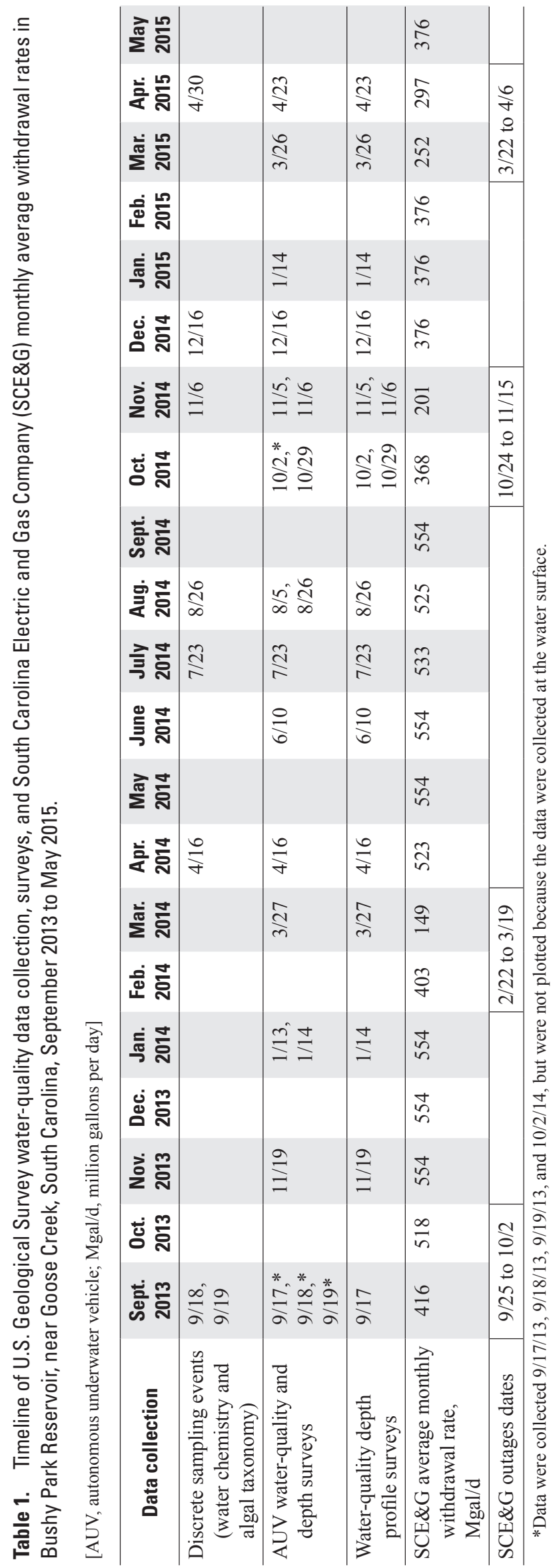


extent of the study was the Bushy Park Reservoir, from the Back River Dam to the confluence of Durham Canal and the West Branch of the Cooper River, and the two tributaries that form the reservoir - the Back River and Foster Creek (fig. 1).

Benefits of this investigation to the CWS and others include accurate data and analysis on the water quantity and water quality of Bushy Park Reservoir that will provide baseline conditions and an understanding of the available quantity of freshwater for the reservoir and the causes of T\&O issues. An understanding of the environmental factors that control cyanobacteria dominance in Bushy Park Reservoir has the potential to allow water-resource managers to apply long-term management strategies to prevent conditions under which cyanobacteria dominate and to implement short-term treatment technologies to reduce or limit the development of $\mathrm{T} \& \mathrm{O}$ compounds.

\section{Description of the Study Area}

The Bushy Park Reservoir is located in the lower part of the Edisto-Santee River Basin (fig. 1). This basin covers 17,092 square miles $\left(\mathrm{mi}^{2}\right)$ and is the second largest drainage basin on the East Coast (Seaber and others, 1987). The climate of the Bushy Park Reservoir watershed is classified as humid subtropical (Pidwirny, 2011). Mean annual precipitation from 1981 to 2010 for the weather station located at the Charleston International Airport (Station USW00013880) was 51.03 inches, and the corresponding mean temperature was 65.9 degrees Fahrenheit $\left({ }^{\circ} \mathrm{F}\right)$ (National Oceanic and Atmospheric Administration, undated).

The land cover of Bushy Park Reservoir, Foster Creek, and Back River drainage basin, which ends halfway up Durham Canal, is predominantly forest (36.2 percent), wetlands (35.5 percent), and developed (21.1 percent) (Homer and others, 2015; Conrads and others, 2017b). The remaining types of land cover are pasture, water, and barren land. The reservoir is mesotrophic to eutrophic and is heavily vegetated with aquatic plants that thrive only in freshwater, such as water hyacinth (Eichhornia crassipes), water primrose (Ludwigia uruguayensis), and hydrilla (Hydrilla verticillata) (South Carolina Department of Natural Resources, 2014). The South Carolina Department of Natural Resources (SCDNR) applies herbicides to the aquatic growth on an annual and as needed basis. Application rates do not require interruption of municipal and industrial withdrawals.

The construction of the Bushy Park Reservoir and Durham Canal is part of the long history of anthropogenic changes to the Santee and Cooper Rivers (Kjerfve and Magill, 1990). Rice plantations, with large diked fields along the banks of the Cooper and Wando Rivers, flourished in the 18th and 19th centuries. With the advent of mechanized rice harvesting, rice production diminished, because heavy machinery was unsuitable for the clayey soils of the area.

To provide a convenient freshwater reservoir for industrial and municipal water use for the 1954-created Bushy
Park Industrial Complex, the Bushy Park Dam and Durham Canal were built in 1955 and 1956, respectively, by the Bushy Park Authority (a legislative committee of city and county government officials and area utilities) to form Bushy Park Reservoir. The Back River was dammed at the lower end near the confluence with the Cooper River to create the Bushy Park Reservoir, and Durham Canal was constructed as a conduit between the upper end of the reservoir and the freshwater reaches of the Cooper River (fig. 1). The Charleston Public Works (CPW) purchased the assets of the Bushy Park Authority in 1964 and controls use of the waters from the reservoir for municipal and industrial supply. Presently (2017), five facilities have water-withdrawal intakes on Bushy Park Reservoir - the South Carolina Electric and Gas Company (SCE\&G) Williams Station, the CWS, DAK Americas, British Petroleum (BP) Amoco, and Cooper River Partners (CRP) (fig. 1).

In 1985, the U.S. Army Corps of Engineers rediverted flows from Lake Moultrie to the Santee River to alleviate a severe sedimentation problem in Charleston Harbor that had been created by the diversion of freshwater flows. After the rediversion project, the flows to the Cooper River were reduced from the annual mean flow of 15,600 cubic feet per second $\left(\mathrm{ft}^{3} / \mathrm{s}\right)$ to a weekly mean flow of $3,000 \mathrm{ft}^{3} / \mathrm{s}-\mathrm{a}$ level that would alleviate sedimentation in the harbor while ensuring an adequate freshwater source to the Bushy Park Reservoir at the mouth of the Durham Canal (South Carolina Water Resources Commission, 1979).

The flow and circulation dynamics of the Bushy Park Reservoir are quite complex. The water level, water velocity, and flow direction in the Bushy Park Reservoir are constantly changing due to the tides and flows from the Cooper River, industrial withdrawals, and meteorological conditions. The tidal effects on the reservoir are caused by orbital mechanics and are highly predictable. Historically, the Back River was a tidal slough (as was the Cooper River) with very little net flow. The Back River was dominated by the tidal exchange at the confluence with the Cooper River. After the construction of the Back River Dam and Durham Canal in the 1950s, the tidal exchange shifted to the confluence of the upper reaches of the Back River and Durham Canal, and net flow from the reservoir was through Durham Canal to the Cooper River. The Back River changed from a tidal brackish marsh to a freshwater tidal marsh. In 1973, SCE\&G constructed the Williams Station, a coal-fired powerplant that withdraws water from the reservoir for cooling and returns the water to the Cooper River. The flow patterns of the Bushy Park Reservoir are dominated by the large withdrawal by SCE\&G for cooling water for the Williams Station plant. The volume of the withdrawal, more than 500 million gallons per day $(\mathrm{Mgal} / \mathrm{d})$, is the dominant factor in the water budget and circulation pattern of the reservoir. When the plant is operating and withdrawing water, the net outflow from the reservoir is through the Williams Station and not through Durham Canal. Figure 2 shows daily precipitation, the tidally filtered daily flow for Durham Canal, the 7-day average flow in Durham Canal, and the withdrawal 


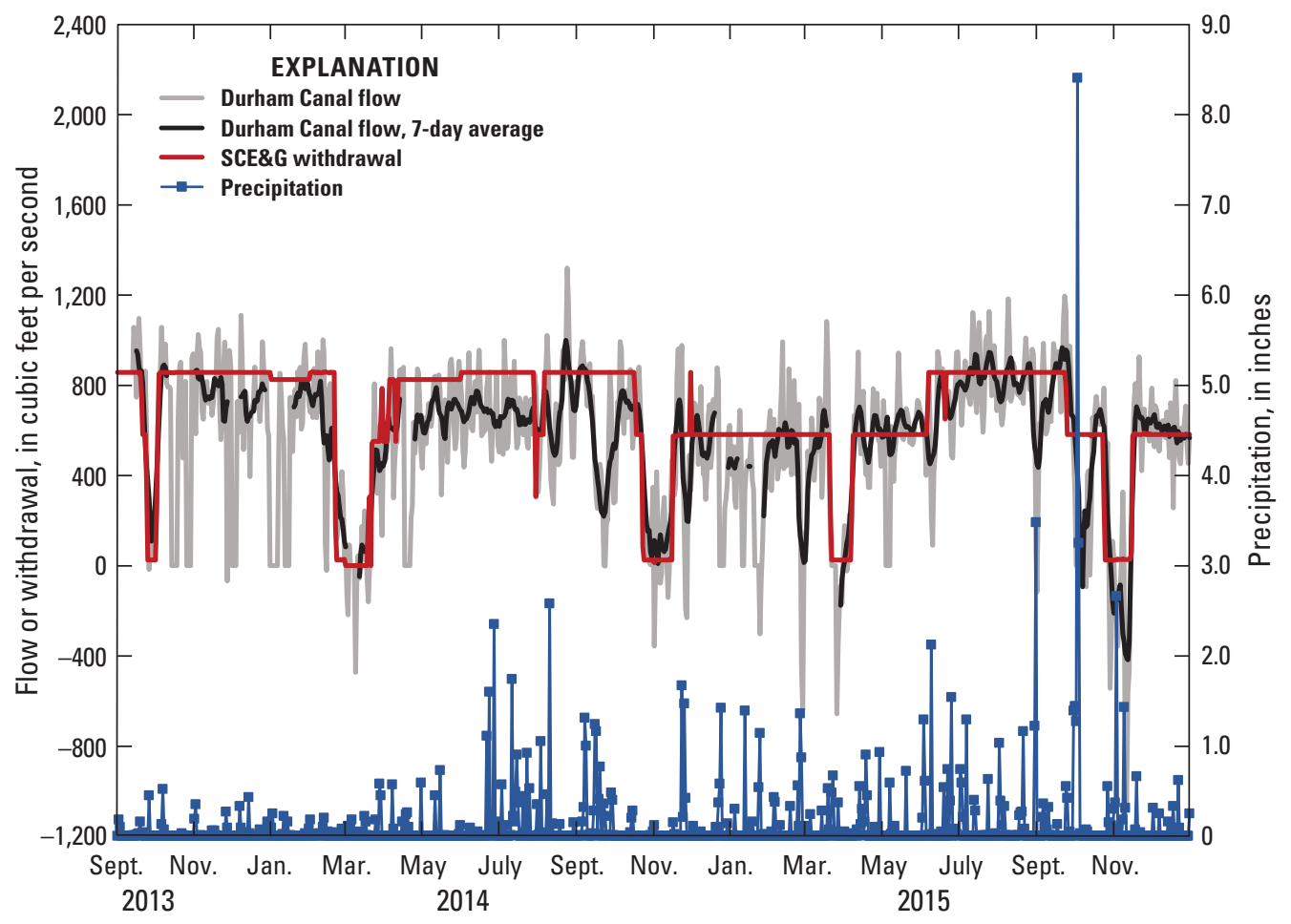

Figure 2. Precipitation at the Charleston Water System Intake (station 0217206110), daily flows and 7-day average flows in Durham Canal, and withdrawal rates by the Williams Station from Bushy Park Reservoir, near Goose Creek, South Carolina, for the period September 1, 2013, to December 31, 2015 (Conrads and others, 2017b). The sign of the Durham Canal flow was reversed (multiplied by negative one) for plotting purposes.

rates (in cubic feet per second) for the Williams Station for the period September 2013 to December 2015 (Conrads and others, 2017b). The flows in Durham Canal and the withdrawals are of similar magnitudes. When the Williams plant has an outage, the net flow in Durham Canal quickly changes from into the reservoir to a small net flow to the Cooper River. Periods of extended rainfall can cause the net flow in Durham Canal to either decrease into the reservoir or reverse to the Cooper River as in the case of the heavy rainfall in early October 2015.

\section{Previous Studies}

Over the years, a number of ecological and modeling studies of the Bushy Park Reservoir and its tributaries have been conducted. In the 1970s, 1980s, and 1990s, studies of Foster Creek were conducted to address the effect of runoff from military, commercial, and residential areas. A summary of these studies can be found in Campbell and Bower (1996). Highlights of other previous studies that are of interest to the current study are discussed in this section.

The water quality of Foster Creek and Bushy Park Reservoir has improved overall since the late 1970s, following elimination in 1983 of wastewater discharges into
Foster Creek (South Carolina Department of Health and Environmental Control, 2004). Jordan, Jones \& Goulding, Inc., (1988) investigated the cause of unpleasant T\&O in municipal drinking water in the Charleston area and assessed the overall water quality in Foster Creek and Back River. The study arrived at four conclusions:

1. The entire Foster Creek, Bushy Park Reservoir, Durham Canal, and Back River system met South Carolina Department of Health and Environmental Control (SCDHEC) standards for Class B waters, with the exception of below standard dissolvedoxygen concentrations (DOC) in Foster Creek and Back River;

2. Bushy Park Reservoir and its tributaries (including Foster Creek) were eutrophic and supported large amounts of aquatic vegetation;

3. Naturally occurring $\mathrm{T} \& \mathrm{O}$ compounds were found throughout the system but were highest in Foster Creek and the Back River; and

4. Foster Creek samples had higher fecal coliform bacteria concentrations than Bushy Park Reservoir samples. 
The SCDHEC monitors the water-quality conditions in Bushy Park Reservoir (referred to as Back River Reservoir [station CSTL-124] by SCDHEC) near the dam to determine if the water quality supports the designated aquatic life and recreational use. The SCDHEC has reported that Bushy Park Reservoir had total nitrogen, total phosphorus, and chlorophyll $a$ concentrations that met established numeric nutrient criteria in 2004, 2010, and 2014, but dissolvedoxygen concentrations were not within required levels (South Carolina Department of Health and Environmental Control, 2004, 2010, 2014a, 2014b, 2014c). Low dissolvedoxygen concentrations also were reported as an impairment for Foster Creek, a tributary near the CWS intake.

The SCDNR manages the aquatic invasive and nuisance species of macrophytes in Bushy Park Reservoir. The SCDNR reported that, historically, the reservoir (referred to as Back River Reservoir in SCDNR reports) has been heavily vegetated with aquatic plants that thrive only in freshwater, including invasive species of water hyacinth (Eichhornia crassipes), water primrose (Ludwigia hexapetala), and hydrilla (Hydrilla vertcillata), and nuisance species of fanwort (Cabomba caroliniana), Frog's bit (Limnobium spongia) and giant cutgrass (Zizaniopsis miliacea) (South Carolina Department of Natural Resources, 2014). The SCDNR reported that macrophytes cover about 360 acres of the 850 -acre surface area of the reservoir. As part of the management plan to control the aquatic growth, the SCDNR has applied herbicides seasonally over the past decades (South Carolina Department of Natural Resources, 2014).

\section{Approach and Methods}

Water-quality data were collected for this study to gain insight on the convergence of environmental factors that tend to occur between the physical, chemical, biological, and circulation processes within Bushy Park Reservoir that cause the production and release of cyanobacterial by-products of geosmin and MIB. A characterization of the hydrology and circulation of the reservoir is presented in Conrads and others (2017b).

The water-quality data collected for the study were a combination of discrete water-column sampling at seven locations in the reservoir (table 2; fig. 3) and longitudinal water-quality profiling surveys of the reservoir and tributaries, which were conducted to capture the temporal and spatial water-quality dynamics of Bushy Park Reservoir (Conrads and others, 2017a). The discrete water-column samples were collected near the surface (3.3-foot [ft; 1-meter $\{\mathrm{m}\}]$ depth) and analyzed for geosmin, MIB, chlorophyll $a$, pheophytin $a$, nutrient, major ions, trace metals, actinomycetes, and suspended-sediment concentrations, and for phytoplankton cell densities and biovolumes (table 3). Discrete sampling locations were assigned a site identification composed of "CWS" followed by a number from 1 to 7 , with lower numbers in the upper portion of the reservoir and Durham Canal, increasing downstream toward the dam in the lower portion of the reservoir (table 2; fig. 3). Sites CWS-1 and CWS-2 represent contributions to the reservoir from Cooper River and Durham Canal, respectively. Sites CWS-3 and CWS-4 represent the middle portion of the reservoir and are near the SCE\&G intake. Sites CWS-5 (CWS intake location) and CWS-7 at the dam represent the lower portion of the reservoir. Site CWS-6 is located on Foster Creek, which contributes inflow into Bushy Park Reservoir between sites CWS-5 and CWS-7.

Water-quality profiling surveys were conducted with an AUV equipped with a multiparameter water-quality-sonde bulkhead. Data collected by the AUV included water temperature, dissolved oxygen, $\mathrm{pH}$, specific conductance, turbidity, total chlorophyll as fluorescence (estimate of algal biomass), and phycocyanin as fluorescence (estimate of cyanobacteria biomass) data (table 4; fig. 4). Although chlorophyll $a$ is the dominant pigment in most phytoplankton, different phytoplankton groups contain other types of chlorophyll and accessory (carotenoids, phycobilins [for example, phycocyanin]) pigments. In addition to chlorophyll $a$, green algae also contain chlorophyll $b$, while diatoms, dinoflagellates, and brown algae contain chlorophyll $c$. The total chlorophyll present in the water was estimated based on in situ fluorescence of phytoplankton excited by a laser with a wavelength of 435-470 nanometers as recorded by the YSI 6025 probe (table 4). Cyanobacteria in freshwater systems contain the accessory pigment phycocyanin, and in situ fluorescence of cyanobacteria was measured by the YSI 6131 probe.

All data used in this study are available online. The data from the USGS gaging network and discrete water-quality sampling are available at the U.S. Geological Survey National Water Information System (NWIS) portal (U.S. Geological Survey, 2016). Phytoplankton taxonomic, vertical waterquality profile, and AUV survey data are available at Conrads and others (2017a).

The method used for planning the collection of waterquality data was to schedule bimonthly water-quality AUV surveys of large portions of the reservoir with periodic discrete sampling and additional surveys during potential T\&O events ("on call" water-quality surveys). Many of these surveys coincided with velocity and flow data collection before and after withdrawal outages at the Williams Station.

Sixteen bimonthly water-quality AUV surveys of water temperature, dissolved oxygen, $\mathrm{pH}$, specific conductance, turbidity, total chlorophyll fluorescence (estimate of algal biomass), and phycocyanin fluorescence (estimate of cyanobacteria biomass) were conducted (table 1). Total chlorophyll and phycocyanin measurements are expressed in relative fluorescence units (RFUs); however, an internal algorithm developed by the manufacturer can also provide a generalized estimate of chlorophyll, in micrograms per liter $(\mu \mathrm{g} / \mathrm{L})$, and cyanobacteria (BGA) density, in cells per milliliter, from the RFU output. 


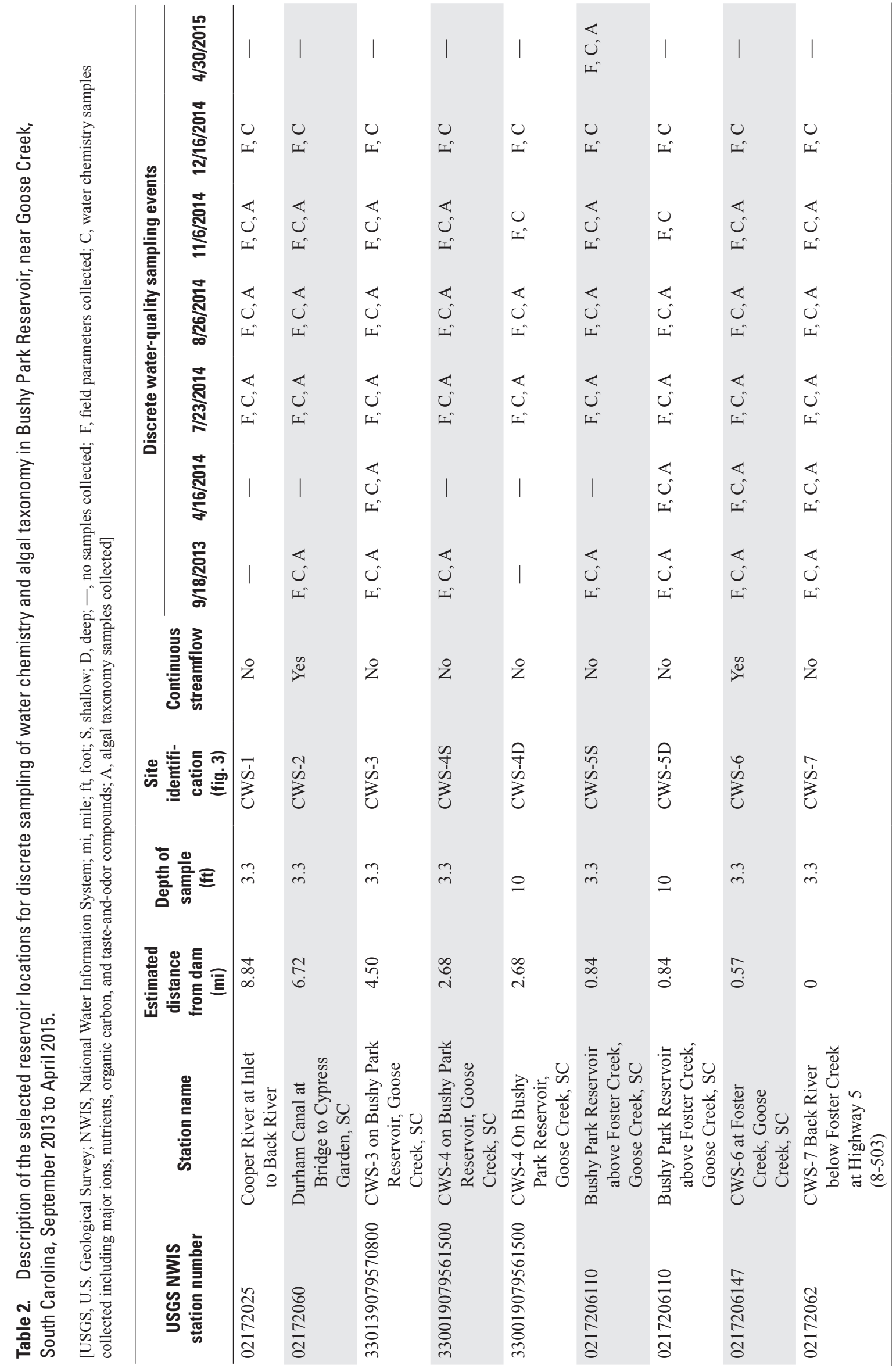




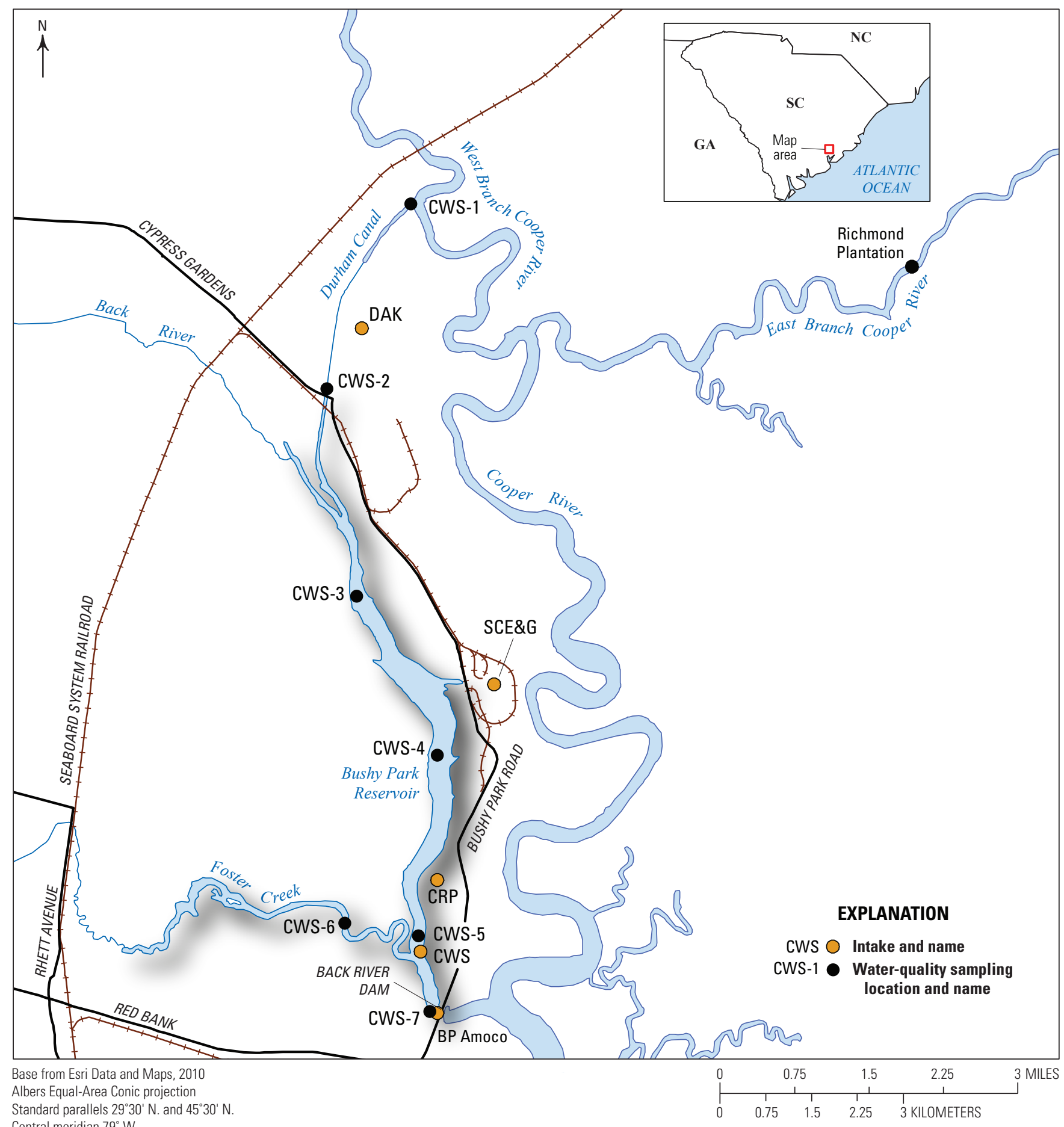

Figure 3. Locations and names of water-quality sampling sites and industrial withdrawal intakes in the Bushy Park Reservoir, near Goose Creek, South Carolina, September 2013 to April 2015 [BP Amoco, British Petroleum Amoco; DAK, DAK Americas; SCE\&G, South Carolina Electric and Gas Williams Station; CRP, Cooper River Partners; CWS, Charleston Water System]. 
Table 3. Description of the analytical tests performed by the U.S. Geological Survey National Water Quality Laboratory (NWQL) and National Environmental Laboratory Accreditation Program-certified contract laboratory on water samples from Bushy Park Reservoir, near Goose Creek, South Carolina, 2013 to 2015.

[Algal taxonomic analysis was performed by Linda C. Ehrlich, Ph.D., Spirogyra Diversified Environmental Services; taste-and-odor compound analysis was performed by Underwriter Laboratories/Eurofins Eaton Analytical, Inc. Abbreviations: - , not available; NWIS, U.S. Geological Survey National Water Information System; CAS, Chemical Abstracts Service; $\mathrm{mg} / \mathrm{L}$, milligram per liter; $\mu \mathrm{g} / \mathrm{L}$, microgram per liter; NH3, ammonia; NO2, nitrite; NO3, nitrate; $\mu \mathrm{S} / \mathrm{cm}, \mathrm{micro}-$ siemens per centimeter at 25 degrees Celsius; deg Cel, degrees Celsius; $\mu \mathrm{m}^{3} / \mathrm{mL}$, cubic micrometer per milliliter; cells $/ \mathrm{mL}$, cells per milliliter; cm, centimeter; ng/L, nanogram per liter; EPA, U.S. Environmental Protection Agency; TSS, total suspended solids; TDS, total dissolved solids]

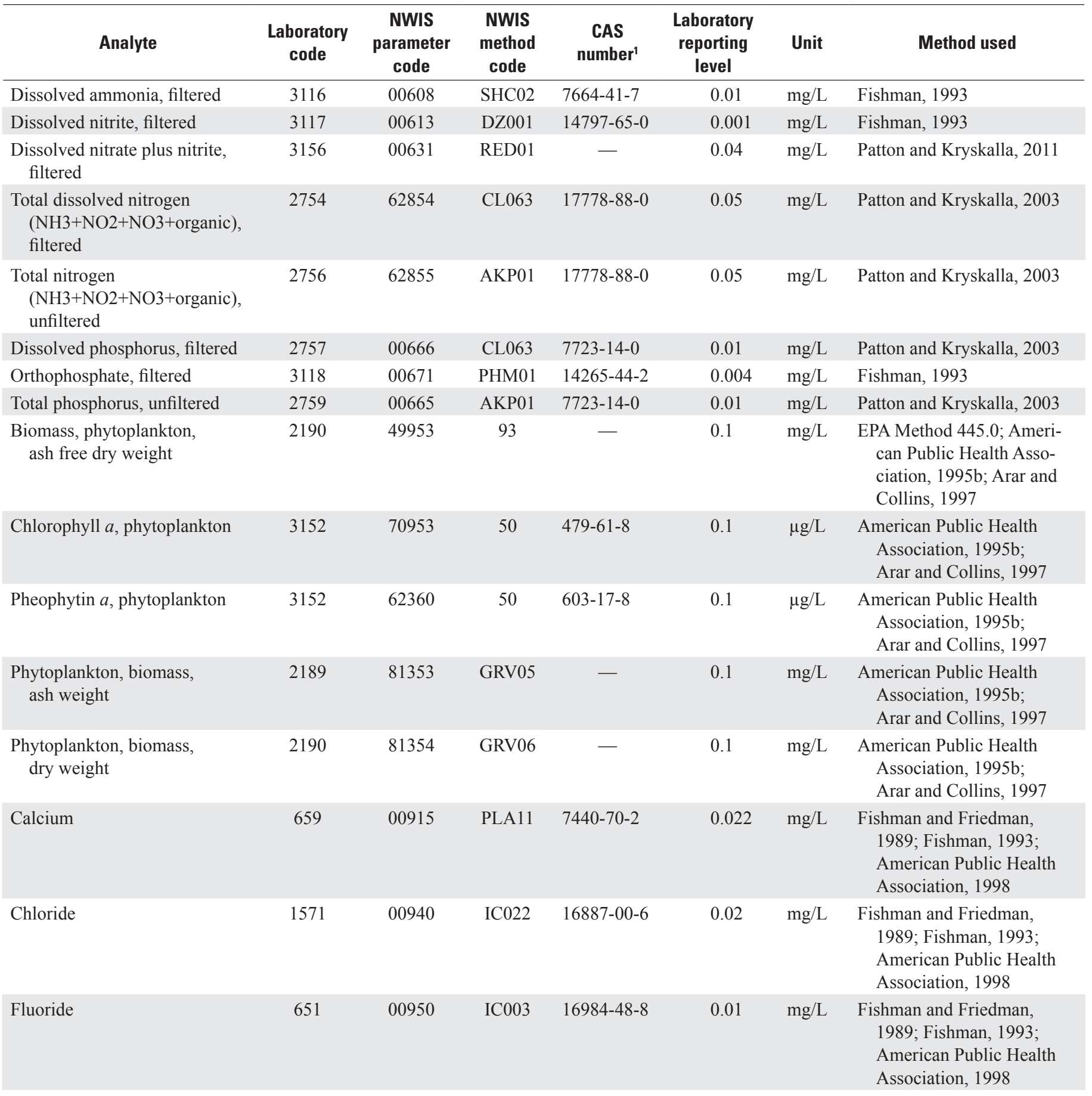


Table 3. Description of the analytical tests performed by the U.S. Geological Survey National Water Quality Laboratory (NWQL) and National Environmental Laboratory Accreditation Program-certified contract laboratory on water samples from Bushy Park Reservoir, near Goose Creek, South Carolina, 2013 to 2015.-Continued

[Algal taxonomic analysis was performed by Linda C. Ehrlich, Ph.D., Spirogyra Diversified Environmental Services; taste-and-odor compound analysis was performed by Underwriter Laboratories/Eurofins Eaton Analytical, Inc. Abbreviations: - , not available; NWIS, U.S. Geological Survey National Water Information System; CAS, Chemical Abstracts Service; $\mathrm{mg} / \mathrm{L}$, milligram per liter; $\mu \mathrm{g} / \mathrm{L}$, microgram per liter; NH3, ammonia; NO2, nitrite; NO3, nitrate; $\mu \mathrm{S} / \mathrm{cm}, \mathrm{micro}-$ siemens per centimeter at 25 degrees Celsius; deg Cel, degrees Celsius; $\mu \mathrm{m}^{3} / \mathrm{mL}$, cubic micrometer per milliliter; cells $/ \mathrm{mL}$, cells per milliliter; cm, centimeter; ng/L, nanogram per liter; EPA, U.S. Environmental Protection Agency; TSS, total suspended solids; TDS, total dissolved solids]

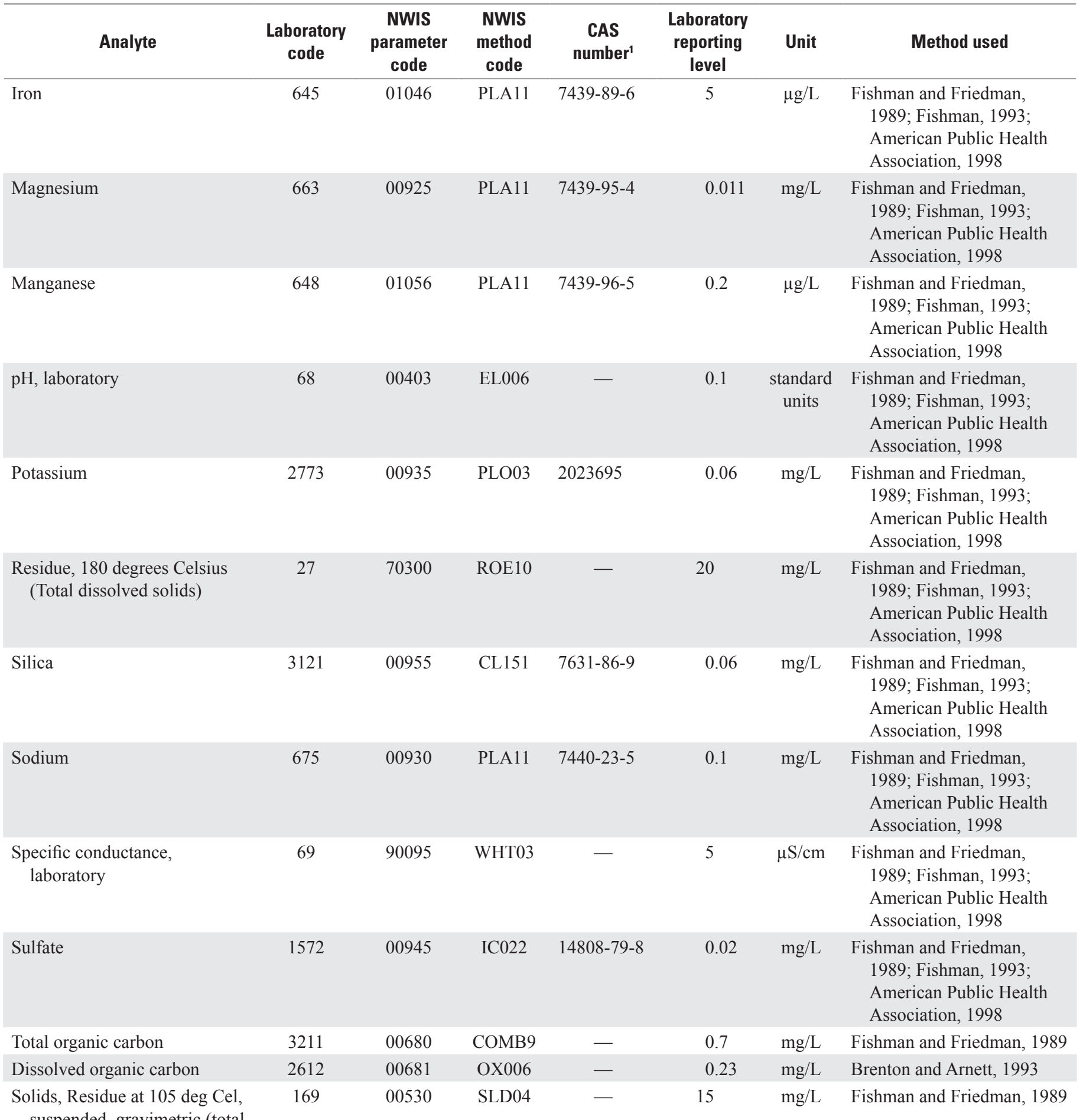

suspended, gravimetric (total suspended solids) 
Table 3. Description of the analytical tests performed by the U.S. Geological Survey National Water Quality Laboratory (NWQL) and National Environmental Laboratory Accreditation Program-certified contract laboratory on water samples from Bushy Park Reservoir, near Goose Creek, South Carolina, 2013 to 2015.-Continued

[Algal taxonomic analysis was performed by Linda C. Ehrlich, Ph.D., Spirogyra Diversified Environmental Services; taste-and-odor compound analysis was performed by Underwriter Laboratories/Eurofins Eaton Analytical, Inc. Abbreviations: - , not available; NWIS, U.S. Geological Survey National Water Information System; CAS, Chemical Abstracts Service; mg/L, milligram per liter; $\mu \mathrm{g} / \mathrm{L}$, microgram per liter; NH3, ammonia; NO2, nitrite; NO3, nitrate; $\mu \mathrm{S} / \mathrm{cm}$, microsiemens per centimeter at 25 degrees Celsius; deg Cel, degrees Celsius; $\mu \mathrm{m}^{3} / \mathrm{mL}$, cubic micrometer per milliliter; cells $/ \mathrm{mL}$, cells per milliliter; cm, centimeter; ng/L, nanogram per liter; EPA, U.S. Environmental Protection Agency; TSS, total suspended solids; TDS, total dissolved solids]

\begin{tabular}{|c|c|c|c|c|c|c|c|}
\hline Analyte & $\begin{array}{l}\text { Laboratory } \\
\text { code }\end{array}$ & $\begin{array}{c}\text { NWIS } \\
\text { parameter } \\
\text { code }\end{array}$ & $\begin{array}{c}\text { NWIS } \\
\text { method } \\
\text { code }\end{array}$ & $\begin{array}{c}\text { CAS } \\
\text { number }^{1}\end{array}$ & $\begin{array}{c}\text { Laboratory } \\
\text { reporting } \\
\text { level }\end{array}$ & Unit & Method used \\
\hline $\begin{array}{l}\text { Ultraviolet absorbance at } \\
254 \text { nanometers }\end{array}$ & - & 66700 & - & - & 0.01 & $\mathrm{~cm}^{-1}$ & $\begin{array}{l}\text { American Public Health } \\
\text { Association, 1995a }\end{array}$ \\
\hline $\begin{array}{l}\text { Ultraviolet absorbance at } \\
280 \text { nanometers }\end{array}$ & - & 61726 & - & - & 0.01 & $\mathrm{~cm}^{-1}$ & $\begin{array}{l}\text { American Public Health } \\
\text { Association, 1995a }\end{array}$ \\
\hline Actinomycetes & AIA & 63688 & - & - & & & $\begin{array}{l}\text { American Public Health } \\
\text { Association, 2005b }\end{array}$ \\
\hline Geosmin, whole water & $\mathrm{V} 210$ & 68288 & - & $19700-21-1$ & 2 & $\mathrm{ng} / \mathrm{L}$ & $\begin{array}{l}\text { American Public Health } \\
\text { Association, 2005a; modi- } \\
\text { fied EPA method 524.2; } \\
\text { Standard Methods 6040C; } \\
\text { Capillary Gas Chromatog- } \\
\text { raphy/Mass Spectrometry/ } \\
\text { Selected Ion Storage }\end{array}$ \\
\hline $\begin{array}{l}\text { 2-methylisoborneol (MIB), } \\
\text { whole water }\end{array}$ & V210 & 68289 & - & $2371-42-8$ & 2 & $n g / L$ & $\begin{array}{l}\text { American Public Health } \\
\text { Association, 2005a; modi- } \\
\text { fied EPA method 524.2; } \\
\text { Standard Methods 6040C; } \\
\text { Capillary Gas Chromatog- } \\
\text { raphy/Mass Spectrometry/ } \\
\text { Selected Ion Storage }\end{array}$ \\
\hline $\begin{array}{l}\text { Isobutyl methoxy pryazine } \\
\text { (IBMP), whole water }\end{array}$ & V210 & - & - & $24683-00-9$ & 2 & $\mathrm{ng} / \mathrm{L}$ & $\begin{array}{l}\text { American Public Health } \\
\text { Association, 2005a; modi- } \\
\text { fied EPA method 524.2; } \\
\text { Standard Methods 6040C; } \\
\text { Capillary Gas Chromatog- } \\
\text { raphy/Mass Spectrometry/ } \\
\text { Selected Ion Storage }\end{array}$ \\
\hline $\begin{array}{l}\text { Isopropyl methoxy pyrazine } \\
\text { (IPMP), whole water }\end{array}$ & V210 & - & - & $25773-40-4$ & 2 & $n g / L$ & $\begin{array}{l}\text { American Public Health } \\
\text { Association, 2005a; modi- } \\
\text { fied EPA method 524.2; } \\
\text { Standard Methods 6040C; } \\
\text { Capillary Gas Chromatog- } \\
\text { raphy/Mass Spectrometry/ } \\
\text { Selected Ion Storage }\end{array}$ \\
\hline $\begin{array}{l}\text { 2,4,6-Trichloroanisole (TCA), } \\
\text { whole water }\end{array}$ & $\mathrm{V} 210$ & - & - & $87-40-1$ & 2 & $\mathrm{ng} / \mathrm{L}$ & $\begin{array}{l}\text { American Public Health } \\
\text { Association, 2005a; modi- } \\
\text { fied EPA method 524.2; } \\
\text { Standard Methods 6040C; } \\
\text { Capillary Gas Chromatog- } \\
\text { raphy/Mass Spectrometry/ } \\
\text { Selected Ion Storage }\end{array}$ \\
\hline $\begin{array}{l}\text { Phytoplankton taxonomic } \\
\text { analysis }\end{array}$ & - & - & - & - & 1 & $\begin{array}{l}\mu \mathrm{m}^{3} / \mathrm{mL} \\
\text { cells } / \mathrm{mL}\end{array}$ & Ehrlich, 2010 \\
\hline
\end{tabular}

${ }^{1}$ CAS Registry Number ${ }^{\circledR}$ is a Registered Trademark of the American Chemical Society. CAS recommends the verification of the CAS numbers through CAS Client Services. 
Table 4. Manufacturer's specifications for the water-quality sensors in the handheld water-quality sondes and in the bulkhead sonde of the autonomous underwater vehicle.

$\left[\mathrm{mS} / \mathrm{cm}\right.$, millisiemen per centimeter; \pm , plus or minus; \%, percent; ${ }^{\circ} \mathrm{C}$, degrees Celsius; foot, $\mathrm{ft} ; \mathrm{m}$, meter; ppt, part per thousand; $\mathrm{mg} / \mathrm{L}, \mathrm{milligram}$ per liter; NTU, nephelometric turbidity units; RFU, relative fluorescence units; $\mu \mathrm{g} / \mathrm{L}$, microgram per liter; cells/mL, cells per milliter; >, greater than; - , not specified; $\mathrm{R}^{2}$, Pearson r-squared]

\begin{tabular}{|c|c|c|c|c|c|c|c|}
\hline Sensor name & Sensor type & Range & $\begin{array}{l}\text { Detection } \\
\text { limit }\end{array}$ & Resolution & Accuracy & Linearity & $\begin{array}{c}\text { Estimated } \\
\text { lag, in } \\
\text { seconds }\end{array}$ \\
\hline Conductivity & 6560 & 0 to $100 \mathrm{mS} / \mathrm{cm}$ & - & $\begin{array}{c}0.001 \text { to } \\
0.1 \mathrm{mS} / \mathrm{cm}\end{array}$ & $\begin{array}{c} \pm 0.5 \% \\
+0.001 \mathrm{mS} / \mathrm{cm}\end{array}$ & - & 0.5 \\
\hline Temperature & 6560 & -5 to $50^{\circ} \mathrm{C}$ & - & $0.01{ }^{\circ} \mathrm{C}$ & $\pm 0.15^{\circ} \mathrm{C}$ & - & 2.1 \\
\hline Depth & NA & $\begin{array}{l}0 \text { to } 656 \mathrm{ft} \\
(200 \mathrm{~m})\end{array}$ & - & $0.001 \mathrm{ft}$ & $\pm 1 \mathrm{ft}( \pm 0.3 \mathrm{~m})$ & - & - \\
\hline Salinity & NA & 0 to $70 \mathrm{ppt}$ & - & $0.01 \mathrm{ppt}$ & $\pm 1 \%$ or $0.1 \mathrm{ppt}$ & - & - \\
\hline $\mathrm{pH}$ & FR6589; 6561 & 0 to 14 units & - & 0.01 units & \pm 0.2 units & - & $7.1^{*}$ \\
\hline $\begin{array}{l}\text { Optical dissolved } \\
\text { oxygen }\end{array}$ & 6150 & 0 to $50 \mathrm{mg} / \mathrm{L}$ & - & $0.01 \mathrm{mg} / \mathrm{L}$ & $\pm 0.1 \mathrm{mg} / \mathrm{L}$ or $1 \%$ & - & 5.5 \\
\hline Turbidity & 6136 & 0 to $1,000 \mathrm{NTU}$ & - & $0.01 \mathrm{NTU}$ & $\pm 2 \%$ or $0.3 \mathrm{NTU}$ & - & 2.1 \\
\hline $\begin{array}{l}\text { Phycocyanin } \\
\text { fluorescence } \\
\text { (***estimated as } \\
\text { blue-green algae } \\
\text { cell density) }\end{array}$ & 6131 & $\begin{array}{c}0 \text { to } 280,000 \text { cells } / \mathrm{mL} ; \\
0 \text { to } 100 \mathrm{RFU}\end{array}$ & 220 cells $/ \mathrm{mL}$ & $\begin{array}{l}1 \text { cell } / \mathrm{mL} \\
0.1 \mathrm{RFU}\end{array}$ & - & $\mathrm{R}^{2}>0.9999$ & 2.1 \\
\hline
\end{tabular}

${ }^{*}$ Can vary with age of sensor.

**Determined from cultures of Isochrysis sp. and chlorophyll $a$ concentration determined from extractions.

*** Estimated from cultures of Microcystis aeruginosa.

The discrete water-quality data collection was conducted concurrently with the water-quality surveys but at less frequent intervals. The discrete sampling occurred seven times during the study period, and samples were collected at the CWS intake and at as many as six other locations (fig. 3). Concurrent with the water-quality surveys and discrete sampling, vertical water-quality profiles of field properties were collected at a limited number of locations along the water-quality surveys or at the discrete sampling locations. Detailed descriptions of the data collection and analysis are provided below. Data-collection dates are listed in table 1.

\section{Discrete Water-Quality Data Collection}

In conjunction with 7 of the 16 AUV surveys, watercolumn samples were collected at 1 to 7 locations in Bushy Park Reservoir and major tributaries (Foster Creek and Durham Canal; table 2). The data were evaluated to describe the limnological conditions and phytoplankton community structure in the reservoir and to verify the AUV output in relation to in situ chlorophyll and phycocyanin fluorescence measurements (tables 1, 2; Conrads and others, 2017a). These discrete water-column samples, collected during 


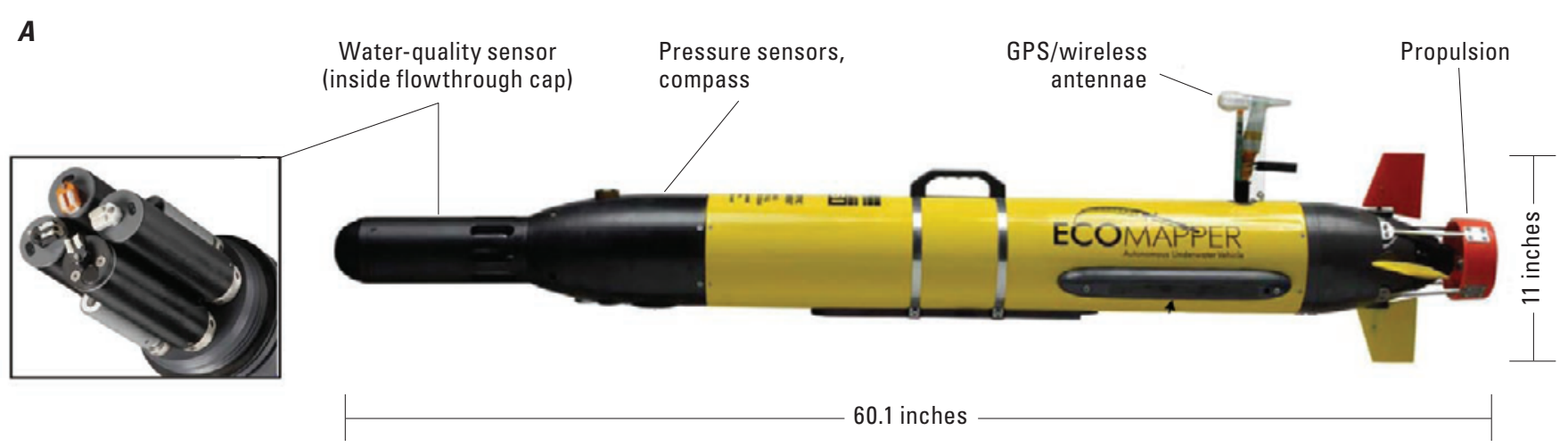

$\boldsymbol{B}$

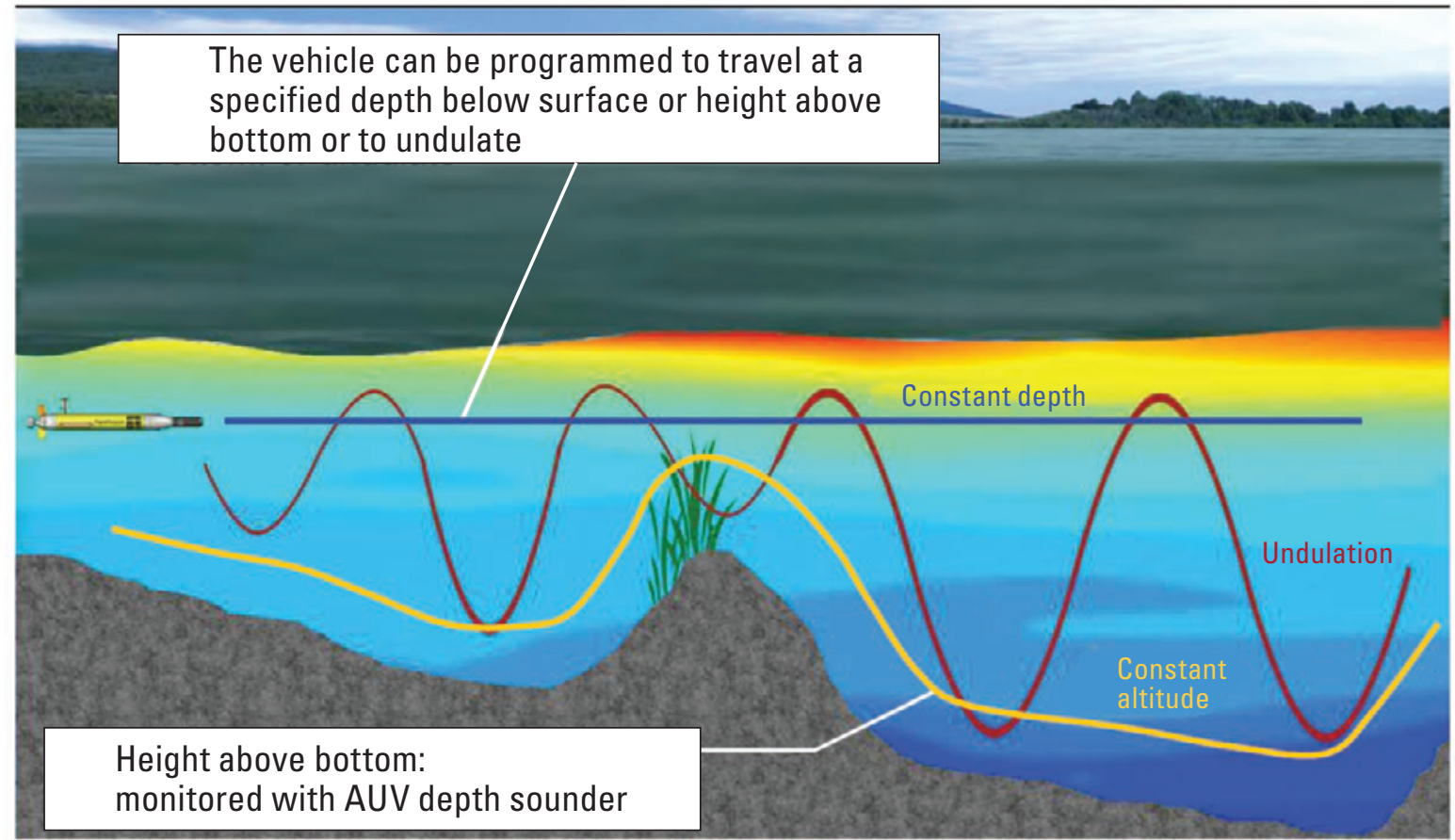

Figure 4. Diagrams of the autonomous underwater vehicle (AUV) used for water-quality surveys in Bushy Park Reservoir, near Goose Creek, South Carolina, September 2013 to April 2015: (A) major components, including a closeup of the water-quality sensors inside the flowthrough cap and $(B)$ three survey modes (constant depth, constant altitude, and undulation). Surveys in Bushy Park Reservoir typically were run as undulations. Modified from YSI, Inc. (2008) and modified from Jackson (2013b).

September 2013 to April 2015, were analyzed for biological, physical, and chemical constituents.

Reservoir discrete sampling frequency varied seasonally and spatially with greater numbers of samples collected during the peak algal growth period (spring to late summer; table 2). In general, water samples at all sites were collected near the surface (3.3-ft [1-m] depth) within the photic zone to allow comparison among locations in the reservoir (the exception was site CWS-5 in April 2014). Additionally, concurrent water samples were collected at a 10-ft (3.3-m) depth at site
CWS-5 to assess the environmental conditions at the intake depth (fig. 3). On the basis of the AUV survey output, a zone of greater chlorophyll and phycocyanin fluorescence periodically was observed near the $10-\mathrm{ft}(3.3-\mathrm{m})$ depth in the middle portion of the reservoir, so a concurrent water sample at that depth was added to the site CWS-4 location during the July, August, November, and December 2014 sampling events (fig. 3).

Water-column samples were collected and processed according to USGS protocols and guidelines (U.S. Geological 
Survey, variously dated; Graham and others, 2008, 2009). Because one of the main goals was to verify sonde measurements with laboratory-derived data, discrete-depth point samples were collected at one location in a cross section with a peristaltic pump sampler and tubing attached to a multiparameter sonde. Water was pumped from the selected depth directly into the sample bottle or filtration system during sample processing. The attached sonde provided Global Positioning System (GPS) location and field measurements of water temperature, dissolved oxygen, $\mathrm{pH}$, specific conductance, turbidity, total chlorophyll as fluorescence (estimate of algal biomass), and phycocyanin as fluorescence (estimate of cyanobacteria biomass) during the exact same time, location, and depth of sampling as the water-column samples. At locations where water movement was negligible, transparency (Secchi disk depth) and light attenuation were measured at the time of sampling; however, increasing water movement due to changing tidal conditions in and near Durham Canal frequently prevented these properties from being measured.

Reservoir depth-profile measurements of pigment fluorescence (an estimate of chlorophyll and an estimate of phycocyanin), specific conductance, $\mathrm{pH}$, dissolved-oxygen concentrations, and water temperature were made at $3.3-$ and $10-\mathrm{ft}$ (1- to 3.3-m, respectively) depths along each transect using a field-calibrated multiparameter sonde (tables 2, 4). Photosynthetically active radiation (PAR) at the time of sampling was measured with a portable light meter that had an accuracy, for the 0 to 55 degrees Celsius $\left({ }^{\circ} \mathrm{C}\right)$ range, of $+/-0.6$ percent of reading and $+/-3$ counts on the least significant digit displayed and linearity of $+/-0.05$ percent (user specifications found at https://www.licor.com/env/products/light/light_meter.html/). Measurements of PAR were made in the 0 to 1,999 range with a 0.1 micromole of photons per second per square meter $\left(\mu \mathrm{mol} / \mathrm{s}-\mathrm{m}^{2}\right)$ resolution.

Water-column samples were analyzed for total (dissolved and particulate) and dissolved nitrogen species of nitrate, nitrite, and ammonia and for total phosphorus and dissolved orthophosphate by the USGS National Water Quality Laboratory (NWQL) in Denver, Colorado (Fishman, 1993; Patton and Kryskalla, 2003, 2011) (table 3). Additionally, water samples were analyzed for total and dissolved organic carbon (Fishman and Friedman, 1989; Brenton and Arnett, 1993, respectively), major ions, and trace metals (Fishman and Friedman, 1989; Fishman, 1993; American Public Health Association, 1998). Ultraviolet absorbance at 254 and 280 nanometers (estimate of the humic content or reactive fraction of organic carbon) was measured by using an ultraviolet-visible (UV-Vis) spectrum spectrophotometer at the USGS South Atlantic Water Science Center in Columbia, South Carolina (American Public Health Association, 1995a). Samples for chlorophyll $a$, pheophytin $a$ (pigment degradation product of chlorophyll $a$ ), and phytoplankton ash-free dry mass were collected on 0.47 -micron glass-fiber filters and analyzed according to standard methods and U.S. Environmental Protection Agency (EPA) method 445.0, respectively (American Public Health Association, 1995b; Arar and Collins, 1997) by the USGS NWQL. For analysis of total geosmin and MIB, samples were collected into 40-milliliter $(\mathrm{mL})$ glass septum vials, and the whole-water samples were analyzed by a contract laboratory-Underwriter Laboratories/Eurofins (Eaton) in South Bend, Indiana - by solid-phase microextraction (SPME) using gas chromatograph and mass spectrometry according to Standard Method 6040D (American Public Health Association, 2005a). Samples for the determination of actinomycetes concentration were collected as raw water aliquots in sterile 1-liter plastic bottles and analyzed by the USGS Ohio Microbiology Laboratory in Columbus, Ohio. The double-agar layer (DAL) method with Actinomycete Isolation Agar (AIA) was used for enumeration of actinomycetes (American Public Health Association, 2005b). Whole-water samples were analyzed for total suspended solids as solids, residue at $105^{\circ} \mathrm{C}$, (Fishman and Friedman, 1989) and for suspended-sediment concentrations (SSCs) and sand/fine fraction at the USGS Kentucky Water Science Center Sediment Laboratory in Louisville, Kentucky. Methods for SSCs are described in Shreve and Downs (2005).

Additionally, water samples were used for taxonomic characterization and enumeration of phytoplankton by contract laboratories, Greenwater Laboratories (September 2013 sample and two duplicate quality-control samples in 2014) and Spirogyra Diversified Environmental Services (April 2014April 2015). A 250-mL aliquot was collected and preserved in the field with $1 \mathrm{~mL}$ of Lugol's solution per $100 \mathrm{~mL}$ of sample (Ehrlich, 2010). Counts were conducted at multiple magnifications to include organism sizes spanning several orders of magnitude. A minimum of 400 natural units (single cells, colonies, or filaments) were counted for each sample to ensure a robust statistical enumeration of the phytoplankton community. Phytoplankton samples were classified at the genus and species level, when possible, with special consideration given to identification of potential geosmin-producing cyanobacteria. Phytoplankton data were analyzed to determine if the algal community structure was dominated by cyanobacteria at the time of sampling. Phytoplankton data were reported as cell density, in cells per milliliter (cells $/ \mathrm{mL}$ ), and as biovolume, in cubic micrometer per milliliter $\left(\mu \mathrm{m}^{3} / \mathrm{mL}\right)$, for each species. Phytoplankton biovolume was calculated by multiplying cell density (the number of cells in a sample [cells $/ \mathrm{mL}]$ ) by the volume of each cell $\left(\mu \mathrm{m}^{3}\right)$. Plots showing the phytoplankton data can be found in the "Characterization of Reservoir Water Quality" section of this report.

\section{Discrete Water-Quality Data Analysis}

Water-quality data were censored below the laboratory reporting level (LRL) for several constituents, including geosmin (18 percent censored), MIB (24 percent), nitrate plus nitrite ( 88 percent), ammonia (37 percent), orthophosphate (18 percent), dissolved phosphorus (12 percent), and total phosphorus (10 percent). Therefore, a nonparametric statistical analysis on ranked data was used, in general, whereby censored values were given the same rank and were ranked below estimated and quantitative (detections above the LRL) 
values (Childress and others, 1999; Helsel, 2005). Estimated values that were semiquantitative detections below the LRL were given the same rank, that is, above censored values but below detected values (Childress and others, 1999; Helsel, 2005).

Several exploratory statistical data analyses were applied to the water-quality and phytoplankton data to evaluate the influence of environmental factors on T\&O occurrence. For chemical, physical, and a subset of phytoplankton group data, a permutation test (number of replications $=5,000$ ) was applied to the data to determine if a statistical difference existed (alpha level $=0.05$ ) among groups of data, and the pairwise Wilcoxon multiple comparison test was used to identify which group or groups were different. Initially, water-quality data were evaluated by individual site and depth $(3.3 \mathrm{ft}$ and $10 \mathrm{ft}[1 \mathrm{~m}$ and $3.3 \mathrm{~m}]$ ) to determine if water quality differed significantly among sampling events and between depths by using a t-test (for normally distributed data) or Wilcoxon rank sum test (for non-normal data). Secondly, water-quality data were merged for all sites and depths and evaluated to determine if water quality differed significantly among sampling events and seasons (winter-January, February, March; spring — April, May, June; summer-July, August, September; fall-October, November, December). On the basis of findings from the permutations test, water-quality data from selected sites (CWS-5, CWS-7, CWS-4, CWS-2) were evaluated by the Spearman rho correlation procedure, a rank-based nonparametric method to measure the strength of the monotonic bivariate relation between the environmental factors and geosmin and MIB concentrations, actinomycetes concentrations, and cyanobacteria biomass metrics (Helsel and Hirsch, 1992). Strong relations between geosmin, MIB, and cyanobacteria metrics and a number of potential waterquality, hydrodynamic, and algal drivers were identified. Potential water-quality drivers included nutrients (total nitrogen, dissolved nitrate plus nitrite, dissolved ammonia, total phosphorus, total nitrogen to total phosphorus [TN:TP] ratio, silica, dissolved organic carbon, iron, manganese), basic water characteristics (major ions, water temperature, dissolved oxygen, transparency, $\mathrm{pH}$ ), and potential sources of geosmin (chlorophyll $a$, actinomycetes concentration, total phytoplankton biovolume, cyanobacterial biovolume, cyanobacterial dominance, proportion of potential geosmin producers in the cyanobacteria group).

The presence of many species that compose the phytoplankton community in Bushy Park Reservoir requires the use of robust statistical methods to identify changes over time or distance. For this dataset, several routines in the PRIMER 7.0 multivariate statistical software program were used to evaluate seasonal and spatial changes in phytoplankton communities and assess relations between phytoplankton community structure and associated environmental variables (Clarke, 1993; Clarke and others, 2014; Clarke and Gorley, 2015). Specifically, the multivariate approach was used to determine if the seasonal and spatial pattern of phytoplankton species was statistically related to the chemical species at a range of sites and, if so, how strong was that relation. This approach uses nonparametric statistical tests, which is a good fit with the non-normal distribution of the chemical data. Initial data exploratory analyses were conducted using the resemblance matrices for the biweekly and median pharmaceutical datasets. A nonhierarchial cluster analysis (LINKTREE) with similarity profile tests (SIMPROF with 999 permutations) was performed to identify statistically significant groupings of sites with similar phytoplankton community patterns. The results of the cluster analysis were displayed in a heat map (or shade plot) that provides information about the phytoplankton species that may be driving the clustering. The next step was to project the resemblance matrices into 2- and 3-dimensional (2D and 3D) space by nonmetric multidimensional scaling (nMDS) analysis, which is permutated 50 times on the ranked distances, where the goodness of fit of the projection is measured by a sum-of-squares-derived stress coefficient. Samples that plot near each other in 2D nMDS space are more alike than samples that plot far away; however, to quantify that relation, further statistical analysis is needed.

Hypotheses of temporal (seasonal, annual) and spatial (depth, reservoir location) similarities in the taxonomic composition and biovolumes of phytoplankton communities were examined with a series of one-way analysis of similarity (ANOSIM) tests, which are multivariate, nonparametric analogs of analysis of variance (Clarke and others, 2014). The ANOSIM test results are given as a Global R test statistic, which is a measure, between 0 and 1 , of the degree of separation of the groups in 2D space. Because Global $R$ is a correlation-based coefficient, its value does not change with added samples, only the level of significance (p-value) is subject to change. The ANOSIM tests performed for this study used 100 permutations, producing a minimum p-value of 0.001 (Clarke and others, 2014). Four classes of samples for the ANOSIM tests were established: (1) sites; (2) location in the reservoir (upper, lower, middle); (3) season (winter, January-March; spring, April-June; summer, July-September; fall, October-December); and (4) sample depth (shallow at $3.3-\mathrm{ft}$ depth, or deep at $10-\mathrm{ft}$ depth).

Although ANOSIM compared grouping patterns in data to different categorical factors, it cannot account for gradient changes in environmental characteristics. Therefore, the RELATE statistical program in PRIMER was used to determine (1) if the grouping patterns of phytoplankton species (using the resemblance matrix) were related to the grouping pattern of environmental conditions (using the resemblance matrix) in the Bushy Park Reservoir and (2) if so, how strong was that relation. The BEST statistical routine in PRIMER was used to identify individual environmental characteristics that best explained the grouping pattern of phytoplankton species biovolumes (resemblance matrix). The BEST routine tests the null hypothesis that there is no relation or link between the two groups of data by using random permutation. Analyses were conducted on square-root transformed and standardized phytoplankton species biovolumes (in cubic micrometers per milliliter) and log-transformed and normalized environmental 
variables. Preliminary analyses of cell densities (cells per milliliter) yielded similar results but are not presented in this report. Additionally, phytoplankton taxonomy provided by the two separate contract laboratories were assessed separately to prevent any pattern due to potential analyst differences.

Spearman rho correlation analysis also was applied to water-quality data to evaluate the strength of association among $\mathrm{T} \& \mathrm{O}$ concentrations and environmental factors (Helsel and Hirsch, 1992). An alpha level of 0.05 (95-percent confidence) for significant correlations was selected for the analysis.

\section{Water-Quality Spatial Surveys}

Multiple water-quality surveys of Bushy Park Reservoir were completed by using the EcoMapper Iver2 AUV built by Yellow Springs Instrument (YSI), Inc., and OceanServer Technology, Inc. (fig. 4A; Conrads and others, 2017a). The AUV can cost-effectively collect spatially dense data by surveying large areas in minimal time compared to traditional, manned boat surveys and sampling. The description and operation of the AUV and the post-processing of the data are well documented in Jackson (2013a), and much of the information presented below and in appendix 1 comes from that report. The water-quality sensor suite is composed of a YSI 6600 V2-4 bulkhead equipped with a YSI 6560FR fast response temperature/conductivity probe, a YSI 6589FR fast response $\mathrm{pH}$ sensor, a YSI 6150FR fast response ROX optical dissolved-oxygen sensor, a YSI 6136 turbidity sensor, a YSI 6025 chlorophyll $a$ sensor, and a YSI 6131 BGA-PC phycocyanin (BGA) sensor. Manufacturer's specifications for each of the probes are provided in table 4. All water-quality sensors made measurements at a rate of 1 hertz $(\mathrm{Hz})$. The water-quality sensor was calibrated prior to deployment and after completing the survey.

The AUV performs autonomous surveys of water bodies and when properly programmed requires no assistance during execution of the survey. Programming a survey involves obtaining a high-resolution georeferenced aerial photograph of the water body (typically a USGS digital orthoquarterquadrangle) and determining locations of any potential obstructions (from initial reconnaissance). The aerial imagery and obstructions information are then imported into Vector Map (Vector Map, 2015), the primary programming software for the AUV, and used as a background for survey planning. Within Vector Map, the user creates missions (surveys) by generating a field of numbered waypoints for the AUV to visit. The points are numbered sequentially, and the AUV will follow the set order, executing commands at each waypoint. Each waypoint has a set of associated commands, including dive mode, speed, dive angle, depth or height above bottom, sonar settings, and park commands. Dive mode options include (1) constant depth, where the AUV will achieve and maintain a specific depth below the surface by using its redundantpressure sensors and vertical uplooking beam; (2) constant altitude (height) above bottom, where the AUV will maintain a specified height above the bottom by using its vertical downlooking beam; and (3) undulate, where the vehicle will undulate between two depths (or a combination of a depth and height above bottom) at a specified dive angle (fig. 4B).

For Bushy Park Reservoir, the missions included paths of centerline, "zigzag" (paths of a gradual back and forth while traveling up or down stream), or "lawnmower" (paths of bank to bank with designated longitudinal spacing) (fig. 5). Individual missions varied in spatial coverage. Overall missions covered the area from Back River Dam to the railroad bridge

A

B

C

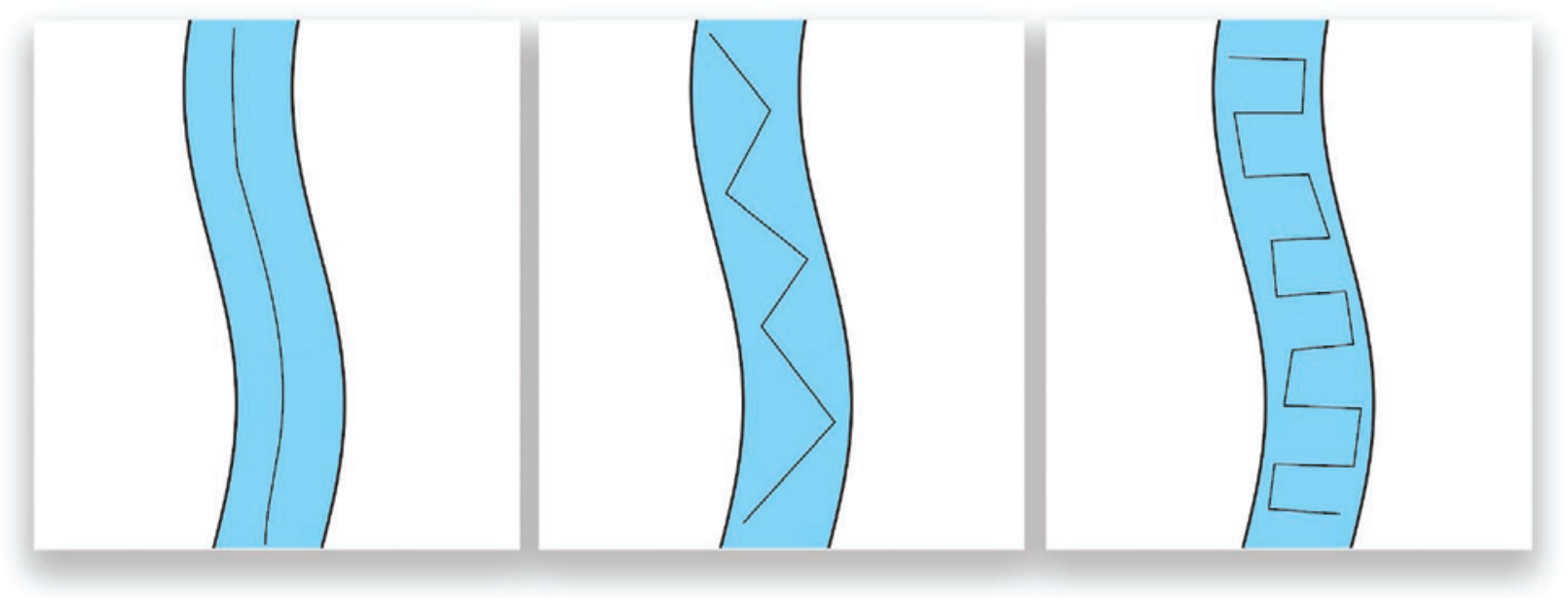

Figure 5. Examples of three mission routes used by the autonomous underwater vehicle during water-quality surveys on Bushy Park Reservoir, near Goose Creek, South Carolina, September 2013 to April 2015: (A) centerline, (B) "zigzag," and (C) "lawnmower." 
over Durham Canal (fig. 3). A few missions went upstream into Back River to the USGS streamgage 021720603 and up Foster Creek approximately 2 miles (near site CWS-6). During the initial runs, side-scan sonar was used to detect obstructions on the bottom that could present a problem if the AUV were to operate near the bottom of the reservoir. Figure 6 shows an image from the side-scan sonar (instrument settings were Gain-12, Range-50, and Frequency-low) in the lower reach of the reservoir between Back River Dam and the confluence with Foster Creek. The image is from initial AUV surface runs with the sonar collecting bathymetric data of the reservoir bottom. The image shows an abrupt change in depth that is probably a result of dredging the lower reach of the river to create the Back River Dam. Once the bottom features were determined, the emphasis of the missions switched from general reconnaissance to intense water-quality data collection.

To obtain data through a larger portion of the water column, undulating missions were used, consisting of dive patterns between at or near the water surface to a set distance

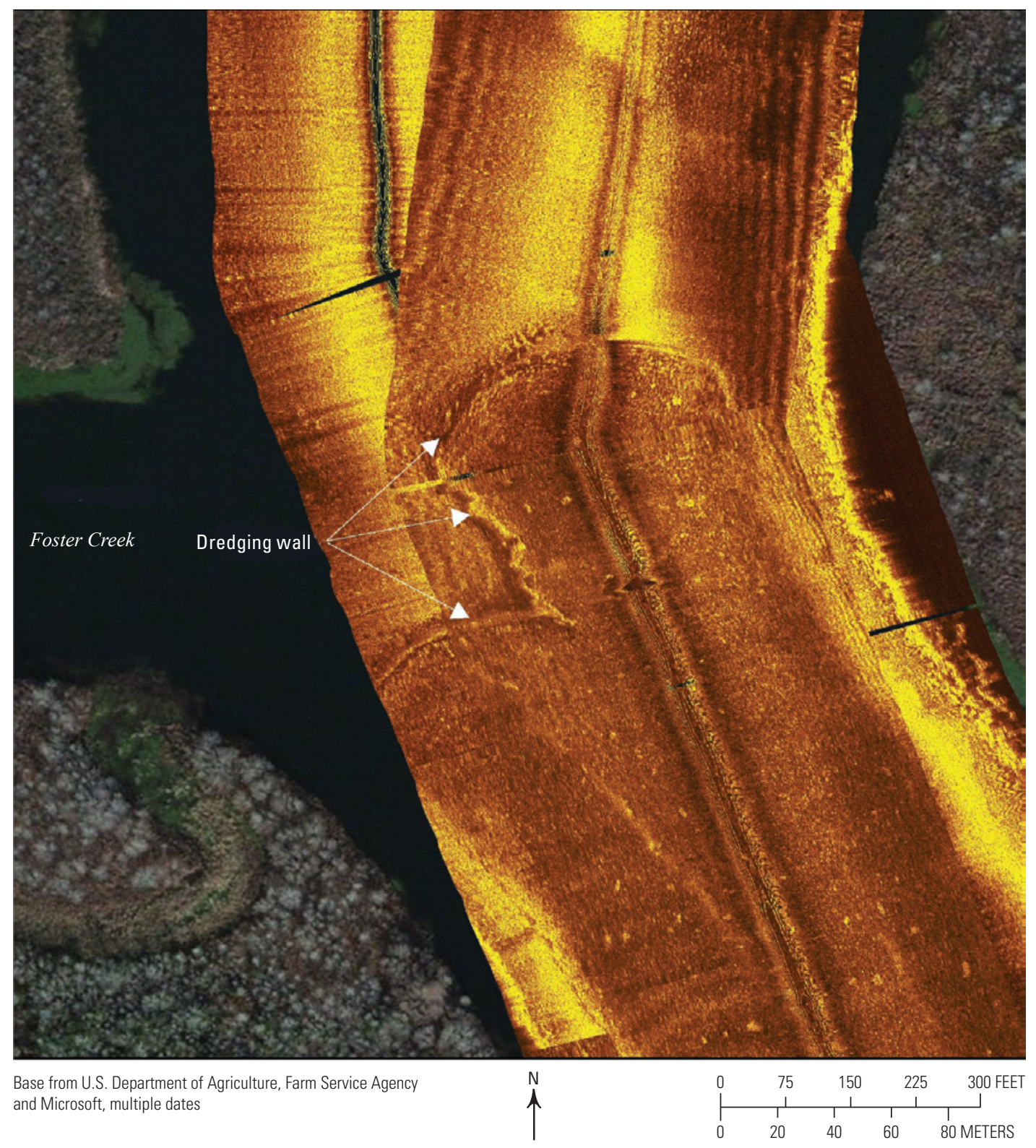

Figure 6. Side-scan sonar image from autonomous underwater vehicle of the lower reach of Bushy Park Reservoir, near Goose Creek, South Carolina, on September 17 and 18, 2013. Arrows pointing to dredging wall indicate an abrupt change in depth that is likely a result of dredging the lower reach of the river to create the Back River Dam. 
above the bottom (fig. 4B). These undulating missions, combined with the lawnmower or zigzag patterns (fig. 5), were used to collect a detailed 3D dataset for each property measured. To understand the seasonal patterns occurring in the reservoir, missions were developed and reused several times with no change. During mission runs that coincided with intense sampling, the reusable mission was modified to collect additional data around the sampling points, enabling verification of sampling data to AUV data. Figure $7 A$ shows the plan view of a lawnmower mission overlaid on the bathymetric data collected during the study. Undulating and zigzag missions showing chlorophyll data are provided in figure $7 B$ and $7 C$. The zigzag mission is vertically offset for clarity of the visual presentation.

The 3D data from the AUV missions are collected at 1 -second intervals and can be visualized by interpolating between the measured values and creating a longitudinal 2D plot showing the variability of the values from top to bottom of the water column and along the length of the AUV mission. An example of the 2D plot is provided in figure 8, which shows the vertical and longitudinal distribution of water temperature in June 2014 from the lower portion of the reservoir near the Back River Dam to the powerlines below the confluence with Durham Canal (fig. 7A). Depths at the lower reach of the reservoir were close to $40 \mathrm{ft}$ and demonstrated relatively strong thermal stratification and an approximate $16{ }^{\circ} \mathrm{C}$ difference between the surface near site CWS-4 and bottom depths near the dam. Additionally, the longitudinal plot indicated about $2{ }^{\circ} \mathrm{C}$ cooler water temperature near the surface at site CWS-4 than elsewhere in the reservoir. Plots for seven physical properties (water temperature, specific conductance, dissolved oxygen, $\mathrm{pH}$, turbidity, chlorophyll, and phycocyanin [estimated as BGA]) for the $16 \mathrm{AUV}$ missions are shown in appendix 2.

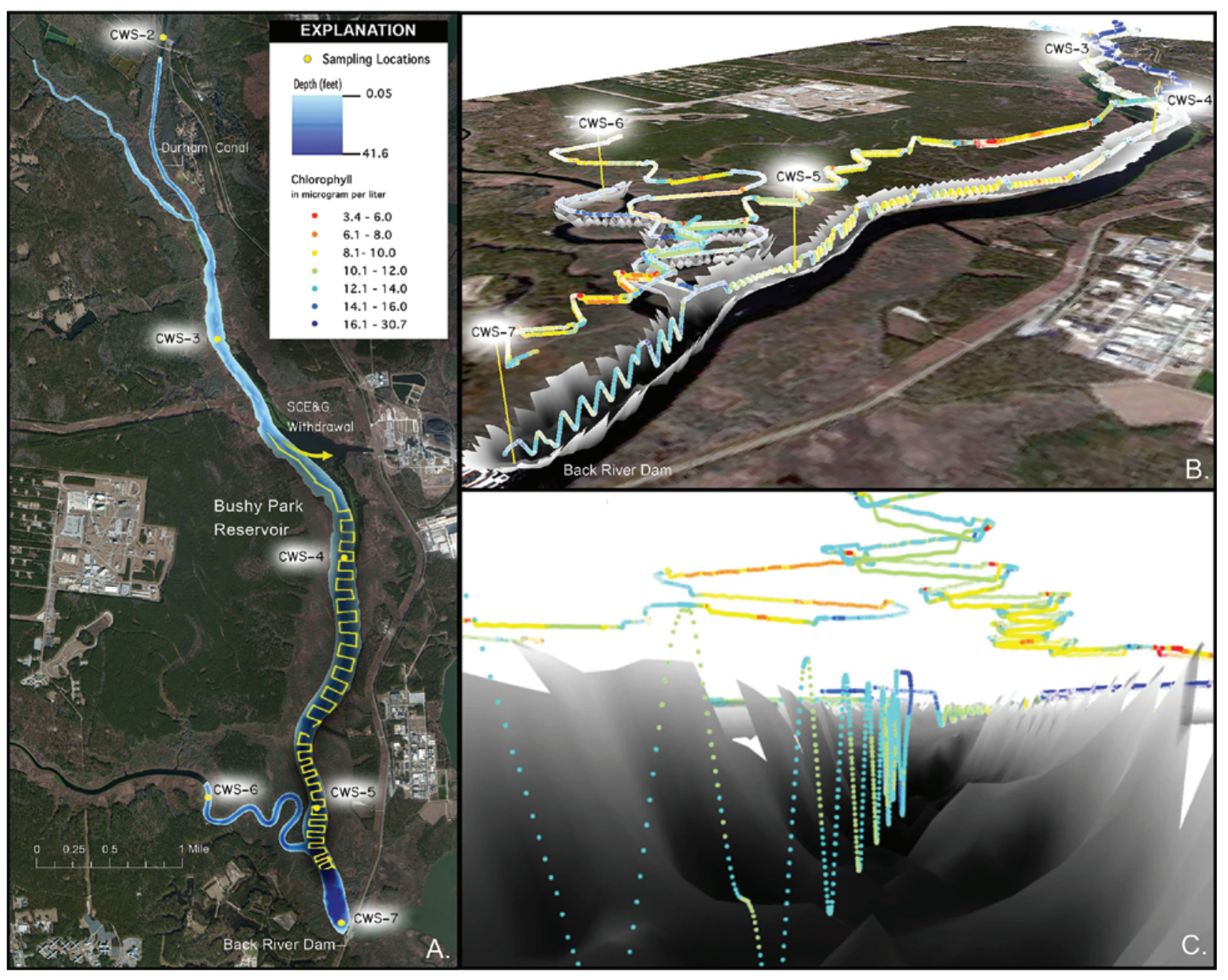

Figure 7. Examples of the autonomous underwater vehicle missions and data collection at Bushy Park Reservoir, near Goose Creek, South Carolina, on September 17 and 18, 2013: (A) plan view showing a "lawnmower" mission path and bathymetry depths, $(B)$ side view showing chlorophyll data from a surface mission (elevation exaggerated to show both missions) and undulating mission, and $(C)$ detail of the two missions looking upstream from the Back River Dam. 


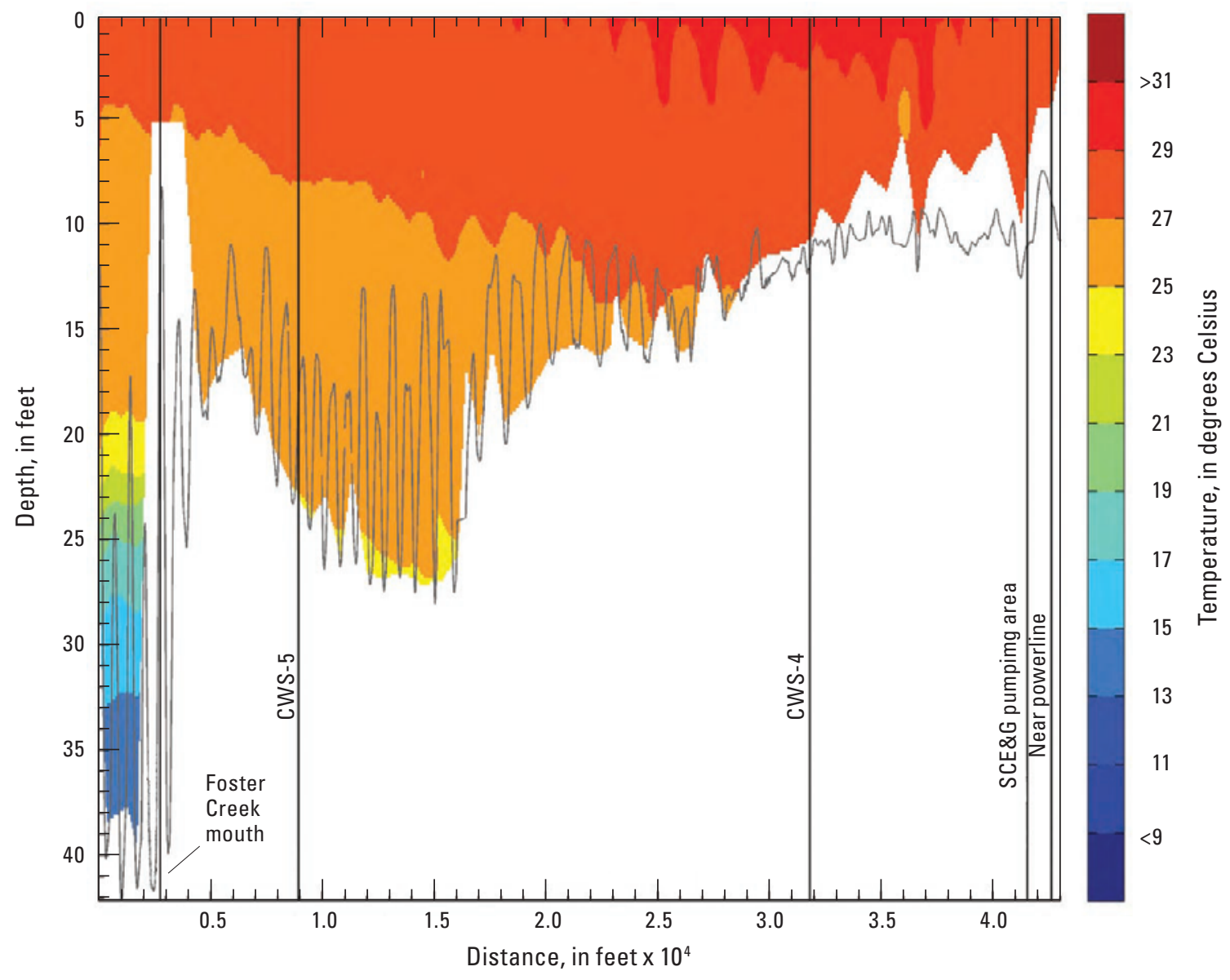

Figure 8. Longitudinal plot of water temperature depth profile from the autonomous underwater vehicle survey of the lower end of Bushy Park Reservoir near the Back River Dam to the powerlines near site CWS-3 and below the confluence with Durham Canal for June 10, 2014.

\section{Verification of Physical Properties Measured by the Autonomous Underwater Vehicle}

Water-quality profiles were collected with a hand-held calibrated sonde (field meter) in a manned boat concurrent with the AUV sonde to identify and verify diurnal- and depth-related changes during the AUV survey and water-quality sampling events and to make GPS-specific water-quality measurements in portions of the reservoir that were inaccessible to the AUV (Conrads and others, 2017a). Vertical reservoir profile measurements of water temperature, specific conductance, $\mathrm{pH}$, dissolved-oxygen concentrations, turbidity, chlorophyll $a$ fluorescence (estimate of phytoplankton biomass), and phycocyanin fluorescence (estimate of cyanobacteria or BGA biomass) were collected $1 \mathrm{ft}$ below the water surface and at either 1-ft or 5-ft intervals, thereafter, to the bottom of the reservoir. Plots for these data are shown in appendix 3. In general, data collected with the field meter included the same properties as those collected by the AUV. Some exceptions occurred due to malfunctioning probes or probes not being available on the field meter sonde during the survey.
To verify the accuracy and performance of the AUV-acquired measurements, the performance of the AUV water-quality probes was checked before and after a sampling mission in certified standards and buffers according to manufacturer's and USGS protocols (Wagner and others, 2006; YSI, Inc., 2011). Ratings to define the accuracy of the AUV probes were similar to ratings applied to USGS continuous water-quality records (Wagner and others, 2006). Accuracy ratings assigned were excellent, good, fair, or poor based on differences between the probe measurements and the certified standards and buffers (table 5; Wagner and others, 2006). Calibration protocol and accuracy rating criteria were not established for chlorophyll and phycocyanin fluorescence measurements in Wagner and others (2006). Therefore, ratings were assigned for these properties on the basis of similar rating ranges for the turbidity measurements. For example, a chlorophyll fluorescence check measurement in chlorophyll-free water (deionized water) that is between -0.5 and $0.5 \mu \mathrm{g} / \mathrm{L}$ will be rated as excellent, between 0.5 and $1.0 \mu \mathrm{g} / \mathrm{L}$ will be rated as good, between 1.0 and $1.5 \mu \mathrm{g} / \mathrm{L}$ will be rated as fair, and greater than $1.5 \mu \mathrm{g} / \mathrm{L}$ will be rated 
Table 5. Accuracy ratings of the autonomous underwater vehicle water-quality sensors and the surveys for the Bushy Park Reservoir water-quality study, near Goose Creek, South Carolina, September 2013 to April 2015.

$[\leq$, less than or equal to; $+/-$, plus or minus; $\%$, percent; >, greater than $]$

\begin{tabular}{|c|c|c|c|c|c|c|c|}
\hline Rating & $\begin{array}{c}\text { Water } \\
\text { temperature, } \\
\text { in degrees } \\
\text { Celsius }\end{array}$ & $\begin{array}{c}\text { Specific } \\
\text { conductance, } \\
\text { in microsie- } \\
\text { mens per } \\
\text { centimeter }\end{array}$ & $\begin{array}{c}\text { pH, } \\
\text { in standard } \\
\text { units }\end{array}$ & $\begin{array}{c}\text { Dissolved } \\
\text { oxygen, } \\
\text { in milligrams } \\
\text { per liter }\end{array}$ & Turbidity & $\begin{array}{c}\text { Chlorophyll, } \\
\text { in micrograms } \\
\text { per liter }\end{array}$ & $\begin{array}{l}\text { Blue-green } \\
\text { algae, }{ }^{2} \text { in cells } \\
\text { per milliliter }\end{array}$ \\
\hline Excellent & $\leq+/-0.2$ & $\leq+/-3 \%$ & $\leq+/-0.2$ & $\begin{array}{l}\leq+/-0.3 \mathrm{mg} / \mathrm{L} \text { or } \\
\leq+/-5 \% \text { (which- } \\
\text { ever is greater) }\end{array}$ & $\begin{array}{c}\leq+/-0.5 \mathrm{mg} / \mathrm{L} \text { or } \\
\leq+/-5 \% \text { (which- } \\
\text { ever is greater) }\end{array}$ & $\leq+/-5 \%$ & $\leq+/-5 \%$ \\
\hline Good & $\begin{array}{c}>+1-0.2 \text { to } \\
0.5\end{array}$ & $>+/-3$ to $10 \%$ & $\begin{array}{c}>+/-0.2 \text { to } \\
0.5\end{array}$ & $\begin{array}{c}>+/-0.3 \text { to } \\
0.5 \mathrm{mg} / \mathrm{L} \text { or } \\
>+/-5 \text { to } 10 \% \\
\text { (whichever is } \\
\text { greater) }\end{array}$ & $\begin{array}{c}>+/-0.5 \text { to } \\
1.0 \mathrm{mg} / \mathrm{L} \text { or } \\
>+/-5 \text { to } 10 \% \\
\text { (whichever is } \\
\text { greater) }\end{array}$ & $\begin{array}{c}>+/-5 \text { to } \\
10 \%\end{array}$ & $\begin{array}{c}>+/-5 \text { to } \\
10 \%\end{array}$ \\
\hline Poor & $>+/-0.8$ & $>+/-15 \%$ & $>+/-0.8$ & $\begin{array}{c}>+/-0.8 \mathrm{mg} / \mathrm{L} \text { or } \\
>+/-15 \% \text { (which- } \\
\text { ever is greater) }\end{array}$ & $\begin{array}{c}>+/-1.5 \mathrm{mg} / \mathrm{L} \text { or } \\
>+/-15 \% \text { (which- } \\
\quad \text { ever is greater) }\end{array}$ & $>+/-15 \%$ & $>+/-15 \%$ \\
\hline Survey date & & & & Rating & & & \\
\hline $\begin{array}{r}/ 17 / 2013- \\
9 / 19 / 2013\end{array}$ & Excellent & Excellent & Excellent & Excellent & Excellent & Good & Excellent \\
\hline $11 / 19 / 2013$ & Excellent & Excellent & Excellent & Excellent & Excellent & Excellent & Excellent \\
\hline $\begin{array}{r}1 / 13 / 2014- \\
1 / 14 / 2014\end{array}$ & Excellent & Excellent & Excellent & Excellent & Excellent & Good & Excellent \\
\hline $10 / 2 / 2014$ & Excellent & Excellent & Excellent & Excellent & Excellent & Good & Excellent \\
\hline $10 / 29 / 2014$ & Good & Excellent & Excellent & Excellent & Excellent & Excellent & Excellent \\
\hline $11 / 5 / 2014$ & Good & Excellent & Excellent & Excellent & Excellent & Excellent & Excellent \\
\hline $11 / 6 / 2014$ & Excellent & Excellent & Excellent & Excellent & Excellent & Excellent & Excellent \\
\hline $12 / 16 / 2014$ & Excellent & Excellent & Excellent & Excellent & Excellent & Excellent & Excellent \\
\hline $1 / 14 / 2015$ & Excellent & Excellent & Excellent & Excellent & Excellent & Good & Excellent \\
\hline $3 / 26 / 2015$ & $\begin{array}{l}\text { Good to } \\
\text { excellent }\end{array}$ & Excellent & Excellent & Excellent & Excellent & Good & Excellent \\
\hline $4 / 23 / 2015$ & Excellent & Excellent & Excellent & Excellent & Excellent & Excellent & Excellent \\
\hline
\end{tabular}

${ }^{1}$ Due to the inability of inserting a thermistor in the closed calibration cup of the autonomous underwater vehicle, the temperature rating was based on a side-by-side field reading.

${ }^{2}$ Chlorophyll and blue-green algae concentrations were determined by internal algorithm estimated from chlorophyll and phycocyanin fluorescence. Because accuracy ratings were not established by the U.S. Geological Survey for chlorophyll or blue-green algae at the writing of this report, percentage ratings similar to dissolved oxygen and turbidity were used to rate these parameters. 
as poor. Similarly, a phycocyanin fluorescence measurement in phycocyanin-free water (deionized water) that is between $-1,000$ and 1,000 cells/mL will be rated as excellent, between 1,000 and 2,000 cells/mL will be rated as good, between 2,000 and 3,000 cells $/ \mathrm{mL}$ will be rated as fair, and greater than 3,000 cells/mL will be rated as poor. Drift corrections were applied to AUV field dissolved-oxygen and turbidity measurements made on July 23, 2014, on the basis of post-field data checks. Accuracy ratings for the AUV water-quality probes for 16 surveys (17 missions) ranged from fair to excellent (table 5) for this investigation.

\section{Discrete Data Quality Assurance and Quality Control}

Sample collection and processing were conducted according to water-quality sampling and biological assessment protocols documented in the USGS National Field Manual (U.S. Geological Survey, variously dated; Graham and others, 2008). A total of 65 water samples were collected for analysis. Six of the 65 samples were considered quality-control samples, including field blanks and sequential replicates. Two field blanks were collected and analyzed for geosmin, MIB, chlorophyll $a$, and major ion constituents, and four field blanks were collected and analyzed for nutrients and organic carbon constituents (appendix 4). Field blanks were used to test for bias due to contamination during cleaning, collection, processing, and analysis. Blank water was certified free of inorganic (major ions, nutrients, and trace elements) or organic (geosmin, MIB, and organic carbon) constituents. Constituent concentrations were below the LRL in all blanks except one for five constituents: chloride (0.02 milligram per liter [mg/L] in one of two blanks), manganese $(0.3 \mu \mathrm{g} / \mathrm{L}$ in one of two blanks), total organic carbon (TOC; $1.3 \mathrm{mg} / \mathrm{L}$ in one of four blanks), chlorophyll $a$ (0.02 and $0.03 \mu \mathrm{g} / \mathrm{L}$ in two of two blanks), and pheophytin $a$ (0.02 and $0.03 \mu \mathrm{g} / \mathrm{L}$ in two of two blanks). Environmental concentrations for chloride, chlorophyll $a$, and pheophytin $a$ were orders of magnitude above the field blank concentration and, therefore, considered free from bias by contamination. Only two of 47 environmental samples had manganese concentrations $(0.9 \mu \mathrm{g} / \mathrm{L}$ and $1.1 \mu \mathrm{g} / \mathrm{L}$ ) that were below $1.5 \mu \mathrm{g} / \mathrm{L}$ (five times the field blank concentration) that could potentially be influenced by some level of contamination. However, on the basis of the data quality objectives of the project (nonregulatory), the potential for that level of contamination (26 to 30 percent) was not considered problematic, and the data were used in the analysis. Three of the four blanks analyzed for TOC concentrations had nondetectable levels, and those blanks bracketed the period when the one-time detectable level was present; therefore, any potential contamination was considered limited to that August 2014 time period. During August 2014, the field blank TOC concentration of $1.3 \mathrm{mg} / \mathrm{L}$ was greater than 20 percent of five environmental TOC concentrations (range was 4.9 to $5.7 \mathrm{mg} / \mathrm{L}$; 26 to 23 percent). Therefore, further evaluation of the environmental TOC concentrations was conducted by plotting the TOC concentrations against a surrogate for organic carbon, ultraviolet absorbance at 254 nanometers, to determine if significant deviations could be observed (fig. 9). Because

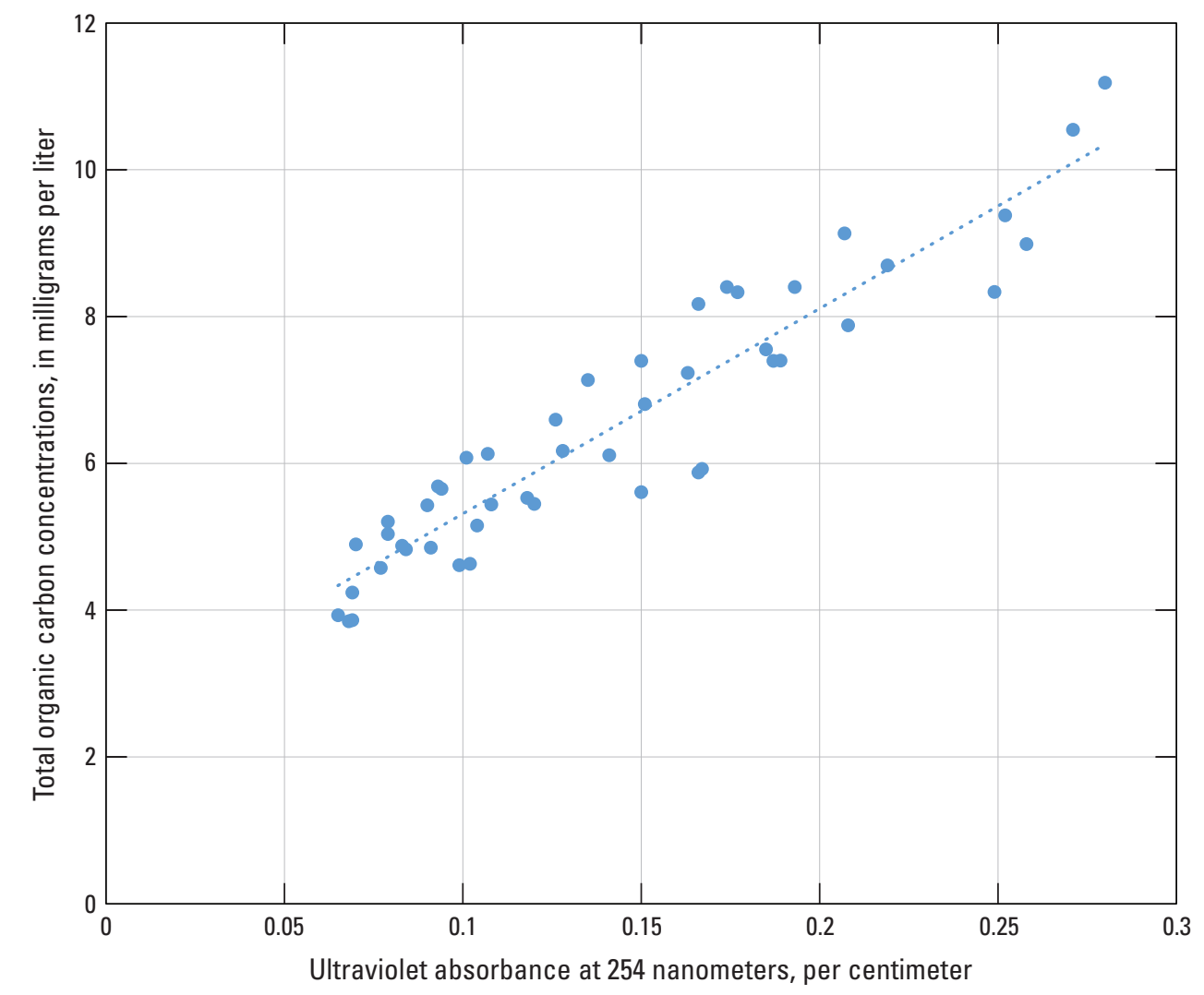

Figure 9. Scatterplot of total organic carbon concentrations and ultraviolet absorbance at 254 nanometers in water-column samples collected in Bushy Park Reservoir, near Goose Creek, South Carolina, 2013 to 2015. 
no observable deviations were identified compared to other sampling events, all TOC concentrations were considered reliable and were used in the assessment.

Comparison of the two environmental and replicate samples demonstrated good reproducibility for major ions, trace metals, and organic carbon (generally below 5 percent relative percent difference [RPD]) (appendix 4). Similar comparison among nutrient species indicated more bias than major ions, especially for ammonia (RPD of 26 and 18 percent) and nitrite (only one of two replicate samples with RPD of 102 percent). Ammonia was used in the data-analysis process even with the large RPD; however, nitrite was not used in the data analysis process, and nitrate plus nitrite was used instead.

\section{Relation Between Sonde Measurements and Laboratory Analysis of Chlorophyll a}

Estimated total chlorophyll measured in situ as fluorescence from the probe was compared to laboratoryderived chlorophyll $a$ concentrations and to the sum of the laboratory-derived chlorophyll $a$ and its degradate, pheophytin $a$ concentrations. For all sites and all sampling events, in situ total chlorophyll was significantly correlated positively to the laboratory-derived chlorophyll $a$ and pheophytin $a$ concentrations ( $\mathrm{rho}=0.484, \mathrm{p}=0.0013$ and $\mathrm{rho}=0.417$, $\mathrm{p}=0.0062$, respectively; fig. 10). However, the low correlation coefficients (rho of 1 indicates perfect correlation) between these compounds appear to indicate that some variability in in situ total chlorophyll is not reflected in the variability in the laboratory-derived concentrations. Plausible reasons for the poor agreement between in situ chlorophyll and laboratoryderived chlorophyll $a$ values include variability in the in situ total chlorophyll attributed to spatial changes in phytoplankton species in the reservoir, water color (change from high DOC water near the dam to lower DOC water near Durham Canal), and turbidity during a sampling event and among the sampling events. All these environmental characteristics can affect the fluorescence measured by the probe and inaccurately attribute the change in fluorescence to increasing or decreasing chlorophyll $a$. Similar findings were observed when comparing the in situ estimated BGA cell count as fluorescence from the probe to the taxonomic-derived cyanobacteria cell densities,

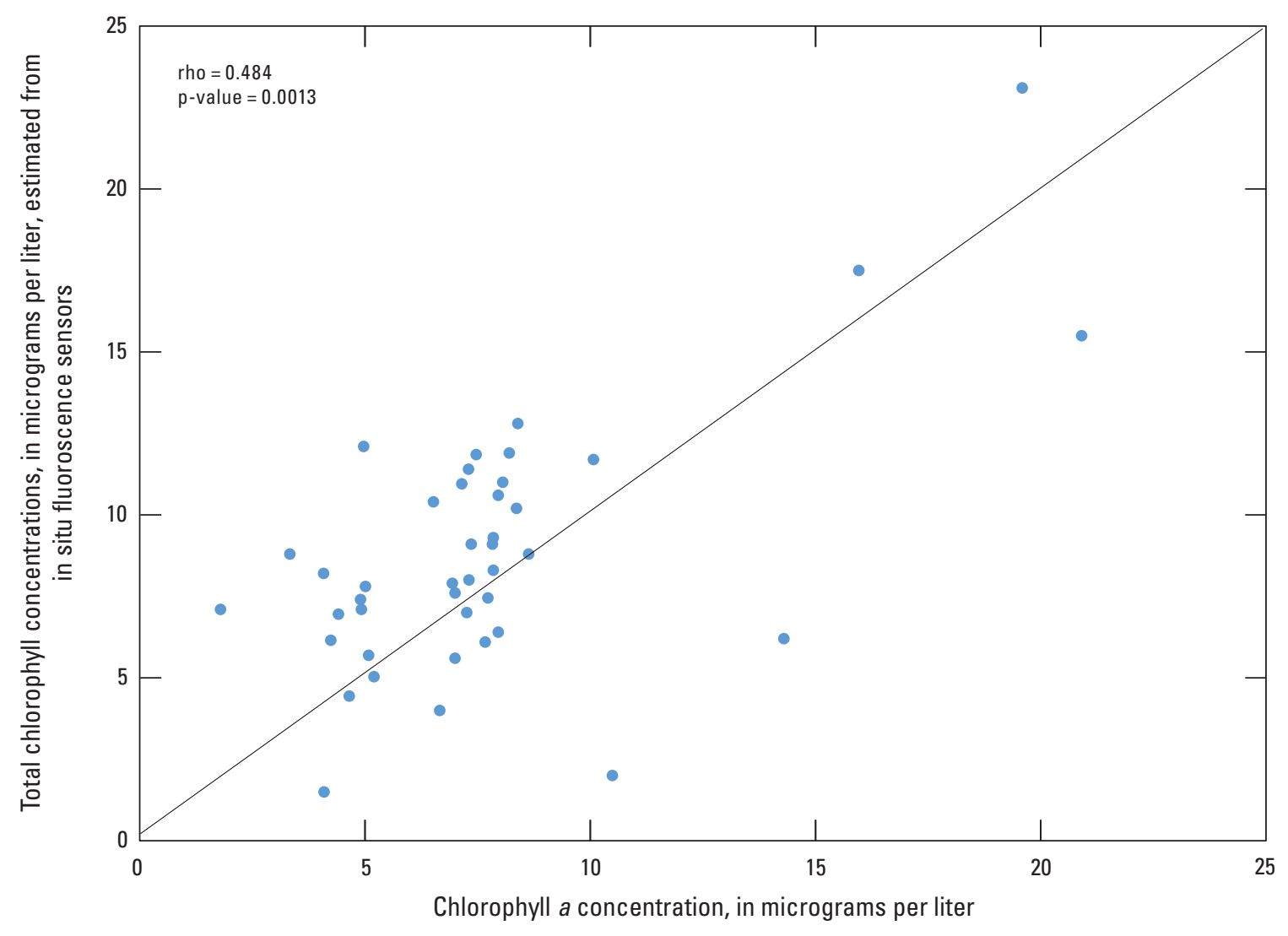

Figure 10. Scatterplot of laboratory-derived chlorophyll a concentrations and estimated total chlorophyll concentrations from in situ fluorescence measured with a YSI 6025 probe in Bushy Park Reservoir, near Goose Creek, South Carolina, 2013 to 2015. A one-to-one correspondence line is drawn for comparison purposes. Spearman rho correlation coefficient and associated probability value are provided. 
and therefore, the in situ cell counts were used as a qualitative indicator of changes in cyanobacteria in the water column. Therefore, for this report, in situ total chlorophyll concentrations estimated from the AUV and field measurements were used as a qualitative, rather than quantitative, indicator of changes in chlorophyll $a$ in the water column.

\section{Characterization of Reservoir Water Quality}

Taste-and-odor episodes are often sporadic, and intensities vary spatially (Peter and others, 2009). The production and release of geosmin and MIB have been related to cyanobacterial blooms or the presence of potential T\&O-producing species of cyanobacteria. The presence and abundance of these species have been attributed to environmental factors, including nutrient concentrations and ratios, light availability, water temperatures, water column stability, and flushing rates (Izaguirre and others, 1982; Smith, 1983; Downing and McCauley, 1992; Smith and others, 1995; Smith and Bennett, 1999; Jacoby and others, 2000; Downing and others, 2001; Paerl and others, 2001; Havens and others, 2003; Graham and others, 2004; Dzialowski and others, 2009; Graham and Jones, 2009). Conversely, releases of geosmin and MIB from cyanobacteria in lakes that are not cyanobacteria-dominated also have been associated with periods of high transparency (clear-water phase) attributed to zooplankton grazing (Durrer and others, 1999; Scheffer, 2004; Jüttner and Watson, 2007). Therefore, the phytoplankton and water-quality data collected in Bushy Park Reservoir were assessed to identify environmental factors that may have contributed to the occurrence of $\mathrm{T} \& \mathrm{O}$ episodes. The complex interaction among the physical, chemical, and biological processes within lakes and reservoirs, however, often makes it difficult to identify the primary environmental factors that cause the production and release of these cyanobacterial by-products.

Phytoplankton taxonomic data were analyzed to determine if changes in the abundance and diversity of community occurred spatially and temporally. Additionally, genera within the cyanobacteria division were assessed for the presence of potential T\&O-producing species. Genera of cyanobacteria, which contain known geosmin and MIB producers, include Anabaena (now referred to as Dolichospermum), Planktothrix, Oscillatoria (now referred to as Jaaginema or Geitlerinema), Aphanizomenon, Lyngbya (now referred to as Planktolyngbya), Pseudanabaena, Symploca (Izaguirre and others, 1982; Rashash and others, 1996; Jüttner and Watson, 2007) and Synechococcus (Taylor and others, 2006). Actinomycetes concentrations also were assessed to determine if elevated concentrations were present during $\mathrm{T} \& \mathrm{O}$ episodes.

The assessment was conducted in three steps. The first step was to characterize the water-quality conditions in the reservoir relative to established guidelines. The second step was to identify any spatial and seasonal variation in water-quality conditions and phytoplankton community structures throughout the reservoir. The second step was conducted to (1) identify the area of the reservoir that most influences the water-quality conditions at the intake (site CWS-5) (for example, Foster Creek inflows [site CWS-6] or Durham Canal inflows [sites CWS-1 and CWS-2]), especially during periods of elevated T\&O concentrations, (2) determine if the $\mathrm{T} \& \mathrm{O}$ concentrations were produced in situ in the reservoir or delivered to the reservoir from either Foster Creek or Durham Canal, and (3) identify the most probable source of the T\&O compounds (actinomycetes bacteria or cyanobacteria), and, if cyanobacteria, identify any phytoplankton species (or genus) that have the potential to produce $T \& O$ compounds during $\mathrm{T} \& \mathrm{O}$ episodes. The final step was to assess whether these spatial and seasonal changes in environmental factors correlate significantly with phytoplankton community structure and geosmin or MIB concentrations.

\section{Reservoir Taste-and-0dor Occurrence}

Discrete, AUV-acquired, and depth-profile water-quality data collected by the USGS in Bushy Park Reservoir from September 2013 to April 2015 were assessed in this report. Additionally, T\&O concentrations from raw (untreated), blended water (Bushy Park Reservoir [dominant source] and Edisto River [secondary source]) and finished water collected by CWS in their distribution system as part of its treatment monitoring are reported but not included in the statistical assessment. The goal of the statistical assessment was to determine which, if any, environmental factors influence phytoplankton community structure and the occurrence of T\&O compounds in CWS source water from Bushy Park Reservoir.

\section{Seasonal Occurrence of Taste-and-Odor Compounds}

Prior to this USGS investigation, internal monitoring by CWS had determined that spring and, less frequently, late summer periods tended to have the greatest potential for $\mathrm{T} \& \mathrm{O}$ occurrence (Rebecca Thames, Charleston Water System, written commun., March 26, 2015) (fig. 11). During these seasons and even with normal treatment techniques applied by $\mathrm{CWS}$ to reduce $\mathrm{T} \& \mathrm{O}$ compound concentrations in raw water, T\&O occurrence tended to increase above the human detection level, as measured by customer complaints. The threshold level for T\&O concentrations in raw water was between 15 and $20 \mathrm{ng} / \mathrm{L}$. In the spring of 2013, raw water had total (geosmin plus MIB) T\&O concentrations above $20 \mathrm{ng} / \mathrm{L}$. During that spring T\&O episode, CWS treated the raw water with powdered activated carbon (PAC) doses of between 8 and 10 parts per million and successfully reduced the T\&O concentrations in the finished water to near $10 \mathrm{ng} / \mathrm{L}$ (fig. 11). $\mathrm{T} \& \mathrm{O}$ concentrations that were below $15 \mathrm{ng} / \mathrm{L}$ in finished water tended to reduce the customer complaints considerably. 

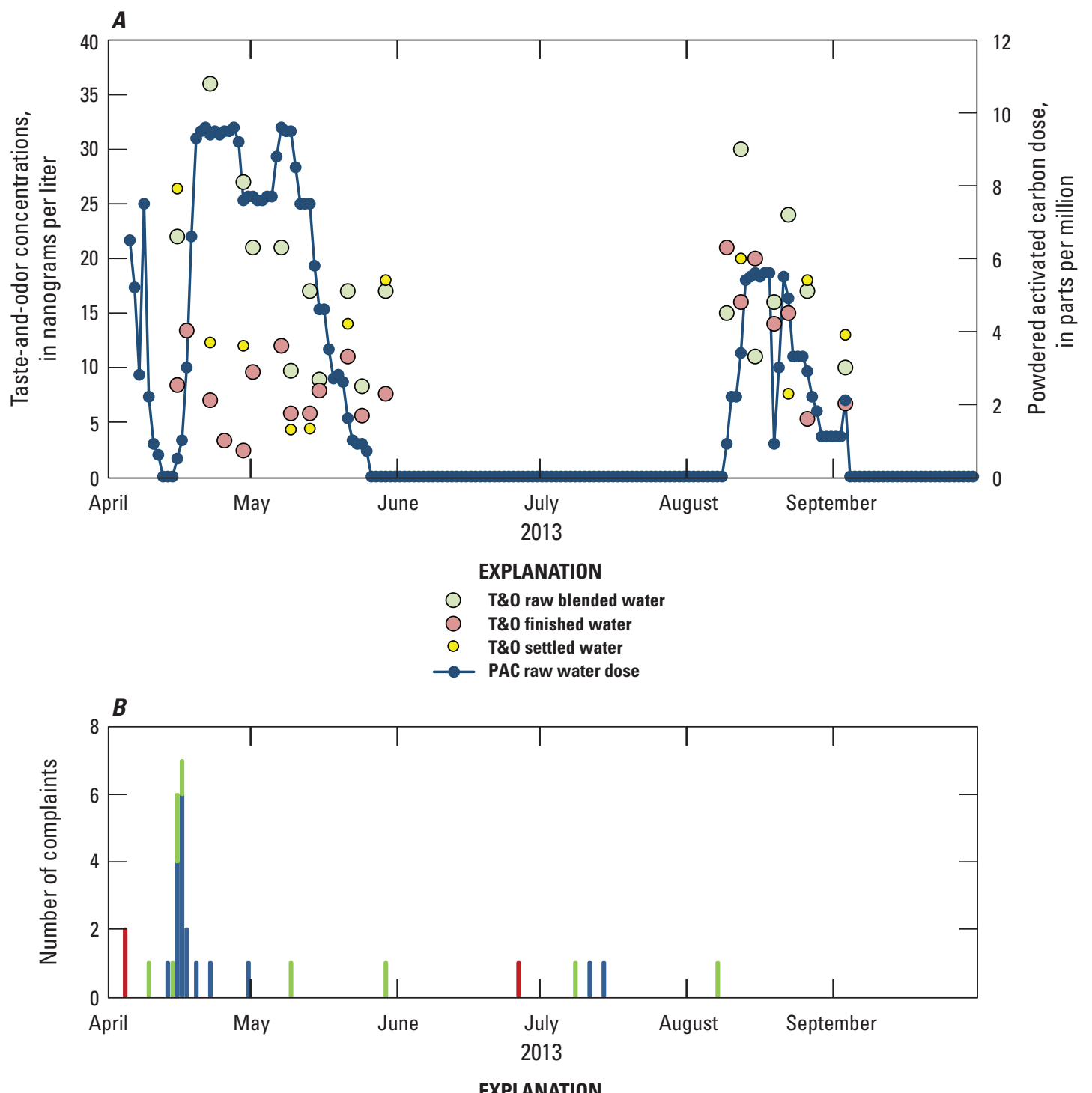

EXPLANATION

T\&O customer complaints unknown source

Other customer complaints

T\&O earthy musty complaints

Figure 11. A, The temporal variability in taste-and-odor (T\&O) concentrations as combined geosmin and 2-methylisoborneol concentrations in raw blended (Bushy Park Reservoir and Edisto River), settled, and finished water (colored circles) and the corresponding powdered activated carbon (PAC) doses used by Charleston Water Systems as a treatment technique (blue line) in the spring and fall of 2013. B, Associated temporal variability in number of complaints related to $T \& 0$ problems by Charleston Water System customers.

Therefore, an assessment of the source water of Bushy Park Reservoir was needed to identify any changes in environmental conditions and phytoplankton community structure during these seasonal periods that may promote T\&O production.

During the study period, T\&O concentrations varied by dominant form of $\mathrm{T} \& \mathrm{O}$ constituent, sampling period, and location in the reservoir (fig. 12). Water-column samples had MIB concentrations consistently below $20 \mathrm{ng} / \mathrm{L}$ and only once exceeded $15 \mathrm{ng} / \mathrm{L}$, which occurred at the CWS-6 (Foster Creek) site. Nonetheless, there was a general trend of greater MIB near the dam compared to the upper portion of the reservoir, including the September 2013, April 2014, and July 2014 sampling events. During the September and July sampling events, Foster Creek (at site CWS-6) had the greatest MIB concentrations compared to other sites in the reservoir, indicating the potential that Foster Creek may have served as a source of MIB to the reservoir during those periods. In this scenario, actinomycetes or cyanobacteria could be the producer of MIB. During the April sampling event, however, the MIB concentration in Foster Creek (site CWS-6) was lower 

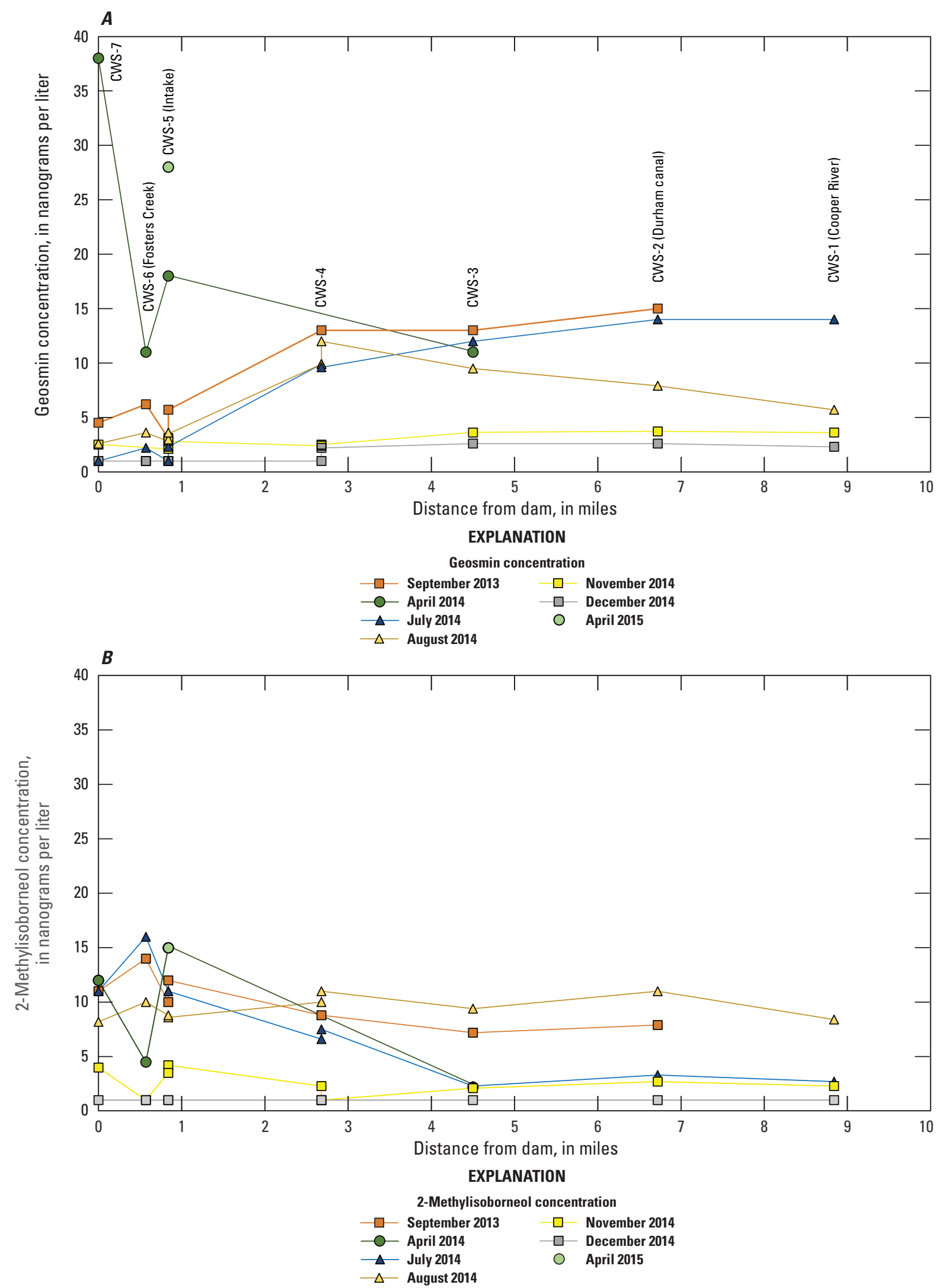

Figure 12. ( $A$ ) Geosmin and $(B)$ 2-methylisoborneol (MIB) concentrations at selected locations plotted by distance from Bushy Park Reservoir Dam, Goose Creek, South Carolina, for sampling events from September 2013 to April 2015. 
than concentrations in the reservoir near the dam, indicating that the in situ production of MIB by cyanobacteria was more likely the dominant source.

In contrast to MIB, there was a general trend of increasing geosmin concentrations in the upper portion of the reservoir, especially near Cooper River and Durham Canal (sites CWS-1 and CWS-2, respectively) during the September 2013, July 2014, and August 2014 sampling events. However, geosmin concentrations never exceeded $15 \mathrm{ng} / \mathrm{L}$ in this portion of the reservoir. Water-column samples collected during the spring period exhibited increased geosmin concentrations at two locations in the reservoir near the dam (sites CWS-7 and CWS-5 [intake]), and unlike MIB, concentrations in Foster Creek (site CWS-6) were lower than in the reservoir, indicating a high probability of in situ production of geosmin in the reservoir by cyanobacteria.

During the study period, a constant production of MIB near the dam and geosmin in the middle and upper portions of the reservoir seemed to occur during the summer and early fall, but concentrations were relatively low, between 10 and $15 \mathrm{ng} / \mathrm{L}$. At site CWS-5, the dominant T\&O compound tended to be MIB at a 2- or 3-to-1 ratio with geosmin during the summer and fall. However, during springtime episodes in which $\mathrm{T} \& \mathrm{O}$ concentrations were elevated above the CWS treatment threshold, the spatial distribution of geosmin concentrations greater than $15 \mathrm{ng} / \mathrm{L}$ ( 28 to $38 \mathrm{ng} / \mathrm{L}$ ) seems to be best explained by in situ production in the lower portion of the Bushy Park Reservoir near the dam rather than transport from Foster Creek or Durham Canal. This pattern seems to indicate a possible shift in phytoplankton communities, (or, at least, cyanobacteria communities) from MIB producers to geosmin producers. Therefore, identification of spatial and seasonal variation in water quality and phytoplankton community was evaluated to explain this shift in T\&O occurrence.

\section{Characterization of Water-Quality Conditions in Bushy Park Reservoir}

Statistical summaries of field measurements (table 6), major ion, trace metal, and organic carbon concentrations (table 7), and nutrient, chlorophyll $a$, actinomycetes, and T\&O concentrations (table 8) were produced in tabular format. Discrete water-quality data from each sampling event are provided in appendix 5. Chemical data are stored in the USGS National Water Information System and are publicly available through the NWISWeb database (U.S. Geological Survey, 2016). Water-quality profile and AUV-derived data were compiled in tabular and graphical formats (appendixes 2,3) (Conrads and others, 2017a).

Depth profiles and AUV surveys of water temperature, $\mathrm{pH}$, dissolved oxygen, and specific conductance were assessed to determine the degree and extent of thermal stratification during the study period (appendixes 2, 3). Additionally, the profile and survey data were used to identify areas within the reservoir where greater phytoplankton and cyanobacteria densities were most likely occurring. Bushy Park Reservoir tended to stratify thermally at a depth of about $20 \mathrm{ft}$ from June to early October. The stratification was limited to the deeper portions of the reservoir near the dam and often dissipated within the reservoir near site CWS-5 (appendix 2, August 26, 2014, longitudinal survey, water temperature). Where thermally stratified, a corresponding depletion of dissolved oxygen also occurred at about the same depth and resulted in an anoxic hypolimnion below the 25 - $\mathrm{ft}$ depth (appendix 2, August 26, 2014, longitudinal survey, dissolved oxygen) as well as an increase in specific conductance, likely due to remobilized metals and phosphorus under reducing conditions (appendix 2, August 26, 2014, longitudinal survey, specific conductance). In general, chlorophyll $a$ exhibited some spatial variation, but no strong consistent pattern or "hot spot" was observed. Phycocyanin, estimated as BGA cell density, seemed to be greater in the upper portion of the reservoir, but those differences may be attributed to increased turbidity and potential change in phytoplankton community structure that may affect fluorescence. In cross section, at sites CWS-5 and CWS-4 for example, changes in phycocyanin levels were observed at about the 10-ft depth.

During the study period, field measurements of $\mathrm{pH}$ were consistently within the SCDHEC criterion range of 6 to 9 for freshwaters, with median $\mathrm{pH}$ ranging from 6.6 to 7.3 (table 6; South Carolina Department of Health and Environmental Control, 2014c). Greater transparency of the water column is beneficial to phytoplankton productivity because it allows for deeper penetration of photosynthetically available light to phytoplankton communities. Median transparencies (measured in the field as Secchi disk depths) ranged from 1.4 to $1.5 \mathrm{~m}$ at the seven sites. Related to transparency, the amount of particles in the water column that scatter light is measured in the field as turbidity. Turbidity at the time of sampling was below the SCDHEC criterion level of 25 nephelometric turbidity units (NTU) for freshwaters, and median turbidity measurements ranged from 1.3 to 5.0 formazin nephelometric units (FNU). Comparatively, the amount of suspended sediment in the water column was low at all sites, with median suspended-sediment concentrations ranging from 2 to $6 \mathrm{mg} / \mathrm{L}$ (table 7).

Dissolved ammonia nitrogen and dissolved nitrate plus nitrite species are the readily bioavailable forms of nitrogen for phytoplankton, especially for the noncyanobacteria groups (Wetzel, 2001). During the study period at all sites sampled in Bushy Park Reservoir, dissolved ammonia concentrations generally were above the LRL of $0.01 \mathrm{mg} / \mathrm{L}$ (35 percent censored at LRL), and median concentrations ranged from $<0.010$ to $0.016 \mathrm{mg} / \mathrm{L}$ (table 8 ). At all sites sampled, dissolved nitrate plus nitrite concentrations rarely were above the LRL of $0.04 \mathrm{mg} / \mathrm{L}$ (87.5 percent censored at LRL), and detectable concentrations typically were reported at only 1 of 5 sampling events at each site. Detectable dissolved nitrate plus nitrite concentrations at sites CWS-1 $(0.05 \mathrm{mg} / \mathrm{L})$, CWS-4S $(0.05 \mathrm{mg} / \mathrm{L})$, and CWS-5S $(0.11 \mathrm{mg} / \mathrm{L})$ were measured in December 2014 and at sites CWS-3 $(0.29 \mathrm{mg} / \mathrm{L})$, CWS-6 (0.08 mg/L), and CWS-7 (0.06 mg/L) in April 2014 
Table 6. Statistical summary of the field measurements made during discrete water-column sampling at selected locations in Bushy Park Reservoir, near Goose Creek, South Carolina, September 2013 to April 2015.

[n, number of samples; $25 \%, 25$ th percentile; $75 \%$, 75 th percentile; cm-1, per centimeter; $\mathrm{mg} / \mathrm{L}$, milligram per liter; $\%$, percent; ${ }^{\circ} \mathrm{C}$, degrees Celsius; $\mathrm{m}$, meter; $\mu \mathrm{mol} / \mathrm{s}-\mathrm{m}^{2}$, micromoles of photons per second per square meter; FNU, formazin nephelometric units]

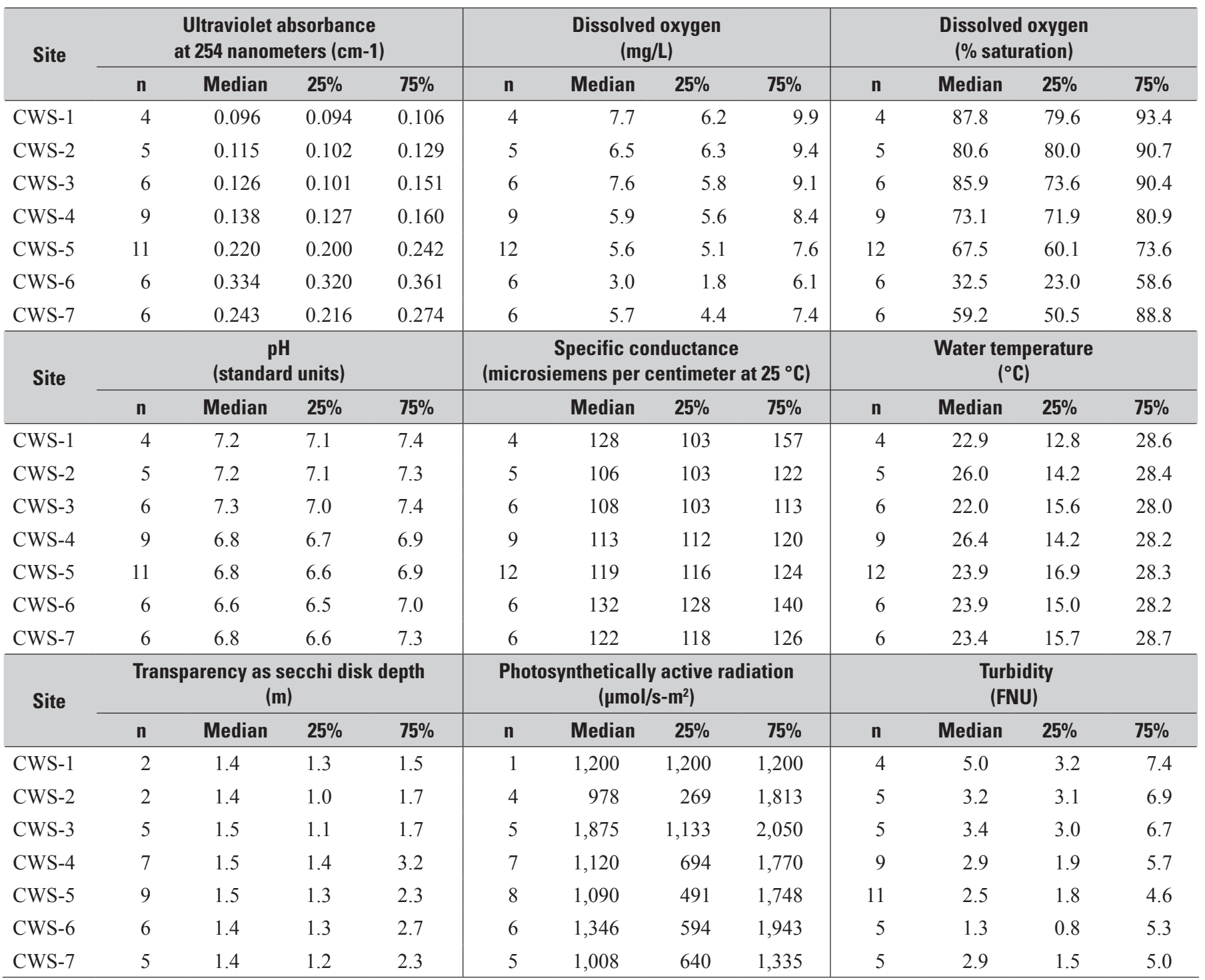

( $\mathrm{T} \& \mathrm{O}$ response survey trip). The maximum concentration was measured at site CWS-3, April 16, 2014 (appendix 5). Dissolved forms of phosphorus, including orthophosphate, also are readily bioavailable forms of phosphorus for phytoplankton, especially for the noncyanobacteria groups (Wetzel, 2001). Dissolved orthophosphate and total phosphorus concentrations frequently were above the LRL of $0.004 \mathrm{mg} / \mathrm{L}$ (only 17 and 10 percent censored below LRL, respectively) (appendix 5). During the study period at all sites sampled in Bushy Park Reservoir, median dissolved orthophosphate concentrations ranged from $<0.004$ to $0.033 \mathrm{mg} / \mathrm{L}$.
Unlike dissolved concentrations, total concentrations (which include dissolved and particulate forms and inorganic and organic forms) of nitrogen and phosphorus are used to assess the trophic state of a reservoir (Carlson, 1977; Wetzel, 2001), and numeric criteria have been established for lakes and reservoirs in South Carolina for the Middle Atlantic Coastal Plain ecoregion of the State where Bushy Park Reservoir is located (South Carolina Department of Health and Environmental Control, 2014c). The SCDHEC criterion for total nitrogen concentrations is $1.50 \mathrm{mg} / \mathrm{L}$. At all sites sampled, total nitrogen concentrations did not exceed 
Table 7. Statistical summary of major ion, trace metal, and organic carbon concentrations in discrete water-column samples collected at selected locations in Bushy Park Reservoir, near Goose Creek, South Carolina, September 2013 to April 2015.

[n, number of samples; $25 \%, 25$ th percentile; $75 \%, 75$ th percentile; $\mathrm{mg} / \mathrm{L}$, milligram per liter; $\mu \mathrm{g} / \mathrm{L}$, microgram per liter]

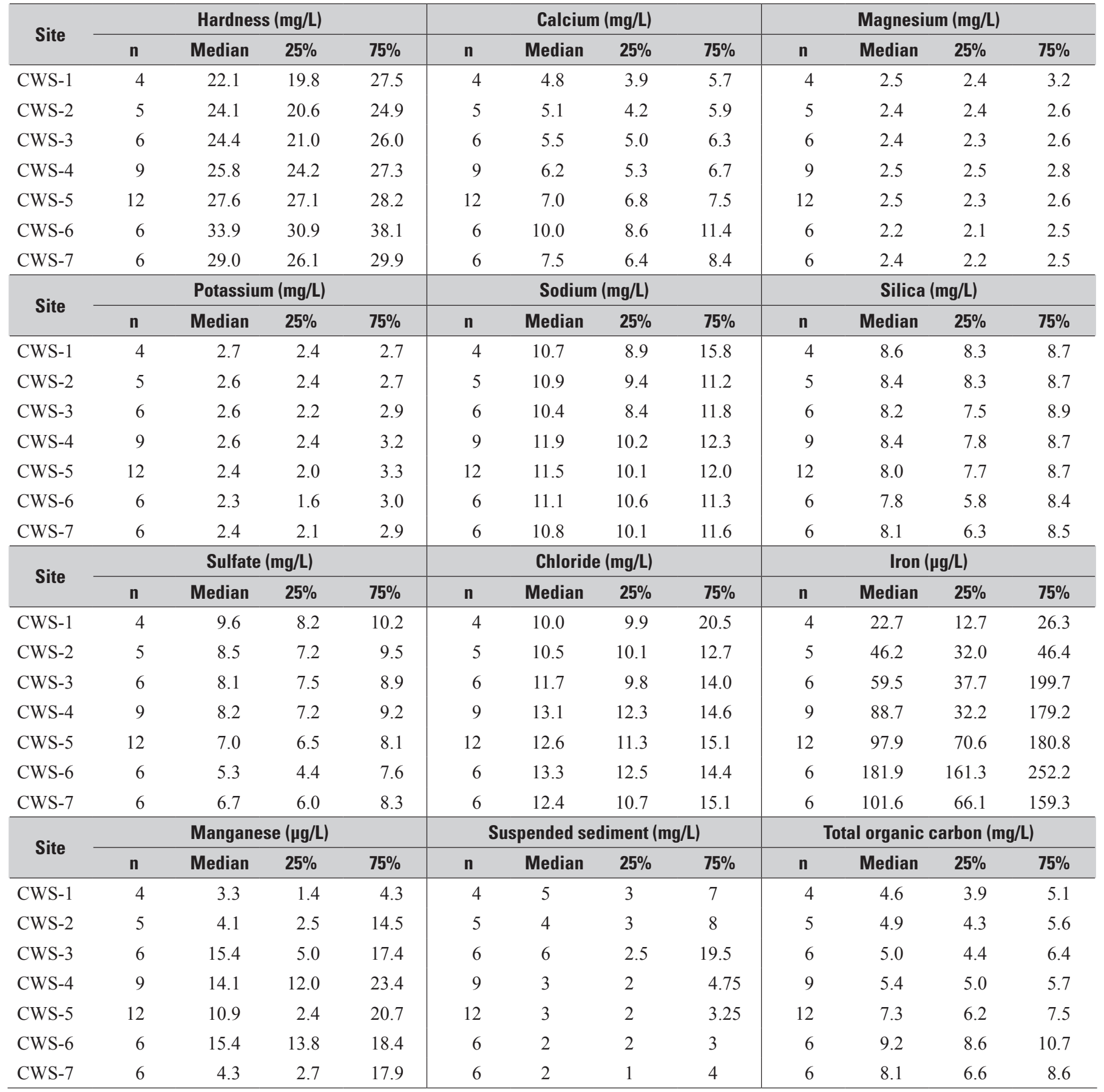


Table 8. Statistical summary of the nutrient, chlorophyll a, actinomycetes, and taste-and-odor concentrations in discrete watercolumn samples collected at selected locations in Bushy Park Reservoir, near Goose Creek, South Carolina, September 2013 to April 2015.

[n, number of samples; $25 \%$, 25th percentile; 75\%, 75th percentile; $\mathrm{mg} / \mathrm{L}$, milligram per liter; $\mathrm{N}$, nitrogen; P, phosphorus; $\mu \mathrm{g} / \mathrm{L}$, microgram per liter; ng/L, nanogram per liter; col/100 mL, colonies per 100 milliliters; <, less than]

\begin{tabular}{|c|c|c|c|c|c|c|c|c|c|c|c|c|}
\hline \multirow{2}{*}{ Site } & \multicolumn{4}{|c|}{ Chlorophyll a ( $\mu \mathrm{g} / \mathrm{L})$} & \multicolumn{4}{|c|}{ Ammonia (mg/L) } & \multicolumn{4}{|c|}{ Nitrate plus nitrite (mg/L as $\mathrm{N}$ ) } \\
\hline & $\mathbf{n}$ & Median & $25 \%$ & $75 \%$ & n & Median & $25 \%$ & $75 \%$ & $\mathbf{n}$ & Median & $25 \%$ & $75 \%$ \\
\hline CWS-1 & 4 & 7.2 & 5.1 & 8.1 & 4 & $<0.010$ & $<0.010$ & 0.019 & 4 & $<0.04$ & $<0.04$ & 0.044 \\
\hline CWS-3 & 6 & 6.8 & 4.1 & 8.5 & 6 & 0.013 & $<0.010$ & 0.026 & 6 & $<0.04$ & $<0.04$ & 0.087 \\
\hline CWS-4 & 7 & 7.1 & 5.6 & 8.8 & 9 & 0.012 & $<0.010$ & 0.019 & 9 & $<0.04$ & $<0.04$ & $<0.04$ \\
\hline CWS-6 & 6 & 11.2 & 8.4 & 14.9 & 6 & 0.016 & $<0.010$ & 0.023 & 6 & $<0.04$ & $<0.04$ & $<0.04$ \\
\hline CWS-7 & 5 & 10.2 & 7.1 & 11.3 & 6 & $<0.010$ & $<0.010$ & 0.053 & 6 & $<0.04$ & $<0.04$ & $<0.04$ \\
\hline \multirow{2}{*}{ Site } & \multicolumn{4}{|c|}{ Total organic nitrogen (mg/L as $\mathbf{N}$ ) } & \multicolumn{4}{|c|}{ Dissolved organic nitrogen (mg/L as $\mathrm{N}$ ) } & \multicolumn{4}{|c|}{ Total nitrogen (mg/L as $\mathrm{N}$ ) } \\
\hline & $\mathbf{n}$ & Median & $25 \%$ & $75 \%$ & n & Median & $25 \%$ & $75 \%$ & $\mathbf{n}$ & Median & $25 \%$ & $75 \%$ \\
\hline CWS-1 & 4 & 0.18 & 0.16 & 0.26 & 4 & 0.12 & 0.11 & 0.20 & 4 & 0.35 & 0.32 & 0.38 \\
\hline CWS-5 & 12 & 0.21 & 0.19 & 0.23 & 12 & 0.15 & 0.14 & 0.19 & 12 & 0.43 & 0.39 & 0.48 \\
\hline CWS-6 & 6 & 0.23 & 0.21 & 0.25 & 6 & 0.18 & 0.18 & 0.20 & 6 & 0.47 & 0.44 & 0.54 \\
\hline CWS-7 & 6 & 0.20 & 0.20 & 0.22 & 6 & 0.15 & 0.14 & 0.18 & 6 & 0.46 & 0.40 & 0.47 \\
\hline \multirow{2}{*}{ Site } & \multicolumn{4}{|c|}{ Orthophosphate (mg/L as P) } & \multicolumn{4}{|c|}{ Total phosphorus (mg/L as P) } & \multicolumn{4}{|c|}{ 2-methylisoborneol (ng/L) } \\
\hline & $\mathbf{n}$ & Median & $25 \%$ & $75 \%$ & n & Median & $25 \%$ & $75 \%$ & $\mathbf{n}$ & Median & $25 \%$ & $75 \%$ \\
\hline CWS-1 & 4 & $<0.004$ & $<0.004$ & 0.005 & 4 & 0.030 & 0.014 & 0.034 & 4 & 2.5 & 1.3 & 7.0 \\
\hline CWS-2 & 5 & 0.004 & $<0.004$ & 0.006 & 5 & 0.025 & 0.016 & 0.028 & 5 & 3.3 & 1.9 & 9.5 \\
\hline CWS-3 & 6 & 0.004 & 0.004 & 0.006 & 6 & 0.026 & 0.025 & 0.039 & 6 & 2.3 & 1.8 & 7.8 \\
\hline \multirow[t]{2}{*}{ Site } & \multicolumn{4}{|c|}{ Geosmin (ng/L) } & \multicolumn{4}{|c|}{ Actinomycetes (col/100 mL) } & \multicolumn{4}{|c|}{$\begin{array}{l}\text { Biomass to chlorophyll a ratio } \\
\text { (unitless) }\end{array}$} \\
\hline & n & Median & $25 \%$ & $75 \%$ & n & Median & $25 \%$ & $75 \%$ & $\mathbf{n}$ & Median & $25 \%$ & $75 \%$ \\
\hline CWS-1 & 4 & 4.7 & 2.6 & 11.9 & 4 & 9 & 5 & 15 & 4 & 983 & 945 & 1,190 \\
\hline CWS-2 & 5 & 7.9 & 3.2 & 14.5 & 5 & 10 & 8 & 16 & 5 & 1,031 & 573 & 1,170 \\
\hline CWS-3 & 6 & 10.3 & 3.4 & 12.3 & 6 & 9 & 5 & 12 & 6 & 933 & 693 & 1,315 \\
\hline CWS-4 & 9 & 9.6 & 2.3 & 11.0 & 9 & 9 & 7 & 11 & 9 & 1,257 & 864 & 1,316 \\
\hline CWS-5 & 12 & 2.8 & 1.3 & 5.2 & 12 & 7 & 5 & 9 & 12 & 764 & 402 & 1,152 \\
\hline CWS-6 & 6 & 2.9 & 1.0 & 7.4 & 6 & 10 & 9 & 13 & 6 & 1,003 & 435 & 1,547 \\
\hline CWS-7 & 6 & 2.6 & 1.0 & 12.9 & 6 & 6 & 4 & 12 & 6 & 972 & 577 & 3,880 \\
\hline
\end{tabular}


$0.84 \mathrm{mg} / \mathrm{L}$ (this maximum concentration was measured at site CWS-3, April 16, 2014) and generally were near the study area-wide median of $0.40 \mathrm{mg} / \mathrm{L}$ and reservoir-wide (omit Foster Creek) median of $0.39 \mathrm{mg} / \mathrm{L}$. Therefore, concentrations at sites located in Bushy Park Reservoir were well below the SCDHEC numeric total nitrogen criterion for lakes of $1.50 \mathrm{mg} / \mathrm{L}$ during the study period.

During the study period, total phosphorus concentrations at sites located in Bushy Park Reservoir were below the SCDHEC numeric total phosphorus criterion for lakes of $0.09 \mathrm{mg} / \mathrm{L}$. Concentrations at sites within the reservoir generally were near the reservoir-wide median of $0.037 \mathrm{mg} / \mathrm{L}$, and the maximum total phosphorus concentration was $0.067 \mathrm{mg} / \mathrm{L}$. A maximum total phosphorus concentration of $0.095 \mathrm{mg} / \mathrm{L}$, however, was measured at Foster Creek (site CWS-6), which is a tributary to the reservoir, on April 16, 2014.

Chlorophyll $a$ is a pigment found in phytoplankton; therefore, chlorophyll $a$ concentrations commonly are used to estimate the algal biomass present in a reservoir (Wetzel, 2001). Pheophytin $a$ is the degraded form of the chlorophyll $a$ pigment, resulting from the loss of a magnesium ion. Chlorophyll $a$ concentrations are used to assess the trophic state of a reservoir (Carlson, 1977; Wetzel, 2001) and a numeric criterion of $40 \mu \mathrm{g} / \mathrm{L}$ has been established for lakes and reservoirs in the Middle Atlantic Coastal Plain ecoregion of South Carolina (South Carolina Department of Health and Environmental Control, 2014a). During the study period at all sites sampled in Bushy Park Reservoir, chlorophyll $a$ concentrations did not exceed $20.9 \mu \mathrm{g} / \mathrm{L}$ (this maximum concentration was measured at site CWS-5, July 23, 2014), which is well below the SCDHEC chlorophyll $a$ criterion level for reservoirs. However, chlorophyll $a$ concentrations did fluctuate among sites and sample periods.

\section{Spatial and Seasonal Changes in Water-Quality Conditions in Bushy Park Reservoir}

Near-surface (about 3.3-ft depth) and deeper photic zone (about 10-ft depth, the location of the intake pipe) samples were collected at sites CWS-4 and CWS-5 periodically during the sampling events. A comparison between the mean concentrations of 3.3-ft and 10-ft depth samples indicated no difference in water chemistry at these sampling points. Nutrient, T\&O, organic carbon, and chlorophyll $a$ concentrations were statistically similar at the shallow and deep depth zones. Additionally, no differences were identified between phytoplankton biovolumes and cell densities with depth. Therefore, both deep and shallow samples were combined and included in the data analysis discussed in the section that follows (table 9).

Selected constituents were evaluated by using permutation one-factor tests to determine if spatial differences in water chemistry in Bushy Park Reservoir were present during the study period (table 10). Foster Creek (site CWS-6), one of the major tributaries to the lower portion of Bushy Park Reservoir near the dam, has classic "blackwater" (high humic content) stream water-quality characteristics. These characteristics include lower dissolved oxygen (DO) and higher total and dissolved organic carbon (TOC, DOC, respectively) and ultraviolet absorbance at 254 nanometers (UVA; an estimate of the humic content of the organic carbon) than the tributaries (Cooper River, site CWS-1; Durham Canal, site CWS-2) in the upper portion of the reservoir (table 10; fig. 13). This characteristic signature of high UVA and DOC can be observed at sites in the lower portion of the reservoir (CWS-7 and CWS-5), indicating dystrophic conditions for the reservoir in that region (table 10; fig. 13). The blackwater signature appears to dissipate in the water column near sites CWS-4 and CWS-3.

In general, Foster Creek (site CWS-6) had greater total phosphorus, dissolved orthophosphate, and total nitrogen concentrations and total hardness than sites on Cooper River (CWS-1) and Durham Canal (CWS-2) (table 10; figs. 14, 15). These signatures, however, are more indicative of the human development (residential and commercial) within the watershed rather than natural blackwater conditions. Dissolved iron concentrations were greater in the reservoir than in Cooper River and Durham Canal (sites CWS-1 and CWS-2, respectively; fig. 15). As was observed with the blackwater signature, nutrient levels at sites CWS-5 and CWS-7 also appeared to be influenced by contributions from Foster Creek (site CWS-6), whereby total phosphorus and total nitrogen concentrations in the lower portion of Bushy Park Reservoir generally were elevated relative to the upper portion of the reservoir (table 10; fig. 14). On the basis of chlorophyll $a$ concentrations only, however, the elevated nutrient concentrations did not appear to influence algal productivity because no significant increase in chlorophyll $a$ concentrations was identified in the lower portion of the reservoir (table 10; fig. 16). Additionally, no overall spatial differences in mean geosmin and MIB concentrations were identified among sites in the reservoir (table 10; fig. 16).

Statistically significant differences in water chemistry were identified among the three seasons during which samples were collected for the study (fall, spring, summer). A general springtime pattern of elevated geosmin concentrations occurred in Bushy Park Reservoir as observed by CWS monitoring of the raw blended water (table 11; fig. 17). In fact, geosmin concentrations had distinct differences among the seasons (spring $>$ summer $>$ fall). During the spring when geosmin concentrations were elevated, water chemistry of the reservoir also indicated higher levels of dissolved iron, dissolved nitrate plus nitrite, total nitrogen, and total phosphorus than during the fall and summer (table 11). Although geosmin concentrations were different among all three seasons, MIB concentrations were elevated similarly in the spring and summer seasons compared to concentrations in the fall. Correspondingly, chlorophyll $a$ (estimate of total algal biomass) concentrations were higher during the spring and summer seasons compared to those in the fall. No seasonal differences were identified in actinomycetes, dissolved ammonia, dissolved orthophosphate, dissolved manganese, hardness, or total organic carbon concentrations or ultraviolet absorbance at 254 nanometers. 
Table 9. Summary of the permutation one-factor test (t-test) and pairwise Wilcoxon multiple comparison tests (U) to identify differences in environmental conditions in Bushy Park Reservoir, near Goose Creek, South Carolina, September 2013 to April 2015 , between shallow (1-3 feet) and deep (9-10 feet) samples.

[Depths that share the same letter are statistically similar, and sites that have different letters are statistically different, such that A $>$ B $>$ C, and so on. -, not determined]

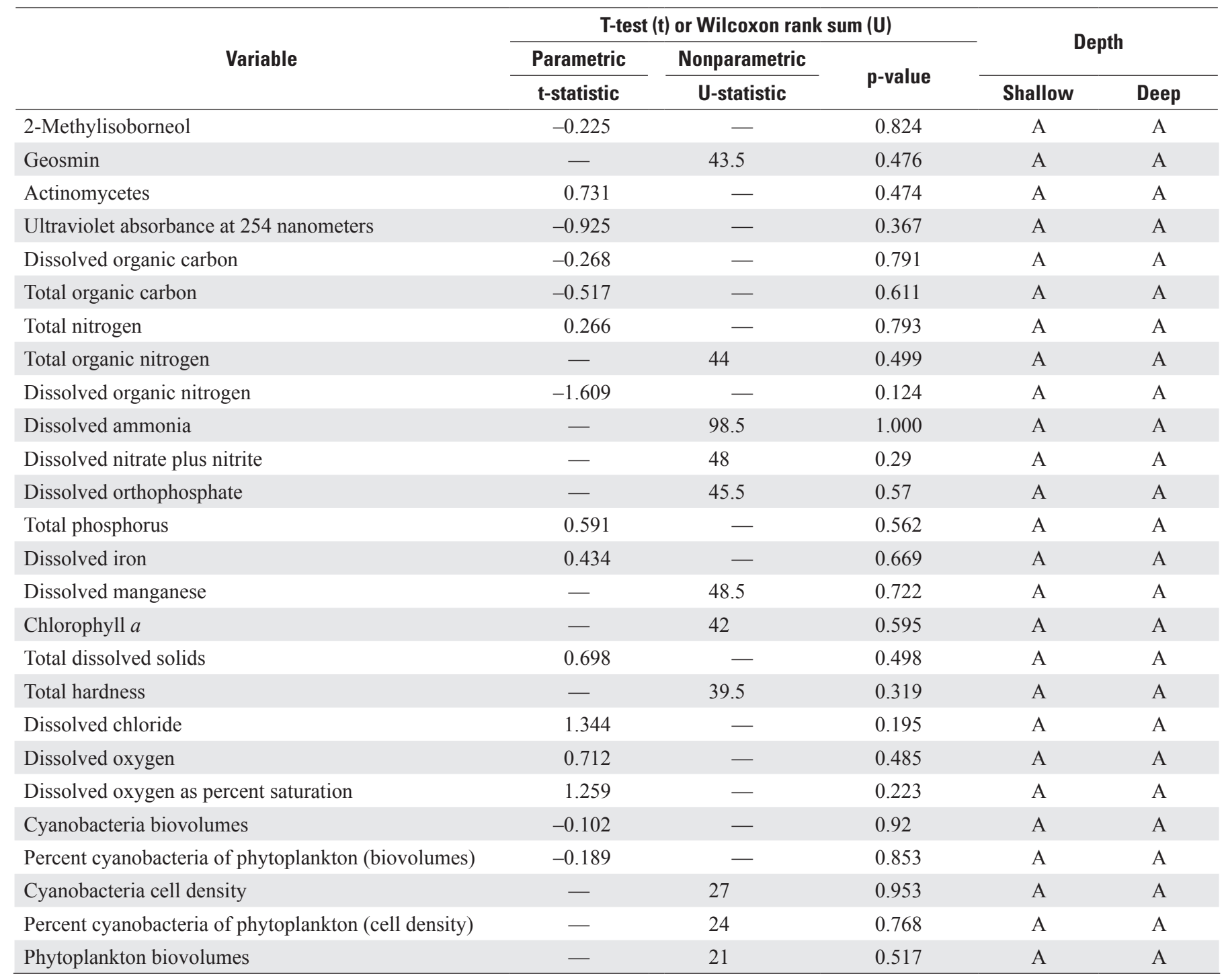


Table 10. Summary of the permutation one-factor test and pairwise Wilcoxon multiple comparison tests to identify differences in environmental conditions in Bushy Park Reservoir, near Goose Creek, South Carolina, September 2013 to April 2015, among sites.

[Sites that share the same letter are statistically similar, and sites that have different letters are statistically different, such that A $>$ B $>$ C, and so on. n, number of samples; <, less than]

\begin{tabular}{|c|c|c|c|c|c|c|c|c|c|}
\hline \multirow{2}{*}{ Variable } & \multicolumn{2}{|c|}{$\begin{array}{l}\text { Permutation test } \\
\quad(n=5,000)\end{array}$} & \multicolumn{7}{|c|}{ Pairwise Wilcoxon multiple comparison test } \\
\hline & F-statistic & p-value & CWS-1 & CWS-2 & CWS-3 & CWS-4 & CWS-5 & CWS-6 & CWS-7 \\
\hline Geosmin & 0.29 & 0.94 & A & A & A & A & A & A & A \\
\hline Actinomycetes & 0.77 & 0.594 & A & A & A & A & A & A & A \\
\hline Dissolved organic carbon (DOC) & 43.09 & $<0.001$ & $\mathrm{D}$ & $\mathrm{D}$ & $\mathrm{CD}$ & $\mathrm{C}$ & $\mathrm{B}$ & A & $\mathrm{B}$ \\
\hline Total organic carbon (TOC) & 23.39 & $<0.001$ & $\mathrm{D}$ & $\mathrm{D}$ & $\mathrm{CD}$ & $\mathrm{C}$ & $\mathrm{B}$ & A & $\mathrm{B}$ \\
\hline DOC:TOC ratio & 1.50 & 0.202 & A & A & A & A & A & A & A \\
\hline Total nitrogen & 2.45 & 0.04 & $\mathrm{C}$ & $\mathrm{C}$ & $\mathrm{AB}$ & $\mathrm{BC}$ & $\mathrm{AB}$ & A & $\mathrm{AB}$ \\
\hline Dissolved nitrate plus nitrite & 0.68 & 0.667 & A & A & A & A & A & A & A \\
\hline Dissolved orthophosphate & 27.75 & $<0.001$ & $\mathrm{~B}$ & $\mathrm{~B}$ & $\mathrm{~B}$ & $\mathrm{~B}$ & $\mathrm{~B}$ & A & $\mathrm{B}$ \\
\hline Total phosphorus & 8.70 & $<0.001$ & $\mathrm{C}$ & $\mathrm{C}$ & $\mathrm{BC}$ & $\mathrm{C}$ & $\mathrm{B}$ & A & $\mathrm{B}$ \\
\hline Dissolved iron & 4.28 & 0.002 & $\mathrm{C}$ & $\mathrm{BC}$ & $\mathrm{B}$ & $\mathrm{AB}$ & A & A & $\mathrm{AB}$ \\
\hline Dissolved manganese & 1.72 & 0.14 & A & A & A & A & A & A & A \\
\hline Chlorophyll $a$ & 0.58 & 0.745 & A & A & A & A & A & A & A \\
\hline Total dissolved solids & 0.67 & 0.671 & A & A & A & A & A & A & A \\
\hline Total hardness & 6.27 & $<0.001$ & $\mathrm{BC}$ & $\mathrm{D}$ & $\mathrm{C}$ & $\mathrm{C}$ & $\mathrm{B}$ & A & $\mathrm{BCD}$ \\
\hline Dissolved chloride & 0.67 & 0.678 & A & A & A & A & A & A & A \\
\hline
\end{tabular}



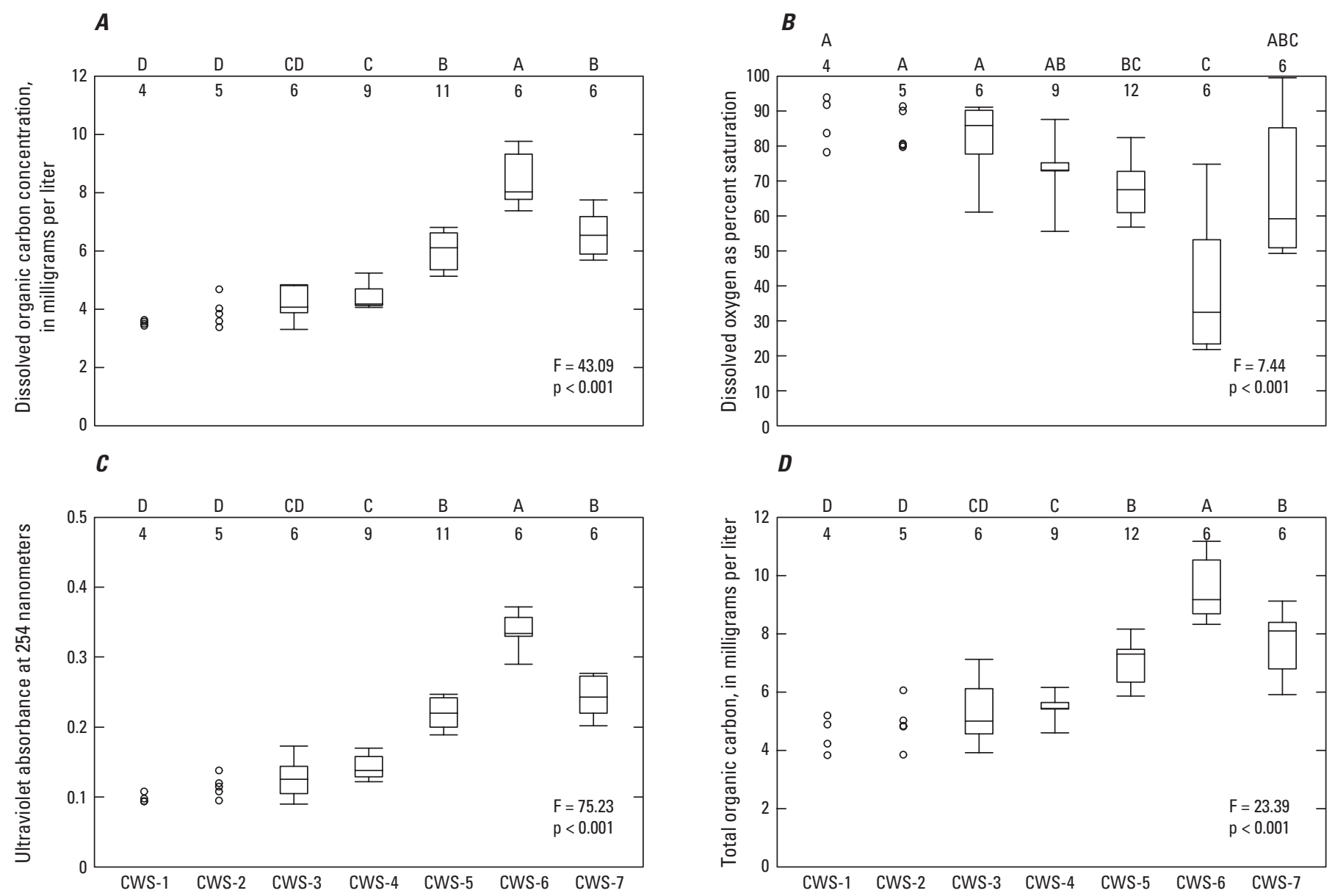

EXPLANATION

Number of samples

Single sample results. No box was plotted

if the number of samples was $\leq 5$

Maximum

75th percentile

50th percentile

(median)

25th percentile

Minimum

Figure 13. Boxplots of $(A)$ dissolved organic carbon concentrations, $(B)$ dissolved oxygen concentration as percent saturation, (C) ultraviolet absorbance at 254 nanometers, and $(D)$ total organic carbon at seven locations in Bushy Park Reservoir, near Goose Creek, South Carolina, September 2013 to April 2015. F-statistic, probability value (p), and letters above each boxplot represent results of the permutation-based multiple comparison test whereby sites that share the same letters are statistically similar and sites that do not share the same letters are statistically different $(A>B>C>D)$. 
$\boldsymbol{A}$

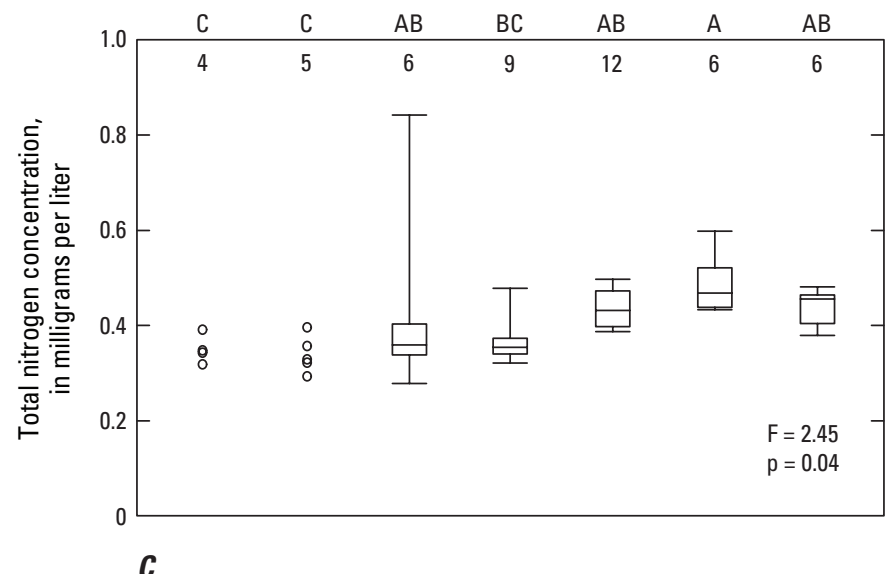

c

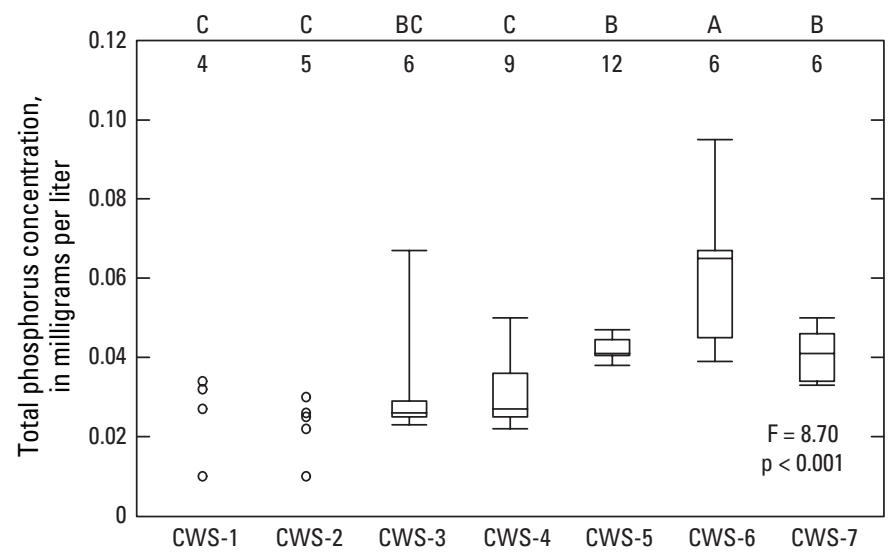

B
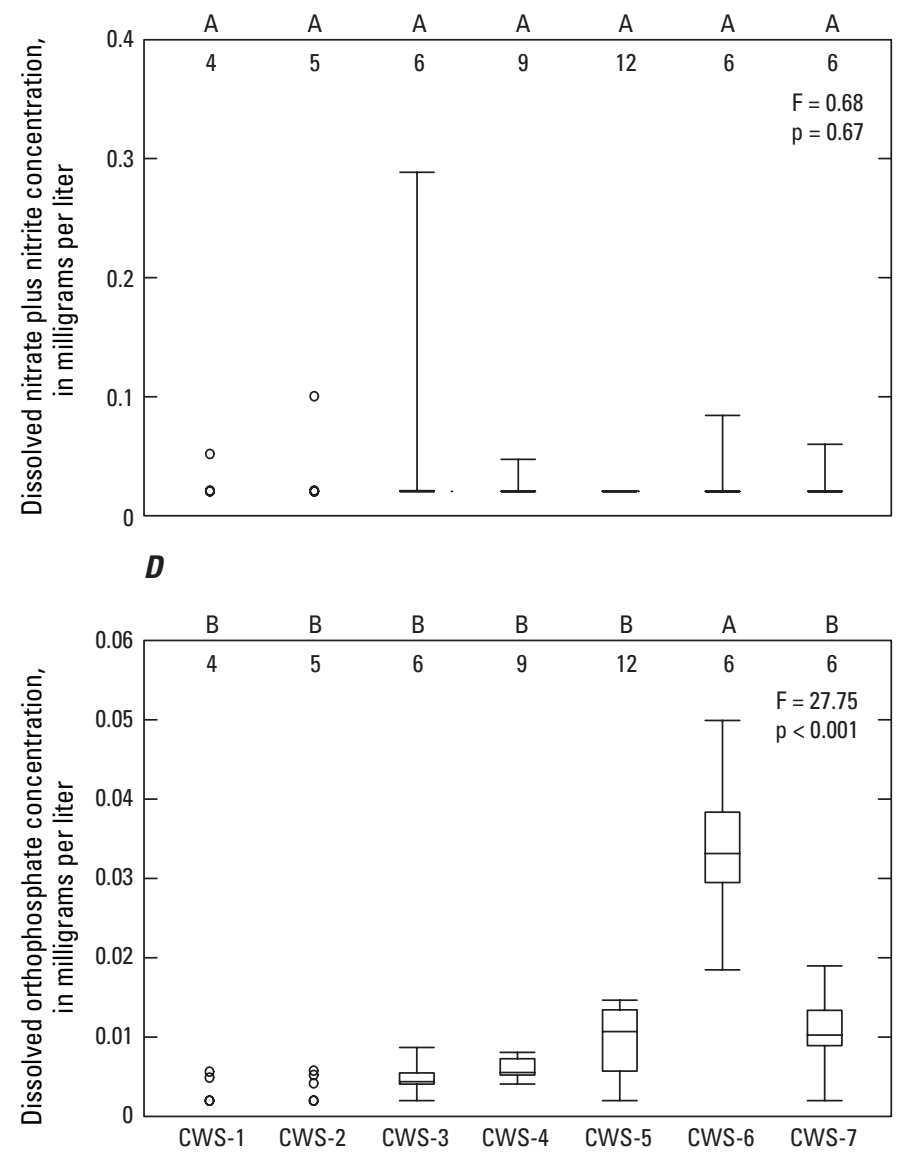

EXPLANATION

6 Number of samples

- Single sample results. No box was plotted if the number of samples was $\leq 5$

$T$ Maximum

50 th percentile

(median)

25th percentile

$\perp$ Minimum

Figure 14. Boxplots of $(A)$ total nitrogen, $(B)$ dissolved nitrate plus nitrite, $(C)$ total phosphorus, and $(D)$ dissolved orthophosphate concentrations at seven locations in Bushy Park Reservoir, near Goose Creek, South Carolina, September 2013 to April 2015. F-statistic, probability value $(p)$, and letters above each boxplot represent results of the permutation-based multiple comparison test whereby sites that share the same letters are statistically similar and sites that do not share the same letters are statistically different $(A>B>C>D)$. 

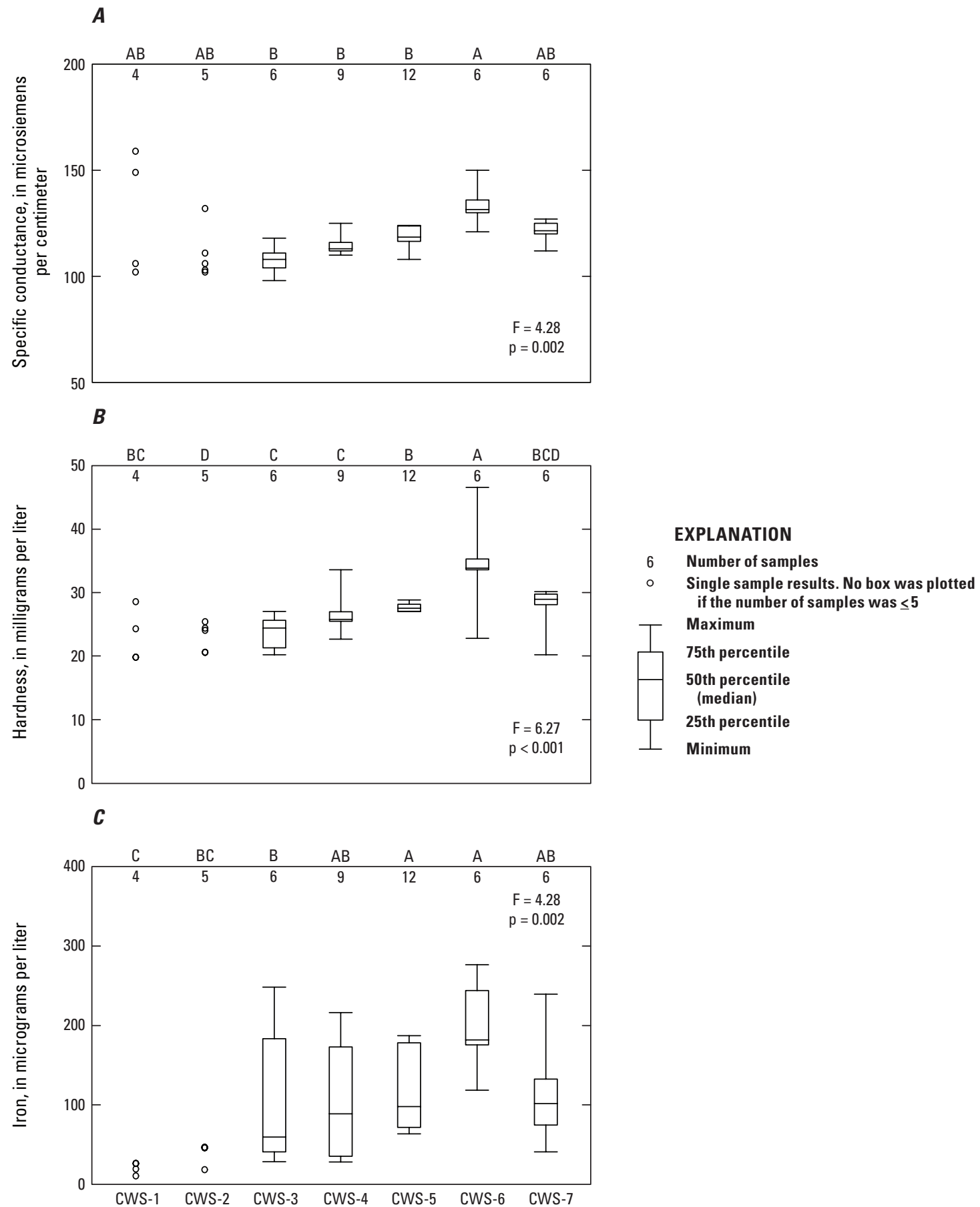

Figure 15. Boxplots of $(A)$ specific conductance at 25 degrees Celsius, $(B)$ total hardness concentration, and $(C)$ dissolved iron concentration at seven locations in Bushy Park Reservoir, near Goose Creek, South Carolina, September 2013 to April 2015. F-statistic, probability value (p), and letters above each boxplot represent results of the permutation-based multiple comparison test whereby sites that share the same letters are statistically similar and sites that do not share the same letters are statistically different ( $>B$ $>$ C $>$ D). 
$\boldsymbol{A}$
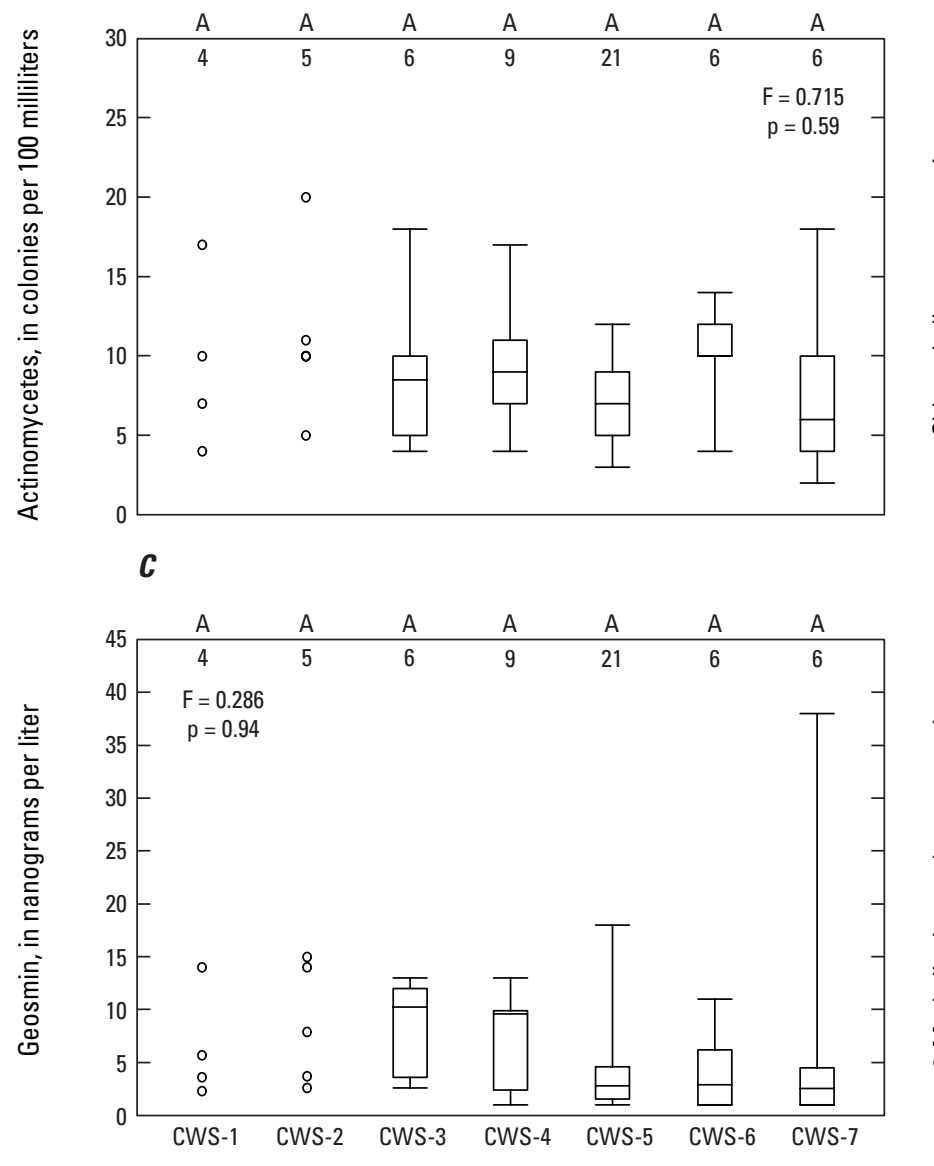

B
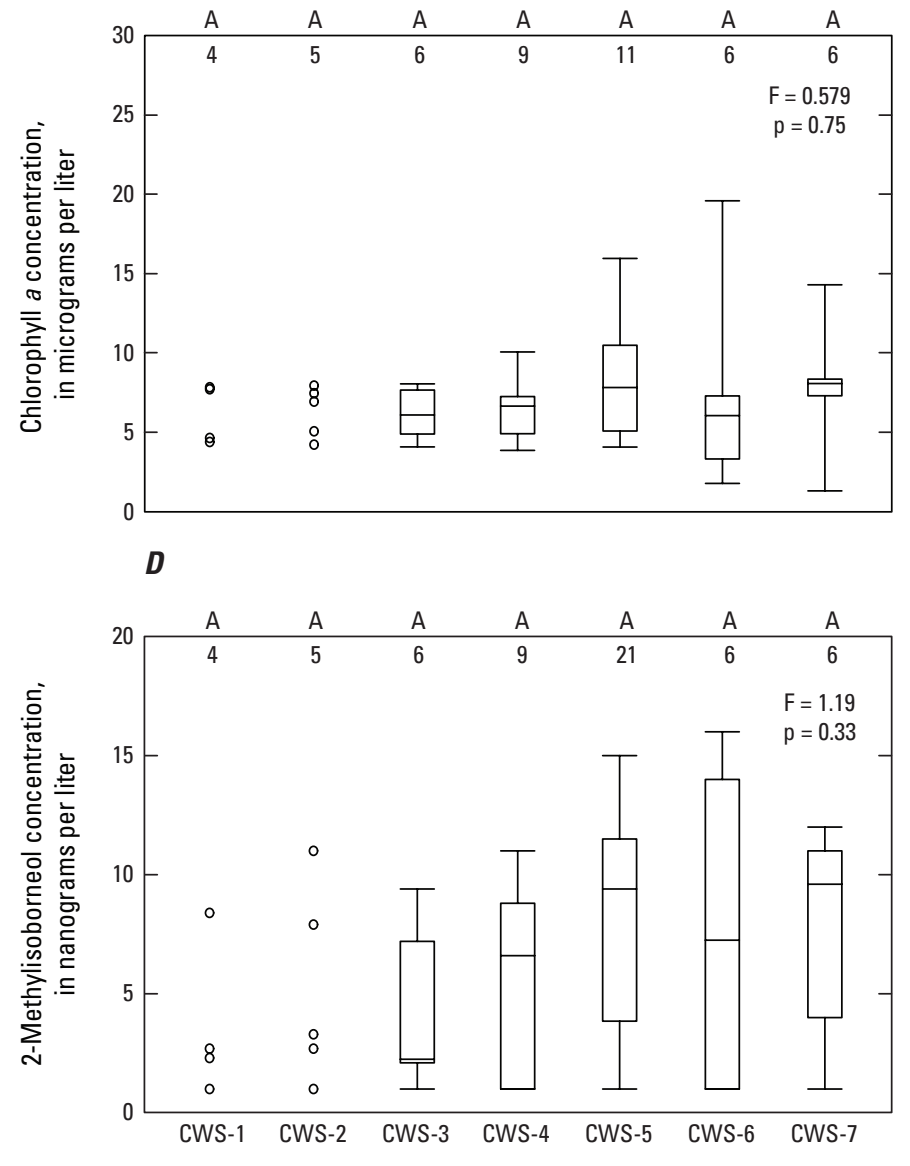

EXPLANATION

6 Number of samples

- Single sample results. No box was plotted

if the number of samples was $\leq 5$

T Maximum

75th percentile

50th percentile

(median)

25th percentile

I Minimum

Figure 16. Boxplots of $(A)$ actinomycetes, $(B)$ chlorophyll $a,(C)$ geosmin, and $(D)$ 2-methylisoborneol (MIB) concentrations at seven locations in Bushy Park Reservoir, near Goose Creek, South Carolina, September 2013 to April 2015. F-statistic, probability value (p), and letters above each boxplot represent results of the permutation-based multiple comparison test whereby sites that share the same letters are statistically similar and sites that do not share the same letters are statistically different $(A>B>C>D)$. 
Table 11. Summary of the permutation one-factor test and pairwise Wilcoxon multiple comparison tests to identify differences in environmental conditions in Bushy Park Reservoir, near Goose Creek, South Carolina, September 2013 to April 2015, among seasons.

[Seasons that share the same letter are statistically similar, and sites that have different letters are statistically different, such that $\mathrm{A}>\mathrm{B}>\mathrm{C}$, and so forth. $\mathrm{n}$, number of samples; $<$, less than]

\begin{tabular}{|c|c|c|c|c|c|}
\hline \multirow[t]{2}{*}{ Variable } & \multicolumn{2}{|c|}{$\begin{array}{l}\text { Permutation test } \\
\qquad(\mathrm{n}=5,000)\end{array}$} & \multicolumn{3}{|c|}{$\begin{array}{c}\text { Pairwise Wilcoxon multiple } \\
\text { comparison test }\end{array}$} \\
\hline & F-statistic & p-value & Spring & Summer & Fall \\
\hline 2-Methylisoborneol & 8.48 & $<0.001$ & A & A & B \\
\hline Geosmin & 21.847 & $<0.001$ & A & $\mathrm{B}$ & $\mathrm{C}$ \\
\hline Actinomycetes & 0.583 & 0.562 & A & A & A \\
\hline Ultraviolet absorbance at 254 nanometers & 2.249 & 0.117 & A & A & A \\
\hline Dissolved organic carbon (DOC) & 3.846 & 0.029 & A & $\mathrm{B}$ & $\mathrm{AB}$ \\
\hline Total organic carbon (TOC) & 2.646 & 0.082 & A & A & A \\
\hline DOC:TOC ratio & 13.67 & $<0.001$ & A & $\mathrm{B}$ & A \\
\hline Total nitrogen & 14.24 & $<0.001$ & A & $\mathrm{B}$ & B \\
\hline Total organic nitrogen & 6.278 & 0.004 & A & $\mathrm{B}$ & B \\
\hline Dissolved organic nitrogen & 3.205 & 0.05 & A & A & A \\
\hline Dissolved ammonia & 2.999 & 0.06 & A & A & A \\
\hline Dissolved nitrate plus nitrite & 7.84 & 0.001 & A & $\mathrm{B}$ & B \\
\hline Dissolved orthophosphate & 0.207 & 0.814 & A & A & A \\
\hline Total phosphorus & 4.337 & 0.019 & A & $\mathrm{B}$ & B \\
\hline Dissolved iron & 3.426 & 0.041 & A & B & B \\
\hline Dissolved manganese & 0.155 & 0.857 & A & A & A \\
\hline Chlorophyll $a$ & 18.32 & $<0.001$ & A & A & B \\
\hline Total dissolved solids & 0.669 & 0.517 & A & A & A \\
\hline Total hardness & 3.114 & 0.054 & A & A & A \\
\hline Dissolved chloride & 1.599 & 0.213 & A & A & A \\
\hline $\mathrm{pH}$ & 19.92 & $<0.001$ & A & $\mathrm{B}$ & B \\
\hline Specific conductance & 0.894 & 0.416 & A & A & A \\
\hline Dissolved oxygen as percent saturation & 2.854 & 0.068 & A & A & A \\
\hline
\end{tabular}

In summary, the spatial and seasonal assessment of water-quality conditions in Bushy Park Reservoir identified differences in water chemistry between the upper and lower portions of the reservoir that correspond to the season and location of elevated geosmin concentrations. The assessment determined that higher levels of dissolved iron, dissolved nitrate plus nitrite, total nitrogen, and total phosphorus were present in the reservoir during the spring compared to levels during the fall and summer. With the exception of dissolved nitrate plus nitrite concentrations, these constituents also were elevated in concentration in the lower portion of the reservoir, where geosmin was determined to reach concentrations above the CWS treatment threshold. On the basis of the spatial and seasonal assessment of actinomycetes concentrations compared to $\mathrm{T} \& \mathrm{O}$ concentrations, there appears to be a greater likelihood of cyanobacteria production as the dominant source of the T\&O episodes rather than actinomycetes. The absence of spatial and seasonal patterns in actinomycetes concentrations does not correspond to the springtime geosmin concentrations that were elevated above the CWS threshold in the lower portion of the reservoir. Additionally, actinomycetes concentrations, although ubiquitous, had a median of about 9 and maximum of about 20 colonies per milliliter, which could be considered low for elevated T\&O production. Nonetheless, the potential exists for actinomycetes to be a secondary source of $T \& O$ production and could explain some of the ubiquitous occurrence of low-level T\&O concentrations observed throughout the summer and early fall months. 
A
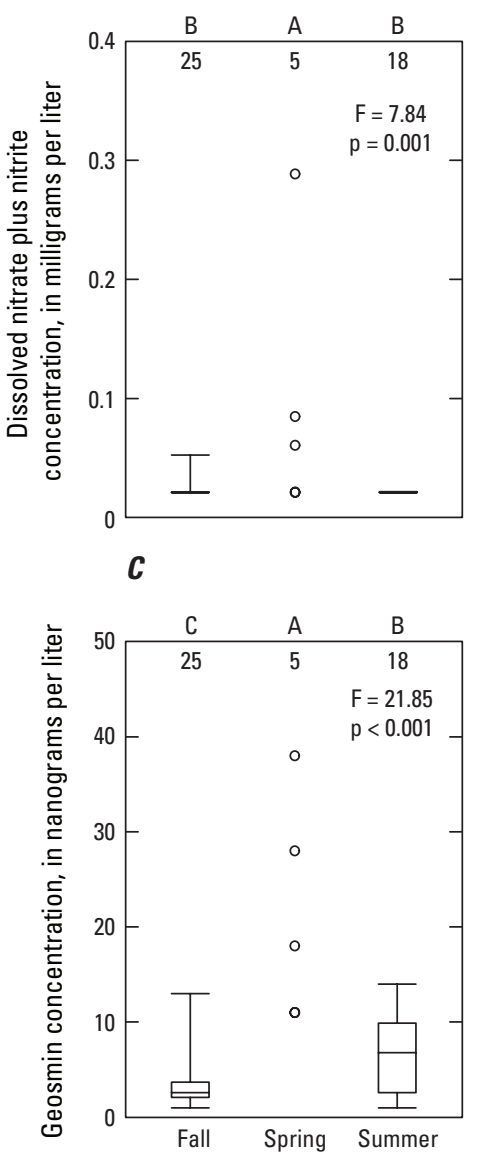

B
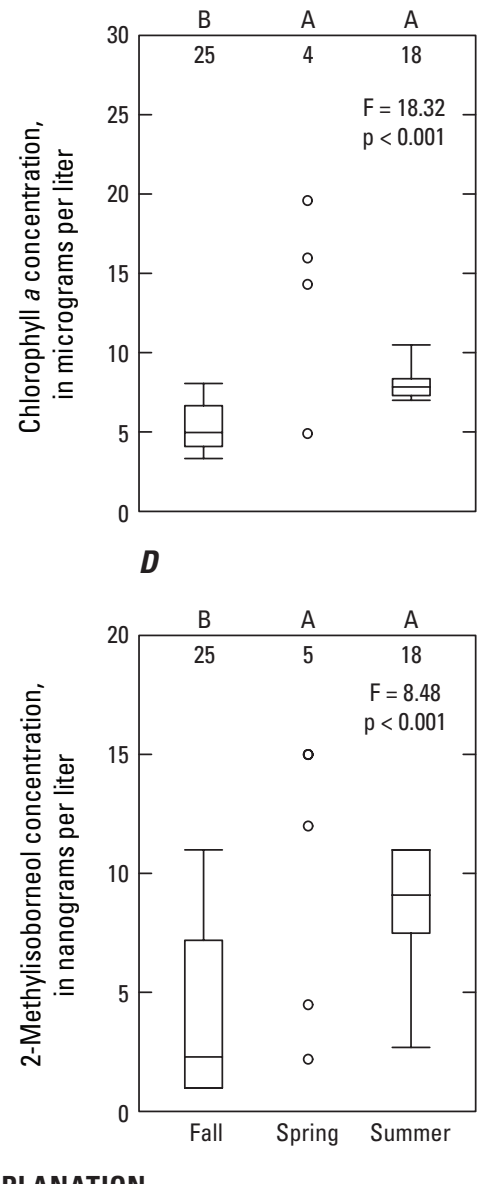

Figure 17. Boxplots of $(A)$ dissolved nitrate plus nitrite, $(B)$ chlorophyll $a,(C)$ geosmin, and (D) 2-methylisoborneol (MIB) concentrations at all seven locations by season in Bushy Park Reservoir, near Goose Creek, South Carolina, September 2013 to April 2015.

\section{Spatial and Seasonal Variation in Phytoplankton Community Structure in Bushy Park Reservoir}

The phytoplankton taxonomic data were summarized by major group (table 12, p. 56). The cell density of phytoplankton was quantified by microscopic cell counts found in 1 milliliter of sample (cells per milliliter). Biovolumes also were computed by using the cell density and the cell volume of the phytoplankton cell, the morphology of which varied by species and species variants. Explicitly, two species of phytoplankton that have different morphologies but the same cell density can have orders of magnitude different biovolumes. The cell density was used as an estimate of the abundance of a species while biovolume was used as an estimate of the biomass present.
In Bushy Park Reservoir, total phytoplankton biovolumes ranged from 748,223 (site CWS-2, July 2014) to 41,701,849 (site CWS-7, November 2014) cubic micrometers per milliliter (table 12). The percentage of the total phytoplankton biovolume that was represented by the cyanobacteria major group ranged from less than 1 to 32.5 percent; therefore, cyanobacteria did not dominate the phytoplankton in relation to overall biomass. Diatom and green algae major groups tended to dominate total phytoplankton biovolume in Bushy Park Reservoir with the exception of the yellow-green algae group during the July, August, and November 2014 sampling periods in the lower portion of the reservoir. These extremely high biovolumes were due to the presence of large-celled Gonyostomum semen that tends to be found in acidic waters and prefers a $\mathrm{pH}$ range of 4.4 to 6.6 and a water temperature range of 11 to $29^{\circ} \mathrm{C}$. 
During the sampling period, total phytoplankton cell densities ranged from 1,810 (site CWS-3, April 2014) to 74,544 (site CWS-2, September 2013) cells per milliliter (cells $/ \mathrm{mL}$ ) (table 12). For recreational waters, the World Health Organization (WHO) has established recommended harmful algal bloom response guidelines that stipulate a range of cyanobacteria cell densities and chlorophyll $a$ concentrations that indicate the relative probability of acute health effects attributed to the likely presence of cyanotoxins (Chorus and Bartram, 1999). The application of those guidelines to the cyanobacteria cell densities and chlorophyll $a$ concentrations observed in Bushy Park Reservoir would place the reservoir in the moderate probability of acute health effects. The percentage of the total phytoplankton cell density represented by the cyanobacteria major group ranged from 13 to 95.5 percent, and at most sites, cyanobacteria seasonally dominated the phytoplankton in relation to abundance of cells. On the basis of cell density, green algae and diatoms were the other predominate groups in the phytoplankton community structure when cyanobacteria were not dominating.
Phytoplankton biovolumes and cell densities were compared by using permutation tests among sites and among seasons to identify differences, if present. No differences among sites were identified during the study period (table 13). These results were similar to the comparison of chlorophyll $a$ concentrations among sites in which no differences were identified (table 10) probably because total phytoplankton biovolumes and chlorophyll $a$ concentrations represent similar bulk measures of the overall phytoplankton community. When these bulk measures of phytoplankton community were compared among seasons, no differences in biovolumes were indicated (table 13); however, cell densities of total phytoplankton, cyanobacteria, percentage of cyanobacteria in total phytoplankton, and number of total cyanobacteria species all were found to be greatest in the fall, intermediate in the summer, and least in the spring.

On the basis of biovolume, cyanobacteria were not the dominant phytoplankton group in Bushy Park Reservoir during the study period. "Bloom" forming levels of G. semen were identified in the reservoir during the summer months;

Table 13. Summary of the permutation one-factor test and pairwise Wilcoxon multiple comparison tests to identify differences in phytoplankton and cyanobacteria biovolume and cell density in Bushy Park Reservoir, near Goose Creek, South Carolina, September 2013 to April 2015, among sites and seasons.

[Sites or seasons that share the same letter are statistically similar, and sites that have different letters are statistically different, such that A $>$ B $>$ C, and so on. n, number of samples; <, less than]

\begin{tabular}{|c|c|c|c|c|c|c|c|c|c|}
\hline \multirow[t]{2}{*}{ Variable } & \multicolumn{2}{|c|}{$\begin{array}{l}\text { Permutation test } \\
\qquad(n=5,000)\end{array}$} & \multicolumn{7}{|c|}{ Pairwise Wilcoxon multiple comparison test } \\
\hline & F -statistic & p-value & CWS-1 & CWS-2 & CWS-3 & CWS-4 & CWS-5 & CWS-6 & CWS-7 \\
\hline Total phytoplankton biovolume & 1.69 & 0.157 & A & A & A & A & A & A & A \\
\hline Total cyanobacteria biovolume & 0.267 & 0.948 & A & A & $\mathrm{A}$ & A & A & A & A \\
\hline $\begin{array}{l}\text { Percent cyanobacteria in total } \\
\text { phytoplankton biovolume }\end{array}$ & 1.61 & 0.175 & A & A & A & A & A & A & A \\
\hline Total phytoplankton cell density & 1.55 & 0.195 & A & A & A & A & A & A & A \\
\hline Total cyanobacteria cell density & 1.62 & 0.175 & A & A & A & A & A & A & A \\
\hline $\begin{array}{l}\text { Percent cyanobacteria in total } \\
\text { phytoplankton cell density }\end{array}$ & 1.92 & 0.110 & A & A & A & A & $\mathrm{A}$ & A & A \\
\hline Number of total cyanobacteria species & 1.01 & 0.439 & A & A & A & A & A & A & A \\
\hline \multirow[t]{2}{*}{ Variable } & \multicolumn{2}{|c|}{$\begin{array}{l}\text { Permutation test } \\
\quad(n=5,000)\end{array}$} & \multicolumn{3}{|c|}{$\begin{array}{l}\text { Pairwise Wilcoxon } \\
\text { multiple comparison test }\end{array}$} & & & & \\
\hline & F -statistic & p-value & Spring & Summer & Fall & & & & \\
\hline Total phytoplankton biovolume & 0.333 & 0.719 & A & A & A & & & & \\
\hline Total cyanobacteria biovolume & 0.116 & 0.891 & A & $\mathrm{A}$ & A & & & & \\
\hline $\begin{array}{l}\text { Percent cyanobacteria in total } \\
\text { phytoplankton biovolume }\end{array}$ & 0.713 & 0.497 & A & A & A & & & & \\
\hline Total phytoplankton cell density & 8.79 & $<0.001$ & $\mathrm{C}$ & B & A & & & & \\
\hline Total cyanobacteria cell density & 9.57 & $<0.001$ & $\mathrm{C}$ & B & A & & & & \\
\hline $\begin{array}{l}\text { Percent cyanobacteria in total } \\
\text { phytoplankton cell density }\end{array}$ & 17.136 & $<0.001$ & $\mathrm{C}$ & B & A & & & & \\
\hline Number of total cyanobacteria species & 34.62 & $<0.001$ & $\mathrm{C}$ & $\mathrm{B}$ & A & & & & \\
\hline
\end{tabular}


however, the genus Gonyostomum was present in historic algal taxonomic data for the reservoir (Andy Fairey, Charleston Water System, written commun., June 1999 and March 2000). Dolichospermum planctonicum was the dominant genera of the cyanobacteria group during spring periods. Geosminproducing genera that were identified in the 2014 and 2015 spring community were not observed in the 1999 and 2000 algal taxonomic data (Andy Fairey, Charleston Water System, written commun., June 1999 and March 2000).

Potential toxin-producing species within the cyanobacteria group were present in the summer of 2014, including Cylindrospermopsis raciborskii (less than 2,000 cells $/ \mathrm{mL}$ ) and Microcystis sp. (less than 1,000 cells $/ \mathrm{mL}$ ). The phytoplankton community, including the cyanobacteria group, had a greater number of cells during the fall and least during the spring when geosmin episodes tended to occur. On the basis of the cyanobacteria cell densities and chlorophyll $a$ concentrations observed in Bushy Park Reservoir, the WHO recreational guidelines indicate a moderate probability of acute health effects attributed to cyanotoxins. Nonetheless, these bulk measures of phytoplankton community were not able to effectively determine if distinct differences in community structure could explain the springtime geosmin episodes. Therefore, a more robust examination of phytoplankton species was conducted by using multivariate analysis.

Results of the cluster analysis on the potential T\&Oproducing species of cyanobacteria were provided in a heat map plot (fig. 18). The heat map is a graphical representation of cyanobacteria data that uses color to indicate the species abundance of the genera. Light blue colors indicate low abundance, shading to darker blue for intermediate abundance, and dark red and black colors for high abundance; no color indicates absence of that species. Six statistically different cluster groups were identified. From left to right, the first group was composed of samples collected in April 2014 and 2015 for all sites. In this group, fewer genera were present, but

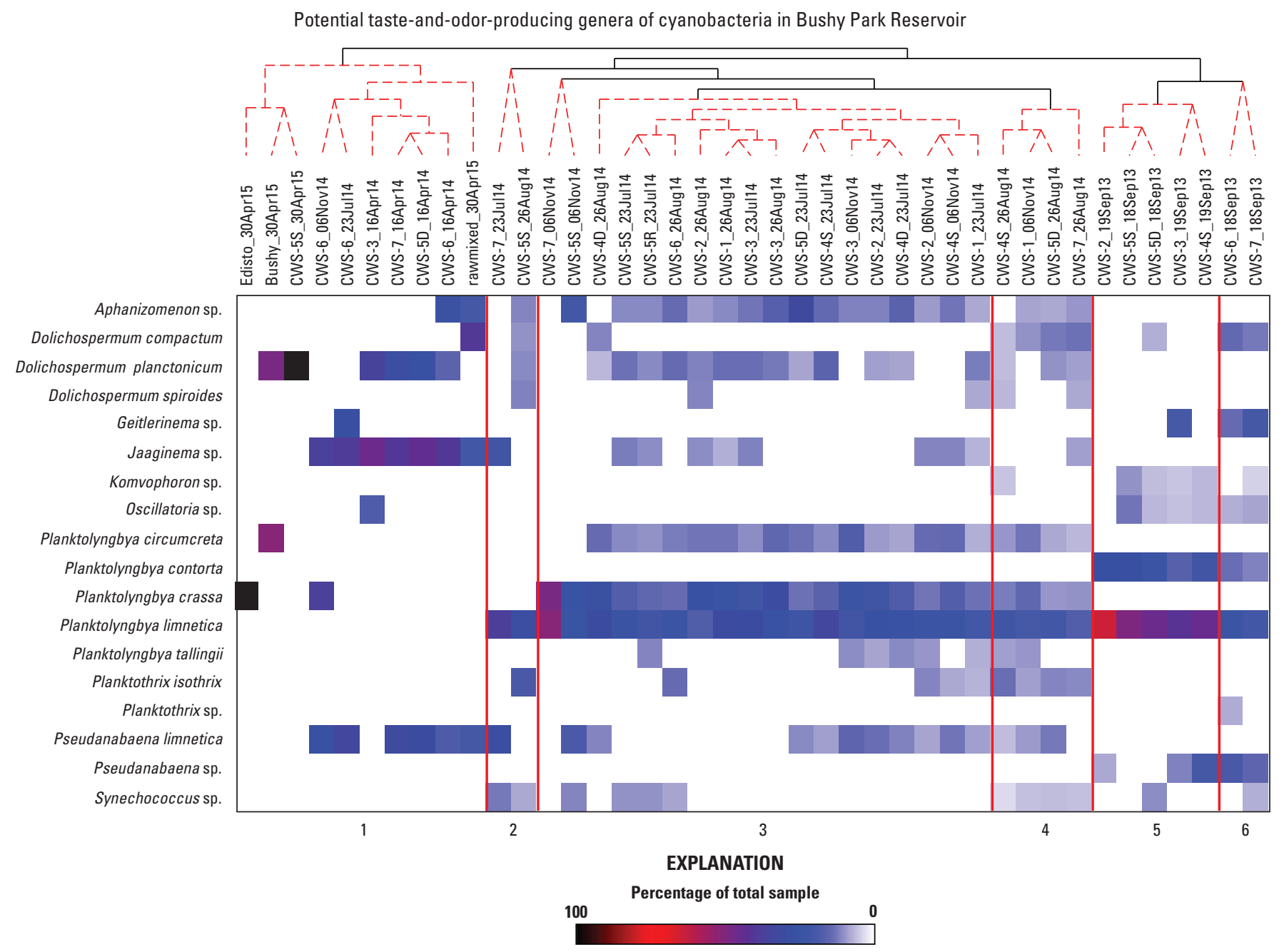

Figure 18. Heat map of standardized cyanobacteria cell densities, reported as percentage of total sample, for potential taste-andodor (T\&O)-producing genera in Bushy Park Reservoir, reordered by results of the hierarchical cluster analysis similarity profile results. Samples within the cluster dendogram of red dashed lines grouped by solid black lines are statistically similar, and samples grouped by different solid black lines are statistically different. Vertical red lines mark cluster groups 1-6. 
at relatively higher abundance than other groups $(D$. planctonica, Jaaginema sp., and Pseudanabaena limnetica were most abundant). The next group contained only two samples (site CWS-7 in July 2014 and site CWS-5 at 3.3-ft depth in August 2014) where Planktolyngbya limnetica was the most abundant species. The next two groups represent samples collected in July, August, and November 2014 at a variety of locations that had many more species and the most abundant species from the Planktolyngbya genera. The last two groups represent samples collected and analyzed in September 2013 by a different contract laboratory and taxonomist. Nonetheless, within the September 2013 samples, differences in cyanobacteria species were present between sites CWS-6 and CWS-7 and sites located in the upper and middle portions of the reservoir. In summary, there appeared to be seasonal and locational changes in the cyanobacteria community that warranted further analysis.

The multivariate analysis, conducted by using analysis of similarity (ANOSIM), identified statistically different phytoplankton communities among sites (global $\mathrm{R}=0.207$, $\mathrm{p}$-value $=0.014$; table 14; fig. 18); however, these differences appear to be mainly attributed to location in the reservoir. Sites near the lower and middle portion of the reservoir had statistically different phytoplankton communities than those in the upper portion of the reservoir (global $\mathrm{R}=0.385, \mathrm{p}=0.001$ ). But the greatest difference in phytoplankton community structure was among the seasons, whereby summer communities were different from spring communities, which were, in turn, different from fall communities (global $\mathrm{R}=0.495$, $\mathrm{p}=0.001$ ) (fig. 19). No difference between communities at shallow (3.3-ft) depths and deeper (10-ft) depths was identified. These community patterns among sites, location, and seasons were similar to patterns in environmental conditions identified previously; therefore, the next test was to determine if the environmental pattern was statistically related to the phytoplankton community pattern.

The RELATE statistical program that correlates similarity matrices for phytoplankton and for environmental variables was applied to the dataset. The routine determined that the environmental variables were correlated to the phytoplankton community. Because a significant relation was identified, the BEST statistical program was used to determine which environmental variables best explained the changes in phytoplankton community, and those best variables included ultraviolet absorbance at 254 nanometers, field $\mathrm{pH}$, potassium, silica, and total nitrogen (and water temperature during the September 2013 sampling event). The algal taxonomy for the September 2013 sampling event was conducted by a different contract laboratory, and inherent differences in the taxonomic evaluation did not allow the September algal data to be combined with the other data and thus were analyzed separately. Therefore, during this study, seasonal changes in the phytoplankton community structure appear to be explained by seasonal changes in water chemistry and may be responsible for episodes of T\&O occurrence, especially geosmin.

Table 14. Summary of the multivariate statistical tests on phytoplankton community data as biovolumes in Bushy Park Reservoir, near Goose Creek, South Carolina, 2013 to 2014.

$[\neq$, not equal to; =, equal to; UVA, ultraviolet absorbance; nm, nanometer]

\begin{tabular}{|c|c|c|c|}
\hline $\begin{array}{c}\text { Analysis of similarity } \\
\text { (ANOSIM) in phytoplankton } \\
\text { community structure } \\
\text { (biovolume) }\end{array}$ & Global R & p-value & Comments \\
\hline Among sites & 0.207 & 0.014 & CWS-7, CWS- $6 \neq$ CWS- 1 , CWS- 2 , CWS-3 \\
\hline Among locations & 0.385 & 0.001 & Upper $\neq$ Lower, Middle \\
\hline Among seasons & 0.495 & 0.001 & Summer $\neq$ Spring $\neq$ Fall \\
\hline RELATE test & rho & p-value & Comments \\
\hline September 2013 & 0.599 & 0.009 & Environmental variables with phytoplankton community \\
\hline April 2014 to November 2014 & 0.697 & 0.001 & Environmental variables with phytoplankton community \\
\hline April 2014 to November 2014 & 0.444 & 0.001 & Environmental variables with cyanobacteria potential taste-and-odor producers \\
\hline BEST subset & rho & p-value & $\begin{array}{l}\text { Selected variables that best explain cyanobacteria potential } \\
\text { taste-and-odor producers }\end{array}$ \\
\hline April 2014 to November 2014 & 0.646 & 0.001 & UVA at $254 \mathrm{~nm}$, potassium, silica, total nitrogen \\
\hline
\end{tabular}




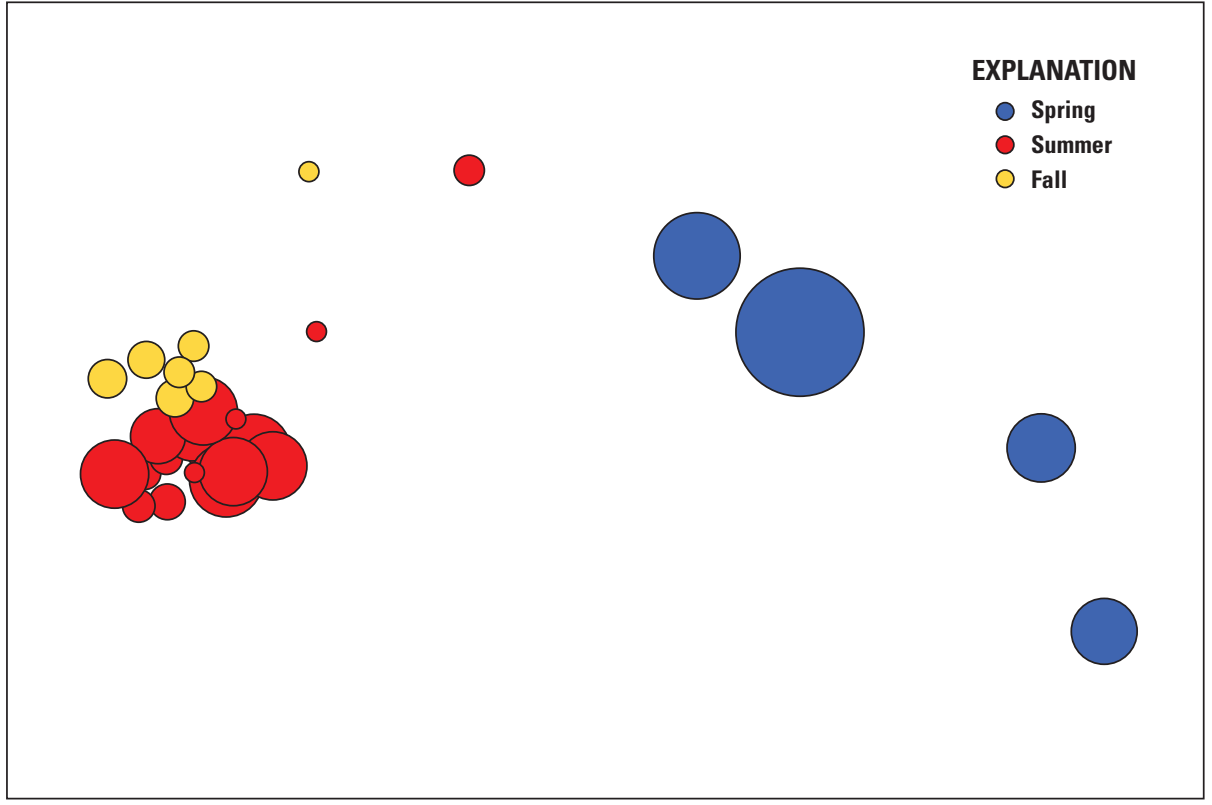

EXPLANATION

Ranges of geosmin concentrations, in nanograms per liter, for each sample represented by varying circle sizes

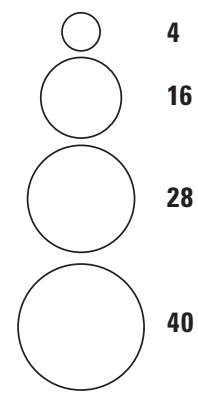

Figure 19. Two-dimensional nonmetric scaling graph of the pattern of fourth-root transformed cyanobacteria cell densities, standardized as percentage of total sample, in Bushy Park Reservoir for selected seasons in 2014. Symbols that plot close to each other are more similar than symbols that plot farther apart. Symbols are color-coded by season. Ranges of geosmin concentrations, in nanograms per liter, for each sample are represented by varying circle sizes, indicating that spring and summer have greater geosmin levels than fall. 


\section{Relation of Environmental Conditions to Taste-and-Odor Occurrence}

Geosmin and MIB concentrations in Bushy Park Reservoir were correlated significantly to several environmental variables during the study period. To evaluate the relation between temporally changing environmental variables and $\mathrm{T} \& \mathrm{O}$ occurrence, a Spearman rho correlation analysis was performed for all samples at one site- the CWS-5 intake location. At this site, increased geosmin concentrations coincided with increased calcium concentrations, Dolichospermum biovolumes, and field $\mathrm{pH}$. Conversely, increased geosmin concentrations coincided with decreased dissolved orthophosphate concentrations and field specific conductance (table 15). Increased MIB concentrations also coincided with increased field $\mathrm{pH}$ and decreased dissolved orthophosphate, as well as increased chlorophyll $a$ concentrations and decreased transparency and dissolved potassium (table 15). Although correlation does not indicate causation, these environmental conditions of greater chlorophyll $a$ and $\mathrm{pH}$ may be indicative of greater algal production. In addition, water with lower dissolved orthophosphate and specific conductance was identified within the Bushy Park Reservoir compared to Foster Creek and may indicate periods of less influence by the tributary (site CWS-5) when geosmin was elevated (figs. 14, 15).

To evaluate the relation between temporally and spatially changing environmental variables and $\mathrm{T} \& \mathrm{O}$ occurrence, a Spearman rho correlation analysis was performed for samples at all sites and depths for the study period. In the previous sections, geosmin concentrations were observed to increase in the upper portion of the reservoir near the Durham Canal during the summer months, but, during the spring, problematic levels of geosmin tended to occur near the dam (fig. 12A). Increased MIB concentrations tended to be greater near the dam during the same time period, including during the spring geosmin events (fig. 12B). In the correlation analysis, increased geosmin concentrations correlated with environmental conditions that included greater suspended sediment, field $\mathrm{pH}, \mathrm{PAR}$, water temperature, dissolved-oxygen percentage of saturation, and concentrations of chlorophyll $a$ (estimated from sonde-derived fluorescence) and pheophytin $a$, which would also be an indication of algal growth. At the same time, elevated geosmin correlated with periods of reduced transparency, specific conductance, and concentrations of major ions (dissolved potassium, chloride, and sodium) and nutrients (dissolved orthophosphate, total phosphorus, and dissolved ammonia) (table 16). These correlations seem to reflect both temporal and spatial changes as seen previously at site CWS-5 whereby lower nutrient and major ion concentrations were identified within the Bushy Park Reservoir compared to Foster Creek (site CWS-6; figs. 14, 15). Increased MIB concentrations correlated with environmental conditions indicative of the "blackwater signature" of Foster Creek (increased organic carbon and decreased dissolved oxygen) and increased algal production (increased chlorophyll $a$, water temperature, PAR) as well as decreased concentrations of major ions, transparency, and inorganic nitrogen (table 16).

Table 15. Spearman correlation coefficients (rho) and probability values ( $p$-value) between two taste-and-odor compounds, geosmin and 2-methylisoborneol (MIB), algal pigments, and associated environmental factors in Bushy Park Reservoir near the Charleston Water Intake (site CWS-5), near Goose Creek, South Carolina, September 2013 to April 2015.

[alpha value $=0.05$; bold and italicized values represent statistically signficant relations; - , left blank because of redundancy; $<$, less than]

\begin{tabular}{|c|c|c|c|c|c|c|}
\hline \multirow{2}{*}{ Selected environmental variables } & \multicolumn{2}{|c|}{ Geosmin } & \multicolumn{2}{|c|}{ MIB } & \multicolumn{2}{|c|}{ Chlorophyll a } \\
\hline & rho & p-value & rho & p-value & rho & p-value \\
\hline Dissolved orthophosphate & -0.721 & 0.007 & -0.838 & $<0.001$ & -0.427 & 0.178 \\
\hline Field specific conductance & -0.665 & 0.017 & -0.366 & 0.233 & -0.226 & 0.484 \\
\hline Dissolved potassium & -0.448 & 0.136 & -0.794 & $<0.001$ & -0.864 & $<0.001$ \\
\hline Transparency & -0.379 & 0.285 & -0.718 & 0.025 & -0.720 & 0.025 \\
\hline Actinomycetes & -0.176 & 0.572 & -0.441 & 0.143 & -0.246 & 0.450 \\
\hline Water temperature & 0.296 & 0.340 & 0.503 & 0.089 & 0.745 & 0.007 \\
\hline Chlorophyll (total from sensor) & 0.483 & 0.110 & 0.824 & $<0.001$ & 0.484 & 0.006 \\
\hline Chlorophyll $a$ & 0.510 & 0.102 & 0.694 & 0.017 & - & - \\
\hline Photosynthetically active radiation (PAR) & 0.533 & 0.160 & 0.549 & 0.164 & 0.660 & 0.264 \\
\hline Dolichospermum biovolume & 0.767 & 0.012 & 0.319 & 0.381 & 0.190 & 0.619 \\
\hline Dissolved calcium & 0.811 & $<0.001$ & 0.496 & 0.094 & 0.264 & 0.416 \\
\hline Field $\mathrm{pH}$ & 0.954 & $<0.001$ & 0.600 & 0.047 & 0.571 & 0.074 \\
\hline
\end{tabular}


Table 16. Spearman correlation coefficients (rho) and probability values ( $p$-value) between two taste-and-odor compounds, geosmin and 2-methylisoborneol (MIB), algal pigments, and associated environmental factors at all locations in Bushy Park Reservoir, near Goose Creek, South Carolina, September 2013 to April 2015.

[alpha value $=0.05$; bold and italicized values represent statistically signficant relations; $<$, less than]

\begin{tabular}{|c|c|c|c|c|c|c|c|}
\hline \multirow{2}{*}{ Variable } & \multicolumn{3}{|c|}{ Geosmin } & \multirow{2}{*}{ Variable } & \multicolumn{3}{|c|}{ 2-Methylisoborneol } \\
\hline & rho & p-value & number & & rho & p-value & number \\
\hline Dissolved orthophosphate & -0.644 & $<0.001$ & 48 & Dissolved potassium & -0.692 & $<0.001$ & 48 \\
\hline Transparency & -0.617 & $<0.001$ & 36 & Dissolved sulfate & -0.593 & $<0.001$ & 48 \\
\hline Dissolved sodium & -0.508 & $<0.001$ & 48 & $\begin{array}{l}\text { Dissolved oxygen as } \\
\text { concentration }\end{array}$ & -0.551 & $<0.001$ & 48 \\
\hline $\begin{array}{l}\text { Phytoplankton biomass to } \\
\text { chlorophyll } a \text { ratio }\end{array}$ & -0.448 & 0.002 & 47 & Transparency & -0.543 & 0.001 & 36 \\
\hline Dissolved potassium & -0.444 & 0.002 & 48 & $\begin{array}{l}\text { Phytoplankton biomass to } \\
\text { chlorophyll } a \text { ratio }\end{array}$ & -0.495 & $<0.001$ & 47 \\
\hline Dissolved chloride & -0.400 & 0.005 & 48 & Dissolved manganese & -0.329 & 0.023 & 48 \\
\hline Total phosphorus & -0.338 & 0.019 & 48 & Dissolved ammonia & -0.314 & 0.030 & 48 \\
\hline Field specific conductance & -0.294 & 0.043 & 48 & $\begin{array}{c}\text { Dissolved oxygen as } \\
\text { percent saturation }\end{array}$ & -0.310 & 0.032 & 48 \\
\hline Dissolved ammonia & -0.280 & 0.054 & 48 & Dissolved nitrate plus nitrite & -0.294 & 0.043 & 48 \\
\hline $\begin{array}{l}\text { Dissolved oxygen as percent } \\
\text { saturation }\end{array}$ & 0.333 & 0.021 & 48 & Dissolved organic carbon & 0.309 & 0.030 & 48 \\
\hline Water temperature & 0.410 & 0.004 & 48 & Total organic carbon & 0.421 & 0.003 & 48 \\
\hline MIB & 0.437 & 0.002 & 48 & Geosmin & 0.437 & 0.002 & 48 \\
\hline $\begin{array}{l}\text { Total chlorophyll (sonde- } \\
\text { derived fluorescence) }\end{array}$ & 0.478 & $<0.001$ & 47 & Dissolved calcium & 0.445 & 0.002 & 48 \\
\hline Pheophytin $a$ & 0.550 & $<0.001$ & 47 & Hardness & 0.457 & 0.001 & 48 \\
\hline $\begin{array}{l}\text { Photosynthetically active } \\
\text { radiation (PAR) }\end{array}$ & 0.554 & $<0.001$ & 36 & $\begin{array}{l}\text { Photosynthetically active } \\
\text { radiation (PAR) }\end{array}$ & 0.482 & 0.003 & 36 \\
\hline Field $\mathrm{pH}$ & 0.600 & $<0.001$ & 47 & Pheophytin $a$ & 0.648 & $<0.001$ & 47 \\
\hline \multirow[t]{2}{*}{ Suspended sediment } & 0.630 & $<0.001$ & 43 & Chlorophyll $a$ & 0.655 & $<0.001$ & 47 \\
\hline & & & & Water temperature & 0.660 & $<0.001$ & 48 \\
\hline
\end{tabular}

\section{Synoptic Assessment of Taste-and-Odor Occurrence in the Bushy Park Reservoir by the Charleston Water System Treatment Plant}

Source water from Bushy Park Reservoir is blended with Edisto River water by the CWS to produce the raw water that is treated and distributed as finished water. Source water from Bushy Park Reservoir is the major component of the raw water, with Edisto River source water typically representing less than 20 percent of the blended raw water. Source water is transported to the Hanahan Water Treatment Plant through two water-supply tunnels, one from each source (fig. 20; Conrads and others, 2017b).
In April 2015, CWS experienced two elevated T\&O events when temperatures in the source water rose above $21^{\circ} \mathrm{C}$ (Rebecca Thames, Charleston Water System, written commun., March 26, 2015) (fig. 21). At the beginning of the event during the first part of the month, CWS analyzed raw water in the Bushy Park tunnel and raw blended and treated water from supply lines in the plant and identified that raw blended and treated water had high concentrations of geosmin that were not observed in the Bushy Park tunnel raw water. That finding suggests that the Edisto River may have contributed to the $\mathrm{T} \& \mathrm{O}$ event. The most probable $\mathrm{T} \& \mathrm{O}$ source in a free-flowing river would be actinomycetes or cyanobacteria that form mats on the streambed or are attached to debris or vegetation. 


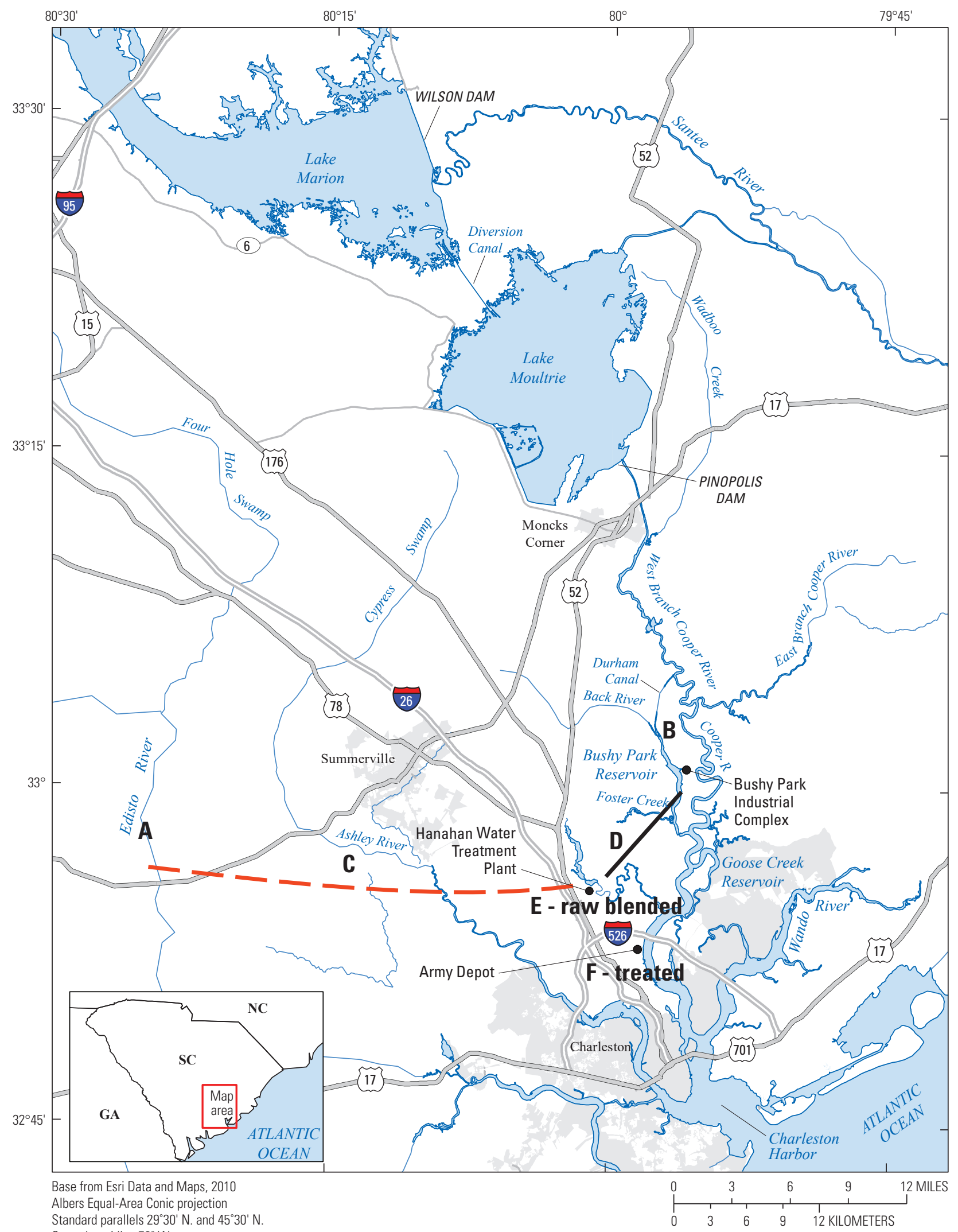

Central meridian $79^{\circ} \mathrm{W}$

Figure 20. Area of the synoptic assessment of taste-and-odor occurrence in Edisto River [A] and Bushy Park Reservoir [B], April 2015. Source water flows through supply tunnels [C and D, respectively] into the Hanahan Water Treatment Plant where it is blended [E] and treated [F]. The red dashed line indicates the general area of the Edisto River tunnel, and the solid black line indicates the general area of the Bushy Park tunnel. 

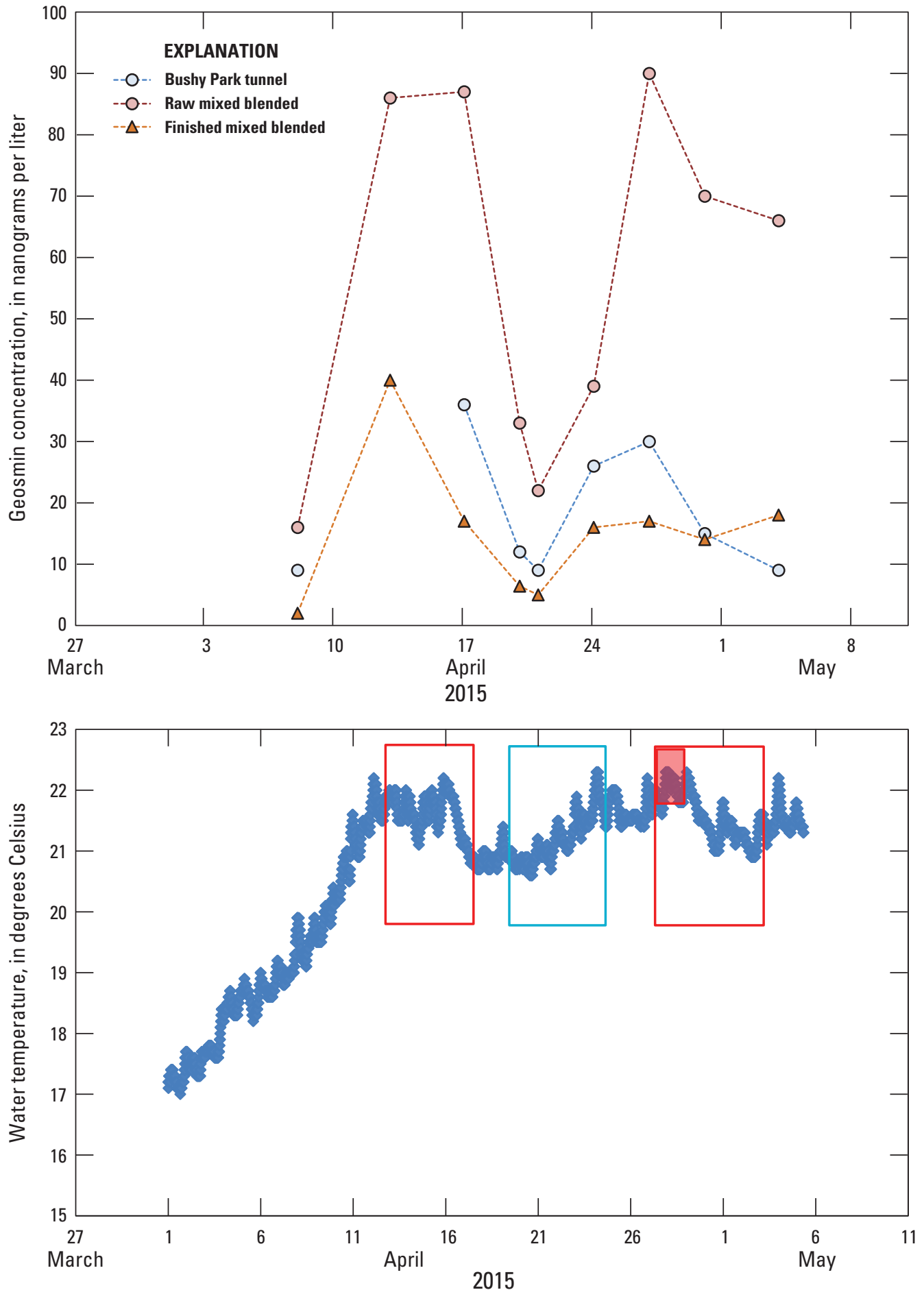

Figure 21. Temporal variability in geosmin concentrations in Bushy Park tunnel, raw blended (Bushy Park Reservoir and Edisto River), and finished water (top graph) and corresponding water temperatures in Bushy Park tunnel (bottom graph) in April 2015. In the bottom plot, red open boxes indicate periods of elevated geosmin, the red shaded box indicates the period of USGS sampling, and the blue open box indicates a period of low geosmin concentrations. 
When the second April T\&O event began, CWS requested the USGS participate in a synoptic sampling of both raw water sources at the intakes and in the tunnels, raw blended, and treated water to evaluate the degree of influence of T\&O from the Edisto River. The CWS provided the USGS with estimated travel times for source water in the tunnel to reach the intake, and those times were used to coordinate the synoptic sampling. The Edisto River intake was sampled on the morning of April 29, the Bushy Park Reservoir intake was sampled about 24 hours later on the morning of April 30, and the Edisto River tunnel and supply lines for Bushy Park tunnel, raw blended, and treated water were sampled 6 hours later during the afternoon of April 30 (table 17). Field properties of $\mathrm{pH}$, dissolved oxygen, water temperature, and specific conductance as well as chlorophyll $a$ and phycocyanin fluorescence were measured at the time of sampling. Samples were analyzed for dissolved organic carbon, ultraviolet absorbance at 254 nanometers, geosmin, MIB, and actinomycetes concentrations. Samples from the Bushy Park intake (site CWS-5) also were analyzed for major ions and nutrients, and these data were also included in the previous assessments. Phytoplankton enumeration and identification were performed on water samples.

The Edisto River is a free-flowing, blackwater stream that has dissolved organic carbon with high humic content, as reflected in elevated ultraviolet absorbance at 254 nanometers, compared to Bushy Park Reservoir (0.876 and 0.263 , respectively; table 17). Additionally, at the time of the synoptic sampling, the Edisto River had relatively lower specific conductance than Bushy Park Reservoir $\left(73\right.$ and 123 microsiemens per centimeter at $25^{\circ} \mathrm{C}$, respectively). Therefore, scatterplots of these two constituents were used to evaluate the mixing relation between dissolved organic and inorganic constituents in the two source waters (Edisto River, Bushy Park Reservoir at the CWS intake), source water in the supply tunnels, and raw mixed or blended water at the Hanahan Water Treatment Plant near Goose Creek (fig. 22, top graph). Although there appeared to be minor changes in the chemistry of the source water from the intakes to the tunnels, the raw mixed (blended) water seemed to be a product of simple mixing of the two tunnel waters, with greater contribution from the Bushy Park source than Edisto River (as would be expected). However, a scatterplot of geosmin concentrations and specific conductance identified a discrepancy in the relation between the two tunnel source waters and the raw mixed water. As was observed by CWS during the first April T\&O event, the Bushy Park tunnel water had significantly lower geosmin concentrations than Bushy Park intake water (15 and $28 \mathrm{ng} / \mathrm{L}$, respectively; table 17). Additionally, source water from the Bushy Park intake and tunnel had less geosmin than required to explain the simple theoretical mixing relation of the two source waters to produce geosmin concentrations in the raw mixed water (fig. 22, bottom graph). The scope of the synoptic sampling did not provide sufficient data to identify definitively the reason for the apparent discrepancy between the expected and actual geosmin concentrations in the Bushy Park Reservoir source waters. However, one possible explanation could be that the sampling lines in the Bushy Park tunnel or point samples at the intake may not have adequately captured a representative sample of the source water that was used in the blending of the raw water. In the case of the measured geosmin concentrations in the Bushy Park tunnel compared to the intake, geosmin still in the cellular (particulate) phase could possibly be distributed lower in the tunnel than the dissolved released phase; therefore, geosmin concentrations from the sample lines may only represent the dissolved or released phase of geosmin. Additionally, the travel times of the water in the tunnels for blending may have been incorrectly estimated; therefore, the temporal pulse of water sampled in the Bushy Park intake and tunnel may not adequately reflect the same pulse of water that was blended to form the raw mixed water.

Nonetheless, as determined in the water-quality characterization at sites within the Bushy Park Reservoir, cyanobacteria were indicated to be the more significant source of the geosmin, not actinomycetes, in the April 2015 sampling event. Although the Edisto River intake and tunnel water had relatively high actinomycetes concentrations (130 and 140 colonies per milliliter, respectively) compared to the Bushy Park intake and tunnel ( 2 colonies per milliliter), corresponding geosmin concentrations were below $4 \mathrm{ng} / \mathrm{L}$ for source water from the Edisto River intake and tunnel (table 17). Elevated geosmin concentrations above the CWS treatment threshold were identified in source waters from the Bushy Park Reservoir. The cyanobacteria community at the sampled sites in April 2015 was statistically similar to the community in Bushy Park Reservoir in April 2014 (fig. 18), when geosmin concentrations also were elevated above the human detection threshold (fig. 19). However, the only geosmin-producing genus identified at the Bushy Park intake (site CWS-5) was Dolichospermum planctonicum, which also was observed with Planktolyngbya compactum in the Bushy Park tunnel. Although statistically similar on the basis of cluster analysis, the cyanobacteria community appeared to be somewhat more diverse and varied in the raw mixed sample and contained species, including Dolichospermum compactum (rather than planctonicum), Jaaginema sp., Aphanizomenon sp., and Pseudanabaena limnectica, not identified at the other sampled locations.

This finding appears to support the hypothesis that a different pulse of water was sampled in the source water of Bushy Park Reservoir than was sampled in the raw mixed or blended water at the treatment plant. Further investigation may be required to determine if the uneven mixing of water in the tunnel may produce uneven vertical distribution of geosmin concentrations within the Bushy Park tunnel and if predicted travel times of the source water to the treatment plant need to be adjusted. 


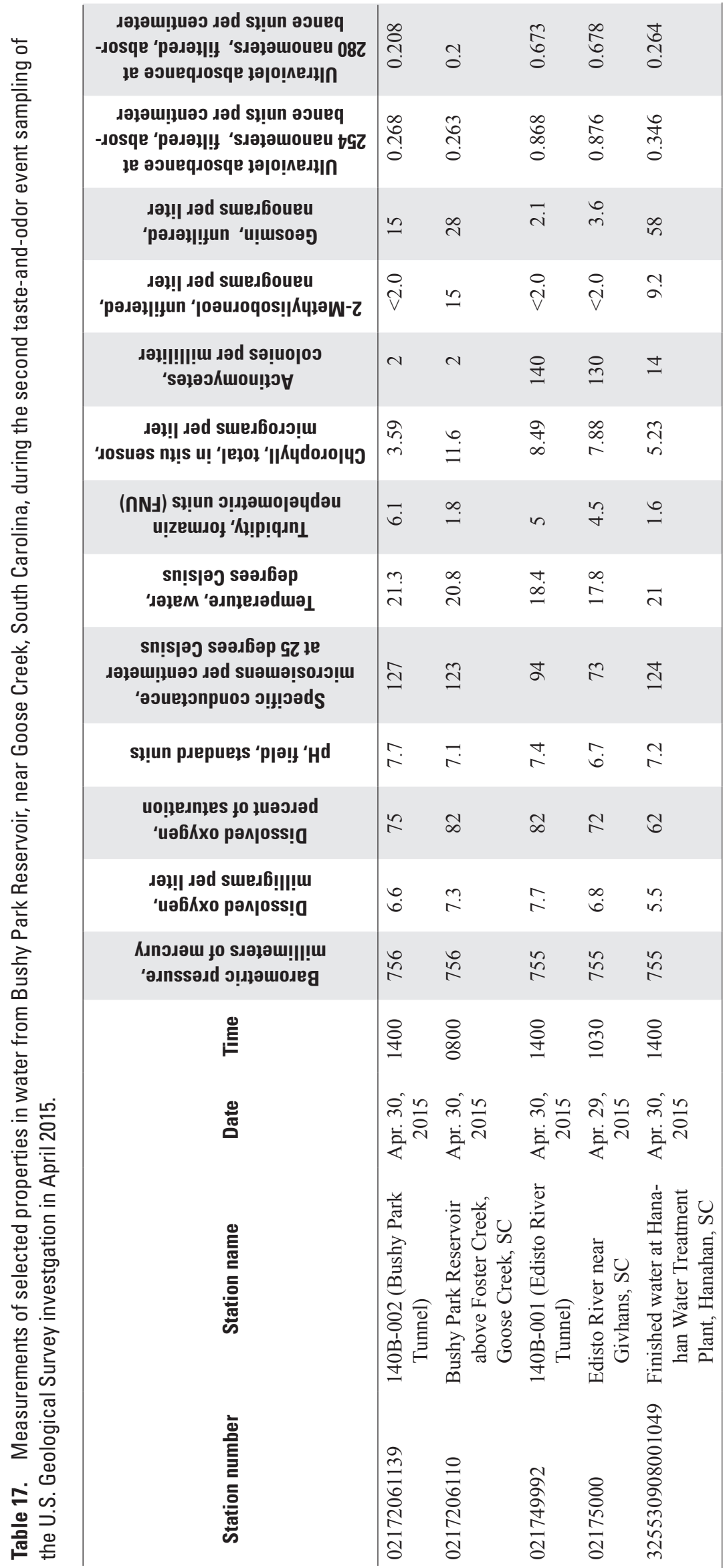



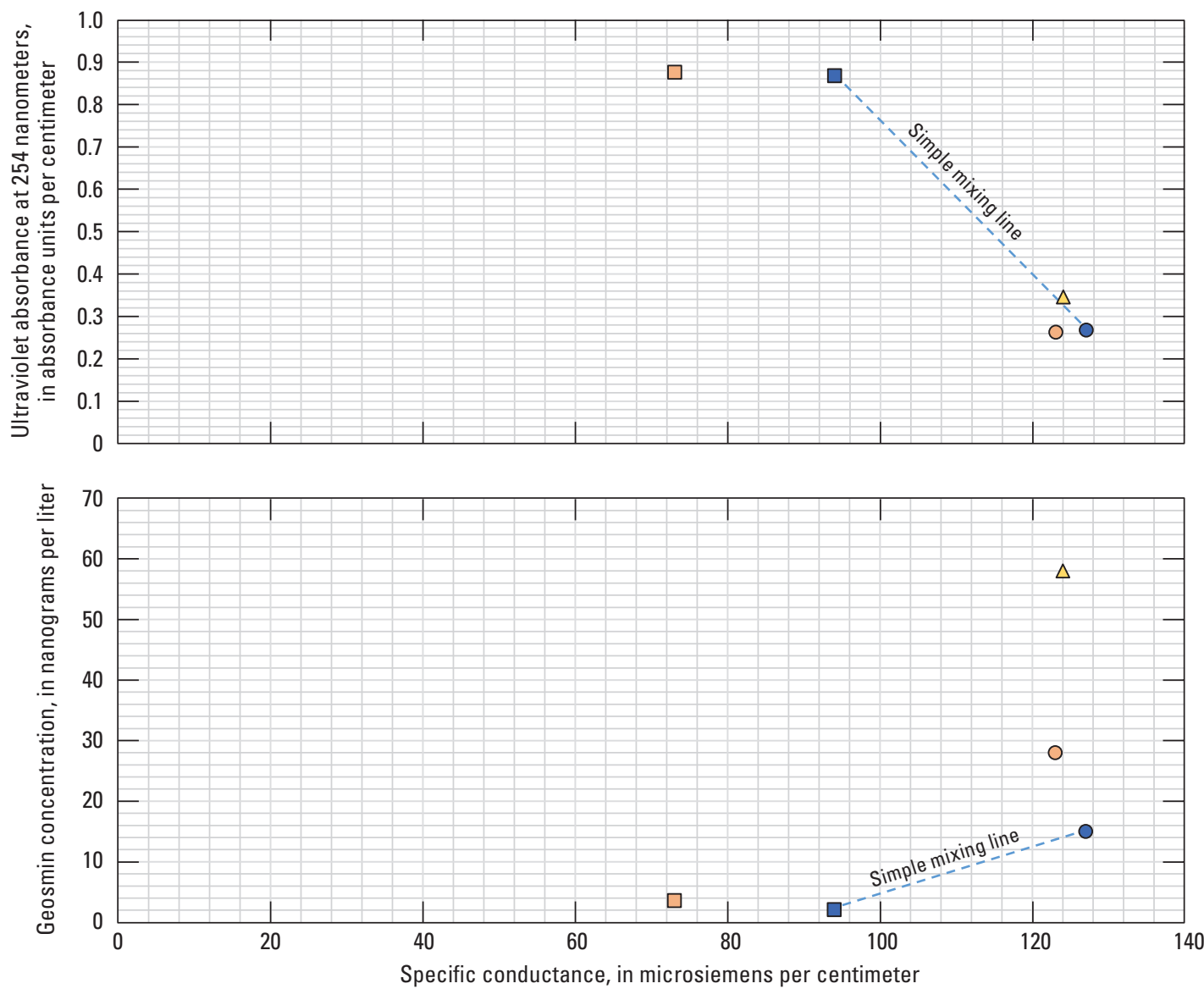

EXPLANATION

- Bushy Park tunnel O Bushy Park intake

$\square$ Edisto River tunnel $\square$ Edisto River intake

$\triangle$ Raw mixed water

Figure 22. Scatterplots of ultraviolet absorbance at 254 nanometers (top graph) and geosmin concentrations, in nanograms per liter (bottom graph), against conservative tracer of specific conductance, in microsiemens per centimeter at 25 degrees Celsius, to support the evaluation of mixing relations between two source waters (Edisto River, Bushy Park Reservoir at the Charleston Water Intake), source water in the supply tunnels, and raw mixed or blended water at the Hanahan Water Treatment Plant near Goose Creek, South Carolina. The simple mixing line represents the mixed water, falling along a line between the two source waters.

\section{Summary}

The Bushy Park Reservoir is the principal water supply for 400,000 people in the greater Charleston, South Carolina, area, which includes homes as well as businesses and industries in the Bushy Park Industrial Complex. As part of a long-range planning process, Charleston Water System approached the U.S. Geological Survey for assistance in understanding the circulation of Bushy Park Reservoir and its effects on water-quality conditions, specifically, taste-and-odor (T\&O) episodes. The water-quality data collected for the study included a combination of discrete water-column sampling at seven locations in the reservoir and longitudinal water-quality profiling surveys of the reservoir and tributaries to capture the temporal and spatial water-quality dynamics of Bushy Park Reservoir. The discrete water-column samples were analyzed for geosmin, 2-methylisoborneol (MIB), chlorophyll $a$, pheophytin $a$, nutrient, major ions, trace metals, actinomycetes, and suspended-sediment concentrations, and for phytoplankton cell densities and biovolumes. Water-quality profiling surveys were conducted with an autonomous underwater vehicle equipped with a multiparameter water-quality-sonde bulkhead. Properties measured by the autonomous underwater vehicle included water temperature, dissolved oxygen, $\mathrm{pH}$, specific conductance, turbidity, total chlorophyll as fluorescence (estimate of algal biomass), and phycocyanin as fluorescence (estimate of cyanobacteria biomass).

The data assessment was conducted in three steps. The first step was to characterize the water-quality conditions in the reservoir relative to established guidelines. The second step was to identify any spatial and seasonal variation in water-quality conditions and phytoplankton community structures throughout the reservoir. The second step was conducted to (1) identify the area of the reservoir that most influences the water-quality conditions at the intake (site CWS-5) (for example, Foster Creek inflows [site CWS-6] or Durham Canal inflows [sites CWS-1 and CWS-2]), especially during 
periods of elevated $\mathrm{T} \& \mathrm{O}$ concentrations, (2) determine if the $\mathrm{T} \& \mathrm{O}$ concentrations are produced in situ in the reservoir or delivered to the reservoir from either Foster Creek or Durham Canal, and (3) identify the most probable source of the T\&O compounds (actinomycetes bacteria or cyanobacteria), and, if cyanobacteria, identify any phytoplankton species (or genus) that have the potential to produce $\mathrm{T} \& \mathrm{O}$ compounds during $\mathrm{T} \& \mathrm{O}$ episodes. The final step was to assess whether these spatial and seasonal changes in environmental factors correlate significantly with phytoplankton community structure and geosmin or MIB concentrations.

Additionally, the profile and survey data were used to identify areas within the reservoir where greater phytoplankton and cyanobacteria densities were most likely occurring. Bushy Park Reservoir tended to stratify thermally at a depth of about 20 feet from June to early October. The stratification was limited to the deeper portions of the reservoir near the dam and often dissipated within the reservoir near the site CWS-5 location. Where thermally stratified, a corresponding depletion of dissolved oxygen also occurred at about the same depth and resulted in an anoxic hypolimnion below the 25 -foot depth and an increase in specific conductance, likely due to re-mobilized metals and phosphorus under reducing conditions. In general, chlorophyll $a$ exhibited some spatial variation, but no strong consistent pattern or "hot spot" was observed. Phycocyanin, estimated as blue-green algae cell density, seemed to be greater in the upper portion of the reservoir periodically, but those differences may be attributed to increased turbidity and the potential change in phytoplankton community structure that affects fluorescence. In cross section, at sites CWS-5 and CWS-4, for example, changes with depth of phycocyanin were observed at about the 10-foot depth.

A constant production of MIB near the dam and geosmin in the middle and upper portions of the reservoir appears to be occurring during the summer and early fall in the reservoir, but concentrations of these compounds tend to be between 10 and 15 nanograms per liter. At site CWS-5, the dominant $\mathrm{T} \& \mathrm{O}$ compound tended to be MIB at a 2- or 3-to-1 ratio with geosmin during the summer and fall. During springtime episodes, however, when T\&O concentrations typically are elevated above the Charleston Water System treatment threshold, the spatial distribution of geosmin concentrations greater than 15 nanograms per liter (28 to 38 nanograms per liter) was best explained by in situ production in the lower portion of the Bushy Park Reservoir near the dam rather than transport from Foster Creek. This pattern seems to indicate a possible shift in phytoplankton communities (or, at least, cyanobacteria communities) from MIB producers to geosmin producers. An identification of spatial and seasonal variation in water quality and phytoplankton community was completed to explain this shift.

The spatial and seasonal assessment of water-quality conditions in Bushy Park Reservoir identified seasonal differences in water chemistry between the upper and lower portions of the reservoir that correspond to the location of elevated geosmin concentrations. The assessment determined that higher levels of dissolved iron, dissolved nitrate plus nitrite, total nitrogen, and total phosphorus were present in the reservoir during the spring compared to concentrations during the fall and summer. With the exception of dissolved nitrate plus nitrite concentrations, these constituents also were elevated in concentration in the lower portion of the reservoir where geosmin concentrations were elevated above the Charleston Water System treatment threshold. On the basis of the spatial and seasonal assessment of actinomycetes concentrations compared to $\mathrm{T} \& \mathrm{O}$ concentrations, cyanobacteria production likely was the dominant source of the T\&O episodes rather than actinomycetes. The lack of spatial and seasonal patterns in actinomycetes concentrations does not correspond to the springtime geosmin concentrations that were elevated above Charleston Water System threshold in the lower portion of the reservoir. Additionally, actinomycetes concentrations, although ubiquitous, have a median of about 9 and maximum of about 20 colonies per milliliter, which can be considered low for elevated T\&O production. Nonetheless, the potential exists for actinomycetes to be a secondary source of $\mathrm{T} \& \mathrm{O}$ production and could explain some of the ubiquitous occurrence of low-level T\&O production, such as MIB, observed throughout the summer and early fall months.

When evaluated by biovolume, cyanobacteria were not the dominant phytoplankton group in Bushy Park Reservoir during the study period. "Bloom-" forming levels of Gonyostomum semen were identified in the reservoir during the summer months; however, the genus Gonyostomum was present in historic algal taxonomic data for the reservoir. Dolichospermum planctonicum (previously Anabaena planktonica) was the dominant genera of the cyanobacteria group during spring periods. The geosmin-producing genera that were identified in the 2014 and 2015 spring community in Bushy Park Reservoir were not observed in the 1999 and 2000 algal taxonomic data.

Potential toxin-producing species within the cyanobacteria group were present in the summer of 2014, including Cylindrospermopsis raciborskii (less than 2,000 cells per milliliter) and Microcystis sp. (less than 1,000 cells per milliliter). The phytoplankton community, including the cyanobacteria group, had a greater number of cells during the fall and least during the spring when geosmin episodes tended to occur. On the basis of the cyanobacteria cell densities and chlorophyll $a$ concentrations observed in Bushy Park Reservoir, the World Health Organization recreational guidelines indicate a moderate probability of acute health effects attributed to cyanotoxins. Nonetheless, these bulk measures of phytoplankton community were not able to effectively determine if distinct differences in community structure could explain the springtime geosmin episodes. Therefore, a more robust examination of phytoplankton species was conducted using a multivariate analysis that identified seasonal changes in phytoplankton community structure. These seasonal phytoplankton communities appeared to be explained by seasonal changes in water chemistry and may be responsible for episodes of $\mathrm{T} \& \mathrm{O}$ occurrence, especially geosmin. The most probable source of geosmin identified during the study was $D$. planctonicum. 
Nonetheless, as determined in the water-quality characterization at sites within the Bushy Park Reservoir, cyanobacteria was indicated to be the more significant source of the geosmin, not actinomycetes, in the April 2015 sampling event. Although the Edisto River intake and tunnel water had relatively high actinomycetes concentrations (130 and 140 colonies per milliliter, respectively) compared to the Bushy Park intake and tunnel ( 2 colonies per milliliter), corresponding geosmin concentrations were below 5 nanograms per liter for source water from the Edisto River intake and tunnel. Elevated geosmin concentrations above the Charleston Water System treatment threshold were identified in source waters from the Bushy Park Reservoir. The cyanobacteria community at the sampled sites in April 2015 was statistically similar to the community in the Bushy Park Reservoir in April 2014, when geosmin concentrations also were elevated. The only geosmin-producing genus identified at the Bushy Park intake (site CWS-5), however, was D. planctonicum, which also was observed with Planktolyngbya compactum in the Bushy Park tunnel. Although statistically similar on the basis of cluster analysis, the cyanobacteria community appeared to be somewhat more diverse and varied in the raw mixed sample and contained species, including Dolichospermum compactum (rather than planctonicum), Jaaginema sp., Aphanizomenon sp., and Pseudanabaena limnectica, not identified at the other sampled locations. This finding appears to support the hypothesis that a different pulse of water was sampled in the source water of Bushy Park Reservoir than what was sampled in the raw mixed or blended water at the treatment plant.

\section{References Cited}

American Public Health Association, American Water Works Association, and Water Environment Federation, 1995a, Standard methods for the examination of water and wastewater (19th ed.), UV-absorbing organic constituents: American Public Health Association, part 5910, p. 5-60 to $5-62$.

American Public Health Association, American Water Works Association, and Water Environment Federation, 1995b, Standard methods for the examination of water and wastewater (19th ed.), Determination of biomass (standing crop): American Public Health Association, part 10200-I, p. 10-25.

American Public Health Association, American Water Works Association, and Water Environment Federation, 1998, Standard methods for the examination of water and wastewater (20th ed.), Metals by plasma emission spectroscopy: American Public Health Association, part 3120, p. 3-37 to 3-43.
American Public Health Association, American Water Works Association, and Water Environment Federation, 2005a, Standard methods for the examination of water and wastewater (21st ed.), Constituent concentration by gas extraction-solid-phase microextraction (SPMD): American Public Health Association, Standard Method 6040D, p. 6-19 to 6-22.

American Public Health Association, American Water Works Association, and Water Environment Federation, 2005b, Standard methods for the examination of water and wastewater (21st ed.), Detection of actinomycetes: American Public Health Association, part 9250, p. 9-109 to 9-111.

Arar, E.J., and Collins, G.B., 1997, Method 445.0, In vitro determination of chlorophyll $a$ and pheophytin $a$ in marine and freshwater algae by fluorescence, Revision 1.2: Cincinnati, Ohio, U.S. Environmental Protection Agency, National Exposure Research Laboratory, Office of Research and Development, $22 \mathrm{p}$.

Brenton, R.W., and Arnett, T.L., 1993, Methods of analysis by the U.S. Geological Survey National Water Quality Laboratory-Determination of dissolved organic carbon by UV-promoted persulfate oxidation and infrared spectrometry: U.S. Geological Survey Open-File Report 92-480, $12 \mathrm{p}$.

Campbell, T.R., and Bower, D.E., 1996, Water quality, bedsediment quality, and simulation of potential contaminant transport in Foster Creek, Berkeley County, South Carolina, 1991-93: U.S. Geological Survey Water-Resources Investigations Report 95-4247, $135 \mathrm{p}$.

Carlson, R.E., 1977, A trophic state index for lakes: Limnology and Oceanography, v. 22, no. 2, p. 361-369.

Charleston Water System, 2016, Annual Water Quality Report (Consumer Confidence Report): Charleston Water System, accessed September 30, 2017, at http://www.charlestonwater. com/232/Water-Quality-Reports.

Childress, C.J.O, Foreman, W.T., Conner, B.F., and Maloney, T.J., 1999, New reporting procedures based on long-term method detection levels and some considerations for interpretations of water-quality data provided by the U.S. Geological Survey National Water Quality Laboratory: U.S. Geological Survey Open-File Report 99-193, 19 p. [Also available at https://water.usgs.gov/owq/ OFR_99-193/.]

Chorus, Ingrid, and Bartram, Jamie, eds., 1999, Toxic cyanobacteria in water-A guide to their public health consequences, monitoring and management: London, E \& FN Spon, $416 \mathrm{p}$. 
Clarke, K.R., 1993, Non-parametric multivariate analyses of changes in community structure: Australian Journal of Ecology, v. 18, no. 1, p. 117-143, accessed March 17, 2017, at https://doi.org/10.1111/j.1442-9993.1993.tb00438.x.

Clarke, K.R., and Gorley, R.N., 2015, Primer version 7-User manual/tutorial: Plymouth, U.K., Primer-E Ltd., 296 p.

Clarke, K.R., Gorley, R.N., Somerfield, P.J., Warwick, R.M., 2014, Change in marine communities-An approach to statistical analysis and interpretation: Plymouth, U.K., Primer-E Ltd., 260 p.

Conrads, P.A., Journey, C.A., Lanier, T.H., Petkewich, M.D., Clark, J.M., and Bradley, P.M., 2017a, Water Quality Data for Bushy Park Reservoir, South Carolina, 2013-2015: U.S. Geological Survey data release, https://doi.org/10.5066/F7NG4NVX.

Conrads, P.A., Petkewich, M.D., Falls, W.F., and Lanier, T.H., 2017b, Hydrologic characterization of Bushy Park Reservoir, South Carolina, 2013-15: U.S. Geological Survey Scientific Investigations Report 2017-5050, 83 p., accessed November, 5, 2017, at https://doi.org/10.3133/sir20175050.

Downing, J.A., and McCauley, Edward, 1992, The nitrogen:phosphorus relationship in lakes: Limnology and Oceanography, v. 37, no. 5, p. 936-945.

Downing, J.A., Watson, S.B., and McCauley, Edward, 2001, Predicting cyanobacteria dominance in lakes: Canadian Journal of Fisheries and Aquatic Sciences, v. 58, no. 10, p. 1905-1908, accessed July 22, 2010, at https://doi.org/ 10.1139/f01-143.

Durrer, M., Zimmermann, U., and Jüttner, F., 1999, Dissolved and particle-bound geosmin in a mesotrophic lake (Lake Zurich)-Spatial and seasonal distribution and the effect of grazers: Water Research, v. 33, no. 17, p. 3628-3636.

Dzialowski, A.R., Smith, V.H., Huggins, D.G., deNoyelles, F., Lim, N.C., Baker, D.S., and Beury, J.H., 2009, Development of predictive models for geosmin-related taste and odor in Kansas, U.S.A., drinking water reservoirs: Water Research, v. 43, no. 11, p. 2829-2840, accessed July 22, 2010, at https://doi.org/10.1016/j.watres.2009.04.001.

Ehrlich, L.C., 2010, Sampling and identification-Methods and strategies, in Manual of water supply practices M57, Algae - source to treatment (1st ed.): American Water Works Association, p. 25-69.

Fishman, M.J., ed., 1993, Methods of analysis by the U.S. Geological Survey National Water Quality Laboratory-Determination of inorganic and organic constituents in water and fluvial sediments: U.S. Geological Survey Open-File Report 93-125, 217 p.
Fishman, M.J., and Friedman, L.C., eds., 1989, Methods for determination of inorganic substances in water and fluvial sediments: U.S. Geological Survey Techniques of WaterResources Investigations, book 5, chap. A1, 545 p.

Graham, J.L., and Jones, J.R., 2009, Microcystin in Missouri reservoirs: Lake and Reservoir Management, v. 25, no. 3, p. 253-263, accessed July 22, 2010, at https://doi.org/ $10.1080 / 07438140903143239$.

Graham, J.L., Jones, J.R., Jones, S.B., Downing, J.A., and Clevenger, T.E., 2004, Environmental factors influencing microcystin distribution and concentration in the Midwestern United States: Water Research, v. 38, no. 20, p. 4395-4404.

Graham, J.L., Loftin, K.A., and Kamman, Neil, 2009, Monitoring recreational freshwaters: LakeLine, v. 29, no. 2 , p. 18-24.

Graham, J.L., Loftin, K.A., Ziegler, A.C., and Meyer, M.T., 2008, Guidelines for design and sampling for cyanobacterial toxin and taste-and-odor studies in lakes and reservoirs: U.S. Geological Survey Scientific Investigations Report 2008-5038, 39 p.

Havens, K.E., James, R.T., East, T.L., and Smith, V.H., 2003, $\mathrm{N}: \mathrm{P}$ ratios, light limitation, and cyanobacterial dominance in a subtropical lake impacted by non-point source nutrient pollution: Environmental Pollution, v. 122, no. 3, p. $379-390$.

Helsel, D.R., 2005, Nondetects and data analysis-Statistics for censored environmental data: New York, Wiley, $250 \mathrm{p}$.

Helsel, D.R., and Hirsch, R.M., 1992, Statistical methods in water resources: Amsterdam, The Netherlands, Elsevier Science Publishers, $522 \mathrm{p}$.

Homer, C.G., Dewitz, J.A., Yang, L., Jin, S., Danielson, P., Xian, G., Coulston, J., Herold, N.D., Wickham, J.D., and Megown, K., 2015, Completion of the 2011 National Land Cover Database for the conterminous United StatesRepresenting a decade of land cover change information: Photogrammetric Engineering and Remote Sensing, v. 81 , no. 5 , p. 345-354, accessed November 10, 2016, at https://www.mrlc.gov/nlcd2011.php.

Izaguirre, G., Hwang, C.J., Krasner, S.W., and McGuire, M.J., 1982, Geosmin and 2-methylisoborneol from cyanobacteria in three water supply systems: Applied and Environmental Microbiology, v. 43, no. 3, p. 708-714.

Jackson, P.R., 2013a, Circulation, mixing, and transport in nearshore Lake Erie in the vicinity of Villa Angela Beach and Euclid Creek, Cleveland, Ohio, September 11-12, 2012: U.S. Geological Survey Scientific Investigations Report 2013-5198, 34 p., accessed November 10, 2016, at https://doi.org/10.3133/sir20135198. 
Jackson, P.R., 2013b, Integrated synoptic surveys using an autonomous underwater vehicle and manned boats: U.S. Geological Survey Fact Sheet 2013-3018, 4 p., accessed February 28, 2018, at https://pubs.usgs.gov/fs/2013/3018/.

Jacoby, J.M., Collier, D.C., Welch, E.B., Hardy, F.J., and Crayton, Michele, 2000, Environmental factors associated with a toxic bloom of Microcystis aeruginosa: Canadian Journal of Fishery and Aquatic Sciences, v. 57, no. 1, p. 231-240, accessed July 22, 2010, at https://doi.org/ $10.1139 /$ f99-234.

Jordan, Jones \& Goulding, Inc., Engineering and Planning, 1988, Foster Creek/Bushy Park Reservoir water quality evaluation final report, Executive Summary: Consultant's report prepared for Commissioners of Public Works, Charleston, S.C., 3 p. [Available from Commissioners of Public Works, Charleston, S.C.]

Jüttner, Friedrich, and Watson, S.B., 2007, Biochemical and ecological control of geosmin and 2-methylisoborneol in source waters: Applied and Environmental Microbiology, v. 73, no. 14, p. 4395-4406, accessed March 12, 2017, at https://doi.org/10.1128/AEM.02250-06.

Kjerfve, Björn, and Magill, K.E., 1990, Salinity changes in Charleston Harbor 1922-1987: Journal of Waterway, Port, Coastal, and Ocean Engineering, v. 166, no. 2, p. 153-168, accessed March 12, 2017, at https://doi.org/10.1061/ (ASCE)0733-950X(1990)116:2(153).

Mau, D.P., Ziegler, A.C., Porter, S.D., and Pope, L.M., 2004, Surface-water-quality conditions and relation to taste-andodor occurrences in the Lake Olathe watershed, Northeast Kansas, 2000-02: U.S. Geological Survey Scientific Investigations Report 2004-5047, 95 p.

National Oceanic and Atmospheric Administration National Centers for Environmental Information, undated, 1981-2010 U.S. annual/seasonal climate normals, accessed September 30, 2017, at https://doi:10.7289/V5PN93JP.

Paerl, H.W., Fulton, R.S., III, Moisander, P.H., and Dyble, J., 2001, Harmful freshwater algal blooms, with an emphasis on cyanobacteria: Science World Journal, v. 1, p. 76-113.

Patton, C.J., and Kryskalla, J.R., 2003, Methods of analysis by the U.S. Geological Survey National Water Quality Laboratory-Evaluation of alkaline persulfate digestion as an alternative to Kjeldahl digestion for determination of total and dissolved nitrogen and phosphorus in water: U.S. Geological Survey Water-Resources Investigations Report 03-4174, 33 p.

Patton, C.J., and Kryskalla, J.R., 2011, Colorimetric determination of nitrate plus nitrite in water by enzymatic reduction, automated discrete analyzer methods: U.S. Geological Survey Techniques and Methods, book 5, chap. B8, 34 p.
Peter, Andreas, Köster, Oliver, Schildknecht, Andrea, and von Gunten, Urs, 2009, Occurrence of dissolved and particle-bound taste and odor compounds in Swiss lake waters: Water Research, v. 43, no. 8, p. 2191-2200, accessed September 17, 2017, at https://doi.org/10.1016/ j.watres.2009.02.016.

Pidwirny, Michael, 2011, Moist mid-latitude climates with mild winters - C climate type: The Encyclopedia of Earth web page, accessed September 17, 2017, at http:/www. eoearth.org/view/article/162272.

Rashash, D.M.C., Hoehn, R.C., Dietrich, A.M., Grizzard, T.J., and Parker, B.C., 1996, Identification and control of odorous algal metabolites: American Water Works Association (AWWA) Research Foundation and AWWA, 242 p.

Scheffer, Marten, 2004, Ecology of shallow lakes: The Netherlands, Kluwer Academic Publishers, 357 p. accessed September 17, 2017, at https://doi.org/10.1007/ 978-1-4020-3154-0.

Seaber, P.R., Kapinos, F.P., and Knapp, G.L., 1987, Hydrologic unit maps: U.S. Geological Survey Water-Supply Paper 2294, 63 p.

Shreve, E.A., and Downs, A.C., 2005, Quality-assurance plan for the analysis of fluvial sediment by the U.S. Geological Survey Kentucky Water Science Center Sediment Laboratory: U.S. Geological Survey Open-File Report 2005-1230, $28 \mathrm{p}$.

Smith, V.H., 1983, Low nitrogen to phosphorus ratios favor dominance by blue-green algae in lake phytoplankton: Science, v. 221, p. 669-671, accessed March 5, 2016, at https://doi.org/10.1126/science.221.4611.669.

Smith, V.H., and Bennett, S.J., 1999, Nitrogen:phosphorus supply ratios and phytoplankton community structure in lakes: Archiv für Hydrobiologie, v. 146, no. 1, p. 37-53, accessed July 22, 2010, at https://doi.org/10.1127/ archiv-hydrobiol/146/1999/37.

Smith, V.H., Bierman, V.J., Jr., Jones, B.L., and Havens, K.E., 1995, Historical trends in the Lake Okeechobee ecosystem, IV. Nitrogen:phosphorus ratios, cyanobacterial dominance, and nitrogen fixation potential: Archiv für Hydrobiologie, Monographische Beiträge, no. 107, p. 71-88.

South Carolina Department of Health and Environmental Control, 2004, State of South Carolina integrated report for 2004, Part II-Assessment and reporting: South Carolina Department of Health and Environmental Control, 95 p., accessed January 12, 2017, at http://www.scdhec.gov/ HomeAndEnvironment/Docs/305b04.pdf. 
South Carolina Department of Health and Environmental Control, 2010, State of South Carolina integrated report for 2010, Part II-Section 305(b) assessment and reporting: South Carolina Department of Health and Environmental Control, 70 p., accessed January 12, 2017, at https://www. scdhec.gov/HomeAndEnvironment/Docs/tmdl_10-305b. pdf.

South Carolina Department of Health and Environmental Control, 2014a, State of South Carolina integrated report for 2014, Part II - Section 305(b) assessment and reporting: South Carolina Department of Health and Environmental Control, 55 p., accessed January 12, 2017, at https://www. scdhec.gov/HomeAndEnvironment/Docs/tmdl_14-305b. pdf.

South Carolina Department of Health and Environmental Control, 2014b, State of South Carolina integrated report for 2014, Part I-Section 303(d) list of impaired waters: South Carolina Department of Health and Environmental Control, 55 p., accessed January 12, 2017, at https://www.scdhec. gov/HomeAndEnvironment/Docs/tmdl_14-303d.pdf.

South Carolina Department of Health and Environmental Control, 2014c, Water classifications and standards: South Carolina Department of Health and Environmental Control, Code of Regulations, State Register, Regulation 61-68, accessed August 19, 2015, at https://www.scdhec.gov/ Agency/docs/water-regs/R.61-68.pdf.

South Carolina Department of Natural Resources, 2014, 2014 South Carolina aquatic management plan, Part II: South Carolina Department of Natural Resources Aquatic Nuisance Species Program, 232 p., accessed January 12, 2017, at http://www.dnr.sc.gov/invasiveweeds/ img/2014parttwo.pdf.

South Carolina Water Resources Commission, 1979, Cooper River controlled low-flow study: S.C. Water Resources Commission, Report No. 131, 352 p.

Suffet, I.H., Corado, Ana, Chou, David, McGuire, M.J., and Butterworth, Steve, 1996, AWWA taste and odor survey: Journal of American Water Works Association, v. 88, no. 4, p. $168-180$.
Taylor, W.D., Losee, R.F., Torobin, Marcia, Izaguirre, George, Sass, Debra, Khiari, Djanette, and Atasi, Khalil, 2006, Early warning and management of surface water taste-and-odor events: American Water Works Association Research Foundation Reports, 268 p.

U.S. Geological Survey, variously dated, National field manual for the collection of water-quality data: U.S. Geological Survey Techniques of Water-Resources Investigations, book 9, chaps. A1-A9, accessed April 6, 2011, at https:// pubs.water.usgs.gov/twri9A.

U.S. Geological Survey, 2016, USGS water data for the Nation: U.S. Geological Survey National Water Information System database, accessed September 28, 2016, at https:// doi.org/10.5066/F7P55KJN.

Vector Map, 2015, Vector Map version 7.0.4 software: Fall River, Mass., OceanServer Technology, Inc.

Wagner, R.J., Boulger, R.W., Oblinger, C.J., and Smith, B.A., 2006, Guidelines and standard procedures for continuous water-quality monitors - Station operation, record computation, and data reporting: U.S. Geological Survey Techniques and Methods, book 1, chap. D3, 83 p.

Wetzel, R.G., 2001, Limnology—Lake and reservoir ecosystems (3d ed.): New York, Academic Press, 1,006 p.

Wnorowski, A.U., 1992, Tastes and odours in the aquatic environment-A review: Water SA, v. 18, no. 3, p. 203-214.

Young, W.F., Horth, H., Crane, R., Ogden, T., and Arnott, M., 1996, Taste and odour threshold concentrations of potential potable water contaminants: Water Research, v. 30, no. 2, p. 331-340.

YSI, Inc., 2008, Ecomapper autonomous underwater vehicle, YSI, Incorporated datasheet, 4 p., accessed January 29, 2018, at http://www.iver-auv.com/ysiauvdatasheet.pdf.

YSI, Inc., 2011, 6-series multiparameter water quality sondes user manual: YSI, Incorporated, accessed December 2, 2017, at https://www.ysi.com/File\%20Library/Documents/ Manuals/069300-YSI-6-Series-Manual-RevJ.pdf. 


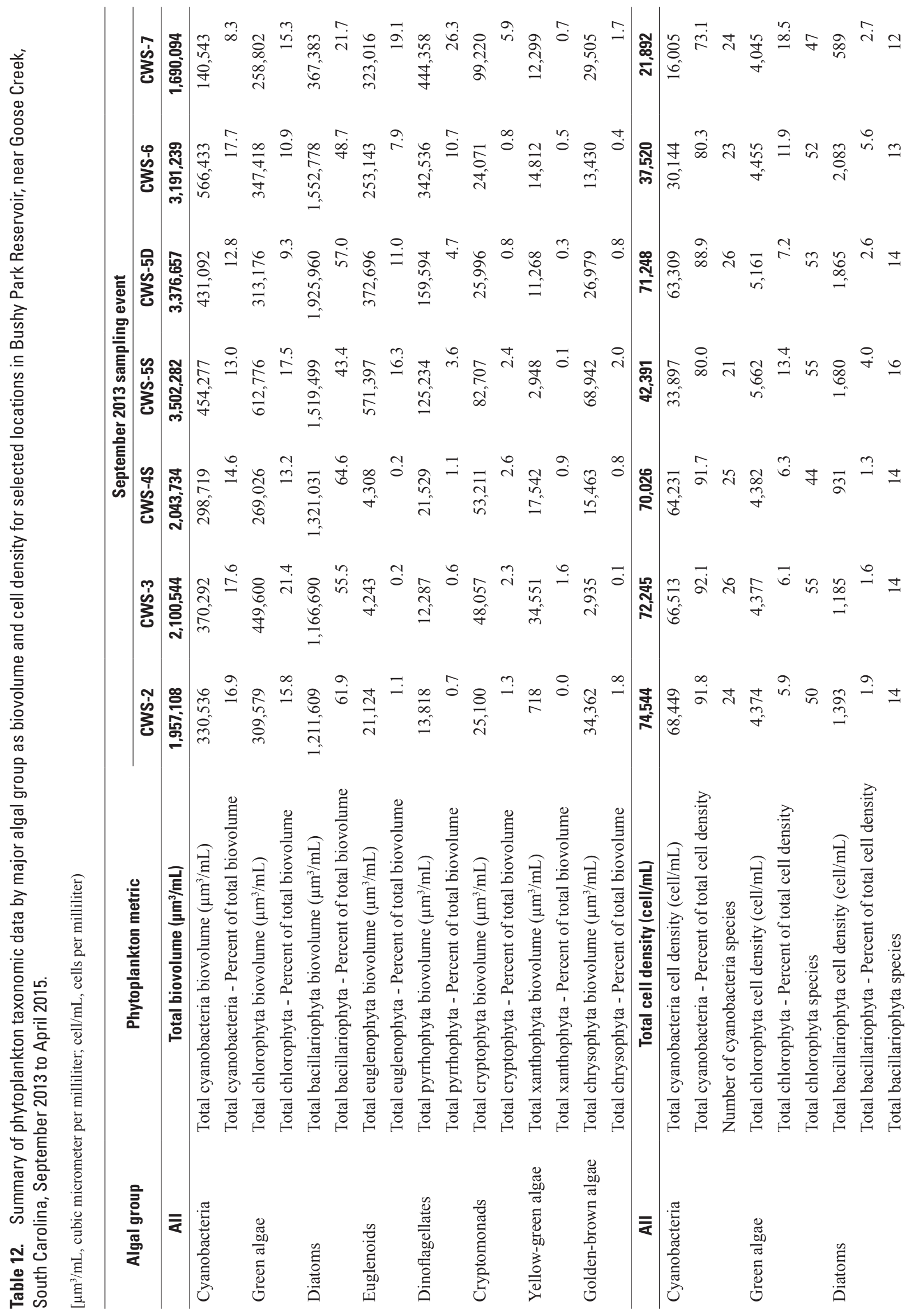




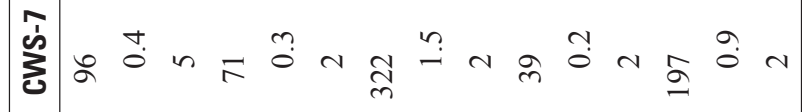

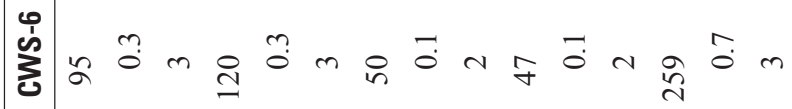

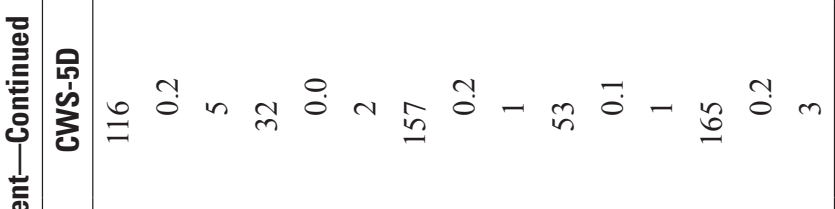

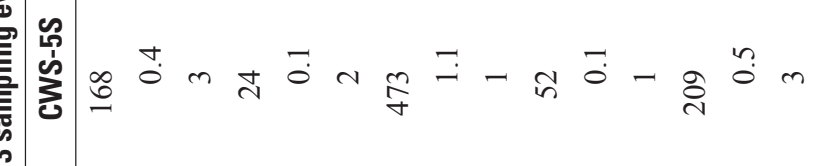

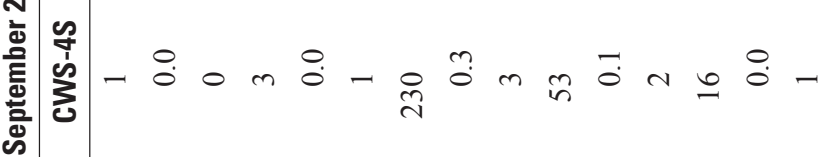

岂

殅

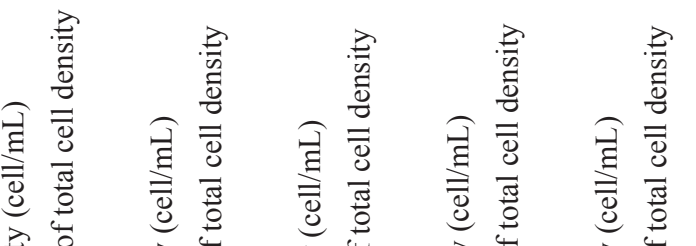

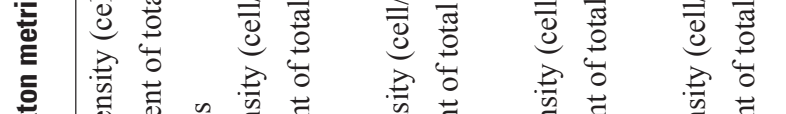

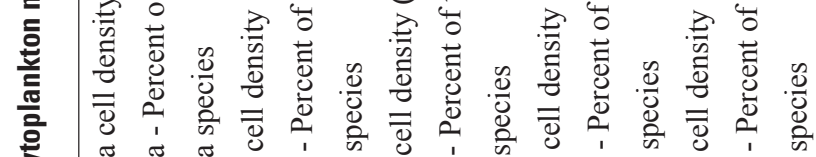

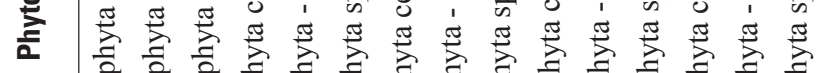

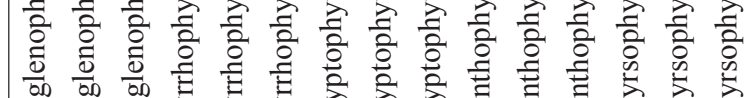

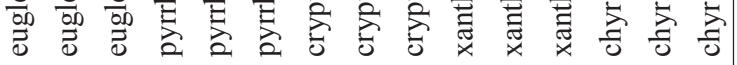

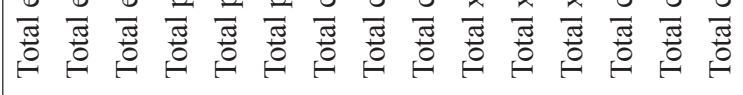

\begin{tabular}{|c|c|c|c|c|c|}
\hline 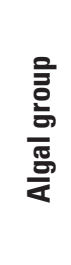 & $\begin{array}{l}\frac{y}{0} \\
0 \\
0 \\
0 \\
00 \\
0 \\
0\end{array}$ & 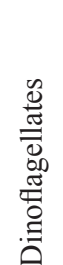 & 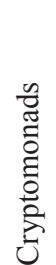 & 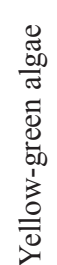 & 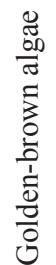 \\
\hline
\end{tabular}




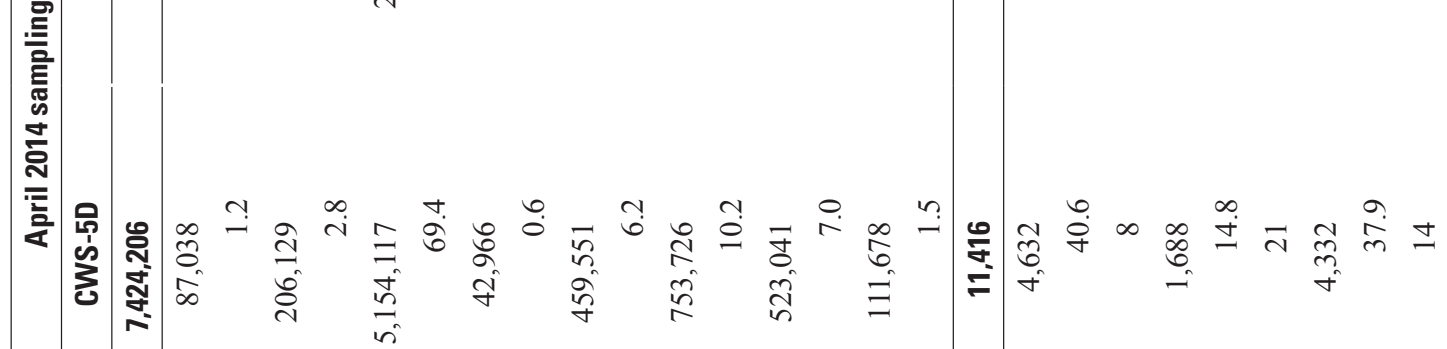

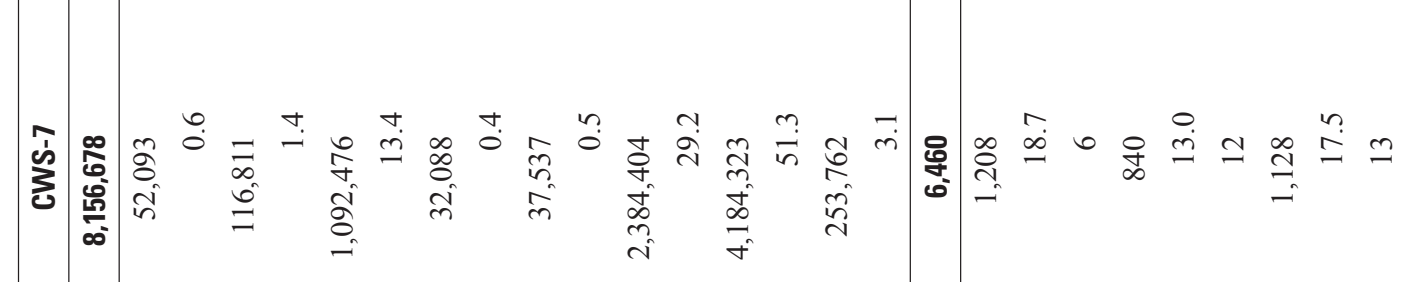

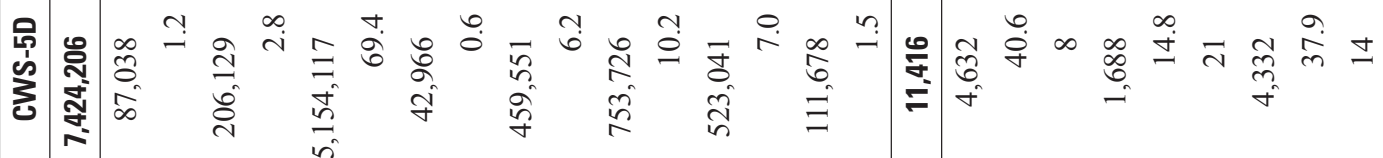

$$
\begin{aligned}
& \text { = }
\end{aligned}
$$

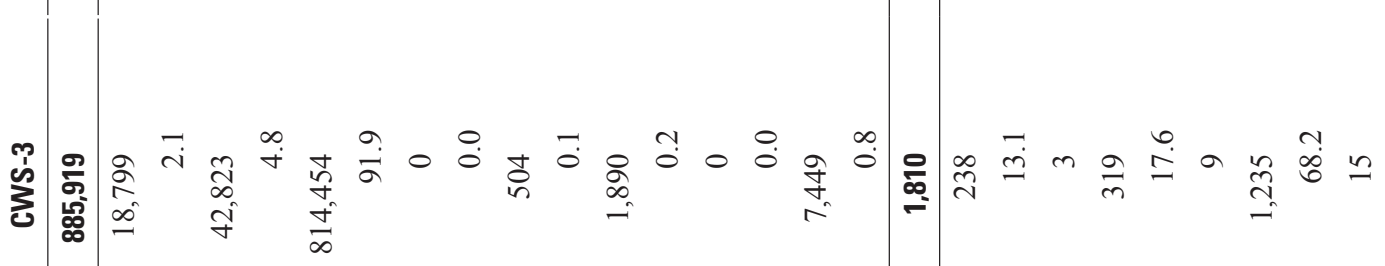$$
\text { ลे }
$$$$
\text { 芩 }
$$ 


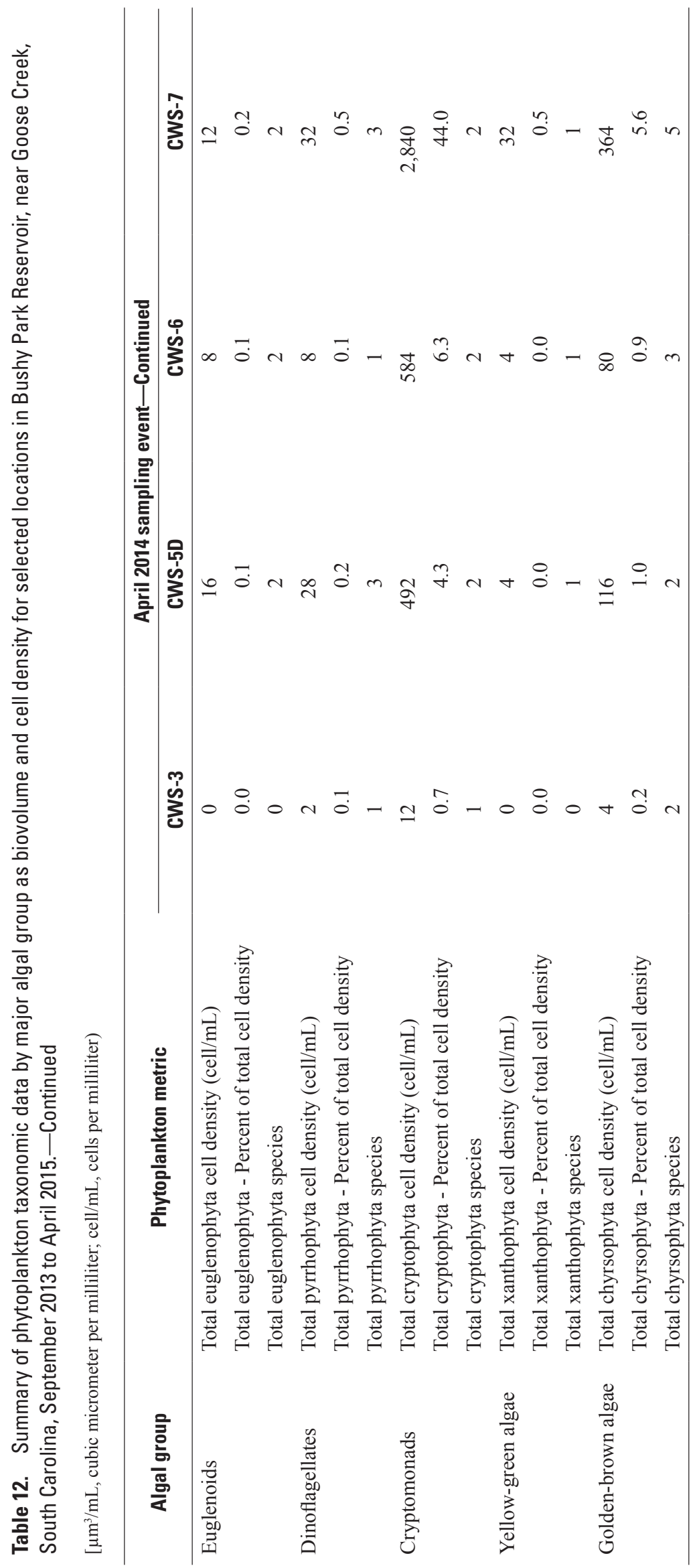




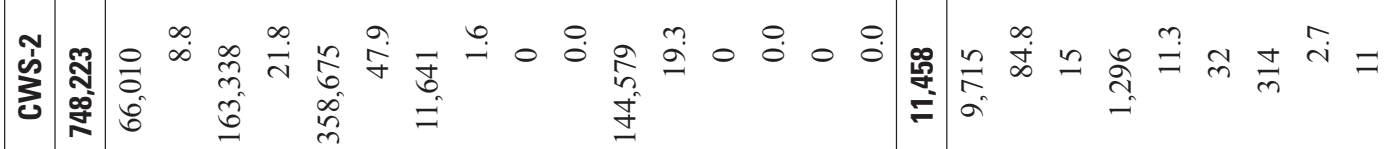

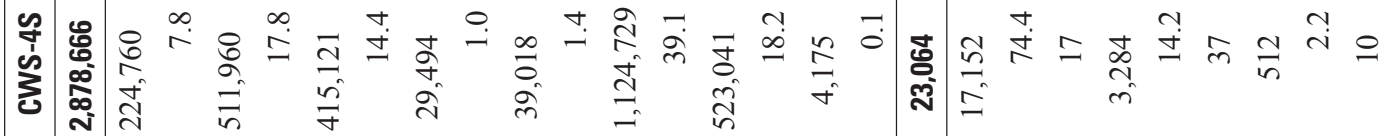

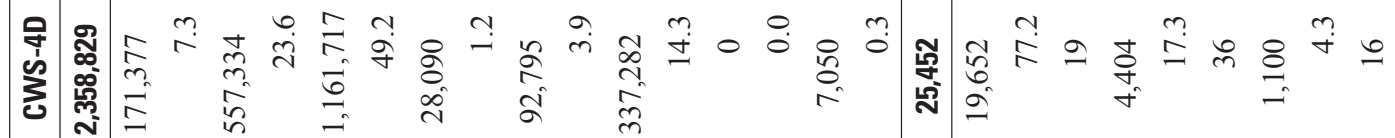

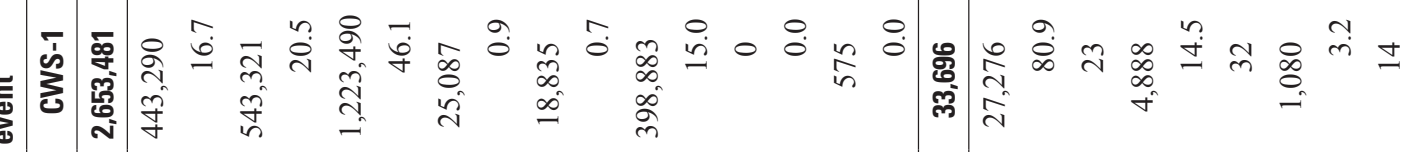

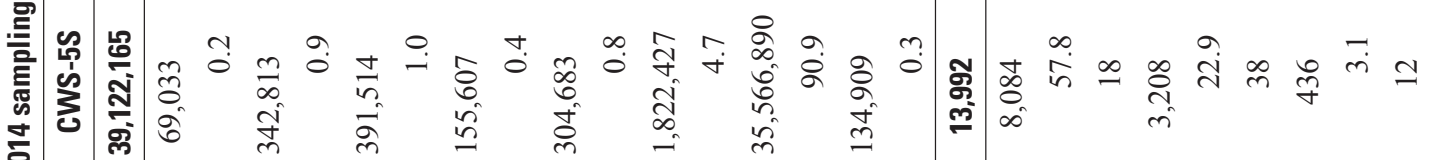
ลิ

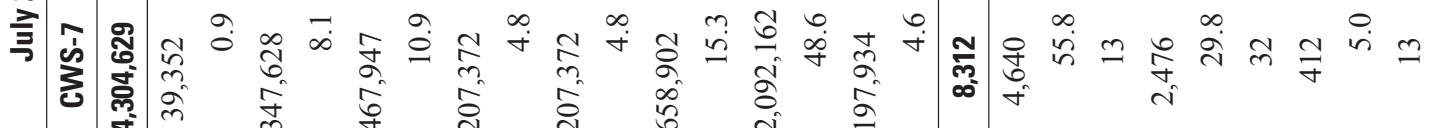

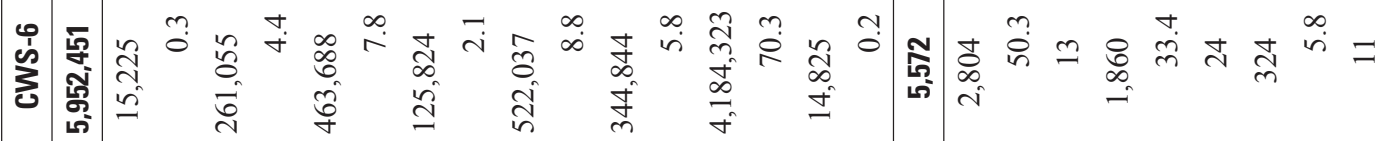

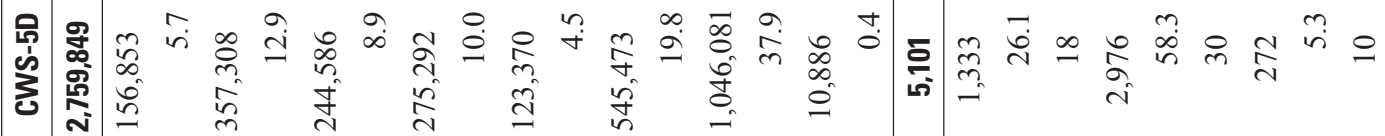

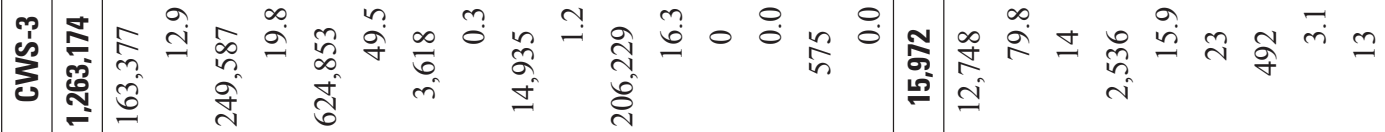

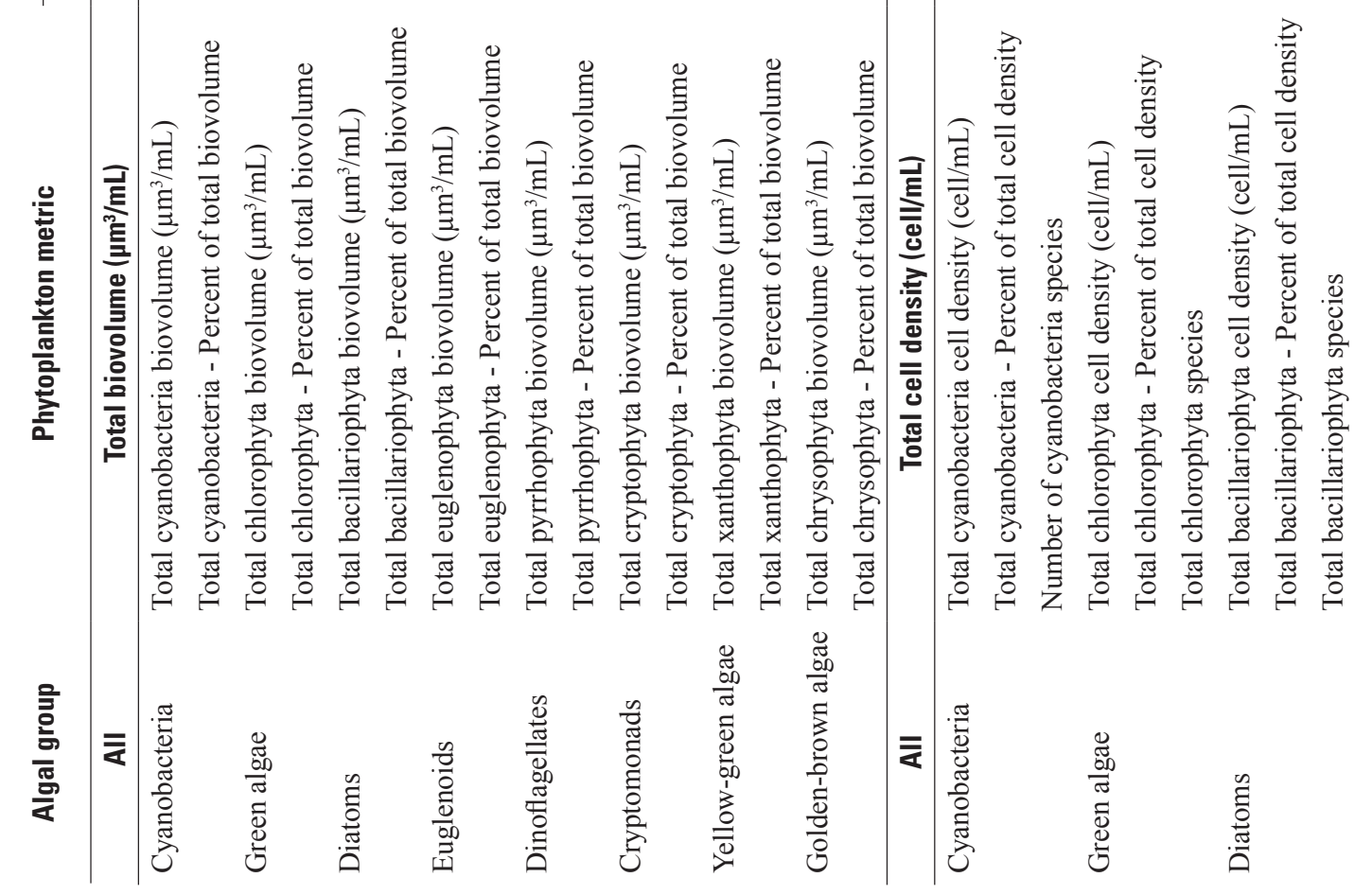




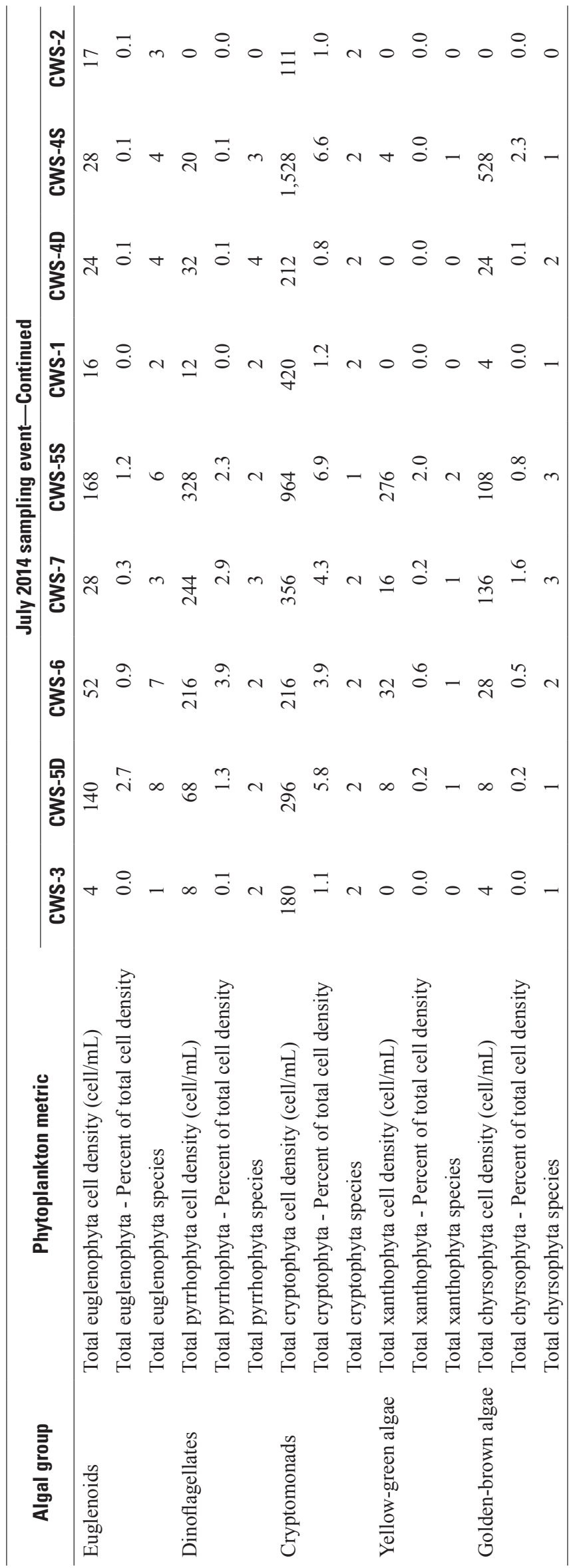




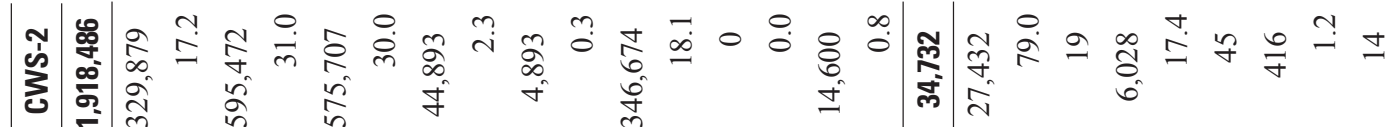

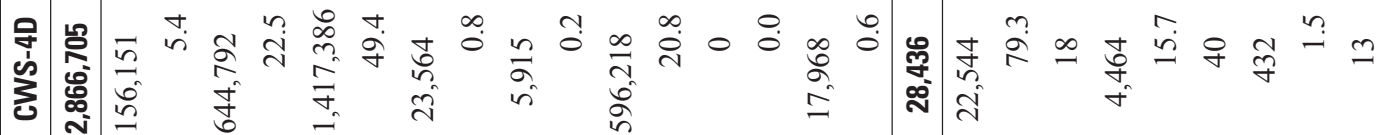

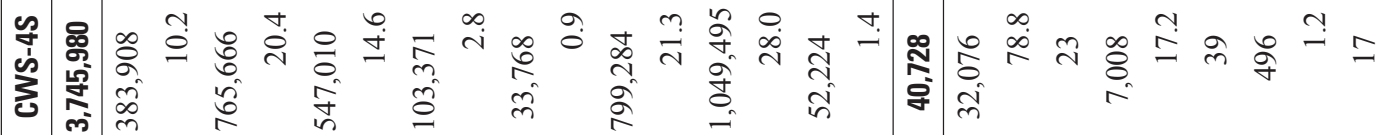

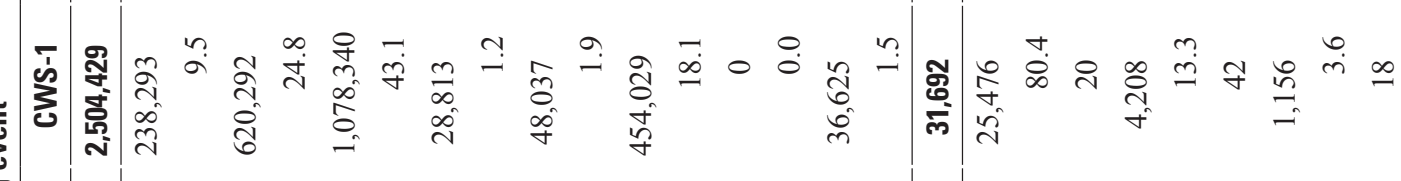

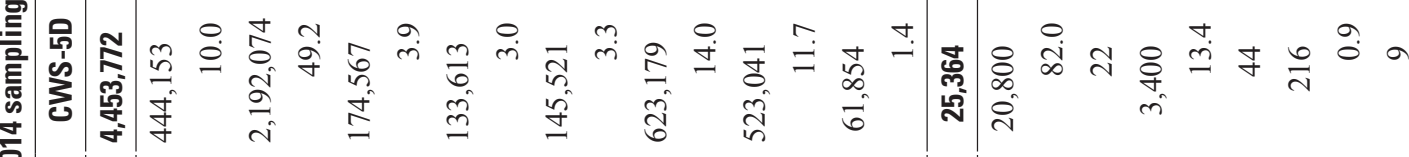

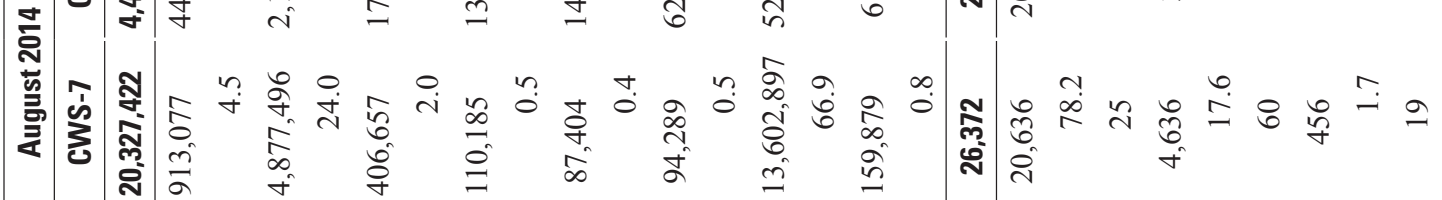

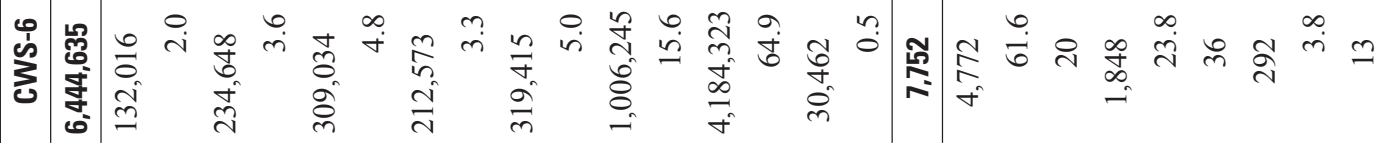

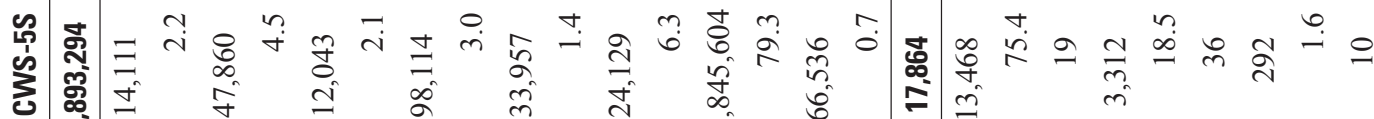

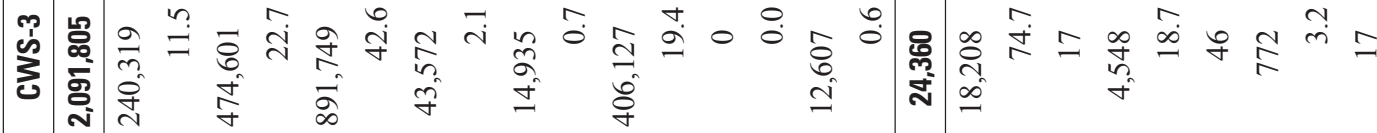

章 导

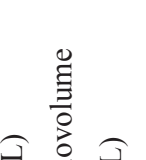

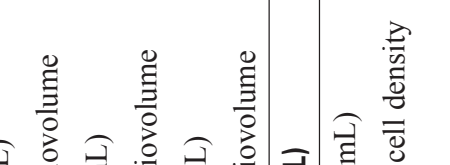

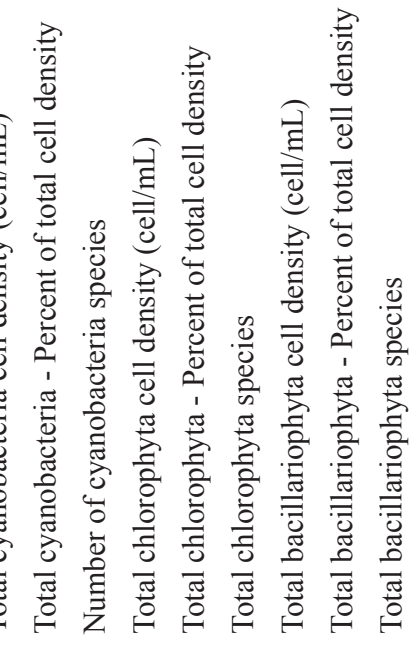




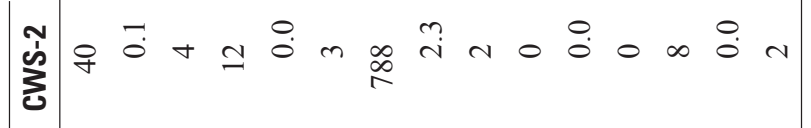

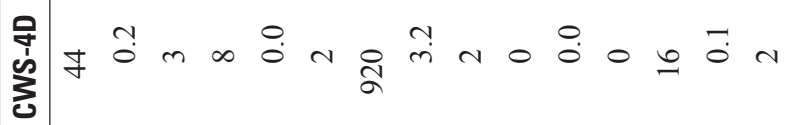

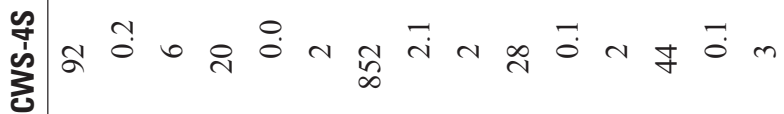

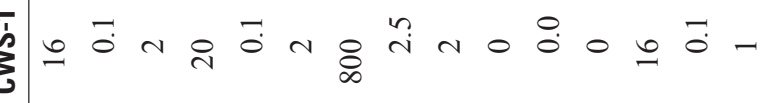

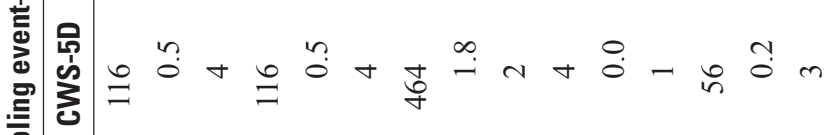

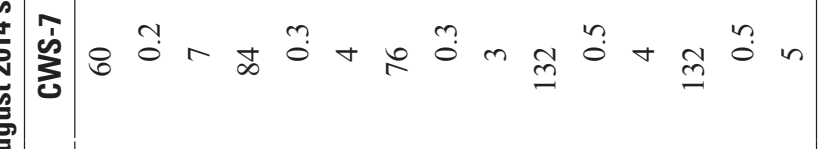

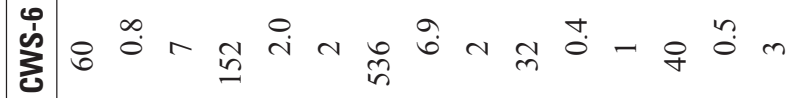

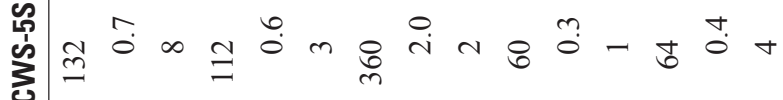

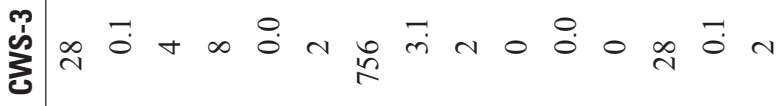

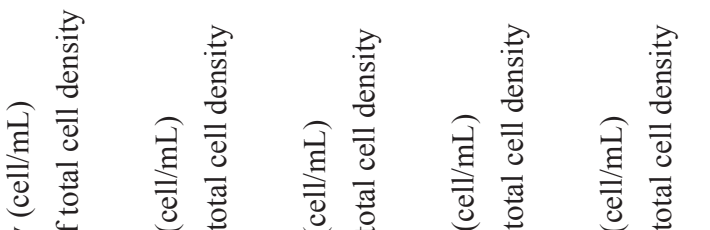




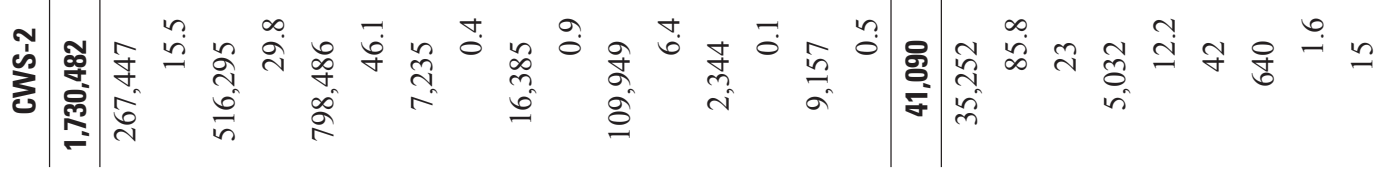

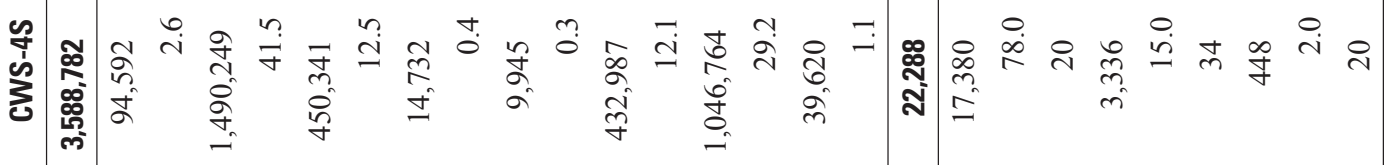

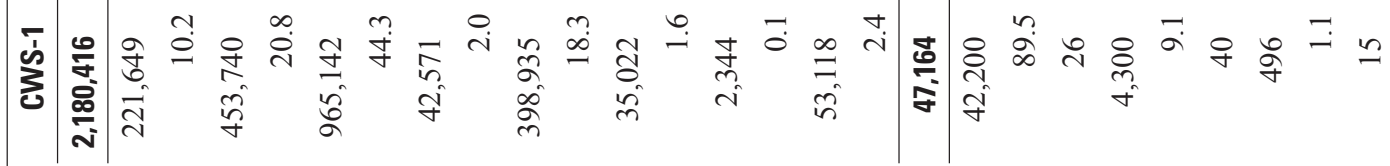

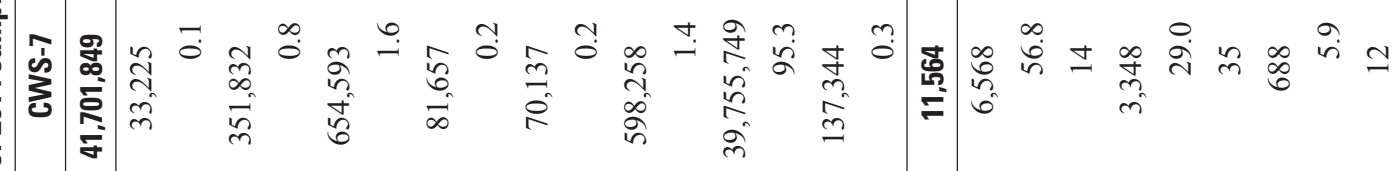

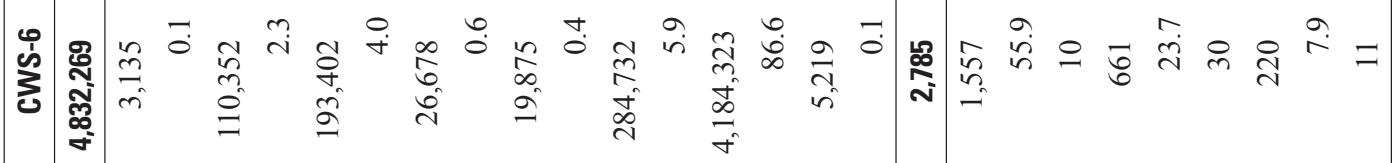

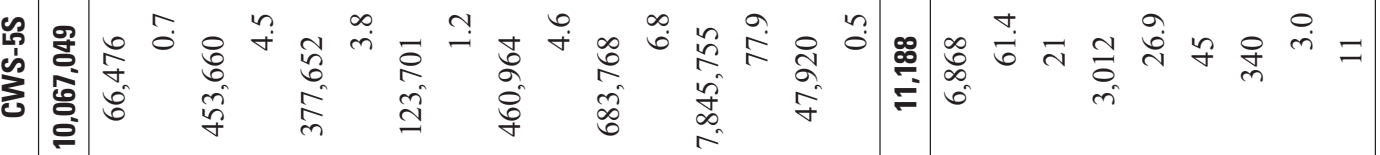

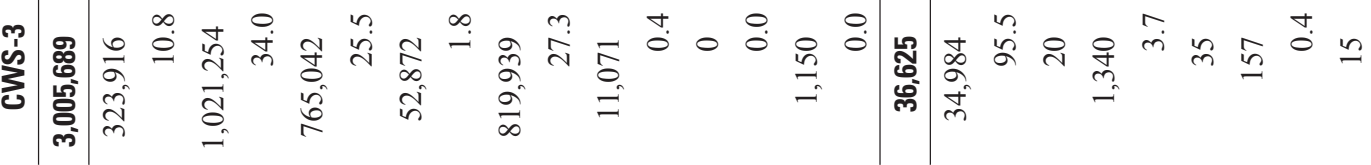

옹

$\frac{\bar{\pi}}{\frac{\pi}{\pi}}$

$\cdot \frac{\bar{a}}{\pi}$

ลे

营

일

동

苨

등

亭

응 음

¿ัँ

पू है

त्रे

言

ํ. 휴

ब志志
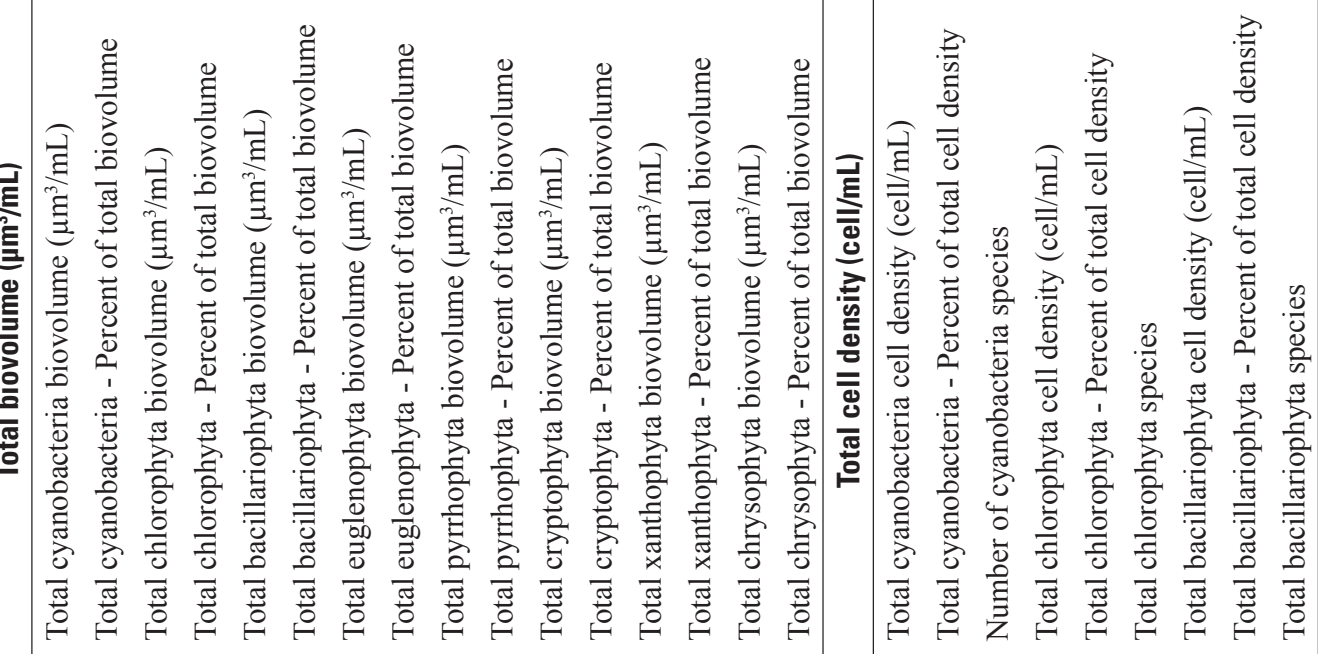

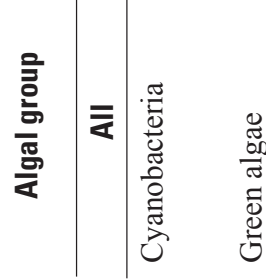
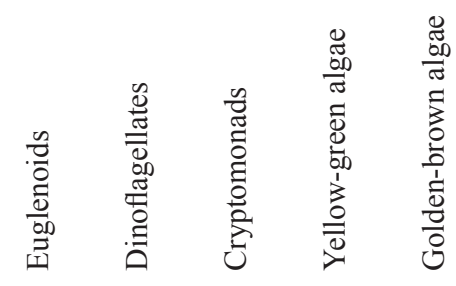

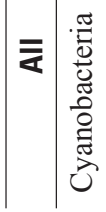

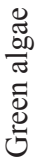




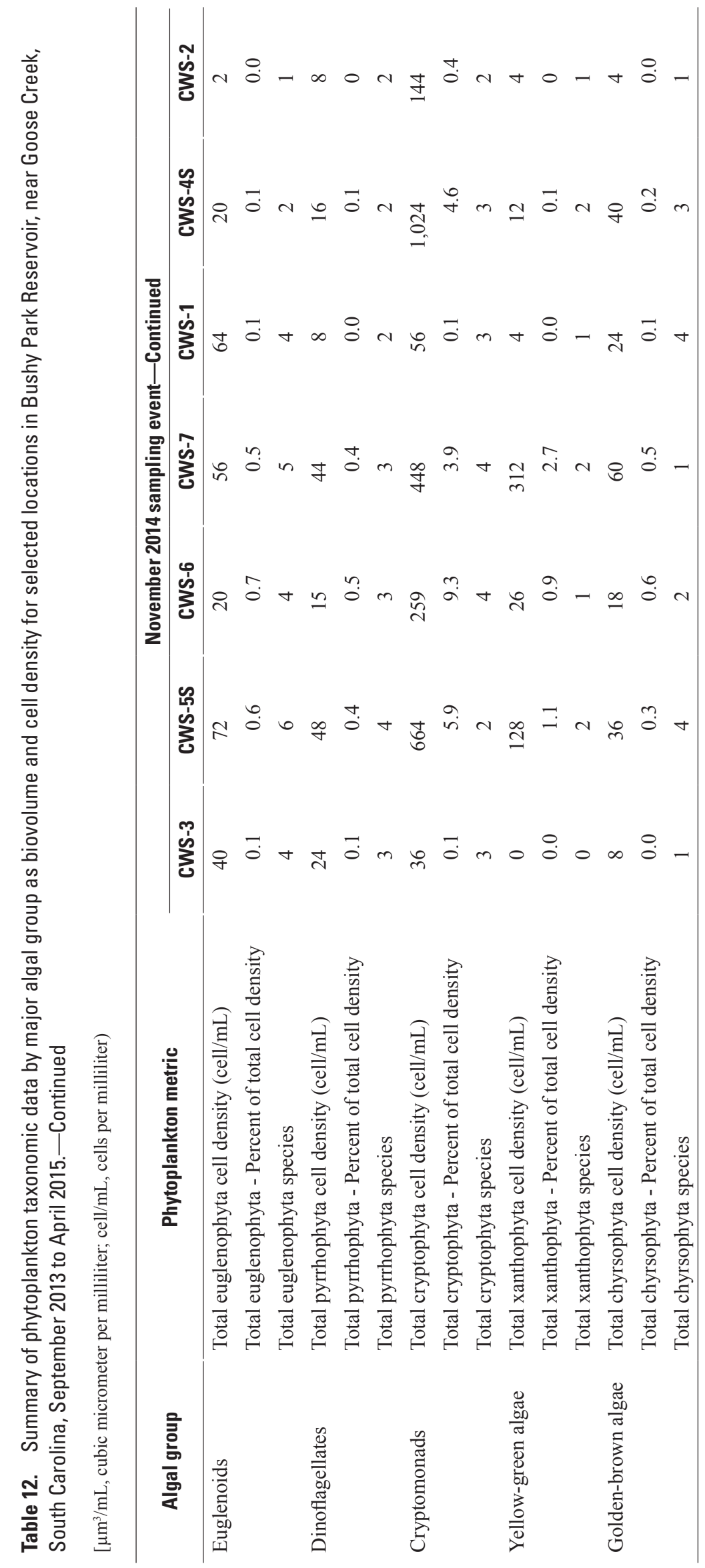




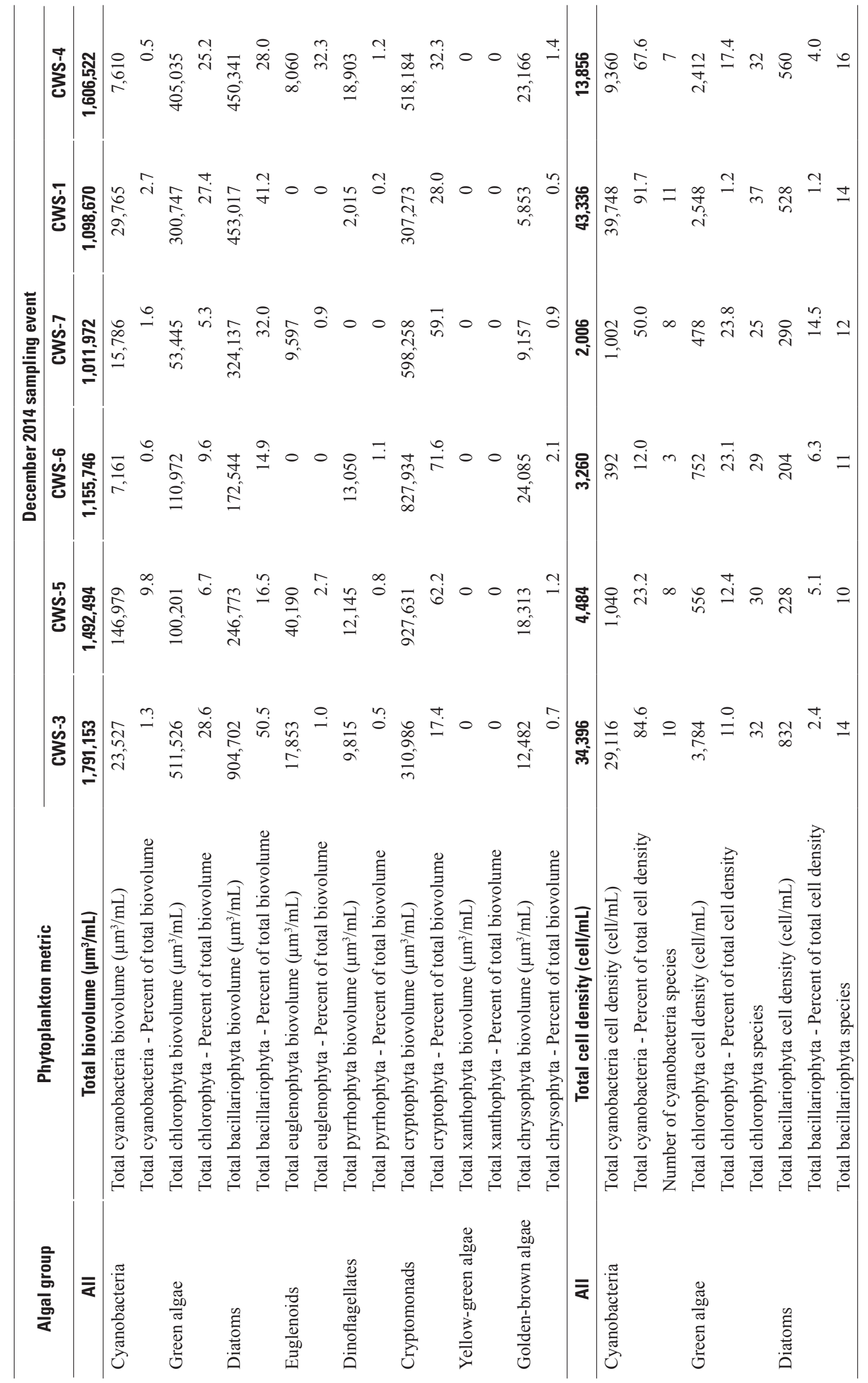




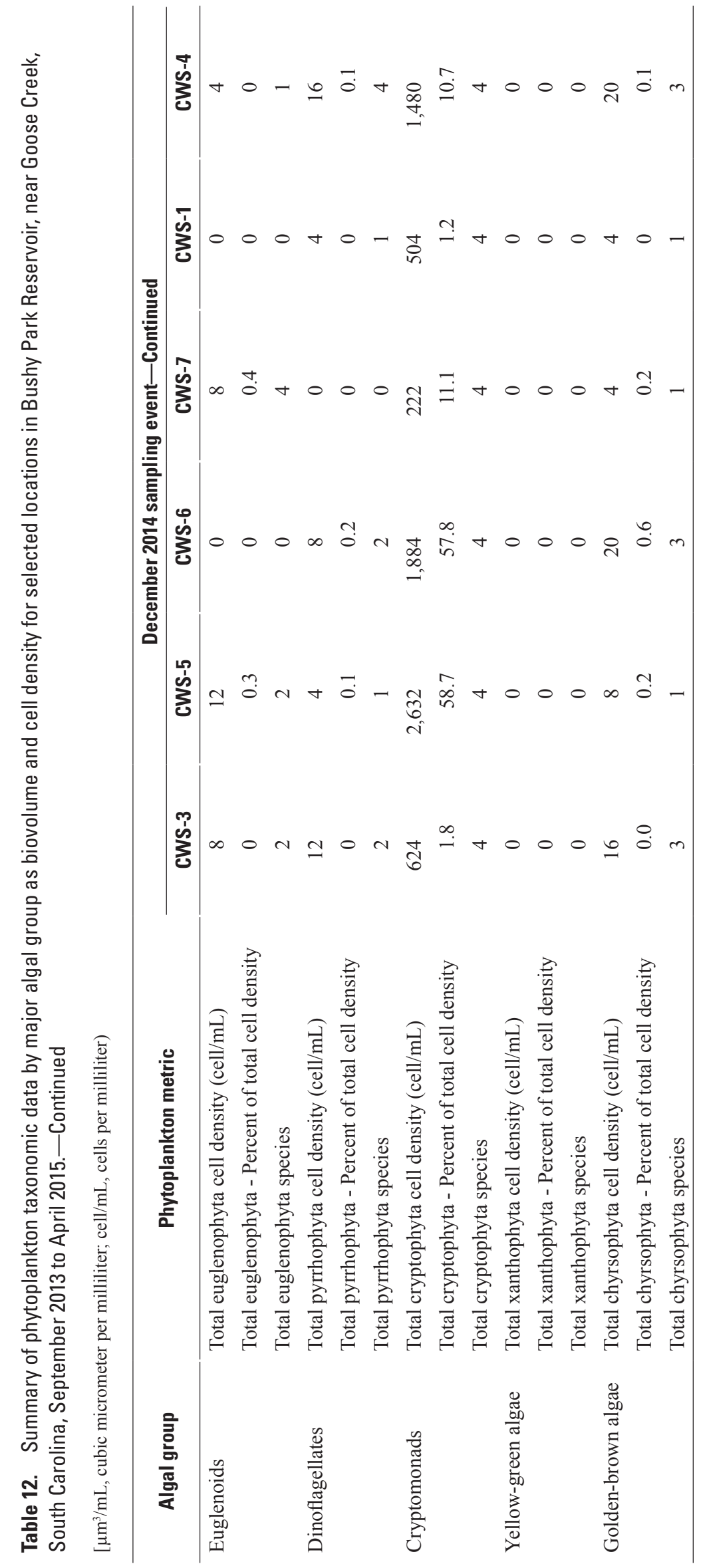




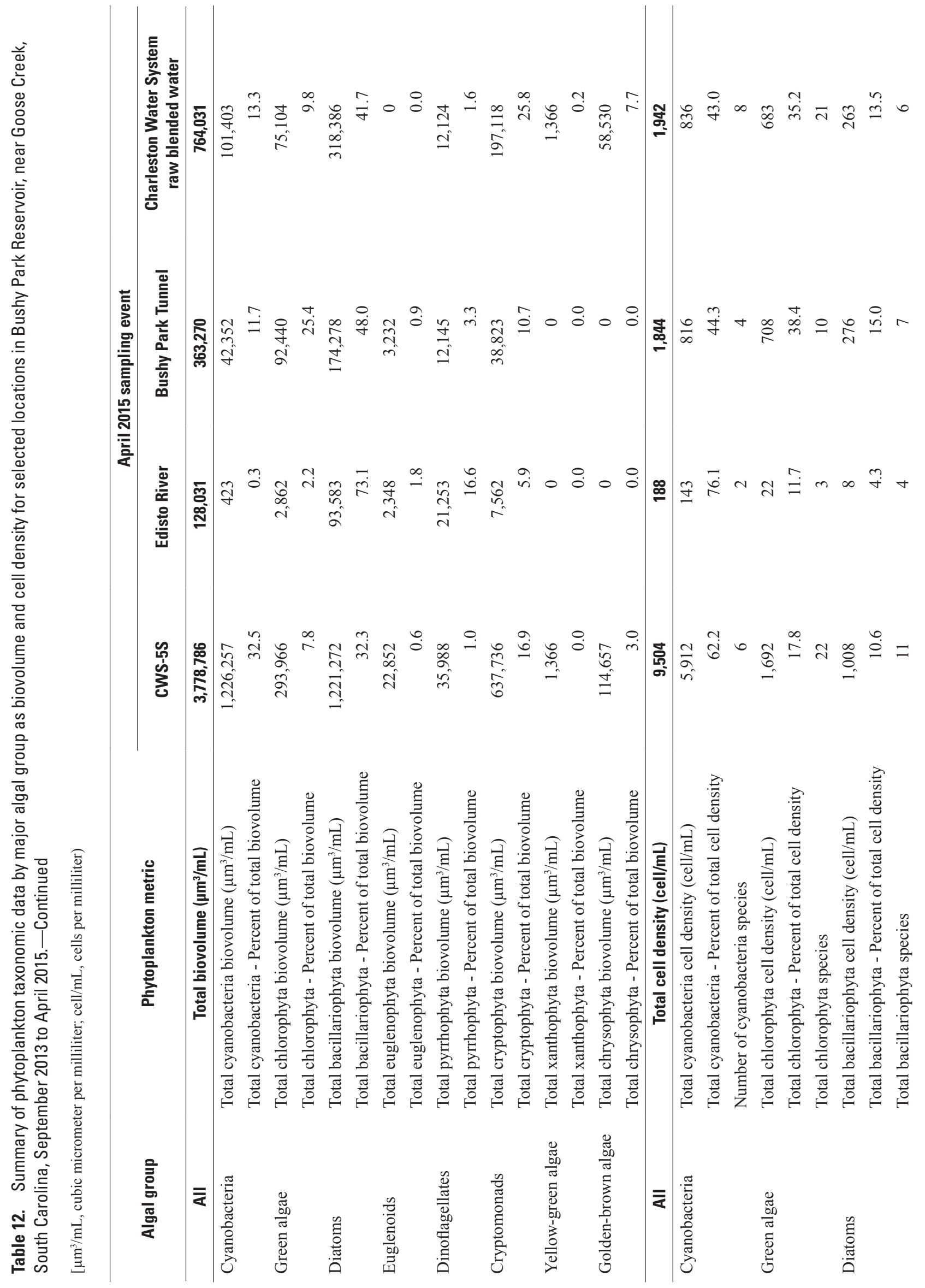




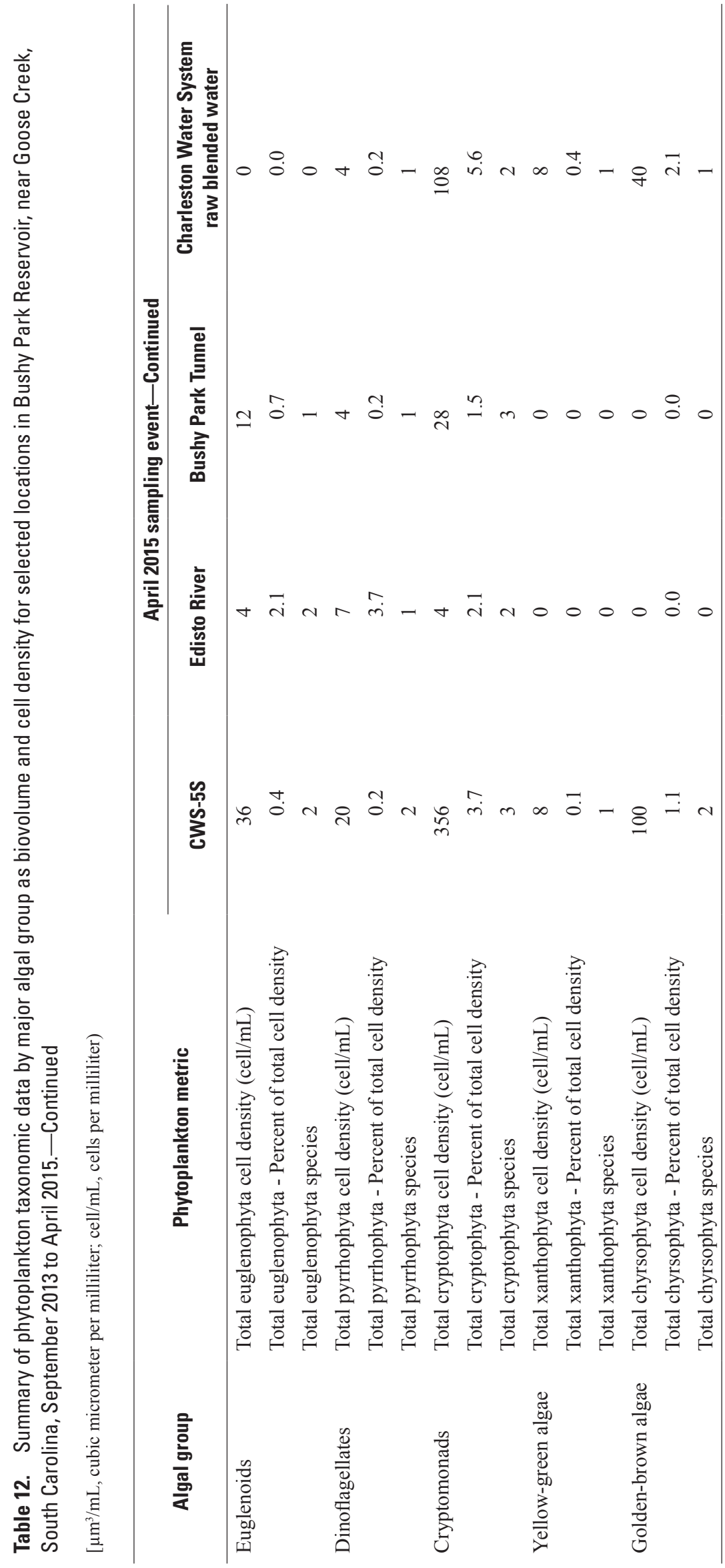





\section{Appendixes 1-5}

Appendix 1. Operation and data processing of the EcoMapper Iver2 autonomous underwater vehicle...

Appendix 2. Plots showing 2D longitudinal profiles for seven parameters for 16 autonomous underwater vehicle water-quality surveys.

Appendix 3. Water-quality profile data collected from the Bushy Park Reservoir, near Goose Creek, South Carolina, between September 2013 and April 2015 .106

Appendix 4. Summary of the quality assurance and quality control data collected in Bushy Park Reservoir, near Goose Creek, South Carolina, September 2013 to April 2015

Appendix 5. Analytical results for water-column samples collected in Bushy Park Reservoir, near Goose Creek, South Carolina, September 2013 to April 2015 


\section{Appendix 1. Operation and data processing of the EcoMapper Iver2 autonomous underwater vehicle}

Multiple water-quality surveys of Bushy Park Reservoir were completed using the EcoMapper Iver2 autonomous underwater vehicle (AUV) built by Yellow Springs Instrument (YSI), Inc., and OceanServer Technology, Inc. (fig. 1-1). The AUV can cost-effectively collect spatially dense water-quality, bathymetric, and side-scan sonar data by surveying large areas in minimal time compared to traditional, manned boat surveys and sampling. The description and operation of the AUV and the post-processing of the data are well documented in Jackson (2013a), and much of the information presented in this appendix comes from that report.

\section{Description of the EcoMapper Iver2}

The AUV is composed of an aluminum hull with carbonfiber nose and tail sections (fig. 1-1). The nose of the AUV houses a V2-4 YSI sonde bulkhead with four optical ports and temperature/conductivity and $\mathrm{pH}$ ports. A pressure sensor also is integrated into the sonde bulkhead for measurement of the sample depth. Aft of the sensor suite on the nose of the vehicle is the Doppler velocimetry log (DVL) instrument. The DVL is a six-beam system for underwater navigation (bottom tracking) and includes vertical beams (uplooking and downlooking) for altitude and depth measurement. Additionally, the DVL provides current-profiling capabilities below the instrument. The tail is composed of four independent control fins and a three-blade propeller. Atop the vehicle near the tail section is the antennae mast, which houses a differential Global Positioning System (GPS) antenna (Wide Area Augmentation
System corrected), a wireless radio antenna that operates with a $802.11 \mathrm{~g}$ wireless networking standard at 2.4 gigahertz, the navigation lights, and an external power plug for vehicle charging. All communication with the vehicle is through the wireless Ethernet radio link. Onboard electronics include an embedded computer running Windows XP and an 80 gigabyte hard drive for data storage. The aft section of the body also houses the integrated Imagenex side-scan sonar transducers, mounted on the port and starboard sides of the vehicle just forward of the tail section.

The water-quality sensor suite is composed of a YSI 6600 V2-4 bulkhead equipped with a YSI 6560FR fast response temperature/conductivity probe, a YSI 6589FR fast response $\mathrm{pH}$ sensor, a YSI 6150FR fast response ROX optical dissolved-oxygen sensor, a YSI 6136 turbidity sensor, a YSI 6025 chlorophyll sensor, and a YSI 6131 BGA-PC phycocyanin (blue-green algae) sensor. Manufacturer's specifications for each of the probes are given in table 4 (main text of report). All water-quality sensors are sampled at a rate of 1 hertz (Hz).

The six-beam DVL system aboard the AUV is composed of four 1-megahertz (MHz) beams oriented vertically at a 25 -degree angle with acoustic beam widths of 3.5 degrees (YSI, Inc., 2011). The additional two 500-kilohertz (kHz) beams are oriented vertically, one uplooking and one downlooking, for range-to-surface and range-to-bed measurements, respectively. The vertical beams have a beam width of 5 degrees, a range of 0.82 foot ( $\mathrm{ft} ; 0.25$ meter $[\mathrm{m}])$ to $262 \mathrm{ft}$ $(80 \mathrm{~m})$, an accuracy of 1 percent of measured range, and a resolution of $0.01 \mathrm{~m}$. The DVL has an internal sampling

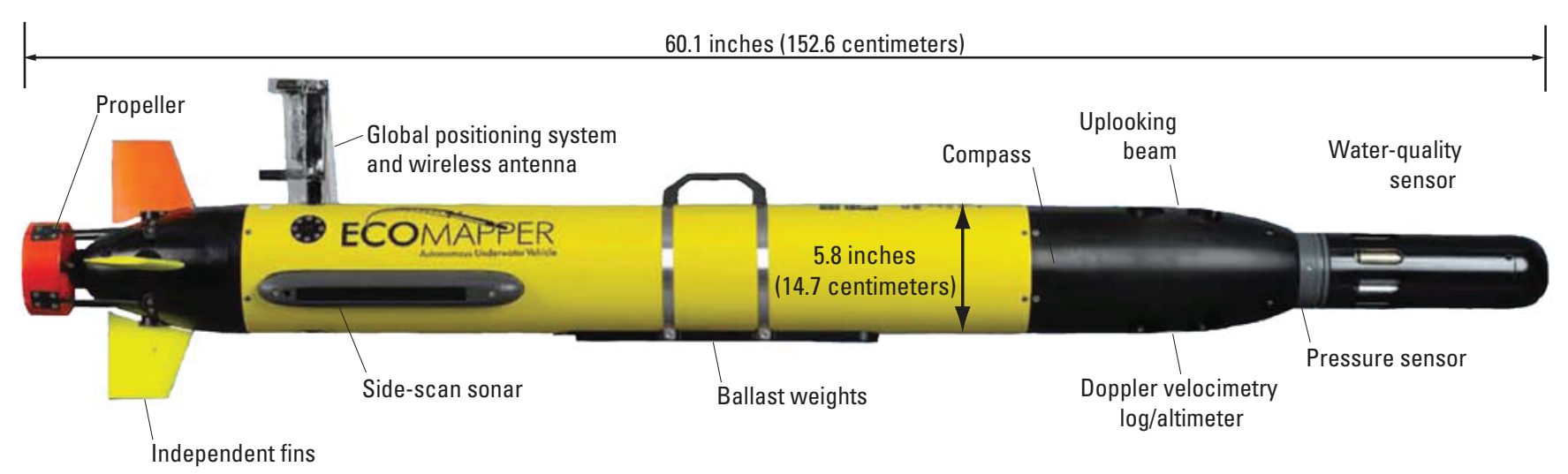

Figure 1-1. Diagram of the EcoMapper Iver2 with components labeled (modified from YSI, Inc., 2010; modified from Jackson, 2013a, b). 
rate of up to $70 \mathrm{~Hz}$ depending on the configuration, but DVL data are averaged and reported at $1 \mathrm{~Hz}$ to the AUV onboard computer. Manufacturer's specifications report the bottom-tracking range of the DVL to be $0.16 \mathrm{ft}(0.05 \mathrm{~m})$ to $98 \mathrm{ft}(30 \mathrm{~m})$, the current profiling velocity range of \pm 32.8 feet per second $(\mathrm{ft} / \mathrm{s})( \pm 10$ meters per second $[\mathrm{m} / \mathrm{s}])$ with an accuracy of $\pm 0.0066 \mathrm{ft} / \mathrm{s}( \pm 0.2$ centimeter per second $[\mathrm{cm} / \mathrm{s}])$ or 0.25 percent of measured profile velocity, and a resolution of $0.032 \mathrm{ft} / \mathrm{s}(0.01 \mathrm{~m} / \mathrm{s})$. The minimum cell size for the DVL profiling is $0.82 \mathrm{ft}(0.25 \mathrm{~m})$, and the maximum number of cells is 128 .

In addition to the DVL, the AUV has several other integrated sensors to aid in navigation. A three-axis digital compass is integrated into the vehicle as is a second pressure sensor. The compass is required for underwater navigation with the DVL and when using dead reckoning. Additionally, the compass is required for proper alignment of velocity data from the DVL. The second pressure sensor is used for navigation of the vehicle and provides depth measurements redundant to the YSI bulkhead pressure sensor and the uplooking vertical beam. According to the manufacturer, the vehicle pressure sensor has a range of $200 \mathrm{ft}(61 \mathrm{~m})$, accuracy of $\pm 0.02 \mathrm{ft}(0.006 \mathrm{~m})$, and resolution of $0.001 \mathrm{ft}$. Finally, the AUV is equipped with a $75-\mathrm{kHz}$ acoustic pinger for location of the vehicle by using a hydrophone from a manned boat. Acoustic images of the bed are obtained by using the integrated Imagenex 330/800 kHz side-scan sonar. Two dualfrequency transducers are mounted on the vehicle near the tail (one on each side) and are angled down at 20 degrees. The range of the sonar is $49 \mathrm{ft}(15 \mathrm{~m})$ to $394 \mathrm{ft}(120 \mathrm{~m})$ and is user configurable. Resolution of the sonar is computed as the range scale divided by 250 (or 500 if only operating one transducer).

\section{Pre-Deployment Planning}

The EcoMapper AUV performs autonomous surveys of water bodies and when properly programmed requires no assistance during execution of the survey. Programming a survey involves obtaining a high-resolution georeferenced aerial photograph of the water body and determining locations of any potential obstructions (from initial reconnaissance). The aerial imagery and obstructions information are then imported into Vector Map (Vector Map, 2015), the primary programming software for the AUV, and used as a background for survey planning. Within Vector Map, the user creates missions (surveys) by generating a field of numbered waypoints for the AUV to visit. The points are numbered sequentially, and the AUV will follow the set order, executing commands at each waypoint. Each waypoint has a set of associated commands, including dive mode, speed, dive angle, depth or height above bottom, sonar settings, and park commands. Dive mode options include (1) constant depth, where the AUV will achieve and maintain a specific depth below the surface by using its redundant-pressure sensors and vertical uplooking beam; (2) constant height above bottom, where the AUV will maintain a specified height above the bed by using its vertical downlooking beam; and (3) undulate, where the vehicle will undulate between two depths (or a combination of a depth and height above bottom) at a specified dive angle (fig. 1-2). The speed command sets the speed over ground of the AUV and is limited to 2.5 knots at the surface and 4 knots underwater. Sonar settings can be adjusted for each waypoint and include the range, gain, frequency, and transducer configuration (single-side or both sides). Lastly, park commands can be issued at any waypoint to force the vehicle to park on the surface at a waypoint and actively maintain that position for a specified period of time. Park commands generally are issued at the end of a mission, at a specified meeting point with the manned boat, for recovery of the AUV. The AUV executes the waypoint commands of the destination waypoint and transitions to the next set of commands after entering the waypoint success radius (user defined) of the destination waypoint. Once the mission is programmed in Vector Map, the mission is transferred to the AUV via the wireless connection as a text-based mission file (*.mis).

Execution of an EcoMapper survey begins with the loading of a mission into the underwater vehicle console (UVC), the onboard control program of the AUV. The UVC decodes the mission command file and controls the AUV sensors, navigation, and propulsion to execute each of the sequential commands. Prior to deployment, the user sets the safety settings within the UVC (settings that allow the AUV to abort a mission if necessary) and loads a safe return path (SRP) file if necessary. (The SRP is a mission file that will execute only upon abortion of the survey mission.) The goal of the SRP is to bring the AUV back to land safely in the event of a system malfunction.

The AUV is placed in the water and checked for proper ballasting (adjustments are made if necessary), and the pressure sensors are zeroed. Internal checks of the GPS receiver, altimeter, and compass also are completed in addition to response checks of all water-quality sensors, DVL system, and the navigation and propulsion systems. If all systems are functional, the mission is started by the UVC, via the wireless connection, with a remote computer aboard the manned boat. The AUV then begins to navigate to each of the programmed waypoints, in sequential order, executing the waypoint commands along the way. All data are recorded to files and stored on the internal hard drive aboard the AUV. Upon completing the mission, the AUV is retrieved at the meeting point, disabled remotely, and recovered by hand. Once onboard, data files are recovered via the wireless network connection, and a new mission is loaded (if necessary). Should the AUV fail to arrive at the meeting point at the scheduled time, the operators should check the beaching point in the SRP to determine if the AUV aborted the mission and returned to shore. If the AUV aborts the mission for any reason, the data files contain a set of error codes that explain the reason. 


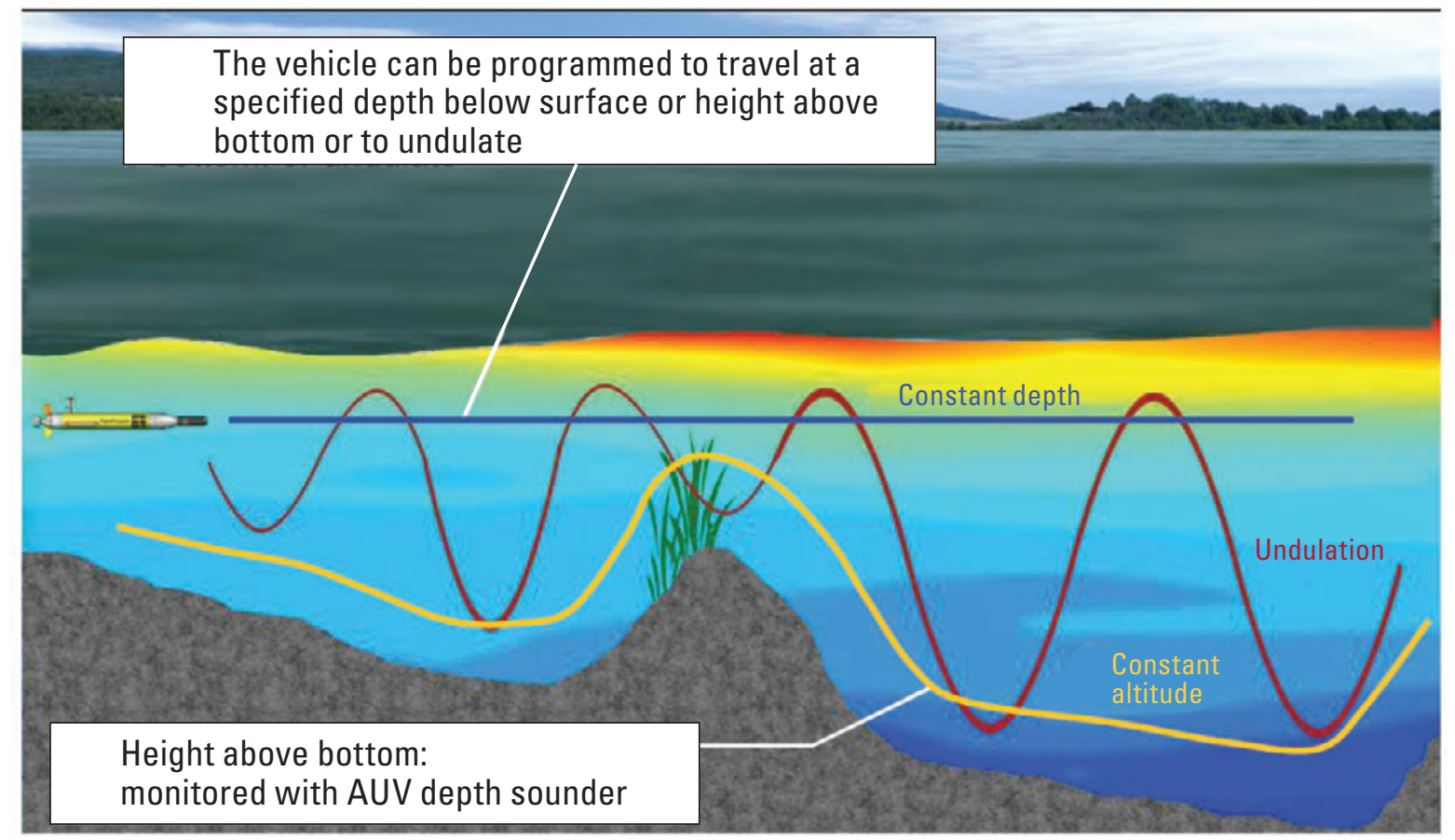

Figure 1-2. Schematic showing three survey modes (constant depth, constant altitude, and undulation) for the autonomous underwater vehicle. Modified from Jackson, 2013b).

\section{Calibration of the EcoMapper Sensors}

Calibration check and re-calibration procedures were conducted on all water-quality sensors prior to and after deployment according to procedures outlined by YSI and the U.S. Geological Survey (USGS) National Field Manual (YSI, Inc., 2011; Wilde, variously dated; respectively). When possible, calibrations were done in the controlled environment of a laboratory. The AUV thermistor is not user calibrated, but rather is periodically checked for accuracy against a National Institute of Standards and Technology-certified thermometer in a thermal bath over a range of temperatures. Typically, the chlorophyll and blue-green algae sensors are calibrated (zeroed) in deionized water by using a one-point calibration method. The one-point calibration method results in relative chlorophyll and blue-green algae distributions rather than absolute concentrations. If absolute concentrations are required by the project, the sensors are post-calibrated with a second point by using samples collected in the field in close proximity to the AUV during data collection and analyzed by a qualified laboratory.

Calibration of the vehicle compass was achieved by running an in-water compass calibration mission composed of four survey sweeps. Each sweep consisted of six 400-ft underwater legs (three in each direction) at a depth of $7 \mathrm{ft}$ below the surface. Each of the four sweeps was run at a different orientation (north-south, east-west, northeast-southwest, and northwest-southeast). Navigational errors between the actual and computed position of the vehicle were monitored and used to generate a compass-deviation table. The deviation table is composed of compass errors at different headings and was used in real time during subsequent missions to correct the compass heading on the fly. According to the manufacturer, a properly calibrated compass can reduce underwater offline drift (drift equals accumulated error) to 0.5 percent of the underwater run length ( $5 \mathrm{ft}$ drift for 1,000 ft underwater run). Based on past experience, field calibrations have produced underwater drift errors of approximately 1 percent of the underwater run. Because the underwater mission paths were shorter than what the manufacturer recommended, mission underwater run lengths were reduced to keep drift low. Following USGS calibration guidelines, within 24 hours after the deployment, the water-quality sensors on the AUV were rechecked for fouling and electronic drift. Sensor drift due to fouling was not an issue because of the short period of time the AUV was submerged.

\section{EcoMapper Post-Deployment Data Processing}

Raw data files from the AUV include a LOG file (*.log) consisting of georeferenced and time-stamped data from the AUV and onboard sensors in a semicolon-delimited data format. Data include navigation data (waypoint number, speed, heading, depth, altitude, latitude, longitude), vehicle data (pitch, roll, yaw, prop speed, fin settings, dive angle), bathymetry data (water-column depth), and water-quality data 
(temperature, specific conductance, $\mathrm{pH}$, dissolved oxygen, turbidity) from the installed sensors. All data in the LOG file are recorded at a sampling rate of $1 \mathrm{~Hz}$.

In addition to the LOG file, the AUV creates DVL (*.dvl) and PFD (*.pfd) data files. The DVL file contains timestamped series of vehicle position and DVL output. The DVL outputs in this file are related to distance traveled, speed, and range to bottom. In addition, this file contains bottom-track quality indicators to assess quality of the bottom-track data. The PFD data files contain water-velocity profile data as measured by the DVL below the instrument. The velocities contained in this file are organized by cell, or range from the transducers, and have not been corrected for depth or speed of the instrument, heading, pitch, or roll. Therefore, these files contain a very basic form of the velocity-profile data and must be post-processed to obtain meaningful, georeferenced, water-velocity data.

All data are post-processed by using a suite of custom Matlab scripts. This process is detailed in figure 1-3. The processing begins with applying corrections to position and depth. Corrections to the positional data include correction of the vehicle track for underwater drift during dives. Drift generally is induced by compass error or improper calibration and is identified by screening the vehicle track for jumps in position greater than $5 \mathrm{~m}$ in 1 second. Jumps generally will occur when the vehicle surfaces and corrects its position on the basis of GPS data in its track log. Any identified underwater drift is corrected by applying a linear correction between the dive point and the surface point assuming a constant heading and speed. Following the drift correction, a depth correction is applied to the total water column depth to account for the offset of the downlooking vertical beam from the water surface. The time-series data are plotted and then screened manually to identify outliers and remove them from the dataset (fig. $1-4 A$ and $1-4 B$ ). Outliers are identified as individual measurements made at a 1 -second interval that have large deviations from the surrounding points (spikes) that are uncharacteristic of a natural system in which shape gradients are normally smoothed by turbulence and diffusion. Once all outliers have been removed, the user has the option to smooth the time-series data for each variable independently (fig. 1-4C). This process generally is applied only to turbidity,

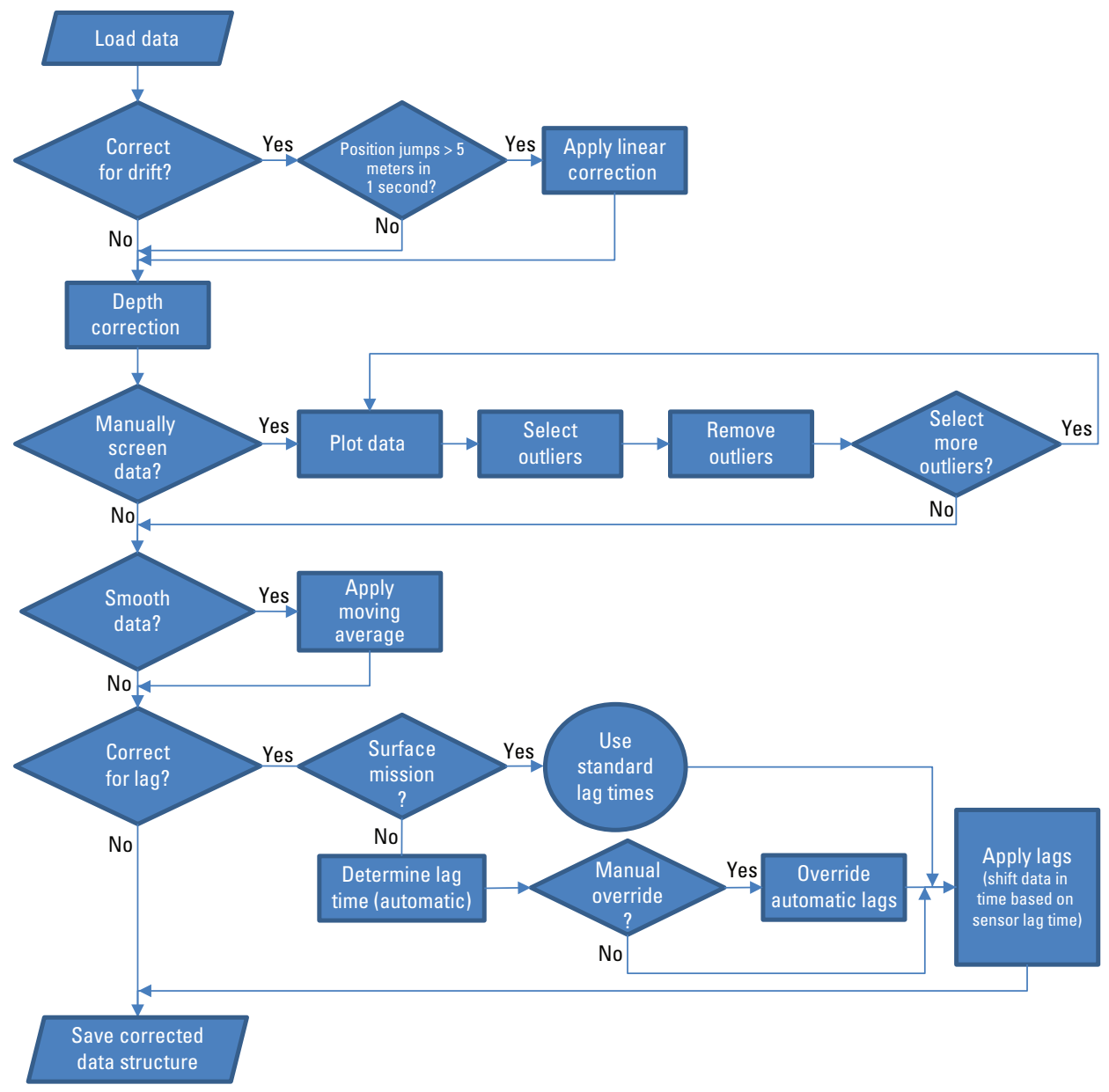

Figure 1-3. Data processing algorithm for LOG files from the autonomous underwater vehicle From Jackson (2013a). [>, greater than] 

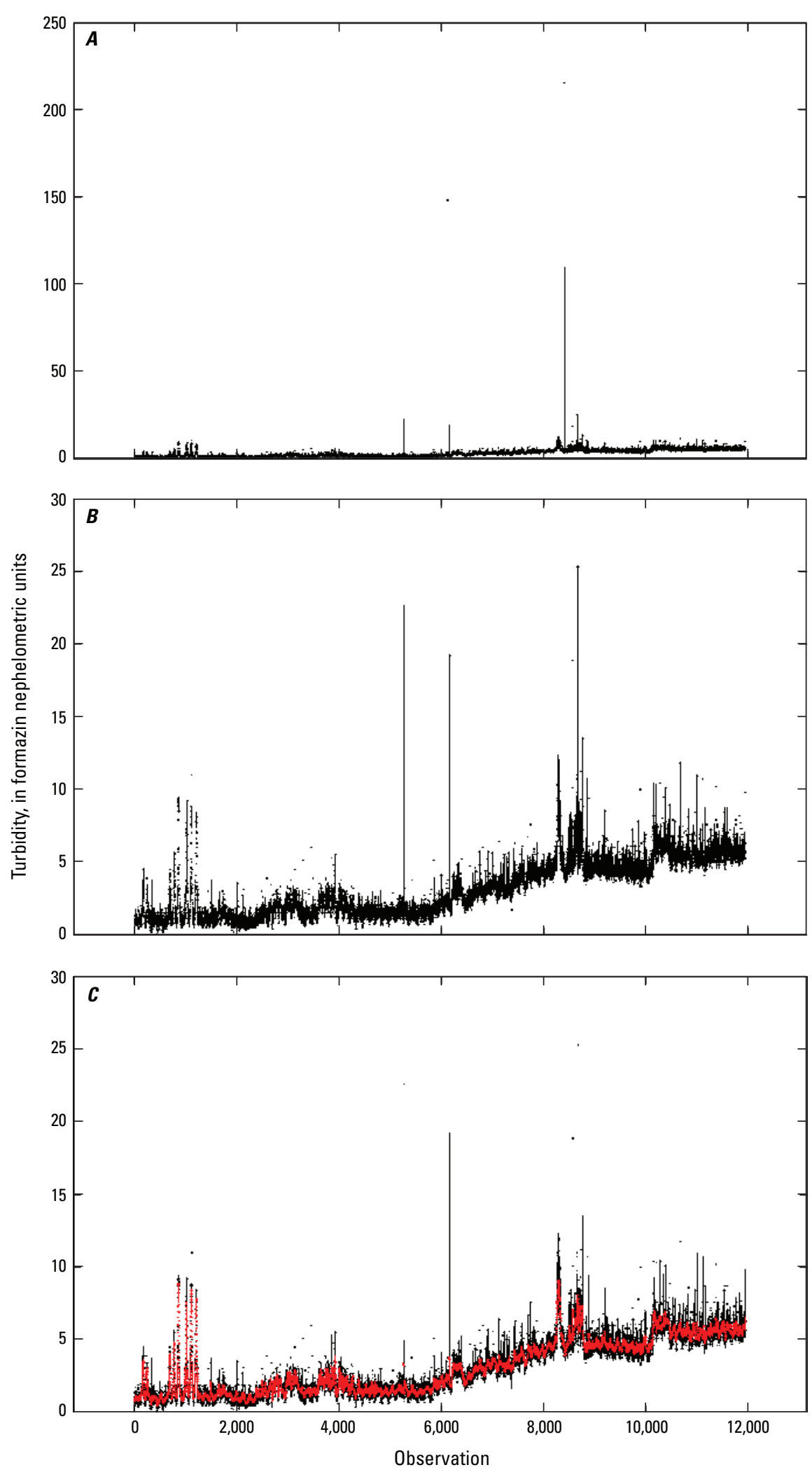

Figure 1-4. Data processing steps: $(A)$ original data, $(B)$ outliers removed, and $(C)$ smoothed time-series data. Note scale change between plots $A$ and $B$. 
chlorophyll, and blue-green algae data, as these data tend to be noisy. During smoothing, a moving average is applied to the data with a user-defined window size. The user, through an iterative process, chooses the window size such that noise is minimized, yet true oscillations of the dataset are maintained.

The final step, if required, in this processing routine is to apply temporal lags to measurements made by each waterquality sensor to account for lags in the sensor response time. Standard lag times have been provided by YSI on the basis of laboratory tests of response time; however, the processing code also determines an empirical lag for each sensor when vertical profile data are available from diving missions. To determine these lag constants, the data for each sensor are plotted as a function of depth, and the variance of the data cloud is computed. Because a lag in the sensor response time will lead to larger variance in a sensor for a given depth, the code seeks to minimize the variance in the sensor by applying a range of lag times to the data and recomputing the variance at each step. The lag time that produces the minimum variance in the vertical profile of each sensor is chosen as the suggested lag time. The user can then override the computed lag times with manual entries of standard values. Once lag times are determined, each sensor is shifted in time by the appropriate lag time. Standard lag times for each of the sensors are given in table 4 (main text of report). The corrected dataset is then saved as a Matlab data structure, which can be used as input for additional processing and visualization scripts.

\section{References Cited in Appendix 1}

Jackson, P.R., 2013a, Circulation, mixing, and transport in nearshore Lake Erie in the vicinity of Villa Angela Beach and Euclid Creek, Cleveland, Ohio, September 11-12, 2012: U.S. Geological Survey Scientific Investigations Report 2013-5198, 34 p., accessed November 16, 2017, at https://doi.org/10.3133/sir20135198.

Jackson, P.R., 2013b, Integrated synoptic surveys using an autonomous underwater vehicle and manned boats: U.S. Geological Survey Fact Sheet 2013-3018, 4 p., accessed February 28, 2018, at https://pubs.usgs.gov/fs/2013/3018/.

Wilde, F.D., ed., variously dated, Field measurements: U.S. Geological Survey Techniques of Water-Resources Investigations, book 9, chap. A6, with sec. 6.0-6.8, accessed August 18, 2015, at https://pubs.water.usgs.gov/twri9A6/.

Vector Map, 2015, Vector Map version 7.0.4 software: Fall River, Mass., OceanServer Technology, Inc.

YSI, Inc., 2010, Ecomapper autonomous underwater vehicle, YSI, Incorporated Datasheet, 4 p., accessed February 28, 2018, at https://www.xylem-analytics.com.au/media/pdfs/ e87-ecomapper-autonomous-underwater-vehicle.pdf.

YSI, Inc., 2011, 6-Series Multiparameter Water Quality Sondes User Manual: YSI, Incorporated, accessed March 15, 2012, at https://www.ysi.com/File\%20Library/ Documents/Manuals/069300-YSI-6-Series-Manual-RevJ.pdf. 


\section{Appendix 2. Plots showing 2D longitudinal profiles for seven parameters for 16 autonomous underwater vehicle water-quality surveys}
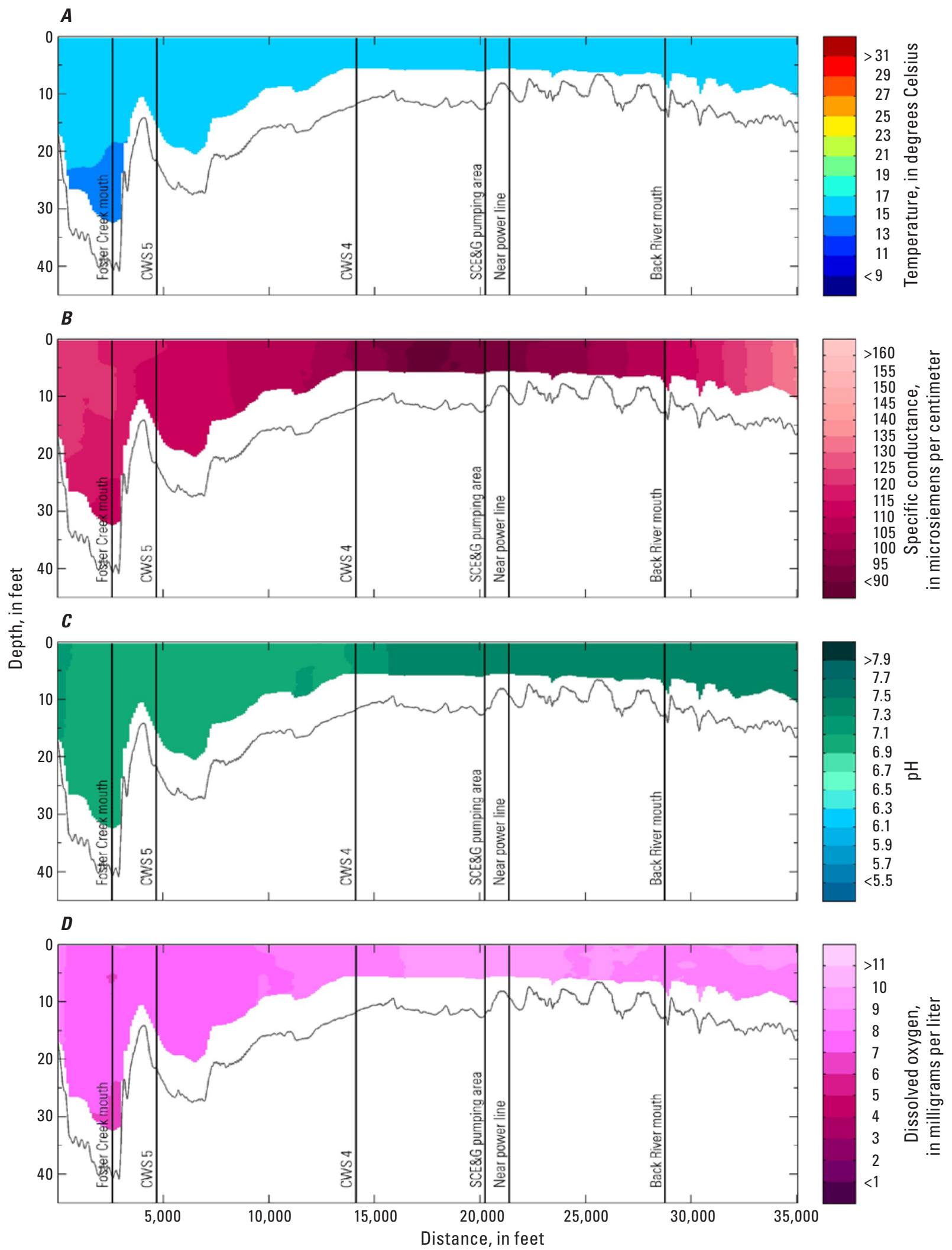

Figure 2-1. Longitudinal plots of $(A)$ water temperature, $(B)$ specific conductance, $(C) \mathrm{pH}$, and $(D)$ dissolved oxygen at Bushy Park Reservoir, November 11, 2013. 

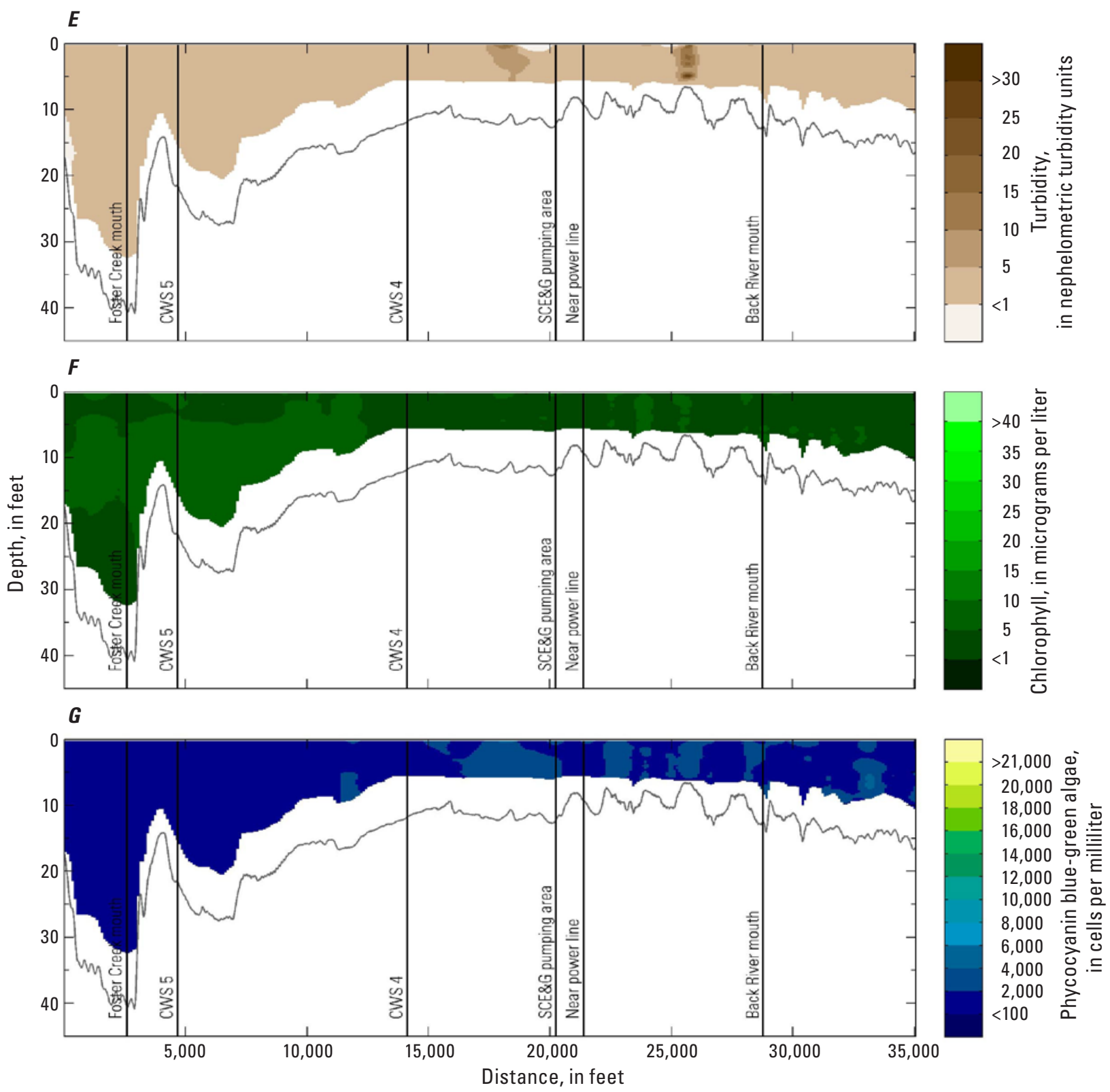

Figure 2-1. (Continued) Longitudinal plots of $(E)$ turbidity, $(F)$ total chlorophyll fluorescence estimated as micrograms per liter, and $(G)$ phycocyanin fluorescence, estimated as blue-green algae, in cells per milliliter at Bushy Park Reservoir, November 11, 2013. 

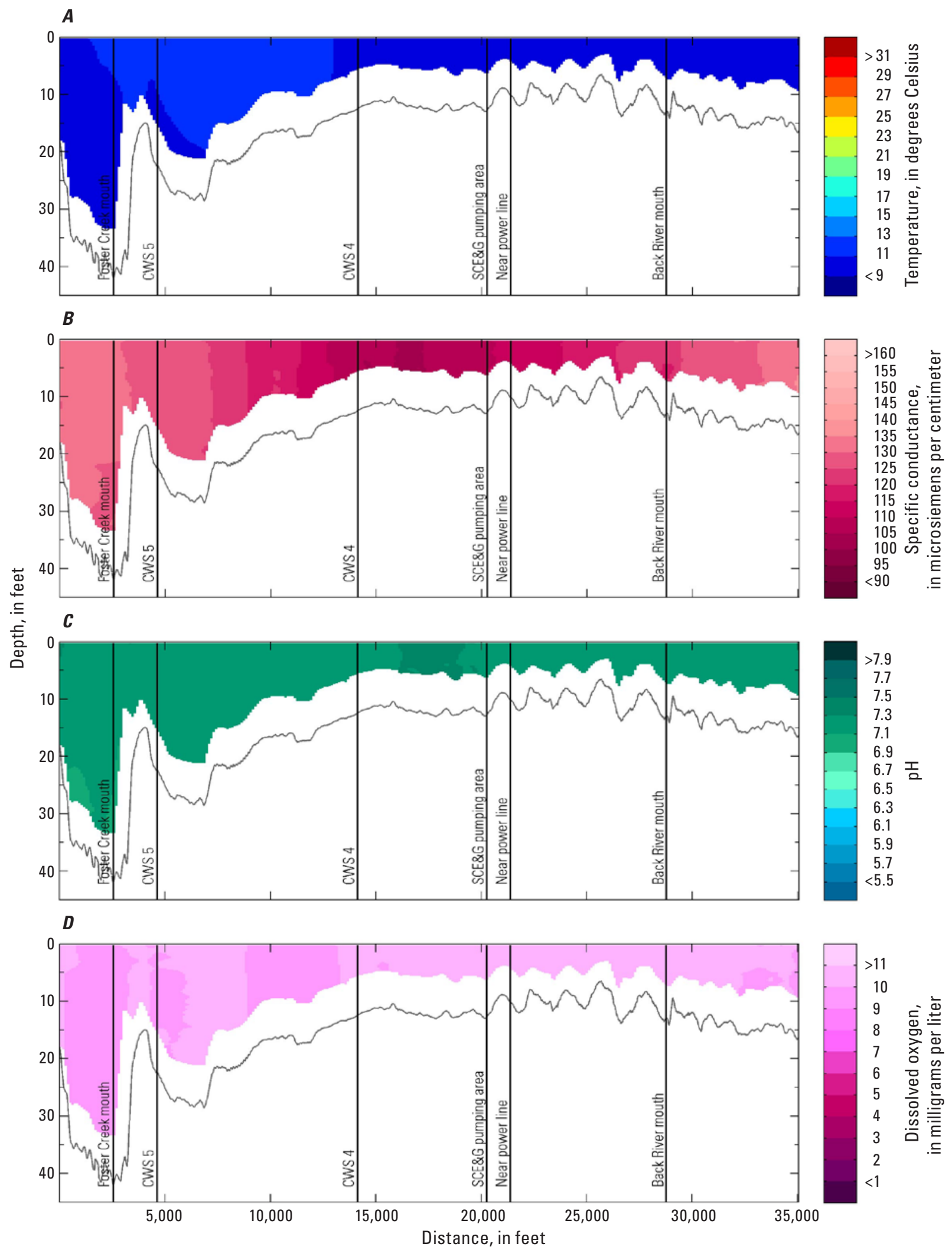

Figure 2-2. Longitudinal plots of $(A)$ water temperature, $(B)$ specific conductance, $(C) \mathrm{pH}$, and $(D)$ dissolved oxygen at Bushy Park Reservoir, January 14, 2014. 

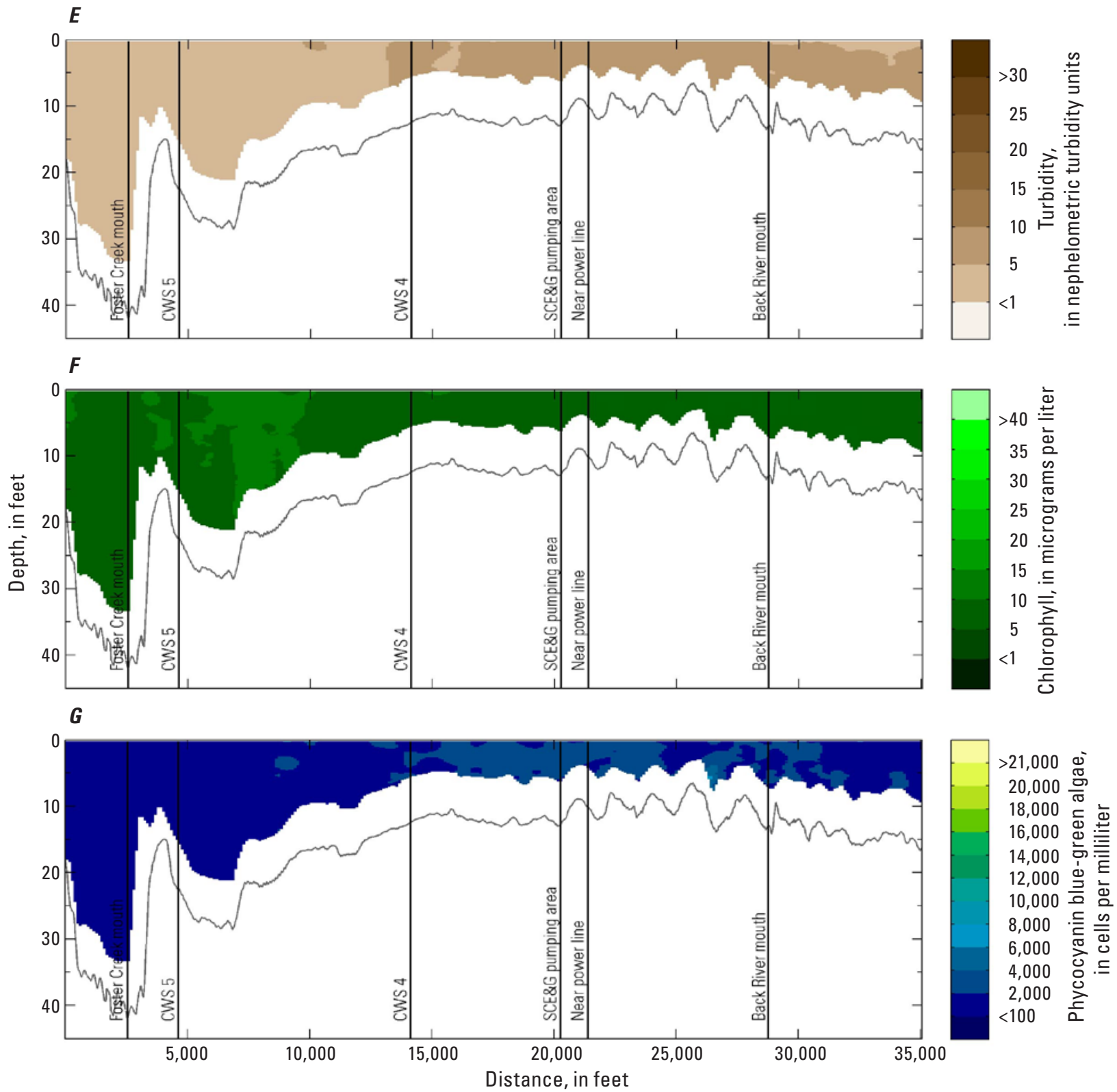

Figure 2-2. (Continued) Longitudinal plots of $(E)$ turbidity, $(F)$ total chlorophyll fluorescence estimated as micrograms per liter, and $(G)$ phycocyanin fluorescence, estimated as blue-green algae, in cells per milliliter at Bushy Park Reservoir, January 14, 2014. 

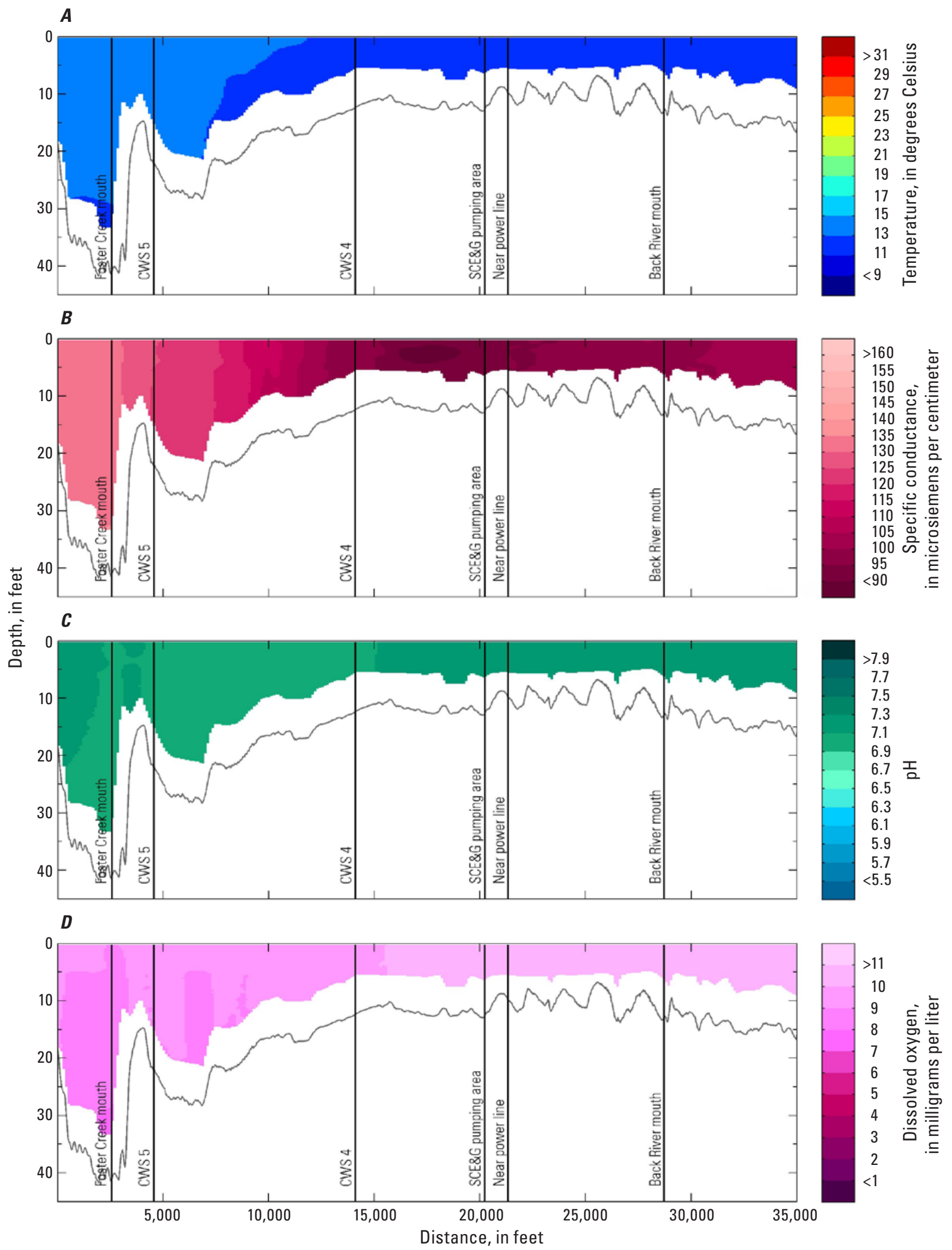

Figure 2-3. Longitudinal plots of $(A)$ water temperature, $(B)$ specific conductance, $(C) \mathrm{pH}$, and $(D)$ dissolved oxygen at Bushy Park Reservoir, March 27, 2014. 

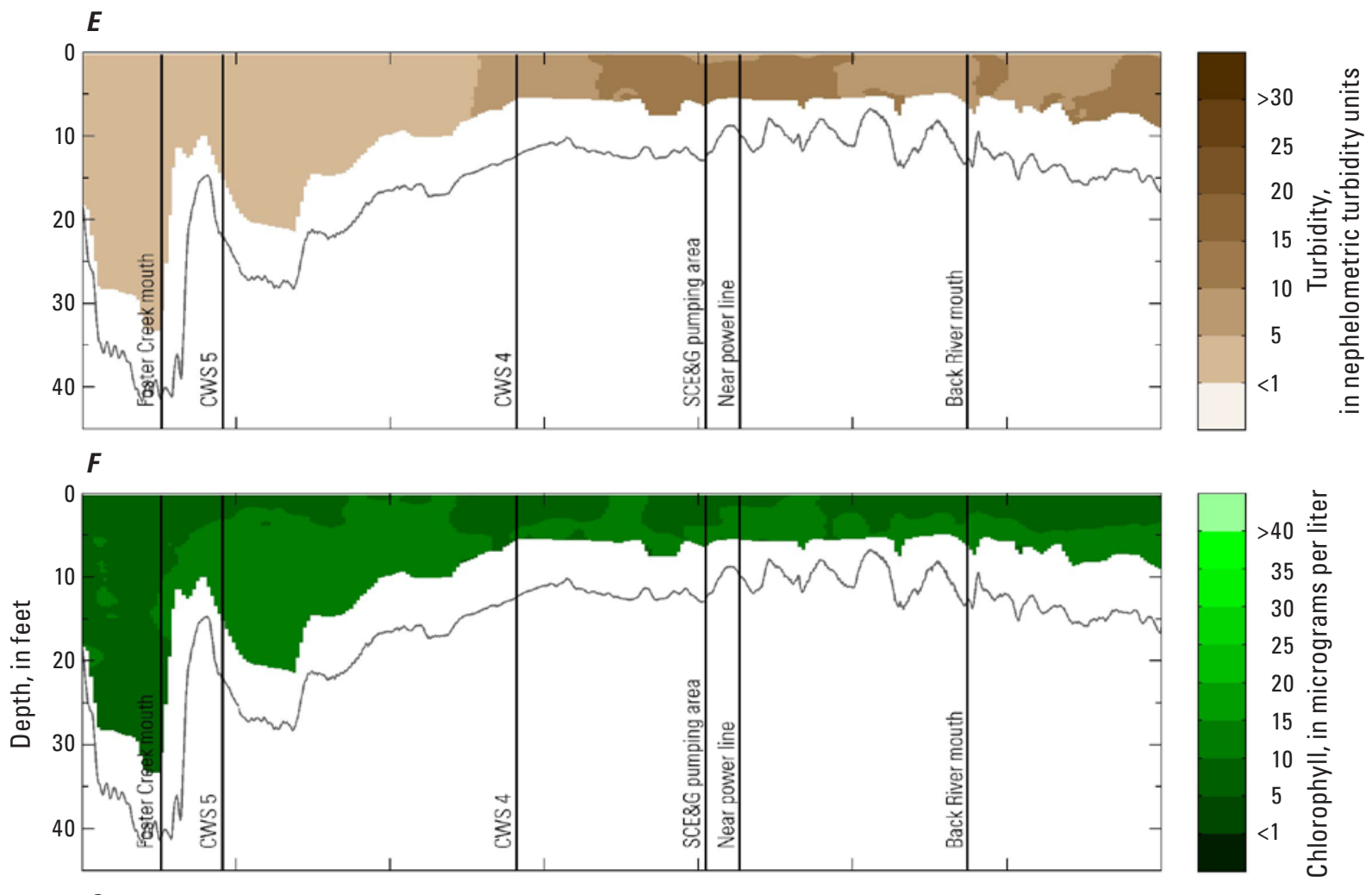

G

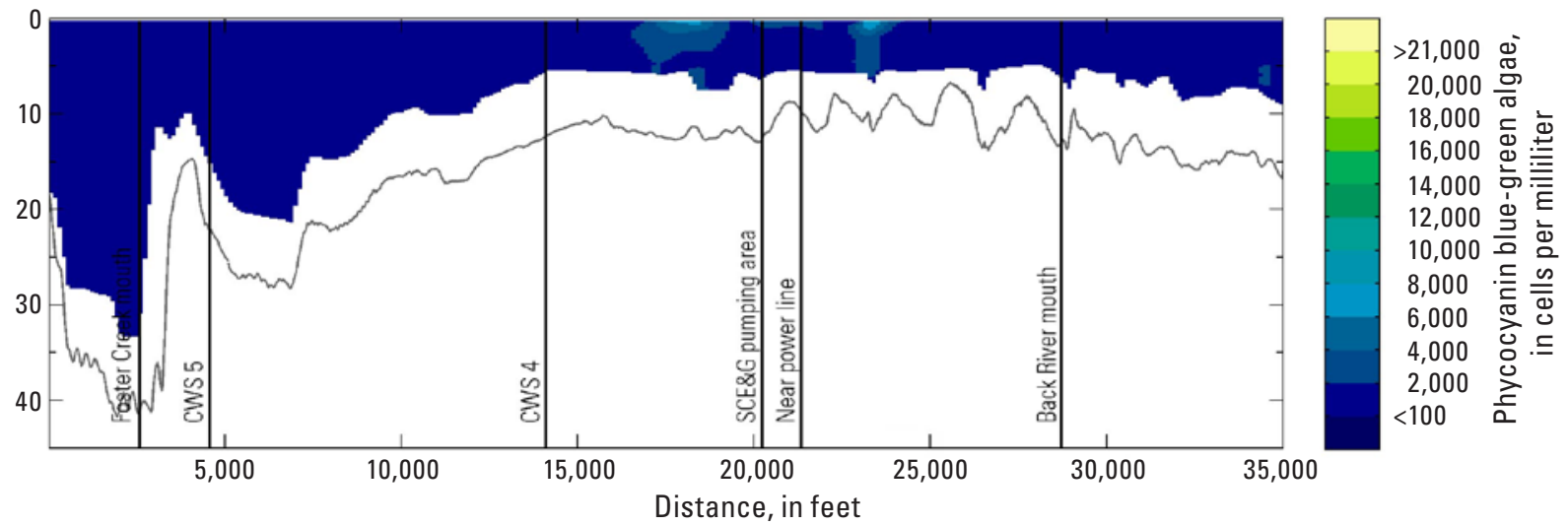

Figure 2-3. (Continued) Longitudinal plots of $(E)$ turbidity, $(F)$ total chlorophyll fluorescence estimated as micrograms per liter, and $(G)$ phycocyanin fluorescence, estimated as blue-green algae, in cells per milliliter at Bushy Park Reservoir, March 27, 2014. 


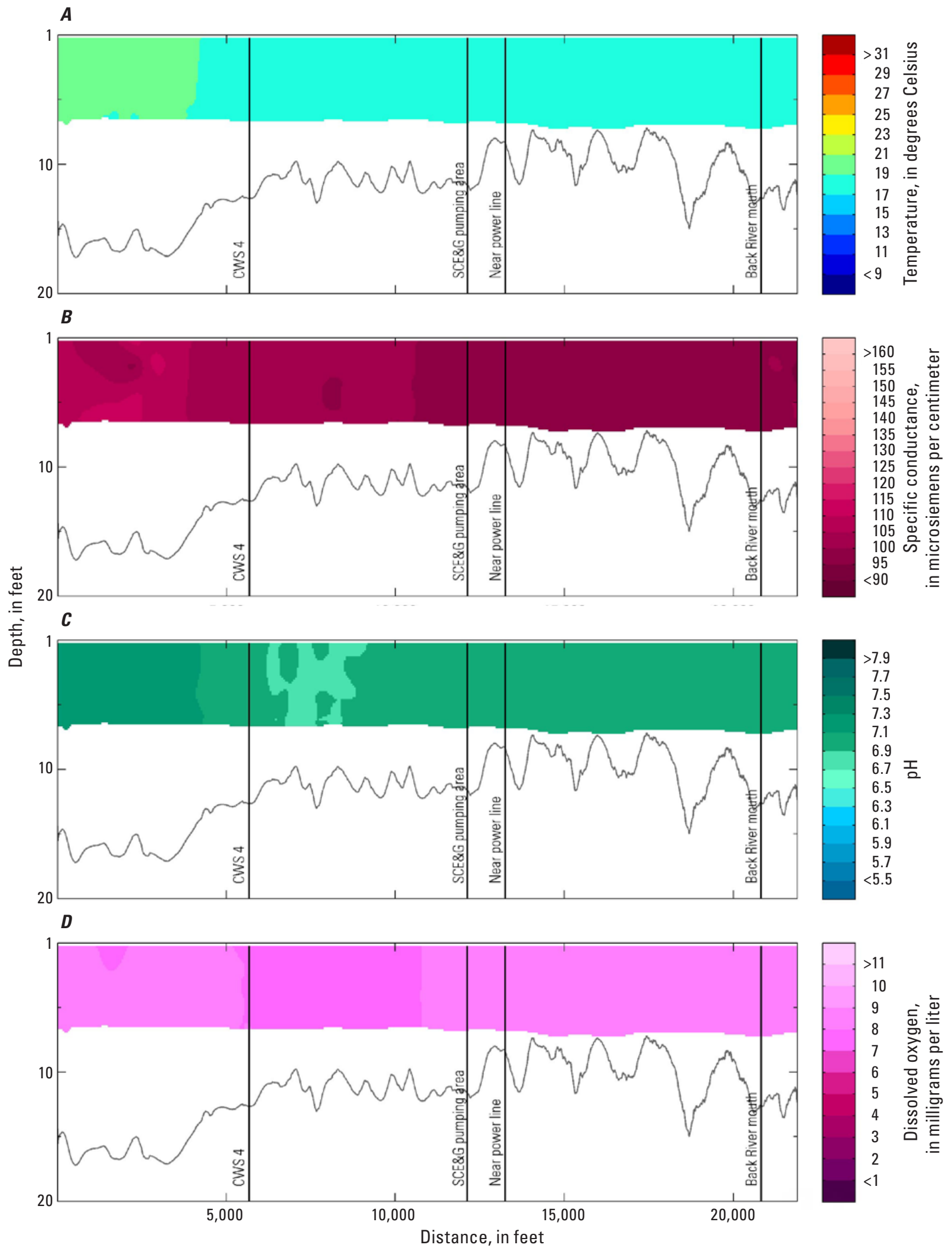

Figure 2-4. Longitudinal plots of $(A)$ water temperature, $(B)$ specific conductance, $(C) \mathrm{pH}$, and $(D)$ dissolved oxygen at Bushy Park Reservoir, April 16, 2014. 


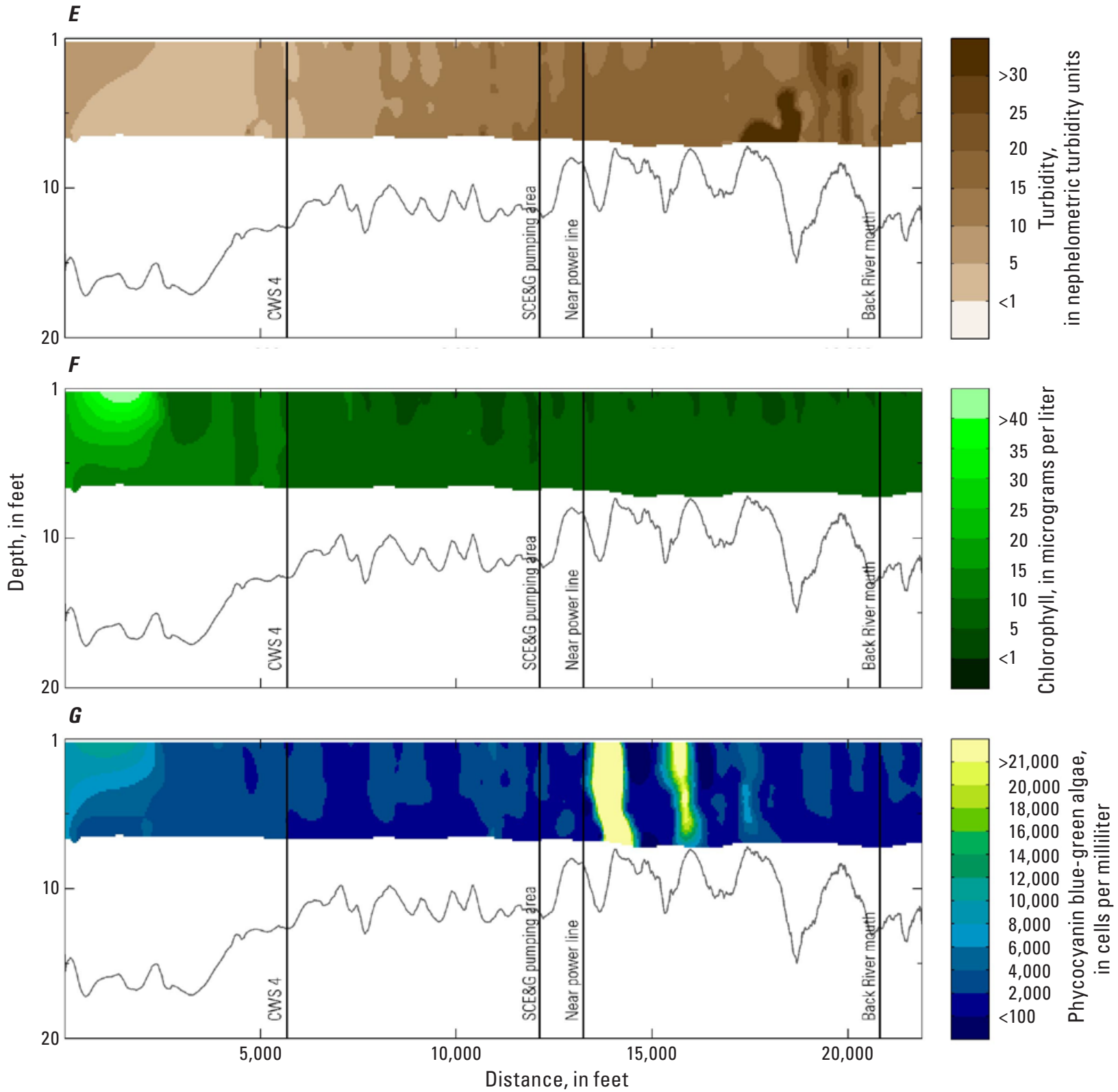

Figure 2-4. (Continued) Longitudinal plots of $(E)$ turbidity, $(F)$ total chlorophyll fluorescence estimated as micrograms per liter, and $(G)$ phycocyanin fluorescence, estimated as blue-green algae, in cells per milliliter at Bushy Park Reservoir, April 16, 2014. 

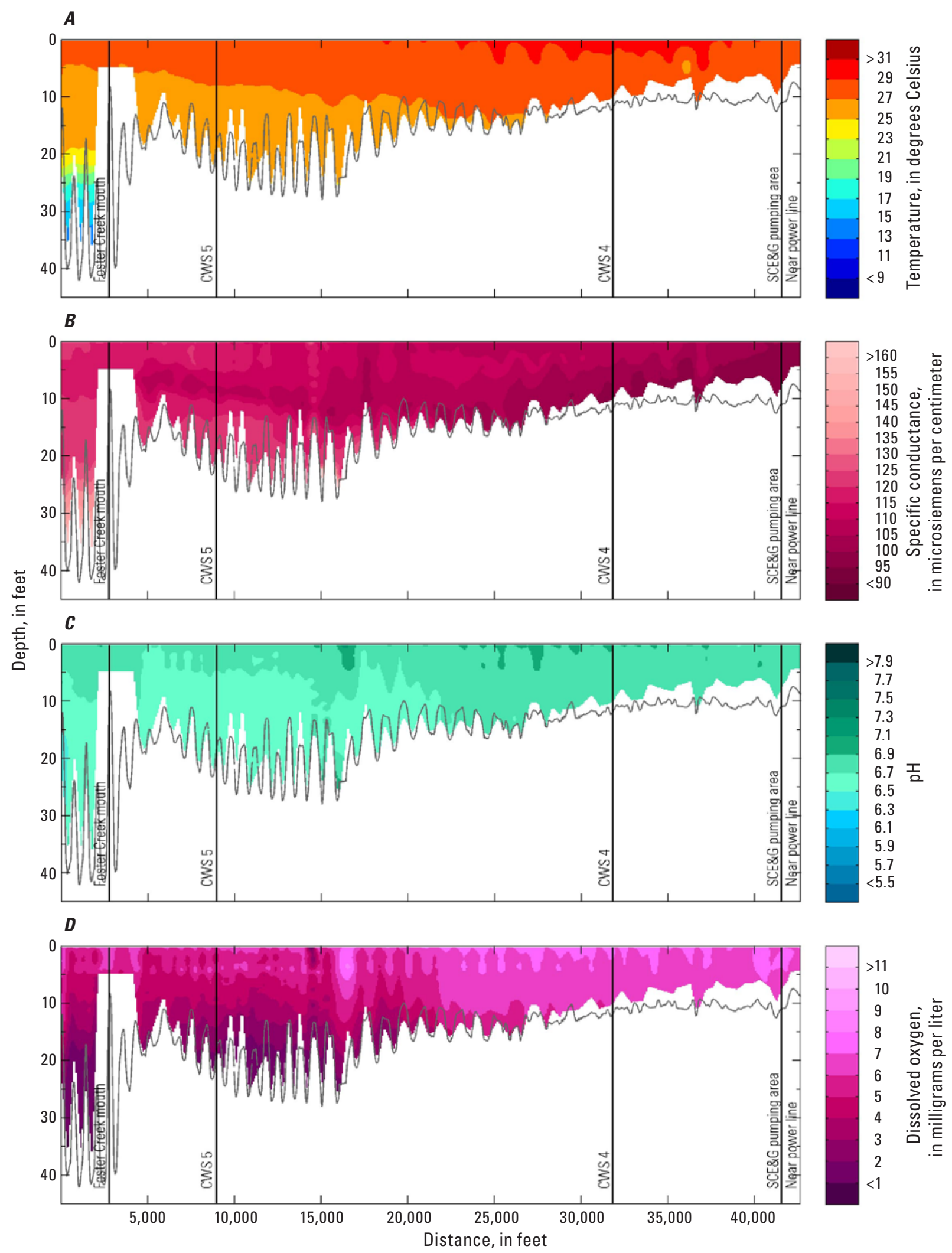

Figure 2-5. Longitudinal plots of $(A)$ water temperature, $(B)$ specific conductance, $(C) \mathrm{pH}$, and $(D)$ dissolved oxygen at Bushy Park Reservoir, June 10, 2014. 

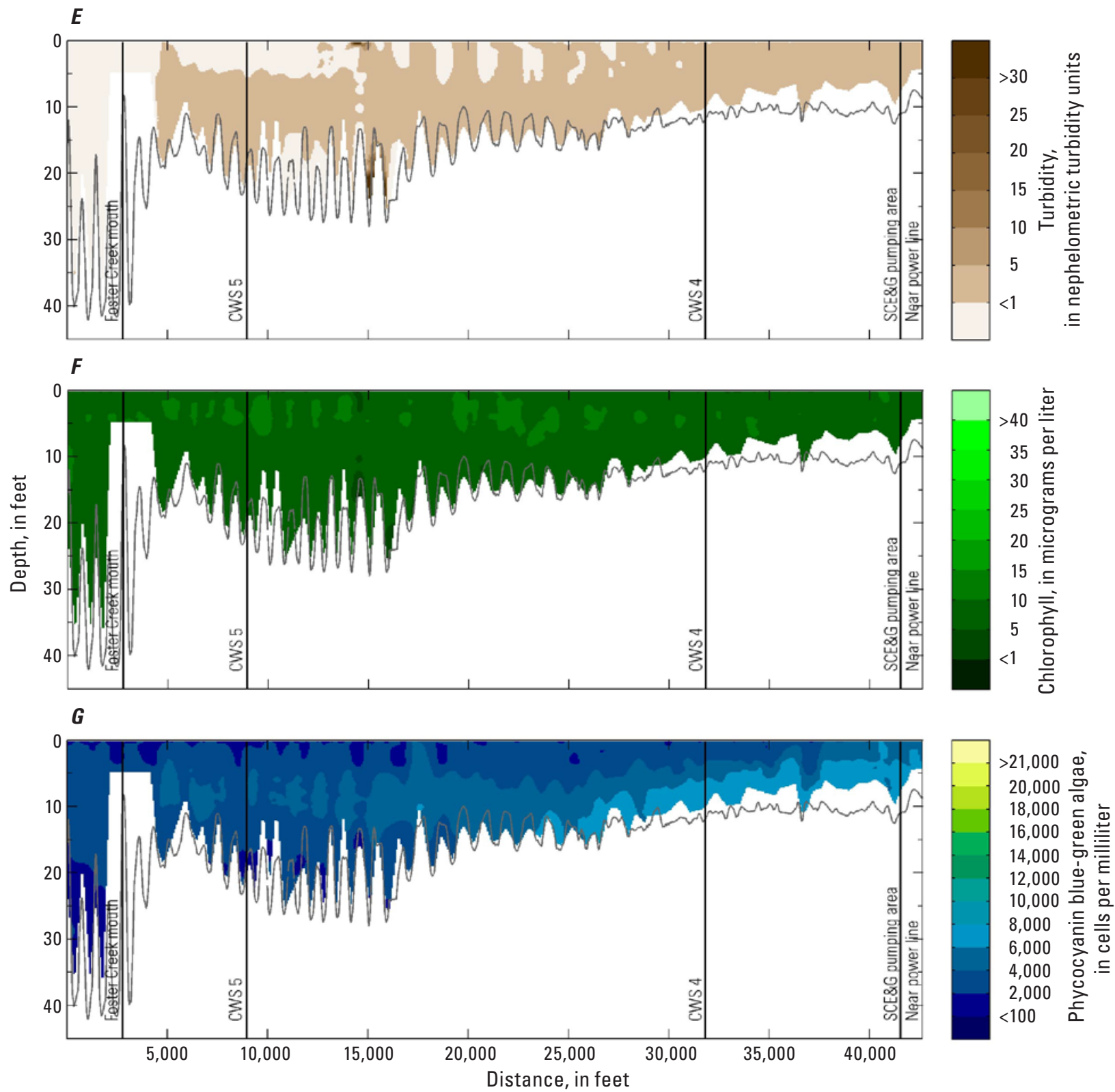

Figure 2-5. (Continued) Longitudinal plots of $(E)$ turbidity, $(F)$ total chlorophyll fluorescence estimated as micrograms per liter, and $(G)$ phycocyanin fluorescence, estimated as blue-green algae, in cells per milliliter at Bushy Park Reservoir, June 10, 2014. 

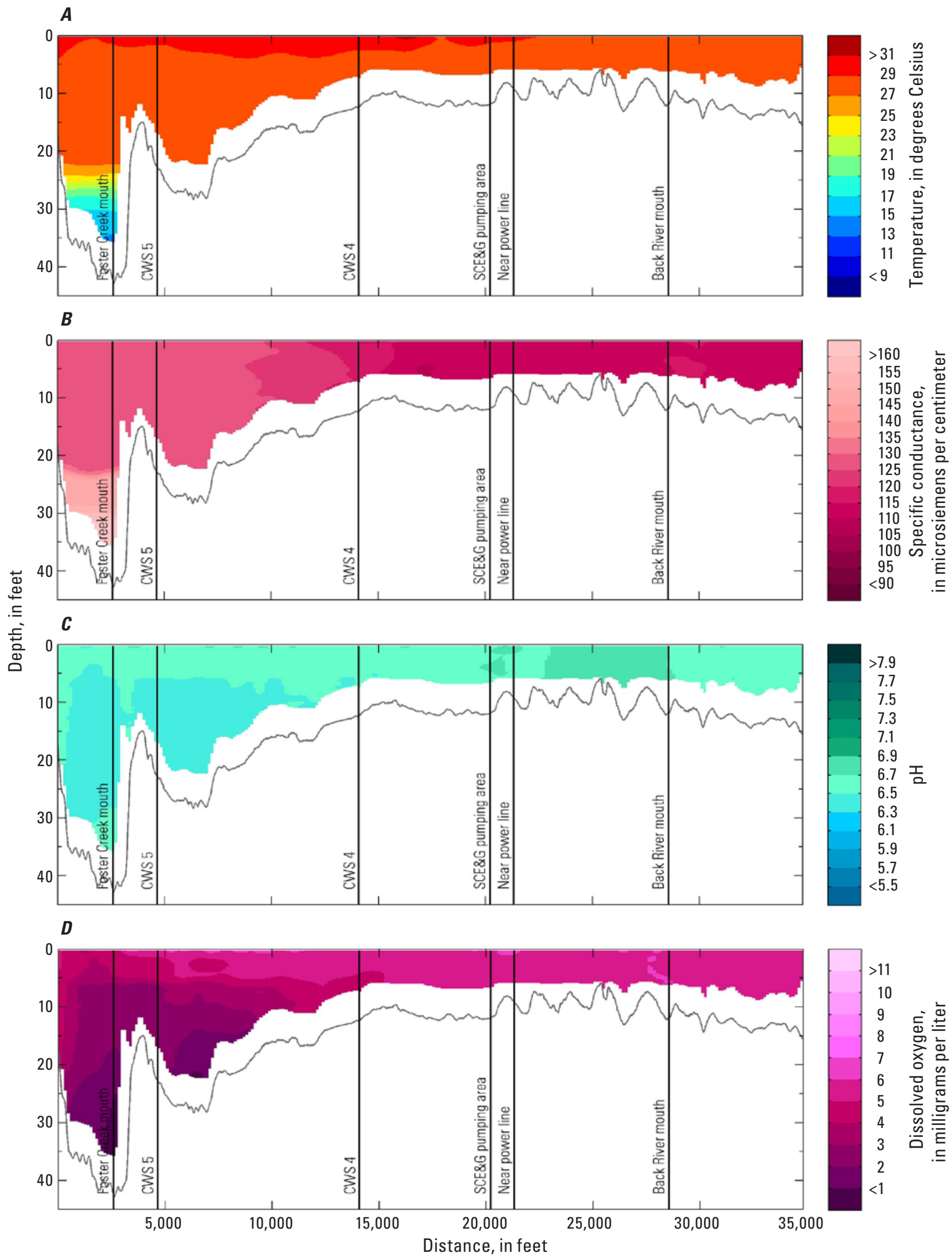

Figure 2-6. Longitudinal plots of $(A)$ water temperature, $(B)$ specific conductance, $(C) \mathrm{pH}$, and $(D)$ dissolved oxygen at Bushy Park Reservoir, July 23, 2014. 

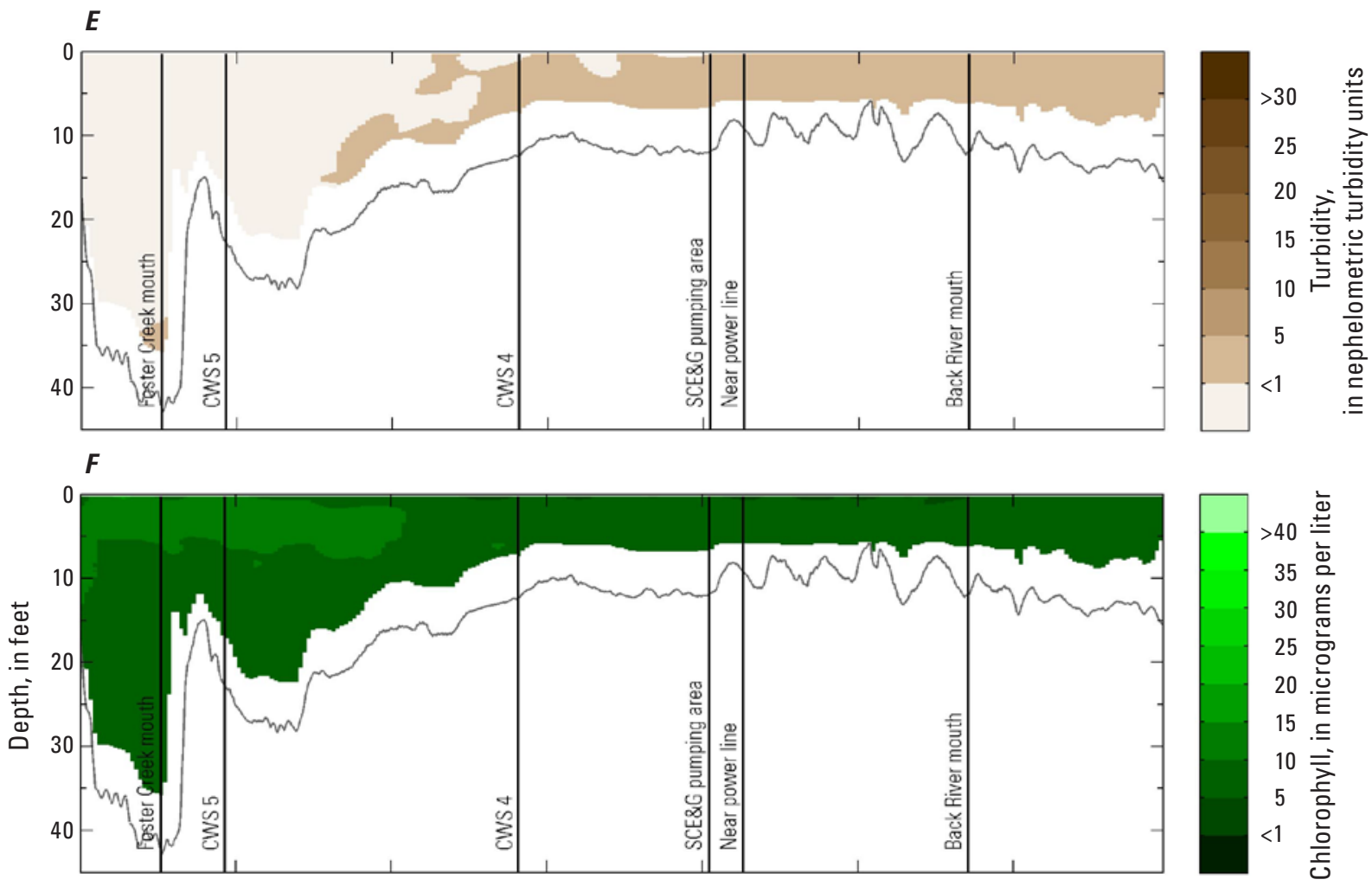

G

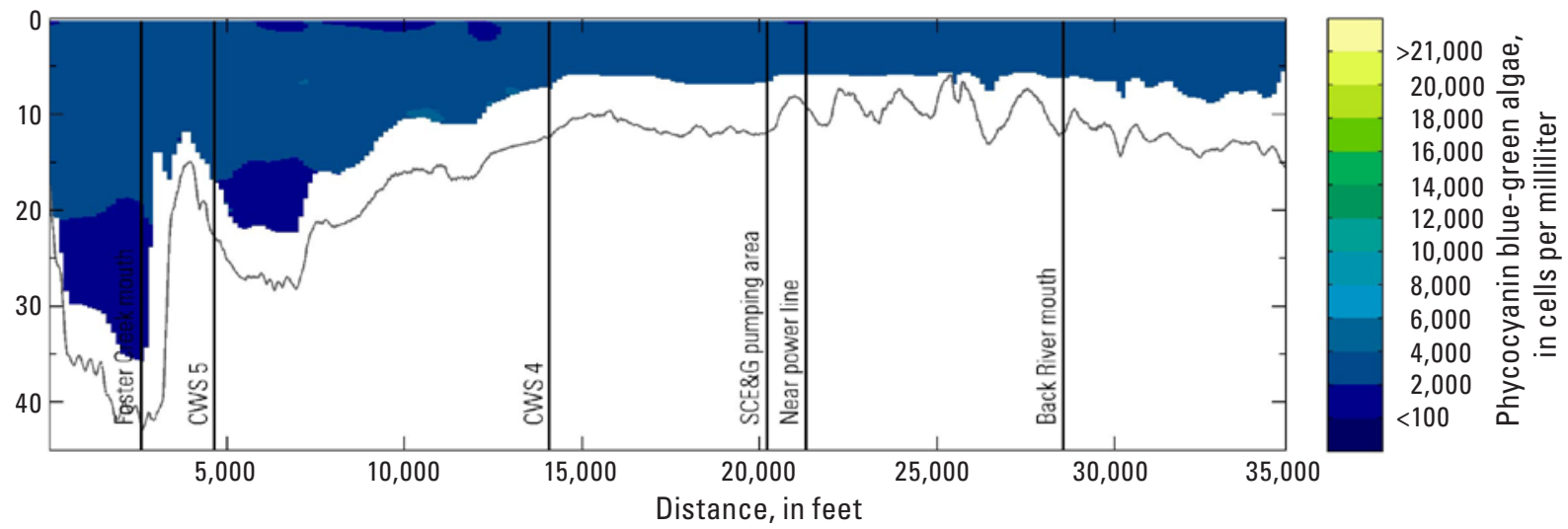

Figure 2-6. (Continued) Longitudinal plots of $(E)$ turbidity, $(F)$ total chlorophyll fluorescence estimated as micrograms per liter, and $(G)$ phycocyanin fluorescence, estimated as blue-green algae, in cells per milliliter at Bushy Park Reservoir, July 23, 2014. 

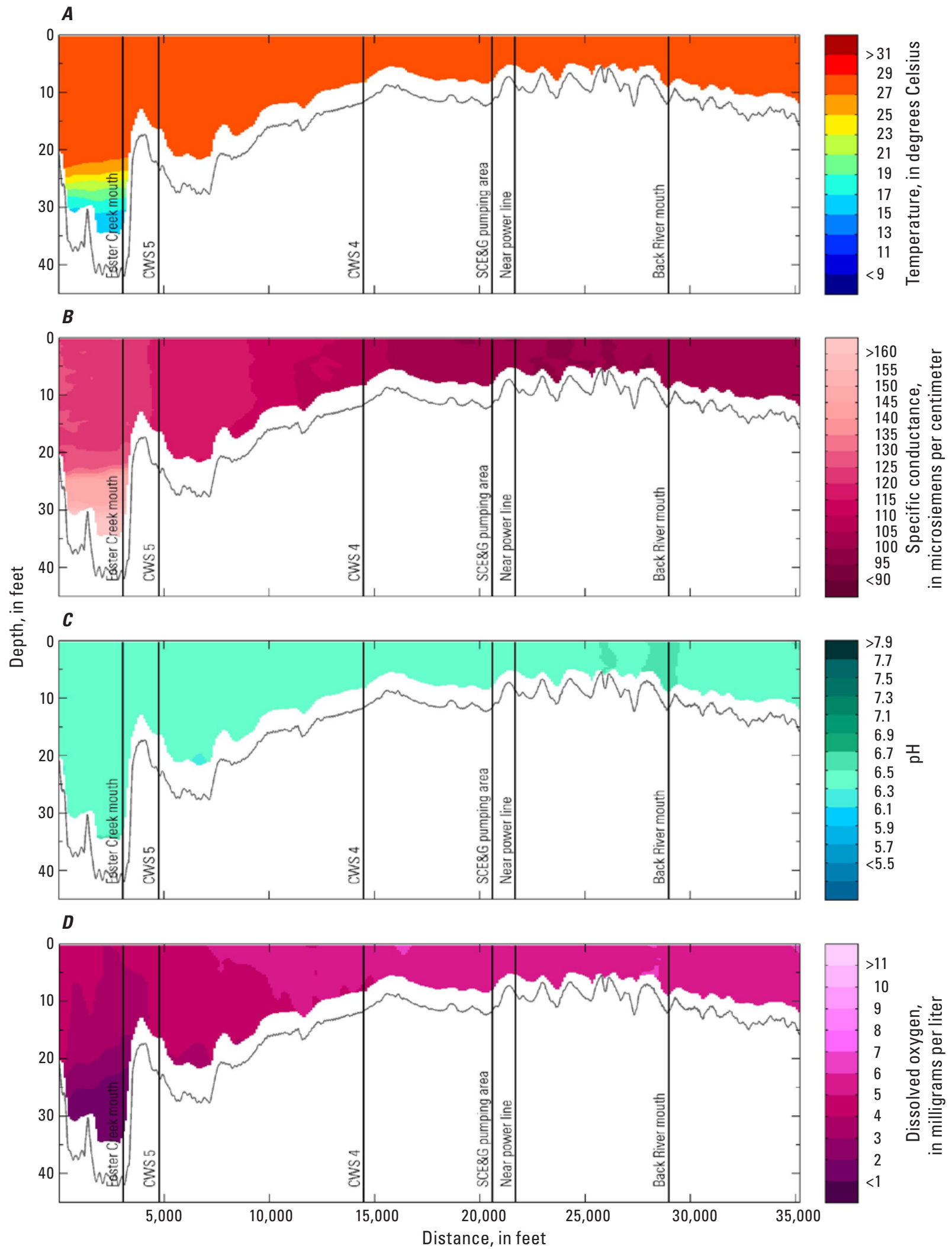

Figure 2-7. Longitudinal plots of $(A)$ water temperature, $(B)$ specific conductance, $(C) \mathrm{pH}$, and $(D)$ dissolved oxygen at Bushy Park Reservoir, August 5, 2014. 

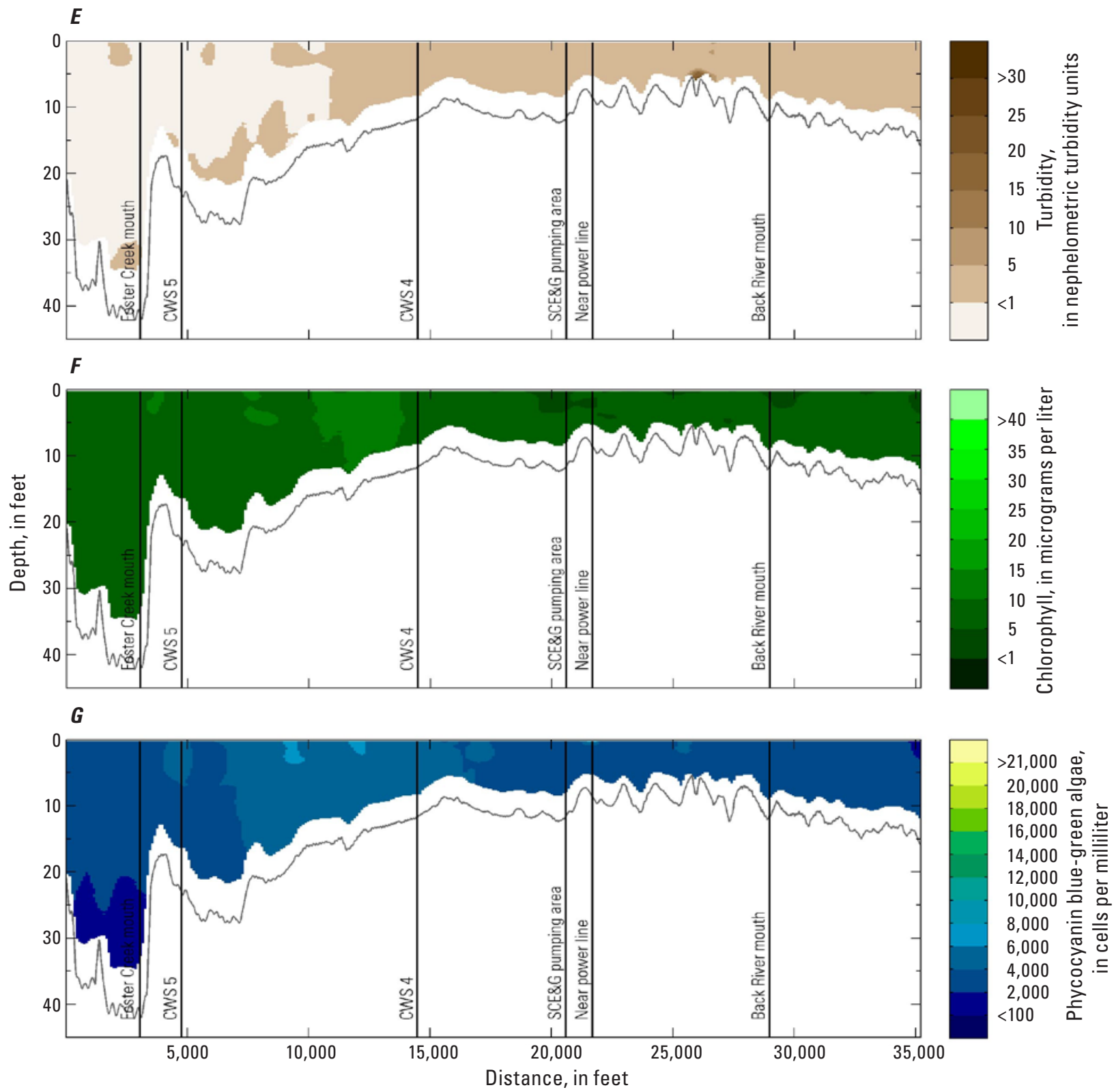

Figure 2-7. (Continued) Longitudinal plots of $(E)$ turbidity, $(F)$ total chlorophyll fluorescence estimated as micrograms per liter, and $(G)$ phycocyanin fluorescence, estimated as blue-green algae, in cells per milliliter at Bushy Park Reservoir, August 5, 2014. 

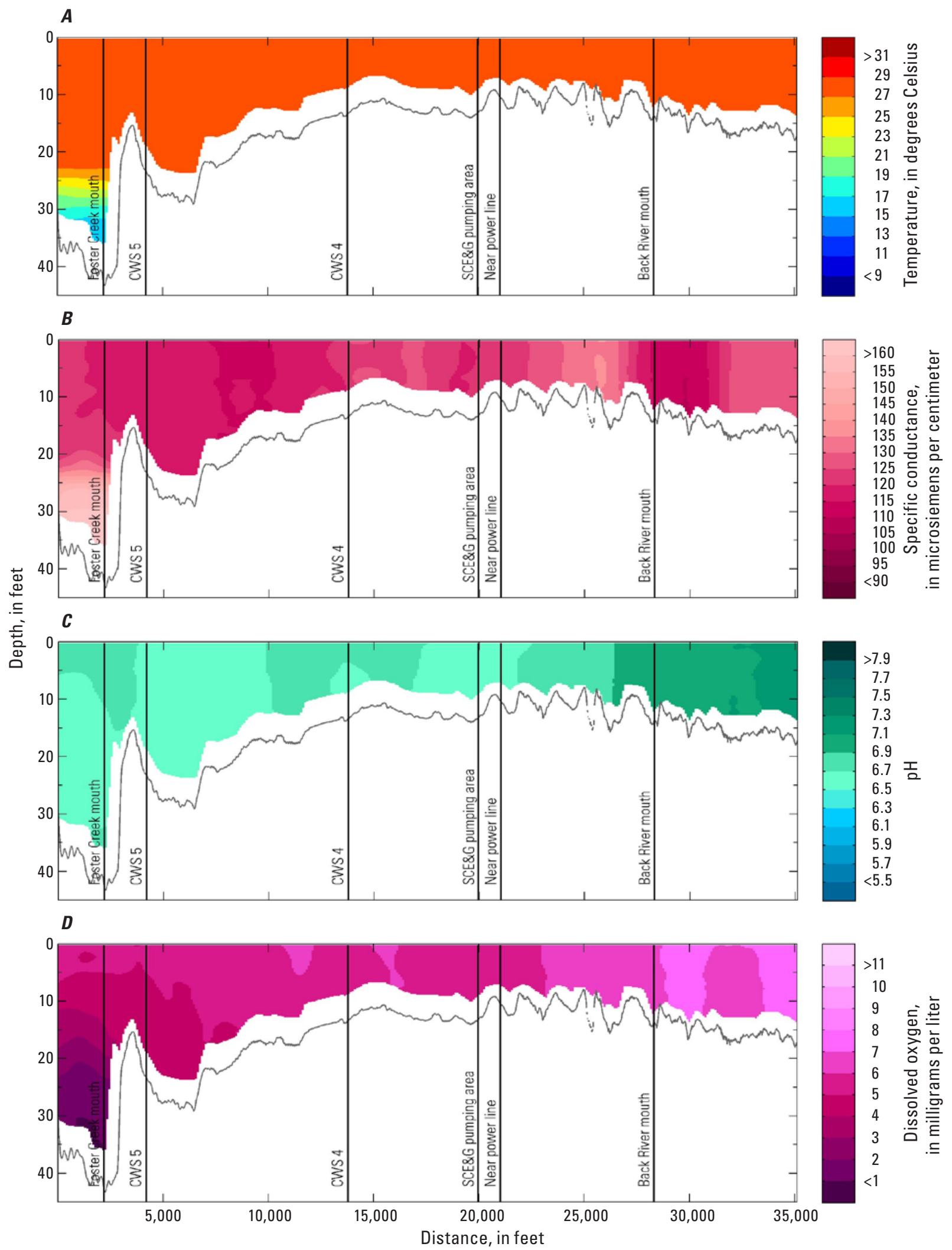

Figure 2-8. Longitudinal plots of $(A)$ water temperature, $(B)$ specific conductance, $(C) \mathrm{pH}$, and $(D)$ dissolved oxygen at Bushy Park Reservoir, August 26, 2014. 

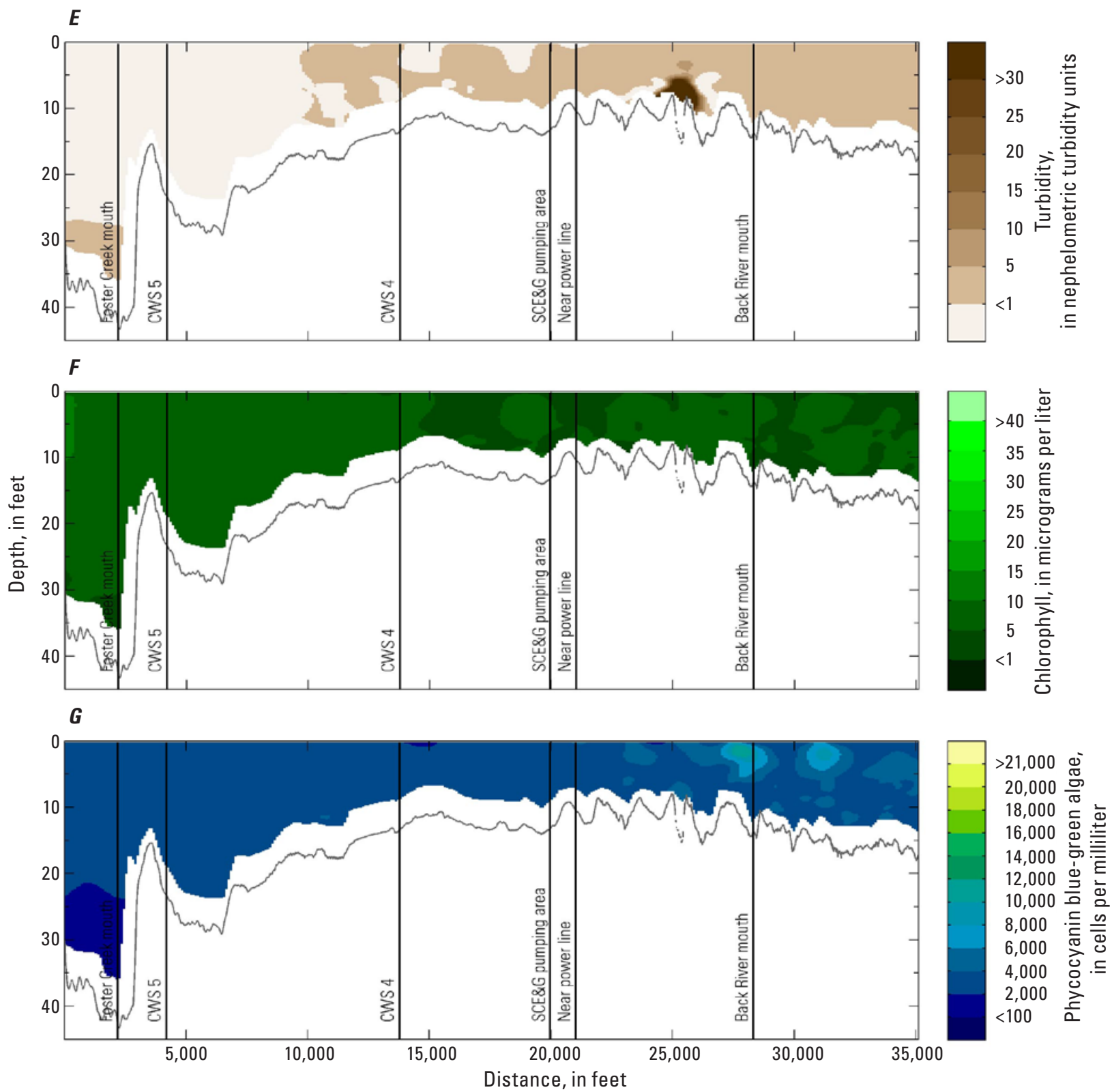

Figure 2-8. (Continued) Longitudinal plots of $(E)$ turbidity, $(F)$ total chlorophyll fluorescence estimated as micrograms per liter, and $(G)$ phycocyanin fluorescence, estimated as blue-green algae, in cells per milliliter at Bushy Park Reservoir, August 26, 2014. 

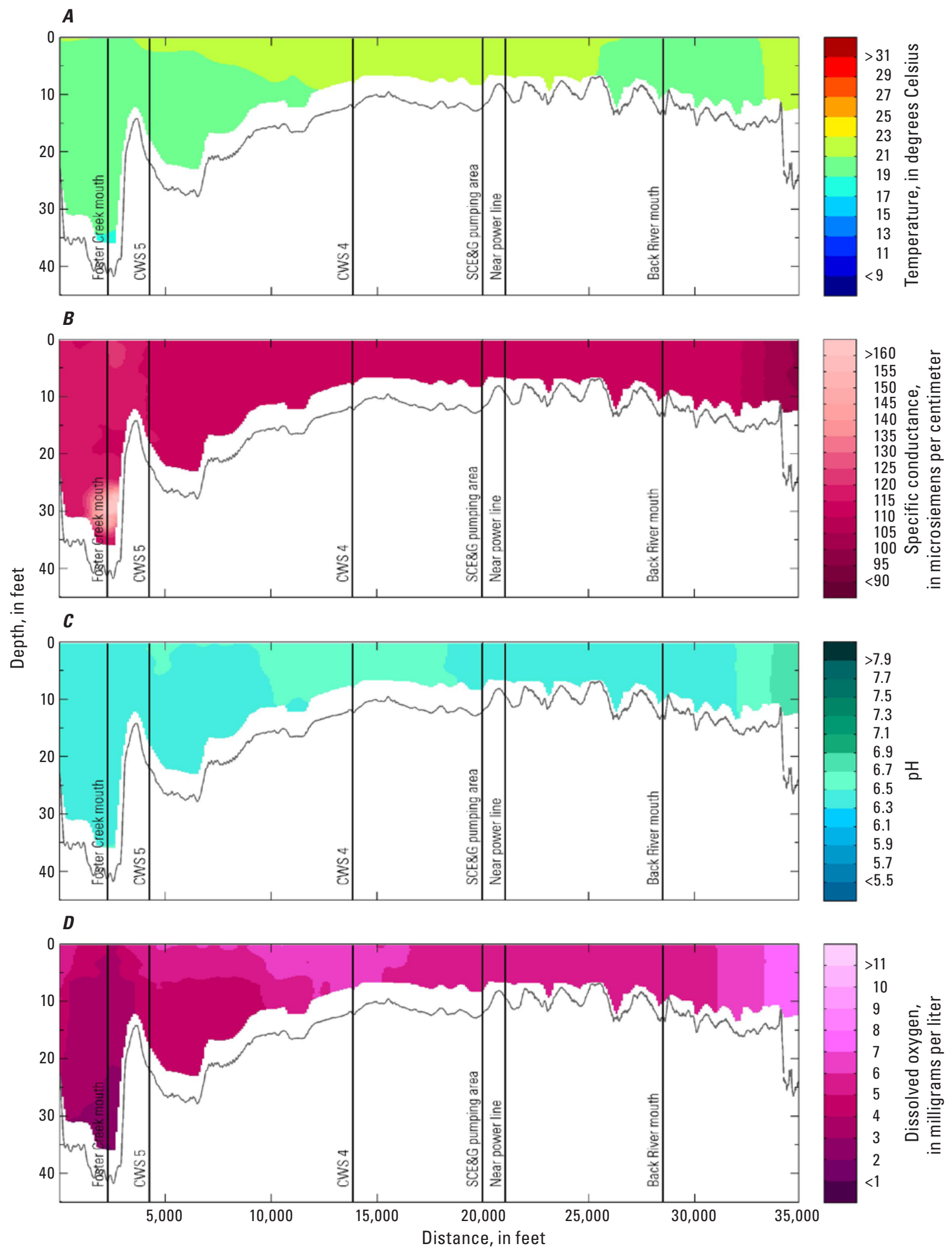

Figure 2-9. Longitudinal plots of $(A)$ water temperature, $(B)$ specific conductance, $(C) \mathrm{pH}$, and $(D)$ dissolved oxygen at Bushy Park Reservoir, October 29, 2014. 

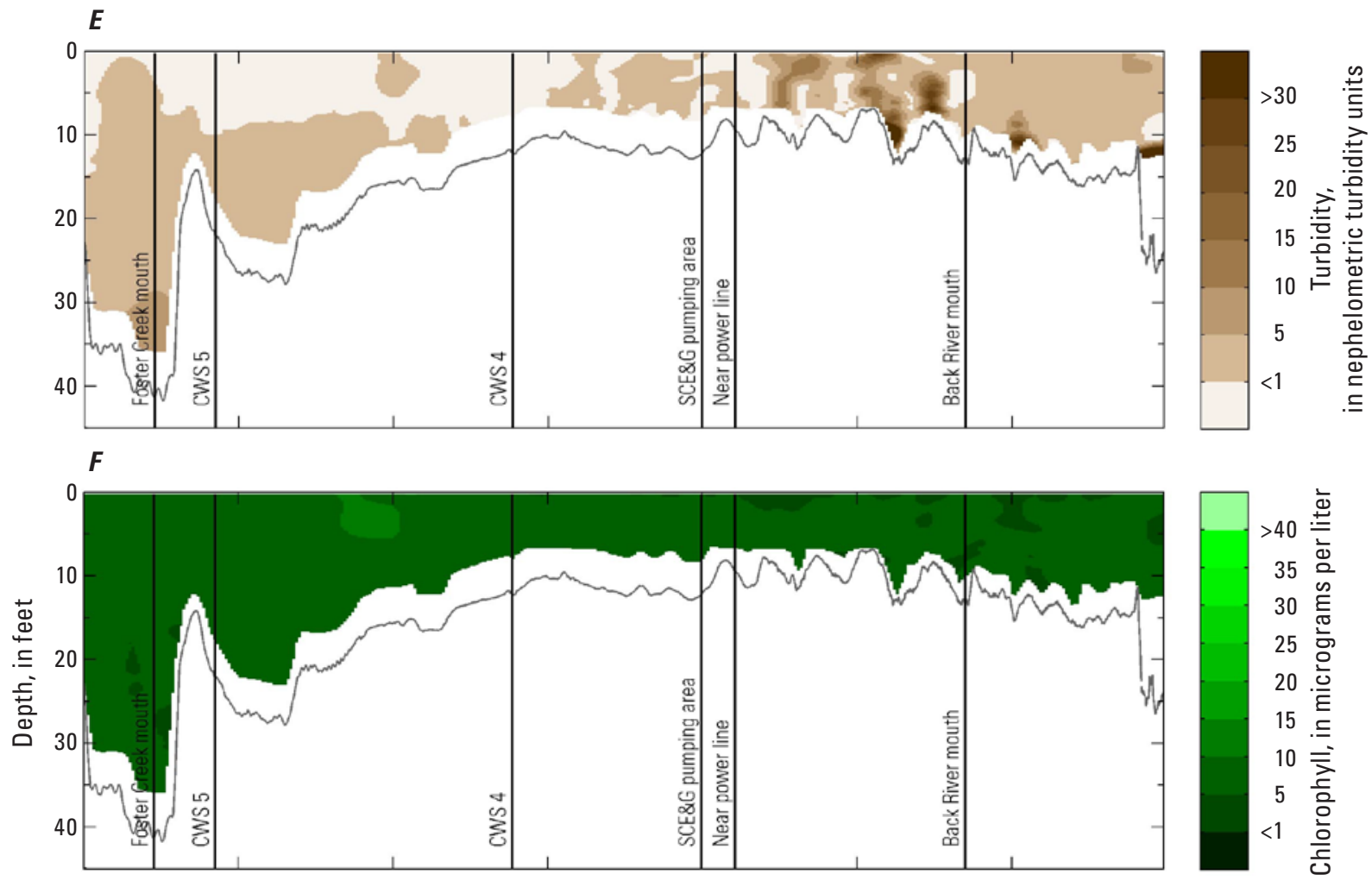

G

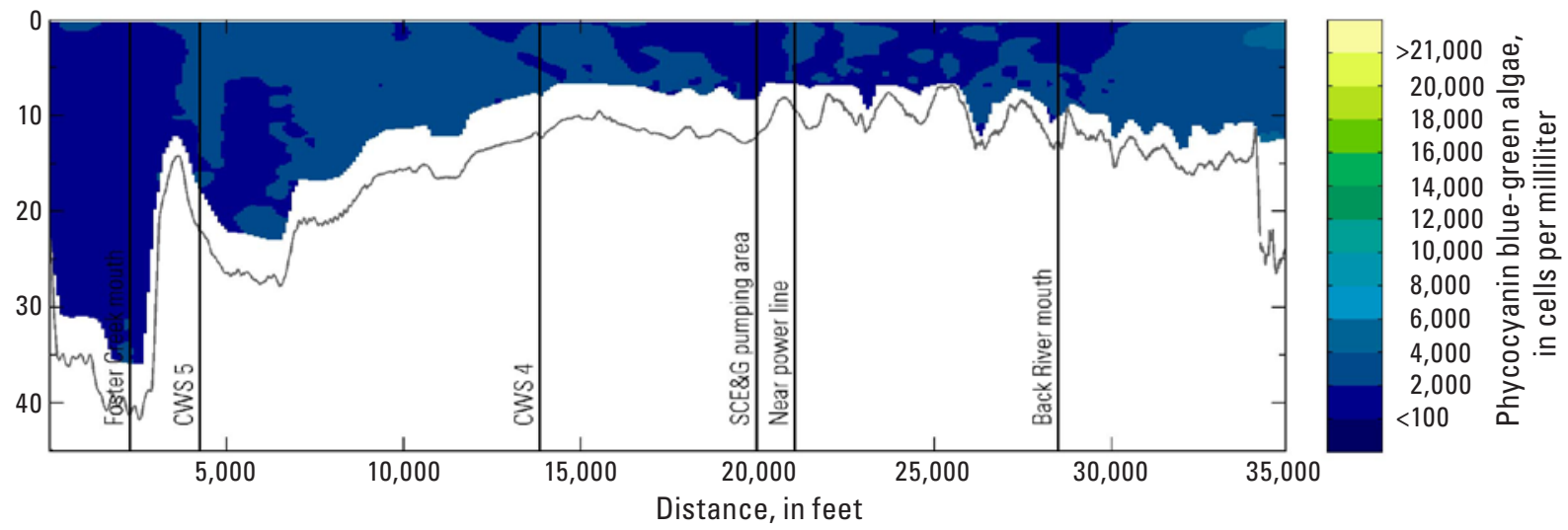

Figure 2-9. (Continued) Longitudinal plots of $(E)$ turbidity, $(F)$ total chlorophyll fluorescence estimated as micrograms per liter, and $(G)$ phycocyanin fluorescence, estimated as blue-green algae, in cells per milliliter at Bushy Park Reservoir, October 29, 2014. 

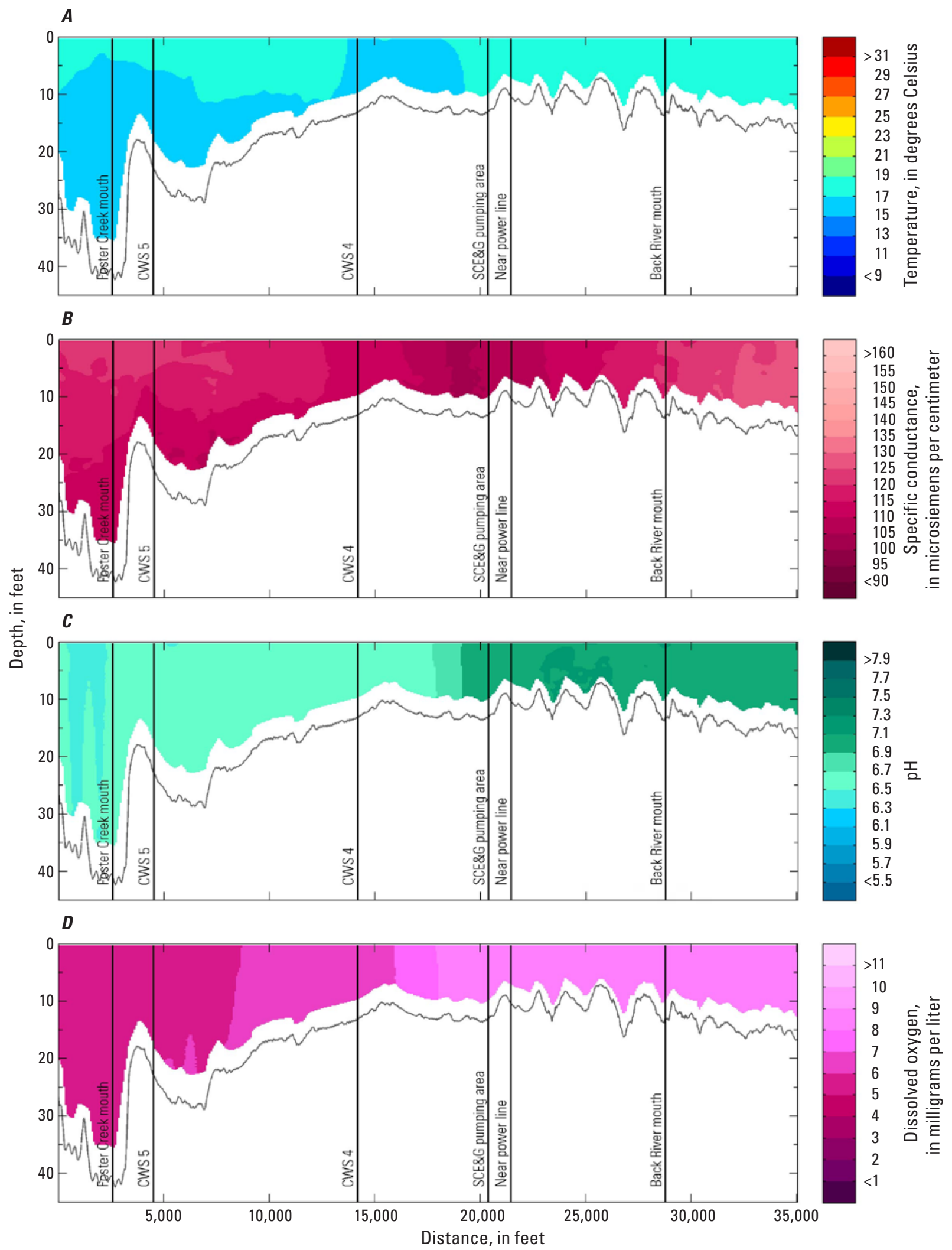

Figure 2-10. Longitudinal plots of $(A)$ water temperature, $(B)$ specific conductance, $(C) \mathrm{pH}$, and $(D)$ dissolved oxygen at Bushy Park Reservoir, November 5, 2014. 

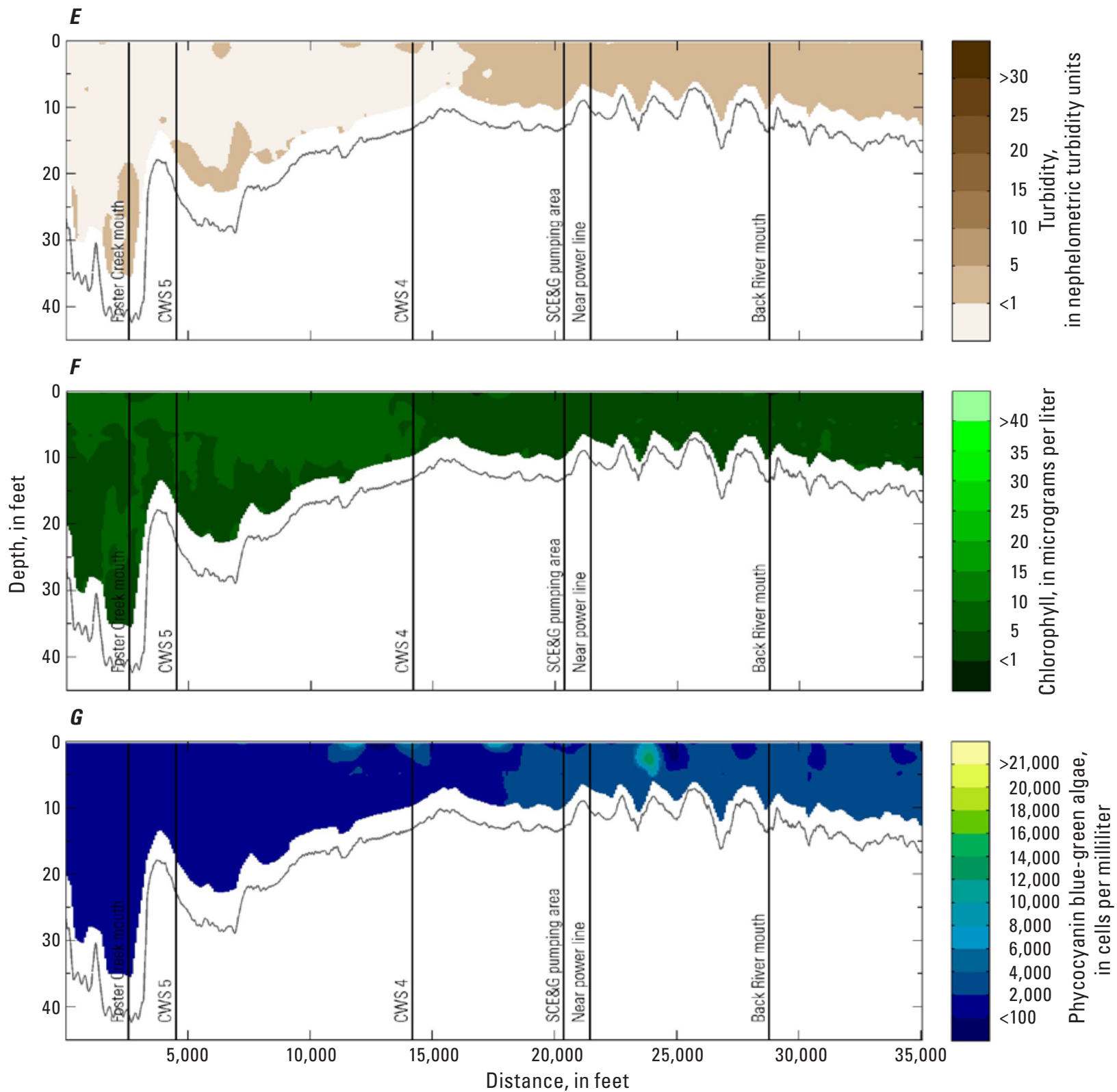

Figure 2-10. (Continued) Longitudinal plots of $(E)$ turbidity, $(F)$ total chlorophyll fluorescence estimated as micrograms per liter, and $(G)$ phycocyanin fluorescence, estimated as blue-green algae, in cells per milliliter at Bushy Park Reservoir, November 5, 2014. 

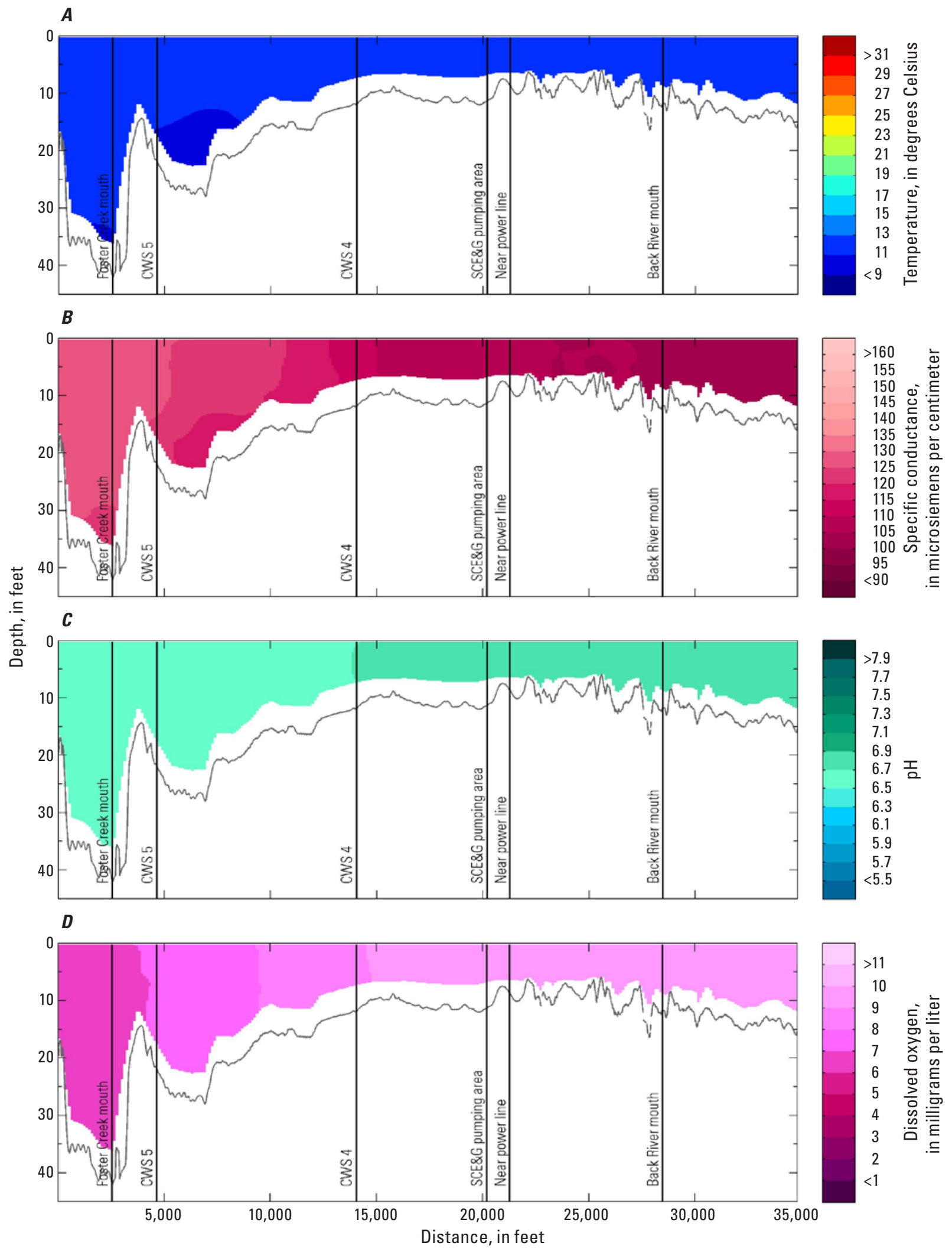

Figure 2-11. Longitudinal plots of $(A)$ water temperature, $(B)$ specific conductance, $(C) \mathrm{pH}$, and $(D)$ dissolved oxygen at Bushy Park Reservoir, December 16, 2014. 

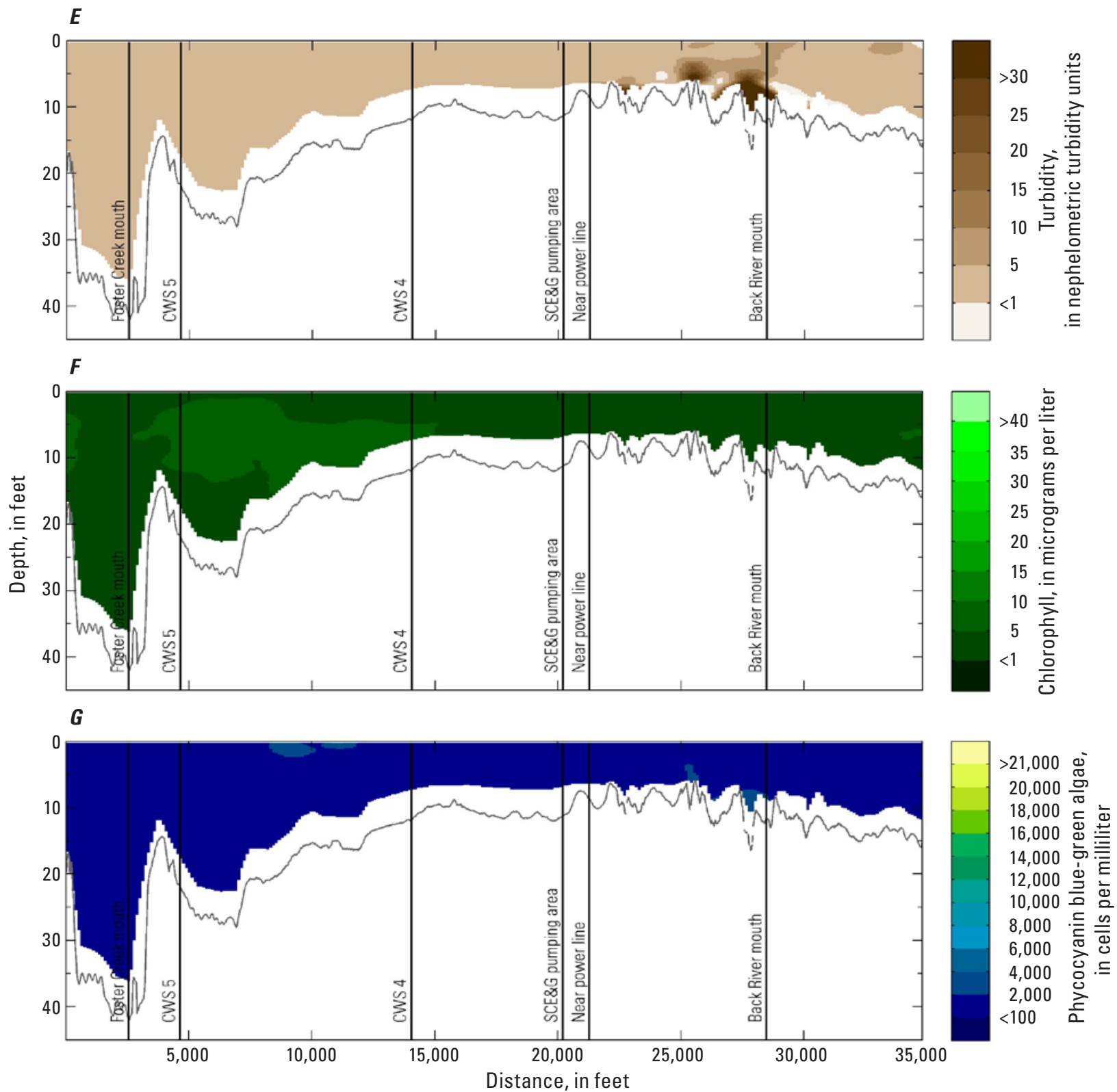

Figure 2-11. (Continued) Longitudinal plots of $(E)$ turbidity, $(F)$ total chlorophyll fluorescence estimated as micrograms per liter, and $(G)$ phycocyanin fluorescence, estimated as blue-green algae, in cells per milliliter at Bushy Park Reservoir, December 16, 2014. 

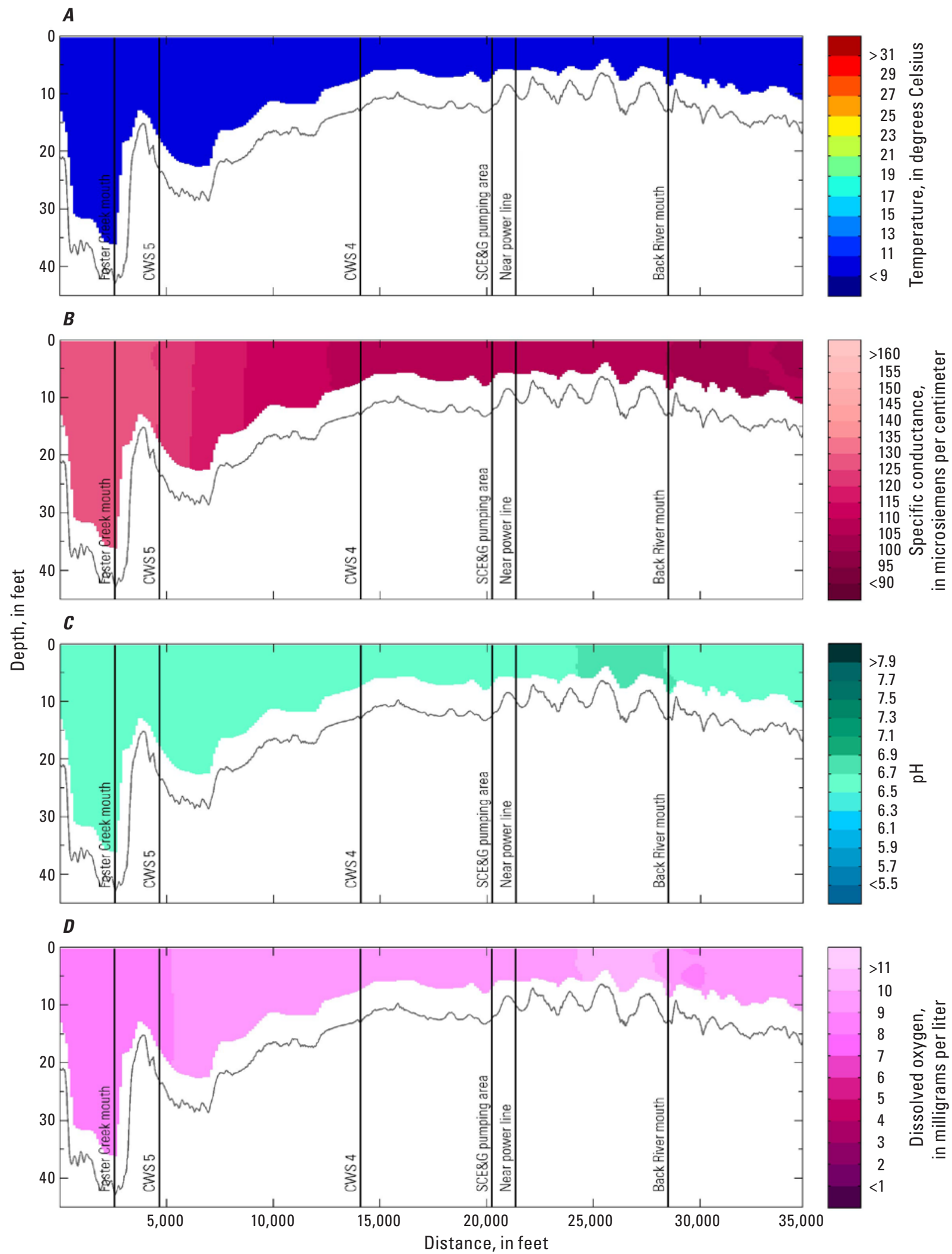

Figure 2-12. Longitudinal plots of $(A)$ water temperature, $(B)$ specific conductance, $(C) \mathrm{pH}$, and $(D)$ dissolved oxygen at Bushy Park Reservoir, January 14, 2015. 

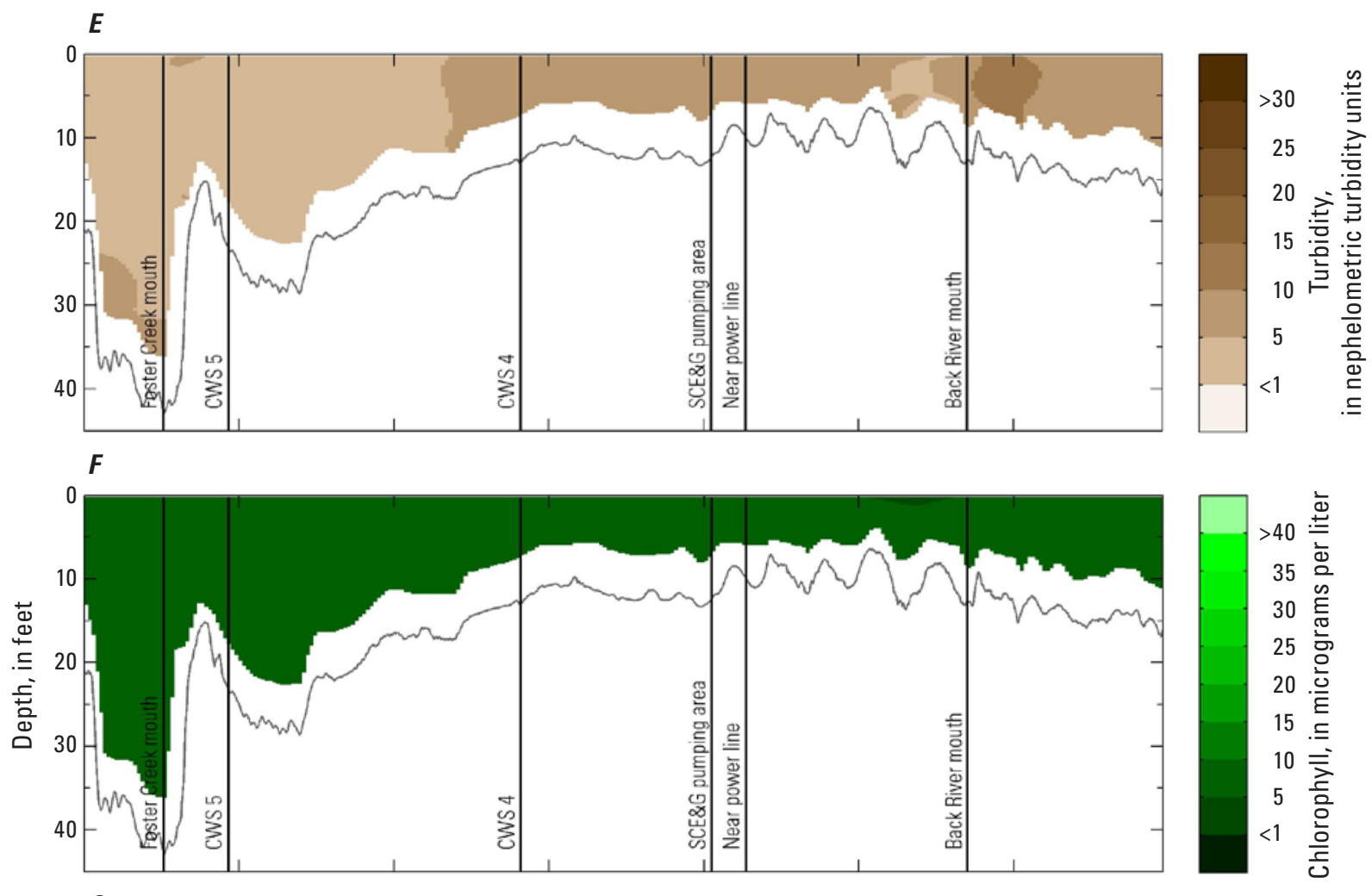

G

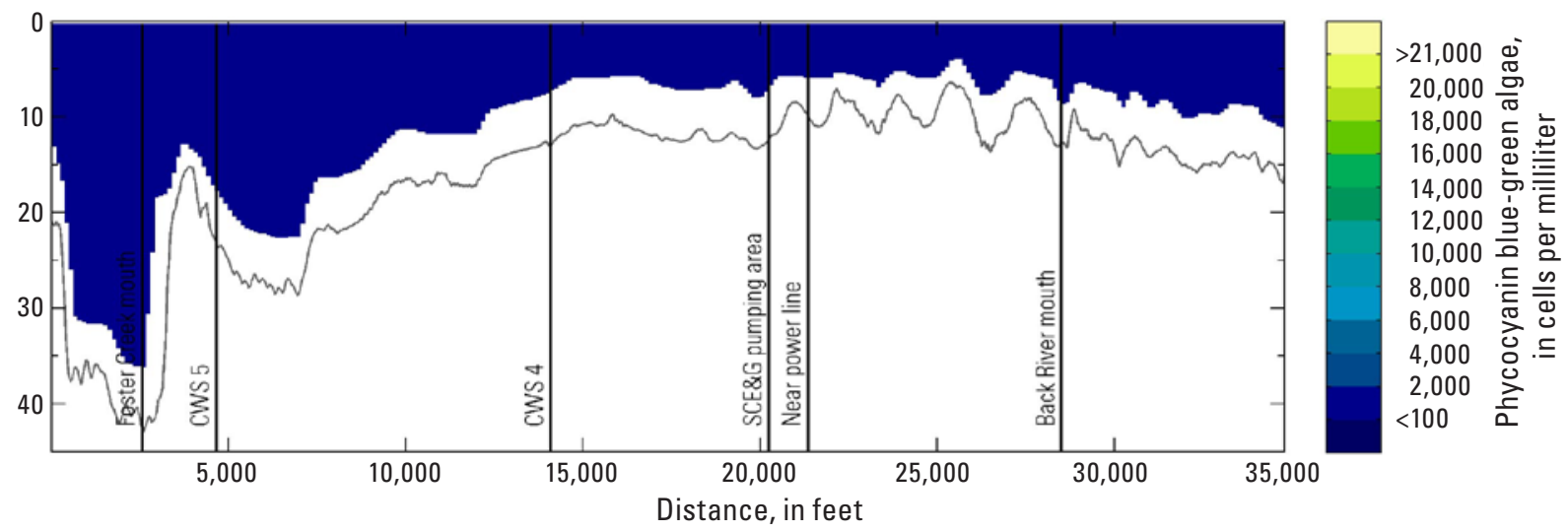

Figure 2-12. (Continued) Longitudinal plots of $(E)$ turbidity, $(F)$ total chlorophyll fluorescence estimated as micrograms per liter, and $(G)$ phycocyanin fluorescence, estimated as blue-green algae, in cells per milliliter at Bushy Park Reservoir, January 14, 2015. 


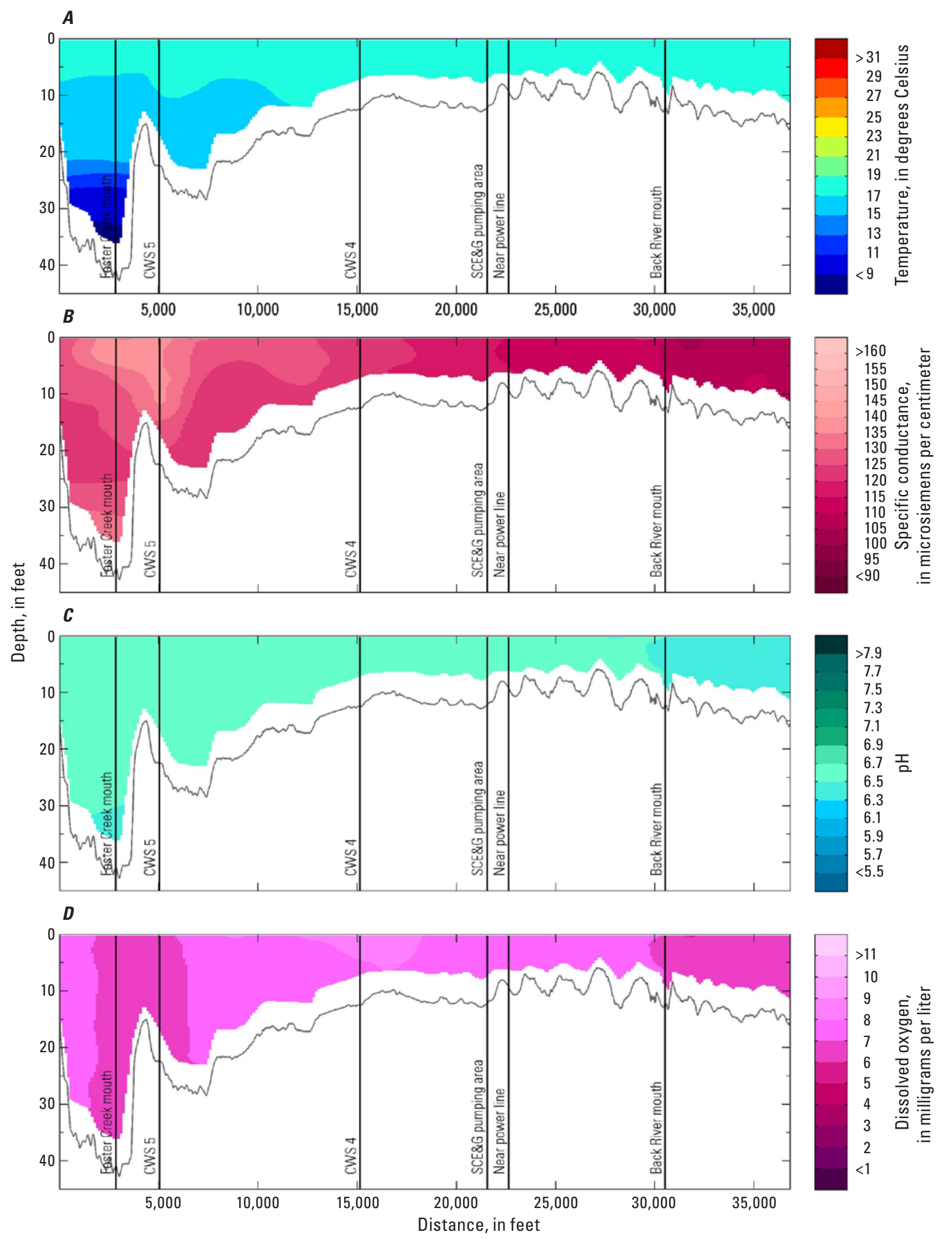

Figure 2-13. Longitudinal plots of $(A)$ water temperature, $(B)$ specific conductance, $(C) \mathrm{pH}$, and $(D)$ dissolved oxygen at Bushy Park Reservoir, March 26, 2015. 

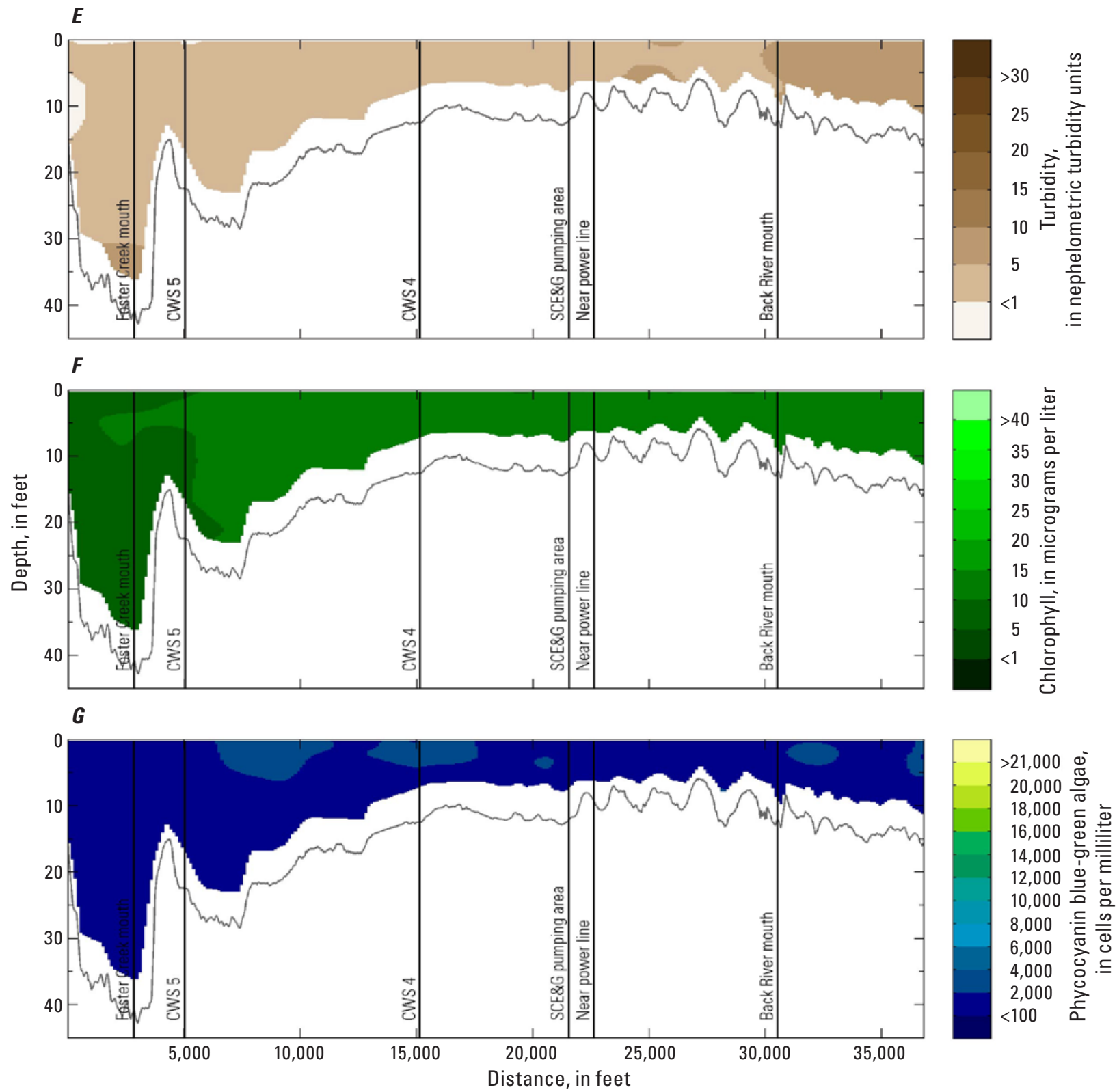

Figure 2-13. (Continued) Longitudinal plots of $(E)$ turbidity, $(F)$ total chlorophyll fluorescence estimated as micrograms per liter, and $(G)$ phycocyanin fluorescence, estimated as blue-green algae, in cells per milliliter at Bushy Park Reservoir, March 26, 2015. 

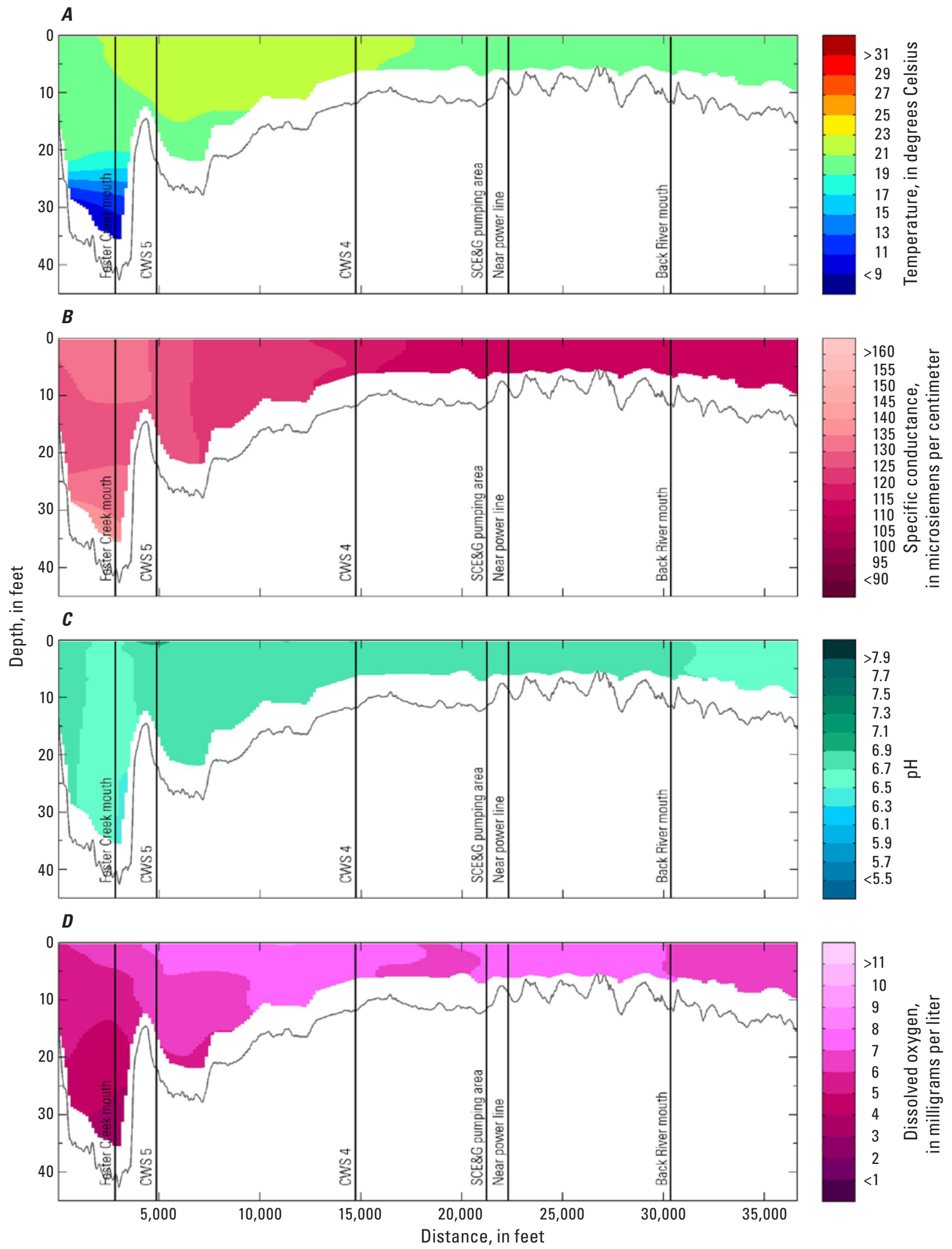

Figure 2-14. Longitudinal plots of $(A)$ water temperature, $(B)$ specific conductance, $(C) \mathrm{pH}$, and $(D)$ dissolved oxygen at Bushy Park Reservoir, April 23, 2015. 

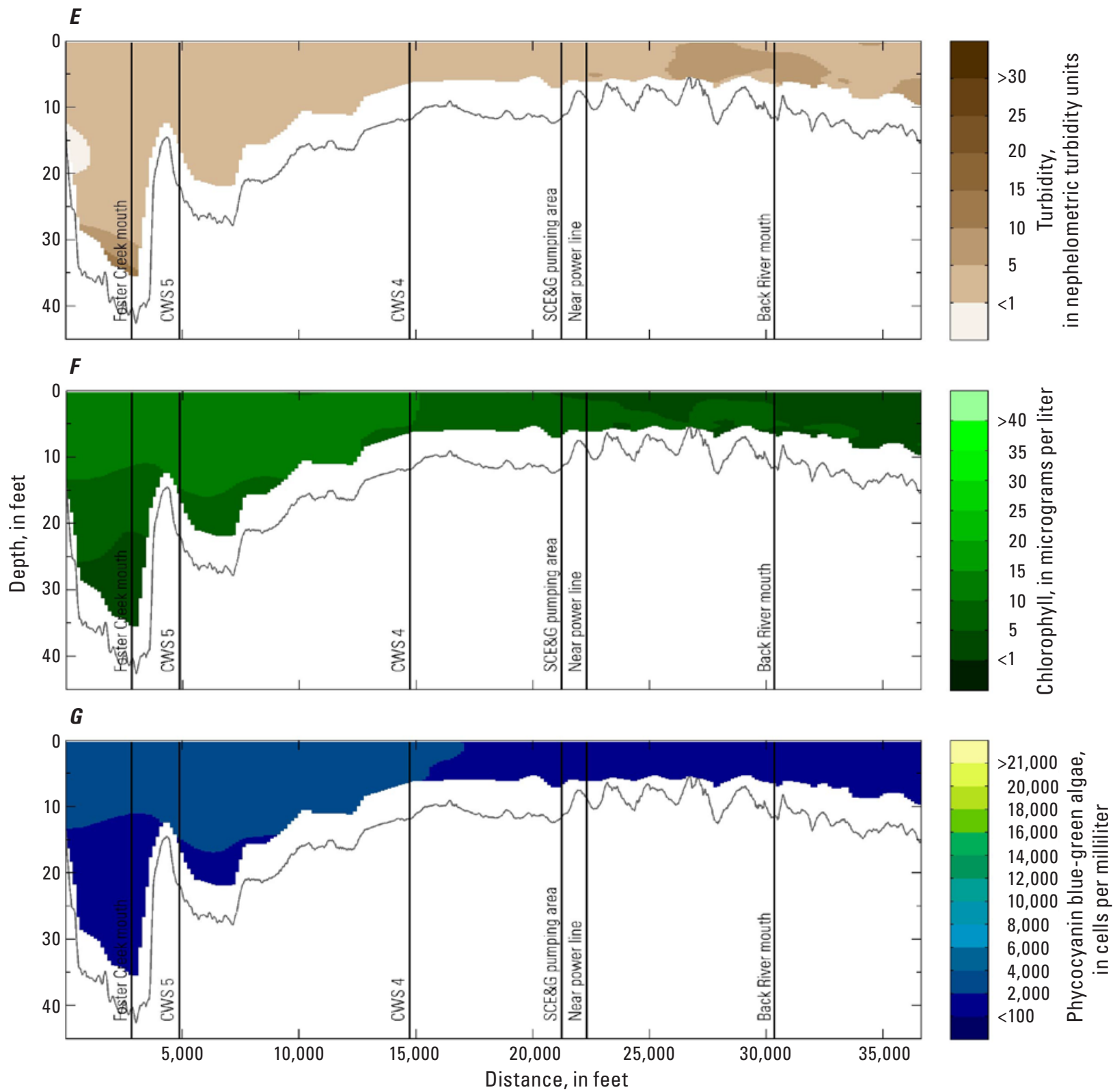

Figure 2-14. (Continued) Longitudinal plots of $(E)$ turbidity, $(F)$ total chlorophyll fluorescence estimated as micrograms per liter, and $(G)$ phycocyanin fluorescence, estimated as blue-green algae, in cells per milliliter at Bushy Park Reservoir, April 23, 2015. 


\section{Appendix 3. Water-quality profile data collected from the Bushy Park Reservoir, near Goose Creek, South Carolina, between September 2013 and April 2015}

[Latitude and longitude coordinates are referenced to the World Geodetic System of 1984 (WGS84). Profiles located at sampling locations include site names and latitude and longitude coordinates. If a profile is not located at a sampling location, no site name is included with the coordinates. Graphs are empty for locations at which the specific water-quality sensor was not available or was malfunctioning. Chlorophyll and blue-green algae concentrations were determined by internal algorithm estimated from chlorophyll and phycocyanin fluorescence]
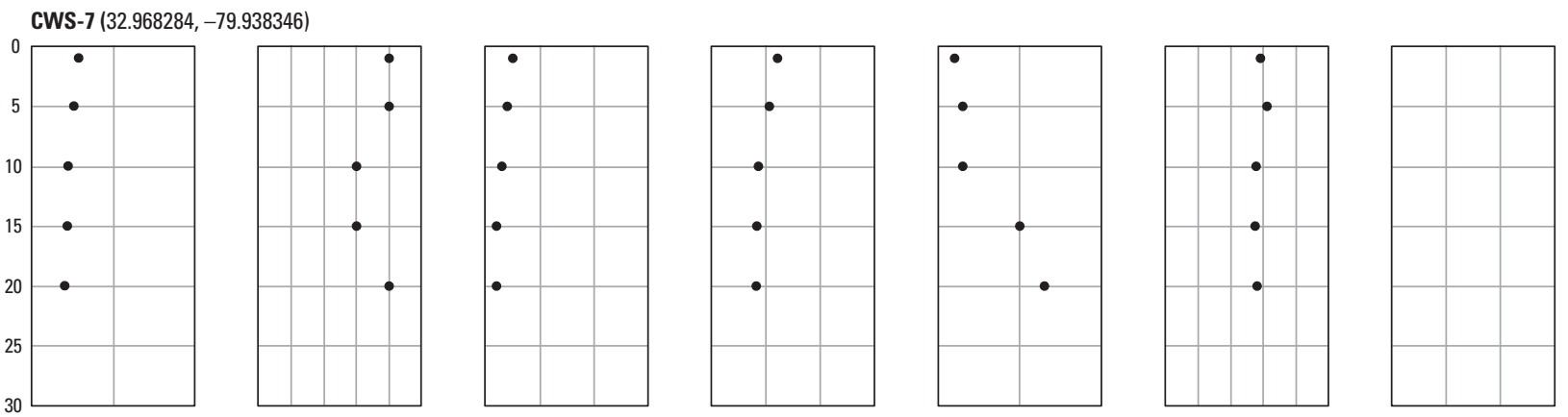

CWS-6 $(32.981175,-79.953775)$
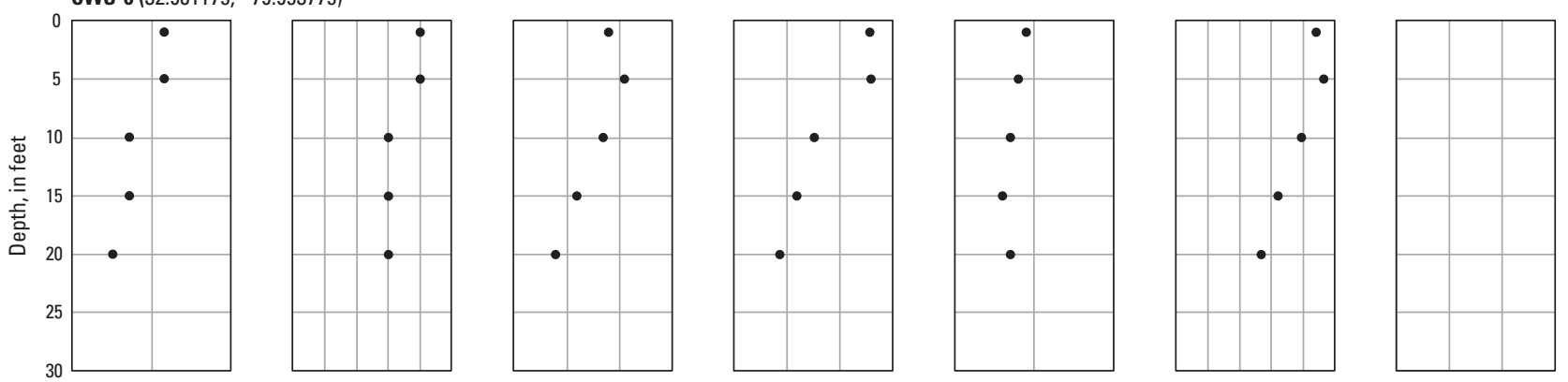

CWS-5 $(32.979972,-79.941094)$
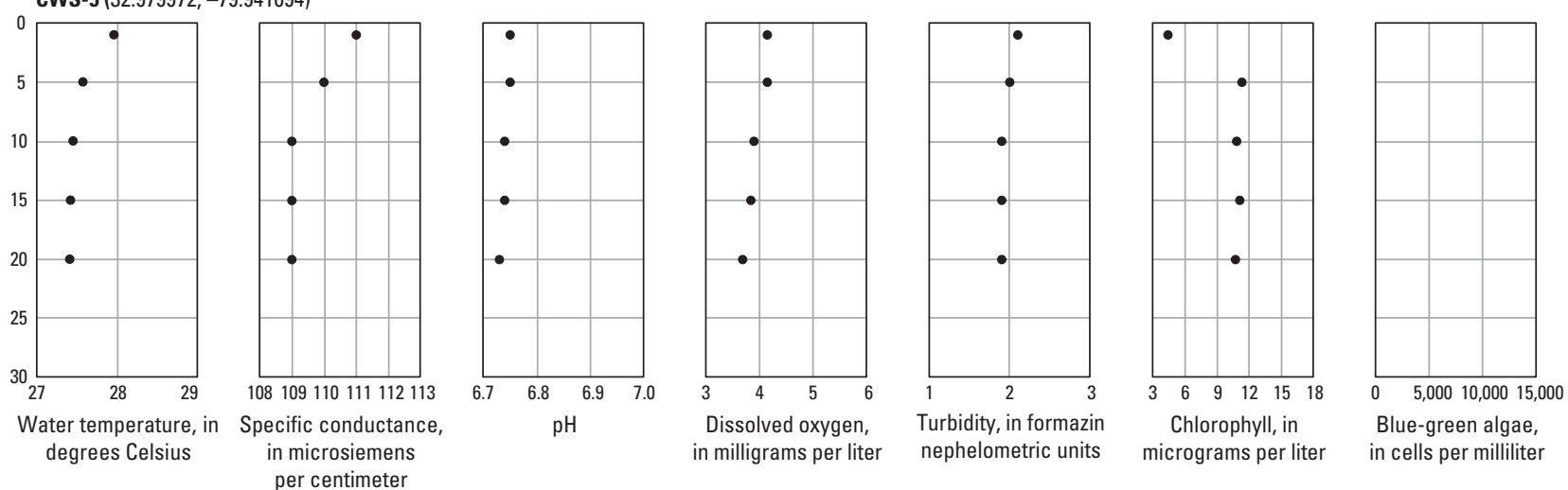

Figure 3-1. Water-quality profile data collected in the Bushy Park Reservoir, near Goose Creek, South Carolina, September 17, 2013. 

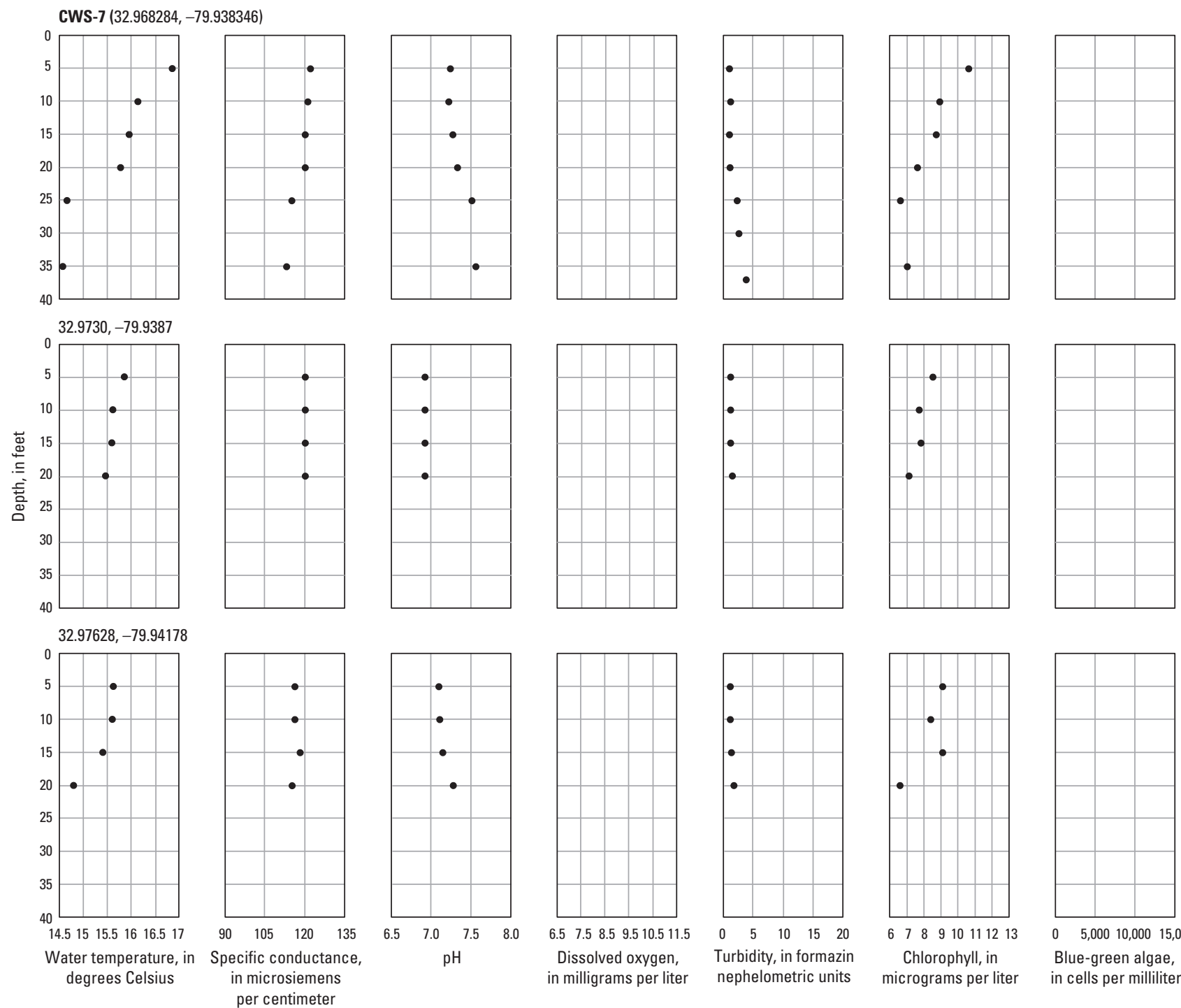

6.57 .58 .59 .510 .511 .5

Dissolved oxygen, in milligrams per liter

nephelometric units

678910111213 Chlorophyll, in micrograms per liter

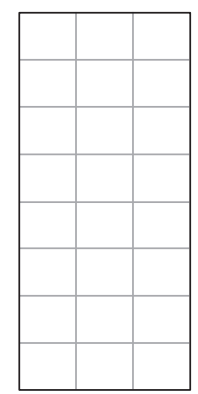

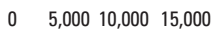

Blue-green algae, in cells per milliliter

Figure 3-2. Water-quality profile data collected in the Bushy Park Reservoir, near Goose Creek, South Carolina, November 19, 2013. 
CWS-5 (32.979972, -79.941094)
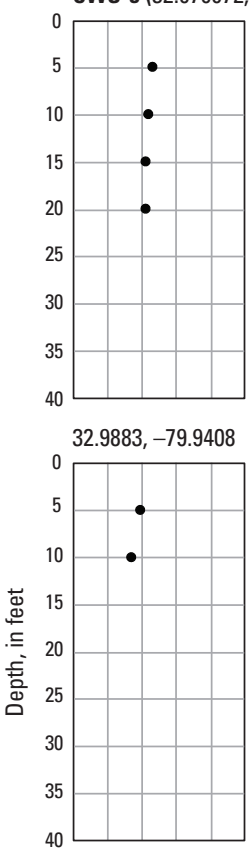

$32.9992,-79.9383$

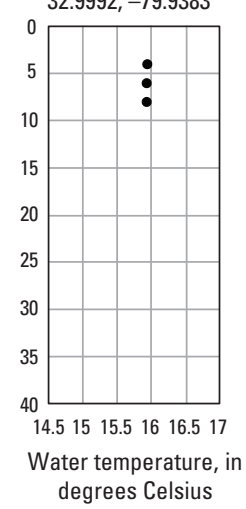

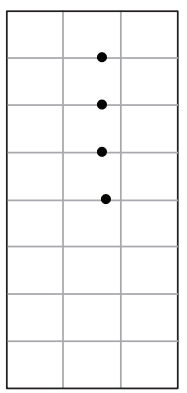
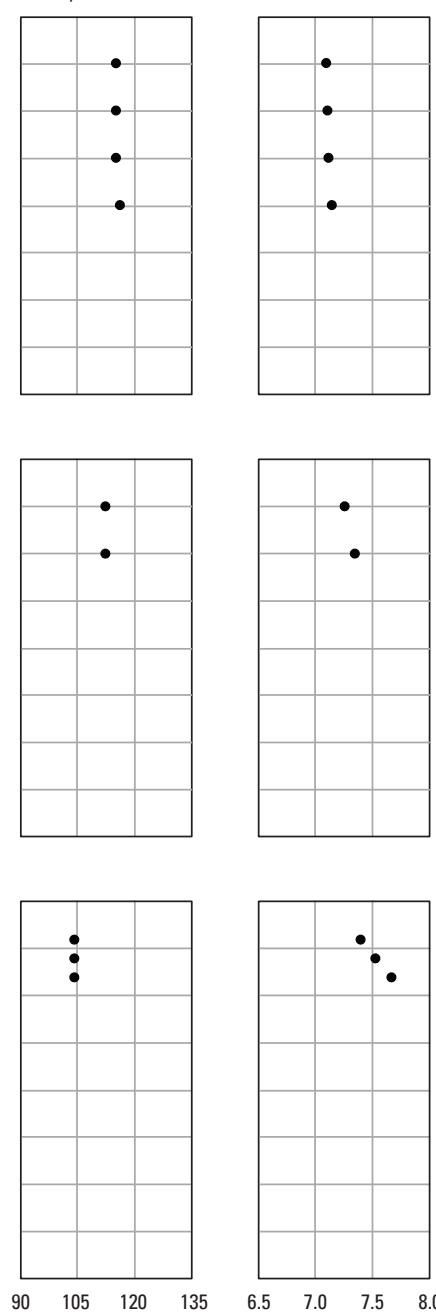

Specific conductance in microsiemens per centimeter
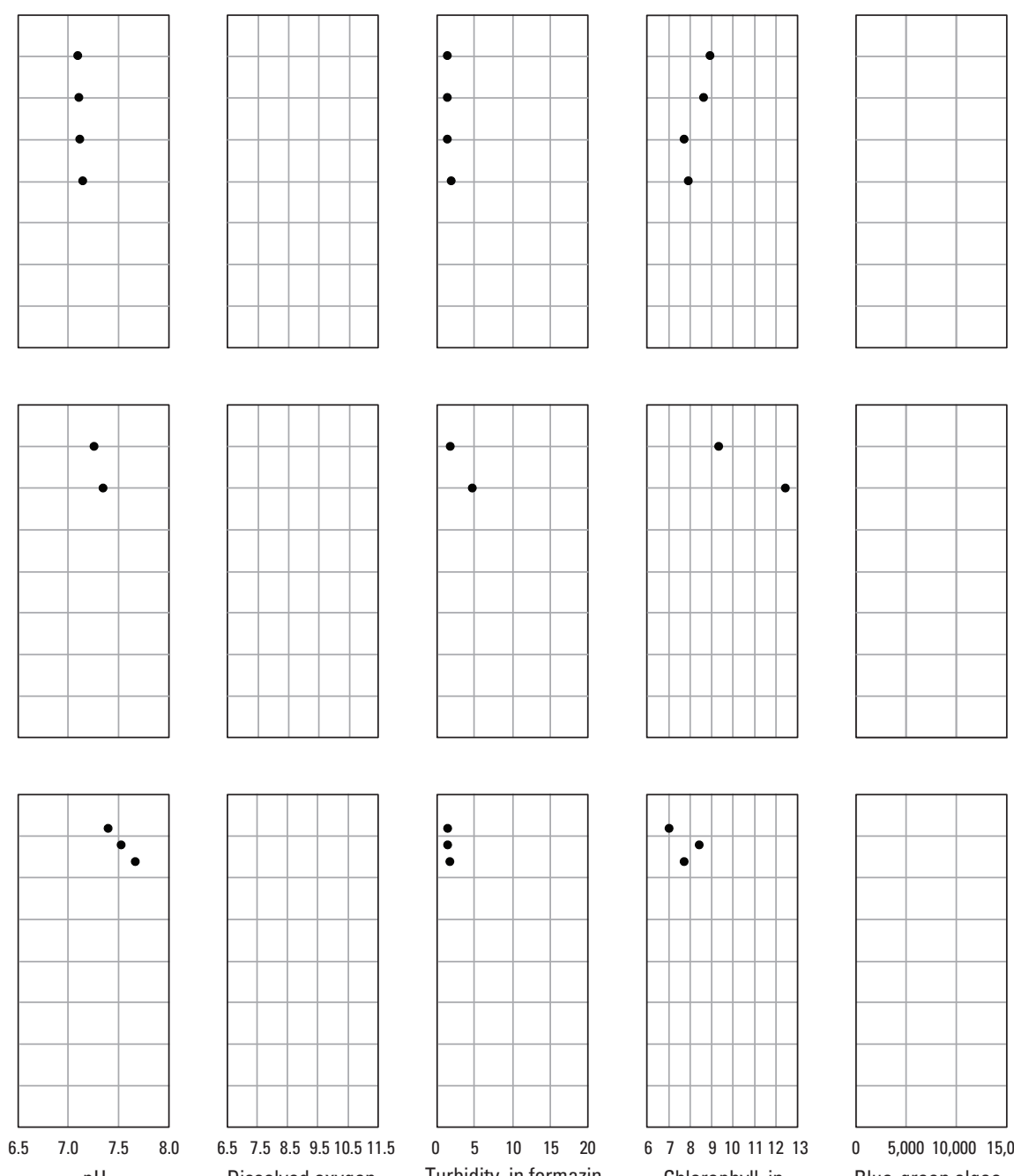

$6.5 \quad 7.5 \quad 8.59 .510 .511 .5$ Dissolved oxygen, in milligrams per liter
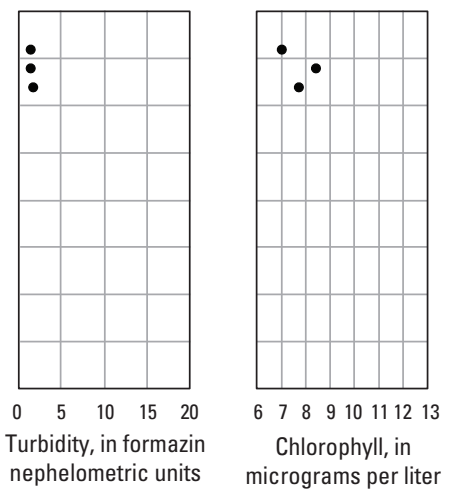

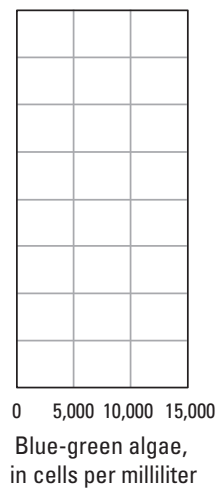

Figure 3-2. (Continued) Water-quality profile data collected in the Bushy Park Reservoir, near Goose Creek, South Carolina, November 19, 2013. 

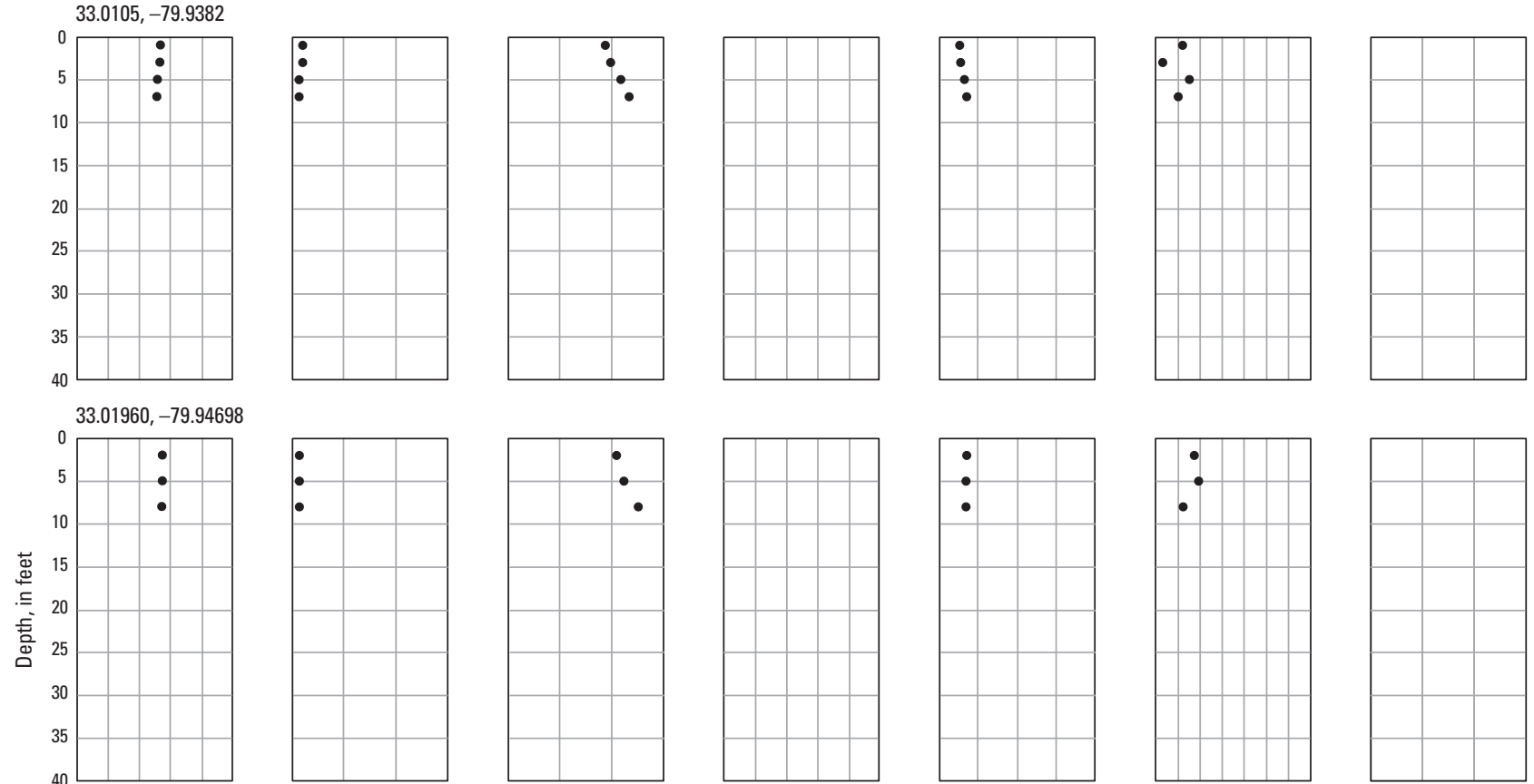

CWS-3 (33.027444, -79.952313$)$
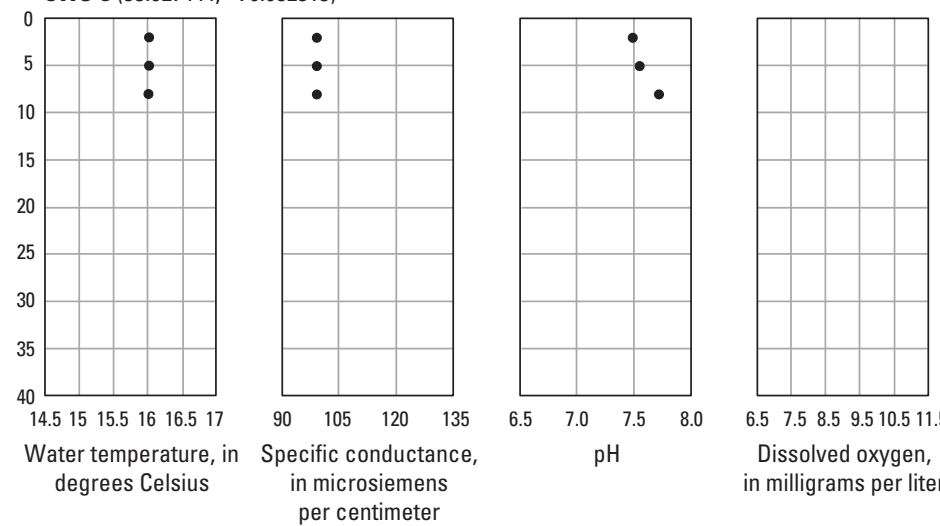

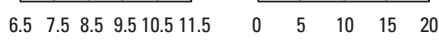

Dissolved oxygen, Turbidity, in formazin in milligrams per liter nephelometric units

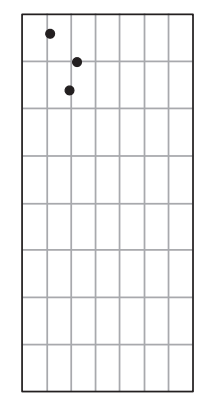

$\begin{array}{llllllll}6 & 7 & 8 & 9 & 10 & 1112 & 13\end{array}$

Chlorophyll, in micrograms per liter

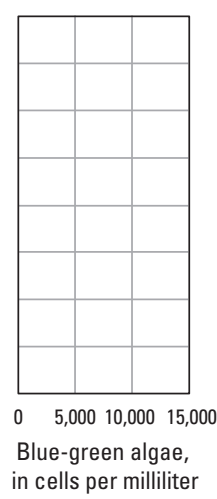

Figure 3-2. (Continued) Water-quality profile data collected in the Bushy Park Reservoir, near Goose Creek, South Carolina, November 19, 2013. 

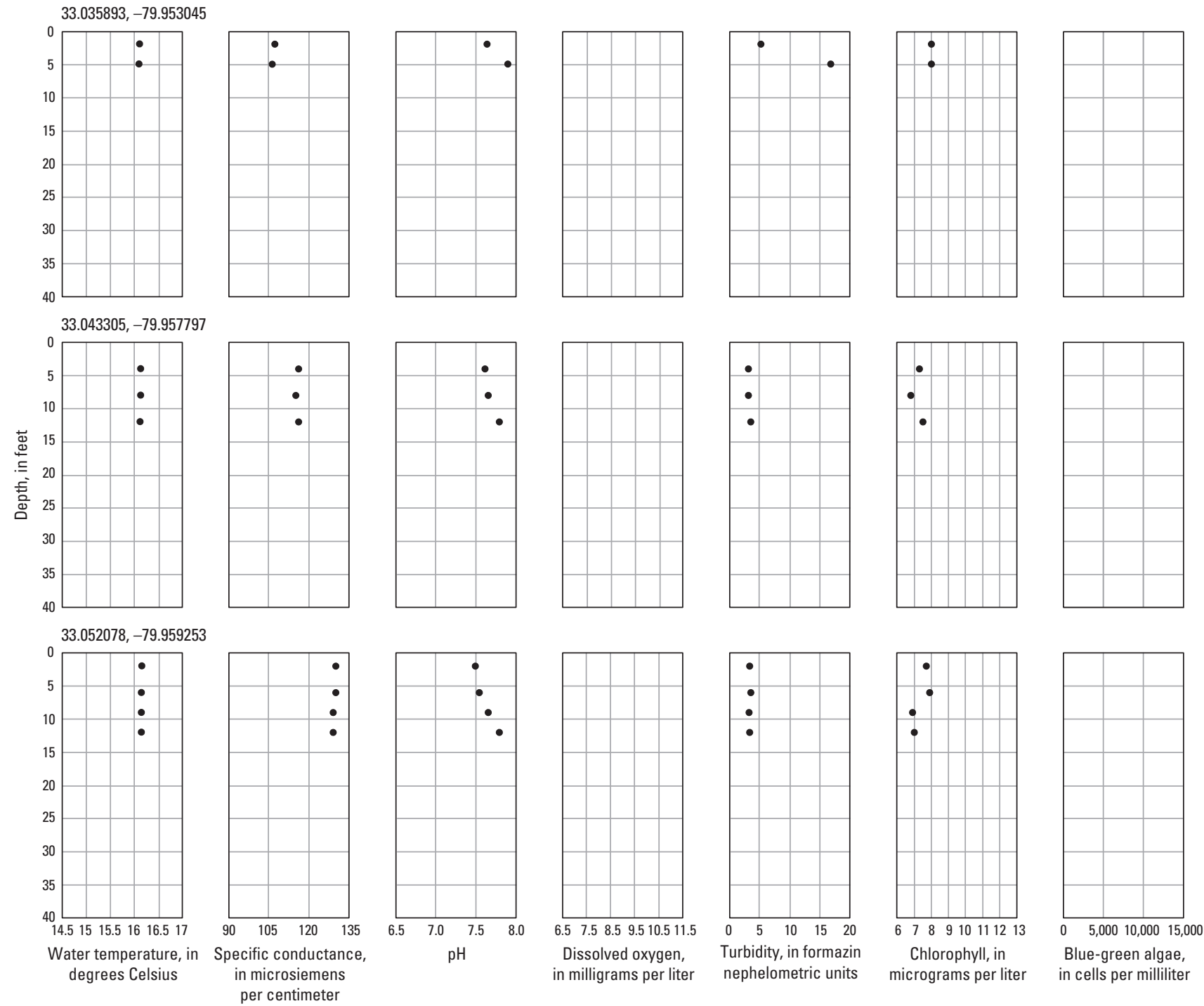

Figure 3-2. (Continued) Water-quality profile data collected in the Bushy Park Reservoir, near Goose Creek, South Carolina, November 19, 2013. 
CWS-7 (32.968284, -79.938346)
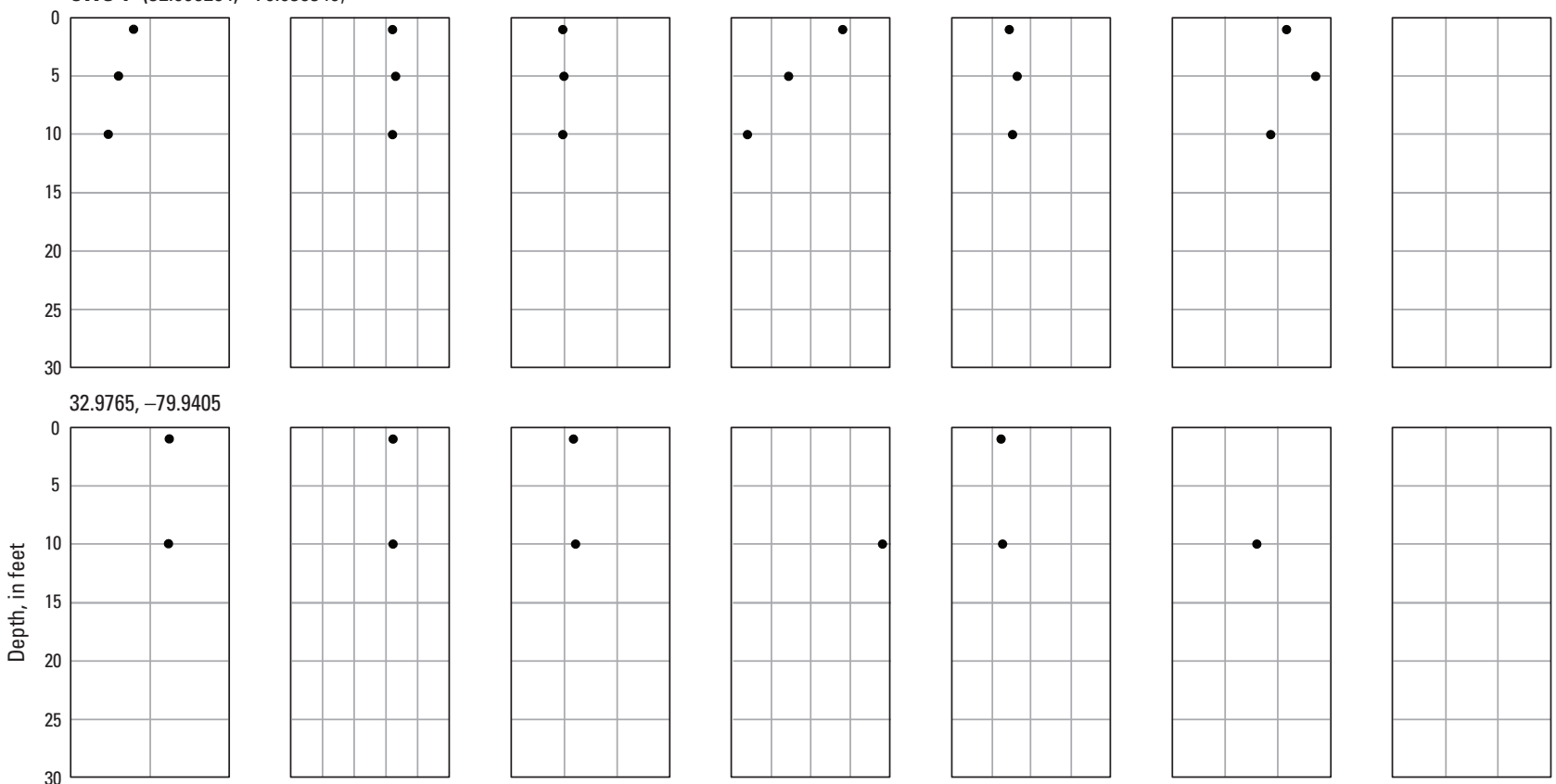

$32.9861,-79.9418$
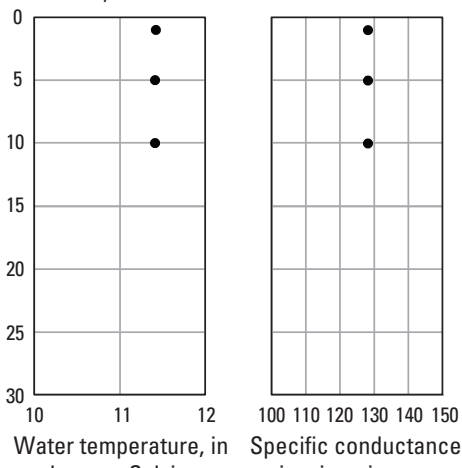

Specific conductance

in microsiemens per centimeter
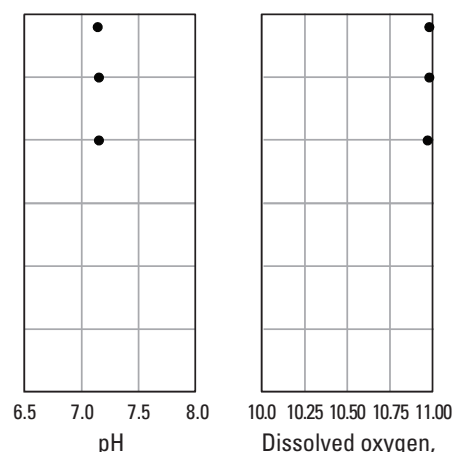

10.010 .2510 .5010 .7511 .00

Dissolved oxygen,

in milligrams per liter
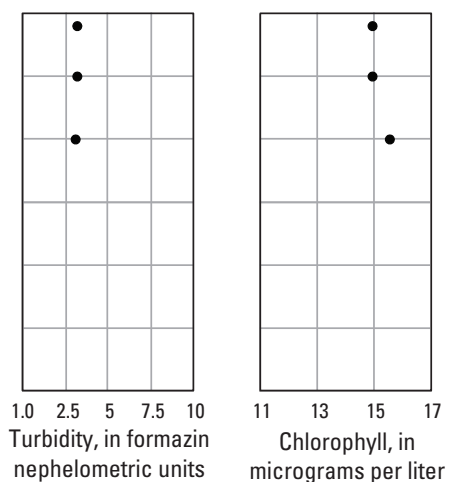

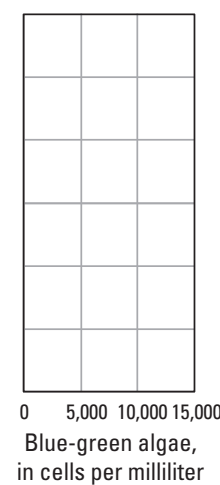

Figure 3-3. Water-quality profile data collected in the Bushy Park Reservoir, near Goose Creek, South Carolina, January 14, 2014. 

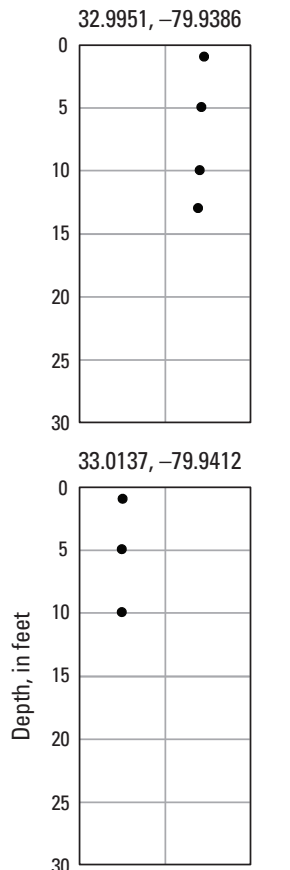

$33.0192,-79.9471$

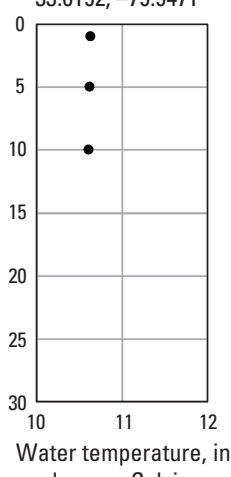

degrees Celsius
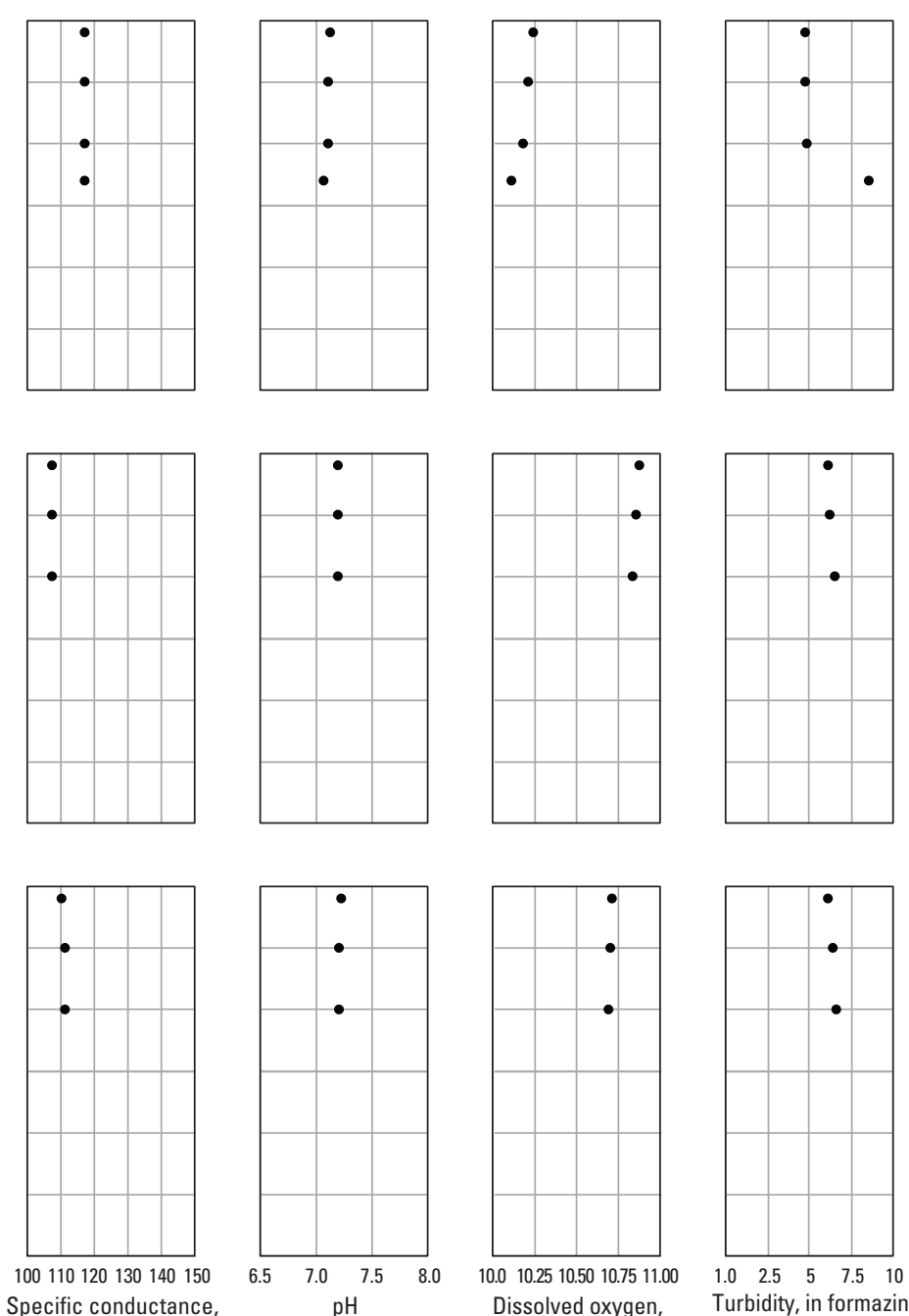

in microsiemens per centimeter
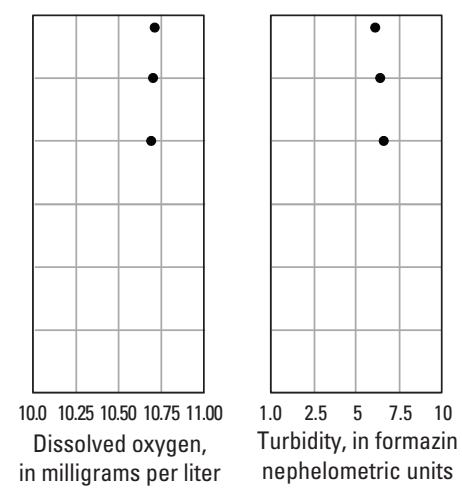
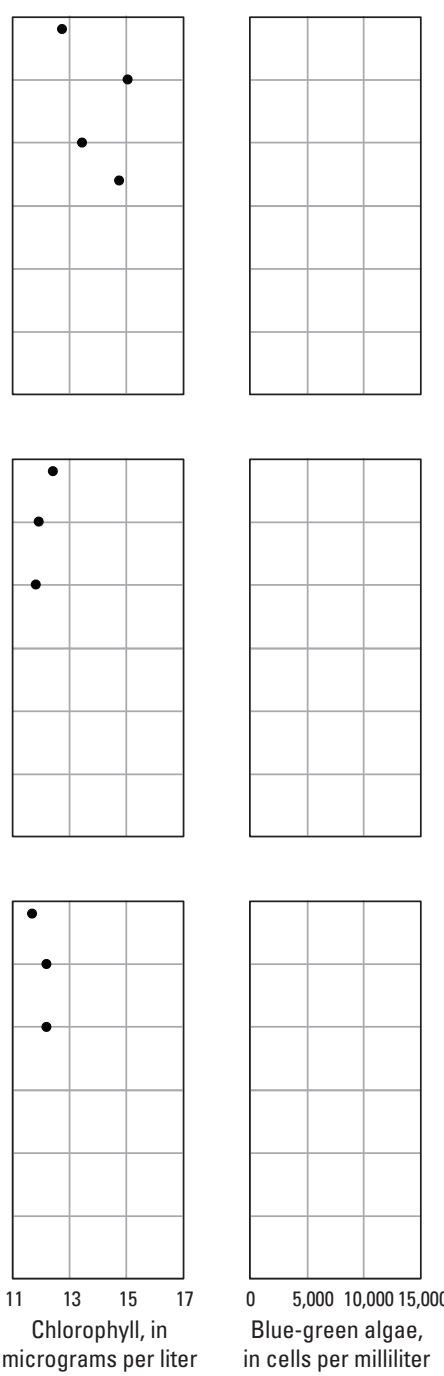

Figure 3-3. (Continued) Water-quality profile data collected in the Bushy Park Reservoir, near Goose Creek, South Carolina, January 14, 2014. 
CWS-3 $(33.027444,-79.952313)$
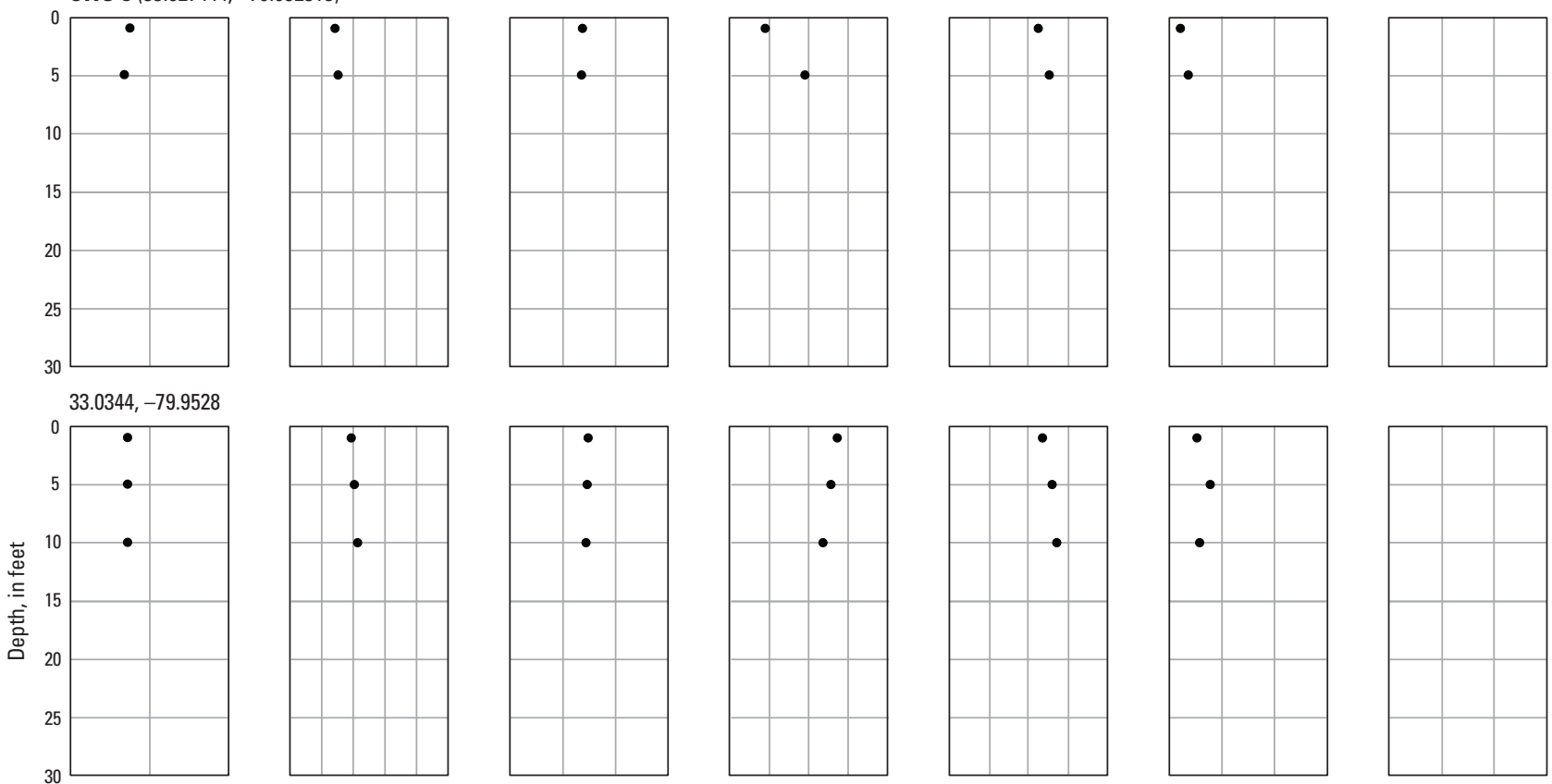

$33.0413,-79.9559$
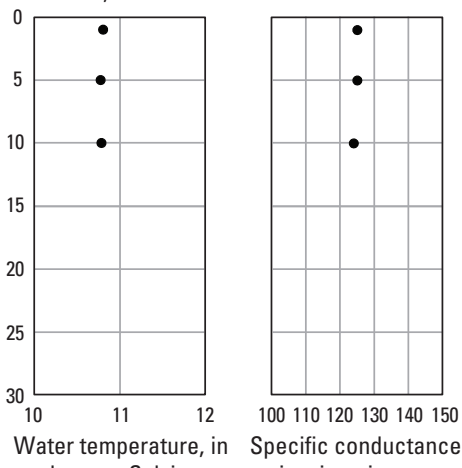

degrees Celsius

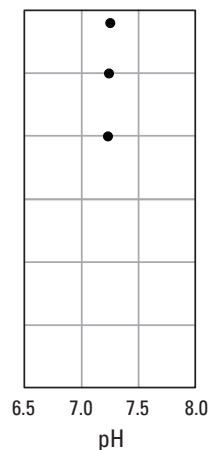

in microsier per centimeter
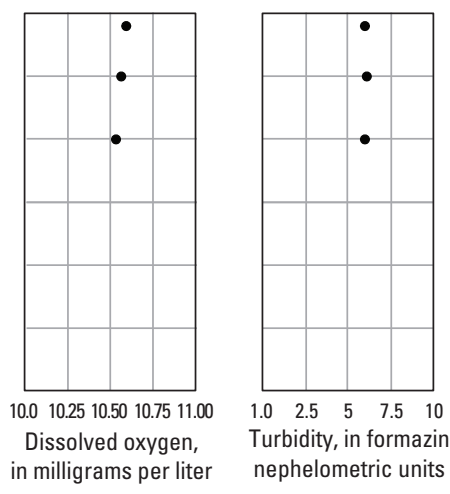
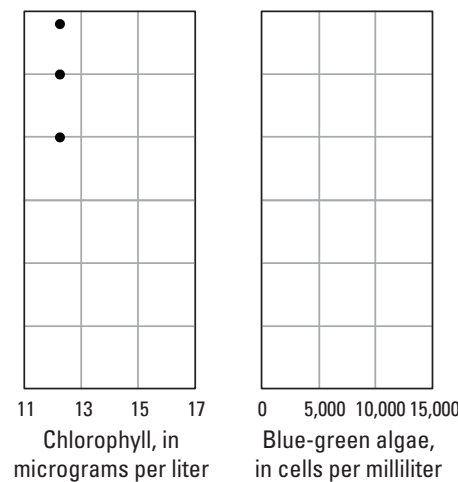

Figure 3-3. (Continued) Water-quality profile data collected in the Bushy Park Reservoir, near Goose Creek, South Carolina, January 14, 2014. 


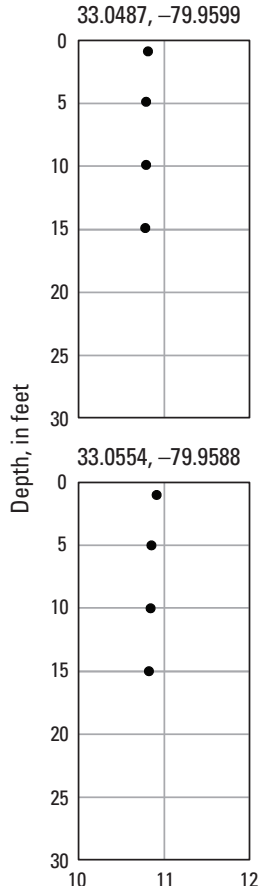

Water temperature, i degrees Celsius
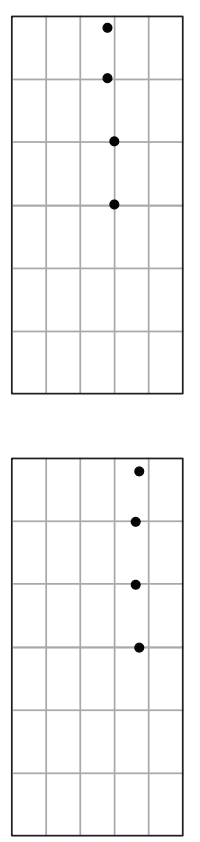

100110120130140150 Specific conductance, in microsiemens per centimeter
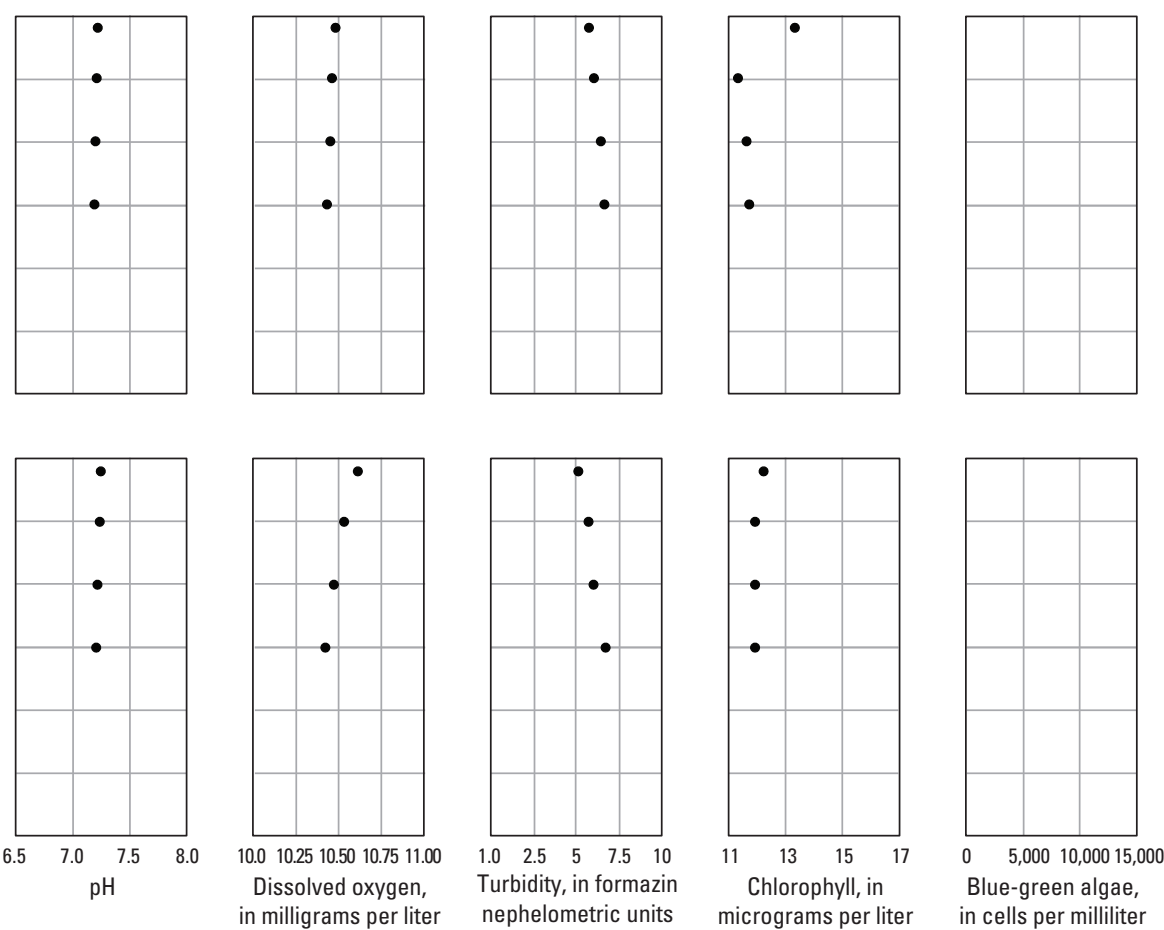

Figure 3-3. (Continued) Water-quality profile data collected in the Bushy Park Reservoir, near Goose Creek, South Carolina, January 14, 2014. 
CWS-7 $(32.968284,-79.938346)$
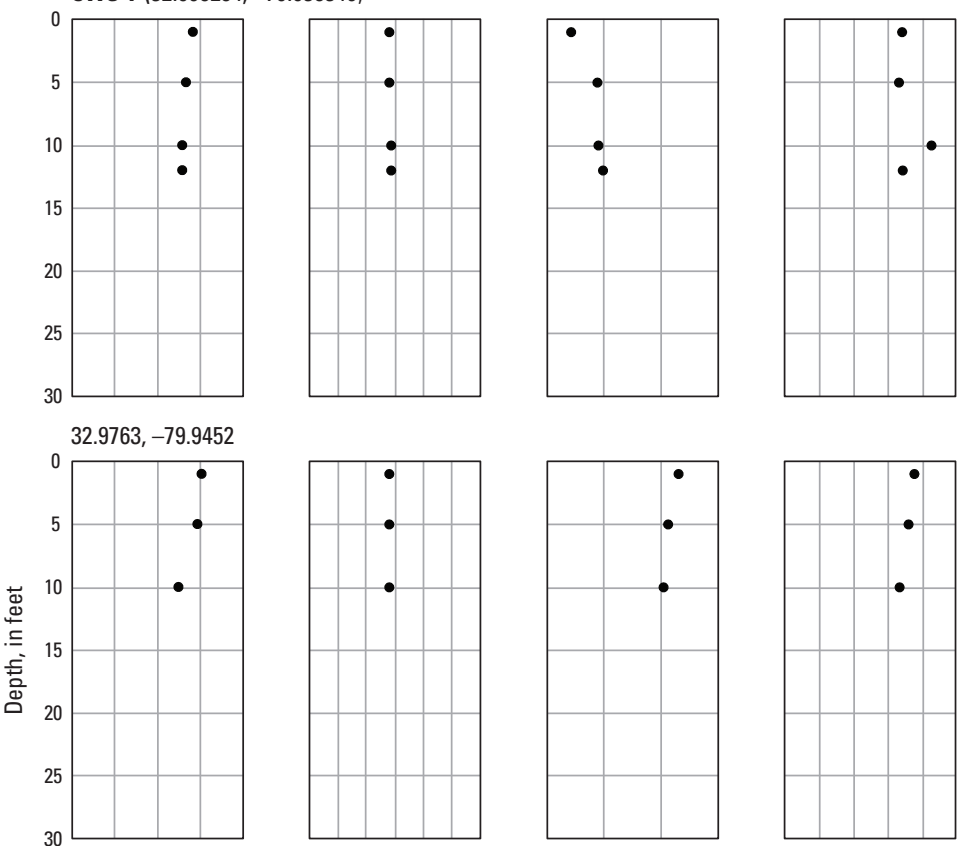

$32.98,-79.9499$

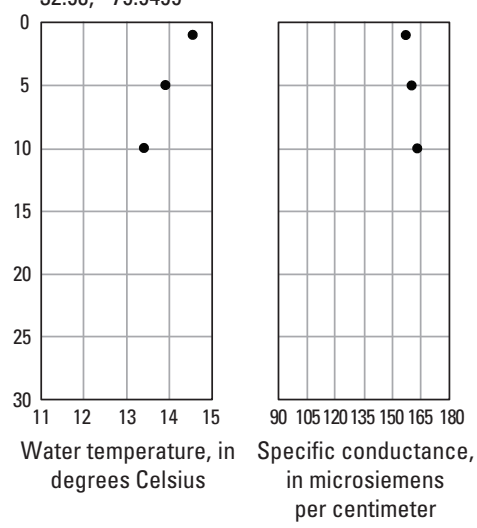

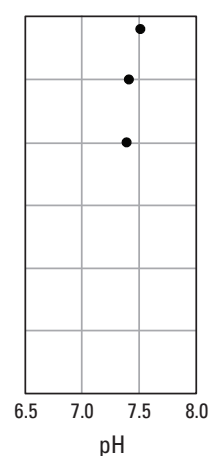

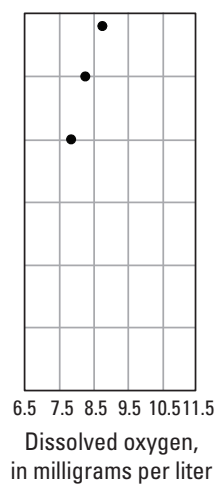

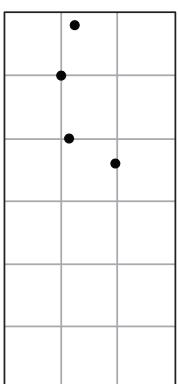
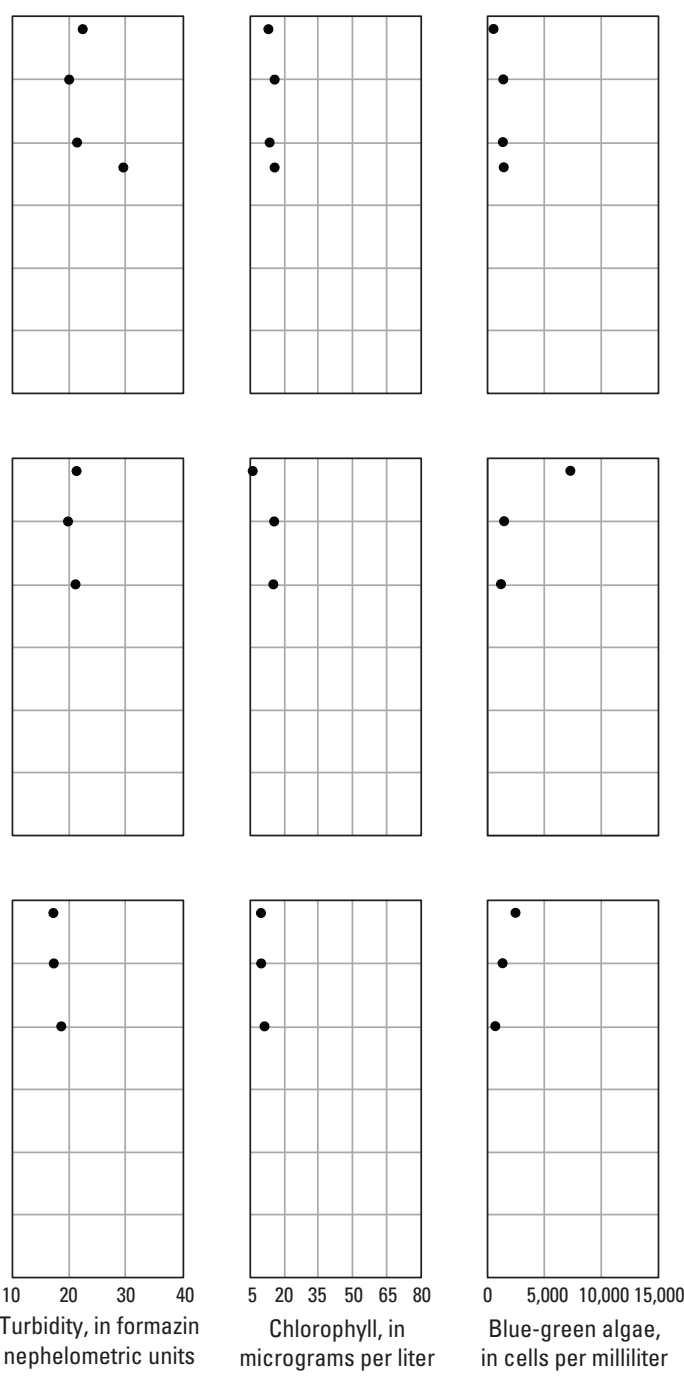

Figure 3-4. Water-quality profile data collected in the Bushy Park Reservoir, near Goose Creek, South Carolina, March 27, 2014. 

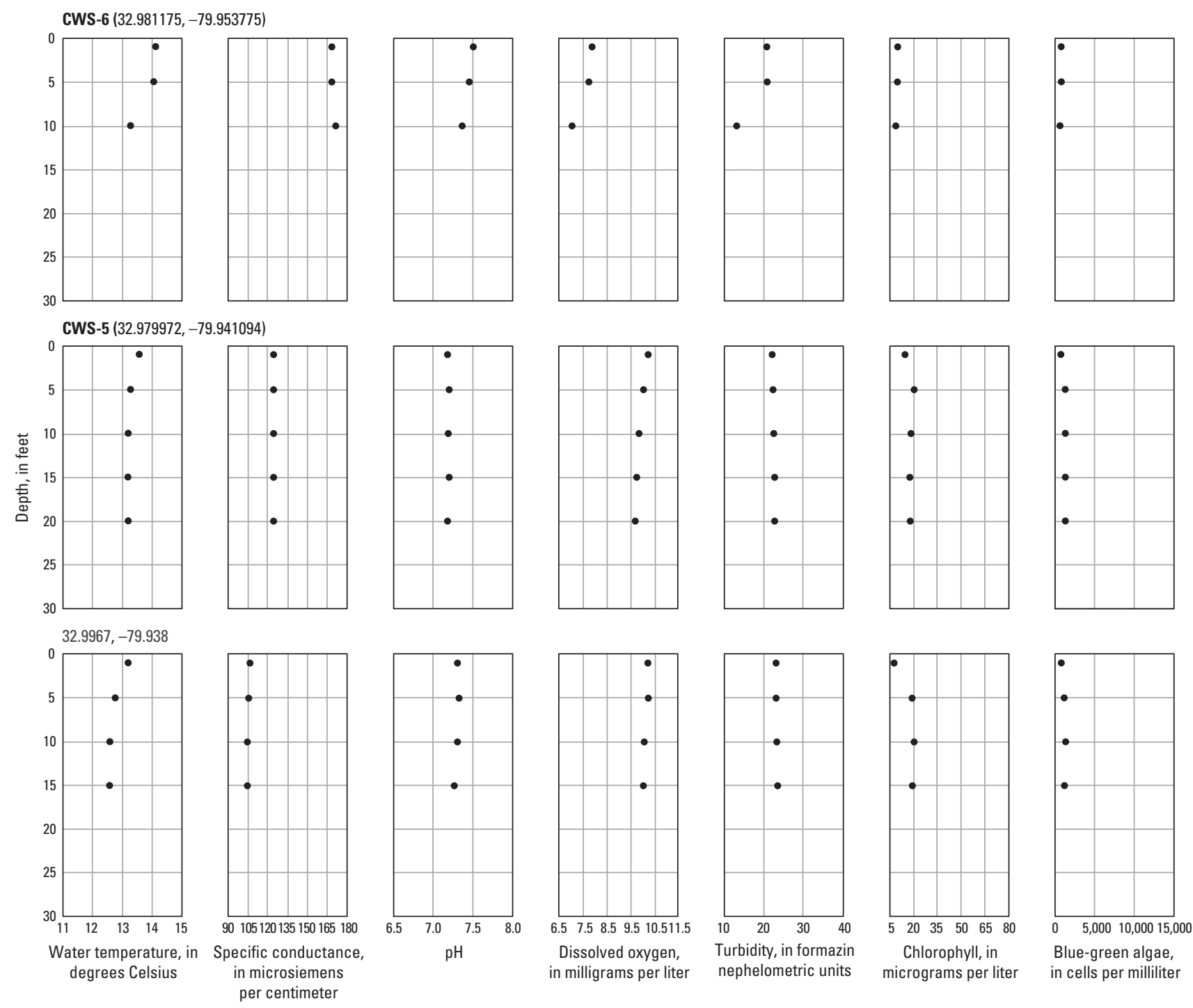

Figure 3-4. (Continued) Water-quality profile data collected in the Bushy Park Reservoir, near Goose Creek, South Carolina, March 27, 2014. 
33.0197, -79.9474
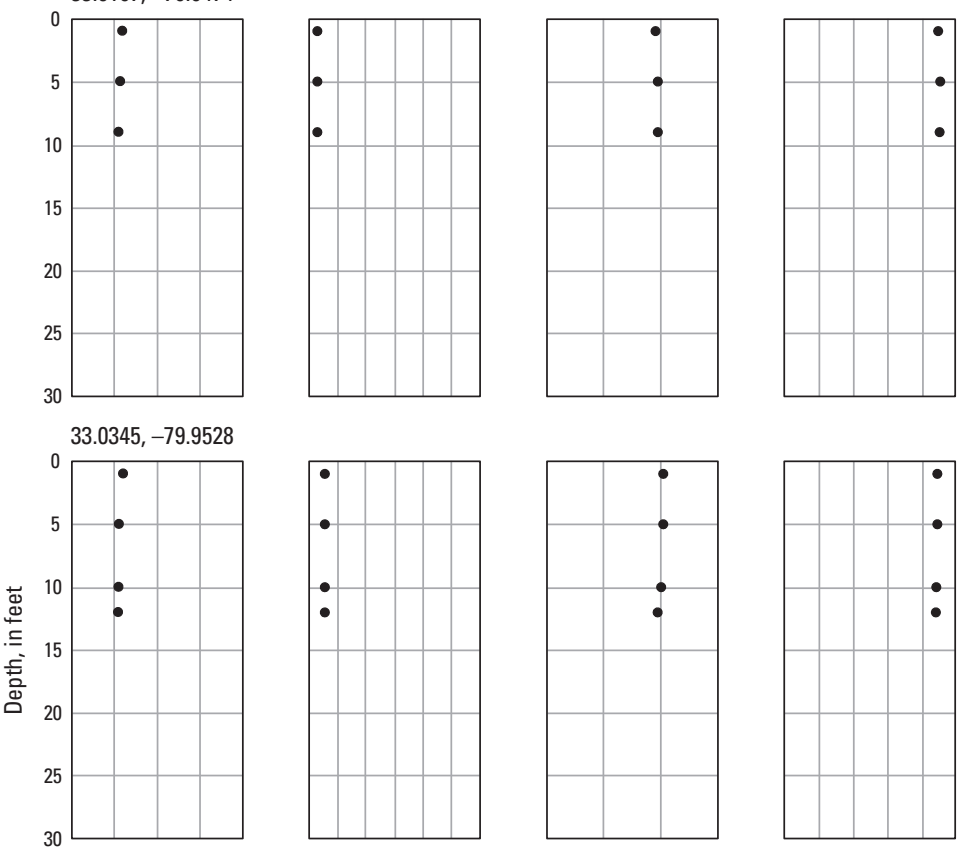

$33.0417,-79.9561$

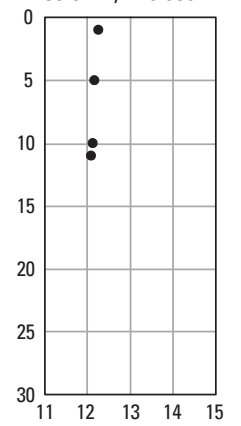

Water temperature, in degrees Celsius

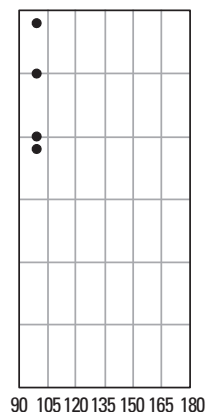

in microsiemens per centimeter
Specific conductance,

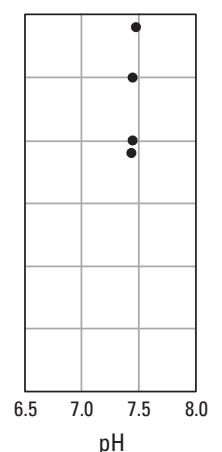

$\mathrm{pH}$

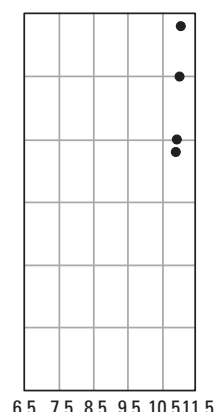

$6.5 \quad 7.5 \quad 8.5 \quad 9.5 \quad 10.511 .5$ Dissolved oxygen, in milligrams per liter
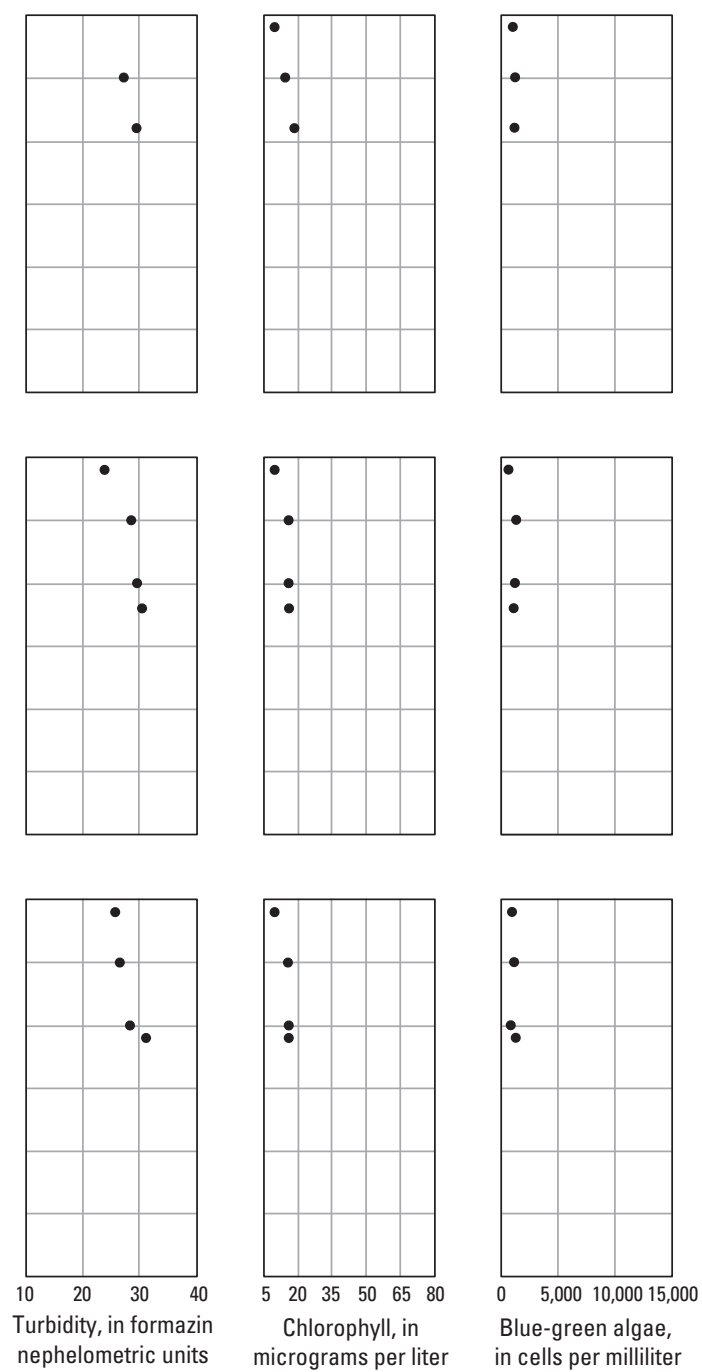

Figure 3-4. (Continued) Water-quality profile data collected in the Bushy Park Reservoir, near Goose Creek, South Carolina, March 27, 2014. 

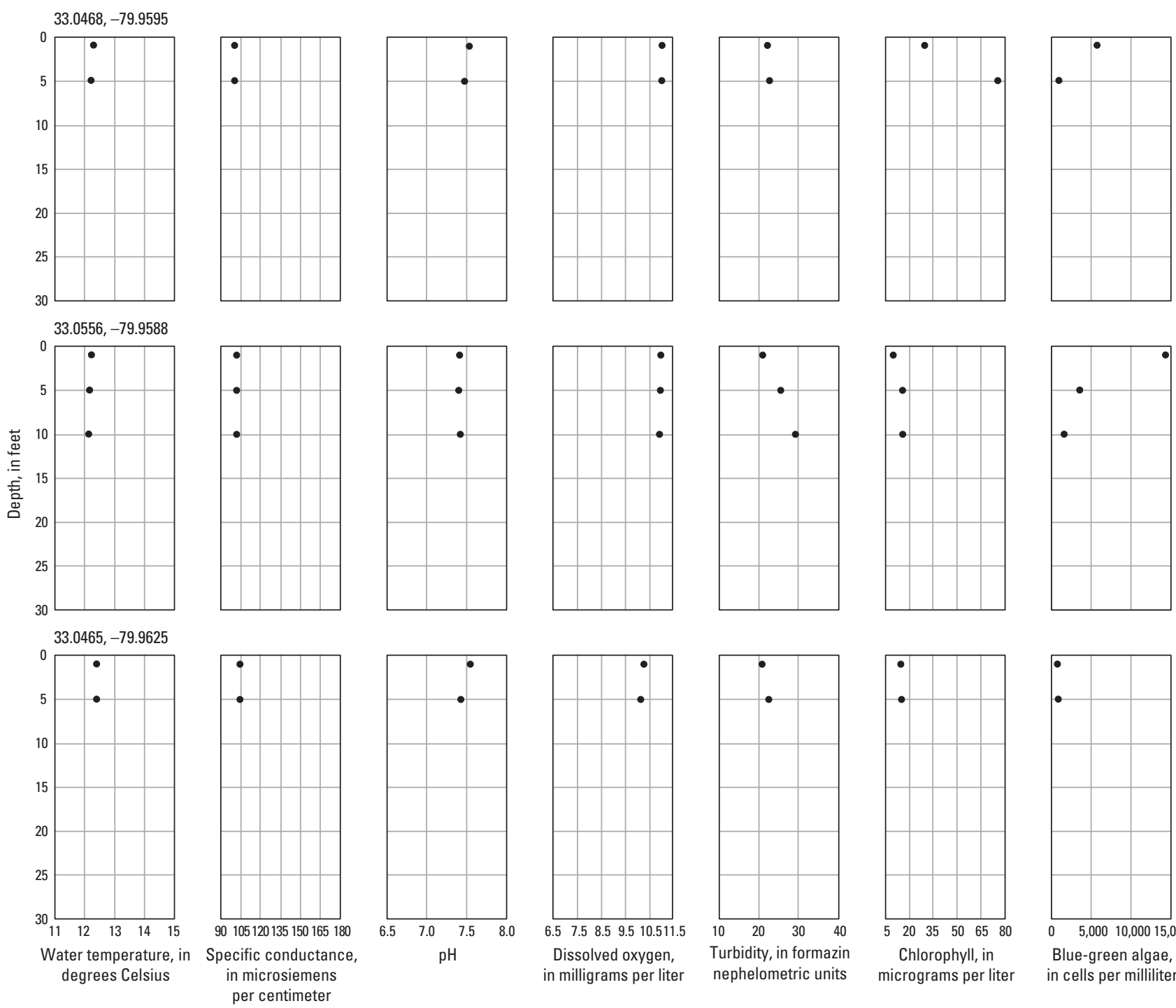

$33.0465,-79.9625$
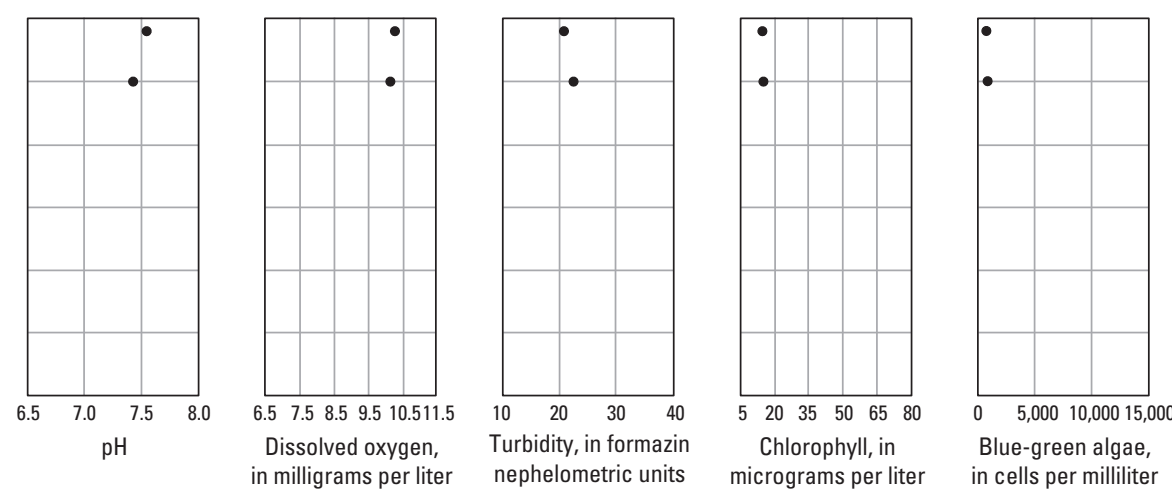

Figure 3-4. (Continued) Water-quality profile data collected in the Bushy Park Reservoir, near Goose Creek, South Carolina, March 27, 2014. 

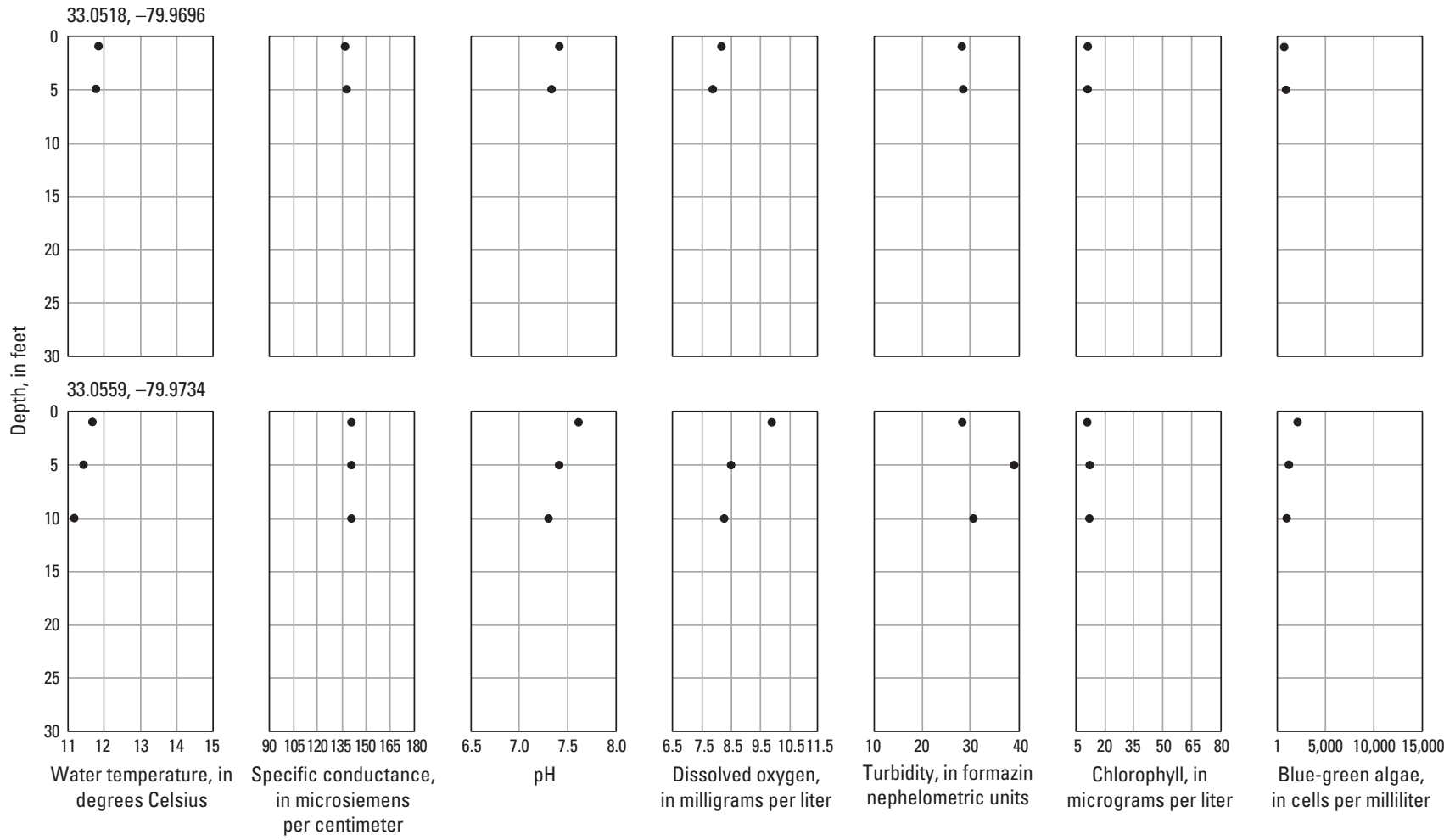

Figure 3-4. (Continued) Water-quality profile data collected in the Bushy Park Reservoir, near Goose Creek, South Carolina, March 27, 2014. 
CWS-7 (32.968284, -79.938346)
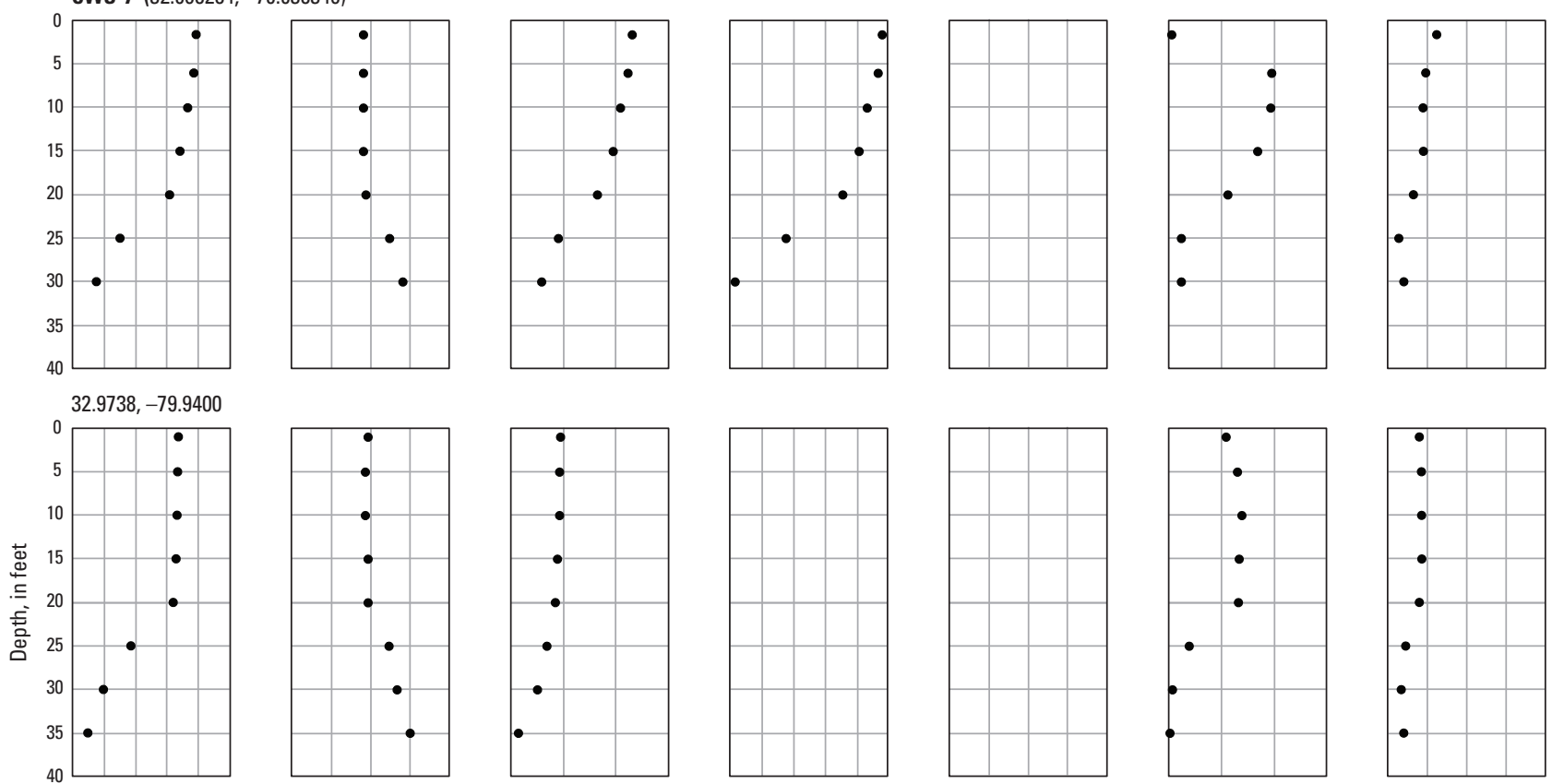

CWS-6 (32.981175, -79.953775)
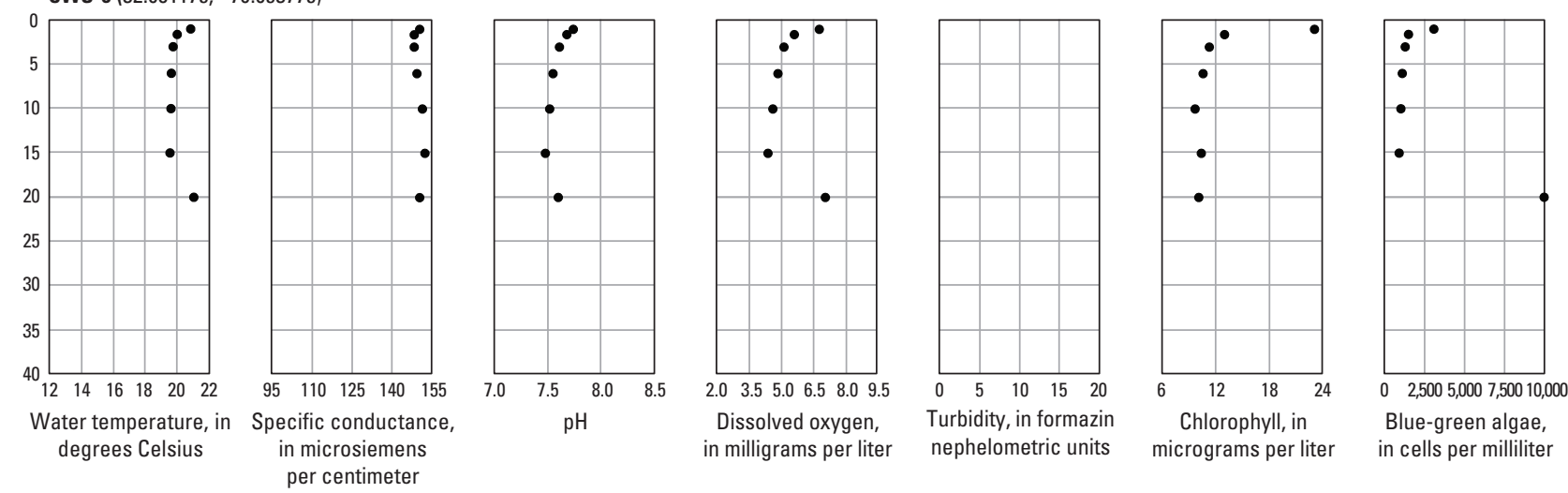

Figure 3-5. Water-quality profile data collected in the Bushy Park Reservoir, near Goose Creek, South Carolina, April 16, 2014. 
$32.9800,-79.9497$
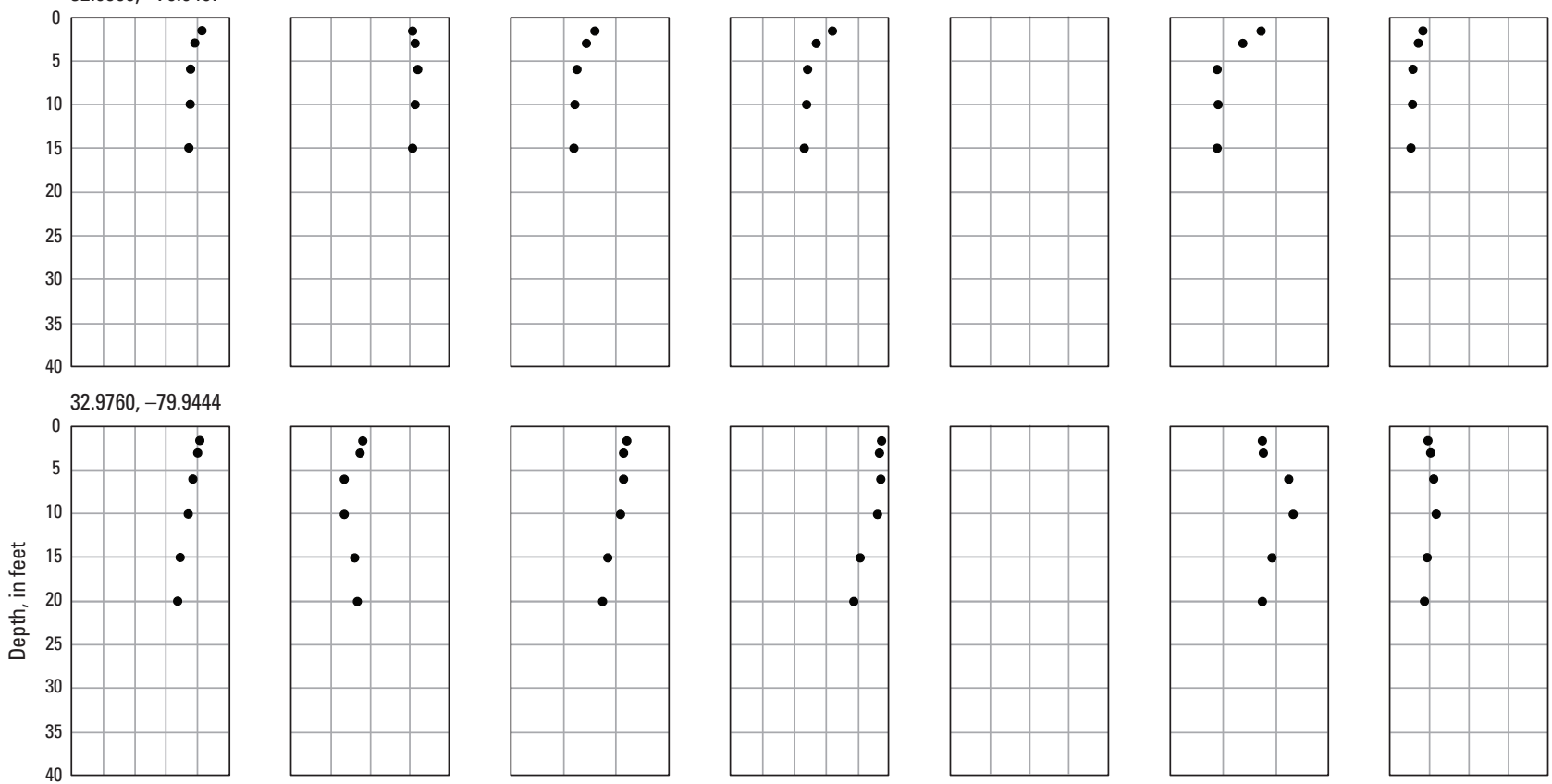

$32.9904,-79.9397$
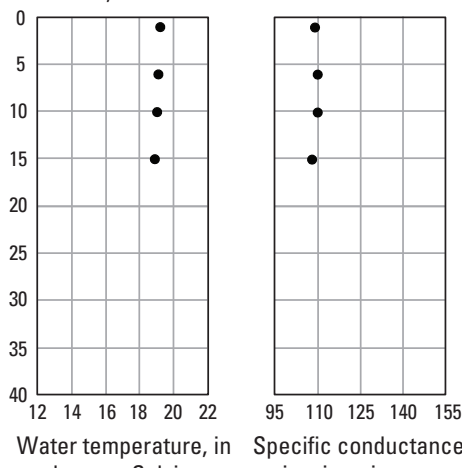

$95 \quad 110 \quad 125 \quad 140 \quad 155$ Specific conductance, in microsiemens
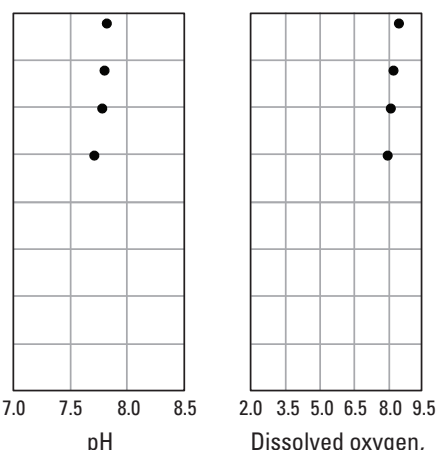

Dissolved oxygen,

in milligrams per liter
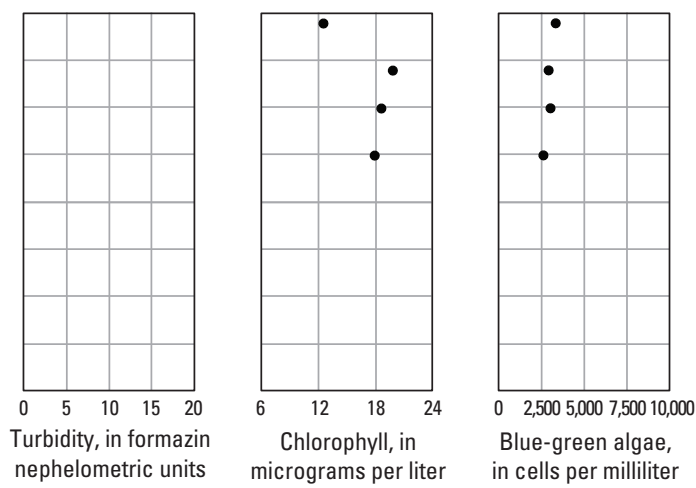

Figure 3-5. (Continued) Water-quality profile data collected in the Bushy Park Reservoir, near Goose Creek, South Carolina, April 16, 2014. 

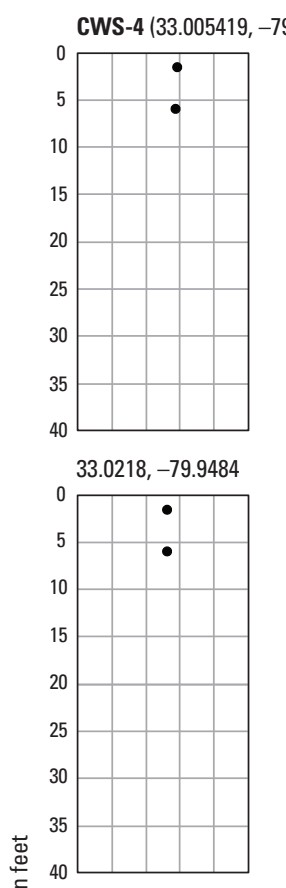

$\stackrel{\Phi}{.} 40$

CWS-3 (33.027444, -79.952313)
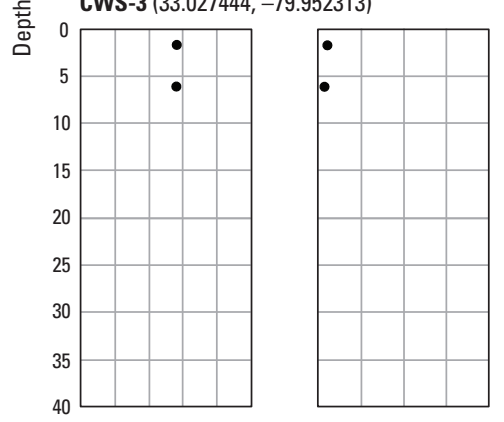

$33.0417,-79.9561$
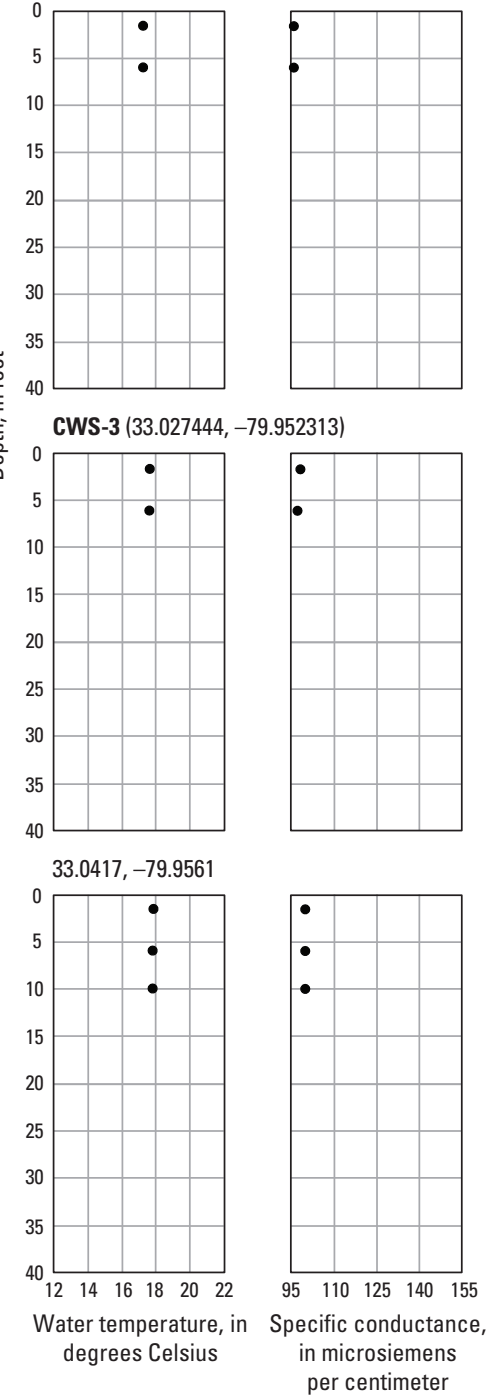
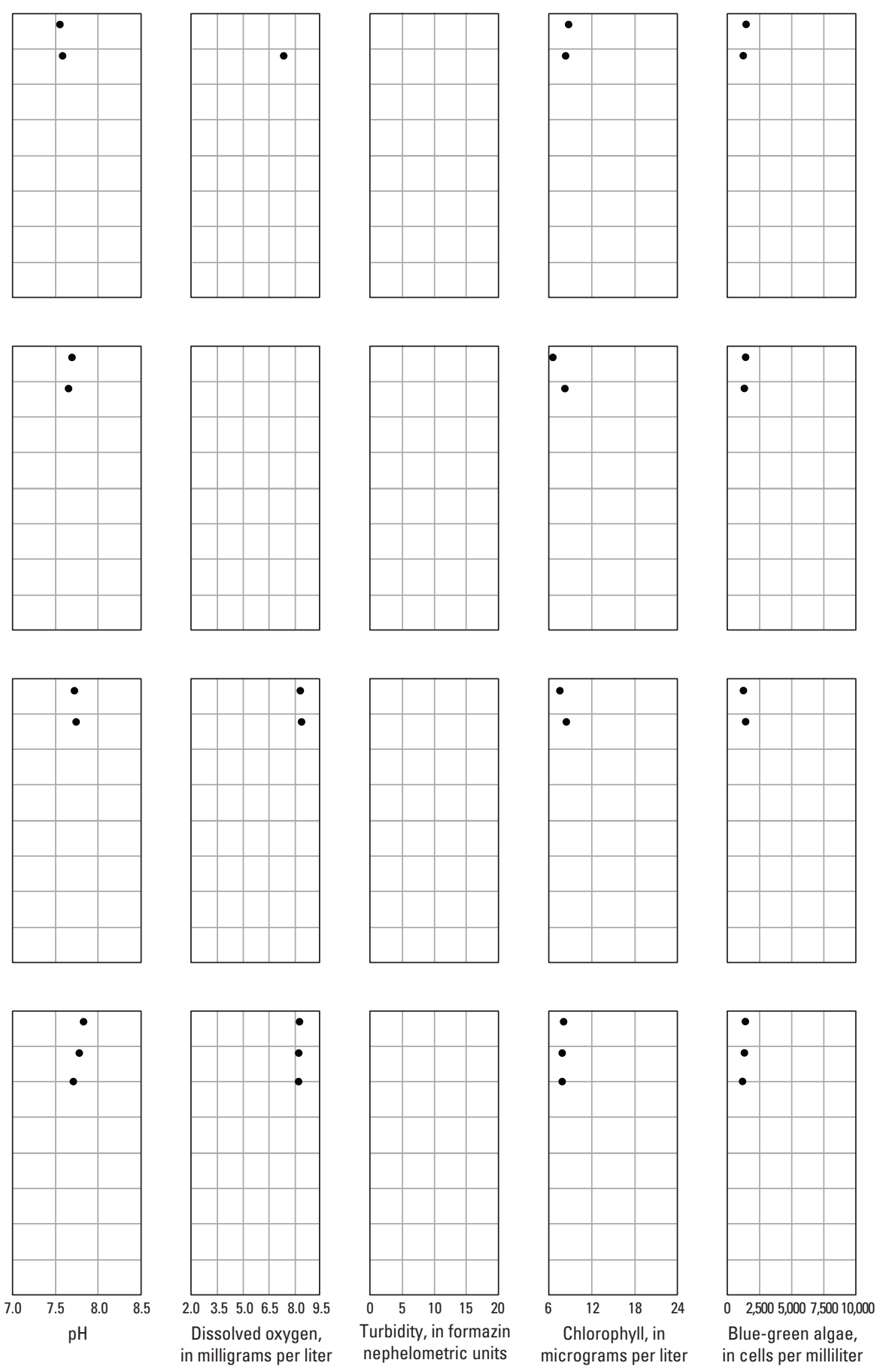

Figure 3-5. (Continued) Water-quality profile data collected in the Bushy Park Reservoir, near Goose Creek, South Carolina, April 16, 2014. 
CWS-7 $(32.968284,-79.938346)$
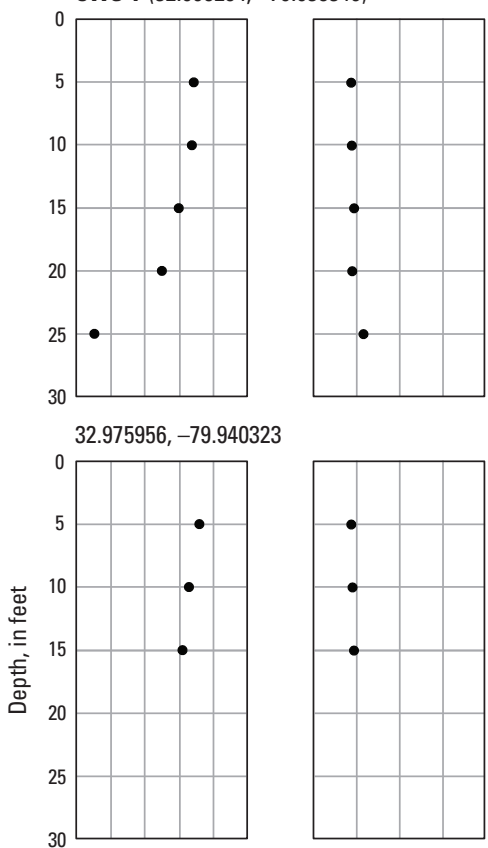

CWS-5 (32.979972, -79.941094)

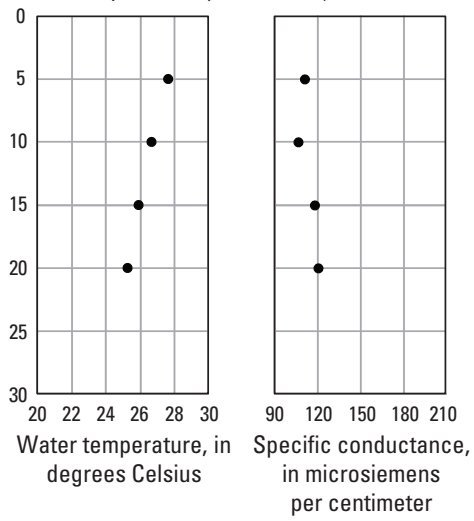

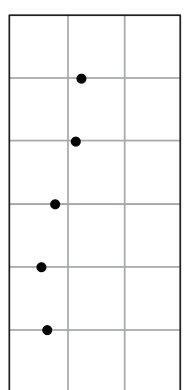
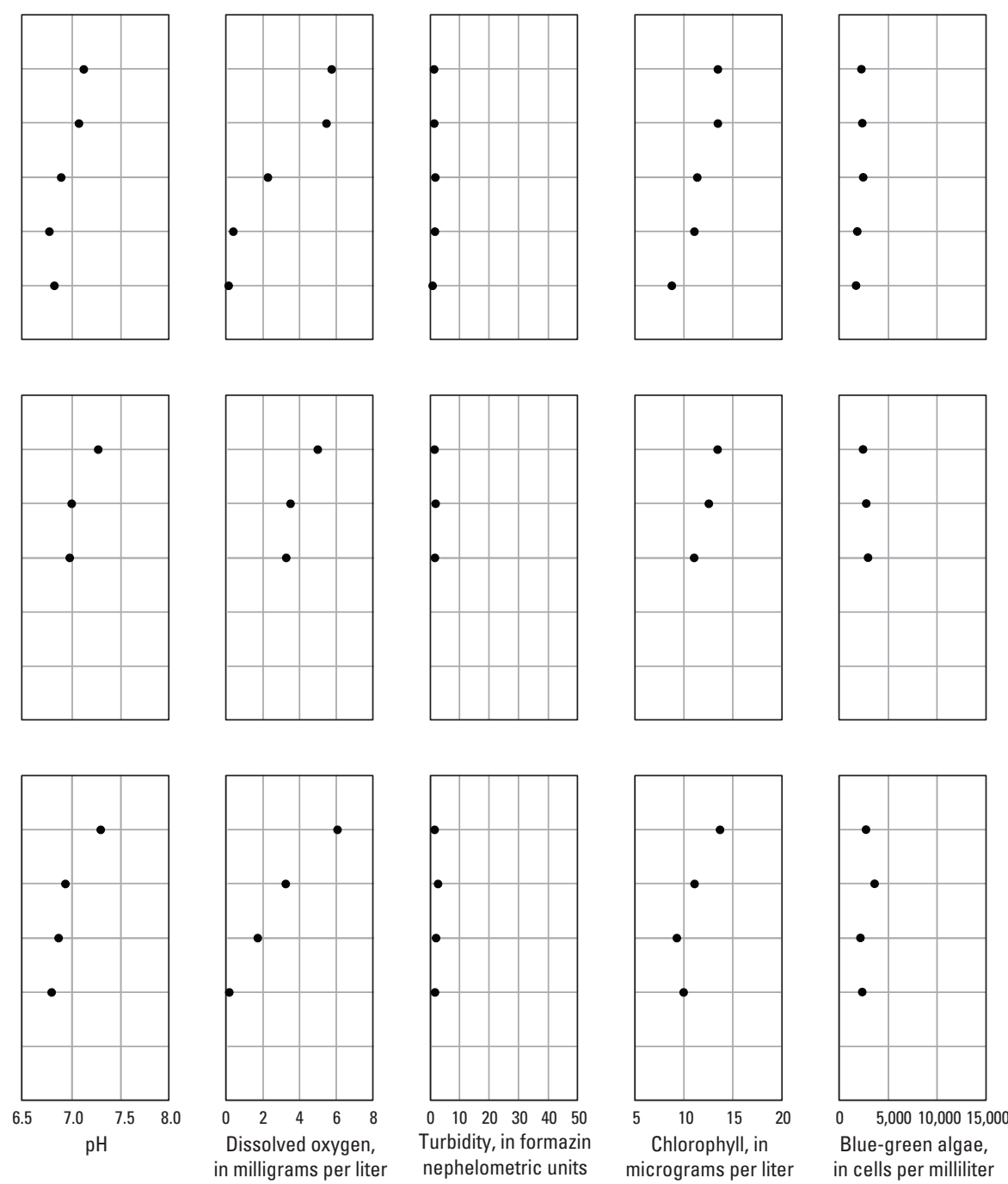

Figure 3-6. Water-quality profile data collected in the Bushy Park Reservoir, near Goose Creek, South Carolina, June 10, 2014. 

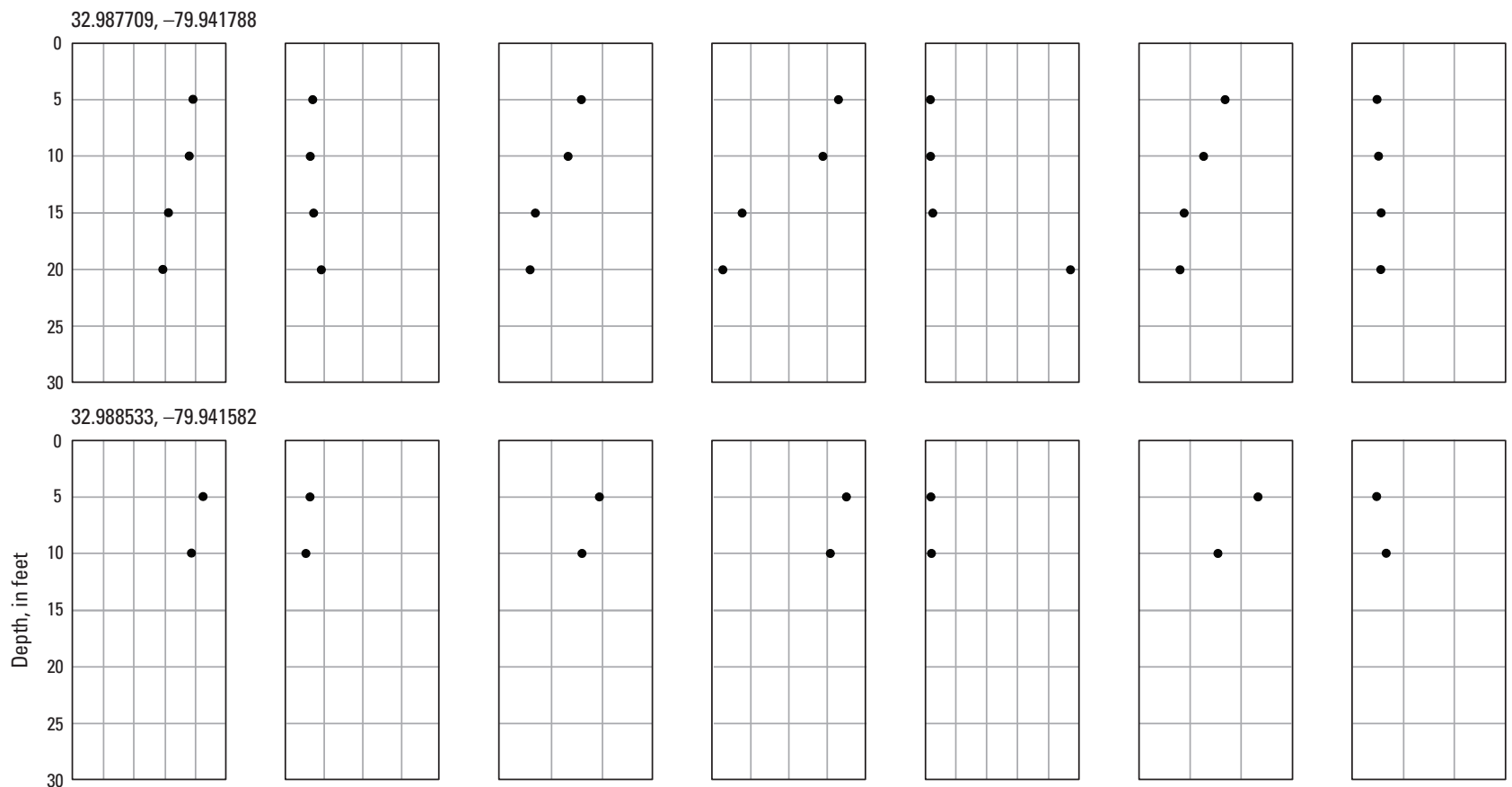

$32.996678,-79.937841$
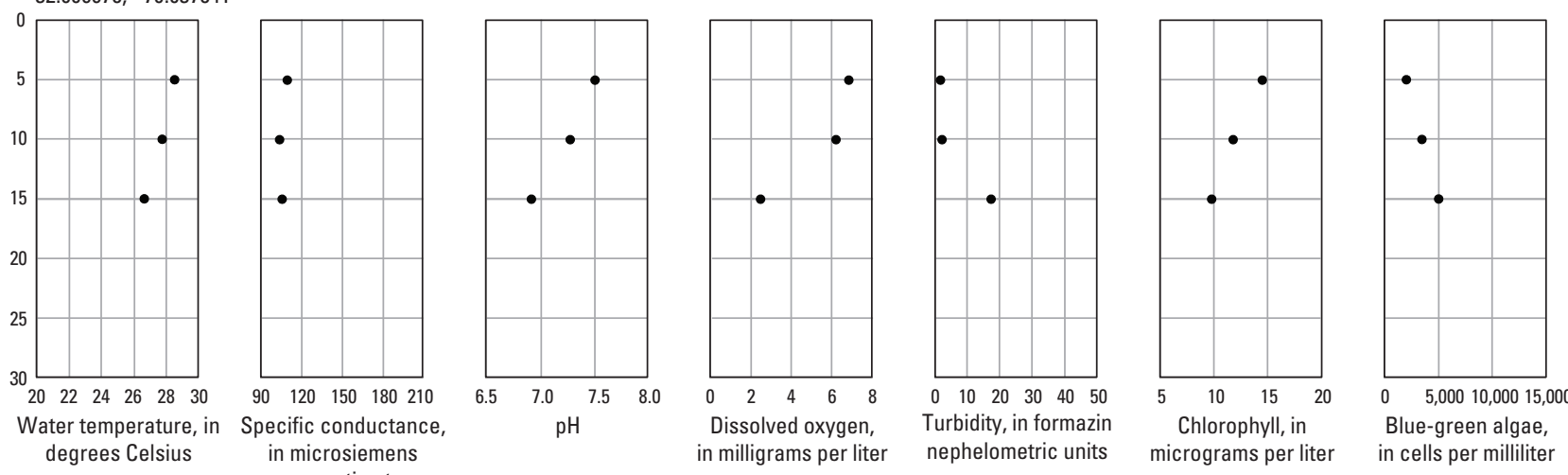

Figure 3-6. (Continued) Water-quality profile data collected in the Bushy Park Reservoir, near Goose Creek, South Carolina, June 10, 2014. 
CWS-4 (33.005419, -79.937590$)$

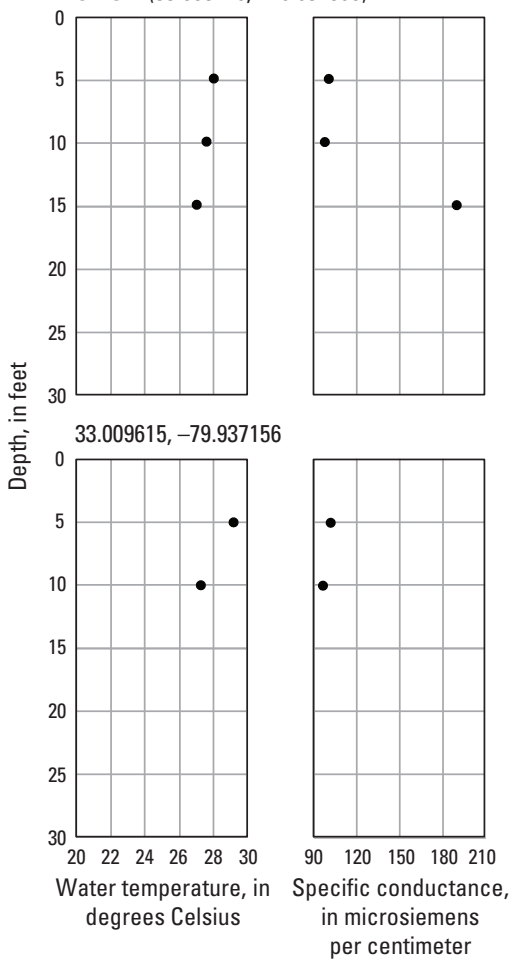

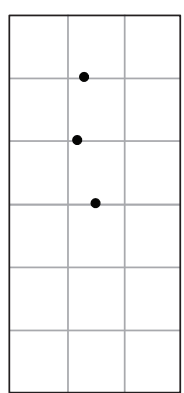
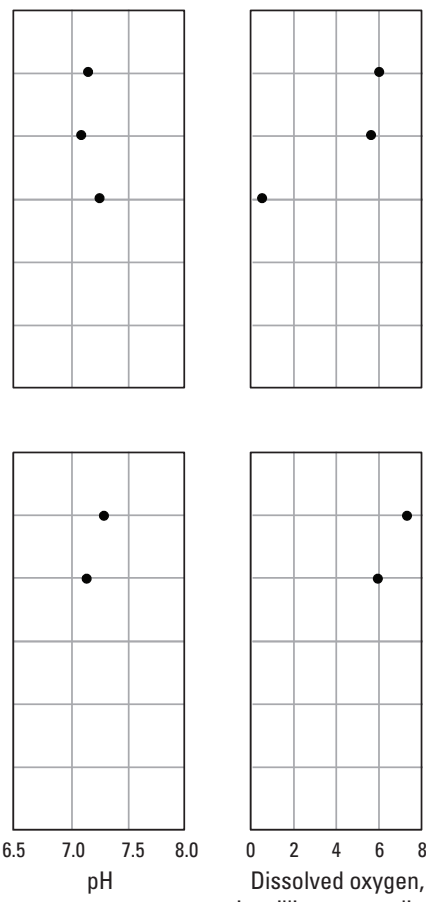
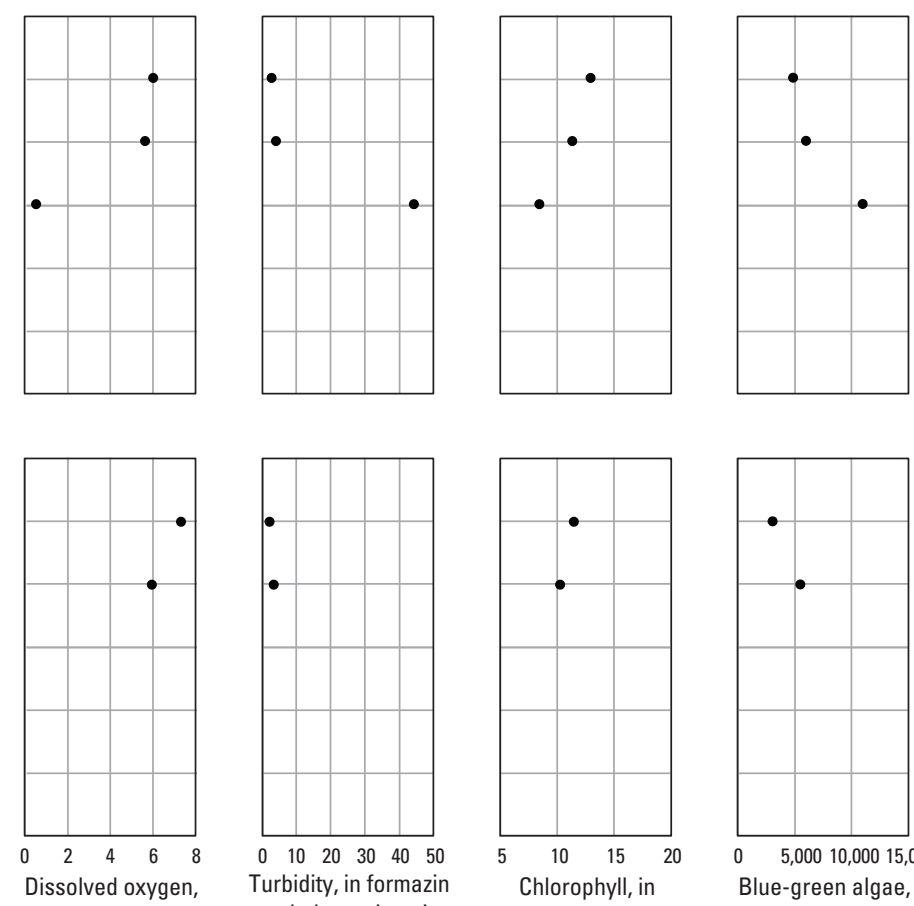

in milligrams per liter
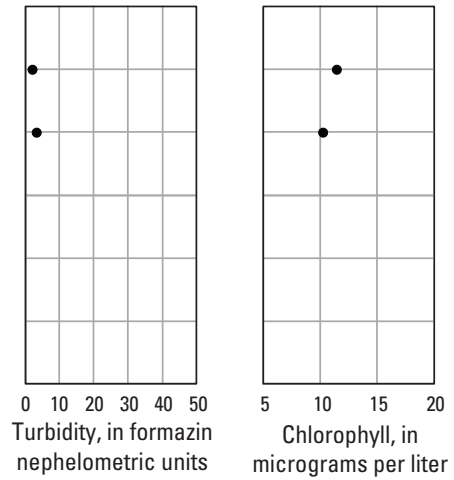

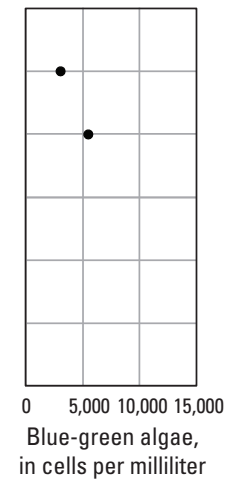

Figure 3-6. (Continued) Water-quality profile data collected in the Bushy Park Reservoir, near Goose Creek, South Carolina, June 10, 2014. 
CWS-7 $(32.968284,-79.938346)$
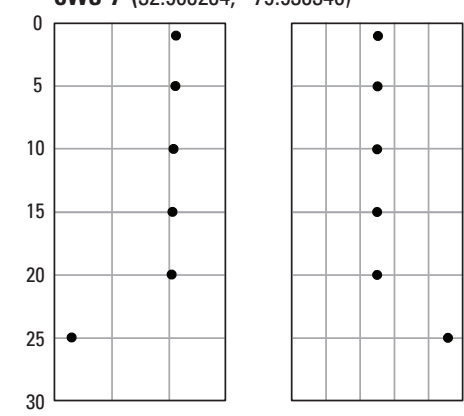

CWS-6 $(32.981175,-79.953775)$
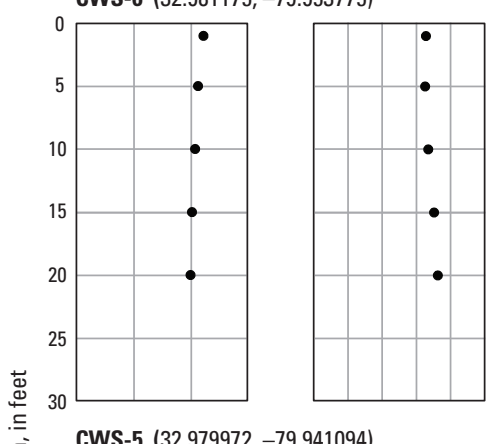

É CWS-5 (32.979972, -79.941094$)$

产

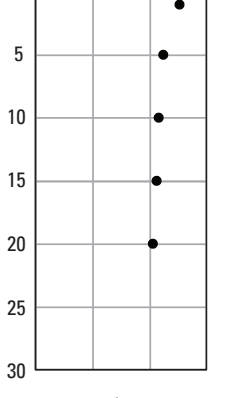

CWS-4 $(33.005419,-79.937590)$
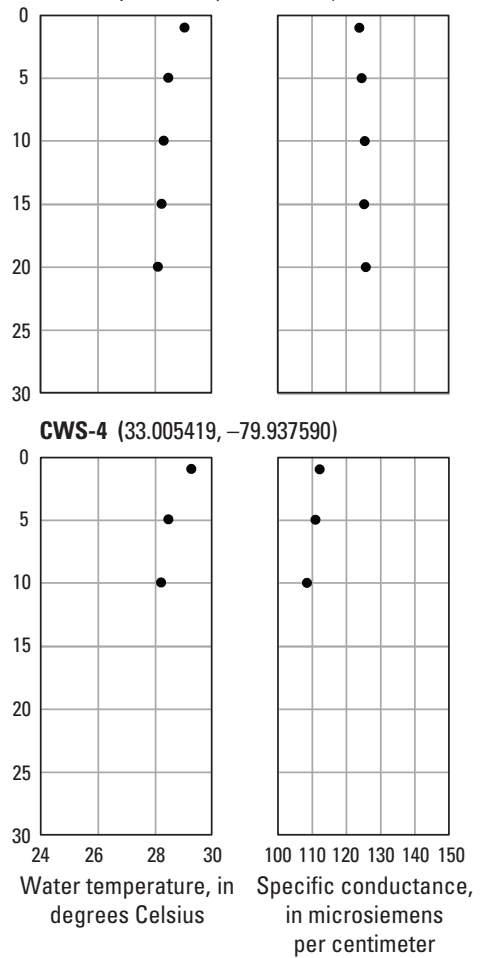
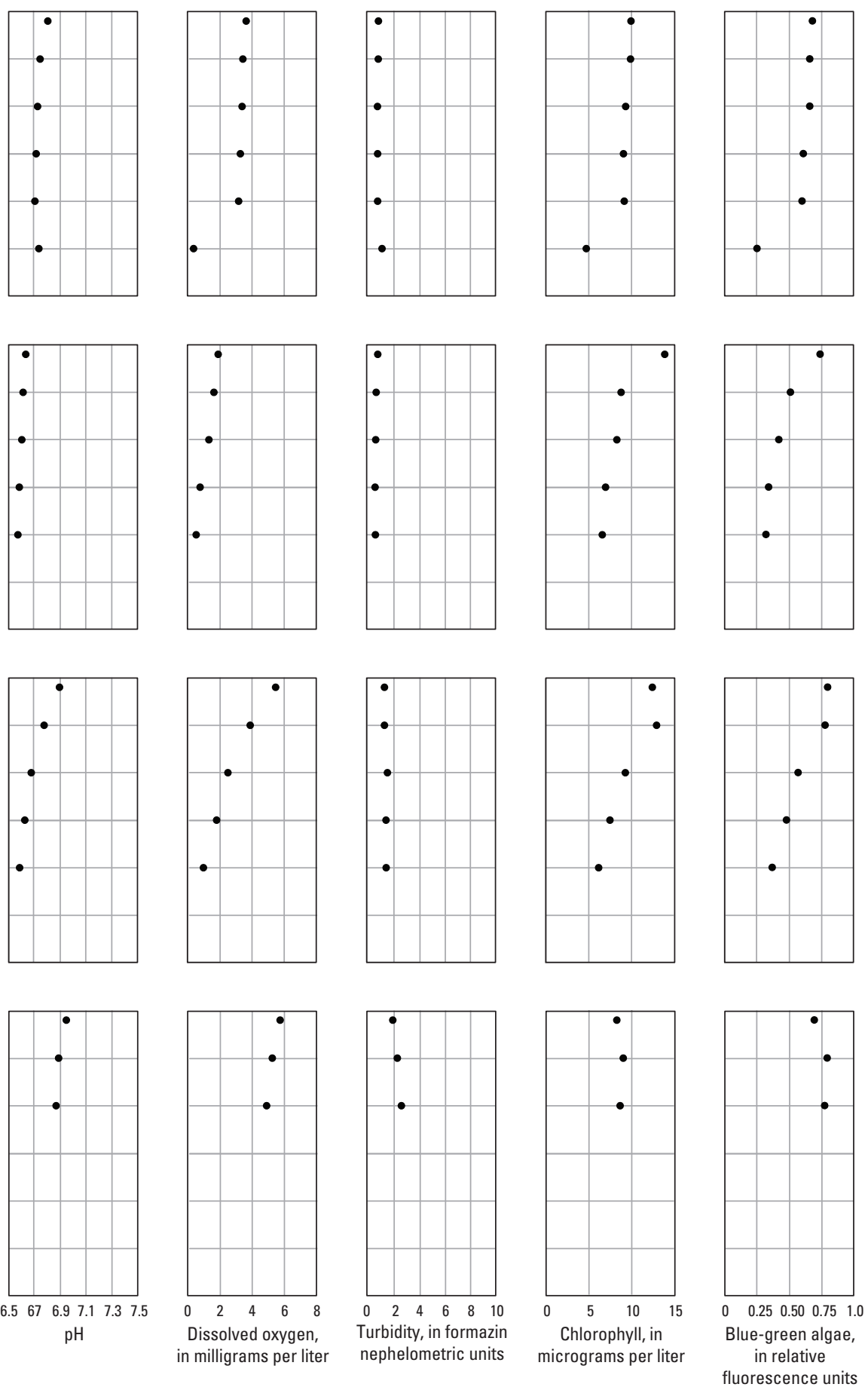

Figure 3-7. Water-quality profile data collected in the Bushy Park Reservoir, near Goose Creek, South Carolina, July 23, 2014. 
CWS-3 $(33.027444,-79.952313)$
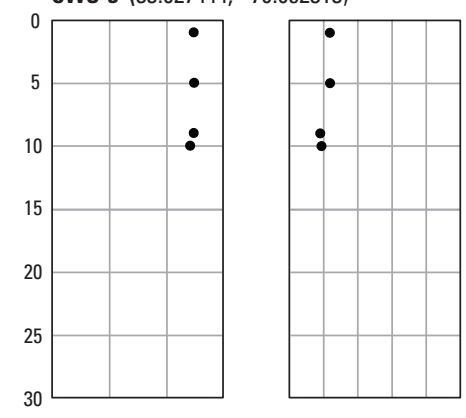

CWS-2 (33.058115, -79.958243)
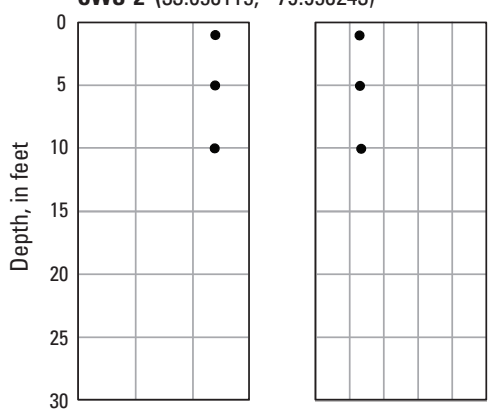

CWS-1 (33.084590, -79.944599)

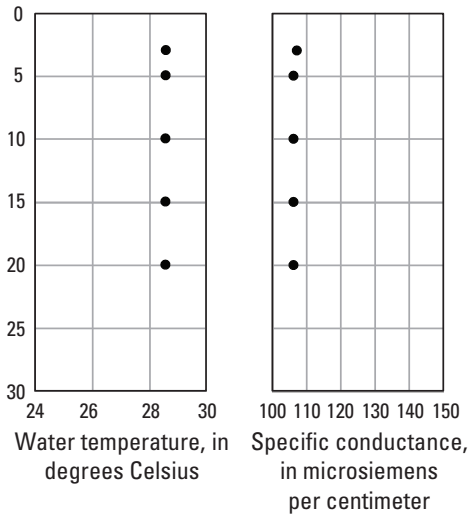

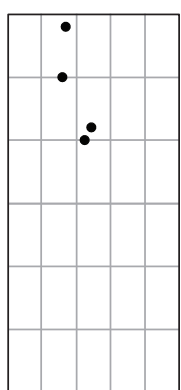
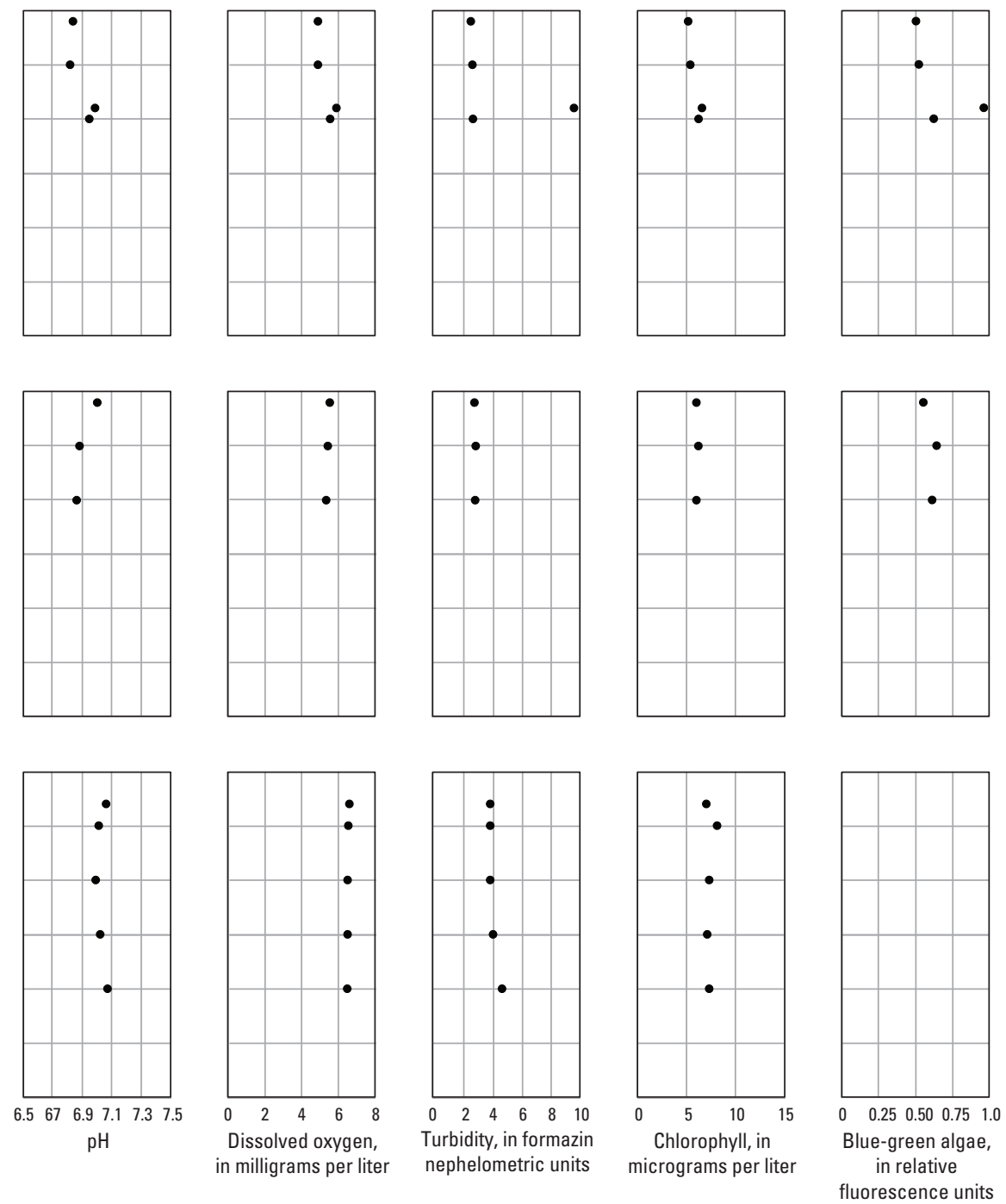

Figure 3-7. (Continued) Water-quality profile data collected in the Bushy Park Reservoir, near Goose Creek, South Carolina, July 23, 2014. 
CWS-7 (32.968284,-79.938346)
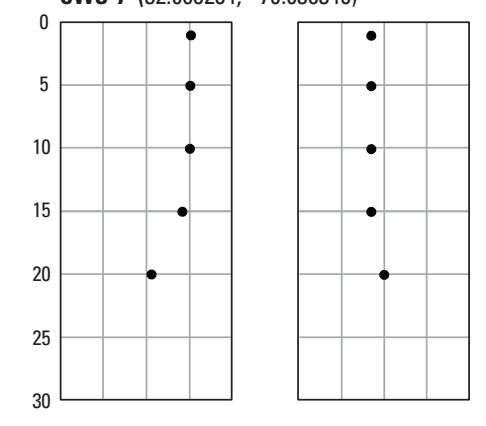

CWS-5 (32.979972, -79.941094)
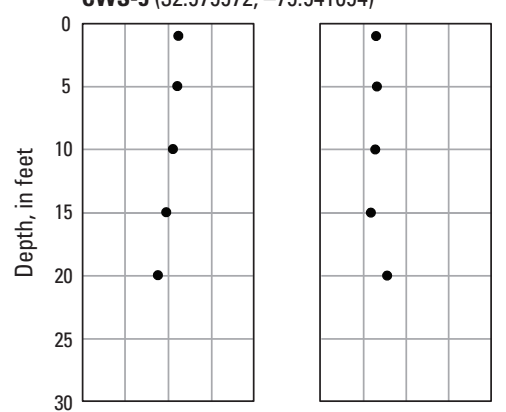

CWS-4 (33.005419, -79.937590)

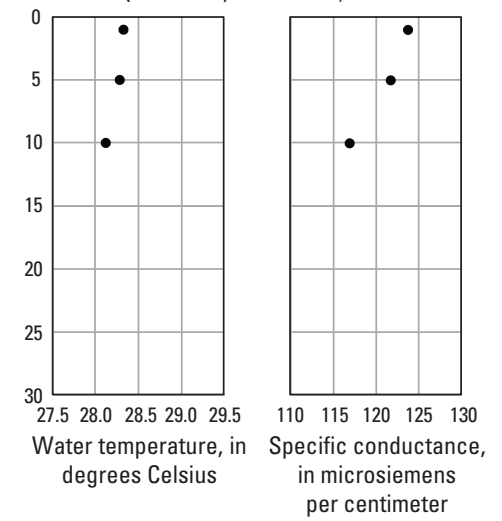

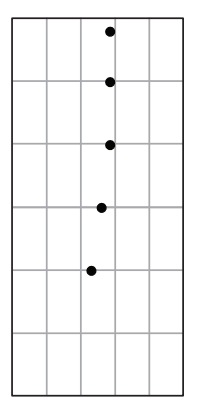
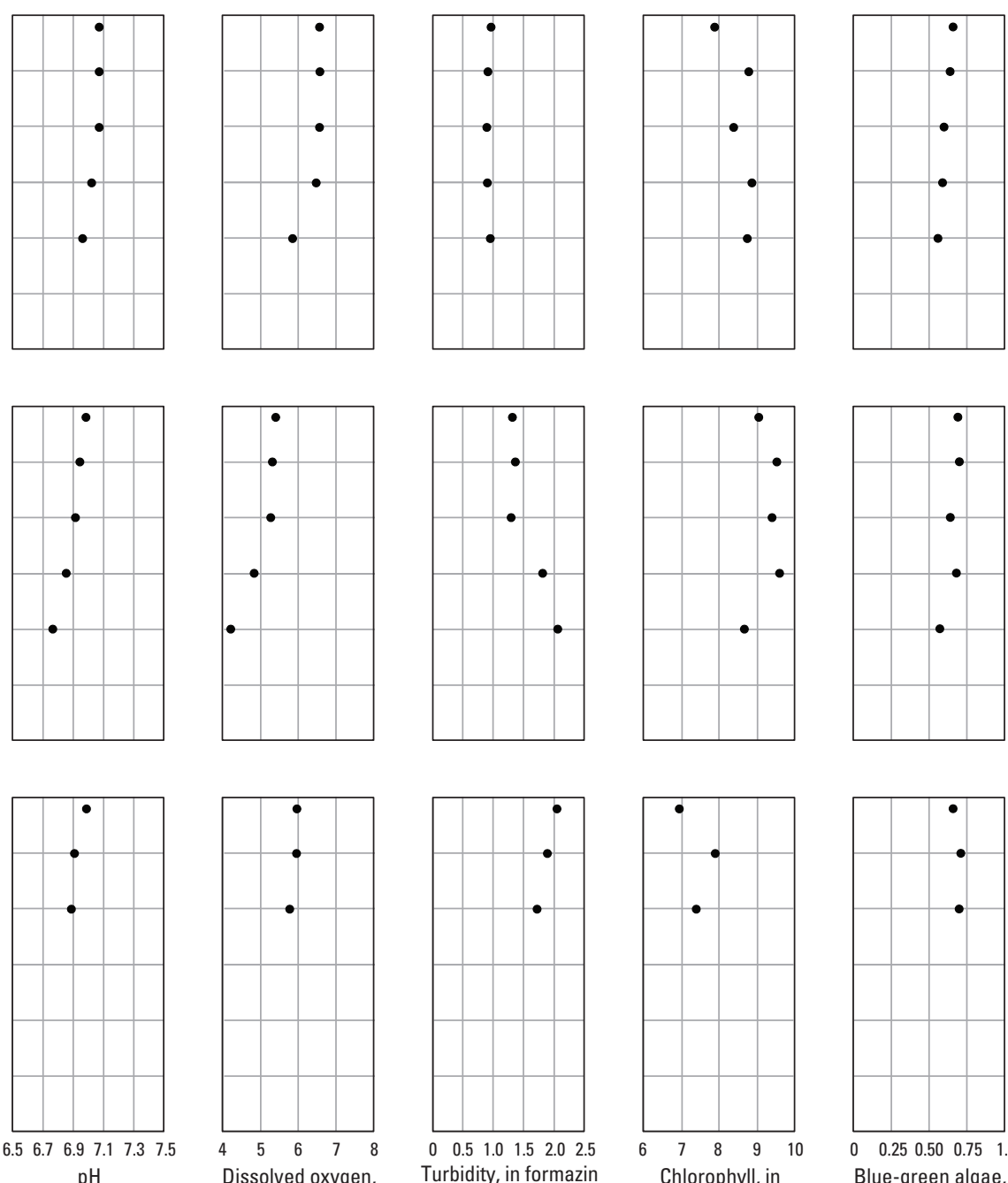

$\mathrm{pH}$

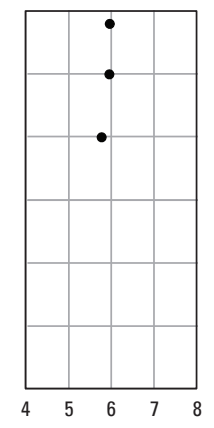

Dissolved oxygen, in milligrams per liter
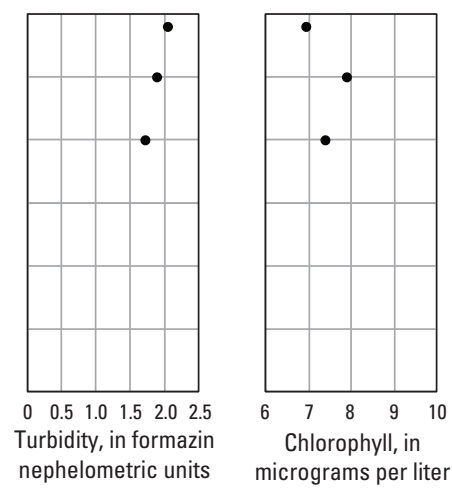

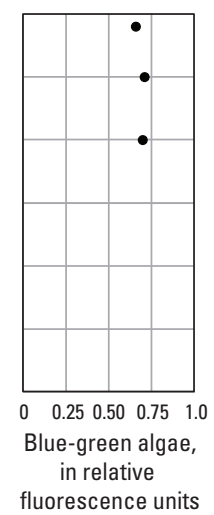

Figure 3-8. Water-quality profile data collected in the Bushy Park Reservoir, near Goose Creek, South Carolina, August 26, 2014. 

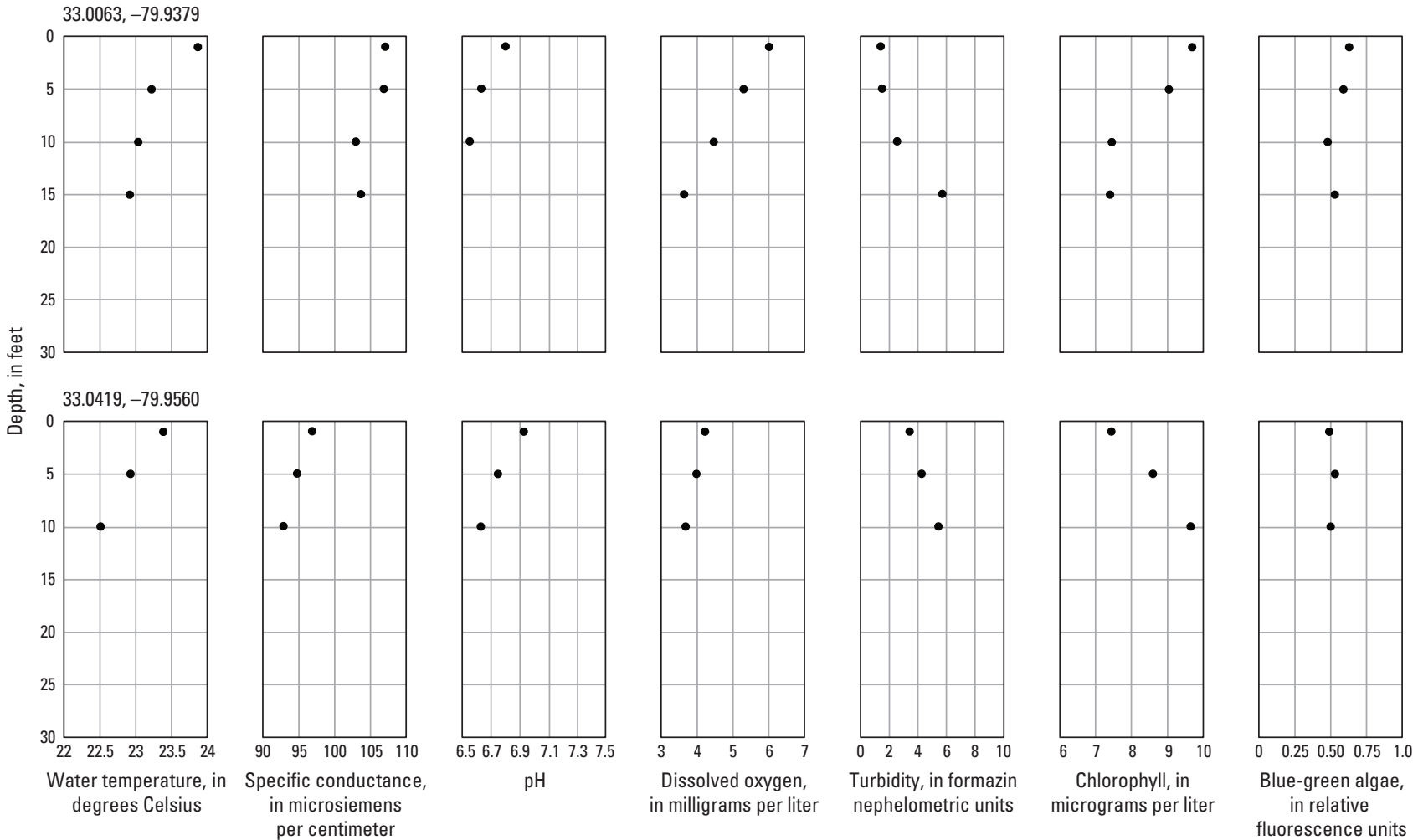

Figure 3-9. Water-quality profile data collected in the Bushy Park Reservoir, near Goose Creek, South Carolina, October 2, 2014. 
CWS-7 (32.968284, -79.938346)
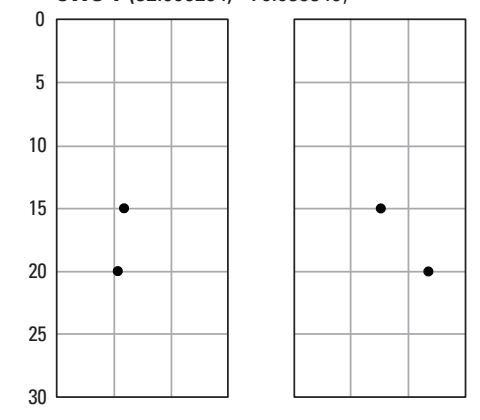

CWS-5 (32.979972, -79.941094)
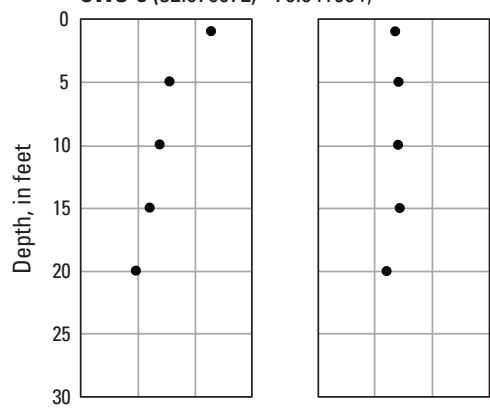

$32.993278,-79.937444$
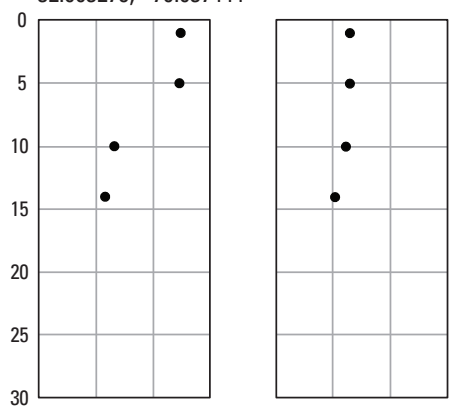

CWS-4 (33.005419, -79.937590$)$

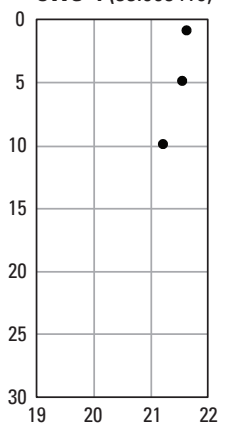

Water temperature, in degrees Celsius

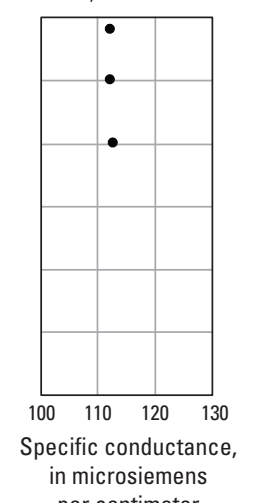

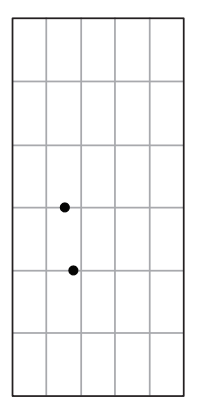
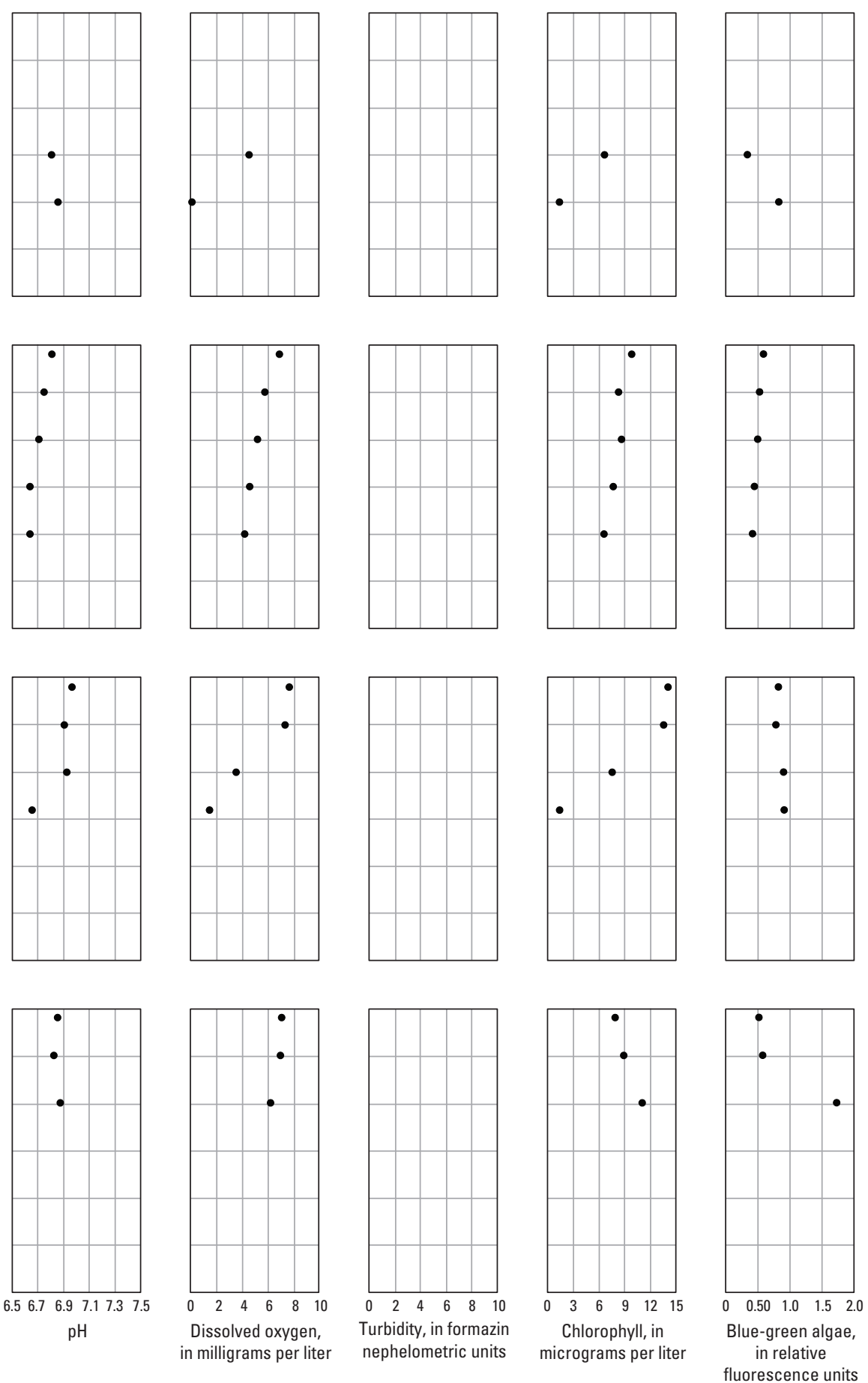

Figure 3-10. Water-quality profile data collected in the Bushy Park Reservoir, near Goose Creek, South Carolina, October 29, 2014. 
$33.022366,-79.948570$
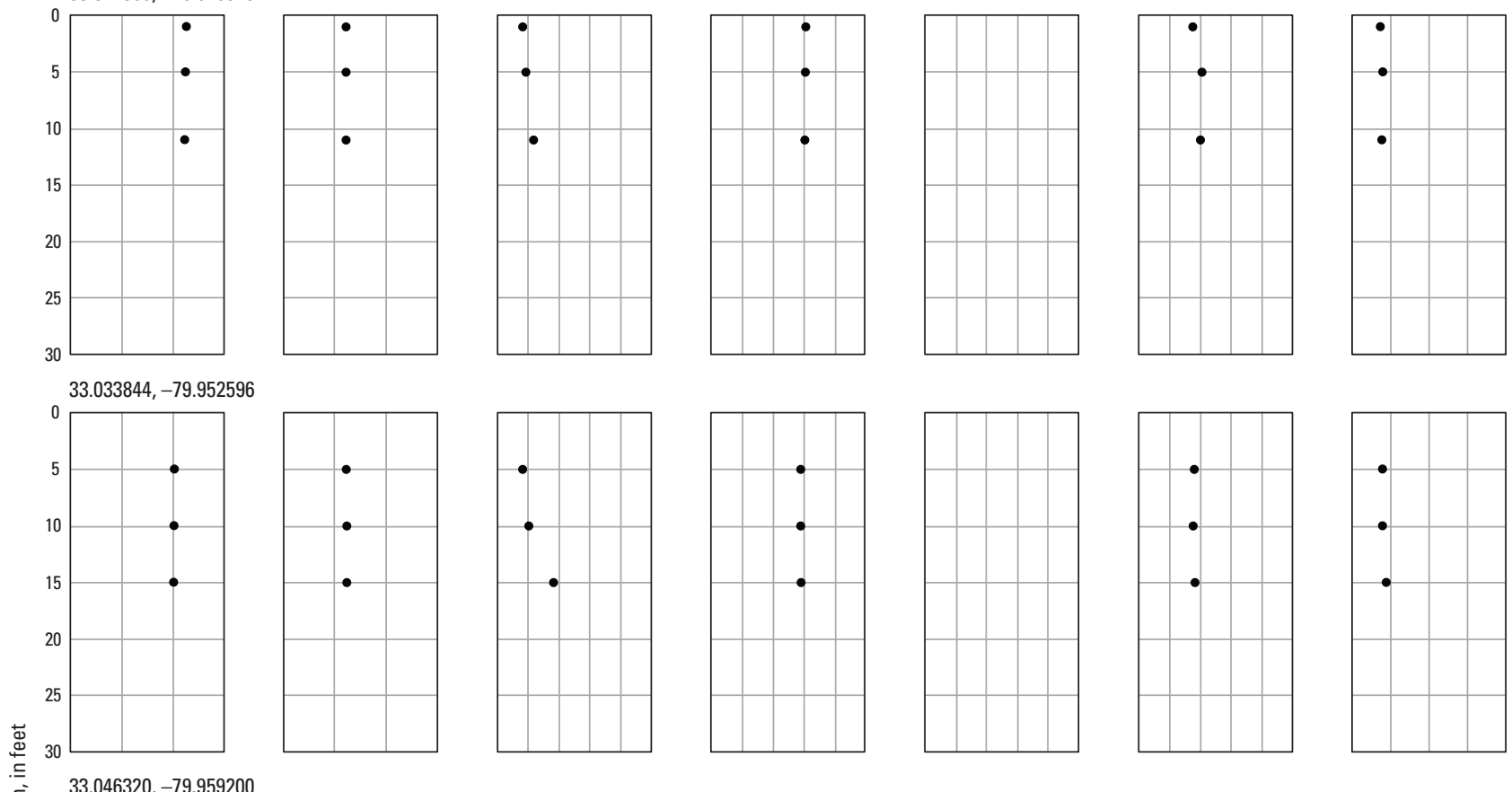

巨苔 $33.046320,-79.959200$
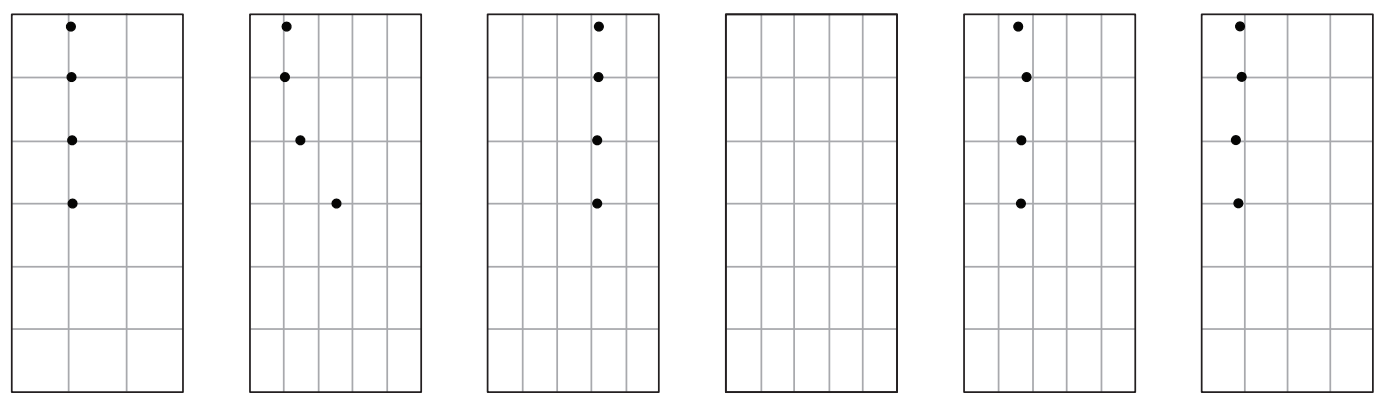

CWS-2 (33.058115, -79.958243)
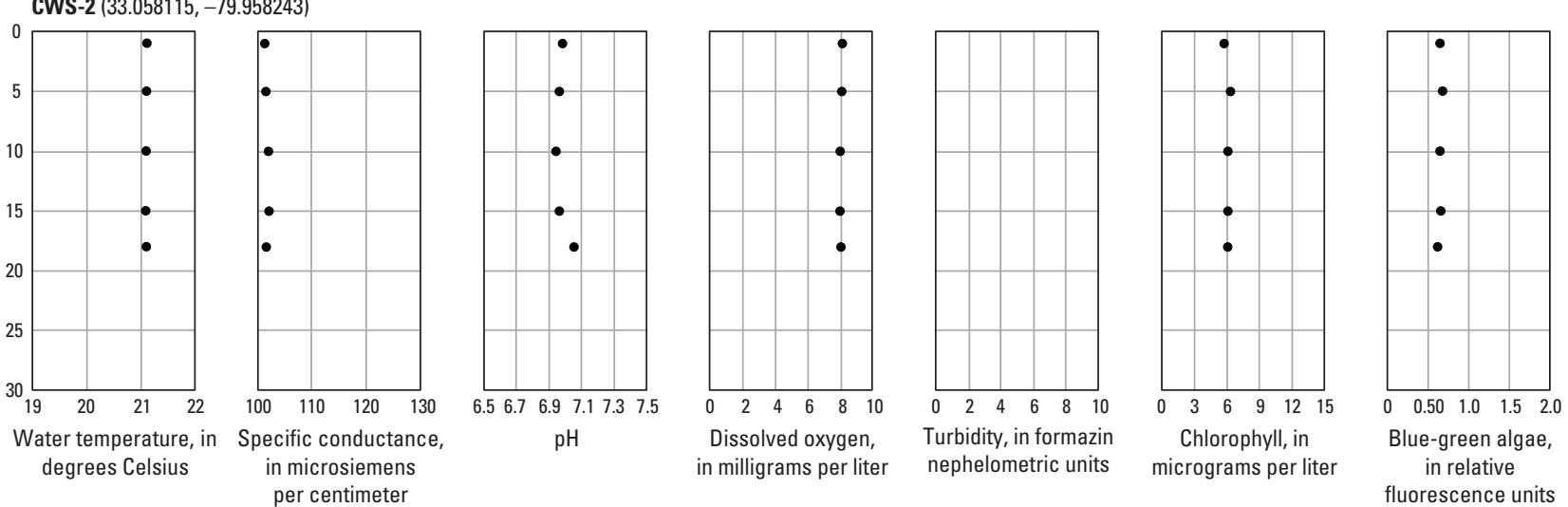

Figure 3-10. (Continued) Water-quality profile data collected in the Bushy Park Reservoir, near Goose Creek, South Carolina, October 29, 2014. 

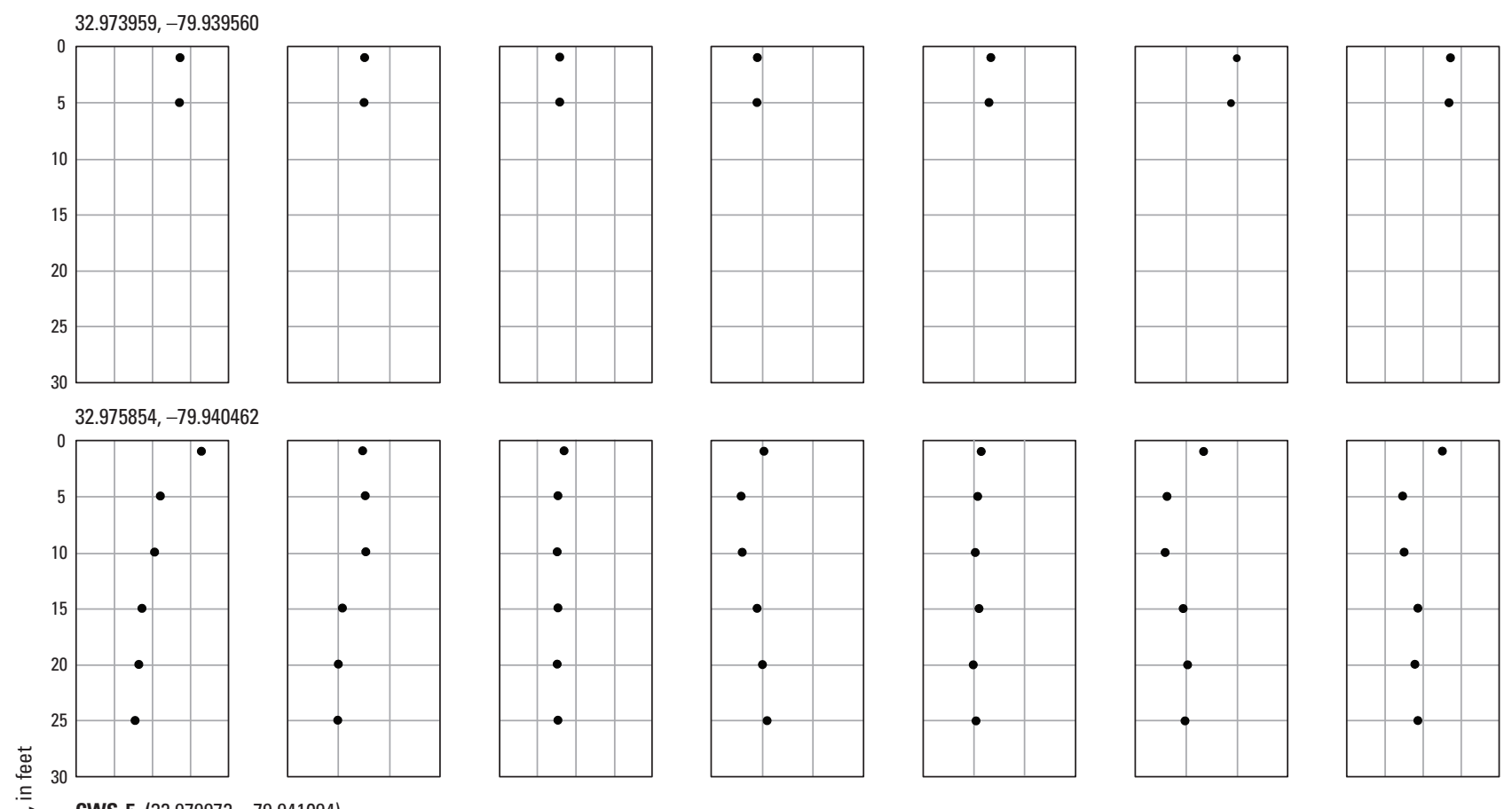

营

CWS-5 $(32.979972,-79.941094)$
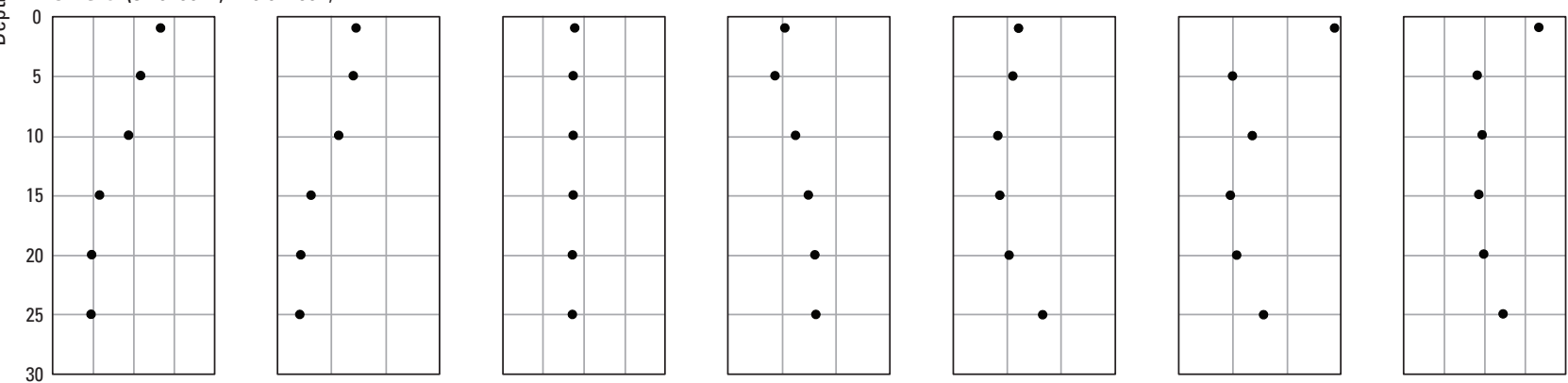

$32.997970,-79.937292$
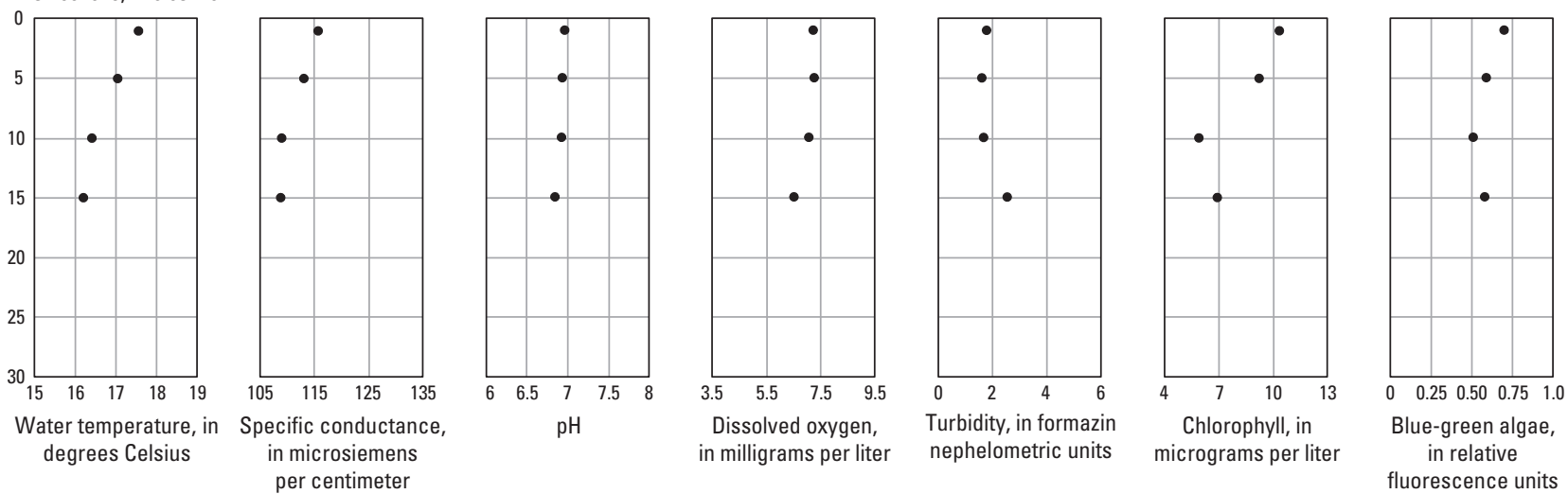

Figure 3-11. Water-quality profile data collected in the Bushy Park Reservoir, near Goose Creek, South Carolina, November 5, 2014. 
$33.022322,-79.948303$
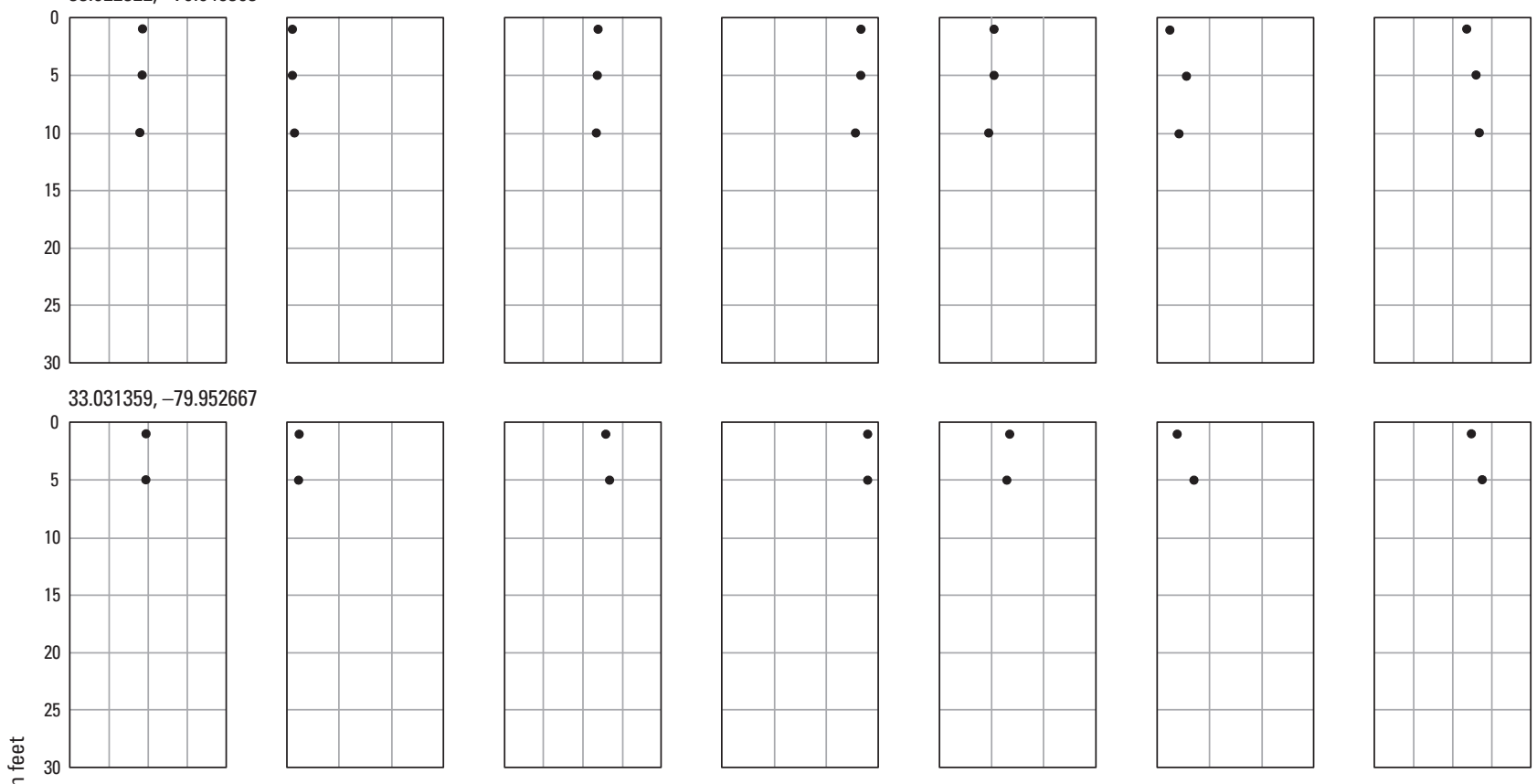

E. 33.043916, -79.958219
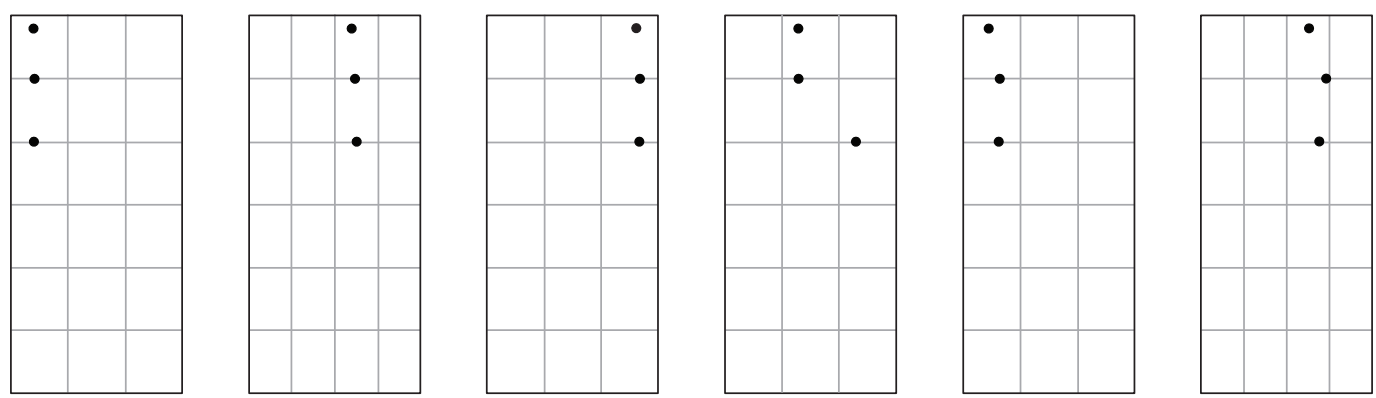

$33.055122,-79.958789$
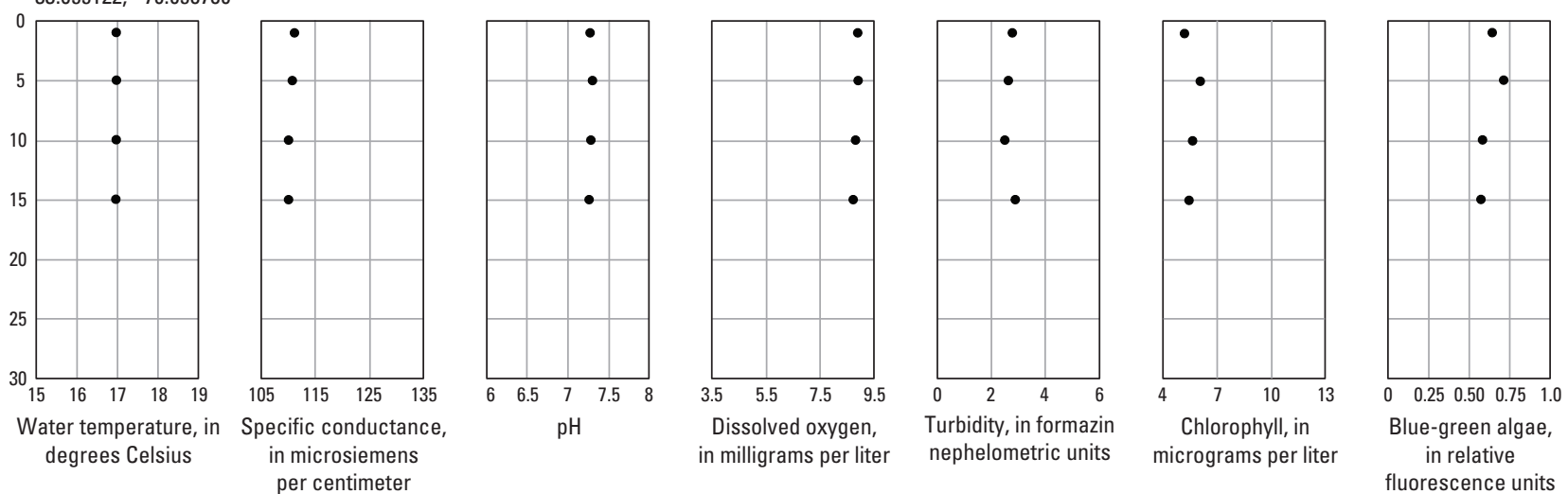

Figure 3-11. (Continued) Water-quality profile data collected in the Bushy Park Reservoir, near Goose Creek, South Carolina, November 5, 2014. 
CWS-7 (32.968284, -79.938346$)$
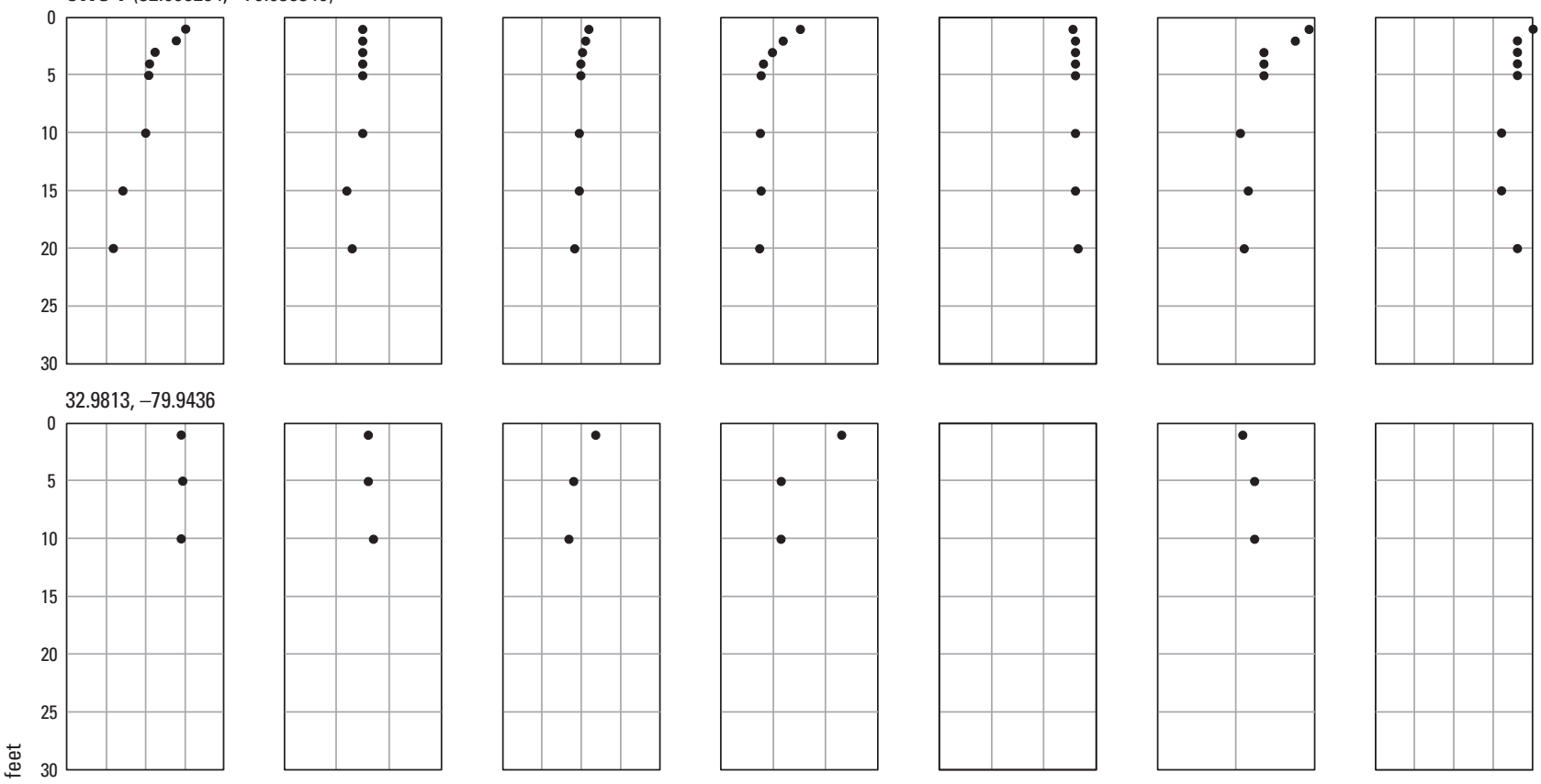

$\cong \quad$ CWS-6 $(32.981175,-79.953775)$

言
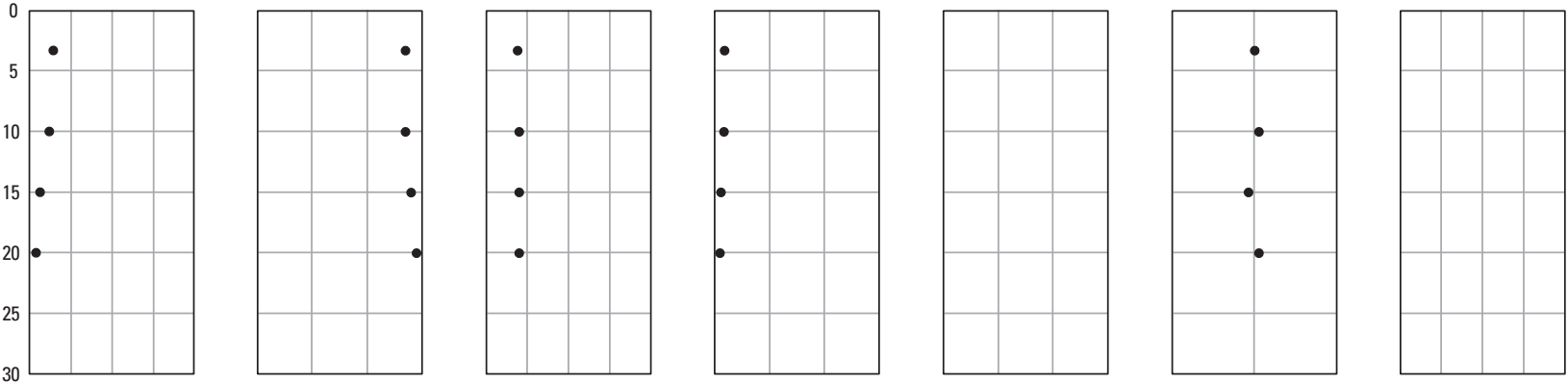

$33.0003,-79.9372$
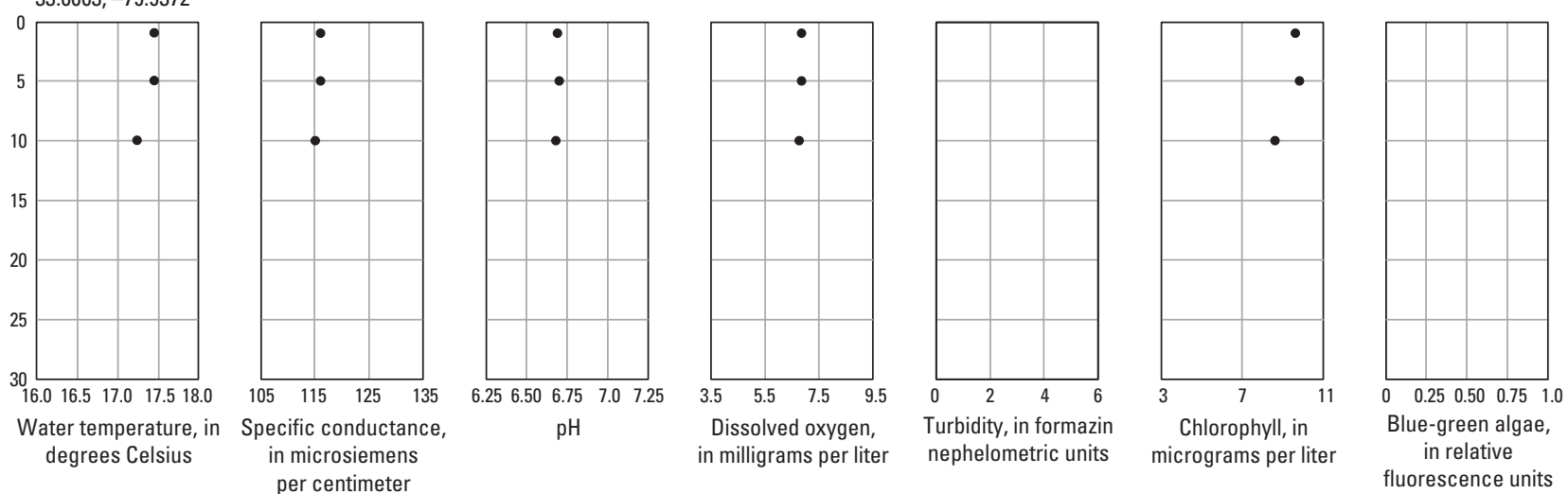

Figure 3-12. Water-quality profile data collected in the Bushy Park Reservoir, near Goose Creek, South Carolina, November 6, 2014. 


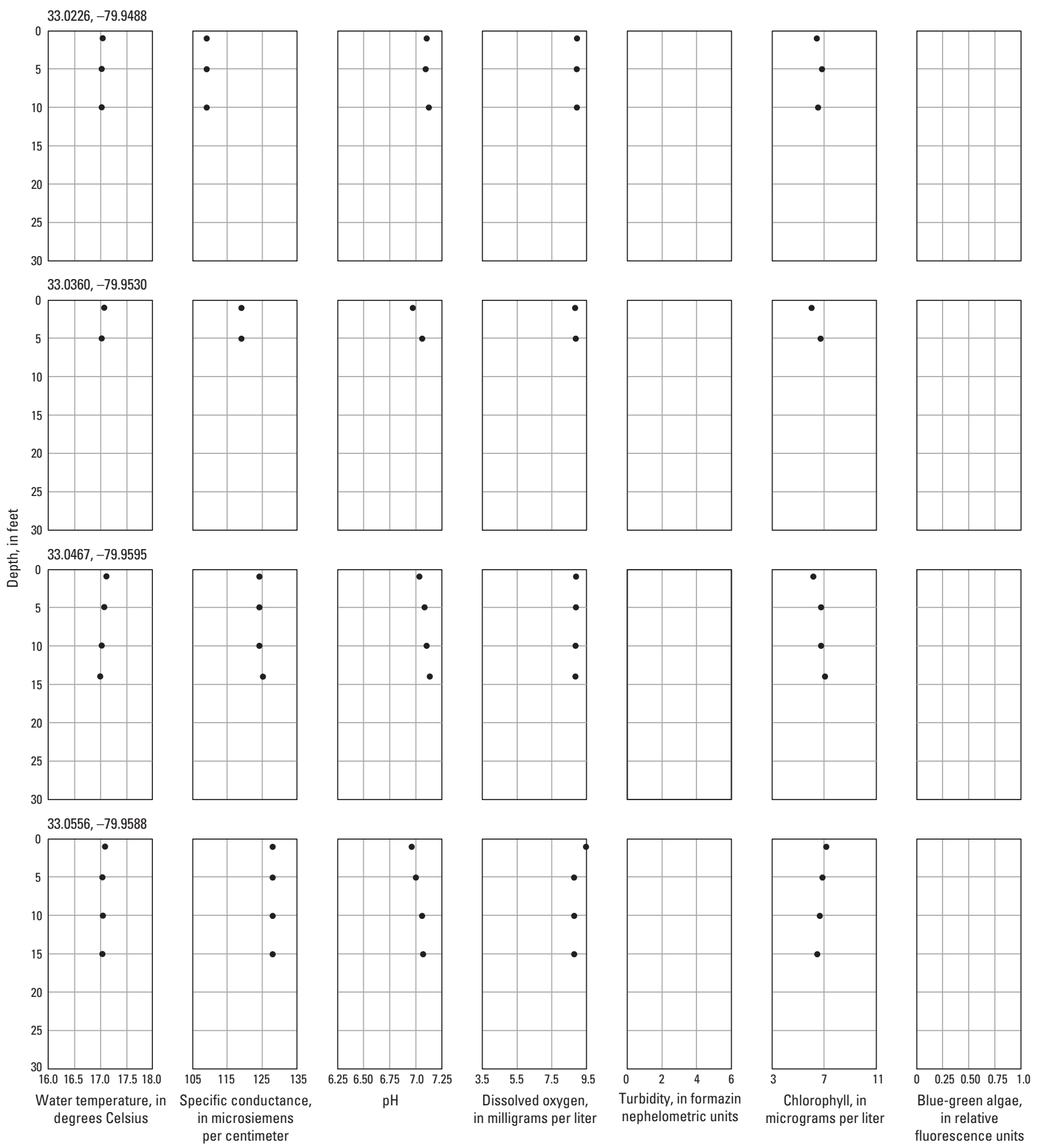

Figure 3-12. (Continued) Water-quality profile data collected in the Bushy Park Reservoir, near Goose Creek, South Carolina, November 6, 2014. 
CWS-7 (32.968284, -79.938346$)$
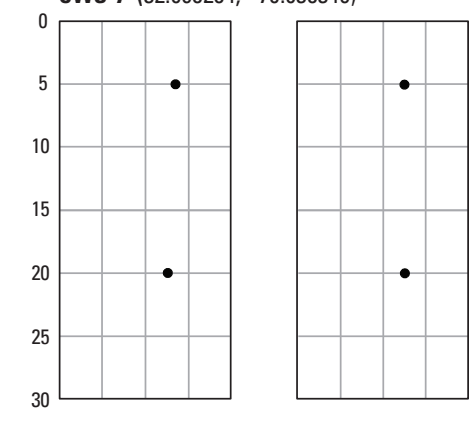

CWS-6 (32.981175, -79.953775)
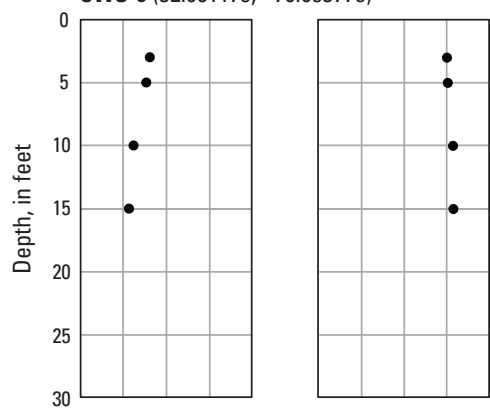

CWS-5 (32.979972, -79.941094$)$

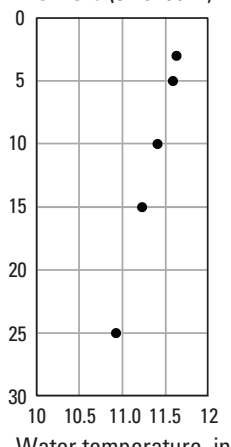

Water temperature, in

degrees Celsius

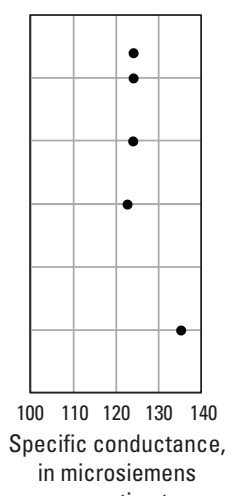

per centimeter
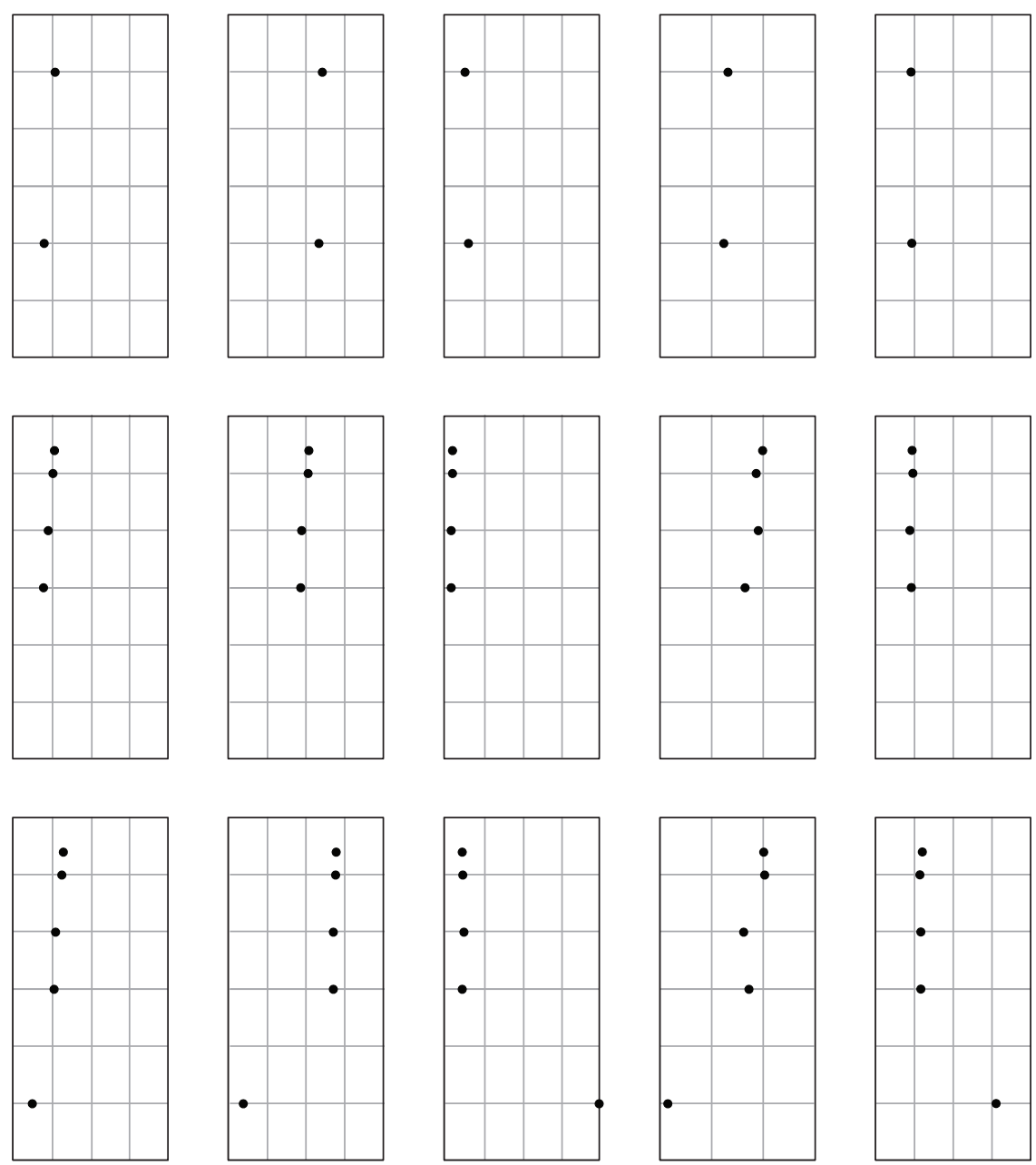

$6.50 \quad 6.75 \quad 7.0 \quad 7.25 \quad 7.50$

$\mathrm{pH}$
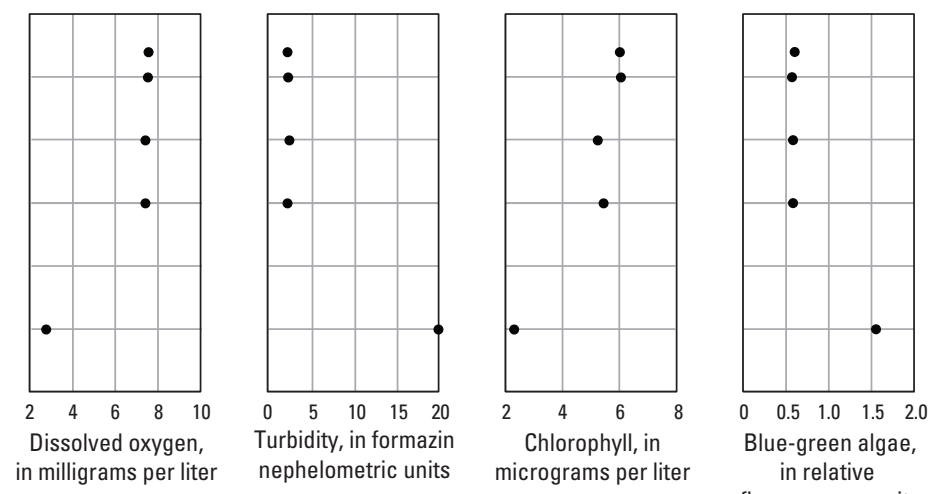

Figure 3-13. Water-quality profile data collected in the Bushy Park Reservoir, near Goose Creek, South Carolina, December 16, 2014. 

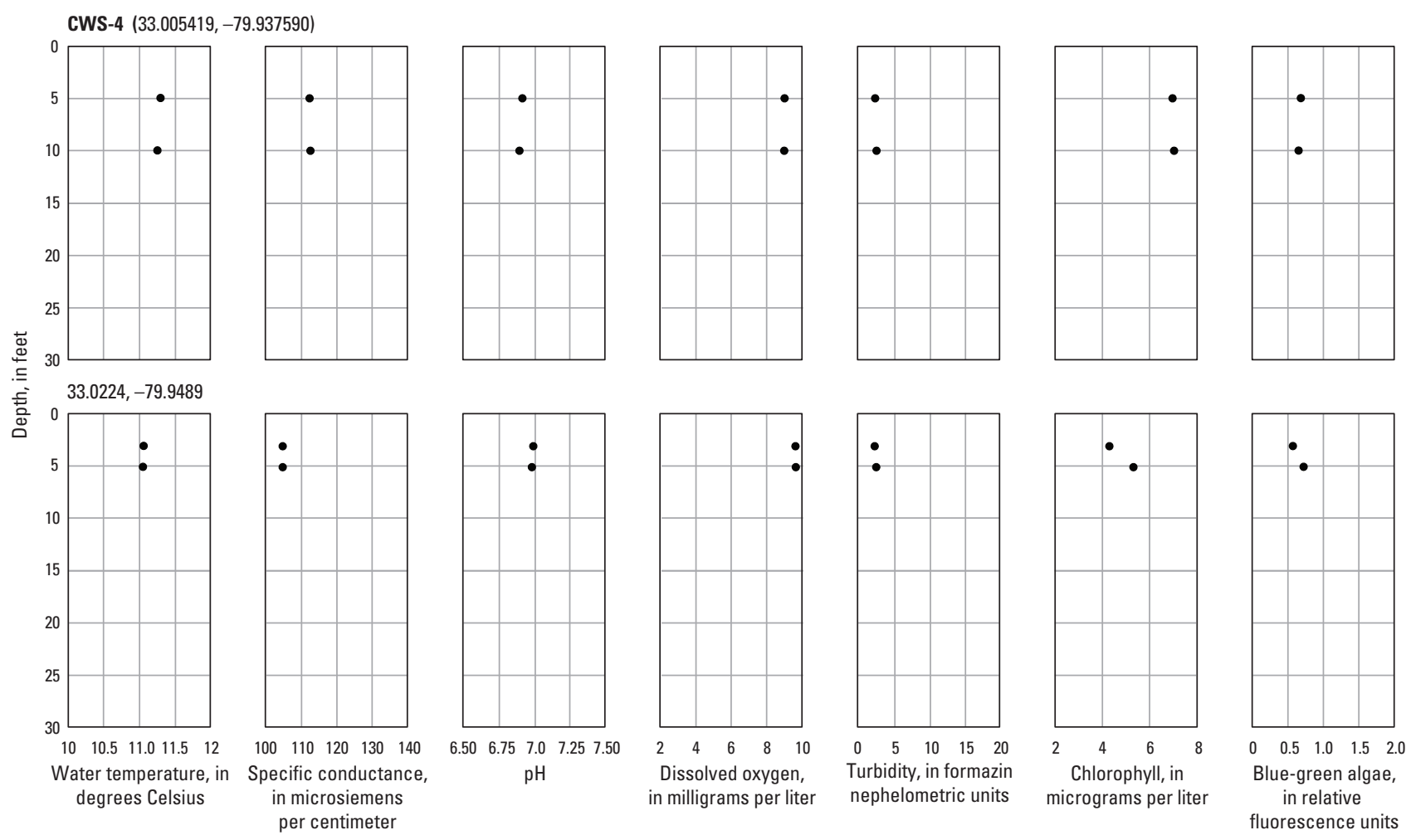

Figure 3-13. (Continued) Water-quality profile data collected in the Bushy Park Reservoir, near Goose Creek, South Carolina, December 16, 2014. 
CWS-7 (32.968284,-79.938346)
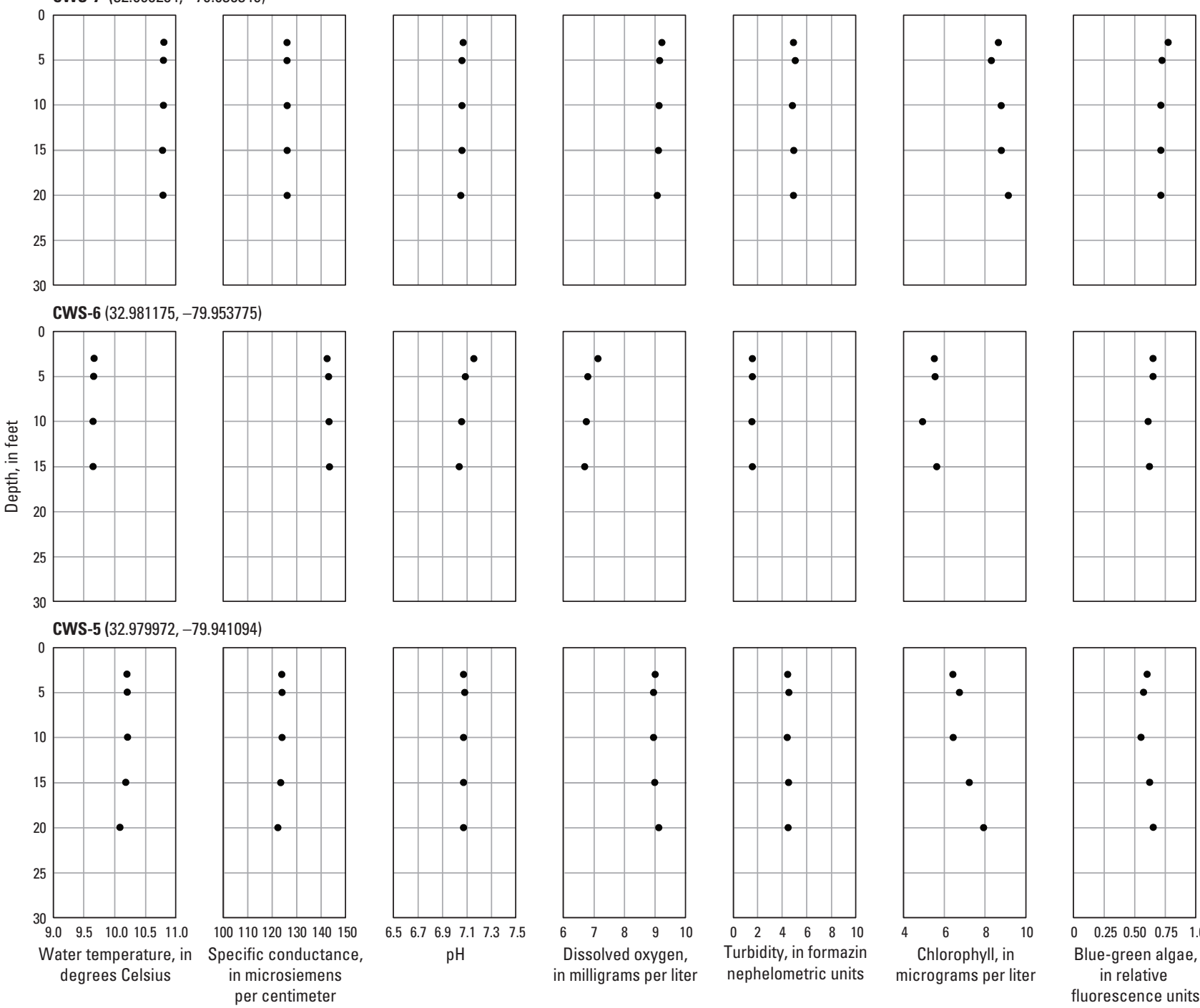

CWS-5 $(32.979972,-79.941094)$
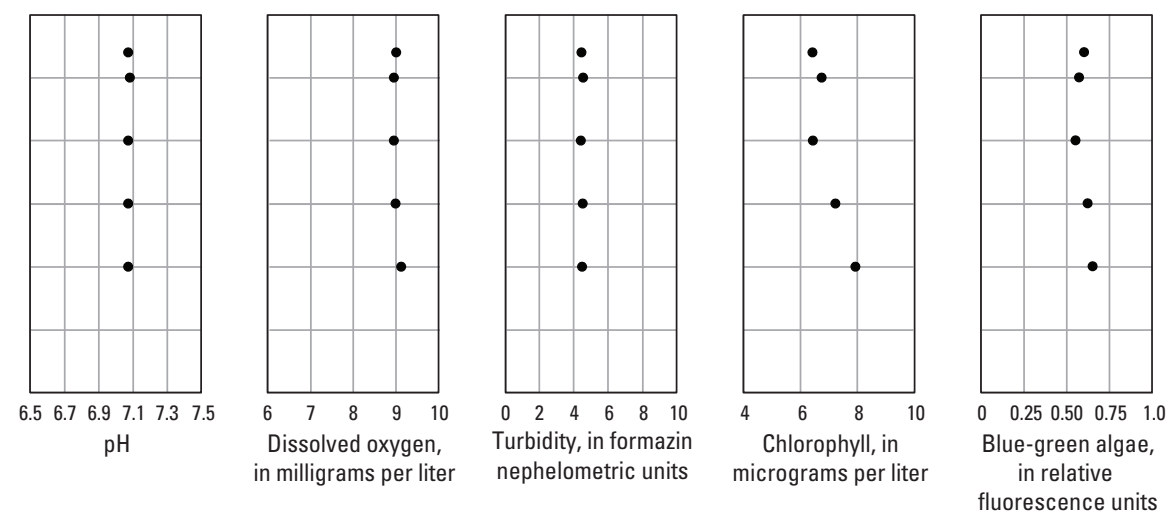

Figure 3-14. Water-quality profile data collected in the Bushy Park Reservoir, near Goose Creek, South Carolina, January 14, 2015. 
CWS-4 $(33.005419,-79.937590)$
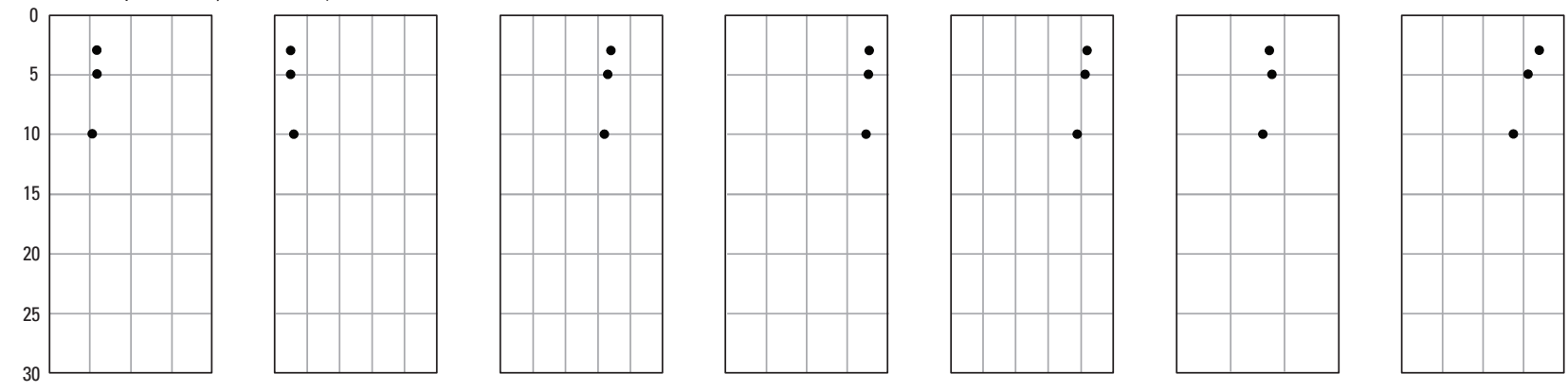

CWS-3 (33.027444, -79.952313)
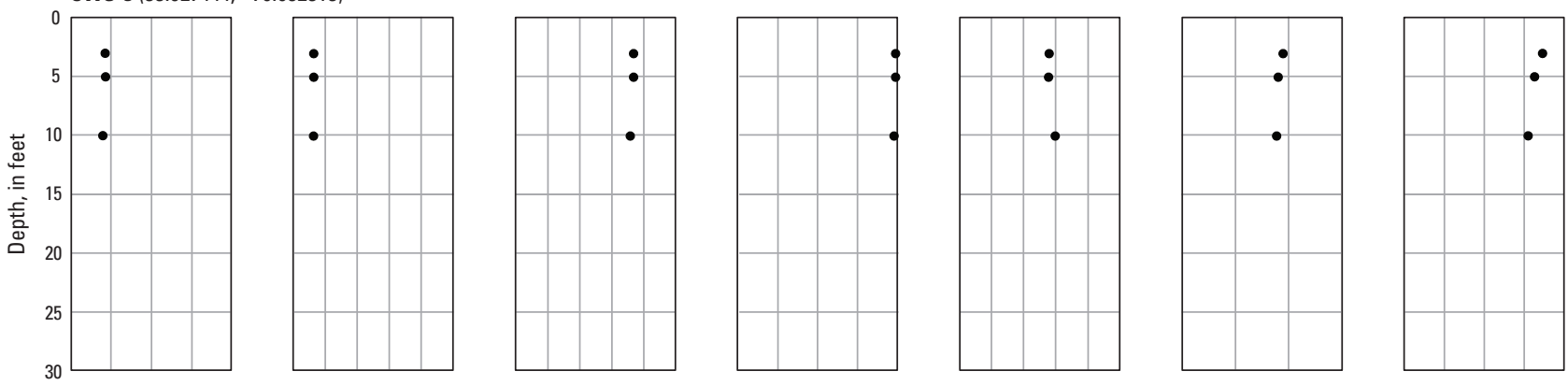

$33.0551,-79.9587$
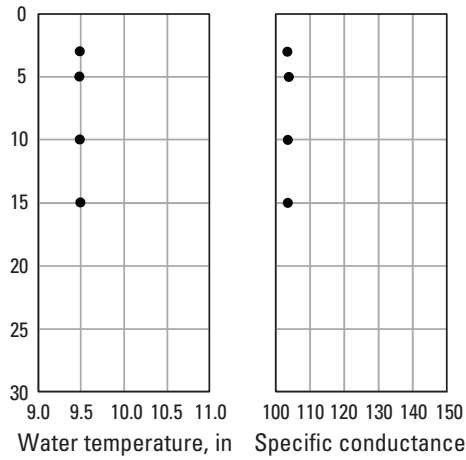

100110120130140150

in microsiemens per centimeter

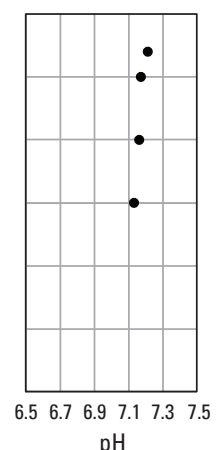

$\mathrm{pH}$
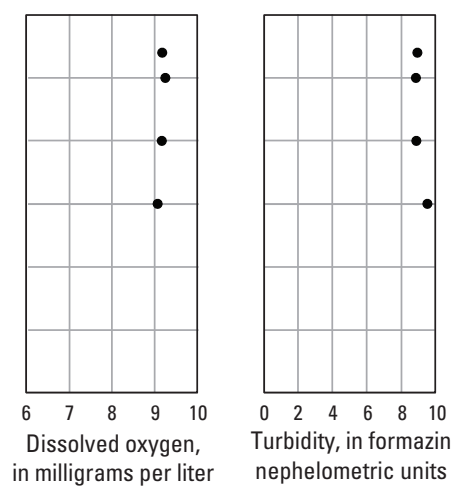
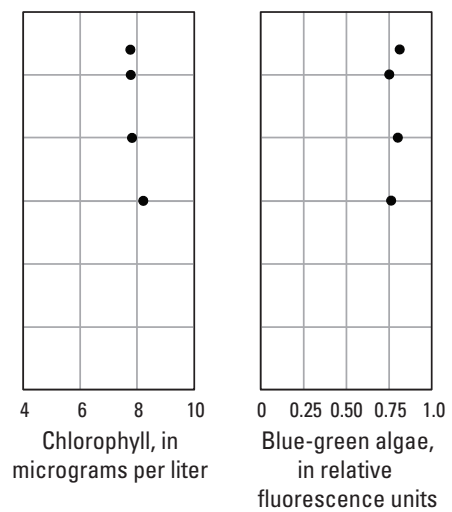

Figure 3-14. (Continued) Water-quality profile data collected in the Bushy Park Reservoir, near Goose Creek, South Carolina, January 14, 2015. 
CWS-7 (32.968284, -79.938346$)$
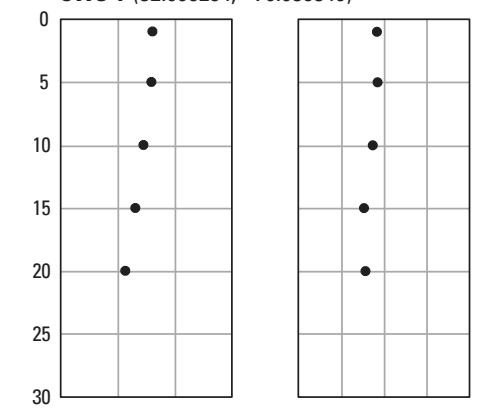

CWS-6 (32.981175, -79.953775)
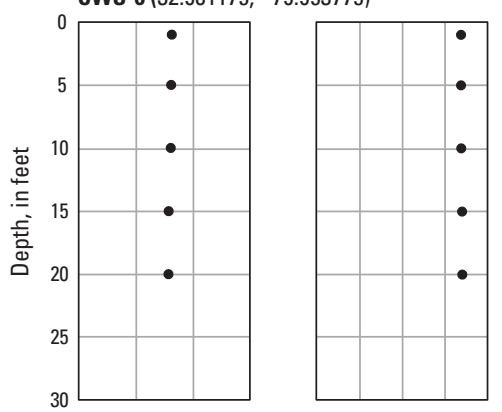

CWS-5 (32.979972,-79.941094)

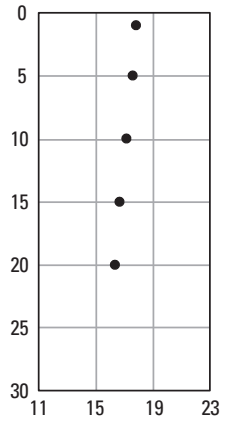

Water temperature, i degrees Celsius

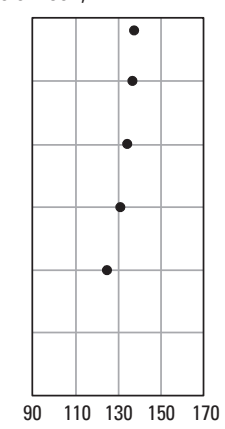

Specific conductance, in microsiemens per centimeter
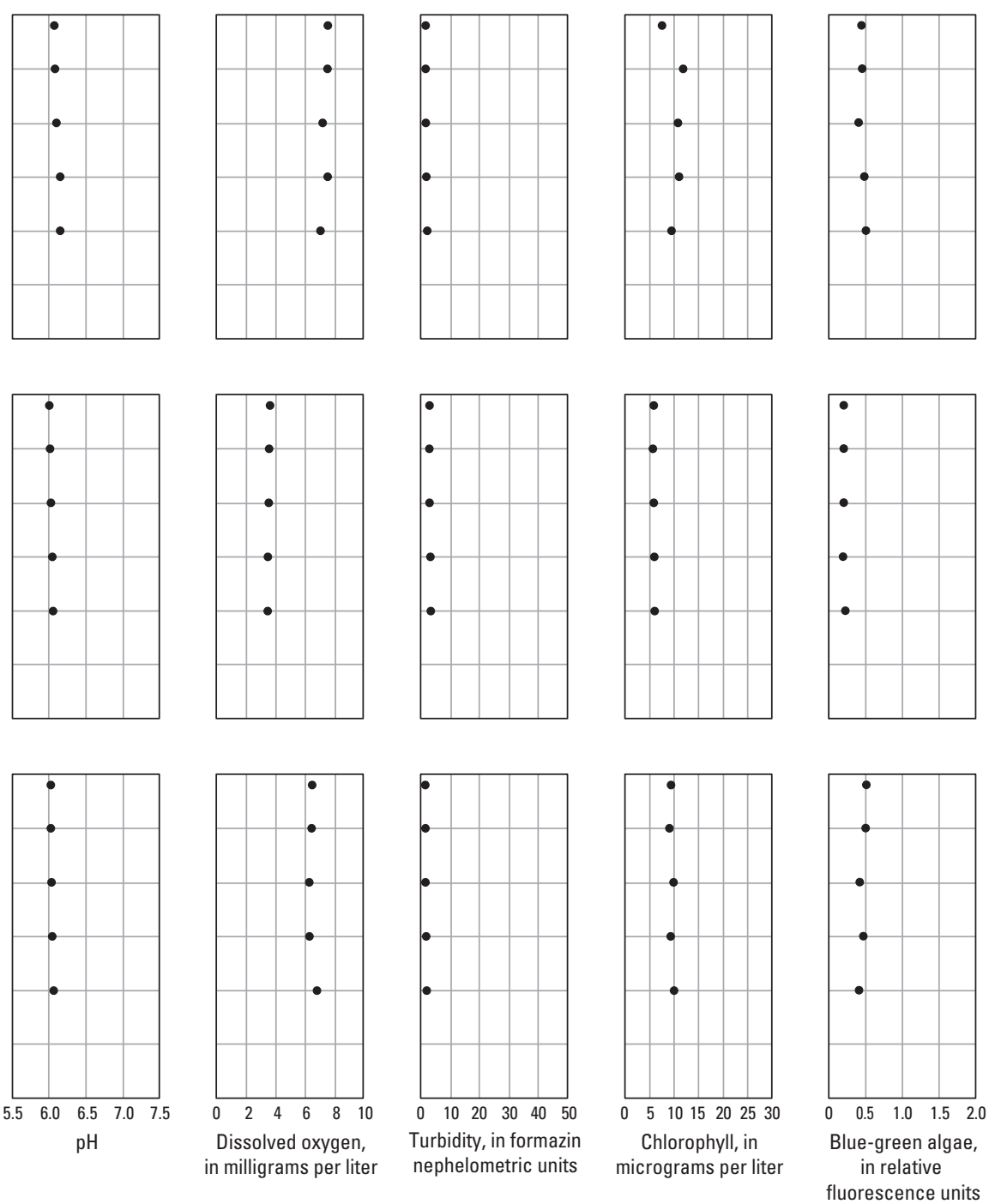

Figure 3-15. Water-quality profile data collected in the Bushy Park Reservoir, near Goose Creek, South Carolina, March 26, 2015 (morning survey). 
$32.988444,-79.941698$
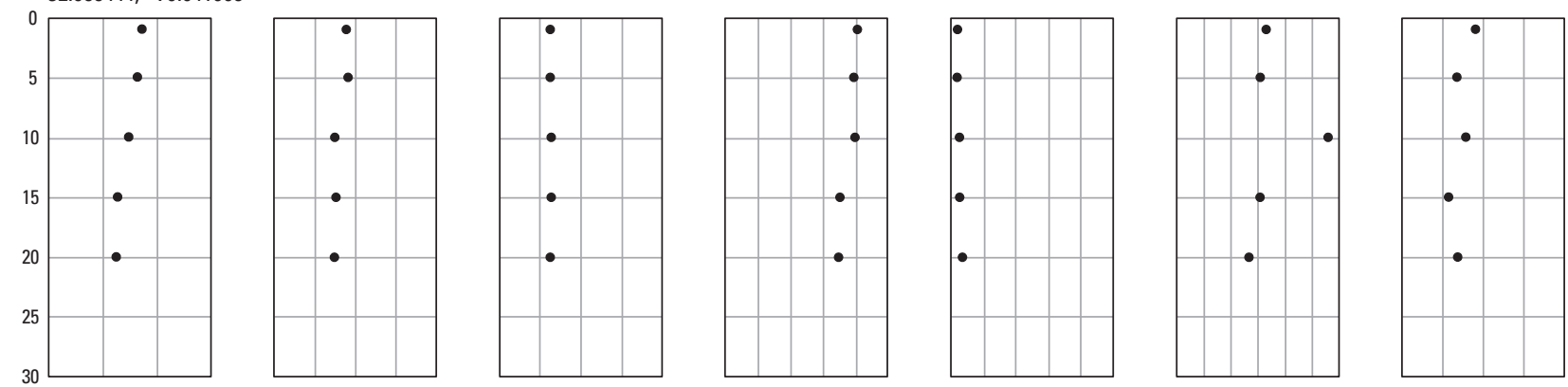

CWS-4 (33.005419, -79.937590)
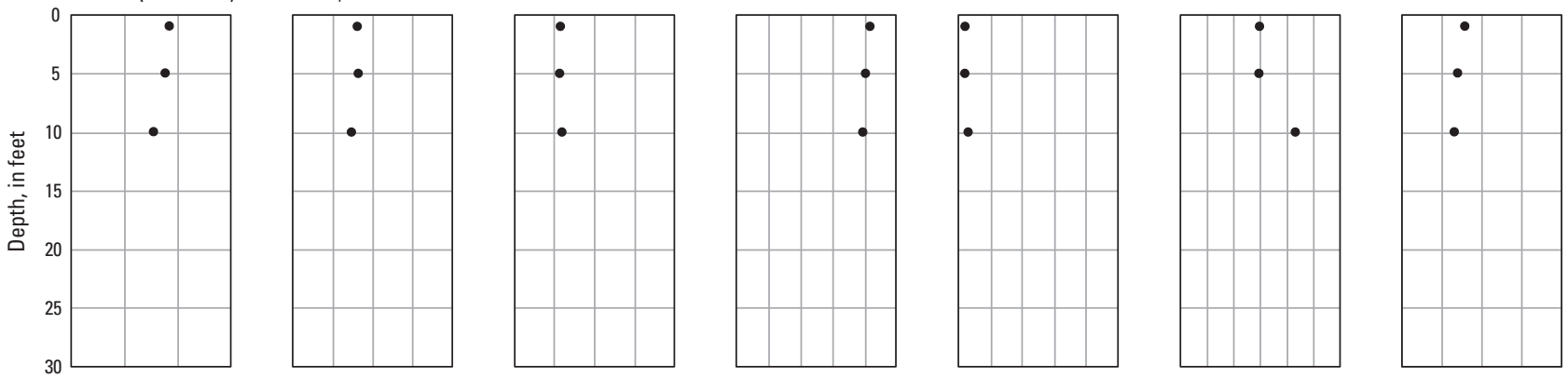

$33.016361,-79.944450$
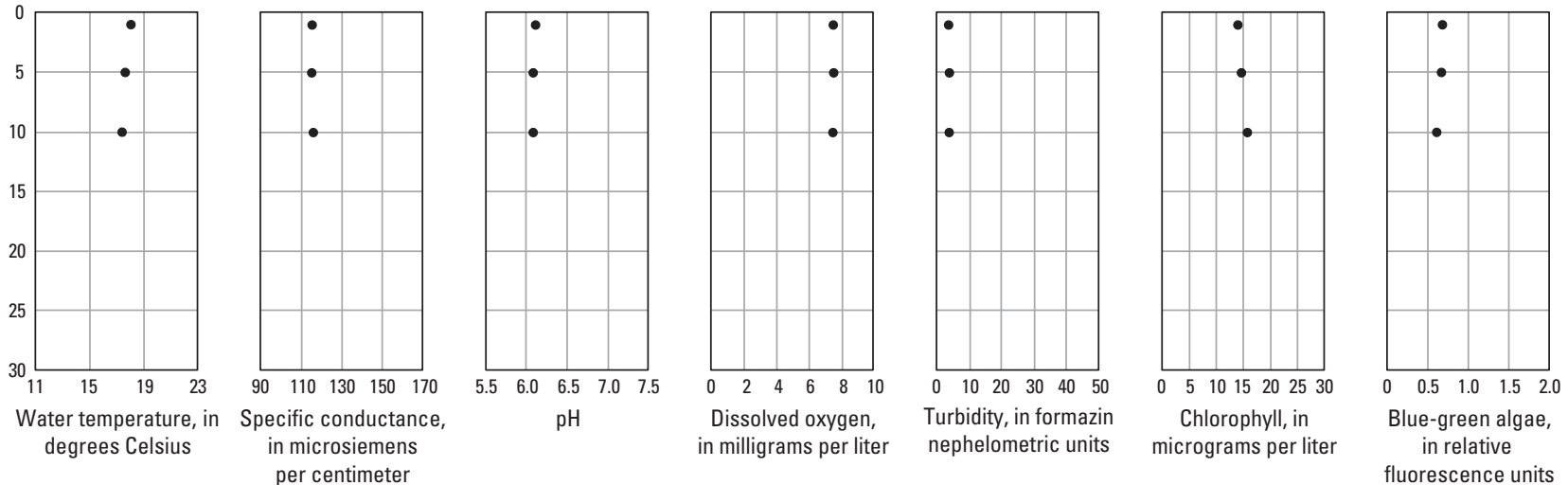

Figure 3-15. (Continued) Water-quality profile data collected in the Bushy Park Reservoir, near Goose Creek, South Carolina, March 26, 2015 (morning survey). 
CWS-3 (33.027444, -79.952313$)$

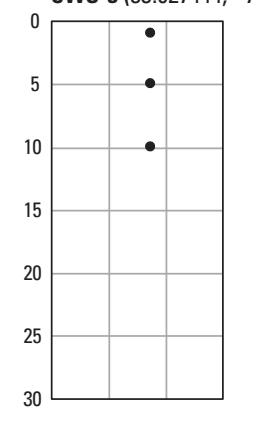

$33.038309,-79.953774$
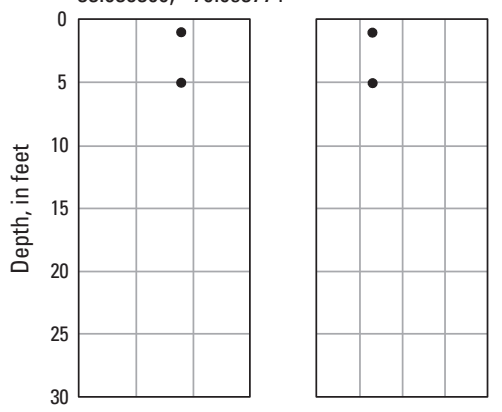

$33.055547,-79.958517$

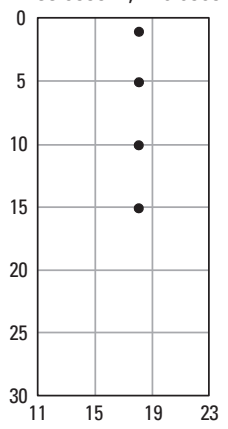

Water temperature, in degrees Celsius

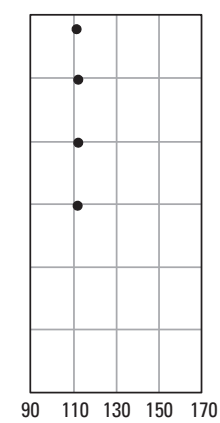

Specific conductance

in microsiemens per centimeter
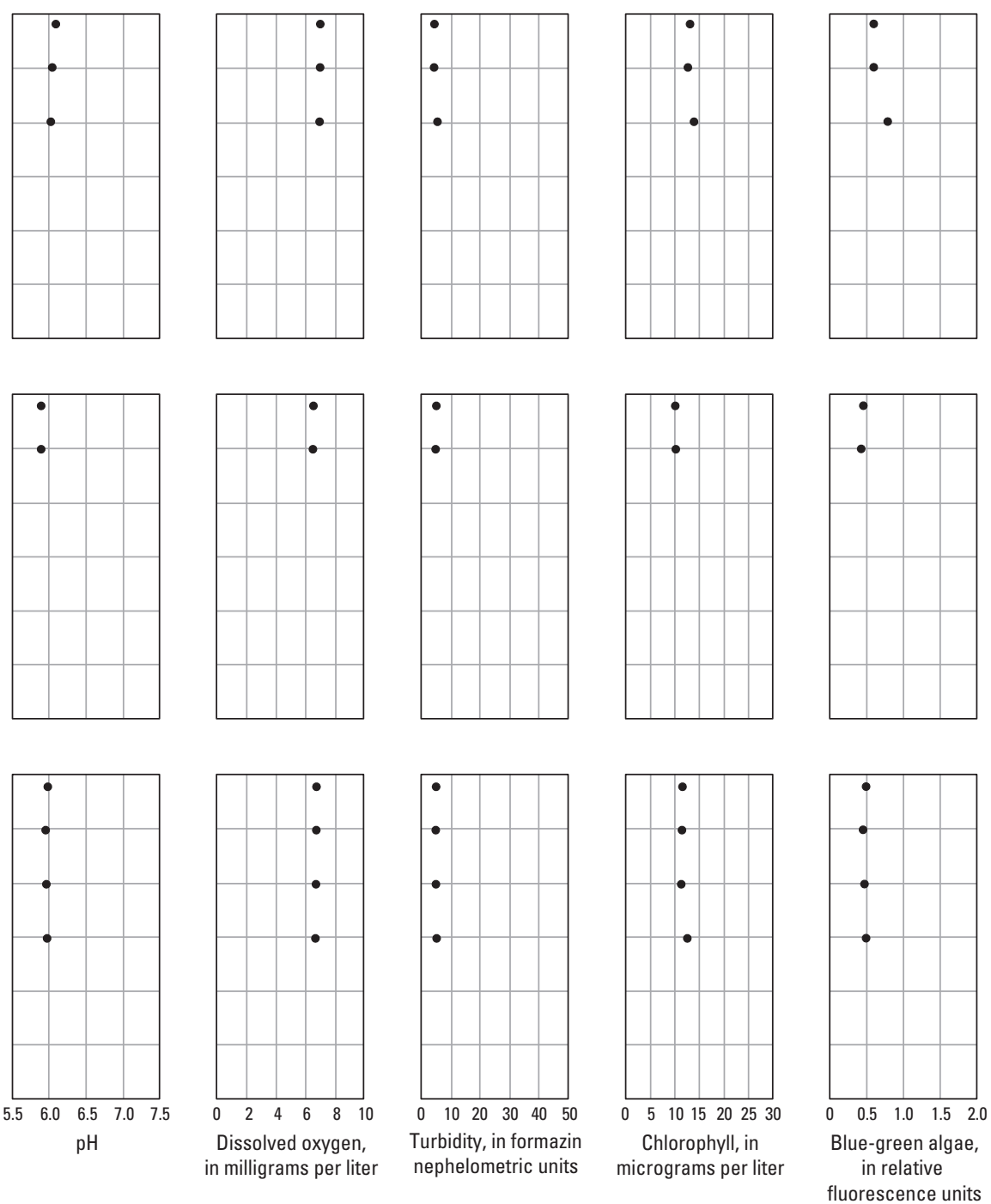

Figure 3-15. (Continued) Water-quality profile data collected in the Bushy Park Reservoir, near Goose Creek, South Carolina, March 26, 2015 (morning survey). 
CWS-7 $(32.968284,-79.938346)$
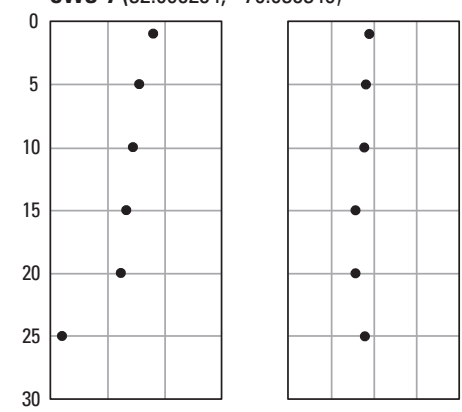

CWS-6 $(32.981175,-79.953775)$
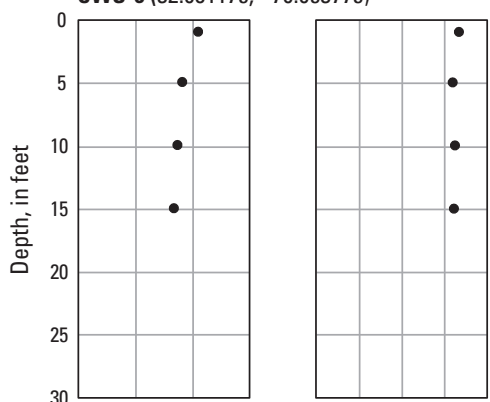

CWS-5 (32.979972, -79.941094$)$

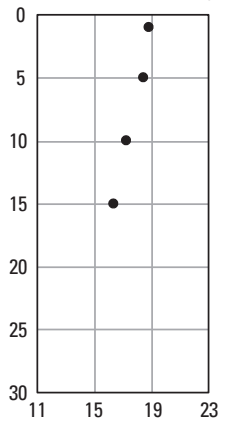

Water temperature, in degrees Celsius

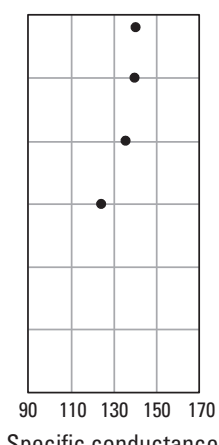

Specific conductance, in microsiemens per centimeter
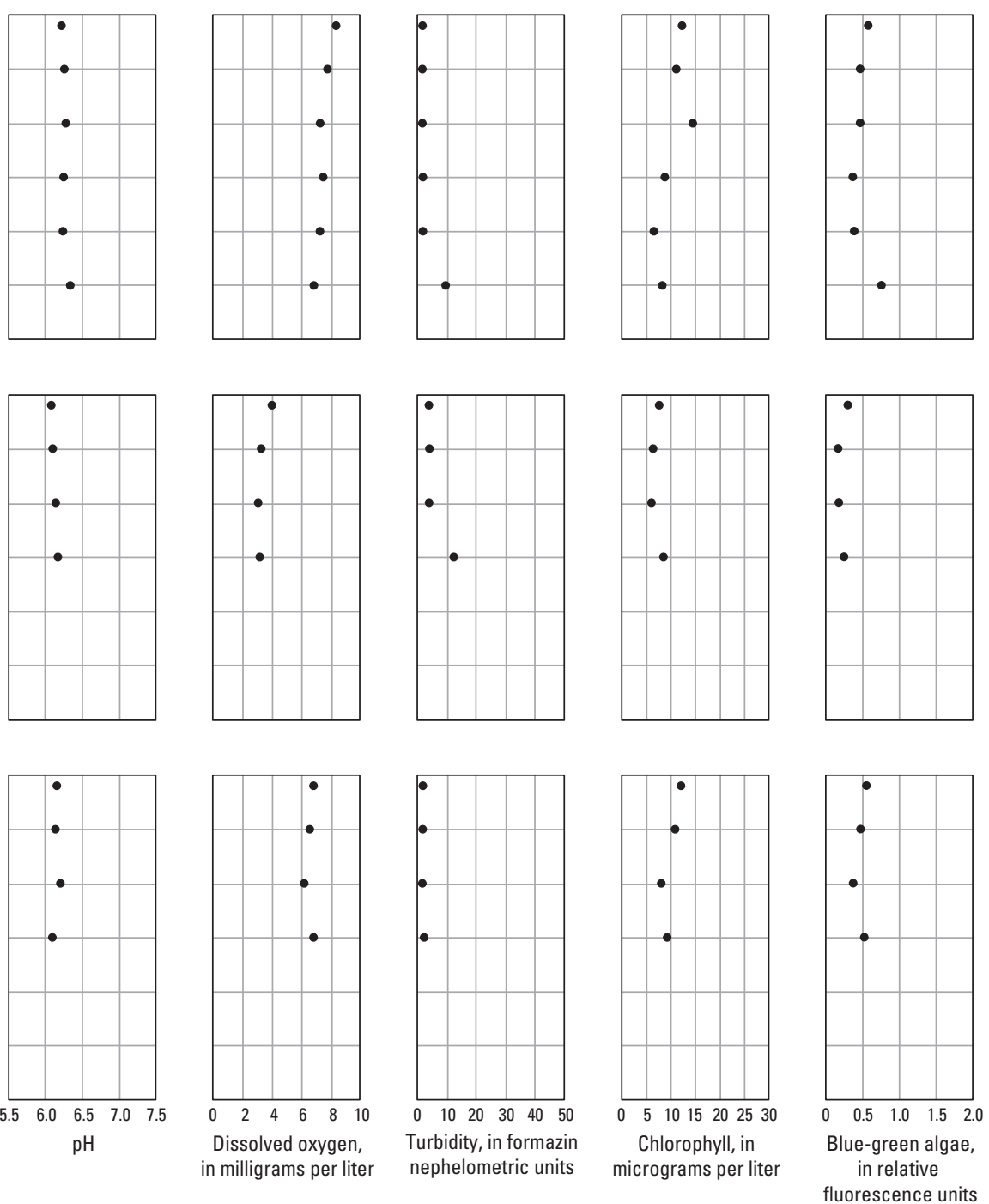

Figure 3-15. (Continued) Water-quality profile data collected in the Bushy Park Reservoir, near Goose Creek, South Carolina, March 26, 2015 (afternoon survey). 


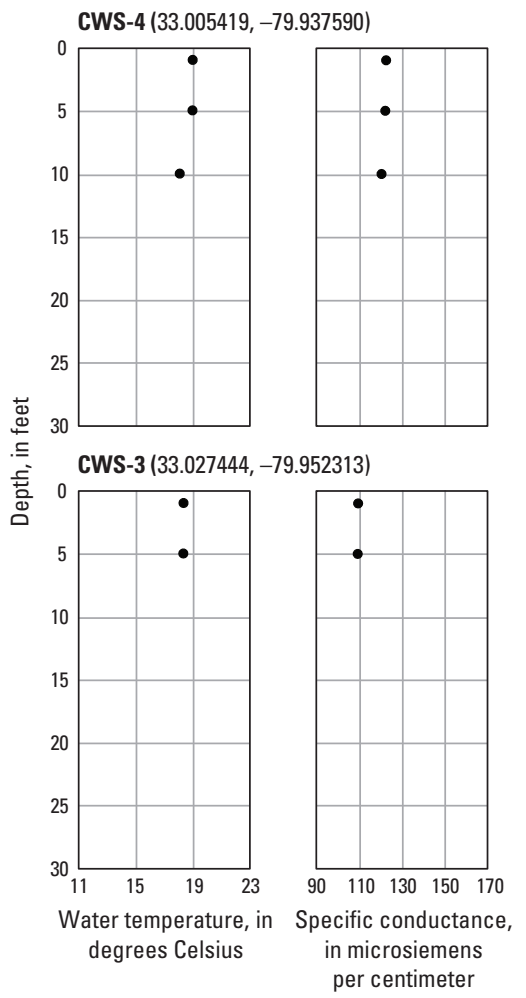

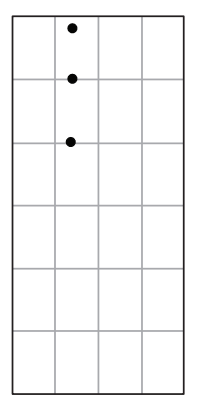
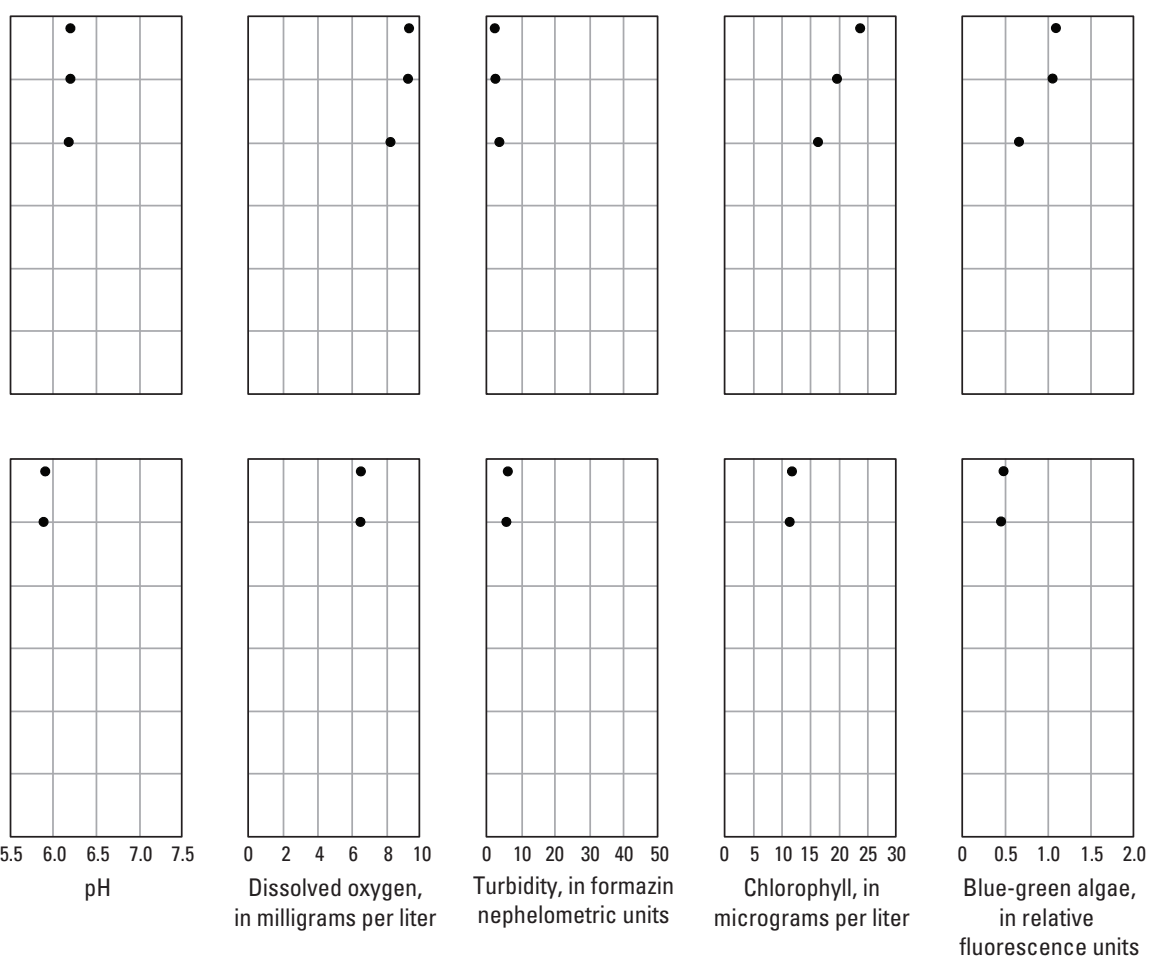

Figure 3-15. (Continued) Water-quality profile data collected in the Bushy Park Reservoir, near Goose Creek, South Carolina, March 26, 2015 (afternoon survey). 
CWS-7 (32.968284, -79.938346)
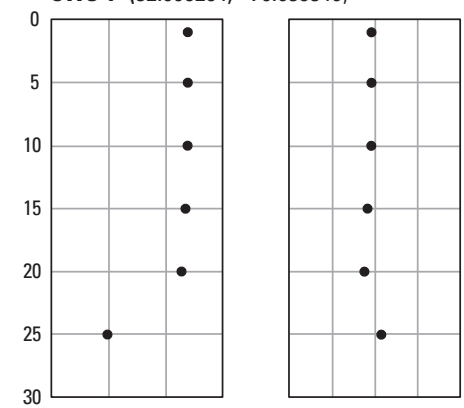

CWS-6 (32.981175, -79.953775)
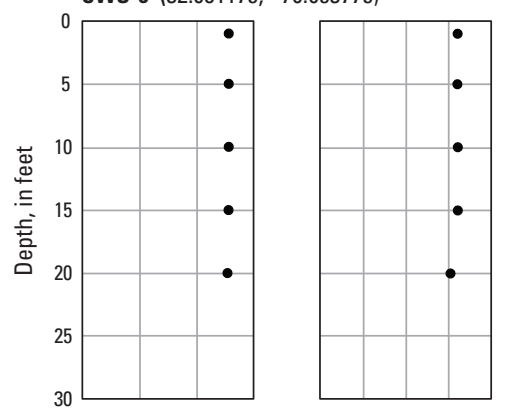

$32.975868,-79.942600$

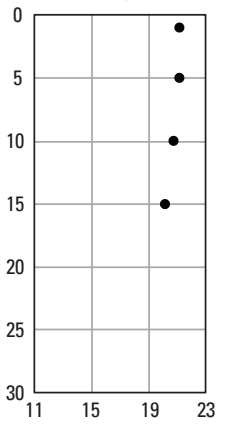

Water temperature, in degrees Celsius

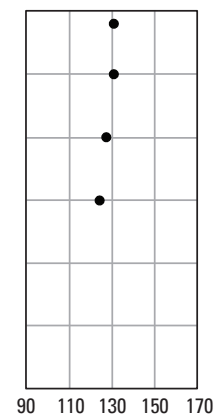

Specific conductance

in microsiemens per centimeter
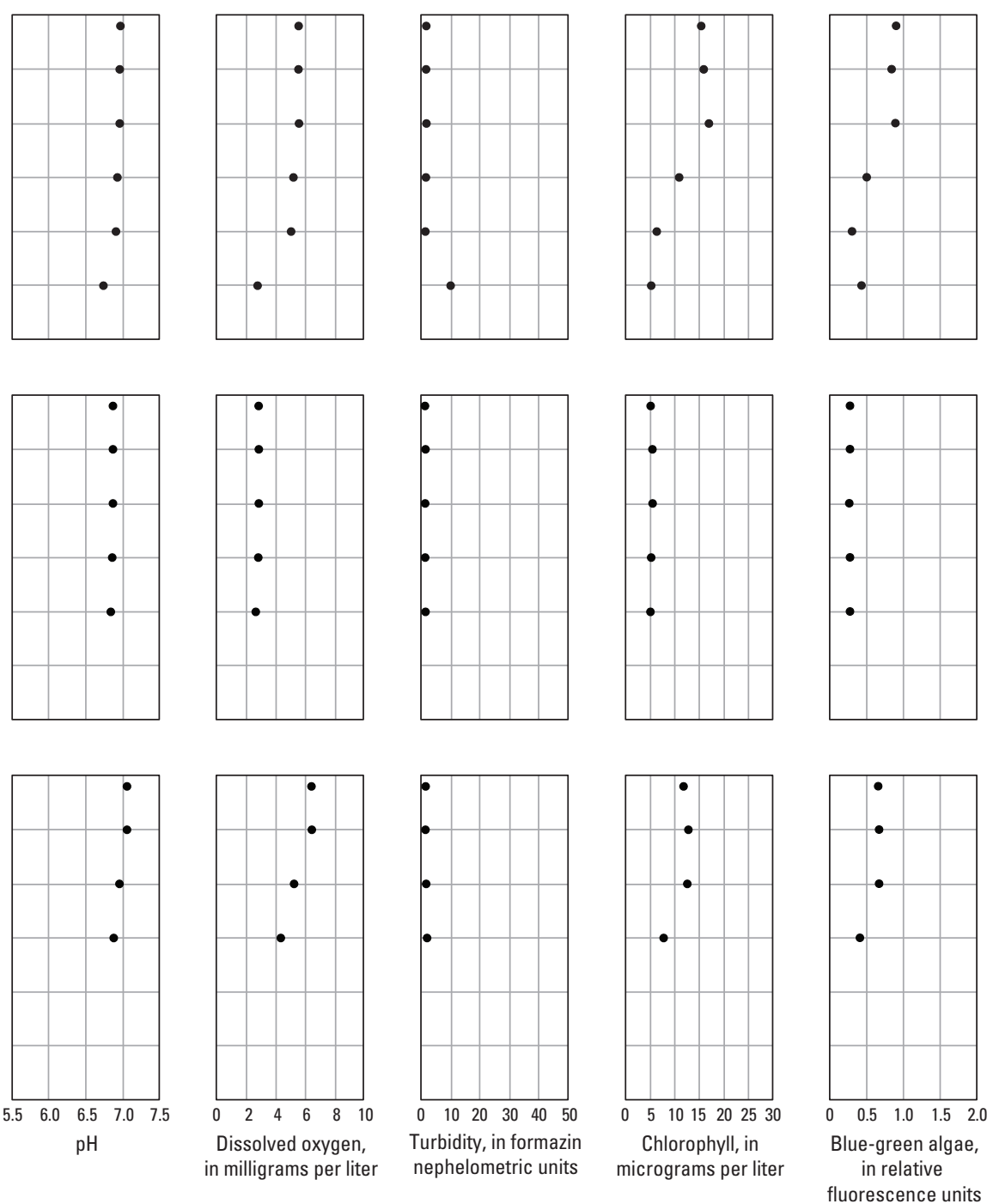

Figure 3-16. Water-quality profile data collected in the Bushy Park Reservoir, near Goose Creek, South Carolina, April 23, 2015 (morning survey). 
CWS-5 (32.979972, -79.941094)
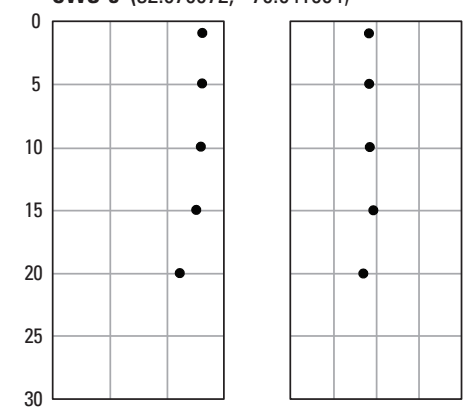

$32.98905,-79.94109$
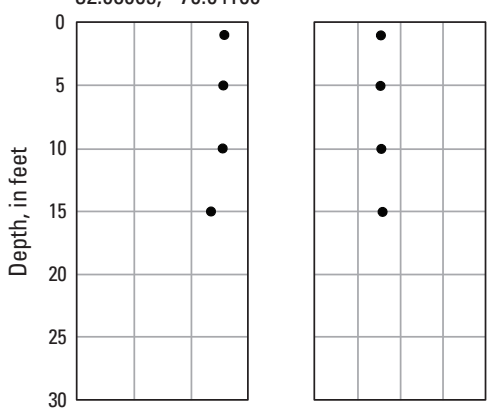

CWS-4 (33.005419, -79.937590)

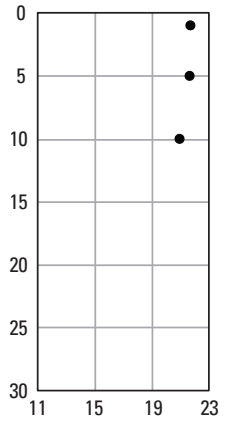

Water temperature, i degrees Celsius

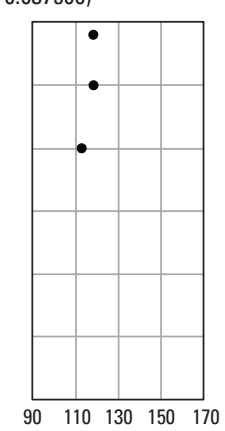

Specific conductance, in microsiemens per centimeter
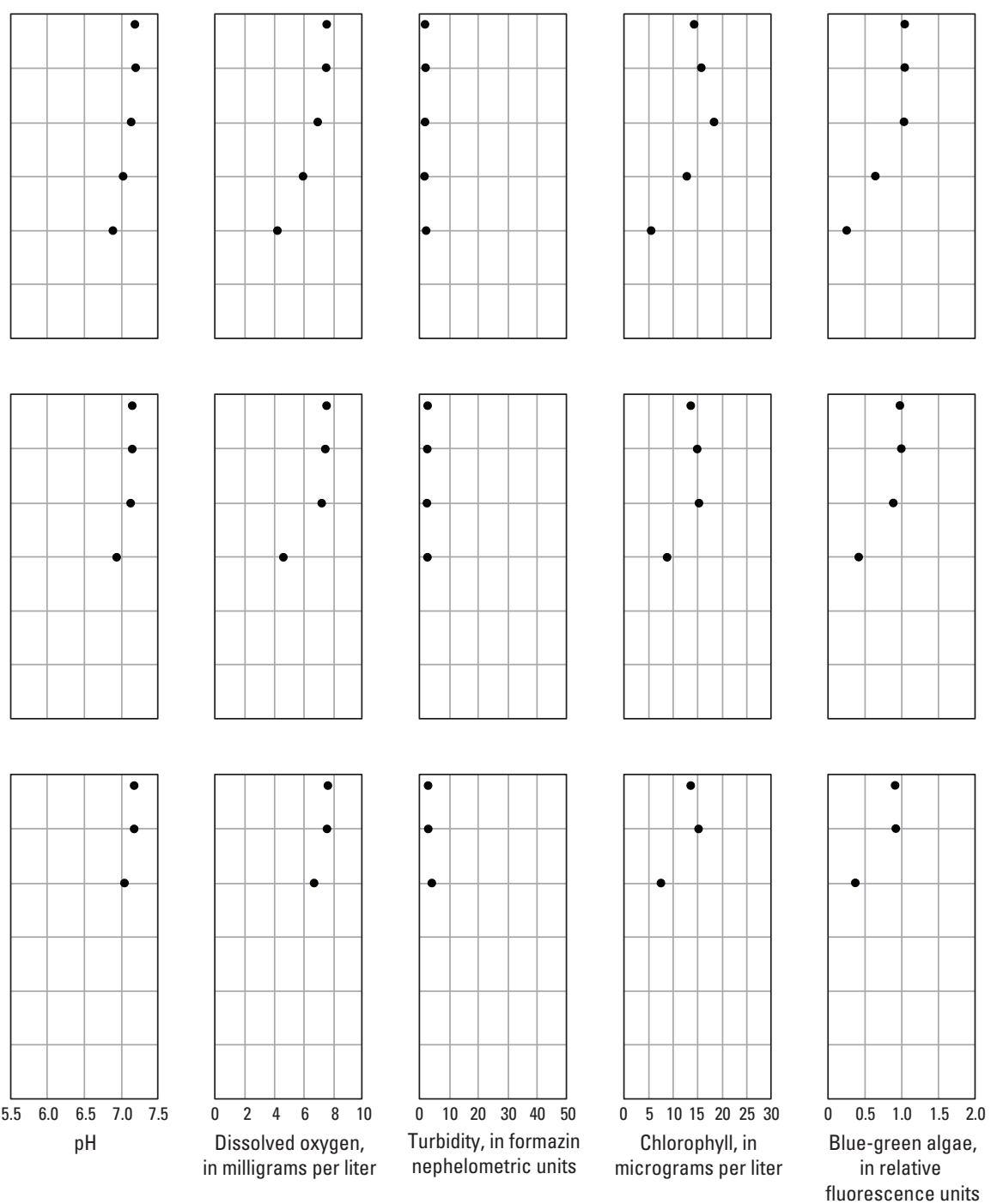

Figure 3-16. (Continued) Water-quality profile data collected in the Bushy Park Reservoir, near Goose Creek, South Carolina, April 23, 2015 (morning survey). 
$33.016216,-79.944509$
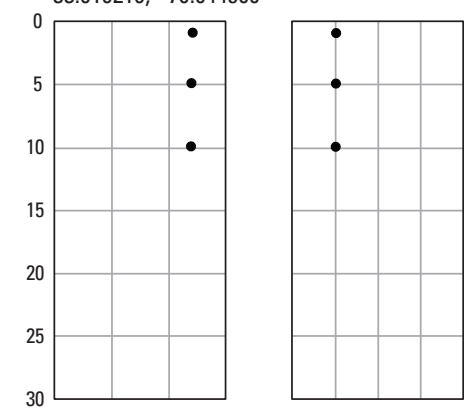

CWS-3 (33.027444, -79.952313$)$
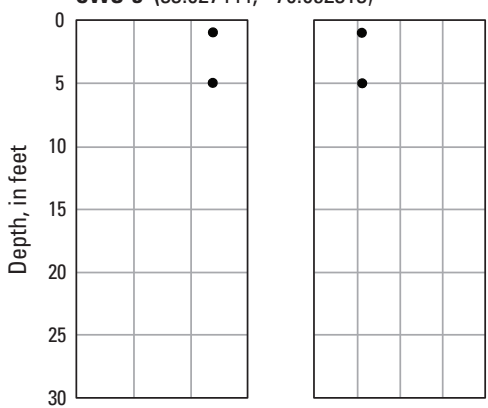

$33.03809,-79.95415$

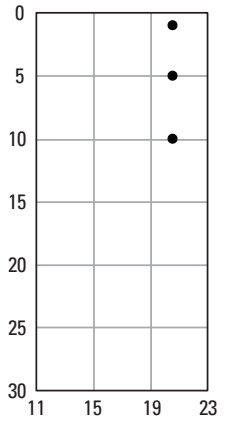

Water temperature, in degrees Celsius

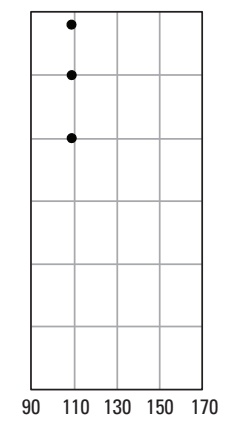

Specific conductance, in microsiemens per centimeter
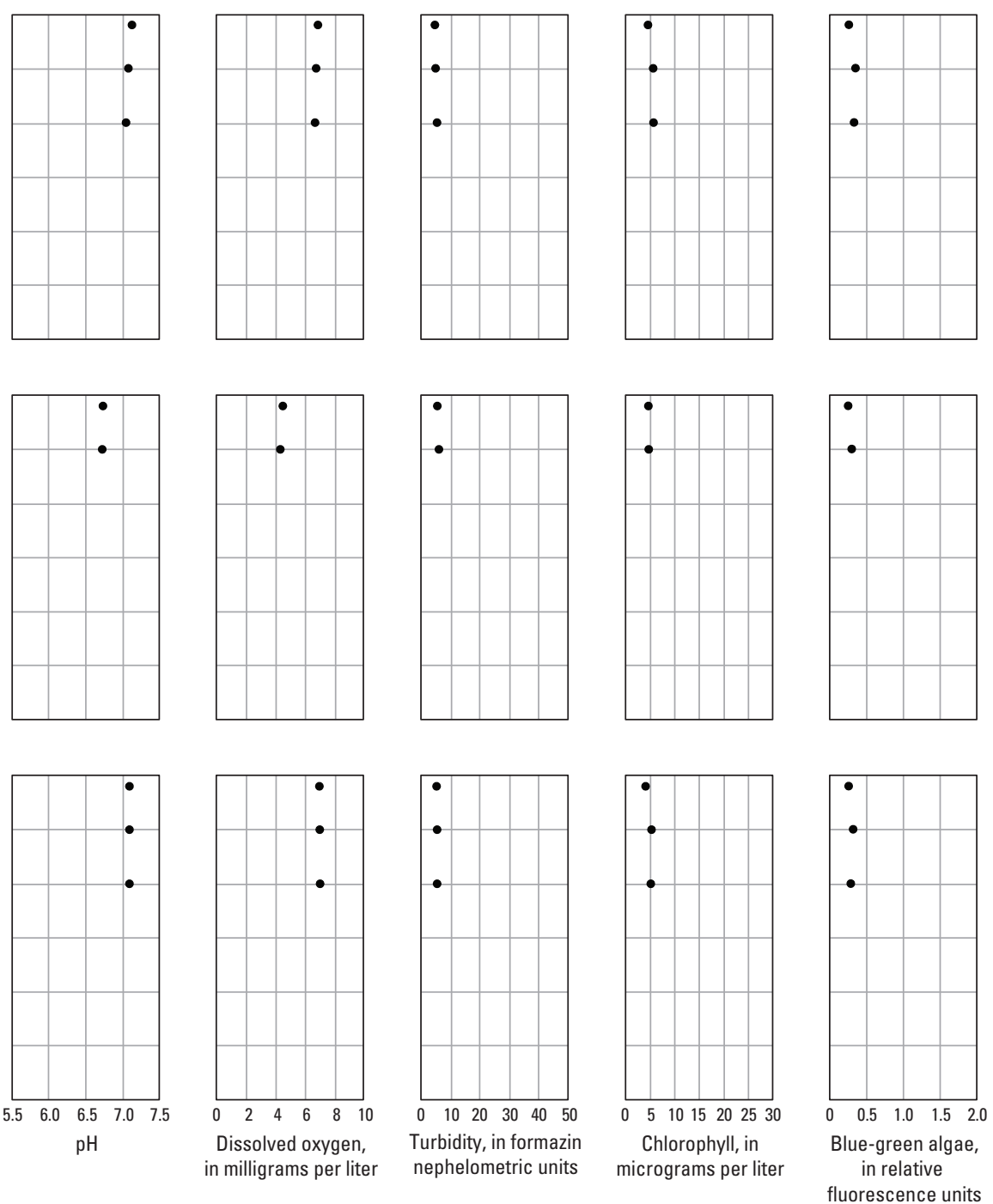

Figure 3-16. (Continued) Water-quality profile data collected in the Bushy Park Reservoir, near Goose Creek, South Carolina, April 23, 2015 (morning survey). 
CWS-7 (32.968284, -79.938346)

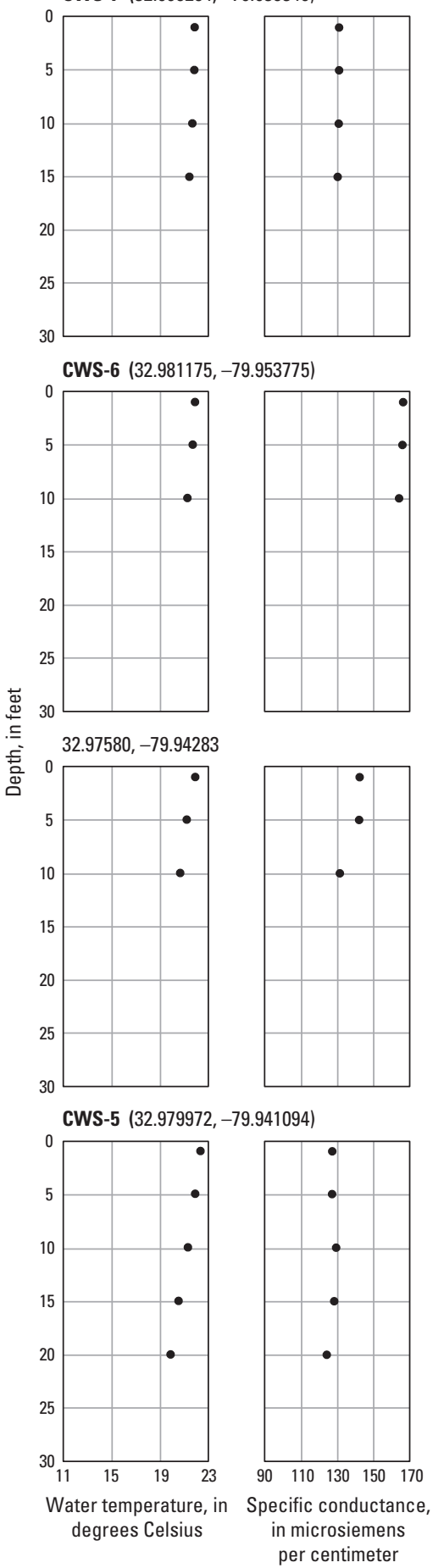

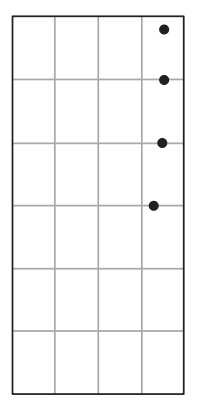
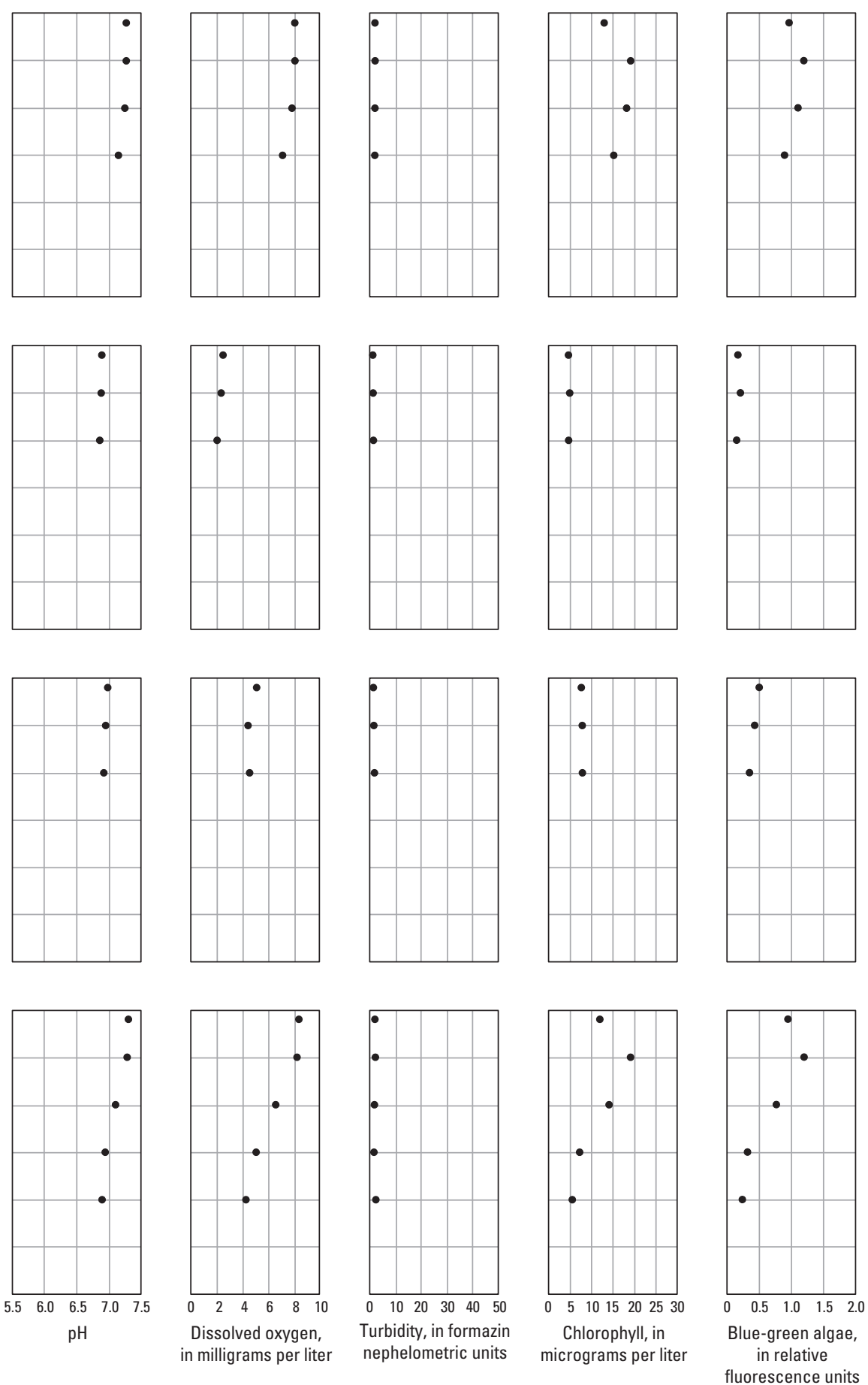

Figure 3-16. (Continued) Water-quality profile data collected in the Bushy Park Reservoir, near Goose Creek, South Carolina, April 23, 2015 (afternoon survey). 
$32.98886,-79.94089$
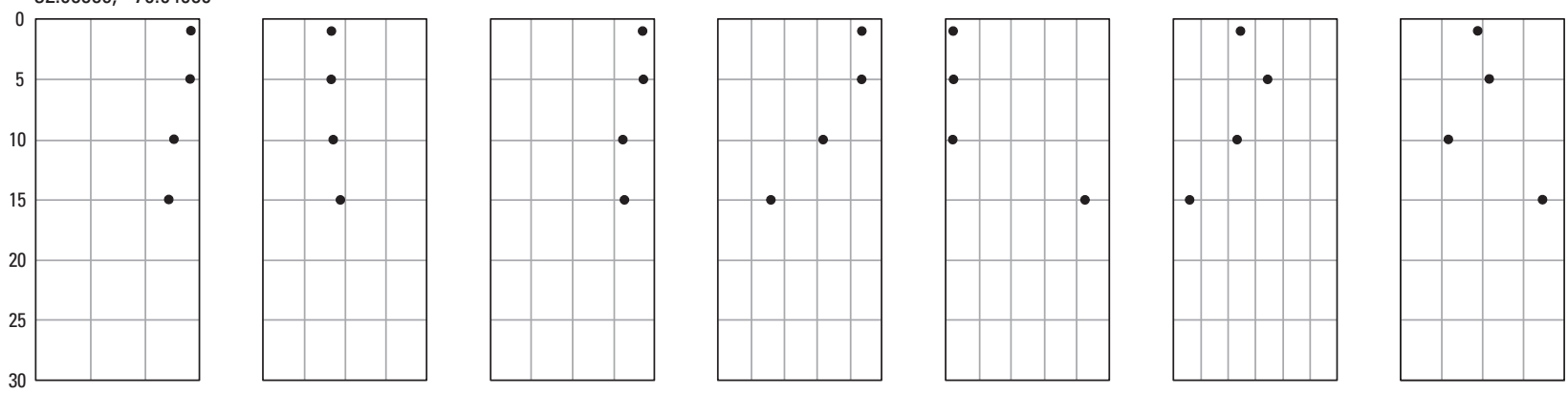

CWS-4 (33.005419, -79.937590)
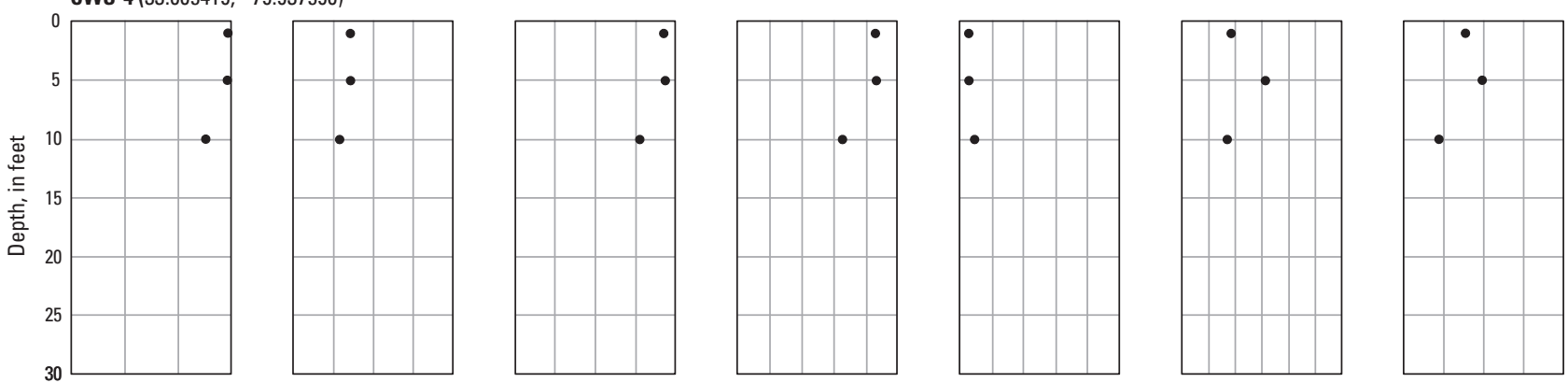

$33.016216,-79.944509$
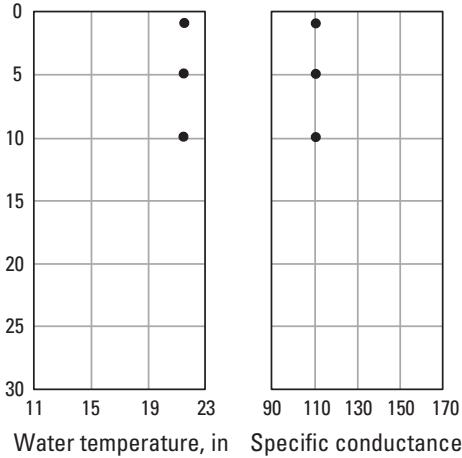

Specific conductance

in microsiemens per centimeter
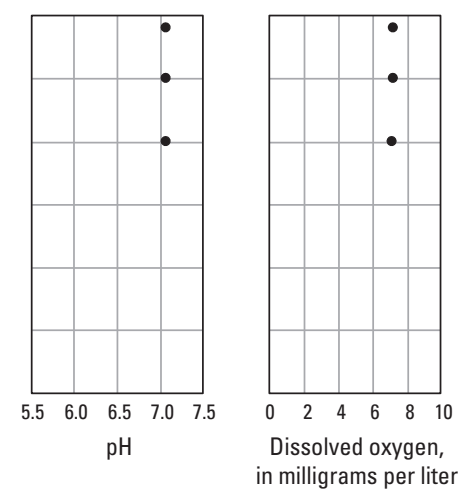
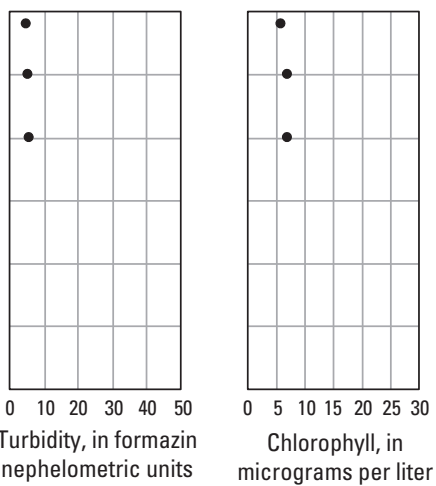

Figure 3-16. (Continued) Water-quality profile data collected in the Bushy Park Reservoir, near Goose Creek, South Carolina, April 23, 2015 (afternoon survey). 
CWS-3 (33.027444, -79.952313)
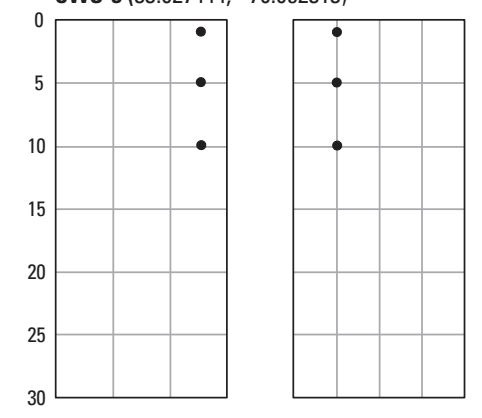

$33.037356,-79.953830$

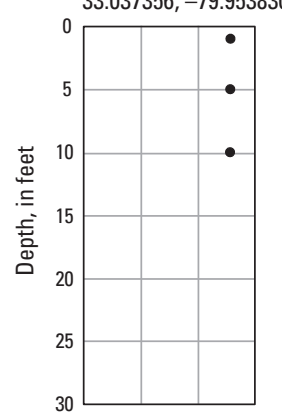

$33.046617,-79.959640$

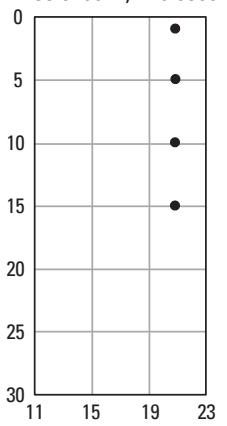

Water temperature, in degrees Celsius
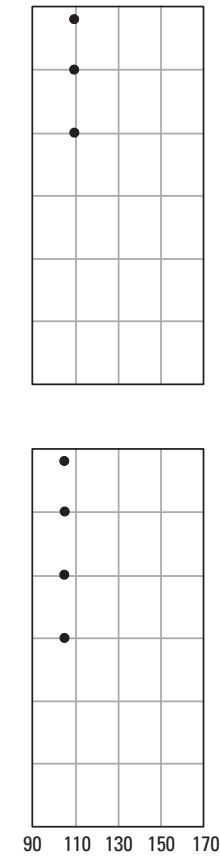

Specific conductance, in microsiemens per centimeter
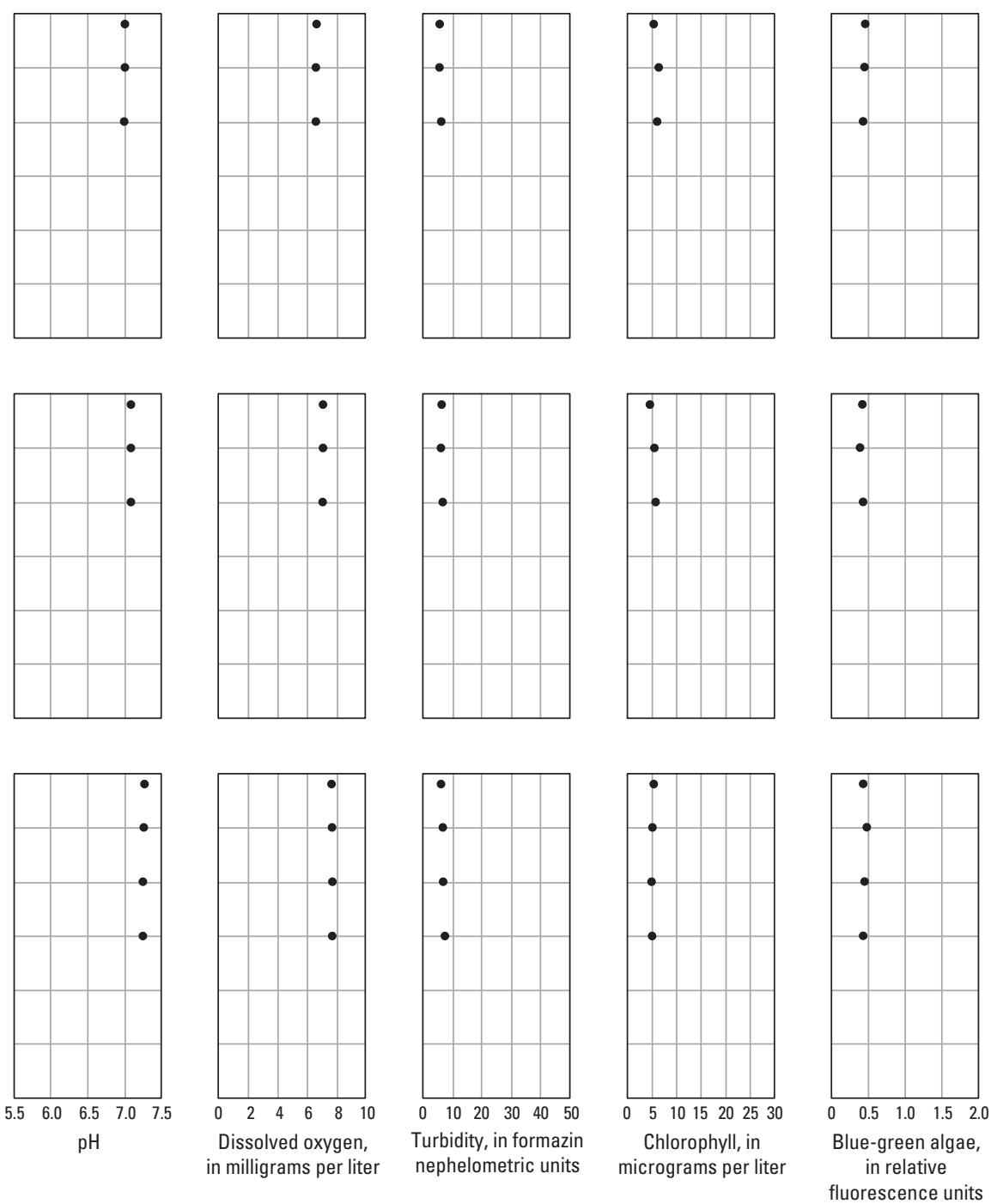

Figure 3-16. (Continued) Water-quality profile data collected in the Bushy Park Reservoir, near Goose Creek, South Carolina, April 23, 2015 (afternoon survey). 
Appendix 4. Summary of the quality assurance and quality control data collected in Bushy Park Reservoir, near Goose Creek, South Carolina, September 2013 to April 2015.

[MIB, 2-methyisoborneol; Mn, manganese; $\mathrm{Cl}$, chloride; $\mathrm{mg} / \mathrm{L}$, milligram per liter; $\mu \mathrm{g} / \mathrm{L}$, microgram per liter; TOC, total organic carbon]

\begin{tabular}{|c|c|c|c|c|c|c|c|c|c|c|c|c|}
\hline Quality control & 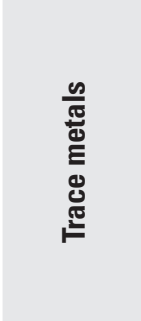 & 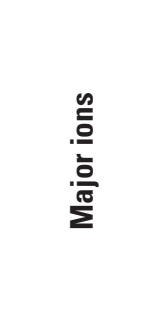 & $\begin{array}{l}\frac{\pi}{E} \\
\frac{E}{E} \\
\frac{E}{\varepsilon}\end{array}$ & 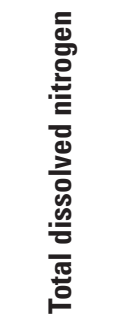 & 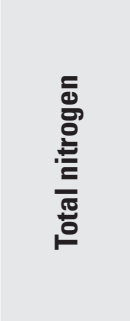 & 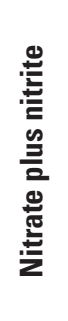 & 竞 & 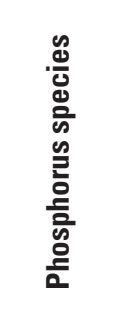 & 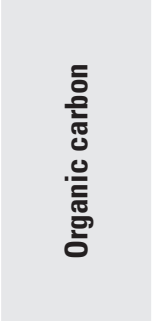 & $\begin{array}{l}\overline{\bar{\lambda}} \\
\overline{\bar{c}} \\
\text { 은 } \\
\text { 음 }\end{array}$ & 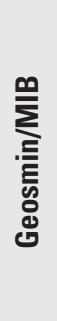 & 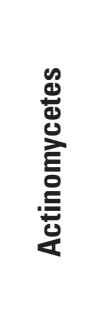 \\
\hline \multicolumn{13}{|c|}{ Field blank } \\
\hline Number & 2 & 2 & 4 & 4 & 4 & 4 & 4 & 4 & 4 & 2 & 2 & 1 \\
\hline Detections & $\begin{array}{c}1(\mathrm{Mn}, \\
0.3 \mu \mathrm{g} / \mathrm{L})\end{array}$ & $\begin{array}{c}1(\mathrm{Cl} \text { at } \\
0.02 \mathrm{mg} / \mathrm{L})\end{array}$ & 0 & 0 & 0 & 0 & 0 & 0 & $\begin{array}{c}1(\mathrm{TOC}, \\
1.3 \mathrm{mg} / \mathrm{L})\end{array}$ & $\begin{array}{l}2(0.02 \text { and } \\
0.03 \mu \mathrm{g} / \mathrm{L})\end{array}$ & 0 & 0 \\
\hline \multicolumn{13}{|c|}{ Sequential replicates } \\
\hline
\end{tabular}




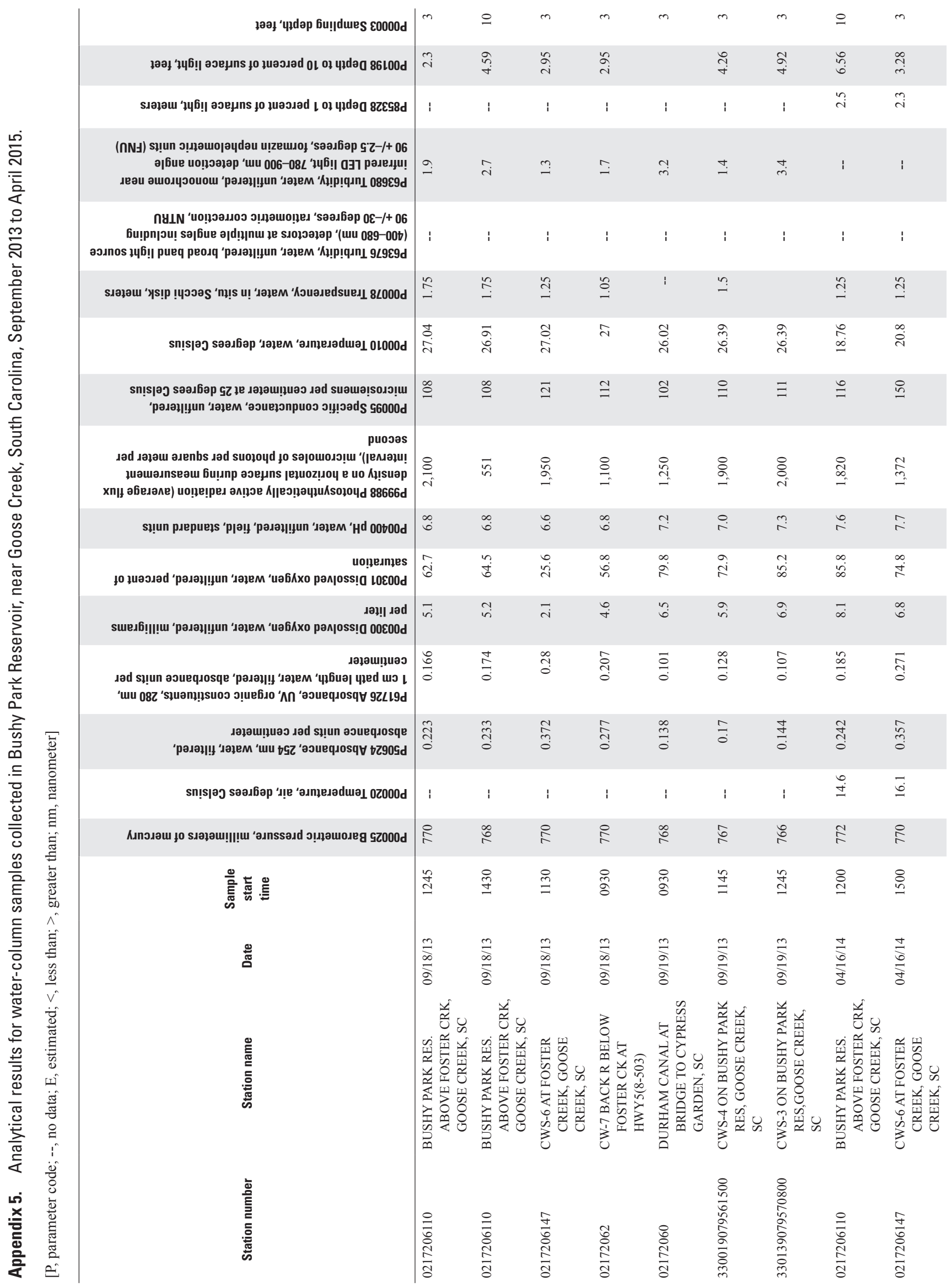




\begin{tabular}{|c|c|c|c|c|c|c|c|c|c|c|}
\hline ґәә, ‘ułdәp fu!ןdues ع0000d & $m$ & $m$ & m & 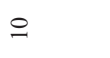 & m & m & m & $m$ & 으 & $m$ \\
\hline 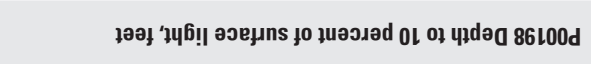 & $\begin{array}{l}\infty \\
\stackrel{\infty}{\sim}\end{array}$ & $\begin{array}{l}\underset{\sigma}{\sigma} \\
\stackrel{i}{ }\end{array}$ & $i$ & $i$ & 1 & $i$ & 1 & i & i & i \\
\hline 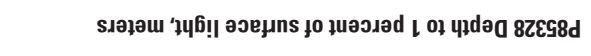 & $\stackrel{n}{\sim}$ & i & $i$ & $i$ & i & 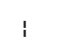 & $i$ & $i$ & 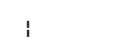 & i \\
\hline 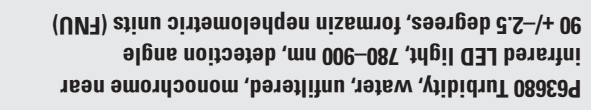 & i & 1 & i & i & i & ले & $\stackrel{n}{n}$ & $\frac{n}{n}$ & $\stackrel{+}{i}$ & $\ddot{0}$ \\
\hline 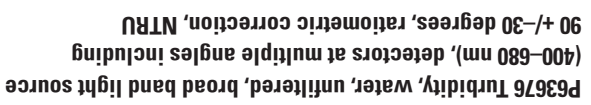 & i & i & $i$ & i & i & 1 & 1 & $i$ & 1 & 1 \\
\hline 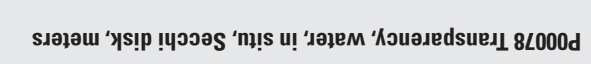 & 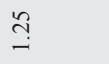 & $\stackrel{n}{\mathfrak{0}}$ & 1 & i & i & $\stackrel{m}{-}$ & - & $\stackrel{m}{\longrightarrow}$ & $\stackrel{m}{-}$ & $\stackrel{\unlhd}{\leftrightarrows}$ \\
\hline 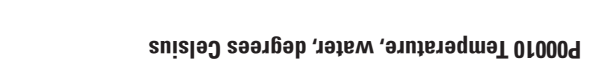 & $\vec{\infty}$ & $\stackrel{+}{\stackrel{5}{2}}$ & i & i & $i$ & $\begin{array}{l}\infty \\
\stackrel{\infty}{n} \\
\infty\end{array}$ & $\begin{array}{l}\text { J } \\
\text { 嗢 }\end{array}$ & $\begin{array}{l}\vec{\infty} \\
\infty \\
\infty\end{array}$ & $\stackrel{2}{\sim}$ & 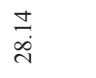 \\
\hline 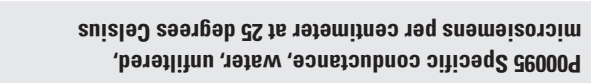 & ป & $\propto$ & i & $i$ & i & 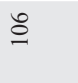 & 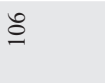 & $\stackrel{n}{\check{c}}$ & $\stackrel{\Xi}{I}$ & 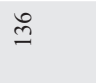 \\
\hline 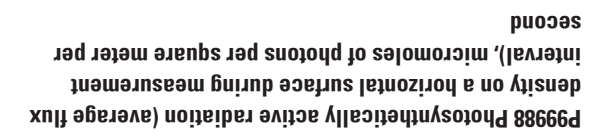 & స్ర & $\stackrel{n}{\infty}$ & 1 & $i$ & i & 1 & $\begin{array}{l}8 \\
\vdots \\
\wedge\end{array}$ & i & i & $\stackrel{\text { \& }}{\mathfrak{G}}$ \\
\hline 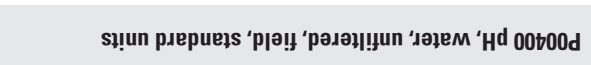 & $\underset{\infty}{\sim}$ & r & $i$ & i & i & $\stackrel{\circ}{r}$ & $\stackrel{\circ}{\circ}$ & $\stackrel{\infty}{6}$ & $\dddot{v}$ & $\stackrel{6}{6}$ \\
\hline 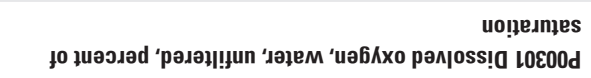 & ๙ุ & ñ & i & i & i & $\vec{\infty}$ & $\stackrel{1}{\infty}$ & $\underset{+}{\stackrel{+}{T}}$ & $\begin{array}{l}0 \\
\infty \\
\infty\end{array}$ & $\stackrel{\infty}{\vec{N}}$ \\
\hline 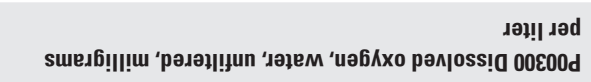 & กู & $\stackrel{+}{\infty}$ & I & I & i & 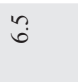 & ?ु. & $\begin{array}{l}\infty \\
\dot{n}\end{array}$ & $\stackrel{m}{i}$ & $\exists$ \\
\hline 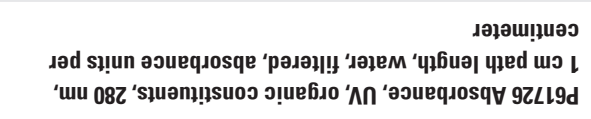 & $\frac{m}{a}$ & $\stackrel{n}{\dddot{m}}$ & $\frac{\mathfrak{m}}{\square}$ & $\stackrel{0}{=}$ & $\stackrel{9}{\stackrel{m}{0}}$ & $\stackrel{0}{\circ}$ & 客 & 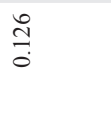 & $\underset{\Xi}{ت}$ & 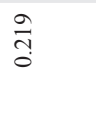 \\
\hline 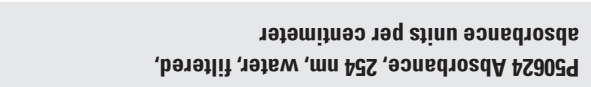 & ஸ̃ & $\stackrel{m}{\stackrel{m}{0}}$ & $\frac{5}{0}$ & $\frac{\dot{H}}{\dot{0}}$ & $\frac{\infty}{-1}$ & $\stackrel{\infty}{\circ}$ & $\begin{array}{l}\stackrel{\infty}{\circ} \\
\stackrel{+}{0}\end{array}$ & $\frac{1}{0}$ & $\stackrel{\infty}{0}$ & సે \\
\hline 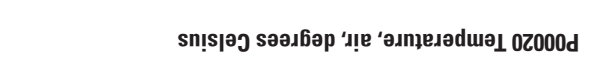 & $\stackrel{\sim}{\dddot{2}}$ & $\overrightarrow{0}$ & I & $i$ & 1 & $\stackrel{\sim}{\Delta}$ & $\stackrel{\sim}{\sim}$ & $\frac{N}{\Delta}$ & $\frac{N}{i}$ & 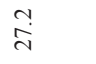 \\
\hline 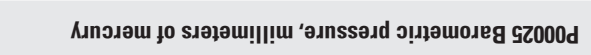 & $\stackrel{?}{尺}$ & $\stackrel{?}{尺}$ & i & i & i & ț & $\mathfrak{2}$ & $\stackrel{0}{2}$ & $\stackrel{0}{\circ}$ & $\underset{\sim}{t}$ \\
\hline 高 壳 & 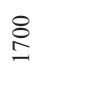 & 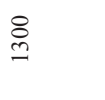 & $\frac{\nabla}{\sigma}$ & $\frac{a}{8}$ & $\stackrel{n}{5}$ & 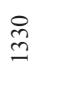 & $\stackrel{n}{\beth}$ & $\stackrel{\varrho}{=}$ & $\stackrel{\ominus}{\Xi}$ & $\stackrel{n}{\stackrel{n}{0}}$ \\
\hline 䒕 & 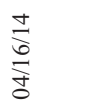 & 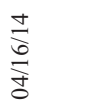 & 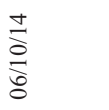 & 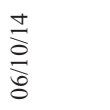 & 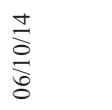 & 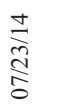 & 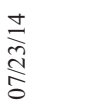 & $\underset{\stackrel{\Xi}{\Xi}}{\stackrel{\Xi}{\sigma}}$ & 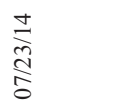 & $\underset{\stackrel{\Xi}{\Xi}}{\stackrel{\Xi}{\sigma}}$ \\
\hline 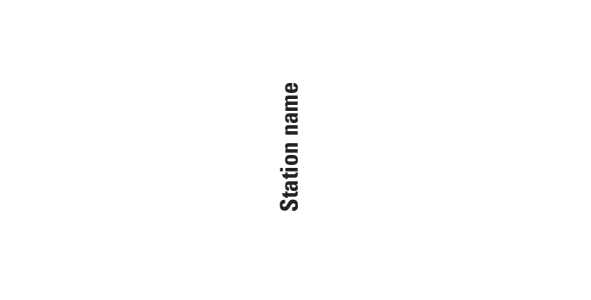 & 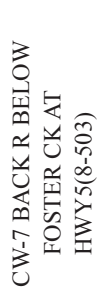 & 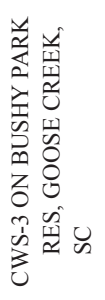 & 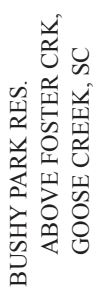 & 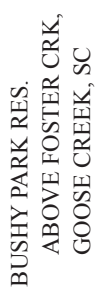 & 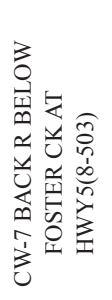 & 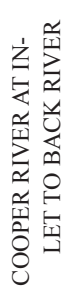 & 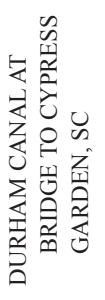 & 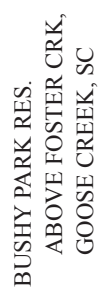 & 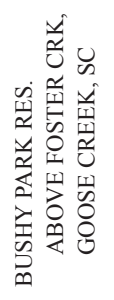 & 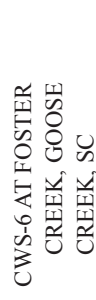 \\
\hline 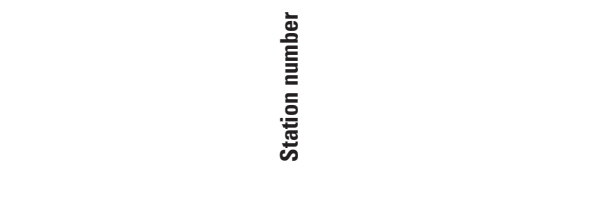 & 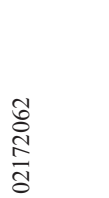 & 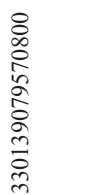 & 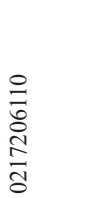 & 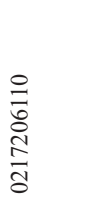 & 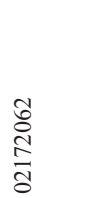 & 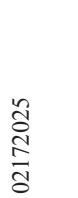 & 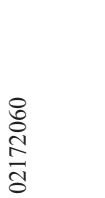 & 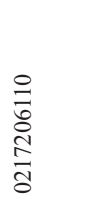 & 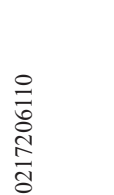 & 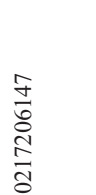 \\
\hline
\end{tabular}




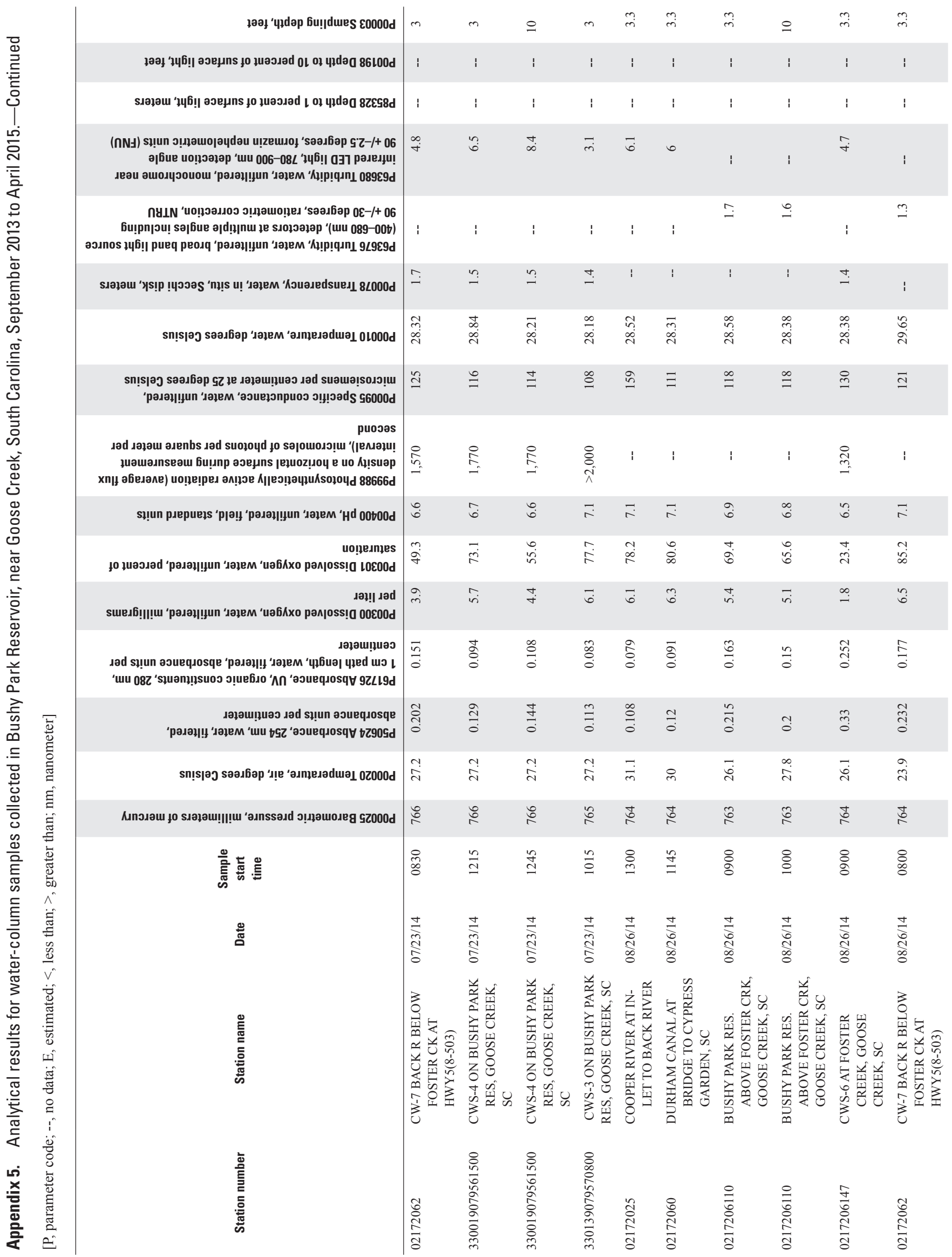




\begin{tabular}{|c|c|c|c|c|c|c|c|c|c|c|}
\hline ґәә, ‘u’dәp 6u!ןdues ع0000d & $\ddot{n}$ & $\ddot{m}$ & 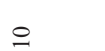 & $\stackrel{m}{m}$ & $\ddot{m}$ & $\ddot{m}$ & $\ddot{m}$ & 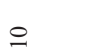 & $\ddot{m}$ & $\ddot{m}$ \\
\hline เәәક ‘ & $i$ & i & i & i & i & i & $\stackrel{\bullet}{\dot{+}}$ & $\begin{array}{l}0 \\
\dot{+}\end{array}$ & i & i \\
\hline 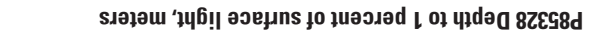 & $i$ & $i$ & $i$ & $i$ & $i$ & $i$ & $i$ & $i$ & $i$ & $i$ \\
\hline 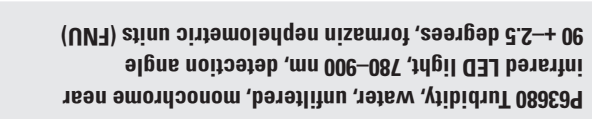 & i & i & i & $\hat{i n}$ & ๙े & $\hat{a}$ & $\stackrel{\odot}{+}$ & $\stackrel{\odot}{+}$ & $\stackrel{\circ}{\stackrel{0}{0}}$ & in \\
\hline 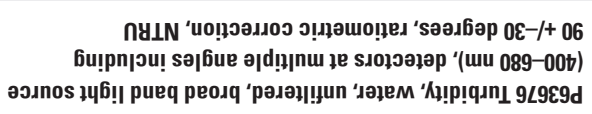 & i & $\stackrel{\sim}{\text { N }}$ & $\stackrel{0}{-}$ & i & i & i & i & i & i & i \\
\hline 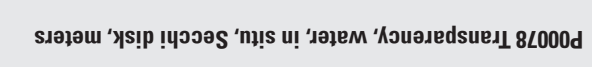 & i & 1 & $i$ & $\dddot{n}$ & i & i & $\stackrel{n}{\sim}$ & $\stackrel{\text { fo }}{-}$ & $\stackrel{+}{i}$ & $\stackrel{\square}{-}$ \\
\hline sn!̣s|әэ sәәдбәр ‘ & i & 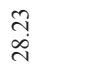 & $\underset{\infty}{\stackrel{\infty}{N}}$ & $\frac{\pi}{\Delta}$ & $\stackrel{2}{\stackrel{2}{n}}$ & $\stackrel{\infty}{\stackrel{\infty}{I}}$ & $\stackrel{n}{\check{2}}$ & $\underset{\substack{\infty \\
\infty}}{\infty}$ & 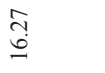 & $\stackrel{8}{\check{g}}$ \\
\hline 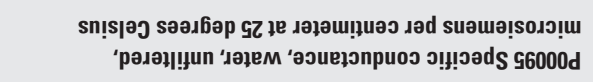 & i & $\stackrel{n}{I}$ & $\stackrel{\Xi}{\beth}$ & $\stackrel{\infty}{=}$ & $\stackrel{g}{\text { g }}$ & $\stackrel{\sim}{2}$ & $\stackrel{\partial}{ }$ & 三 & $\stackrel{\sim}{\sim}$ & ָิ \\
\hline 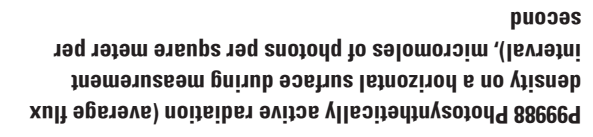 & i & i & i & i & $\underset{\overbrace{}}{\stackrel{\overbrace{}}{f}}$ & $\stackrel{2}{\circ}$ & $\vec{F}$ & 㜿 & \& & 웅 \\
\hline 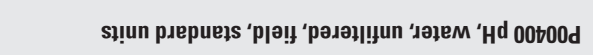 & i & $\stackrel{\infty}{\sigma}$ & $\hat{\sigma}$ & $\hat{\sigma}$ & $\stackrel{m}{r}$ & $\dddot{r}$ & 1 & $\stackrel{\infty}{0}$ & tே. & $\hat{\sigma}$ \\
\hline 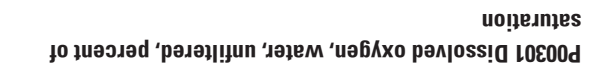 & i & $\stackrel{9}{\circ}$ & $\stackrel{m}{r}$ & 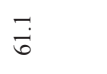 & $\stackrel{\infty}{\sigma}$ & $\frac{m}{a}$ & $\underset{\infty}{\infty}$ & 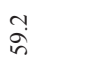 & $\stackrel{m}{m}$ & $\stackrel{\leftrightarrow}{\circ}$ \\
\hline 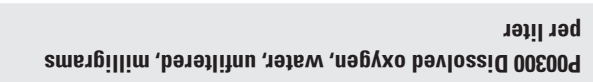 & i & $\begin{array}{l}\dot{b} \\
\dot{n}\end{array}$ & $\hat{i n}$ & $\stackrel{\infty}{+}$ & $\begin{array}{l}\infty \\
\infty \\
\infty\end{array}$ & $\underset{\infty}{\infty}$ & $\begin{array}{l}n \\
\text { in }\end{array}$ & $\begin{array}{l}\infty \\
i\end{array}$ & $\hat{m}$ & $\begin{array}{l}0 \\
\text { in }\end{array}$ \\
\hline 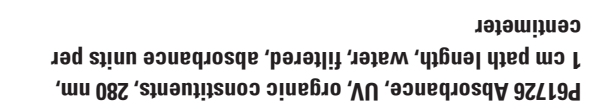 & $i$ & $\stackrel{n}{o}$ & $\stackrel{0}{\circ}$ & $\underset{0}{\stackrel{0}{0}}$ & $\stackrel{\infty}{0}$ & $\stackrel{9}{0}$ & 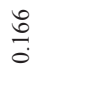 & $\stackrel{n}{\circ}$ & $\stackrel{\substack{+o}}{0}$ & $\underset{\sigma}{0}$ \\
\hline 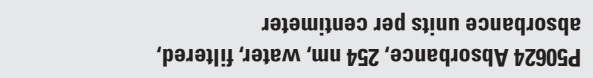 & i & $\stackrel{n}{\dddot{2}}$ & $\frac{1}{1}$ & $\stackrel{\infty}{?}$ & 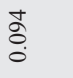 & $\stackrel{n}{o}$ & กิ & กุ & ఝి & స̃ \\
\hline 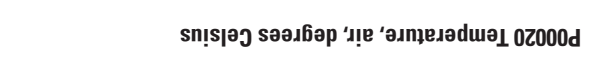 & $i$ & @ి & ஓ & $\stackrel{\infty}{N}$ & $i$ & i & 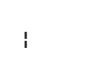 & i & $\begin{array}{l}\infty \\
\stackrel{N}{N}\end{array}$ & i \\
\hline 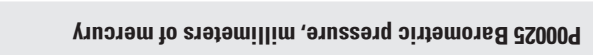 & i & $\underset{r}{t}$ & $\hat{\imath}$ & ర্ & $\stackrel{8}{\circ}$ & ్ㅏㄴ & $\sqrt{2}$ & 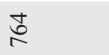 & గె & $\succsim$ \\
\hline 高壱 恶 & 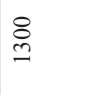 & 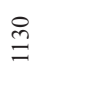 & $\underset{\text { ㅇ }}{\stackrel{2}{ }}$ & $\stackrel{n}{0}$ & 点 & in & 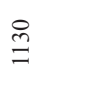 & હે & $\stackrel{n}{\circ}$ & હે \\
\hline Фّઁّ & $\underset{\substack{ \pm \infty \\
\infty}}{ \pm}$ & $\underset{\substack{ \pm \infty}}{ \pm}$ & $\underset{\substack{ \pm \infty}}{ \pm}$ & $\underset{\substack{ \pm \infty}}{ \pm}$ & 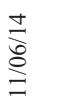 & 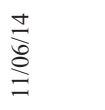 & $\stackrel{\Xi}{\grave{\Xi}}$ & $\stackrel{\Xi}{\Xi}$ & $\stackrel{\Xi}{\Xi}$ & $\stackrel{\Xi}{\Xi}$ \\
\hline 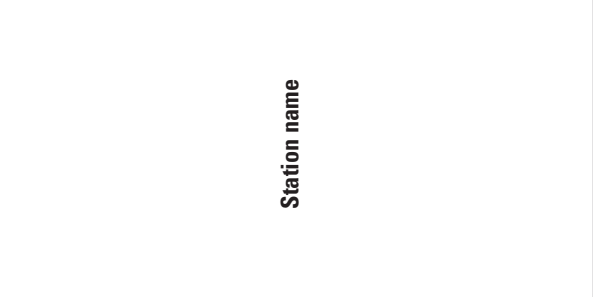 & 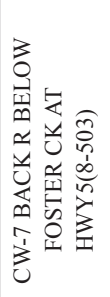 & 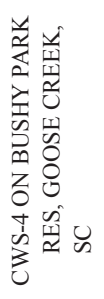 & 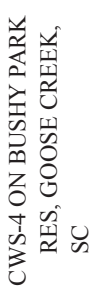 & 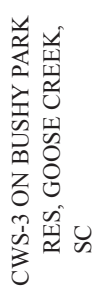 & 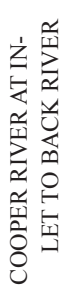 & 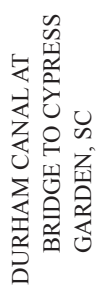 & 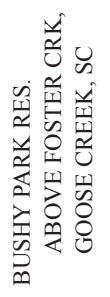 & 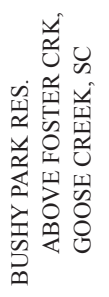 & 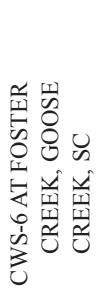 & 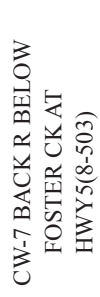 \\
\hline 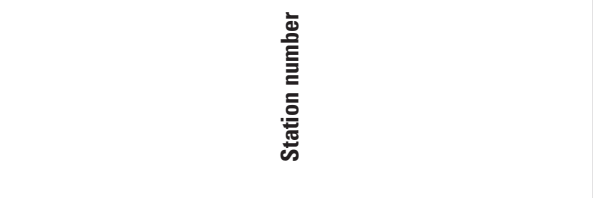 & 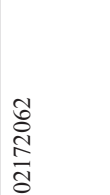 & 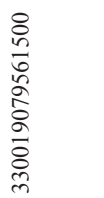 & 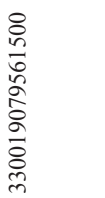 & 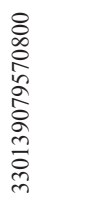 & 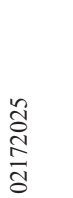 & $\begin{array}{l}8 \\
\stackrel{2}{2} \\
\frac{1}{0}\end{array}$ & 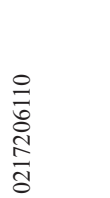 & 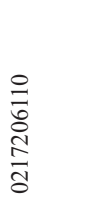 & 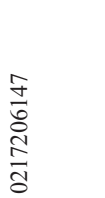 & 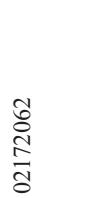 \\
\hline
\end{tabular}




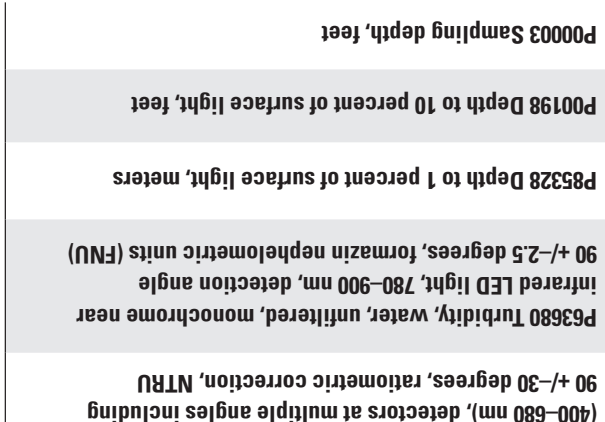
อ्गnos

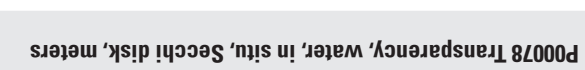

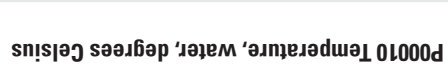

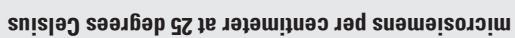

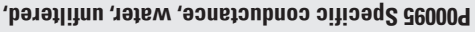

puojes

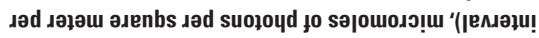

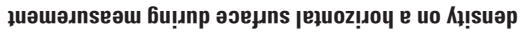

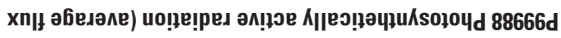

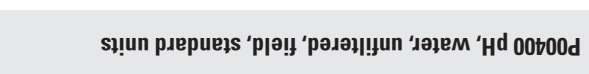

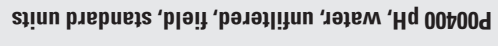

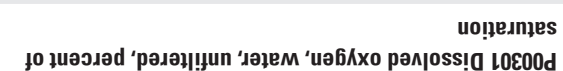

גәџ! jәd

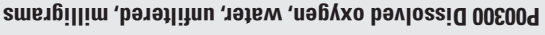

มәเวแ!ฺนวว

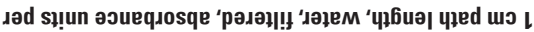

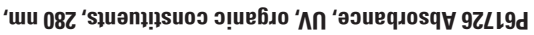

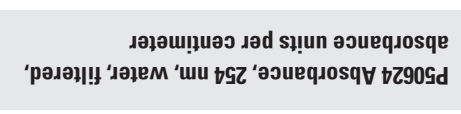

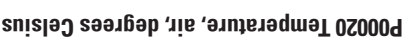

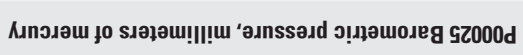

min

繥

产

흘

\begin{tabular}{|c|c|c|c|c|c|c|c|c|c|}
\hline$\ddot{m}$ & 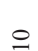 & $\tilde{m}$ & $\ddot{m}$ & $m$ & $\ddot{m}$ & 0 & $\ddot{m}$ & $\stackrel{m}{m}$ & $\ddot{m}$ \\
\hline i & $\stackrel{q}{\dot{f}}$ & i & I & i & i & I & i & i & I \\
\hline i & i & i & フํ & $\nabla$ & i & I & $N$ & I & I \\
\hline$\stackrel{\infty}{+}$ & $\stackrel{\bullet}{+}$ & $\begin{array}{l}\mathbb{N} \\
\mathbb{N} \\
\stackrel{N}{0}\end{array}$ & $\stackrel{\infty}{\sim}$ & $\stackrel{r}{r}$ & $\ddot{n}$ & n & in & $\hat{\sim}$ & $\tilde{\gamma}$ \\
\hline
\end{tabular}

\begin{tabular}{|c|c|c|c|c|c|c|c|c|c|}
\hline$\stackrel{ナ}{\unlhd}$ & $\stackrel{+}{\dot{C}}$ & $\exists$ & $?$ & $I$. & $\stackrel{\infty}{\sim}$ & $\begin{array}{l}\infty \\
\sim\end{array}$ & $\stackrel{+}{\sim}$ & $\stackrel{\infty}{\sim}$ & $\stackrel{\sim}{\sim}$ \\
\hline \begin{tabular}{l}
$\infty$ \\
\multirow{\sigma}{0}{} \\
\end{tabular} & $\stackrel{\infty}{\stackrel{\infty}{\beth}}$ & $\begin{array}{l}= \\
I\end{array}$ & 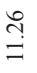 & $\begin{array}{l}\Xi \\
\Xi\end{array}$ & $\stackrel{n}{=}$ & $\stackrel{\stackrel{*}{n}}{=}$ & $\stackrel{\circ}{\circ}$ & $\stackrel{\Xi}{=}$ & $\stackrel{ \pm}{=}$ \\
\hline$=$ & $\cong$ & 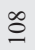 & $\underset{\mathcal{\sigma}}{ }$ & $\hat{\varrho}$ & $\stackrel{ \pm}{\sim}$ & $\underset{\sim}{\stackrel{ \pm}{ }}$ & $\vec{m}$ & $\widehat{\cong}$ & $\cong$ \\
\hline
\end{tabular}

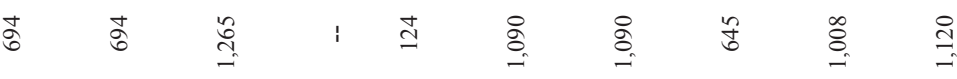

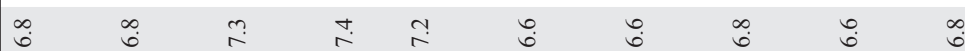

in न न

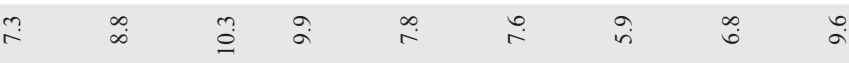

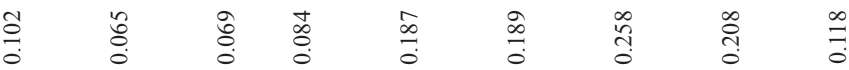

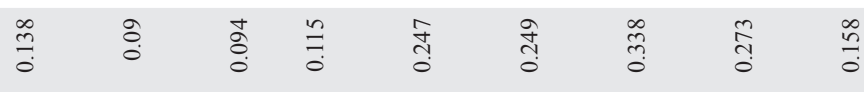

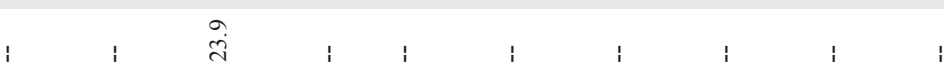

\begin{tabular}{|c|c|c|c|c|c|c|c|c|c|}
\hline$\widehat{6}$ & ชู & $\overparen{3}$ & $\stackrel{8}{1}$ & $\overrightarrow{0}$ & ஜె & ஜ) & ชె & $\underset{గ}{t}$ & $\overrightarrow{0}$ \\
\hline & $\underset{\check{I}}{\Xi}$ & $\underline{n}$ & 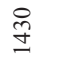 & $\stackrel{m}{m}$ & $\stackrel{0}{=}$ & 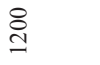 & $\stackrel{ }{\circ}$ & હ & 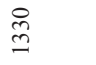 \\
\hline & $\underset{\Xi}{\stackrel{\Xi}{\Xi}}$ & $\underset{\Xi}{\stackrel{\Xi}{\Xi}}$ & $\underset{\text { ป }}{\stackrel{\Xi}{\Xi}}$ & $\begin{array}{l}\underset{\Xi}{ \pm} \\
\stackrel{\Xi}{J}\end{array}$ & 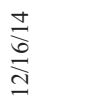 & $\frac{\underset{J}{J}}{\stackrel{\Xi}{J}}$ & 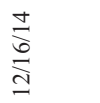 & 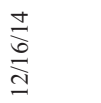 & $\underset{\text { ป }}{\stackrel{ \pm}{\Xi}}$ \\
\hline 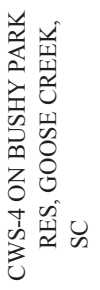 & 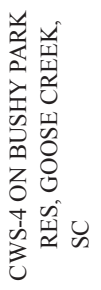 & 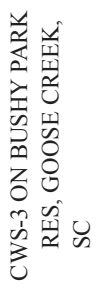 & 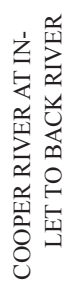 & 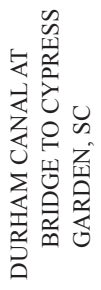 & 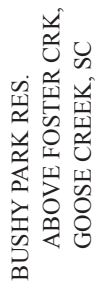 & 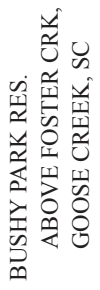 & 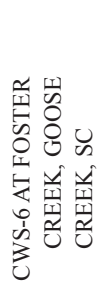 & 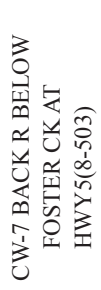 & 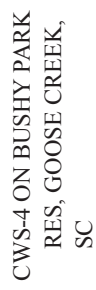 \\
\hline 4 & 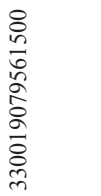 & 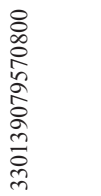 & 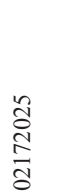 & 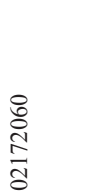 & $\begin{array}{l}0 \\
\bar{\sigma} \\
\delta \\
\stackrel{N}{ } \\
\bar{ป} \\
\delta\end{array}$ & 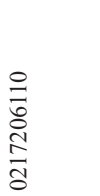 & 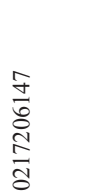 & $\begin{array}{l}\text { రু } \\
\text { ㄱ } \\
\text { ㄱ. }\end{array}$ & $\begin{array}{l}8 \\
\frac{8}{6} \\
\frac{0}{2} \\
\frac{2}{8} \\
\frac{0}{8} \\
\frac{8}{2} \\
m\end{array}$ \\
\hline
\end{tabular}




\begin{tabular}{|c|c|c|c|c|c|c|c|c|c|}
\hline 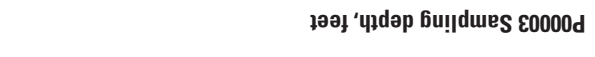 & 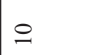 & $m$ & $i$ & $i$ & $i$ & 1 & i & $m$ & i \\
\hline 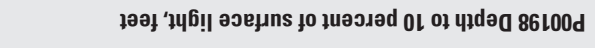 & i & i & i & i & 1 & $i$ & i & i & $i$ \\
\hline 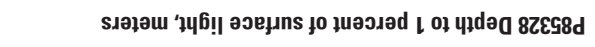 & i & i & i & i & i & i & i & i & i \\
\hline 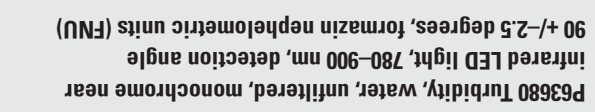 & $\hat{i}$ & $\stackrel{0}{r}$ & 1 & 1 & i & 1 & i & $\stackrel{g}{\stackrel{2}{2}}$ & 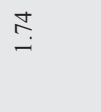 \\
\hline 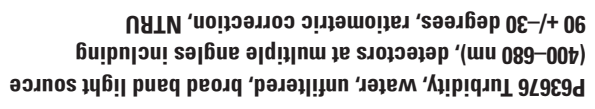 & i & i & i & $\mathrm{i}$ & ! & $i$ & i & i & 1 \\
\hline 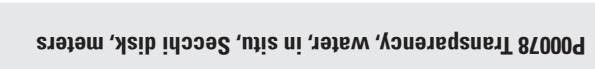 & N & $\cong$ & 1 & i & 1 & 1 & i & 1 & i \\
\hline 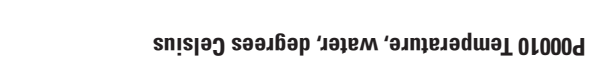 & $\stackrel{\Xi}{\Xi}$ & $\stackrel{\overrightarrow{0}}{\equiv}$ & 1 & 1 & i & i & i & $\stackrel{\infty}{\stackrel{\sim}{\sim}}$ & $\stackrel{m}{\stackrel{n}{0}}$ \\
\hline 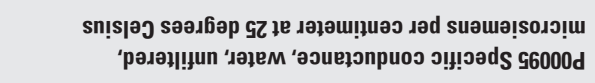 & $\stackrel{m}{=}$ & $\stackrel{\Xi}{\Xi}$ & 1 & 1 & i & $i$ & i & $\begin{array}{l}\text { ¿ } \\
\text { ป }\end{array}$ & $\stackrel{m}{\check{n}}$ \\
\hline 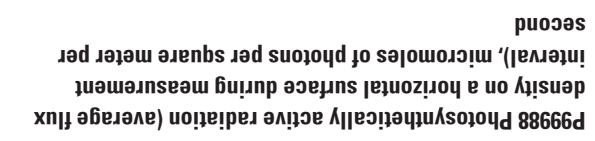 & 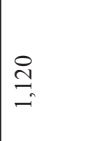 & $\underset{-}{8}$ & 1 & $i$ & i & 1 & 1 & $\stackrel{m}{n}$ & 1 \\
\hline 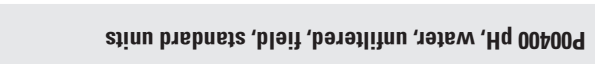 & $\underset{\infty}{\infty}$ & $\stackrel{N}{r}$ & i & i & i & 1 & 1 & $\overparen{r}$ & $\stackrel{N}{r}$ \\
\hline 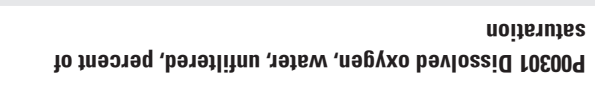 & $\ddot{\infty}$ & กุ & 1 & 1 & 1 & 1 & 1 & $\underset{\infty}{\stackrel{\Delta}{~}}$ & $\grave{\infty}$ \\
\hline 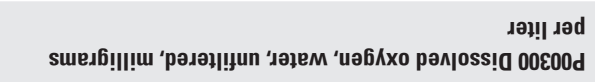 & $\dddot{n}$ & $\stackrel{0}{0}$ & 1 & i & i & 1 & i & $\stackrel{m}{r}$ & $\stackrel{n}{2}$ \\
\hline 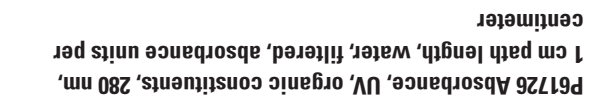 & $\stackrel{?}{3}$ & 今̂ & 1 & I & I & I & I & I & I \\
\hline 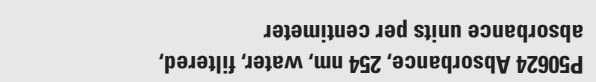 & $\stackrel{\overrightarrow{0}}{0}$ & $\stackrel{n}{0}$ & i & i & i & i & i & i & I \\
\hline 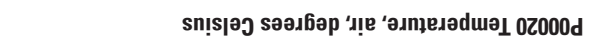 & 1 & I & 1 & 1 & i & 1 & 1 & 1 & 1 \\
\hline 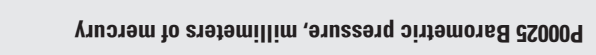 & $\overline{6}$ & $\stackrel{3}{2}$ & I & I & i & i & i & $\stackrel{\circ}{n}$ & $\stackrel{\circ}{n}$ \\
\hline 高壳 恶 & 号 & $\stackrel{n}{\beth}$ & బิ & 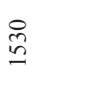 & 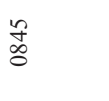 & §̊ & 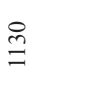 & $\stackrel{8}{\&}$ & §ิ \\
\hline 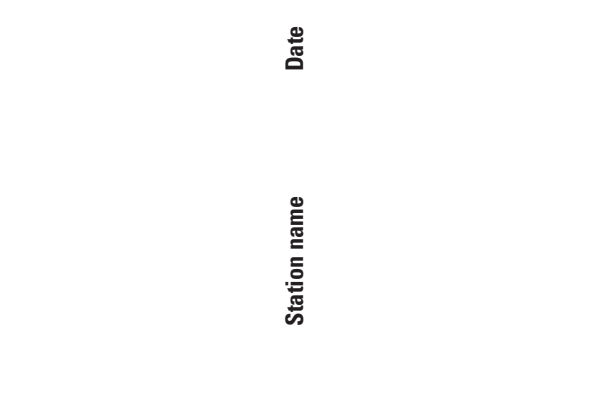 & 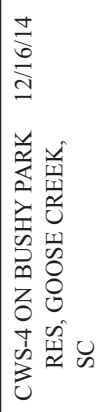 & 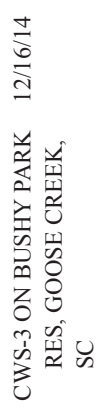 & 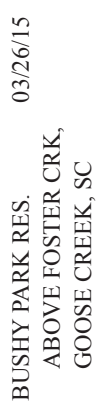 & 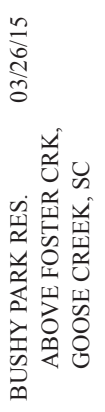 & 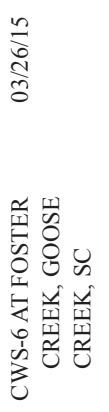 & 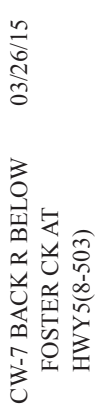 & 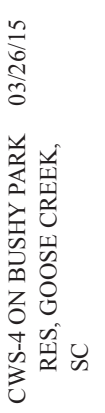 & 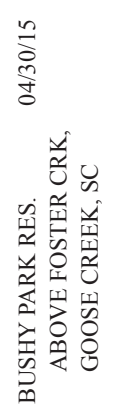 & 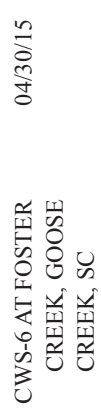 \\
\hline 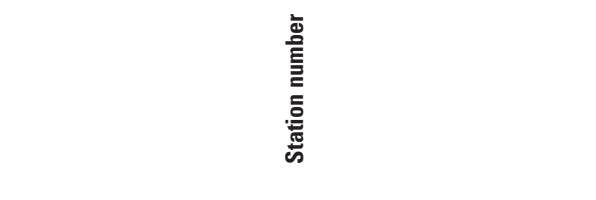 & 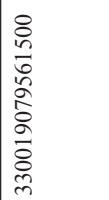 & 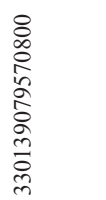 & 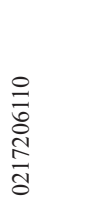 & 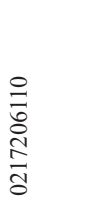 & 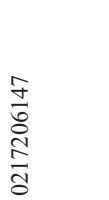 & 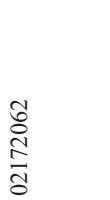 & 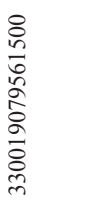 & 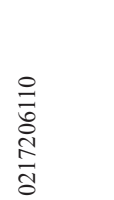 & 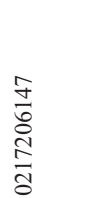 \\
\hline
\end{tabular}




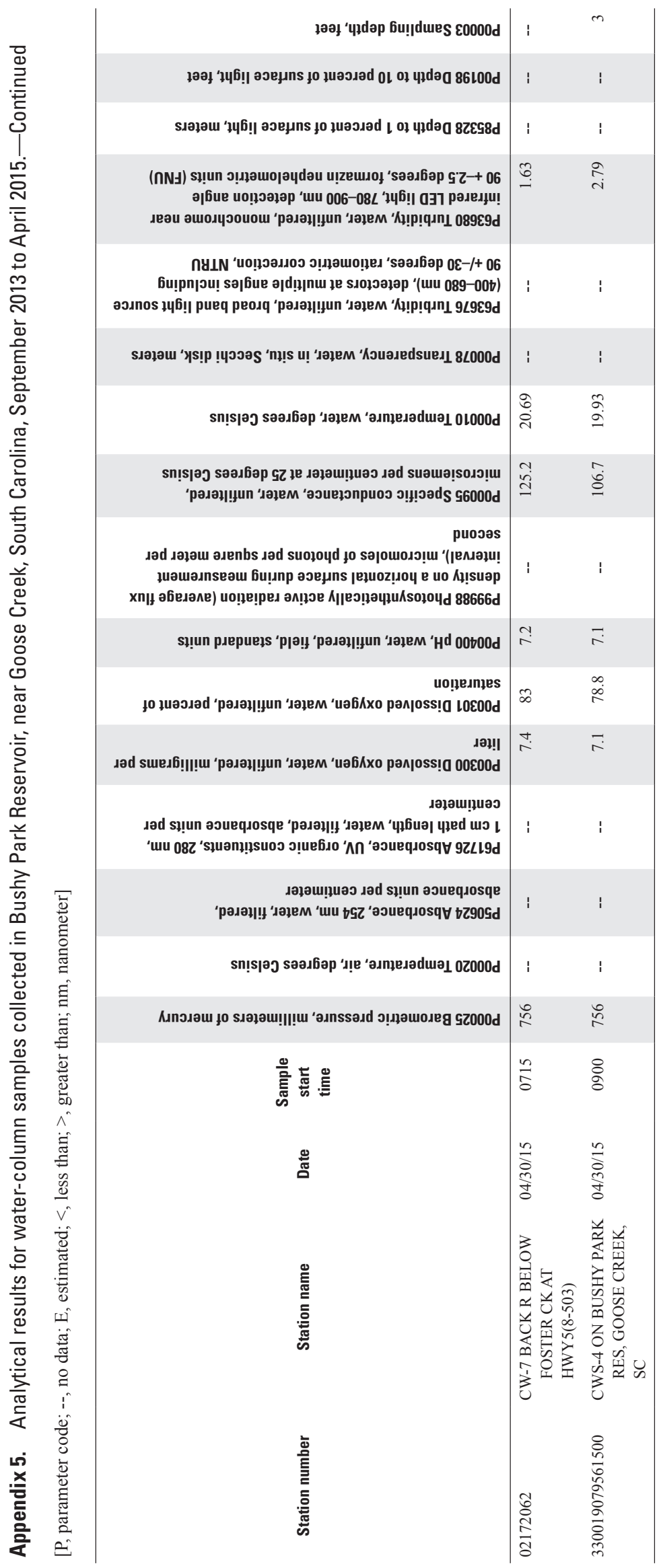


uә60ג!̣u se дәฺ!

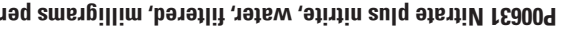

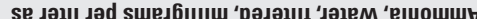

C.

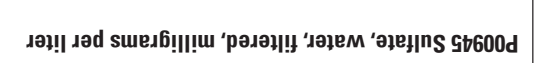

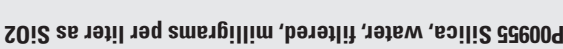

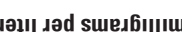

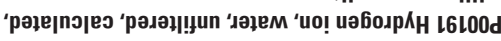

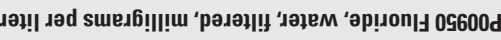

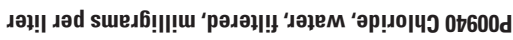

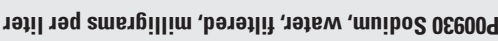

suop̣eo doleu to s\}uә

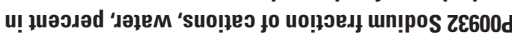

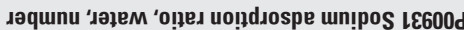

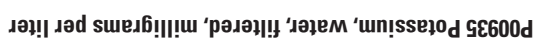

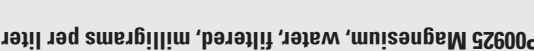

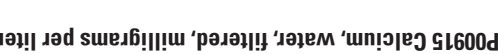

әџ!| גәd

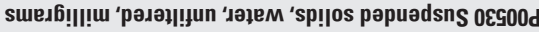

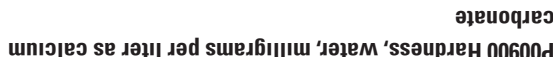

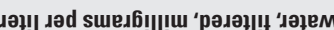

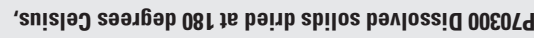

$\stackrel{\square}{\square}$

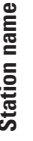

흘

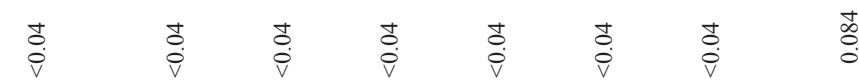

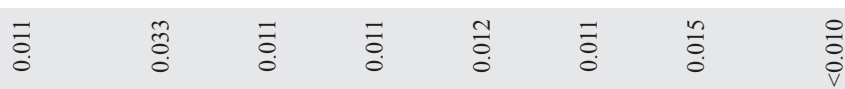

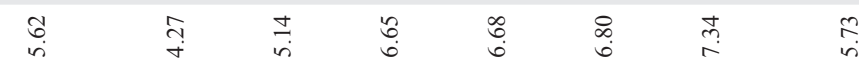

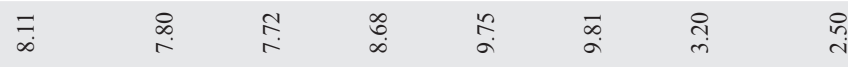

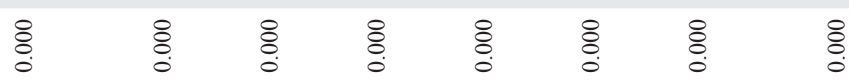

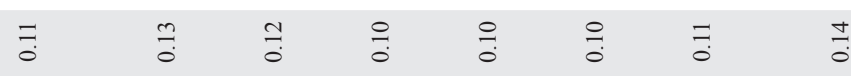

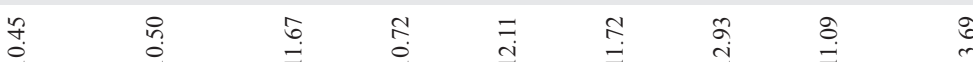

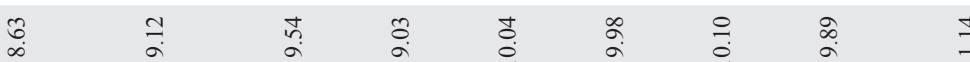

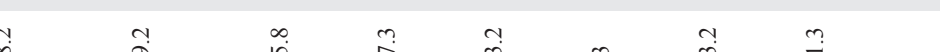

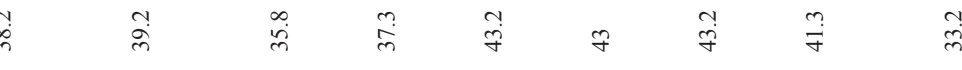

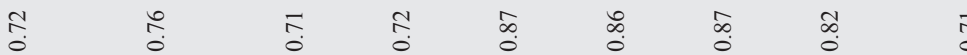

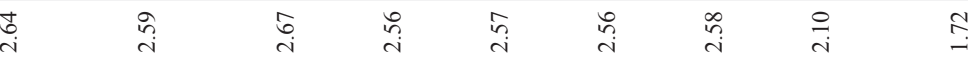

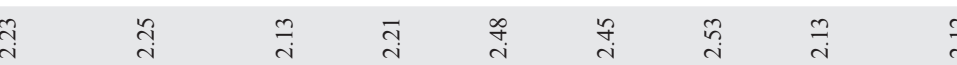

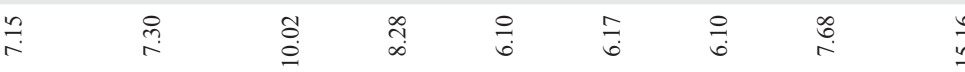

$\stackrel{n}{\vec{v}} \quad \stackrel{n}{\vec{v}} \quad \stackrel{n}{v} \quad \stackrel{n}{\frac{n}{v}} \quad \stackrel{n}{v} \quad \stackrel{n}{\vec{v}} \quad \stackrel{n}{v} \quad \stackrel{n}{\vec{v}} \quad \stackrel{n}{v}$

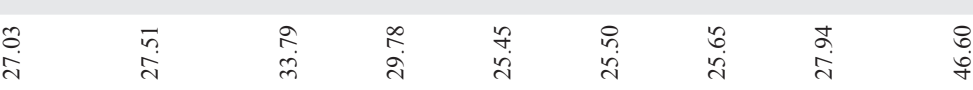

$\approx \approx \infty \quad \infty \quad \infty \quad \infty$

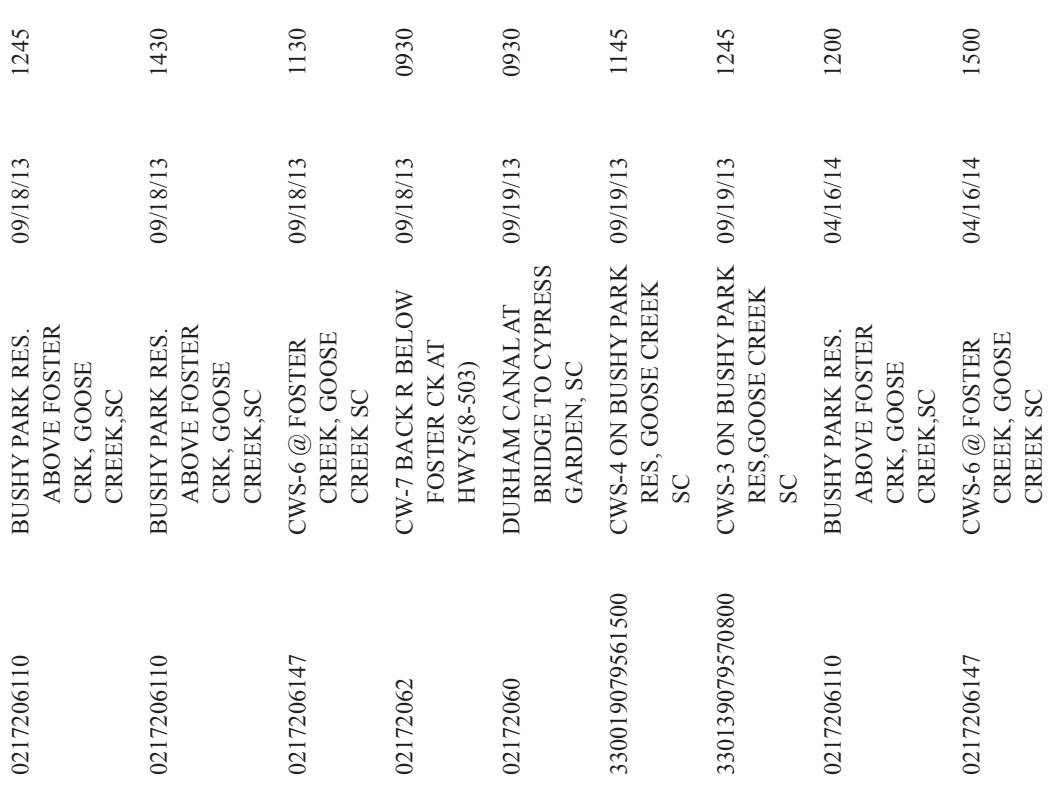




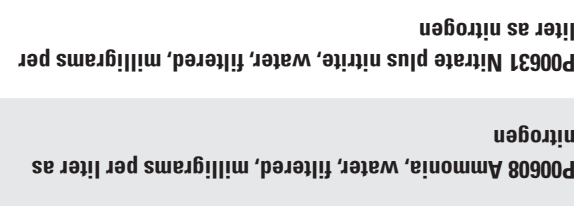

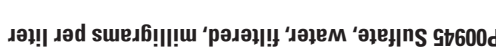

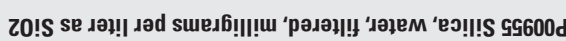

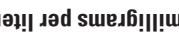

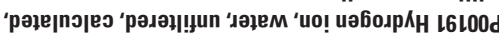

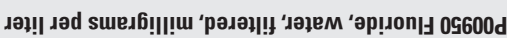

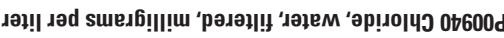

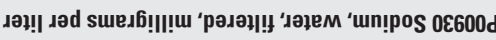

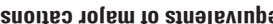

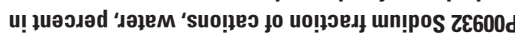

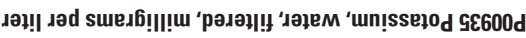

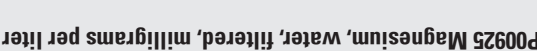

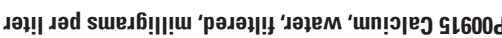

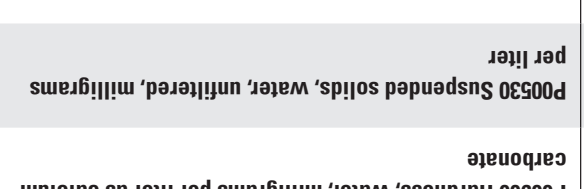

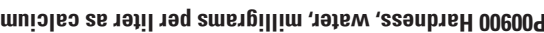

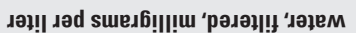

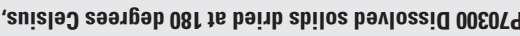

\begin{tabular}{|c|c|c|c|c|}
\hline$\stackrel{0}{0}$ & 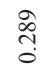 & i & i & I \\
\hline $\begin{array}{l}0 \\
0 \\
0 \\
\dot{0}\end{array}$ & $\begin{array}{l}\text { ஜ } \\
\stackrel{0}{0}\end{array}$ & I & 1 & I \\
\hline$\stackrel{2}{\longrightarrow}$ & $\stackrel{n}{r}$ & i & 1 & I \\
\hline$\stackrel{\infty}{\infty}$ & ஓे & i & i & i \\
\hline$\stackrel{\circ}{\circ}$ & $\stackrel{8}{\circ}$ & i & i & I \\
\hline
\end{tabular}

$\frac{N}{0}$

ก

$\stackrel{\infty}{+}$

$\begin{array}{llll}0 & 0 & H & 0 \\ 0 & 0 & 0 & 0\end{array}$

$\begin{array}{llll}\circ & \overline{1} & \infty & 0 \\ 0 & \vdots & 0 & 0 \\ 0 & 0 & 0 & 0\end{array}$

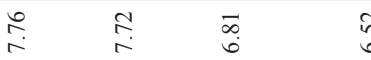

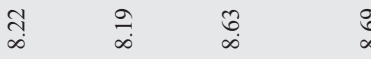

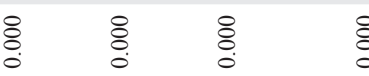

$\stackrel{0}{\circ} \quad \stackrel{0}{0} \quad \stackrel{7}{0} \quad=$

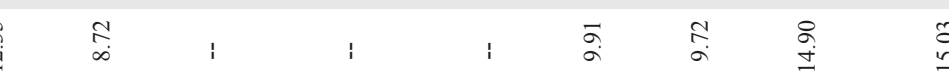

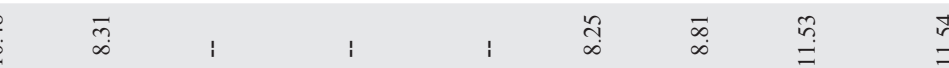

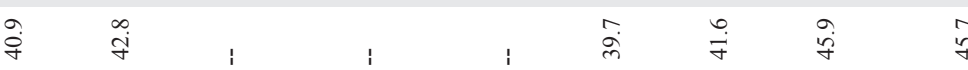

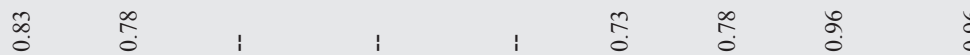

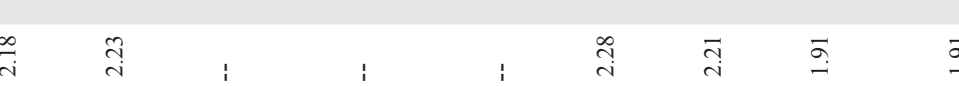

ก ลู

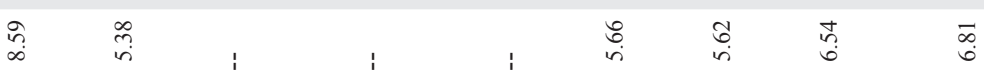

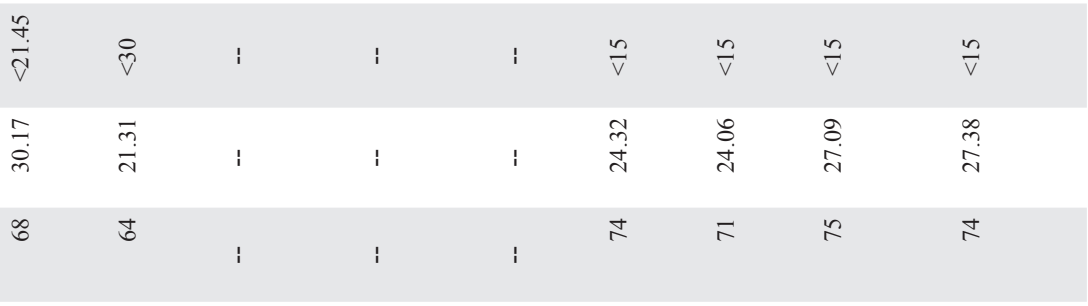

竞

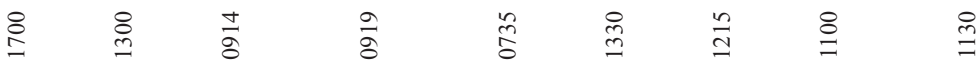

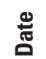

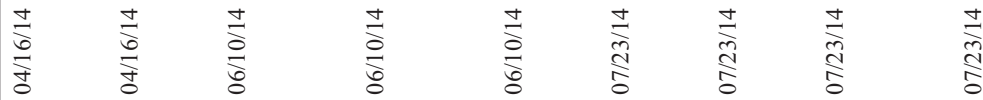

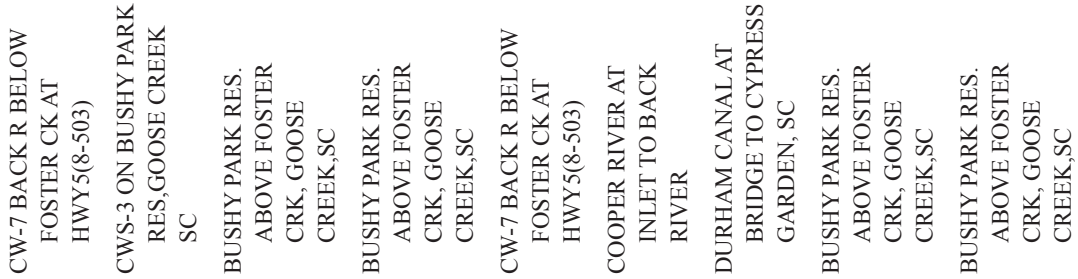

竞 


\begin{tabular}{|c|c|c|c|c|c|c|c|c|c|}
\hline 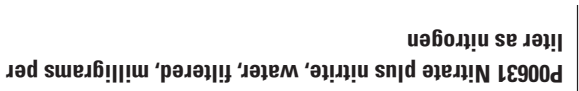 & $\underset{\dot{D}}{\dot{\Delta}}$ & $\stackrel{t}{\dot{\vec{V}}}$ & $\stackrel{t}{\dot{\theta}}$ & $\underset{\dot{\theta}}{g}$ & $\stackrel{\Delta}{\dot{\vec{v}}}$ & $\underset{\dot{v}}{\dot{\theta}}$ & $\stackrel{t}{\dot{\vec{V}}}$ & $\stackrel{t}{\dot{\theta}}$ & $\stackrel{+}{\dot{\theta}}$ \\
\hline 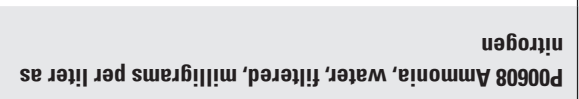 & के & $\begin{array}{l}\stackrel{\circ}{0} \\
\stackrel{\dot{v}}{v}\end{array}$ & $\stackrel{m}{0}$ & 商 & 竞 & $\stackrel{\circ}{\circ}$ & $\begin{array}{l}\stackrel{\circ}{0} \\
\stackrel{\dot{v}}{v}\end{array}$ & $\begin{array}{l}\stackrel{\circ}{0} \\
\stackrel{\dot{v}}{v}\end{array}$ & $\stackrel{\circ}{\stackrel{\nabla}{\nabla}}$ \\
\hline 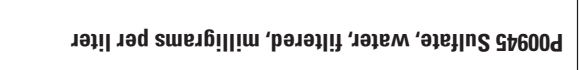 & $\stackrel{f}{+}$ & $\underset{\text { Hु }}{ }$ & $\stackrel{n}{n}$ & $\underset{\sim}{\sim}$ & $\stackrel{\infty}{\stackrel{\infty}{\sim}}$ & $\stackrel{?}{\stackrel{?}{0}}$ & $\begin{array}{l}\overline{5} \\
\infty\end{array}$ & : & in \\
\hline 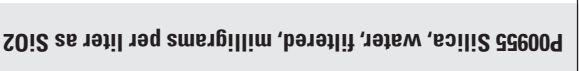 & $\stackrel{i}{i}$ & $\begin{array}{ll}\tilde{N} \\
\infty\end{array}$ & $\underset{n}{n}$ & $\underset{\infty}{\infty}$ & $\underset{\infty}{=}$ & $\underset{\substack{n \\
\infty}}{\infty}$ & $\underset{\infty}{\infty}$ & $\stackrel{R}{\infty}$ & $\underset{\dot{b}}{\infty}$ \\
\hline 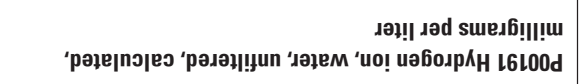 & $\stackrel{\circ}{\circ}$ & $\stackrel{0}{\circ}$ & $\stackrel{0}{\circ}$ & $\stackrel{8}{\circ}$ & $\stackrel{8}{\circ}$ & $\stackrel{\circ}{\circ}$ & $\stackrel{0}{\circ}$ & $\stackrel{0}{\circ}$ & $\stackrel{\circ}{\circ}$ \\
\hline 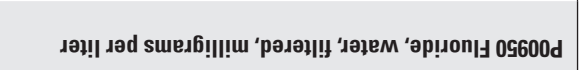 & $\stackrel{\square}{0}$ & $\overline{0}$ & $\stackrel{m}{0}$ & $\frac{1}{0}$ & $\stackrel{9}{\circ}$ & $\overline{0}$ & $\stackrel{0}{\circ}$ & $\stackrel{m}{0}$ & $\stackrel{m}{0}$ \\
\hline 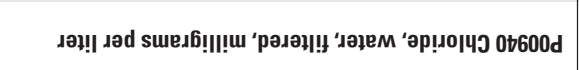 & $\begin{array}{l}\infty \\
\infty \\
\dot{I}\end{array}$ & $\stackrel{n}{n}$ & $\stackrel{n}{a}$ & $\stackrel{\infty}{=}$ & ⿳亠丷⿵冂丶 & $\hat{\tilde{j}}$ & $\stackrel{\infty}{\stackrel{\infty}{\rightarrow}}$ & 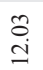 & $\stackrel{\text { a }}{=}$ \\
\hline 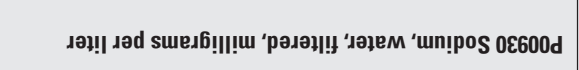 & ลू. & $\stackrel{\text { }}{=}$ & $\stackrel{n}{0}$ & $\stackrel{\overbrace{}}{\stackrel{\overbrace{}}{\varrho}}$ & $\underset{\substack{\infty \\
\infty \\
\infty}}{\infty}$ & $\stackrel{n}{\stackrel{n}{=}}$ & $\stackrel{n}{\stackrel{n}{f}}$ & $\stackrel{\circ}{\stackrel{0}{\Theta}}$ & $\stackrel{\overrightarrow{0}}{\stackrel{0}{0}}$ \\
\hline 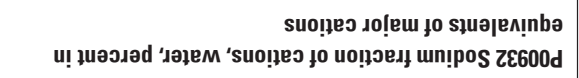 & $q$ & $\dot{f}$ & $\stackrel{4}{\dddot{H}}$ & भे & 当 & $\stackrel{m}{i}$ & $\stackrel{4}{\breve{r}}$ & q & F \\
\hline 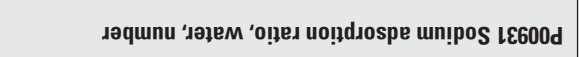 & $\stackrel{\infty}{\infty}$ & $\stackrel{+}{\circ}$ & $\stackrel{\infty}{\infty}$ & $\stackrel{\infty}{\infty}$ & $\begin{array}{c}5 \\
y \\
y\end{array}$ & $\stackrel{?}{-}$ & $\stackrel{\overrightarrow{+}}{-}$ & $\begin{array}{c}\infty \\
\infty \\
\infty\end{array}$ & $\stackrel{\infty}{\infty} \stackrel{\infty}{i}$ \\
\hline 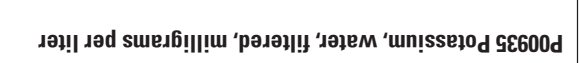 & $\stackrel{\infty}{\stackrel{\infty}{7}}$ & $\stackrel{\infty}{-}$ & $\overrightarrow{\vec{j}}$ & $\overrightarrow{\vec{j}_{i}}$ & ปู & $\underset{i}{i}$ & तิ & $\frac{\overrightarrow{\mathrm{i}}}{2}$ & הి \\
\hline 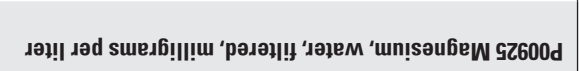 & $\stackrel{\vec{i}}{i}$ & $\stackrel{\sim}{i}$ & $\stackrel{\circ}{i}$ & $\stackrel{\circ}{i}$ & $\stackrel{n}{\text { in }}$ ì & $\underset{\text { gे. }}{\stackrel{q}{r}}$ & 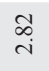 & $\stackrel{\infty}{h}$ & $i n$ \\
\hline 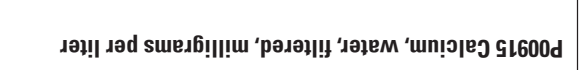 & $\underset{0}{0}$ & $\stackrel{\circ}{\longleftarrow}$ & గ్రి & $\stackrel{\sim}{6}$ & 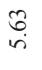 & oे & $\stackrel{m}{i}$ & $\stackrel{\circ}{\stackrel{0}{r}}$ & $\stackrel{m}{r}$ \\
\hline 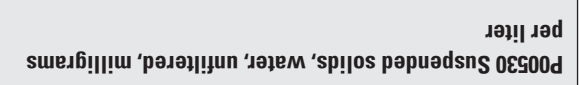 & $\stackrel{n}{v}$ & $\stackrel{n}{v}$ & $\stackrel{n}{v}$ & $\stackrel{n}{v}$ & $\stackrel{n}{v}$ & $\stackrel{\sim}{v}$ & $\stackrel{n}{v}$ & $\stackrel{n}{v}$ & $\stackrel{n}{v}$ \\
\hline 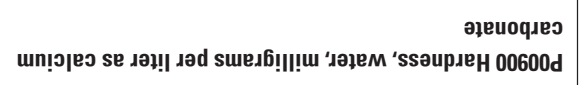 & ळे. & 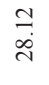 & 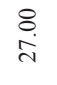 & 总 & $\stackrel{d}{+m}$ & 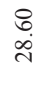 & 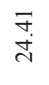 & $\begin{array}{l}\stackrel{i}{4} \\
\stackrel{4}{d}\end{array}$ & $\underset{\infty}{\stackrel{4}{\infty}} \underset{1}{2}$ \\
\hline 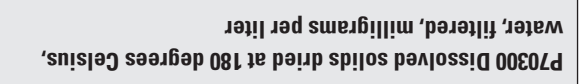 & $\infty$ & $\infty$ & 5 & $\therefore$ & 3 & 2 & 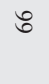 & $\approx$ & 8 \\
\hline 을 & if & ల & $n$ & ig & $\cong$ & 8 & $f$ & 8 & 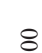 \\
\hline
\end{tabular}

解

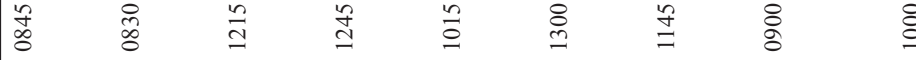

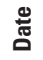

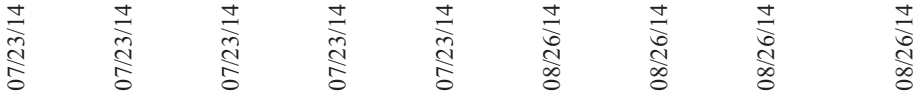

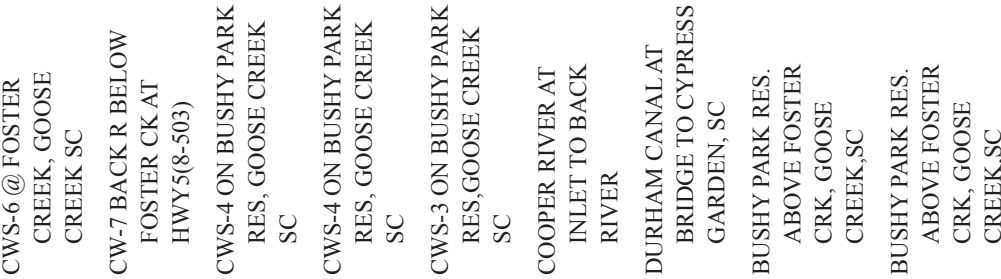

离

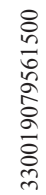

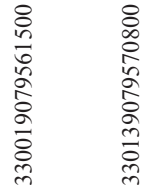

芩

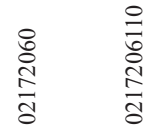

$\frac{\sqrt{3}}{\sqrt{2}}$ 


\begin{tabular}{|c|c|c|c|c|c|c|c|c|}
\hline 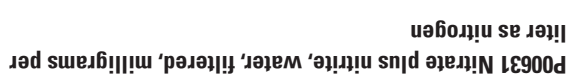 & $\stackrel{\Xi}{\dot{0}}$ & $\stackrel{+}{\stackrel{\leftrightarrow}{+}}$ & i & $\stackrel{+}{\stackrel{\leftrightarrow}{+}}$ & $\stackrel{+}{\stackrel{\leftrightarrow}{\dot{V}}}$ & $\stackrel{\Xi}{\dot{0}}$ & $\stackrel{\Xi}{\dot{0}}$ & $\stackrel{t}{\dot{Q}}$ \\
\hline 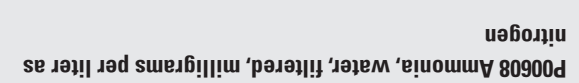 & $\stackrel{m}{0}$ & $\stackrel{\circ}{\circ}$ & i & $\stackrel{\circ}{\circ}$ & $\stackrel{\circ}{\stackrel{0}{0}}$ & $\stackrel{\circ}{\circ}$ & $\stackrel{\circ}{\stackrel{0}{0}}$ & $\stackrel{\circ}{\stackrel{0}{0}}$ \\
\hline дәџ! & $\underset{+}{+}$ & خิ & i & $\underset{\infty}{\grave{\infty}}$ & $\begin{array}{l}\infty \\
\infty \\
\infty \\
\infty\end{array}$ & $\underset{\infty}{\not}$ & $\stackrel{\infty}{\stackrel{\infty}{\Xi}}$ & $\stackrel{2}{\circ}$ \\
\hline 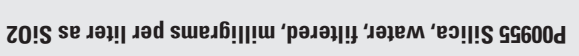 & $\vec{n}$ & $\vec{n}$ & i & 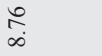 & $\begin{array}{l}\hat{\sigma} \\
\infty\end{array}$ & $\tilde{n}$ & $\begin{array}{l}\stackrel{0}{0} \\
\stackrel{0}{0}\end{array}$ & ఫे \\
\hline 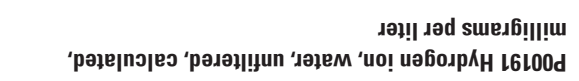 & $\stackrel{8}{8}$ & $\stackrel{8}{\circ}$ & i & $\stackrel{8}{8}$ & $\stackrel{8}{\circ}$ & $\stackrel{8}{8}$ & $\stackrel{-1}{8}$ & $\stackrel{8}{\circ}$ \\
\hline 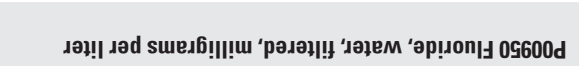 & $\stackrel{1}{0}$ & $\stackrel{m}{0}$ & i & $\exists$ & 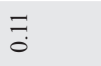 & $\stackrel{\circ}{\circ}$ & 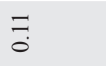 & $\exists$ \\
\hline 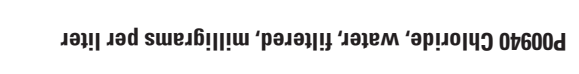 & ๙̃ & $\stackrel{n}{n}$ & i & 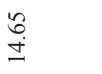 & $\overrightarrow{\tilde{v}}$ & $\begin{array}{ll}\ddot{n} \\
\dot{m}\end{array}$ & $\underset{\mathrm{i}}{\overline{\mathrm{i}}}$ & $\stackrel{+}{\stackrel{+}{\infty}}$ \\
\hline 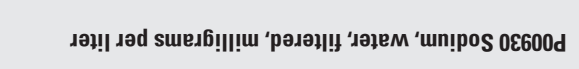 & $\stackrel{m}{\rightleftarrows}$ & $\stackrel{\circ}{\circ}$ & i & $\underset{\sim}{\check{c}}$ & ָิ & $\stackrel{m}{\beth}$ & ํ. & ñ \\
\hline 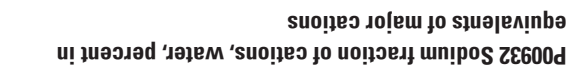 & $\vec{m}$ & $\stackrel{\Im}{\mathcal{Y}}$ & i & $\stackrel{\infty}{+}$ & $\stackrel{\infty}{+}$ & $\frac{2}{\check{\sigma}}$ & $\stackrel{+}{i}$ & 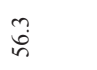 \\
\hline 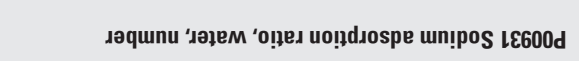 & $\begin{array}{l}0 \\
\infty \\
0\end{array}$ & $\begin{array}{l}\infty \\
\stackrel{0}{0}\end{array}$ & i & $\stackrel{\curvearrowleft}{\sigma}$ & $\stackrel{n}{\circ}$ & $\stackrel{\overbrace{}}{\text { ș }}$ & ำ & $\stackrel{\text { I }}{-}$ \\
\hline 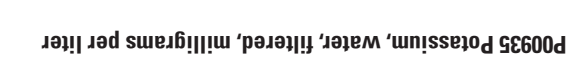 & $\bar{\sigma}$ & $\frac{n}{i}$ & i & $\stackrel{n}{n}$ & $\vec{n}$ & $\stackrel{+}{n}$ & $\begin{array}{l}\curvearrowright \\
\stackrel{N}{N}\end{array}$ & $\vec{i}$ \\
\hline 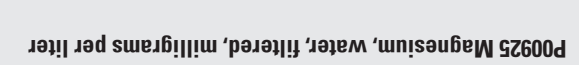 & $\stackrel{n}{\sim}$ & $\begin{array}{l}\infty \\
\stackrel{n}{n}\end{array}$ & i & $\begin{array}{l}\underset{\infty}{~} \\
\stackrel{+}{ }\end{array}$ & $\begin{array}{l}\infty \\
\infty \\
i\end{array}$ & $\stackrel{a}{i}$ & $\frac{\infty}{m}$ & $\begin{array}{l}\stackrel{\infty}{\text { i }} \\
\text { in }\end{array}$ \\
\hline 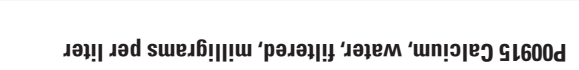 & $\underset{\Xi}{\Xi}$ & $\stackrel{m}{r}$ & i & $n$ & $\begin{array}{l}\infty \\
i \\
i\end{array}$ & $\vec{m}$ & $\stackrel{?}{+}$ & $\stackrel{+}{+}$ \\
\hline 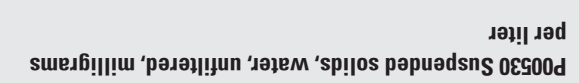 & $\stackrel{n}{v}$ & $\stackrel{n}{\nabla}$ & i & $\stackrel{n}{v}$ & $\frac{n}{v}$ & $\frac{n}{v}$ & $\stackrel{n}{v}$ & $\stackrel{n}{v}$ \\
\hline $\begin{array}{r}\text { әреuоqдеэ } \\
\text { un!э }\end{array}$ & ñ & ì. & i & $\begin{array}{l}\hat{n} \\
\ddot{n}\end{array}$ & $\begin{array}{l}\infty \\
\stackrel{\infty}{1}\end{array}$ & 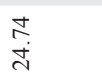 & $\begin{array}{l} \pm \\
\stackrel{ \pm}{d}\end{array}$ & $\underset{\stackrel{N}{i}}{\stackrel{+}{i}}$ \\
\hline 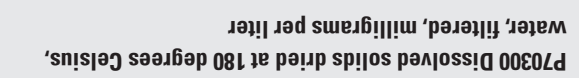 & $\Re$ & 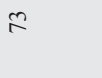 & i & 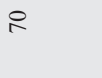 & $\mathrm{N}$ & 3 & 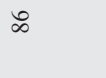 & 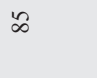 \\
\hline ڤ & ஓ & $\underset{\infty}{\mathscr{D}}$ & 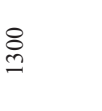 & 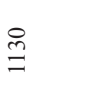 & 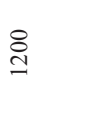 & $\stackrel{n}{0}$ & $\stackrel{\sim}{ \pm}$ & $\stackrel{n}{n}$ \\
\hline 壳 & 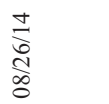 & $\begin{array}{l} \pm \\
\stackrel{\Xi}{d} \\
\infty \\
0\end{array}$ & $\underset{\substack{\Delta \\
\infty \\
0}}{ \pm}$ & $\underset{\substack{ \pm \infty}}{\stackrel{ \pm}{\Delta}}$ & 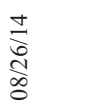 & $\underset{\substack{\Xi \\
\infty}}{ \pm}$ & $\stackrel{\Xi}{\Xi}$ & $\underset{\Xi}{\stackrel{\Xi}{\Xi}}$ \\
\hline 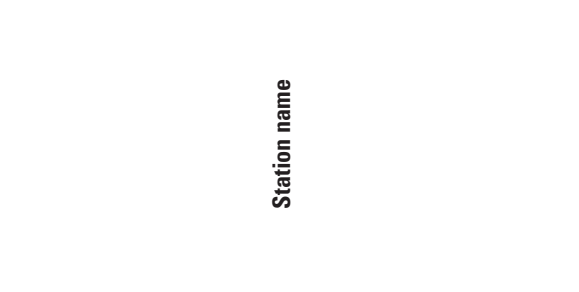 & 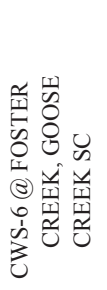 & 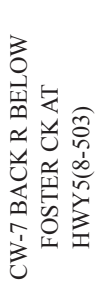 & 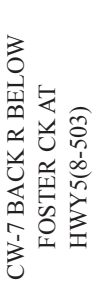 & 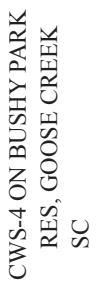 & 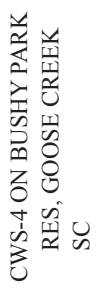 & 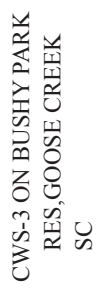 & 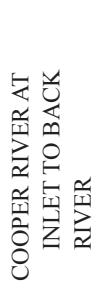 & 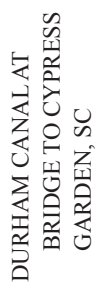 \\
\hline
\end{tabular}




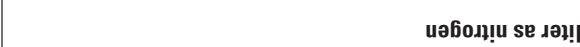

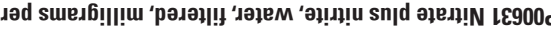

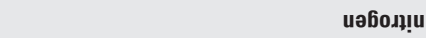

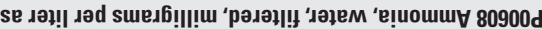

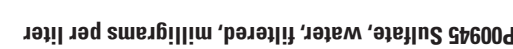

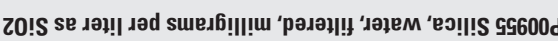

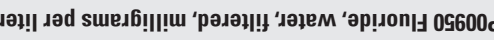

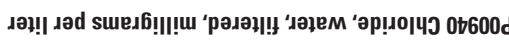

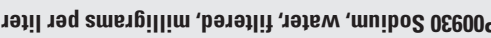
suolıe doleu to słuәремınb

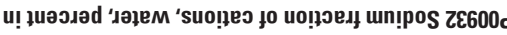

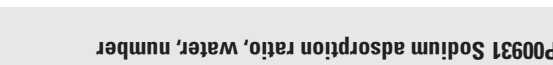

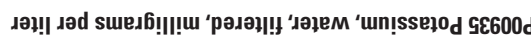

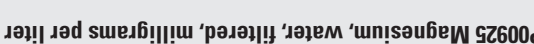

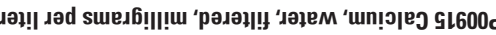
גәฺ! גәd sued6!!I!แ ‘рәдәң!

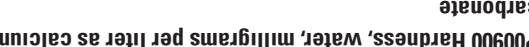

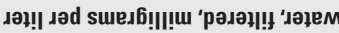

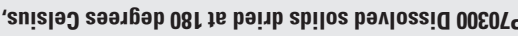
号言

咅

壱

章

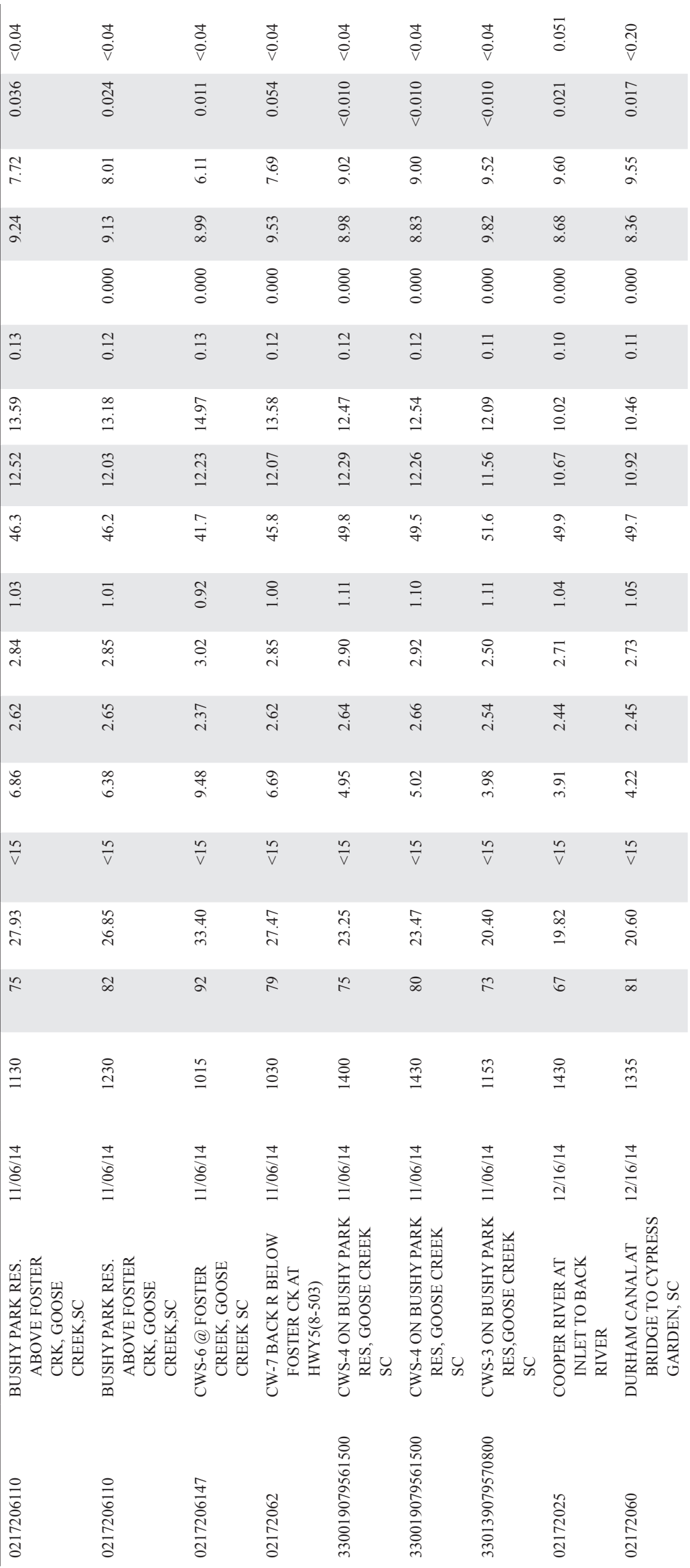




\begin{tabular}{|c|c|c|c|c|c|c|c|c|}
\hline 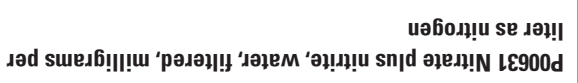 & $\stackrel{\rho}{\circ}$ & $\stackrel{+}{\dot{0}}$ & $\stackrel{\Xi}{\dot{\theta}}$ & 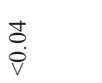 & $\begin{array}{l}\text { Oे } \\
\stackrel{0}{0}\end{array}$ & 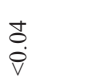 & $\stackrel{+}{\dot{O}}$ & i \\
\hline 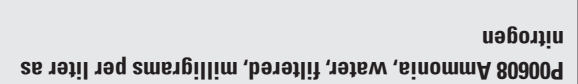 & $\hat{n}$ & $\hat{\infty}$ & $\stackrel{\infty}{\circ}$ & గै & $\stackrel{\infty}{0}$ & 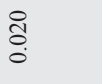 & $\frac{1}{0}$ & 1 \\
\hline 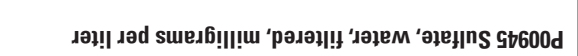 & $\underset{\infty}{\infty}$ & $\underset{\infty}{\tilde{\infty}}$ & જे & $\stackrel{\infty}{\stackrel{\infty}{r}}$ & $\stackrel{J}{\text { J }}$ & 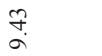 & $\begin{array}{l}\stackrel{0}{0} \\
\dot{a}\end{array}$ & 1 \\
\hline 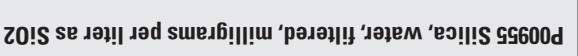 & $\underset{\sigma}{\sigma}$ & $\stackrel{\infty}{\infty}$ & $\hat{\infty}$ & $\stackrel{\infty}{\stackrel{\infty}{r}}$ & $\stackrel{\infty}{\infty}$ & $\overbrace{\infty}^{\infty}$ & $\begin{array}{l}\infty \\
\infty \\
\infty\end{array}$ & i \\
\hline 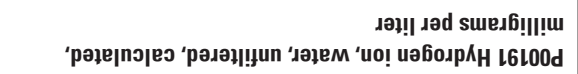 & $\stackrel{8}{8}$ & $\stackrel{8}{\circ}$ & $\stackrel{8}{8}$ & \begin{tabular}{l}
$\stackrel{8}{8}$ \\
\hdashline
\end{tabular} & $\stackrel{8}{8}$ & $\begin{array}{l}\stackrel{8}{0} \\
\stackrel{0}{0}\end{array}$ & $\begin{array}{l}8 \\
8 \\
8\end{array}$ & i \\
\hline 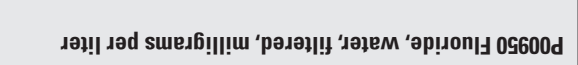 & $\frac{m}{0}$ & $\frac{m}{0}$ & $\frac{m}{0}$ & $\frac{m}{0}$ & $\frac{\text { I }}{0}$ & $=$ & $\frac{0}{0}$ & i \\
\hline 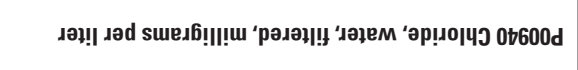 & $\begin{array}{l}= \\
\underline{n}\end{array}$ & $=$ & $\underset{\stackrel{্}{ \pm}}{\stackrel{\Xi}{J}}$ & $\stackrel{\simeq}{\stackrel{n}{n}}$ & 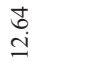 & $\begin{array}{l}\underset{D}{\infty} \\
\stackrel{I}{J}\end{array}$ & さ̊ & i \\
\hline 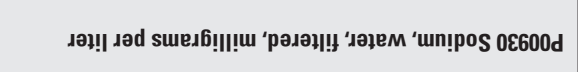 & $\begin{array}{l}0 \\
\check{1} \\
\end{array}$ & $\begin{array}{l}\infty \\
0 \\
\stackrel{\bigcup}{\beth}\end{array}$ & 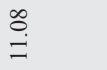 & 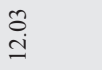 & $\stackrel{\infty}{\Xi}$ & $\begin{array}{l}\infty \\
\stackrel{\infty}{=}\end{array}$ & \begin{tabular}{l}
\multirow{\sigma}{0}{} \\
$\stackrel{0}{0}$
\end{tabular} & 1 \\
\hline 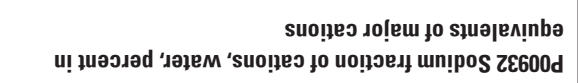 & $\begin{array}{l}0 \\
\ddot{f}\end{array}$ & ํํ & $\begin{array}{l}\infty \\
\infty \\
\infty \\
m\end{array}$ & $\forall$ & $\begin{array}{l}\dot{q} \\
\dot{q}\end{array}$ & $\stackrel{+}{\stackrel{g}{q}}$ & $\stackrel{+}{\stackrel{q}{q}}$ & i \\
\hline 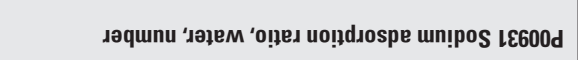 & $\stackrel{\circ}{-}$ & $\stackrel{n}{\circ}$ & $\stackrel{\infty}{\infty}$ & $\stackrel{\infty}{\circ}$ & $\stackrel{ }{=}$ & $\stackrel{\infty}{\circ}$ & $\hat{\sigma}$ & $i$ \\
\hline 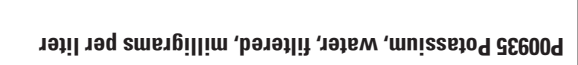 & $\tilde{m}$ & $\vec{n}$ & $\stackrel{\text { Y }}{\mathfrak{r}}$ & 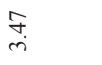 & ๙े & $\begin{array}{l}œ \\
\stackrel{\infty}{i}\end{array}$ & 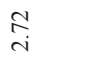 & i \\
\hline 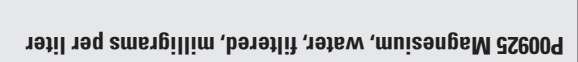 & $\underset{i}{\stackrel{+}{+}}$ & 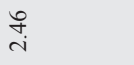 & $\underset{\text { तิ }}{\text { î }}$ & ભે & $\vec{n}$ & $\stackrel{n}{n}$ & $\stackrel{\stackrel{+}{i}}{i}$ & 1 \\
\hline 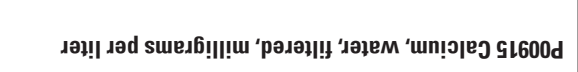 & $\vec{\infty}$ & ڤ్ & $\begin{array}{l}\vec{\infty} \\
\stackrel{0}{a}\end{array}$ & $\underset{\sim}{\sim}$ & $\stackrel{n}{\leftrightarrow}$ & $\stackrel{\circ}{\stackrel{+}{+}}$ & $\stackrel{m}{\underset{+}{+}}$ & 1 \\
\hline 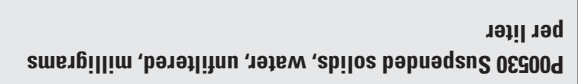 & $\stackrel{n}{v}$ & $\stackrel{n}{v}$ & $\stackrel{n}{v}$ & $\stackrel{n}{v}$ & $\stackrel{n}{v}$ & 2 & $\stackrel{n}{v}$ & I \\
\hline 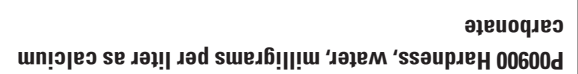 & $\stackrel{n}{\stackrel{2}{2}}$ & $\begin{array}{l}\stackrel{8}{i} \\
\stackrel{2}{N}\end{array}$ & 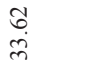 & $\begin{array}{l}\infty \\
\infty \\
\infty \\
i\end{array}$ & $\begin{array}{l}\infty \\
\stackrel{\infty}{0} \\
\text { ปn }\end{array}$ & $\begin{array}{l}\vec{\infty} \\
\stackrel{\lambda}{N}\end{array}$ & $\underset{ก}{\stackrel{ก}{ก}}$ & i \\
\hline 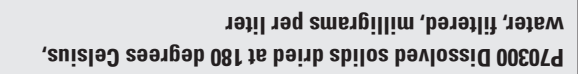 & $\infty$ & $\curvearrowleft$ & $\bar{\infty}$ & 2 & $m$ & $\mathfrak{N}$ & ఫ & 1 \\
\hline 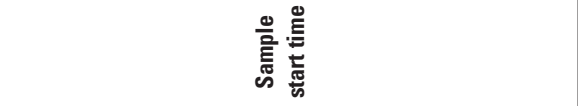 & 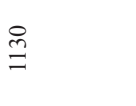 & 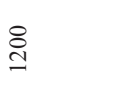 & $\stackrel{\circ}{\circ}$ & లి & 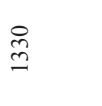 & \& & $\stackrel{n}{\beth}$ & $\tilde{\kappa}$ \\
\hline 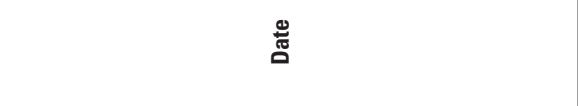 & 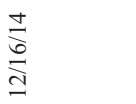 & 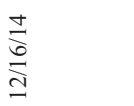 & 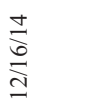 & 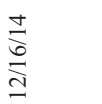 & $\frac{ \pm}{\stackrel{\Xi}{\Xi}}$ & 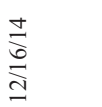 & $\begin{array}{l} \pm \\
\stackrel{\Xi}{\Xi}\end{array}$ & $\frac{\substack{n \\
\vdots}}{\infty}$ \\
\hline 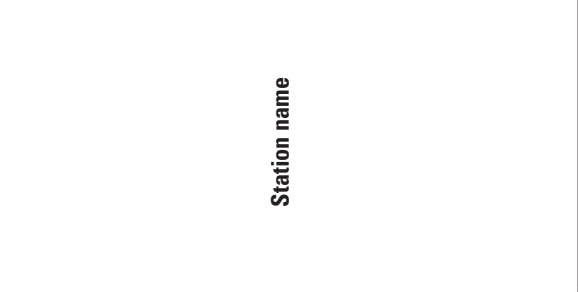 & 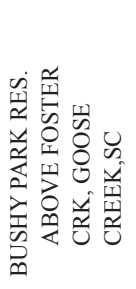 & 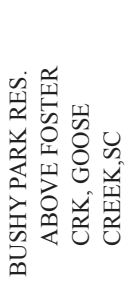 & 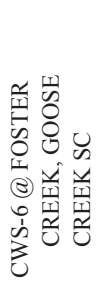 & 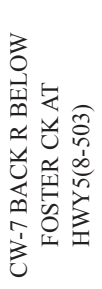 & 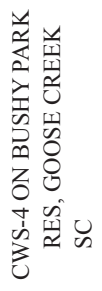 & 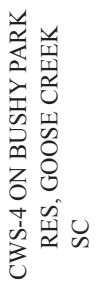 & 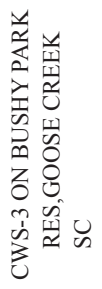 & 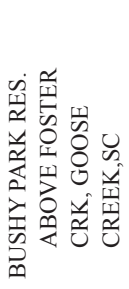 \\
\hline 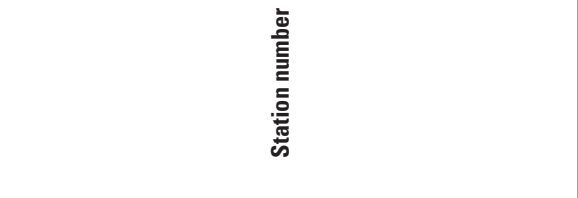 & 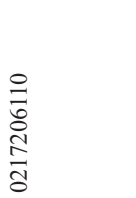 & 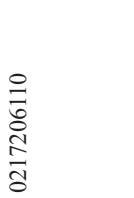 & 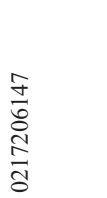 & 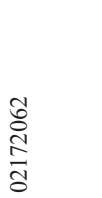 & 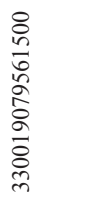 & 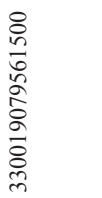 & 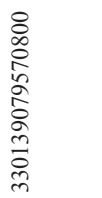 & 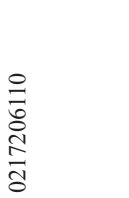 \\
\hline
\end{tabular}




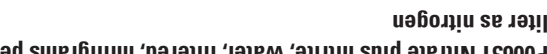
|d әреग!N IE900d uә60ג!ฺ!

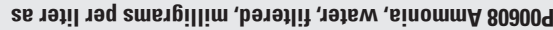

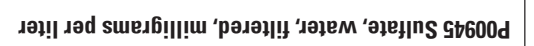

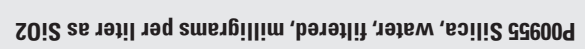

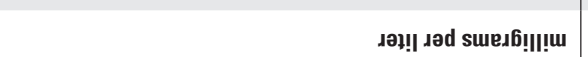

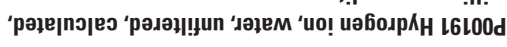

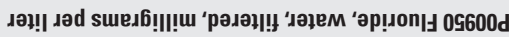

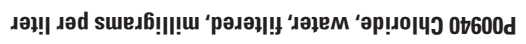

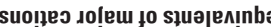

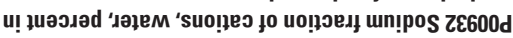

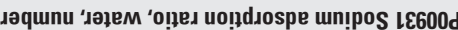

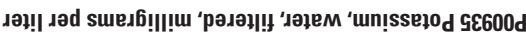

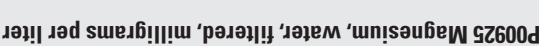

trang

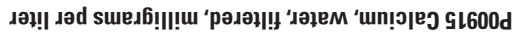

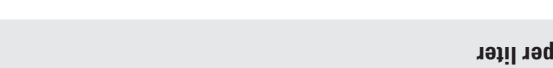

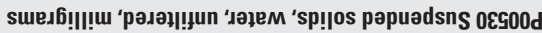

әреuоques

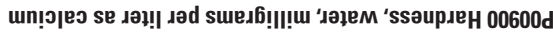

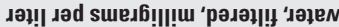

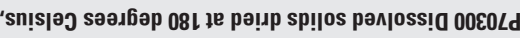

竞

总



i $\quad$ i $\quad$ i

$\infty$

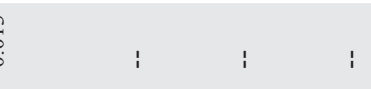

$1+\frac{10}{1+2}$

i i i i

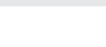

i $\quad i \quad i$

$\begin{array}{lll}1 & 1 & \text { J } \\ \text { i } & 1 & \end{array}$




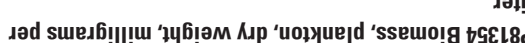

गә!!

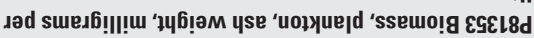

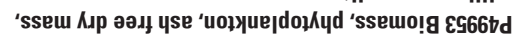

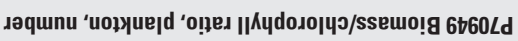

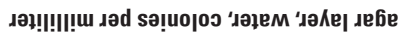

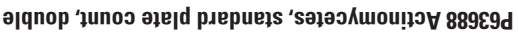

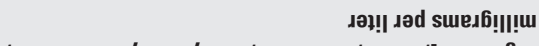

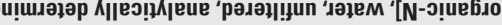

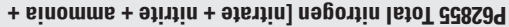

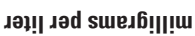

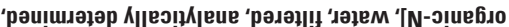

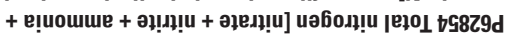

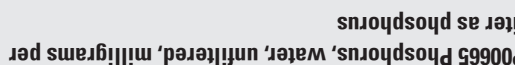

and

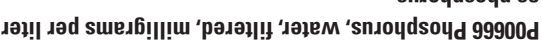

snıoydsoyd se גәџ!।

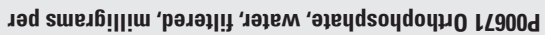

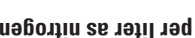

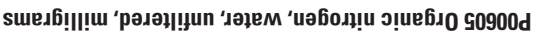

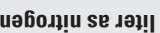

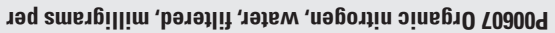

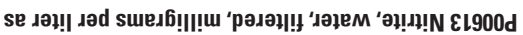

uอ6oג!̣u

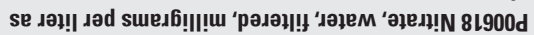

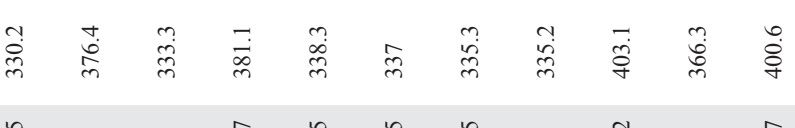

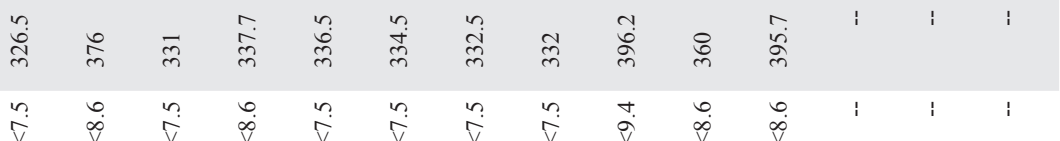

\begin{tabular}{|c|c|c|c|c|c|c|c|c|c|}
\hline & \begin{tabular}{l}
$\infty$ \\
\multirow{+}{*}{}
\end{tabular} & $\begin{array}{l}\infty \\
\text { } ु \\
\text { tे }\end{array}$ & ஸे & $\begin{array}{l}\text { †ें } \\
\text { ळे }\end{array}$ & $\underset{m}{\stackrel{v}{m}}$ & $\underset{⿱ 亠 凶}{\stackrel{+}{ \pm}}$ & $\begin{array}{l}n \\
\stackrel{2}{8} \\
\stackrel{2}{8}\end{array}$ & $\begin{array}{c}\text { Na } \\
\text { ñ } \\
\text { ñ }\end{array}$ & $\begin{array}{l}\stackrel{0}{0} \\
\stackrel{+}{f}\end{array}$ \\
\hline$\sim$ & $n$ & 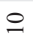 & 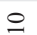 & ㅇ & $a$ & 이 & $r$ & $\nabla$ & 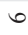 \\
\hline
\end{tabular}

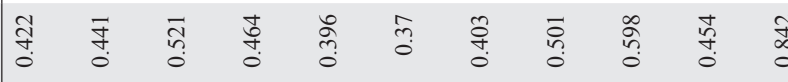

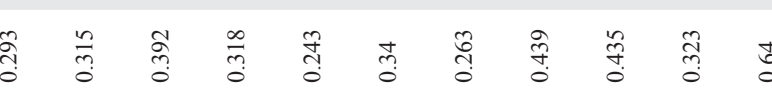

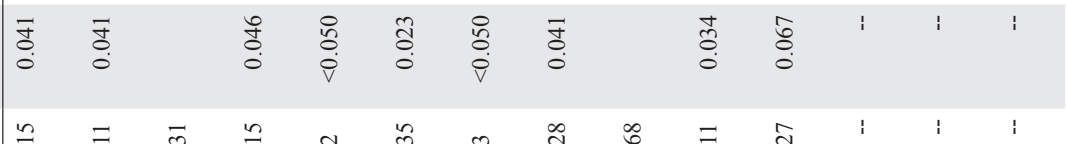

\&.

ก) \&े

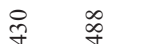

+.

पे के के

$\stackrel{\circ}{\circ}$

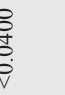

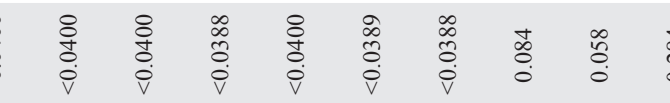

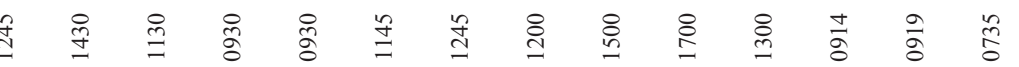

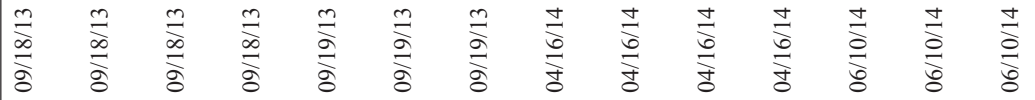

离

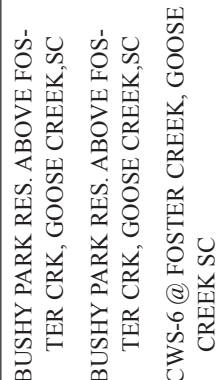

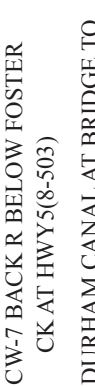

焉

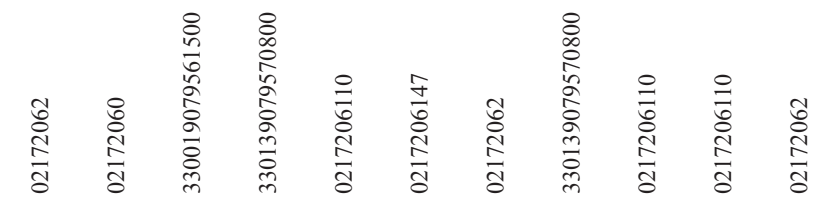




\begin{tabular}{|c|c|c|c|c|c|c|c|c|c|c|c|c|c|c|}
\hline 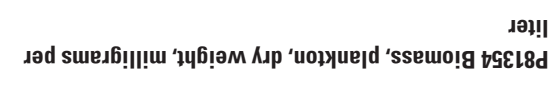 & 我 & $\stackrel{?}{\vec{f}}$ & 竎 & $\stackrel{i n}{m}$ & 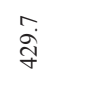 & $\stackrel{n}{\frac{n}{m}}$ & 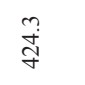 & 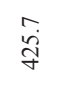 & $\stackrel{n}{m}$ & $\underset{\substack{\infty \\
\infty}}{\infty}$ & $\underset{\substack{+m}}{+}$ & $\bar{F}$ & $\stackrel{\check{q}}{\stackrel{q}{+}}$ & య్రి \\
\hline 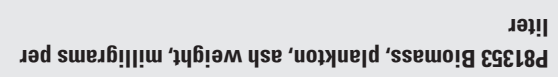 & $\mid \begin{array}{c}\hat{j} \\
\tilde{\gamma}\end{array}$ & $\tilde{q}$ & $\stackrel{3}{b}$ & ते & $\widetilde{\vartheta}$ & $\stackrel{3}{m}$ & $\stackrel{\grave{b}}{f}$ & $\stackrel{?}{\Rightarrow}$ & 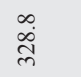 & $\stackrel{m}{?}$ & فें & 字 & $\stackrel{6}{7}$ & $\frac{\infty}{m}$ \\
\hline 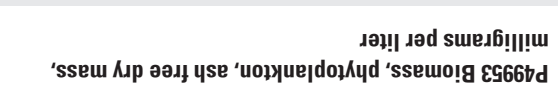 & $\stackrel{\stackrel{\dot{\theta}}{v}}{\mathrm{~V}}$ & 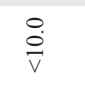 & 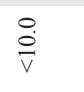 & $\stackrel{n}{\tilde{v}}$ & $\stackrel{\stackrel{\dot{\theta}}{V}}{\mathrm{~V}}$ & $\stackrel{n}{\tilde{v}}$ & $\stackrel{\circ}{\dot{\vec{V}}}$ & $\stackrel{\stackrel{\dot{\theta}}{V}}{ }$ & $\stackrel{n}{\stackrel{n}{v}}$ & $\underset{\infty}{\infty}$ & $\underset{\infty}{\infty}$ & $\stackrel{?}{0}$ & $\stackrel{\circ}{\stackrel{\circ}{V}}$ & $\stackrel{r}{r}$ \\
\hline 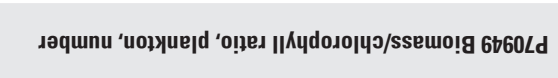 & $\frac{d}{1}$ & $\stackrel{q}{q}$ & $\stackrel{+}{\vec{a}}$ & 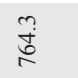 & $\overrightarrow{\vec{k}}$ & ส్ & 垈 & $\stackrel{m}{\vdots}$ & $\stackrel{m}{\infty}$ & $\stackrel{\partial}{\partial}$ & $\overrightarrow{\stackrel{s}{-}}$ & $\frac{\rho}{\dot{\alpha}}$ & $\exists$ & 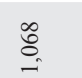 \\
\hline 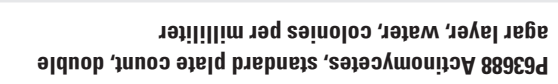 & 은 & 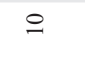 & n & in & $\simeq$ & $a$ & $=$ & $\infty$ & $\infty$ & r & $=$ & 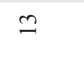 & $\simeq$ & \\
\hline 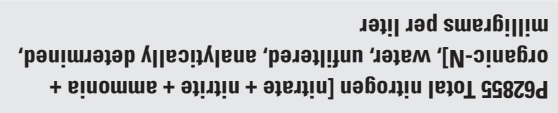 & $\underset{m}{m}$ & हे & f̊. & के & $\underset{\substack{\infty \\
\stackrel{\infty}{0} \\
0}}{0}$ & ồ & $\stackrel{+}{+}$ & $\underset{m}{m}$ & $\underset{\substack{0 \\
0}}{0}$ & $\bar{\delta}$ & సี่ & 管 & $\begin{array}{l}\infty \\
\infty \\
0 \\
0\end{array}$ & $\begin{array}{l}\infty \\
\stackrel{f}{f}\end{array}$ \\
\hline 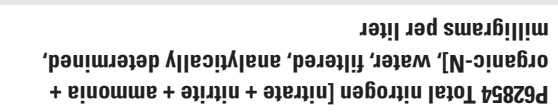 & 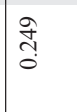 & ర్ల & ते & $\stackrel{\substack{n \\
\sigma}}{a}$ & $\underset{\substack{n \\
3}}{3}$ & 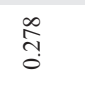 & సิे & $\begin{array}{l}\infty \\
\infty \\
\overbrace{0}^{0}\end{array}$ & 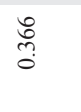 & ָุ & $\stackrel{n}{m}$ & 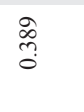 & $\begin{array}{l}\stackrel{\circ}{0} \\
\stackrel{0}{0}\end{array}$ & 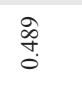 \\
\hline 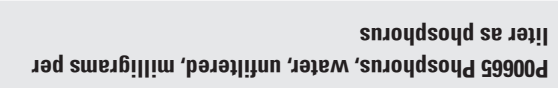 & $\hat{\sigma}$ & हूँ & કै & ț & & $\tilde{c}$ & ¿ू̃ & $\stackrel{\substack{0 \\
0}}{0}$ & 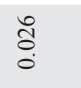 & ळ̂. & 茴 & ț & $\underset{\delta}{\Phi}$ & \\
\hline 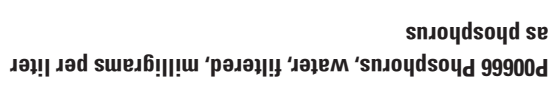 & $\stackrel{\circ}{\grave{0}}$ & $\stackrel{n}{a}$ & $\stackrel{\circ}{\stackrel{0}{\dot{V}}}$ & $\stackrel{n}{0}$ & ${ }_{0}^{ \pm}$ & $\stackrel{2}{0}$ & $\stackrel{\circ}{\stackrel{0}{\dot{V}}}$ & $\stackrel{\substack{6 \\
0}}{0}$ & $\overline{0}$ & $\overline{0}$ & त్ & $\underset{0}{\overrightarrow{0}}$ & $\stackrel{\Omega}{0}$ & $\vec{\circ}$ \\
\hline 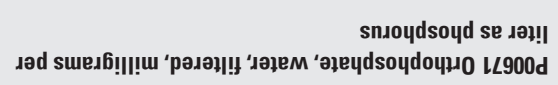 & $\begin{array}{l}\dot{\theta} \\
\dot{\theta} \\
\dot{\theta}\end{array}$ & $\begin{array}{l}\dot{g} \\
\dot{\vec{v}}\end{array}$ & $\stackrel{0}{\circ}$ & $\stackrel{m}{\circ}$ & 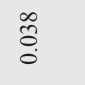 & $\bar{\sigma}$ & 管 & $\stackrel{\infty}{8}$ & $\stackrel{+}{0}$ & $\underset{\stackrel{t}{\circ}}{\dot{\varphi}}$ & $\underset{\stackrel{t}{0}}{\dot{\varphi}}$ & $\stackrel{0}{\circ}$ & $\bar{\Xi}$ & $\stackrel{\pi}{0}$ \\
\hline 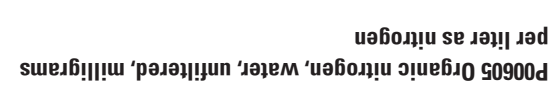 & $\stackrel{m}{\hat{\imath}}$ & 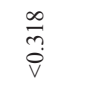 & 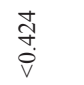 & \&্. & $\underset{\text { के }}{\dot{\vartheta}}$ & $\underset{\substack{\hat{m} \\
\hat{v}}}{i}$ & $\underset{\hat{v}}{\tilde{v}}$ & 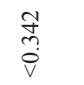 & $\stackrel{\hat{f}}{\stackrel{\leftrightarrow}{v}}$ & $\underset{\vec{\sigma}}{\hat{v}}$ & $\underset{\tilde{N}}{\stackrel{\text { Vे }}{\nabla}}$ & 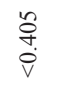 & $\begin{array}{c}\infty \\
\stackrel{\infty}{v} \\
\stackrel{v}{v}\end{array}$ & f. \\
\hline 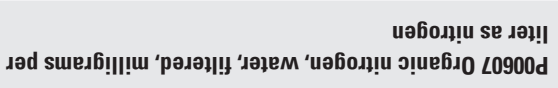 & ते & $\begin{array}{c}\overline{\mathrm{T}} \\
\stackrel{\tilde{V}}{\mathrm{~V}}\end{array}$ & $\underset{\stackrel{F}{i}}{\stackrel{F}{V}}$ & 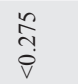 & $\overbrace{\hat{v}}^{\infty}$ & 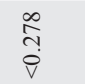 & 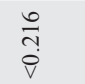 & 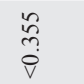 & 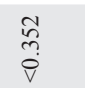 & $\hat{\tilde{̣}}$ & $\stackrel{n}{\hat{m}}$ & $\begin{array}{l}\infty \\
\stackrel{\infty}{?} \\
\hat{v}\end{array}$ & $\begin{array}{l}\stackrel{0}{0} \\
\stackrel{0}{\sim} \\
\stackrel{v}{v}\end{array}$ & 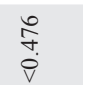 \\
\hline 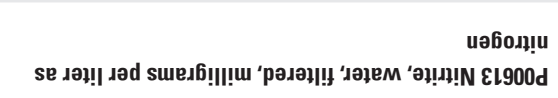 & ठั. & $\stackrel{\Xi}{0}$ & $\stackrel{\circ}{\circ}$ & $\stackrel{\circ}{\circ}$ & 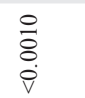 & $\begin{array}{l}\stackrel{0}{0} \\
\dot{0} \\
\dot{\vec{v}}\end{array}$ & $\begin{array}{l}\stackrel{\circ}{\circ} \\
\stackrel{0}{0}\end{array}$ & 官 & 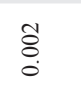 & $\stackrel{\circ}{\circ}$ & $\begin{array}{l}\circ \\
\stackrel{0}{0} \\
\dot{0}\end{array}$ & $\stackrel{\circ}{\circ}$ & $\begin{array}{l}\stackrel{0}{\circ} \\
\dot{0}\end{array}$ & $\stackrel{\circ}{\circ}$ \\
\hline 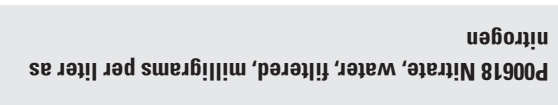 & $\begin{array}{l}\infty \\
\infty \\
\hat{o} \\
\dot{\dot{v}} \\
v\end{array}$ & $\begin{array}{l}\infty \\
\stackrel{\infty}{0} \\
\stackrel{\dot{\theta}}{v}\end{array}$ & 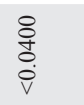 & 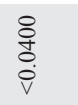 & $\begin{array}{l}8 \\
\substack{+\dot{0}} \\
\dot{0}\end{array}$ & $\begin{array}{l}8 \\
\stackrel{+}{0} \\
\dot{0} \\
\dot{0}\end{array}$ & $\begin{array}{l}8 \\
\substack{0 \\
\dot{0}} \\
\dot{0}\end{array}$ & $\begin{array}{l}\infty \\
\infty \\
\infty \\
\stackrel{0}{v}\end{array}$ & 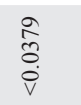 & 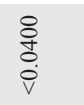 & 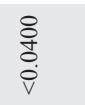 & 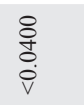 & 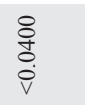 & 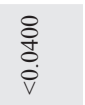 \\
\hline 号志詞 & 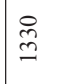 & $\frac{n}{I}$ & $\stackrel{\circ}{\leftrightarrows}$ & $\stackrel{\circ}{\cong}$ & $\begin{array}{l}\text { in } \\
\infty \\
0\end{array}$ & $\begin{array}{l}\tilde{\infty} \\
\infty\end{array}$ & $\stackrel{n}{\beth}$ & ป d & $\stackrel{n}{\varrho}$ & \&్ల & $\stackrel{\text { Ig }}{\Xi}$ & \&̊ & 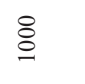 & ๕ \\
\hline 总 & $\underset{\substack{\frac{9}{5} \\
\frac{5}{4}}}{\frac{1}{4}}$ & 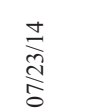 & 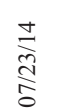 & 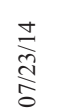 & 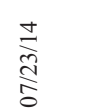 & 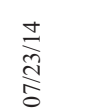 & $\underset{\substack{0 \\
\stackrel{5}{1}}}{\stackrel{4}{1}}$ & 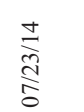 & $\underset{\substack{5 \\
\frac{9}{5}}}{\stackrel{5}{5}}$ & 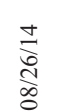 & 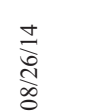 & 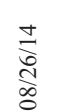 & 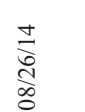 & \\
\hline 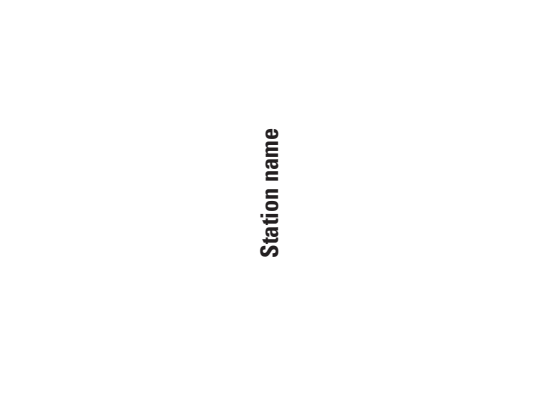 & 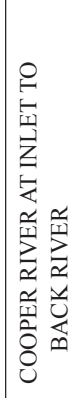 & 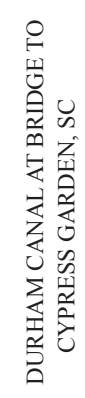 & 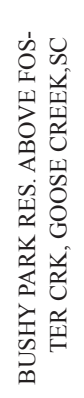 & 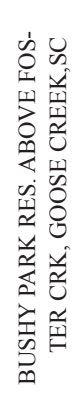 & 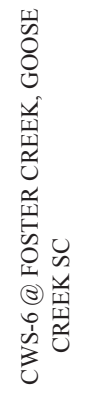 & 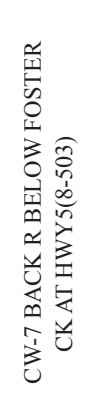 & 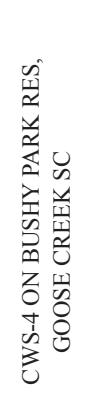 & 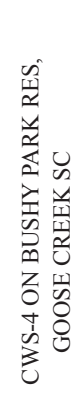 & 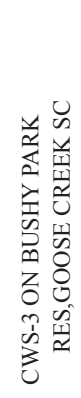 & 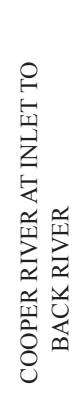 & 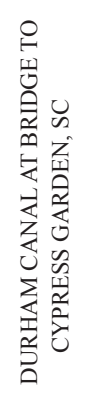 & 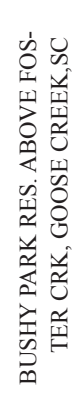 & 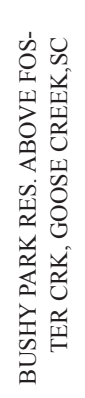 & 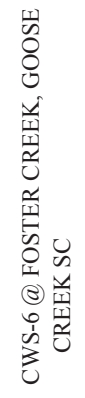 \\
\hline 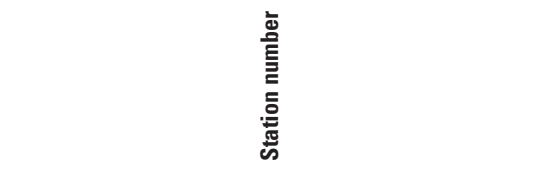 & 苓 & 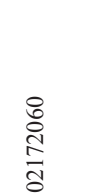 & 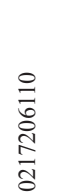 & 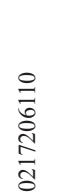 & 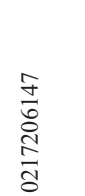 & 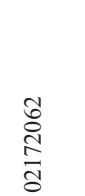 & $\begin{array}{l}0 \\
\text { on } \\
0 \\
0 \\
0 \\
0 \\
0 \\
0 \\
0 \\
0\end{array}$ & 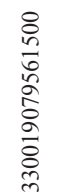 & 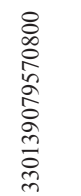 & 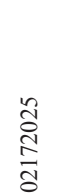 & 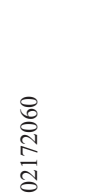 & 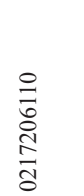 & 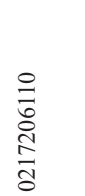 & 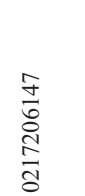 \\
\hline
\end{tabular}




\begin{tabular}{|c|c|c|c|c|c|c|c|c|c|c|c|c|c|c|}
\hline 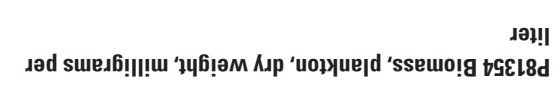 & वें & i & $\widehat{\mathcal{F}}$ & 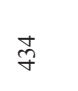 & $\stackrel{q}{q}$ & $\underset{m}{\stackrel{m}{m}}$ & ల్ల & $\overrightarrow{\mathcal{F}}$ & ปั่ & స్ల & $\ddot{\partial}$ & శ్ & $\stackrel{3}{3}$ & $\stackrel{m}{m}$ \\
\hline 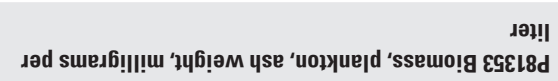 & $\bar{\ni}$ & ' & $\stackrel{\infty}{\forall}$ & $\stackrel{\tilde{Z}}{\nabla}$ & 字 & సें & సี & $\stackrel{3}{b}$ & $\stackrel{\infty}{\forall}$ & $\stackrel{\sim}{\oplus}$ & $\frac{7}{7}$ & $\stackrel{n}{F}$ & $\ddot{\partial}$ & ๗ెे \\
\hline 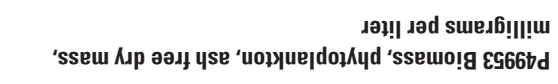 & $\stackrel{\stackrel{\vec{v}}{v}}{\mathrm{v}}$ & ' & $\stackrel{\stackrel{\dot{\vec{V}}}{\mathrm{~V}}}{\mathrm{v}}$ & $\widetilde{\sim}$ & $\stackrel{\stackrel{\ominus}{\vec{V}}}{\mathrm{~V}}$ & $\stackrel{n}{v}$ & $\stackrel{n}{\grave{v}}$ & $\stackrel{\circ}{\mathrm{v}}$ & 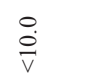 & $\stackrel{n}{v}$ & $\stackrel{\ominus}{\mathrm{v}}$ & $\stackrel{\stackrel{\ominus}{V}}{\mathrm{~V}}$ & $\stackrel{\odot}{\mathrm{v}}$ & $\tilde{\vec{v}}$ \\
\hline 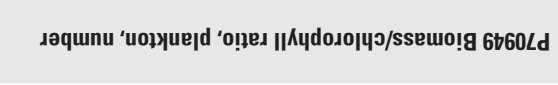 & $\stackrel{\overrightarrow{\mathrm{T}}}{-}$ & i & $\stackrel{\infty}{\stackrel{\infty}{\sim}}$ & के & $\underset{m}{\stackrel{E}{m}}$ & 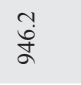 & $\begin{array}{l}\infty \\
\infty \\
\infty \\
\infty\end{array}$ & $\begin{array}{l}0 \\
\infty \\
0 \\
0\end{array}$ & $\stackrel{2}{=}$ & $\ddot{n}$ & a & กิ & $\stackrel{9}{m}$ & $\underset{\infty}{\ddot{\Delta}}$ \\
\hline 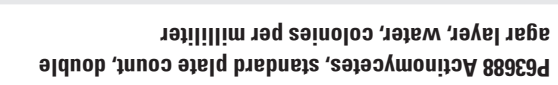 & $\stackrel{\infty}{-}$ & ! & $=$ & + & in & 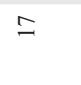 & $\stackrel{\circ}{ }$ & m & $a$ & $\stackrel{\circ}{\circ}$ & $\theta$ & $=$ & $\circ$ & a \\
\hline 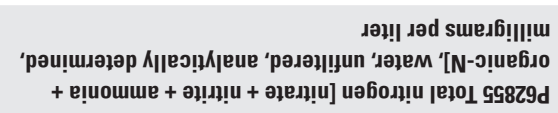 & $\begin{array}{l}0 \\
0 \\
0 \\
0\end{array}$ & : & 芦 & 声 & 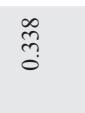 & $\frac{\infty}{3}$ & ते & $\stackrel{0}{7}$ & $\stackrel{n}{3}$ & mे & in & $\overline{3}$ & ते & 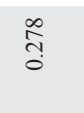 \\
\hline 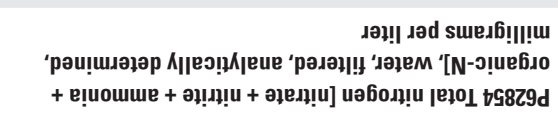 & \begin{tabular}{|l}
$\infty$ \\
$\infty$ \\
0 \\
0
\end{tabular} & i & $\stackrel{\infty}{\substack{d \\
0}}$ & ন্ড & $\stackrel{0}{3}$ & $\stackrel{n}{\stackrel{n}{0}}$ & ๙ุ & సี & $\overrightarrow{\bar{m}}$ & $\underset{\infty}{\infty}$ & $\stackrel{\widetilde{N}}{0}$ & đి & กิ & ते \\
\hline 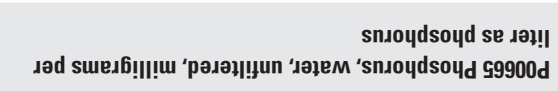 & $\stackrel{0}{0}$ & I & $\stackrel{\text { రे }}{0}$ & $\hat{o}$ & ठे. & 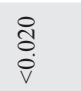 & 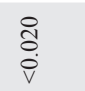 & $\stackrel{\infty}{\grave{0}}$ & $\stackrel{\substack{0 \\
0}}{0}$ & & 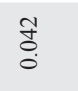 & $\stackrel{n}{0}$ & 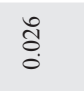 & ฮิ \\
\hline 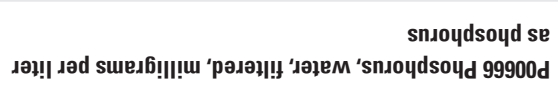 & $\overbrace{0}^{0}$ & : & $\stackrel{m}{a}$ & $\stackrel{2}{0}$ & $\underset{\delta}{0}$ & $\stackrel{a}{0}$ & $\stackrel{\circ}{\stackrel{0}{\dot{v}}}$ & $\stackrel{0}{\partial}$ & त्ठ & $\stackrel{\Omega}{0}$ & 产 & $\begin{array}{l}\overline{0} \\
\dot{0}\end{array}$ & Ĩ & $\begin{array}{l}\stackrel{\circ}{0} \\
\stackrel{\dot{V}}{V}\end{array}$ \\
\hline 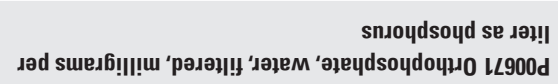 & छे. & i & $\stackrel{n}{0}$ & $\stackrel{t}{0}$ & $\underset{\substack{g \\
\dot{\theta}}}{i}$ & $\stackrel{0}{\circ}$ & $\stackrel{0}{0}$ & $\stackrel{2}{0}$ & $\stackrel{\circ}{\circ}$ & $\stackrel{\infty}{\circ}$ & $\stackrel{m}{0}$ & $\stackrel{8}{\circ}$ & $\stackrel{8}{\circ}$ & 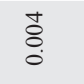 \\
\hline 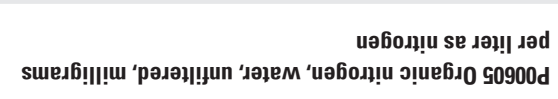 & 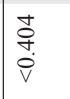 & I & $\stackrel{+}{\leftrightarrow}$ & $\underset{\dot{v}}{\stackrel{f}{v}}$ & $\stackrel{\infty}{\stackrel{\infty}{े}}$ & $\stackrel{\infty}{\stackrel{\infty}{\dot{v}}}$ & 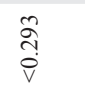 & $\begin{array}{l}\infty \\
\stackrel{\infty}{0} \\
\stackrel{i}{v}\end{array}$ & 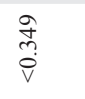 & $\underset{\mathcal{7}}{\stackrel{\sim}{*}}$ & 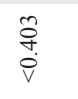 & $\overrightarrow{\tilde{N}}$ & $\stackrel{\sqrt[\pi]{े}}{\stackrel{े}{े}}$ & 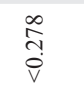 \\
\hline 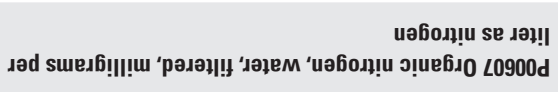 & $\begin{array}{l}\vec{\infty} \\
\stackrel{\vec{p}}{v} \\
\stackrel{v}{v}\end{array}$ & i & 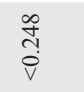 & 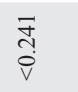 & 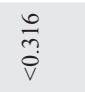 & $\stackrel{n}{\vec{v}}$ & $\stackrel{n}{\tilde{i}}$ & 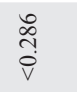 & $\underset{\stackrel{\infty}{i}}{\stackrel{i}{v}}$ & $\stackrel{n}{\tilde{m}}$ & $\stackrel{\infty}{\stackrel{\text { ते }}{\grave{v}}}$ & 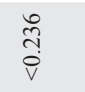 & $\underset{\tilde{n}}{\tilde{y}}$ & $\begin{array}{l}\overrightarrow{\hat{T}} \\
\dot{v}\end{array}$ \\
\hline 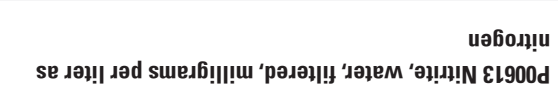 & $\stackrel{\circ}{\circ}$ & i & $\stackrel{\circ}{\circ}$ & $\stackrel{\circ}{\circ}$ & $\begin{array}{l}\stackrel{\circ}{\circ} \\
\stackrel{\dot{\theta}}{v}\end{array}$ & $\stackrel{\circ}{\circ}$ & $\stackrel{\circ}{\circ}$ & $\stackrel{\circ}{\circ}$ & $\stackrel{\circ}{\circ}$ & $\stackrel{\circ}{\circ}$ & $\begin{array}{l}\stackrel{\circ}{\circ} \\
\stackrel{\dot{\varphi}}{v}\end{array}$ & $\stackrel{\circ}{\circ}$ & $\stackrel{\circ}{\circ}$ & $\stackrel{\circ}{\circ}$ \\
\hline 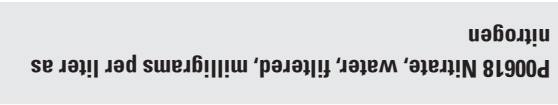 & 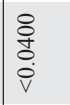 & i & $\begin{array}{l}8 \\
\substack{+\dot{0}} \\
\dot{0}\end{array}$ & 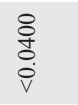 & 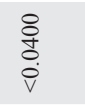 & $\begin{array}{l}8 \\
\substack{+\dot{0}} \\
\dot{0}\end{array}$ & 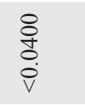 & 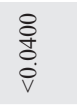 & $\begin{array}{l}\stackrel{t}{d} \\
\stackrel{\dot{v}}{v}\end{array}$ & 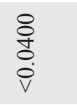 & 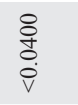 & $\begin{array}{l}8 \\
\stackrel{8}{0} \\
\dot{0} \\
\dot{0}\end{array}$ & $\begin{array}{l}8 \\
\stackrel{8}{0} \\
\stackrel{0}{0} \\
\dot{0}\end{array}$ & $\begin{array}{l}\stackrel{8}{+} \\
+ \\
\dot{0} \\
\dot{0}\end{array}$ \\
\hline 产志递 & $\stackrel{8}{8}$ & 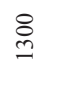 & $\stackrel{\ominus}{=}$ & $\stackrel{్ త ్}{~}$ & $\frac{n}{0}$ & 苫 & $\begin{array}{l}i \\
\stackrel{m}{n}\end{array}$ & $\stackrel{0}{\exists}$ & $\underset{卂}{\beth}$ & $\stackrel{n}{\varrho}$ & ల్ల & 守 & 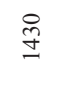 & $\stackrel{\Re}{=}$ \\
\hline 营 & $\begin{array}{l}2 \\
\frac{1}{5} \\
\frac{1}{0} \\
\text { o }\end{array}$ & 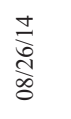 & 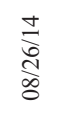 & 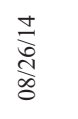 & 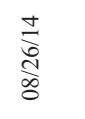 & 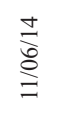 & 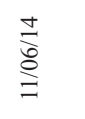 & $\stackrel{+}{\stackrel{ \pm}{\circ}}$ & $\stackrel{+}{\stackrel{\Xi}{\Xi}}$ & $\begin{array}{l}\stackrel{+}{5} \\
\stackrel{5}{\Xi}\end{array}$ & $\underset{\stackrel{J}{\delta}}{\stackrel{\Xi}{\Xi}}$ & 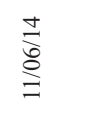 & $\underset{Ð}{\stackrel{J}{\Xi}}$ & $\stackrel{\Xi}{\stackrel{J}{\Xi}}$ \\
\hline 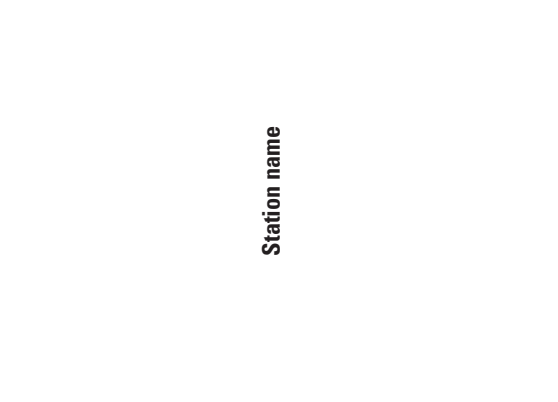 & 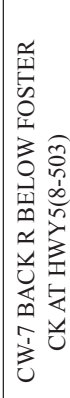 & 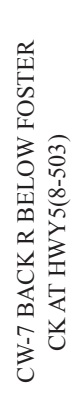 & 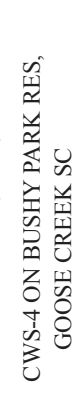 & 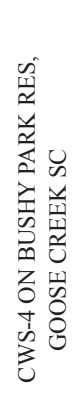 & 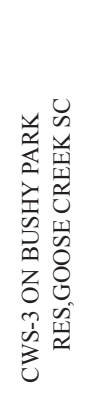 & 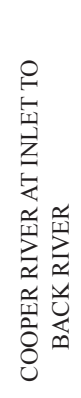 & 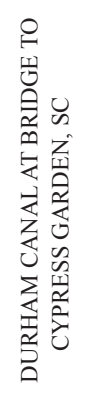 & 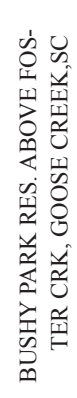 & 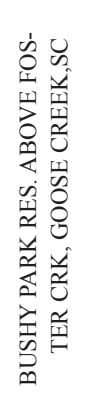 & 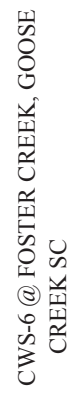 & 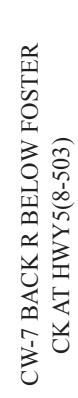 & 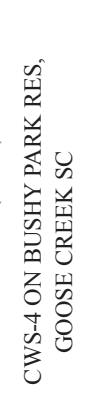 & 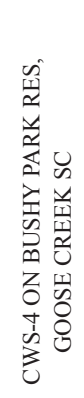 & 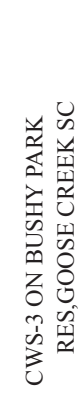 \\
\hline 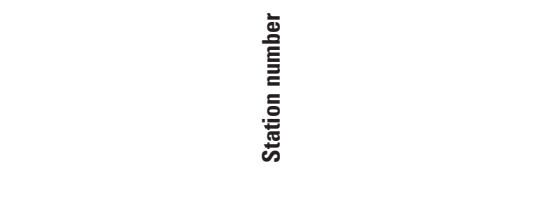 & ర్ర & 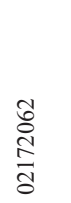 & 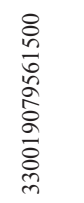 & 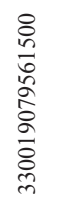 & $\begin{array}{l}8 \\
\text { o } \\
0 \\
1 \\
0 \\
0 \\
0 \\
0 \\
0 \\
0\end{array}$ & 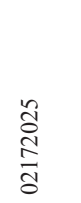 & & 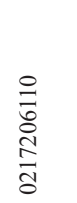 & 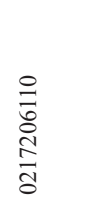 & 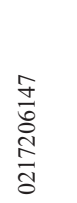 & 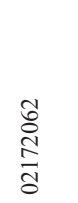 & $\begin{array}{l}8 \\
\text { on } \\
0 \\
0 \\
0 \\
0 \\
0 \\
0 \\
0 \\
0\end{array}$ & 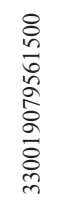 & $\begin{array}{l}8 \\
\text { o } \\
0 \\
1 \\
0 \\
0 \\
0 \\
0 \\
0 \\
0\end{array}$ \\
\hline
\end{tabular}




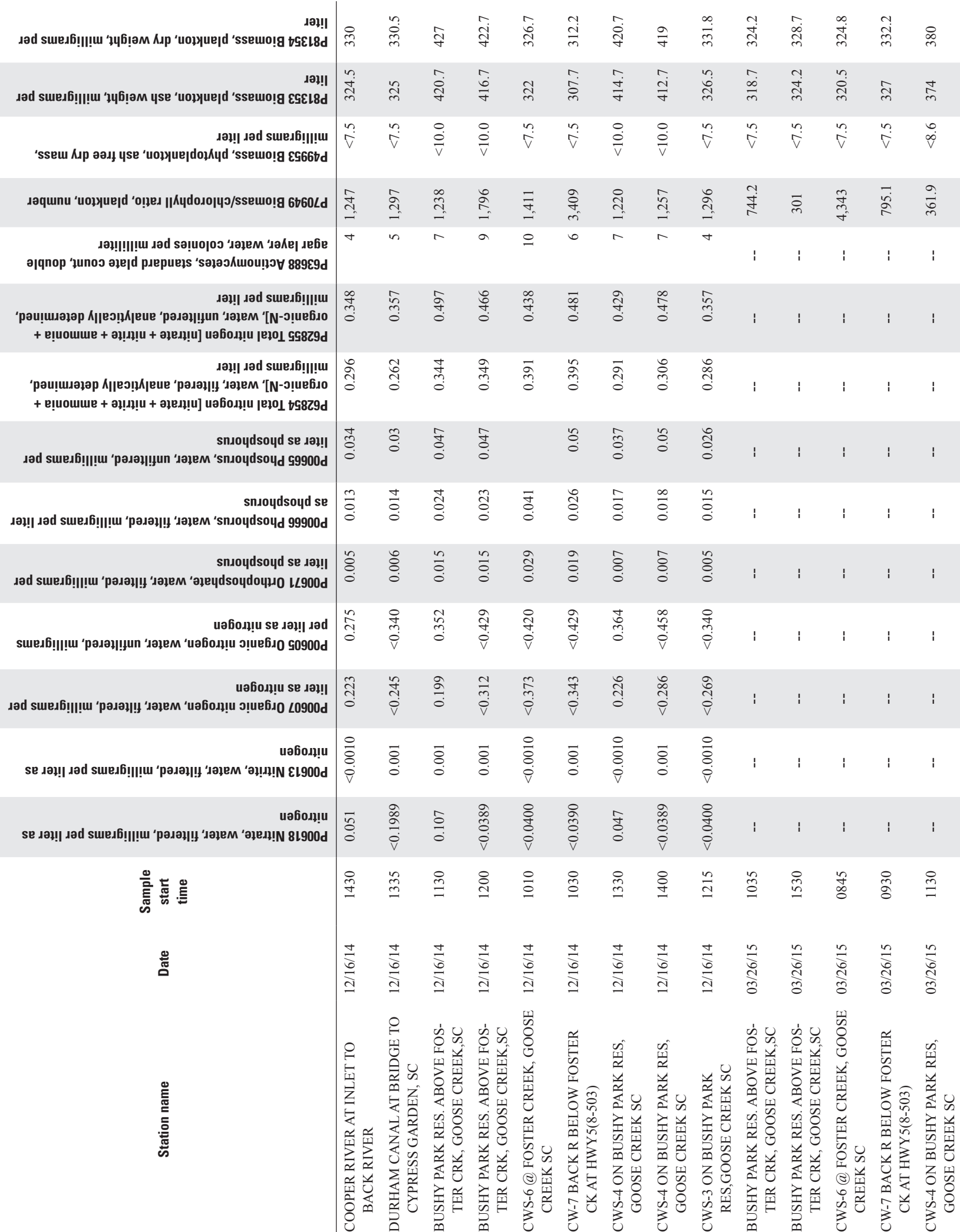




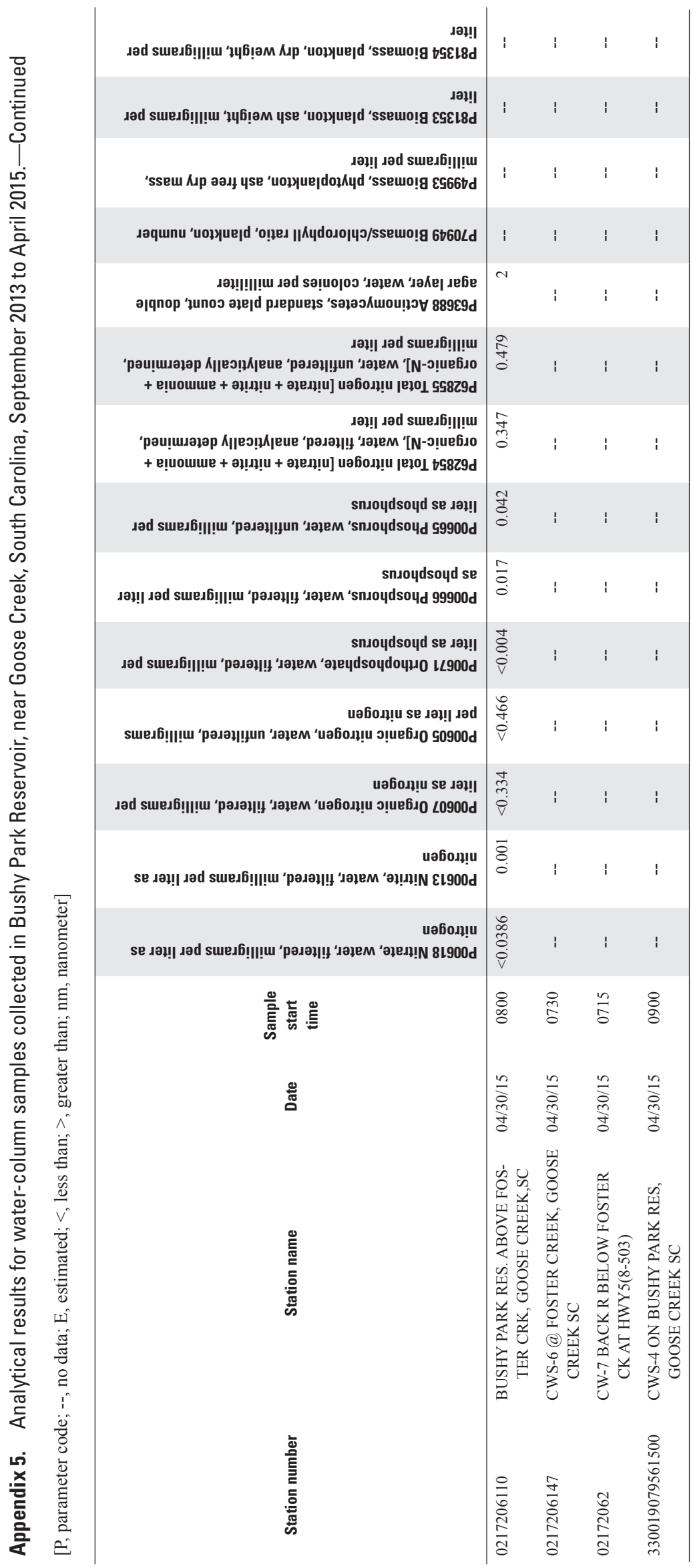




\begin{tabular}{|c|c|c|c|c|c|c|c|c|c|c|c|c|}
\hline 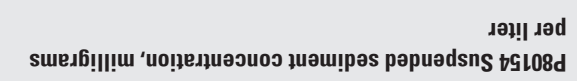 & $m$ & $\nabla$ & N & - & 으 & $n$ & $a$ & 6 & $m$ & in & 요 & 1 \\
\hline 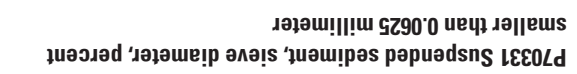 & $\hat{\infty}$ & J & สู & 8 & 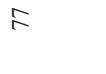 & $\bar{a}$ & $\bar{a}$ & 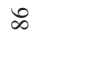 & ळे & $\bar{\sigma}$ & 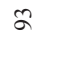 & i \\
\hline 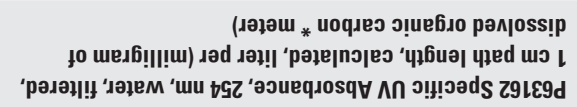 & ণे & $\stackrel{n}{n}$ & ळे & $\hat{n}$ & $\stackrel{n}{i}$ & $\underset{\sim}{\stackrel{ \pm}{n}}$ & aे & $\underset{r}{\stackrel{0}{0}}$ & $\underset{\dot{\theta}}{\ddot{\theta}}$ & m & $\hat{n}$ & I \\
\hline 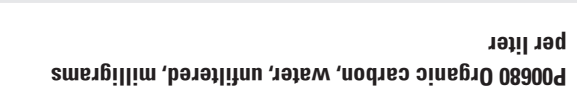 & $\stackrel{\infty}{\infty}$ & $\stackrel{+}{\infty}$ & $\stackrel{\text { Nִ }}{=}$ & $\ddot{a}$ & $\overrightarrow{6}$ & ণֶ & $\overrightarrow{6}$ & $\stackrel{0}{r}$ & $\stackrel{n}{?}$ & $\stackrel{+}{\infty}$ & $\check{r}$ & i \\
\hline 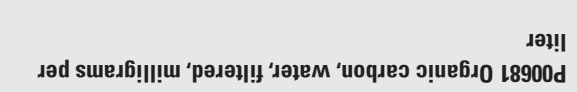 & $\stackrel{t}{\bullet}$ & $\stackrel{b}{6}$ & $\dddot{m}$ & $\stackrel{\infty}{\sim}$ & $\stackrel{+}{\forall}$ & in & $\stackrel{\infty}{+}$ & $\ddot{b}$ & $\stackrel{\infty}{a}$ & $\stackrel{n}{n}$ & $\stackrel{\infty}{+}$ & i \\
\hline 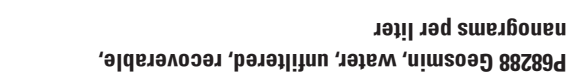 & $\dot{n}$ & $\vec{m}$ & ชู & $\stackrel{n}{+}$ & $\cong$ & $\underline{n}$ & 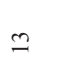 & $\infty$ & $=$ & $\stackrel{\infty}{m}$ & $=$ & 1 \\
\hline 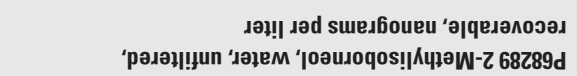 & ㄱ & 으 & \pm & $=$ & $\frac{9}{\pi}$ & $\underset{\infty}{\infty}$ & $\stackrel{1}{2}$ & n & $\dddot{q}$ & $\simeq$ & $\stackrel{N}{n}$ & 1 \\
\hline 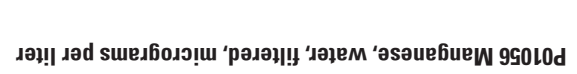 & ํํ & $\stackrel{2}{r}$ & $\stackrel{\forall}{\sigma}$ & $\stackrel{\sim}{n}$ & $\dot{0}$ & $\stackrel{\infty}{0}$ & $\dot{m}$ & 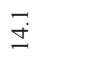 & $\stackrel{m}{n}$ & $\hat{i}$ & $\stackrel{0}{0}$ & i \\
\hline 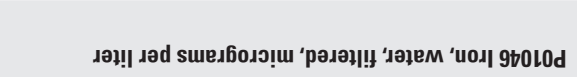 & $\ddot{3}$ & $\stackrel{+}{\infty}$ & $\stackrel{+}{\stackrel{+}{\infty}}$ & $\stackrel{n}{\dot{\infty}}$ & $\stackrel{m}{\infty}$ & $\stackrel{+}{\oplus}$ & $\stackrel{m}{\infty}$ & $\underset{\infty}{\infty}$ & 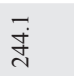 & $\stackrel{\infty}{\approx}$ & $\stackrel{+}{+}$ & i \\
\hline 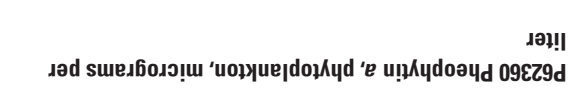 & $\dddot{+}$ & $\ddot{n}$ & 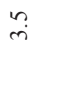 & ชู & $\stackrel{+}{+}$ & $\ddot{n}$ & $\stackrel{F}{F}$ & $\dddot{n}$ & $\ddot{n}$ & $\ddot{\leftrightarrow}$ & $\stackrel{\bullet}{6}$ & I \\
\hline 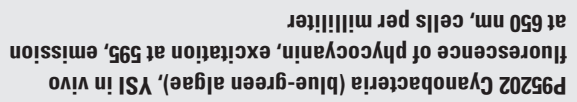 & i & i & i & I & i & I & i & $\begin{array}{l}\text { nु) } \\
\text { तi }\end{array}$ & $\begin{array}{c}\hat{\infty} \\
\infty \\
\infty \\
\text { m. }\end{array}$ & $\begin{array}{l}\infty \\
\infty \\
\infty \\
\infty\end{array}$ & సิ & i \\
\hline 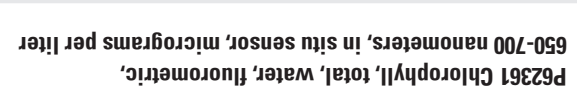 & $\stackrel{+}{\circ}$ & $\begin{array}{l}\infty \\
\stackrel{\beth}{\beth}\end{array}$ & $\overrightarrow{\mathrm{C}}$ & $\stackrel{9}{\Xi}$ & $\stackrel{9}{r}$ & $\stackrel{\circ}{\forall}$ & $\stackrel{0}{=}$ & $\stackrel{n}{I}$ & $\vec{d}$ & ชู & $\stackrel{r}{\stackrel{2}{*}}$ & I \\
\hline 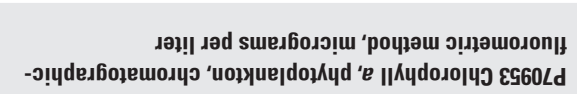 & $\ddot{6}$ & $\stackrel{+}{\infty}$ & $\stackrel{0}{\circ}$ & $\underset{\infty}{\infty}$ & જे & $\hat{\sigma}$ & $\vec{\infty}$ & $\stackrel{0}{0}$ & $\stackrel{\circ}{\circ}$ & $\stackrel{m}{ \pm}$ & $\stackrel{9}{+}$ & i \\
\hline 恶壳导 & $\stackrel{n}{\stackrel{n}{I}}$ & 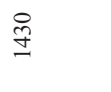 & $\stackrel{\ominus}{=}$ & ̊̊ & ळ̊ & $\stackrel{n}{\Xi}$ & $\stackrel{\text { I }}{I}$ & §્ત & \& & $\stackrel{8}{\circledR}$ & $\underset{8}{8}$ & $\frac{\Delta}{\partial}$ \\
\hline 芯 & $\stackrel{m}{\frac{\infty}{\sigma}}$ & $\frac{m}{\infty}$ & 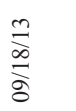 & $\stackrel{m}{\frac{\infty}{\sigma}}$ & $\frac{m}{\frac{m}{a}}$ & $\stackrel{m}{\frac{n}{a}}$ & $\stackrel{\frac{m}{2}}{\frac{m}{2}}$ & $\frac{\stackrel{ \pm}{\Xi}}{\stackrel{0}{0}}$ & $\begin{array}{l}\stackrel{ \pm}{\Xi} \\
\stackrel{\theta}{0}\end{array}$ & $\frac{\underset{\Xi}{\Xi}}{\stackrel{ \pm}{0}}$ & $\underset{⿱ 亠}{\stackrel{\Xi}{J}}$ & $\frac{\Xi}{\stackrel{\Xi}{\Xi}}$ \\
\hline 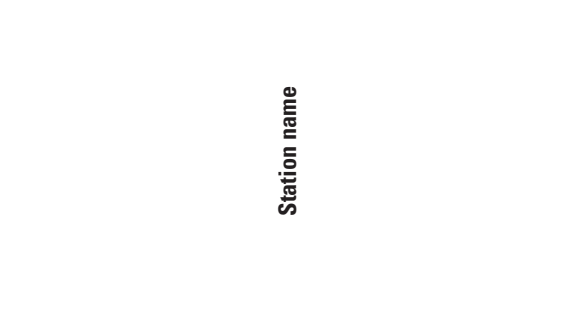 & 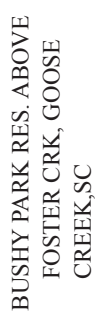 & 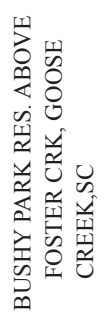 & 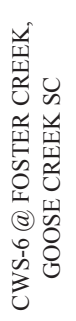 & 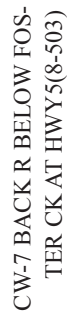 & 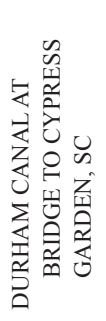 & 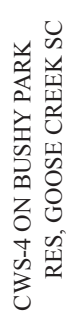 & 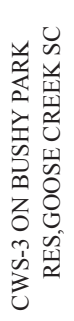 & 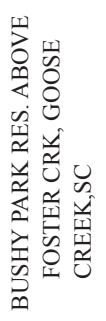 & 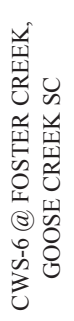 & 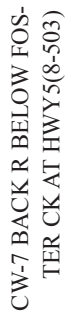 & 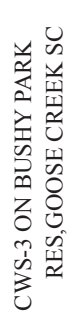 & 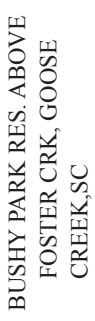 \\
\hline 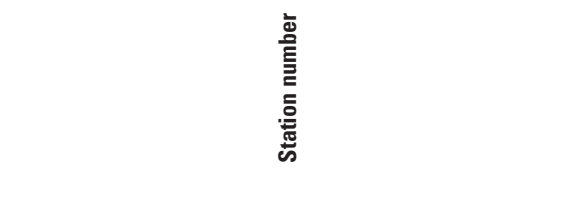 & 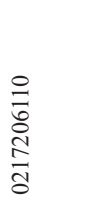 & 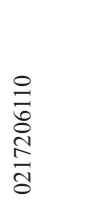 & 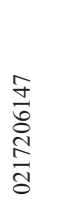 & 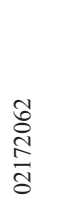 & 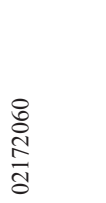 & 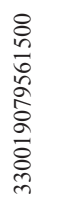 & 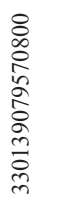 & 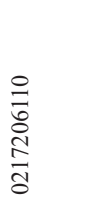 & 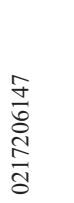 & 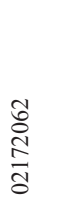 & 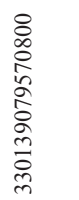 & 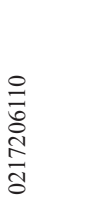 \\
\hline
\end{tabular}




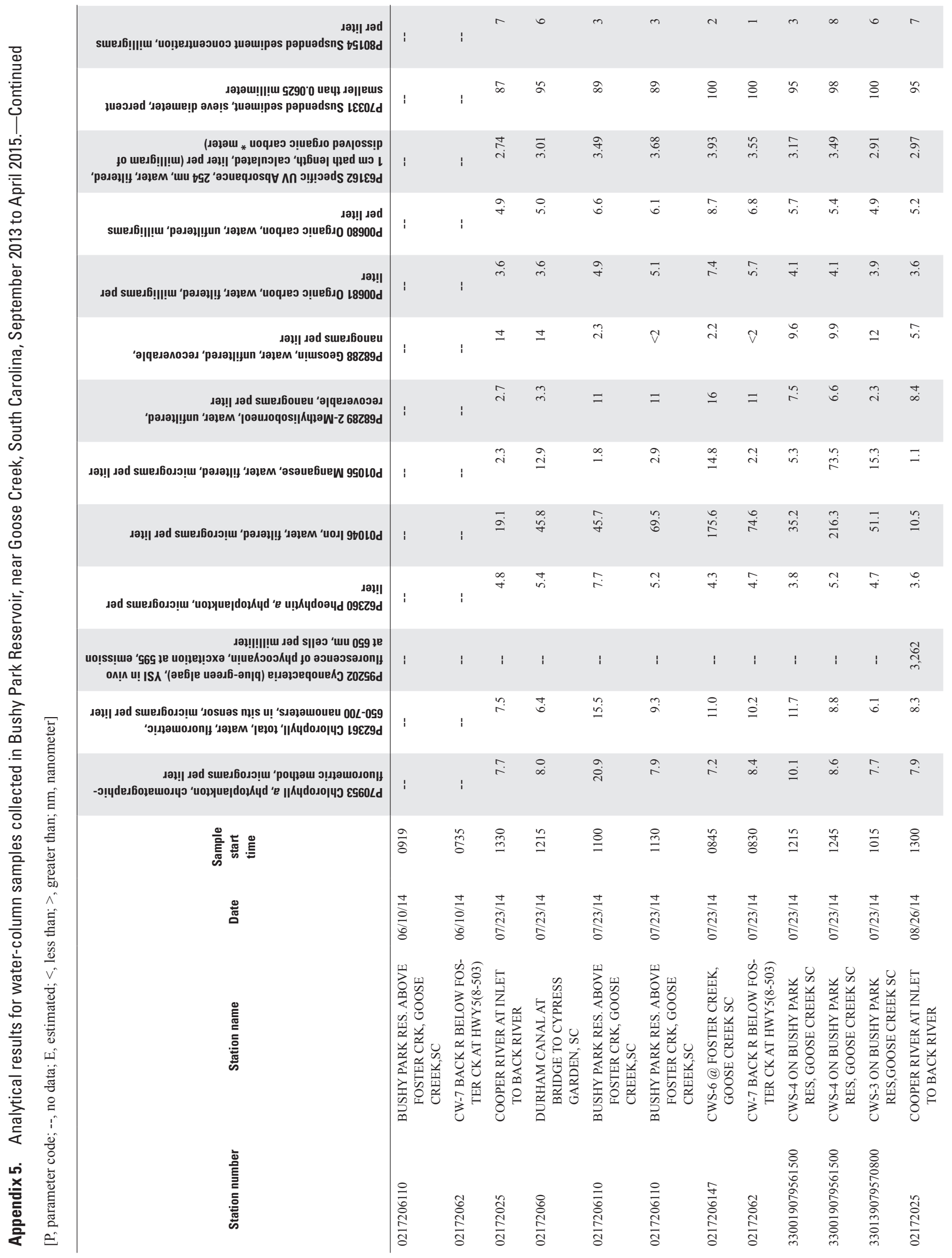




\begin{tabular}{|c|c|c|c|c|c|c|c|c|c|c|c|c|}
\hline 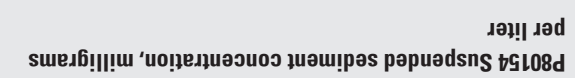 & + & N & - & $\sim$ & N & I & N & $\forall$ & m & $n$ & $n$ & $m$ \\
\hline 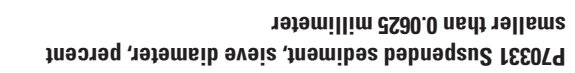 & 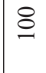 & 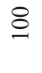 & 8 & 8 & 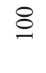 & ' & 8 & 8 & 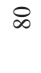 & 8 & 8 & 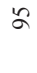 \\
\hline 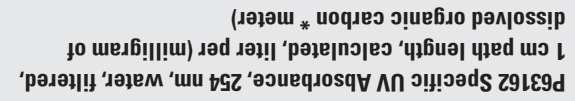 & $\frac{N}{m}$ & $\vec{\sigma}$ & $\stackrel{\infty}{n}$ & $\stackrel{n}{\sim}$ & $\ddot{n}$ & I & $m$ & ๙े & $\stackrel{m}{m}$ & $\stackrel{+i}{i}$ & $\begin{array}{l}\infty \\
i\end{array}$ & ñ \\
\hline 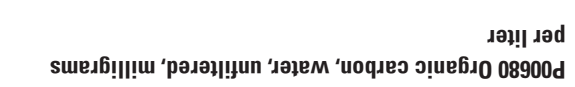 & $\stackrel{g}{\dot{\gamma}}$ & $\stackrel{N}{N}$ & 穴 & ナั & $\stackrel{m}{\infty}$ & I & in & $\underset{i r}{+}$ & in & $\stackrel{\infty}{m}$ & ले & in \\
\hline גәd sue. & $\begin{array}{l}\infty \\
\dot{m}\end{array}$ & $\underset{0}{0}$ & $\begin{array}{l}b \\
\text { in }\end{array}$ & $\stackrel{\infty}{\sim}$ & ఫ্ & I & $\stackrel{\sim}{\forall}$ & $\overrightarrow{+}$ & 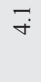 & $\stackrel{+}{m}$ & $\stackrel{+}{\oplus}$ & $\begin{array}{l}\sigma \\
\dot{r}\end{array}$ \\
\hline 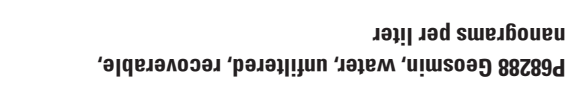 & $\stackrel{9}{\sim}$ & $n$ & $\stackrel{\infty}{\sim}$ & $\begin{array}{l}\dot{r} \\
\dot{r}\end{array}$ & $\begin{array}{l}o \\
\text { i }\end{array}$ & $\stackrel{\sim}{\forall}$ & $\simeq$ & $\hat{a}$ & $a$ & $\stackrel{0}{m}$ & $\dot{r}$ & $\begin{array}{l}o \\
\stackrel{i}{i}\end{array}$ \\
\hline 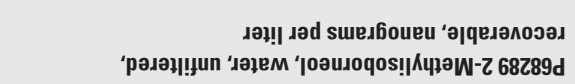 & $=$ & $\stackrel{b}{\infty}$ & $\stackrel{\infty}{\infty}$ & $\stackrel{ }{ }$ & $\stackrel{N}{\infty}$ & $\stackrel{n}{r}$ & $=$ & 으 & $\stackrel{+}{\sigma}$ & $\stackrel{m}{\sim}$ & $\vec{i}$ & $\stackrel{\sim}{+}$ \\
\hline 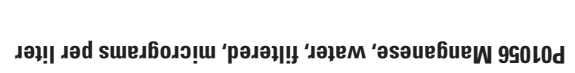 & ஸֶ & $\vec{\infty}$ & $\stackrel{m}{\sim}$ & $\stackrel{\forall}{\stackrel{\Delta}{n}}$ & $\stackrel{\circ}{\stackrel{\Xi}{ \pm}}$ & i & $\stackrel{m}{n}$ & 吉 & 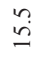 & 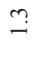 & $\exists$ & $\underset{\infty}{0}$ \\
\hline 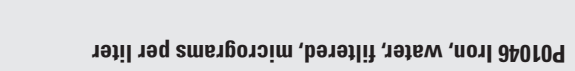 & $\begin{array}{l}\dot{0} \\
\dot{f}\end{array}$ & $\stackrel{m}{n}$ & $\ddot{r}$ & 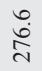 & $\stackrel{n}{2}$ & i & ָั่ & $\stackrel{\infty}{\sim}$ & $\stackrel{\infty}{6}$ & $\stackrel{\infty}{\infty}$ & $\ddot{0}$ & $\stackrel{0}{\stackrel{0}{N}}$ \\
\hline 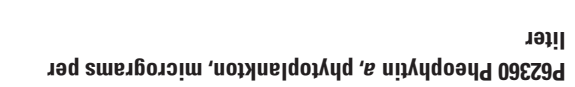 & $m$ & $\stackrel{n}{\forall}$ & $\stackrel{\circ}{+}$ & $\stackrel{?}{\forall}$ & F & i & $n$ & $\stackrel{\infty}{\infty}$ & $\stackrel{m}{m}$ & $\hat{\mathrm{i}}$ & $m$ & $\underset{\sim}{\dot{r}}$ \\
\hline 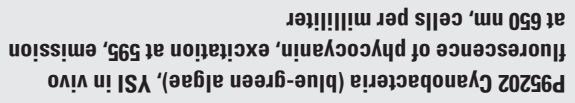 & $\underset{\substack{\tau \\
\infty}}{\infty}$ & 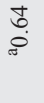 & $\stackrel{\substack{0 \\
0}}{0}$ & $\bar{\sigma}$ & $\underset{8}{6}$ & i & $\stackrel{0}{6}$ & $\stackrel{8}{\circ}$ & $\begin{array}{l}\text { Oे } \\
\infty \\
i\end{array}$ & i & I & î \\
\hline & 9 & $\stackrel{\circ}{i}$ & $\ddot{a}$ & - & $\stackrel{0}{0}$ & & in & $\stackrel{\circ}{\circ}$ & $\sim$ & $\stackrel{+}{+}$ & $i$ & $\vec{a}$ \\
\hline
\end{tabular}

เә1! Jad sup

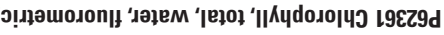

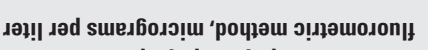

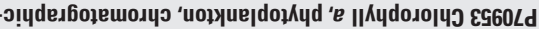

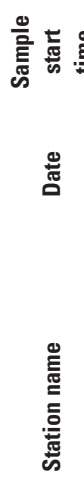

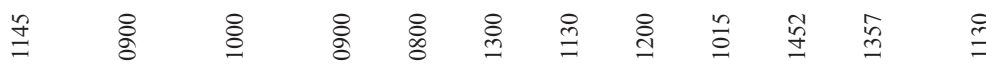

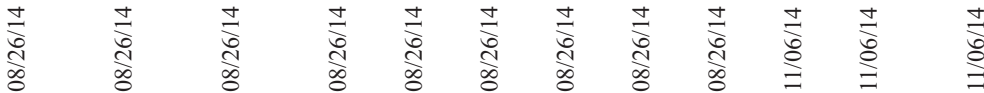

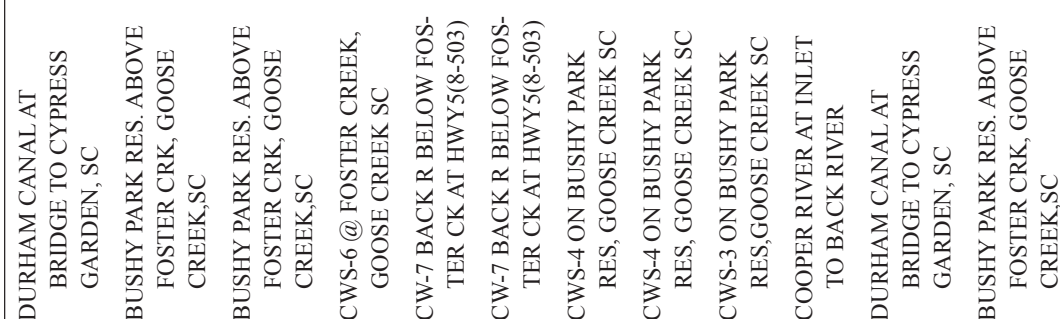

क⿺辶力 


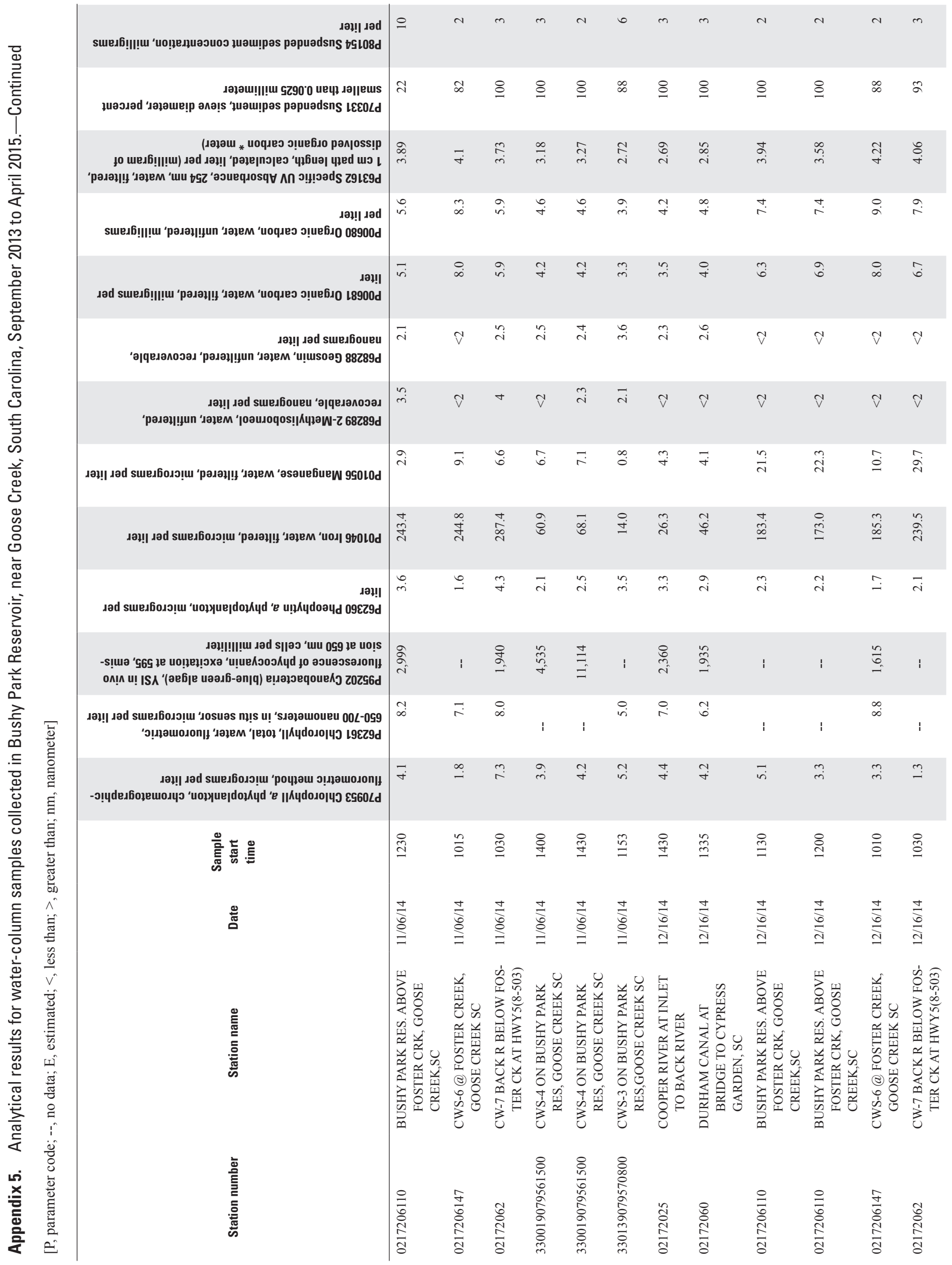




\begin{tabular}{|c|c|c|c|c|c|c|c|c|c|c|c|c|}
\hline 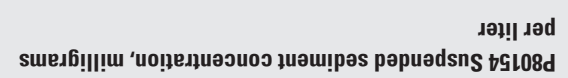 & I & $m$ & & I & 1 & 1 & I & I & 1 & I & I & I \\
\hline 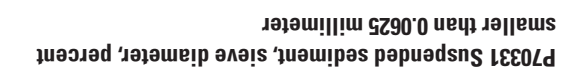 & i & 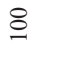 & & i & i & i & i & I & i & i & i & i \\
\hline 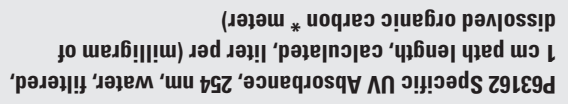 & 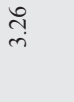 & $\underset{\dot{r}}{\stackrel{m}{q}}$ & $\begin{array}{l}n \\
\dot{6} \\
i\end{array}$ & I & i & 1 & i & I & I & I & I & I \\
\hline 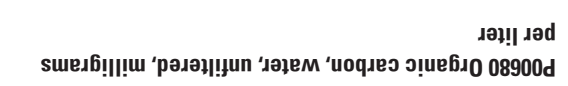 & $\ddot{n}$ & $\stackrel{\dot{r}}{\dot{r}}$ & $\stackrel{\bullet}{+}$ & I & I & 1 & I & I & $\stackrel{n}{N}$ & 1 & i & 1 \\
\hline 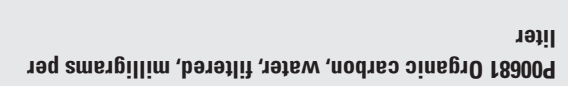 & $\stackrel{\infty}{+}$ & $\stackrel{+}{\dot{t}}$ & $\stackrel{\circ}{+}$ & i & i & I & I & i & $\underset{b}{\infty}$ & I & i & 1 \\
\hline 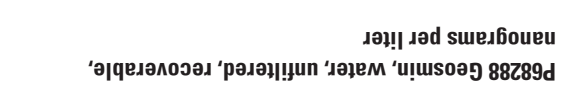 & $\stackrel{\text { ñ }}{n}$ & $\mathrm{~V}$ & $\stackrel{0}{i}$ & I & i & 1 & I & I & $\stackrel{\infty}{\sim}$ & I & i & I \\
\hline 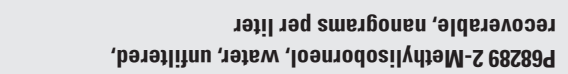 & $\widetilde{V}$ & $\tilde{V}$ & $\widetilde{V}$ & I & i & $i$ & i & I & $\cong$ & i & i & I \\
\hline 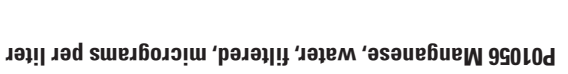 & $\stackrel{\circ}{\dot{ \pm}}$ & $\stackrel{n}{\sim}$ & $\ddot{n}$ & i & i & i & i & i & 9 & i & i & i \\
\hline 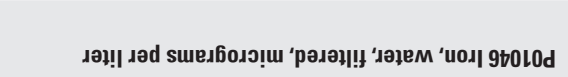 & $\stackrel{r}{\infty}$ & $\stackrel{n}{\infty}$ & $\stackrel{\infty}{\dot{+}}$ & i & i & i & I & I & $\stackrel{0}{\circ}$ & I & I & I \\
\hline גәฺ!! & $\stackrel{4}{i}$ & $\stackrel{\infty}{i}$ & $\vec{m}$ & $\stackrel{+}{\vartheta}$ & $\stackrel{n}{n}$ & $\leftrightarrows$ & $\ddot{n}$ & $\ddot{\circ}$ & 1 & ! & I & ! \\
\hline 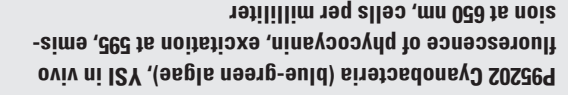 & i & i & $\stackrel{\infty}{\stackrel{\circ}{6}}$ & i & i & i & i & i & i & i & i & i \\
\hline 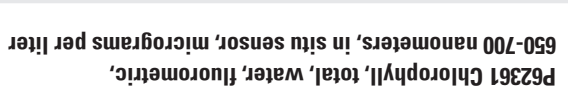 & $\vec{r}$ & $\stackrel{\infty}{\sim}$ & $\stackrel{n}{-}$ & i & i & 1 & I & I & $\begin{array}{l}\emptyset \\
=\end{array}$ & $\stackrel{\leftrightarrow}{\circ}$ & $\begin{array}{l}0 \\
0\end{array}$ & フู \\
\hline 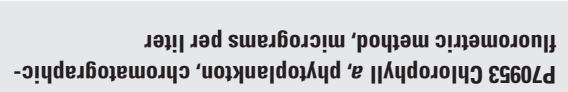 & $\stackrel{q}{+}$ & $\stackrel{\circ}{i}$ & $\overrightarrow{+}$ & $\stackrel{4}{4}$ & $\stackrel{1}{1}$ & $\stackrel{\circ}{\circ}$ & $\dddot{n}$ & $\stackrel{0}{\circ}$ & 1 & I & I & I \\
\hline 高 䔍 壳 & $\stackrel{\substack{m \\
m}}{m}$ & ஓ & $\stackrel{n}{\stackrel{n}{I}}$ & $\tilde{n}$ & 尽 & $\stackrel{\substack{q \\
\infty}}{\circ}$ & ळ̆ & $\stackrel{\ominus}{\varrho}$ & 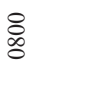 & 尽 & $\frac{n}{\sigma}$ & ஓ \\
\hline 壳 & 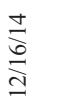 & 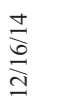 & 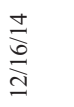 & $\frac{n}{\substack{n \\
\infty}}$ & 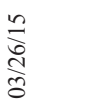 & 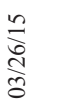 & $\frac{n}{\infty}$ & 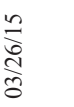 & 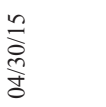 & $\begin{array}{l}\stackrel{n}{0} \\
\stackrel{m}{0}\end{array}$ & 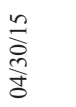 & 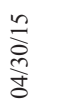 \\
\hline 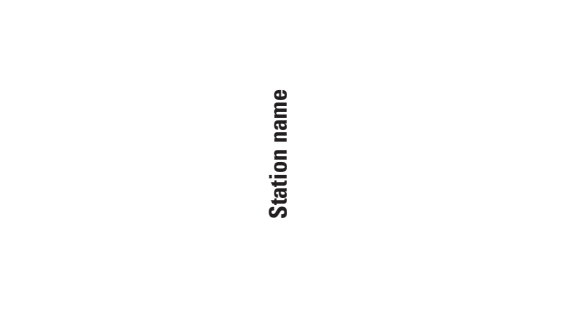 & 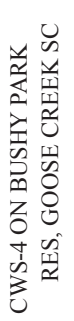 & 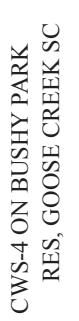 & 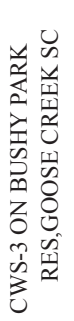 & 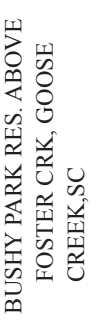 & 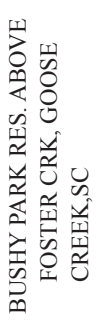 & 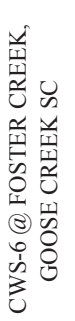 & 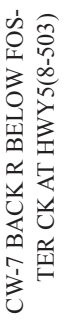 & 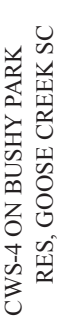 & 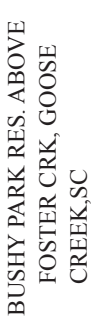 & 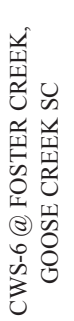 & 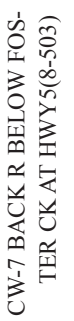 & 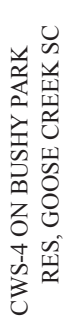 \\
\hline 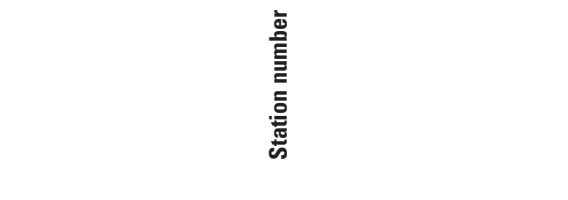 & 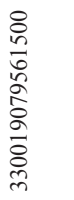 & 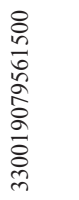 & 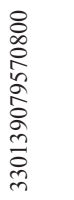 & 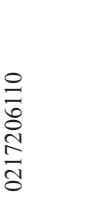 & 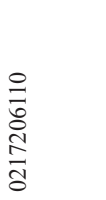 & 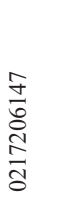 & 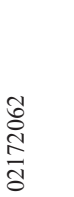 & 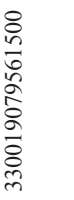 & 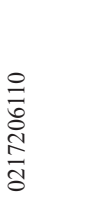 & 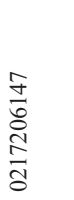 & 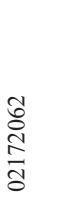 & 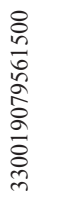 \\
\hline
\end{tabular}



Manuscript was approved January 18, 2018

Publishing support was provided by the USGS Science Publishing Network, Reston Publishing Service Center

For more information about this report, contact

Director, South Atlantic Water Science Center

U.S. Geological Survey

720 Gracern Road

Stephenson Center, Suite 129

Columbia, SC 29210

Or visit the South Atlantic Water Science Center website at https://www.usgs.gov/water/southatlantic/ 


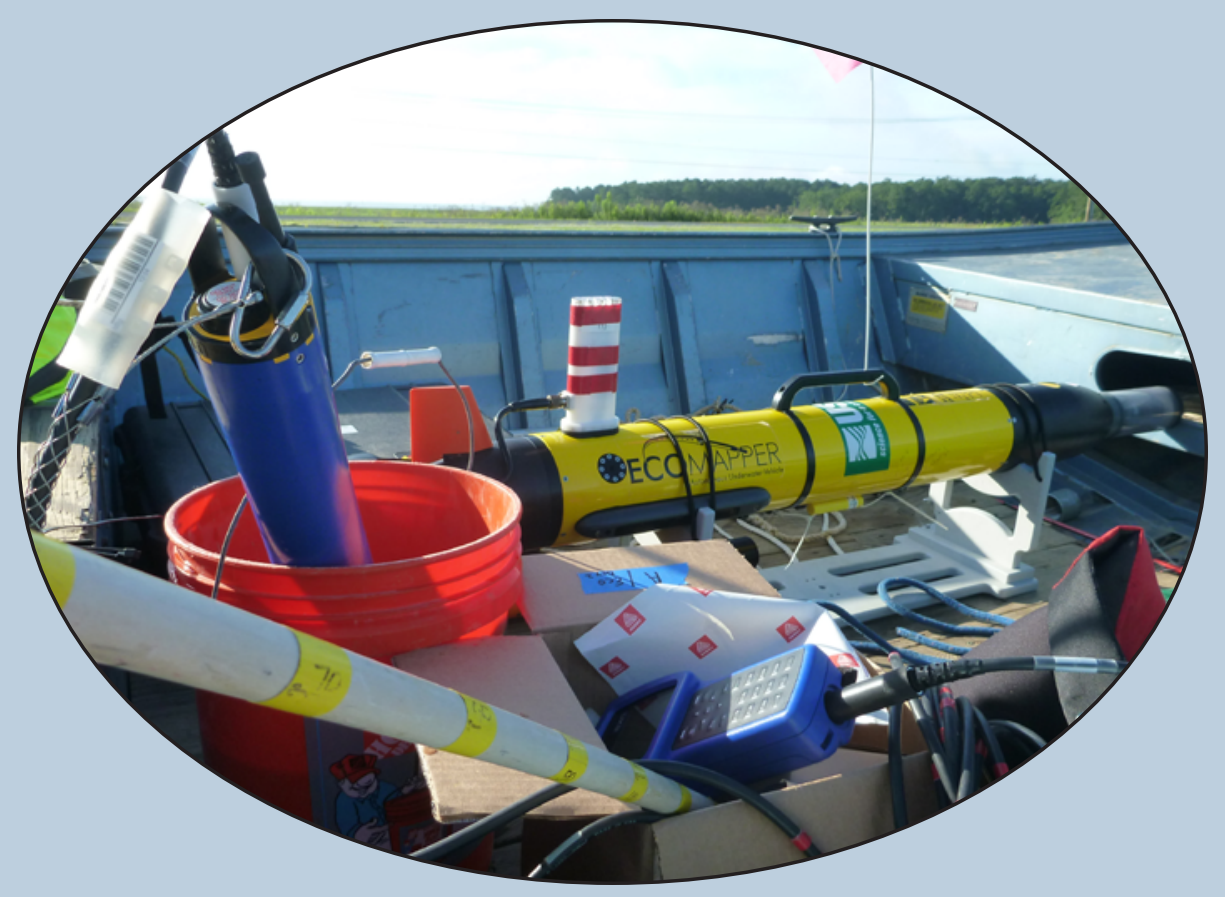

